
Some Rights Reserved

This work is licensed under a

Creative Commons Attribution - NonCommercial - ShareAlike 4.0

International license






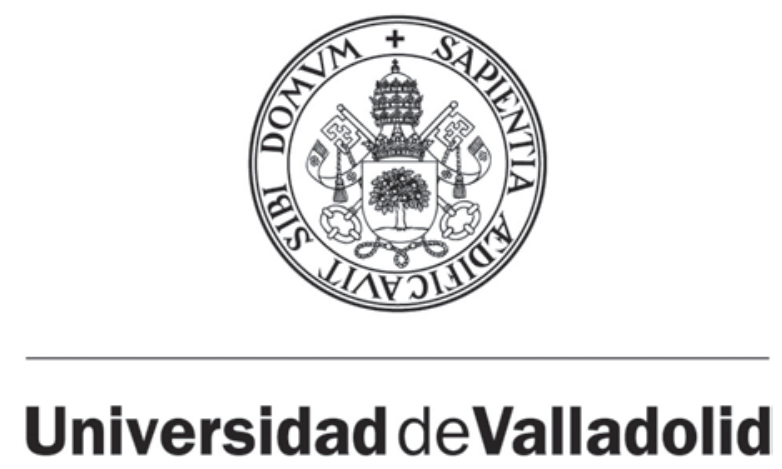

FACULTAD MEDICINA

DEPARTAMENTO DE BIOQUÍMICA, BIOLOGÍA MOLECULAR Y FISIOLOGÍA

TESIS DOCTORAL:

\section{ELR-BASED NANOCOMPLEXES WITH POTENTIAL BIOMEDICAL USES}

Presentada por María Jesús Piña Lancho para optar al grado de Doctora con Mención Internacional por la Universidad de Valladolid

Dirigida por:

Dr. Francisco Javier Arias Vallejo

Dr. José Carlos Rodríguez Cabello 



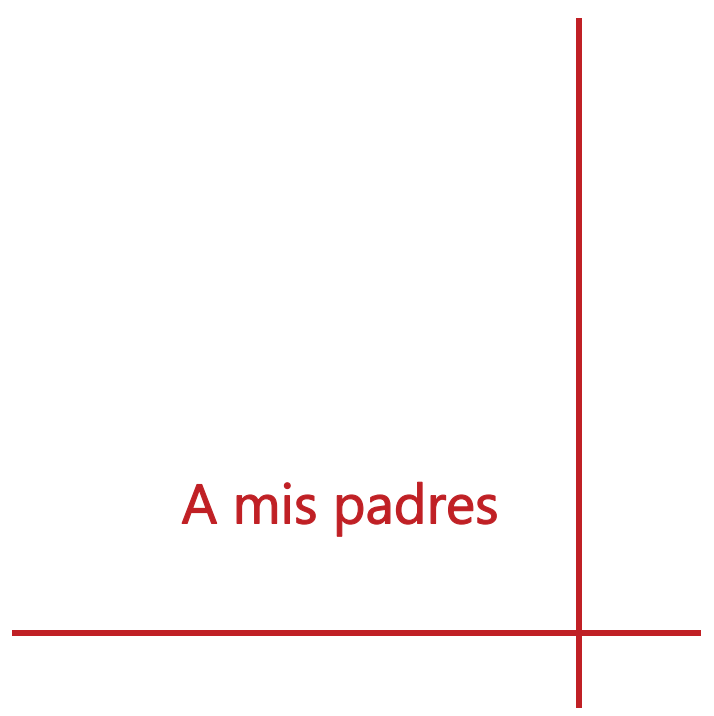




\section{ACKNOWLEDGMENTS}

No hace mucho leí esta cita: "A veces sentimos que lo que hacemos es tan solo una gota en el mar, pero el mar sería menos si le faltara esa gota". Rápidamente me vino a la mente el trabajo realizado durante estos últimos años. Recuerdo perfectamente cuando hace casi 5 años aparecí por Valladolid, ciudad de la que apenas había escuchado y que a duras penas situaba en la provincia (con perdón de los vallisoletanos). Esa entrevista con Javi y Alessandra me abrió la puerta a una nueva etapa de mi vida. De ese día también recuerdo una pareja de físico y químico jugando a ser biólogos bastante bien avenida que me presentaron en el pasillo (Guille e Isra). Con todo decidí hacer la maleta y lanzarme a la vida de capital de provincia.

A lo largo de esta tesis no sólo he aprendido sobre ELRs, light scattering o transfección sino una filosofía de vida. Y es que una tesis te aporta mucho desde el punto de vista profesional y personal. No rendirte nunca, no tener miedo a las purificaciones de ELRs imposibles, a la línea base del DSC o a la toxicidad de la ricina; al fin y al cabo a disfrutar de esa gota de agua que podamos aportar en la infinidad del mar.

Y llega el momento de los agradecimientos propiamente dichos. En primer lugar quisiera agradecer esta oportunidad que me brindaron mis directores de tesis Carlos y Javi. En especial a Javi gracias por tu ayuda siempre que la he necesitado, tus consejos, paciencia y al fin y al cabo gracias por enseñarme a investigar. A los "Senior" Matilde, Merche, Luis, Ana y Ale. Gracias Ale por tu ayuda los últimos meses con nuestras ratoncitas.

Por supuesto no me puedo olvidar del gran equipo humano que tiene este grupo. Gracias a mis compis de alegrías y sufrimientos con los que he compartido más tiempo. Muchos de ellos ya son Doctores de pleno derecho: Menchu por esa primera comida en Valladolid, Guille, Isra, Alicia, Mohamed, Lucia, Arturo, Ito, Dori, Tati y Sergio por tantos buenos momentos, tantas dudas existenciales compartidas sobre los ELRs y por vuestra ayuda. A los nuevos: Soraya gracias por haber vuelto, Sofía ¡Ánimo que ya os queda menos! A Roci ¡muchas gracias por tus consejos y paciencia! 
También a Irene y Vanesa igracias por esos cafés chicas! Y a la nueva secre Alicia. De muchos de ellos me llevo una amistad que sé que perdurará más allá de los muros Bioforgianos.

Esta tesis también me ha llevado a dos lugares como la India y USA donde he realizado dos estancias. Ambas resultaron dos grandes experiencias de las que guardo momentos y personas geniales. Gracias Susan, Prof.Sharma, Ying y Prof. Chilkoti.

Gracias a mis amigas de siempre, Eva, Cris, Carmen. Gracias a mis "bio" Bárbara, María, Fede y Santi. Gracias a mis gorriones: Santi (que estás en todos sitios), Rus, Chechu, Vane, Antonio, Mariángeles, Quique, Maryjane, Torre, Sara, Moya, Raúl, Blas, Maite, Solano, Virginia y Arancha. Gracias a todos por las conversaciones, las risas, por las visitas sorpresa y no sorpresa a Valladolid, por las calderetas, por la cerveza Passer, y por "airearme" durante este tiempo. Gracias Leti por esas cañitas e impro vallisolenas.

Por supuesto gracias a mi familia por apoyarme durante todo este tiempo y por los tuppers mamá.

Y gracias a ti que desde el minuto cero has estado apoyándome incondicionalmente incluso cuando miles de kms nos separaban. Por tu apoyo, comprensión y cariño gracias Nacho.

Gracias a todos aunque probablemente me deje a alguien y gracias a ti por leer este trabajo. 


\section{INDEX}

INDEX

ABSTRACT

RESUMEN

1. INTRODUCTION

1.1 ELASTIN LIKE RECOMBINAMERS............................................................................19

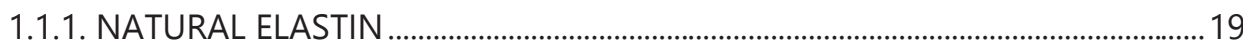

1.1.2. A NEW TERM: "ELR" .............................................................................................. 20

1.1.3. MOLECULAR BASIS OF ITT AND $\triangle T$ Tt................................................................2

1.1.4. FACTORS INFLUENCING THE Tt .............................................................................22

1.1.4.1. INTRINSIC FACTORS......................................................................................2 22

1.1.4.1.1. CONCENTRATION AND CHAIN LENGTH .................................................22

1.1.4.1.2. ELR AMINO-ACID COMPOSITION AND IONIZATION DEGREE........23

1.1.4.2. EXTRINSIC FACTORS: EFFECT OF SALTS...........................................................22

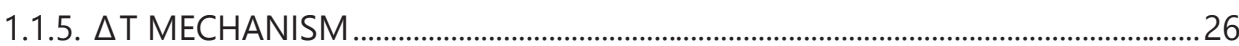

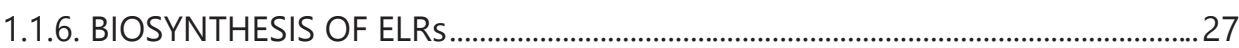

1.1.6.1. MONOMER GENE.............................................................................................2

1.1.6.2. MONOMER OLIGOMERIZATION ......................................................................28

1.1.6.3. E.COLIAS PLATFORM FOR RECOMBINANT PRODUCTION .......................30

1.1.7. ELRs FOR BIOMEDICAL APPLICATIONS ........................................................................31

1.1.7.1. SELF-ASSEMBLED ELRs DIBLOCKS FOR DRUG DELIVERY ...........................34

1.2. BASIC PRINCIPLES ABOUT GENE THERAPY ..............................................................35

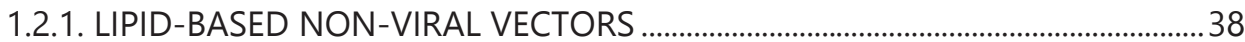

1.2.2. POLYMER-BASED NON-VIRAL VECTORS.............................................................40

1.2.3. ELRs AS NON-VIRAL VECTORS …………………………………………………....42

1.2.4. FACTORS AFFECTING THE TRANSFECTION ………………………………….......43

1.2.4.1. DNA COMPLEXATION .......................................................................................4

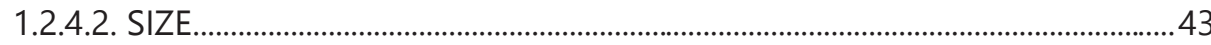

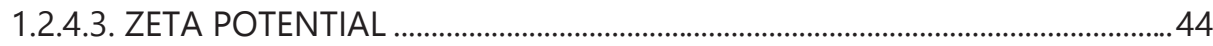


1.2.4.5. MOLECULAR WEIGHT AND BRANCHING ........................................................46

1.2.4.6. PARTICLE SURFACE MODIFICATION ..................................................................... 46

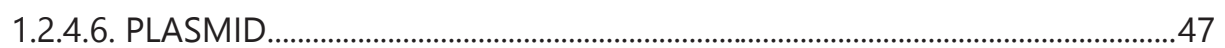

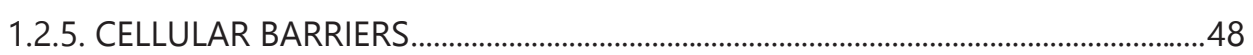

1.2.5.1. INTRA-VENOUS ADMINISTRATION ….............................................................4

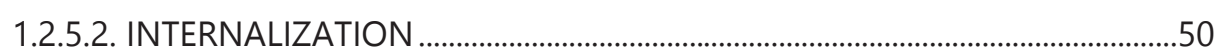

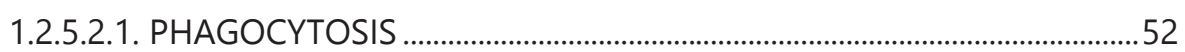

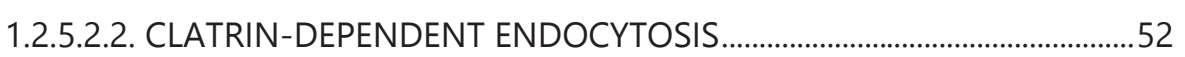

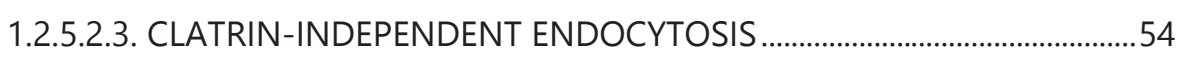

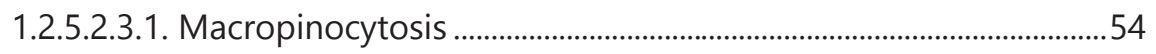



1.2.5.2.3.3. Caveolae and clathrin-independent pathways ................................56



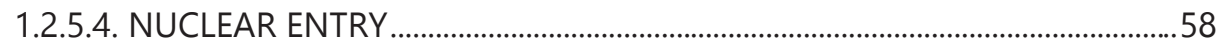

1.3. BASIC PRINCIPLES ABOUT NON-VIRAL BREAST CANCER GENE THERAPY....... 59

1.3.1. TRANSFERENCE OF TUMOR-SUPRESSOR GENES OR SUPRESSION OF ONCOGENES 61

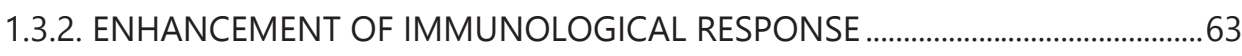

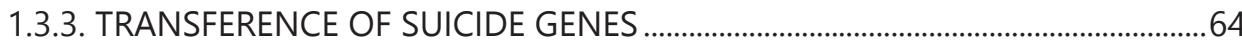

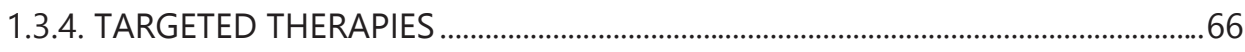

1.3.4.1. MUC1 AS TARGETING AGENT BY APTAMERS.............................................69

1.4. BASIC PRINCIPLES ABOUT RIBOSOME INACTIVATING PROTEINS...................... 72



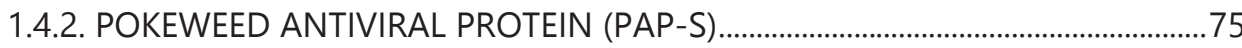

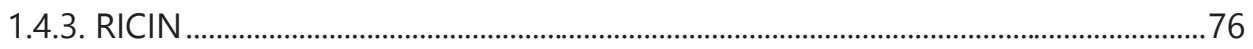

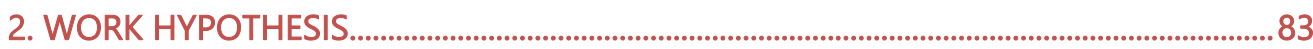

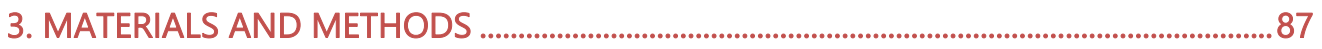

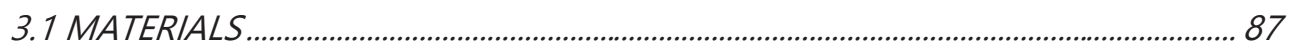

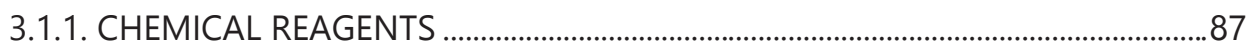


3.1.2. GLASS MATERIAL AND OTHER MATERIALS .88

3.1.3. BUFFERS 88

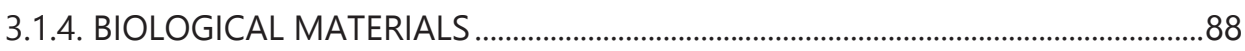

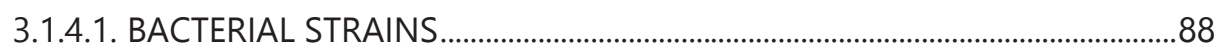

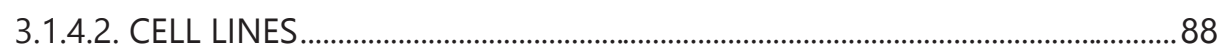

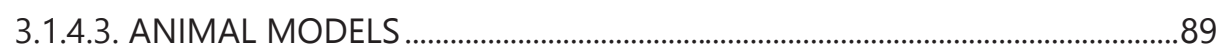

3.1.4.4. OTHER MATERIAL FOR BIOLOGICAL ASSAYS.............................................. 89

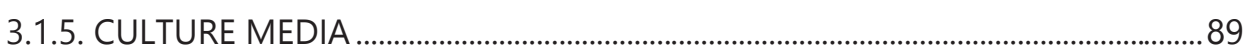

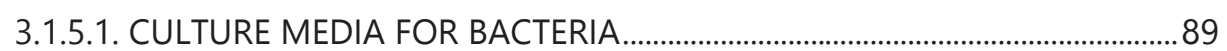

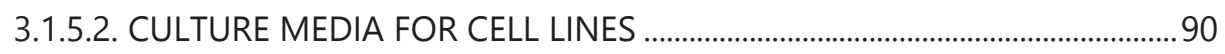

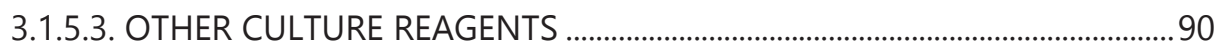

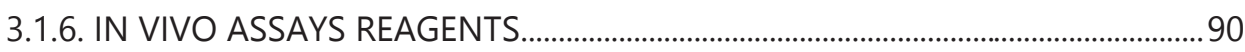

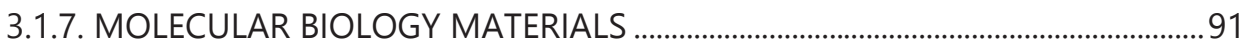

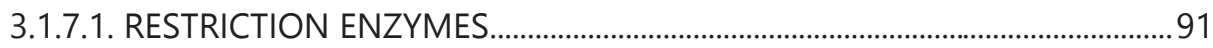

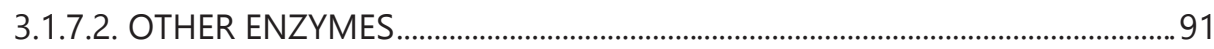

3.1.7.3. CLONING AND EXPRESSION VECTORS ......................................................... 91

3.1.7.4. POLYMERASE CHAIN REACTION (PCR) REAGENTS ....................................95

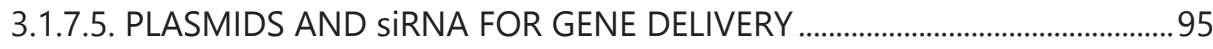

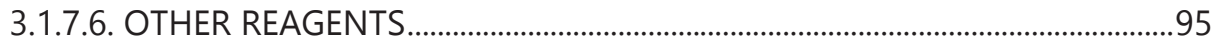

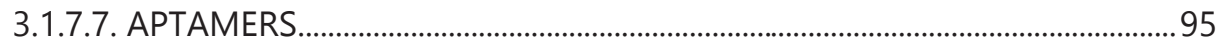

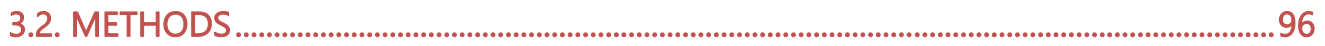

3.2. 1. ELRS DESIGN USING GENETIC ENGINEERING TECHNIQUES..............................96

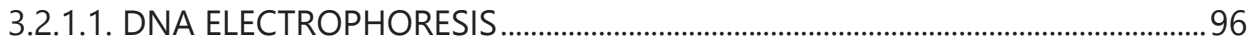

3.2.1.2. PCR

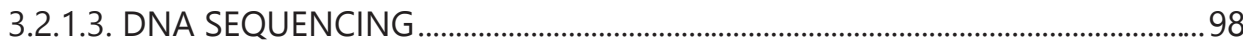

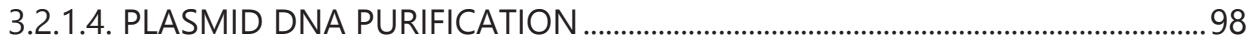

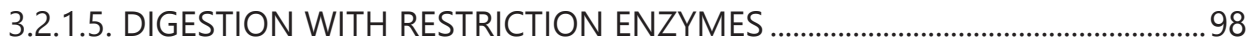

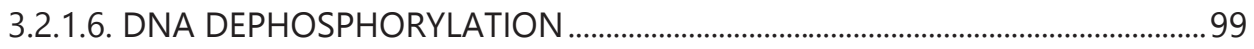

3.2.1.7. DNA PURIFICATION FROM AGAROSE GEL.......................................................99

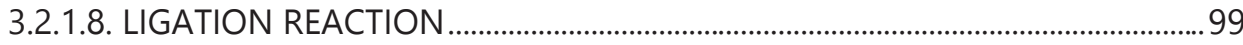

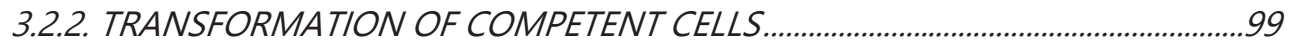


3.2.2.1. XL-1 BLUE SUBCLONING . .99

3.2.2.2. XL-1 BLUE COMPETENT.. . .99

3.2.2.3. EXPRESSION STRAINS: BLR (DE3) AND BL21 Star (DE3). 100

3.2.2.4. GLICEROL STOCK PREPARATION 100

3.2.3. PRODUCTION AND PURIFICATION OF ELR. 100

3.2.3.1. RECOMBINANT POLYMER EXPRESSION...................................................... 100

3.2.3.2. TOTAL PROTEIN FRACTION ANALYSIS .............................................................. 101

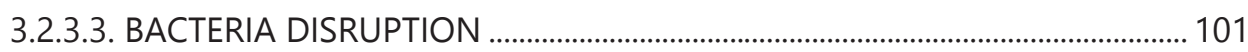

3.2.3.4. PURIFICATION OF ELRs........................................................................................ 102

3.2.3.5. ENDOTOXIN REMOVAL FROM ELRs.................................................................... 103

3.2.3.5.1. DETERMINATION OF ENDOTOXIN LEVELS.............................................. 103

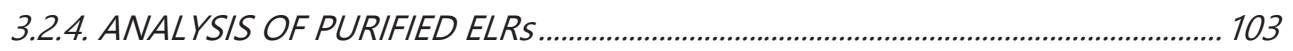

3.2.4.1. SDS-PAGE (Sodium Dodecyl-sulfate Polyacrylamide Gel Electrophoresis)

3.2.4.1.1. SDS-PAGE STAINING .................................................................................... 104

3.2.4.2. AMINO-ACID COMPOSITION ……………………………………………………... 105

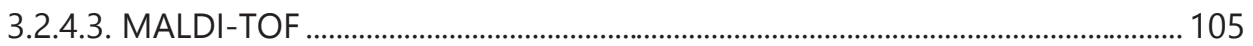

3.2.4.4. DIFFERENTIAL SCANING CALORIMETRY (DSC).............................................. 106

3.2.4.5. ${ }^{1} \mathrm{H}$ NUCLEAR MAGNETIC RESONANCE ('H-NMR)....................................... 106

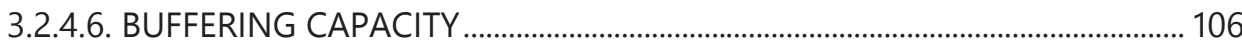

3.2.5. CHEMICAL MODIFICATION OF ELRs ................................................................. 107

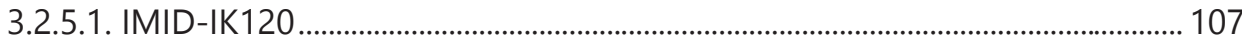

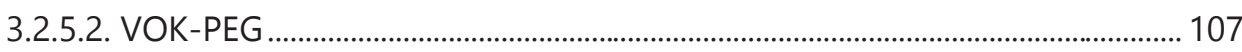

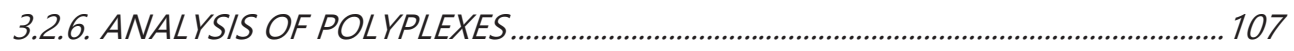



3.2.6.2 GEL RETARDATION AND PROTECTION ASSAY ................................................. 108

3.2.6.3. DYNAMIC LIGHT SCATTERING (DLS) .................................................................. 108

3.2.6.3.1. CALCULATION OF Tt FOR THE ELR IN THE PRESENCE OF pDNA..... 111

3.2.6.4. ZETA POTENTIAL ...................................................................................................... 111

3.2.6.5. TRANSMISSION ELECTRON MICROSCOPY (TEM)............................................ 112

3.2.6.6. THERMAL TURBIDIMETRY............................................................................... 112 
3.2.8.1. RETARDATION ASSAY

3.2.8.2. ABSORBANCE

3.2.8.3. FLOW CITOMETRY

3.2.10.1.1. RED BLOOD CELL (RBC) AGGREGATION

3.2.10.1.2. WHITE BLOOD CELL (WBC) AND PLATELET BLOOD CELL (PBC) AGGREGATION

3.2.11.1. CELL CULTURE.

3.2.11.2. EFFECT OF THE ELRS AND POLYPLEXES COATED WITH APTAMERS ON CELL VIABILITY

3.2.11.2.1. IN VITRO VIABILITY ASSAY OF ELRS.

3.2.11.2.2. IN VITRO VIABILITY ASSAY OF POLYPLEXES COATED WITH APTAMERS

3.2.11.2.3. IN VITRO VIABILITY ASSAY OF POLYPLEXES FUNCTIONALIZED WITH APTAMERS

3.2.12. TRANSFECTION ASSAYS

3.2.12.1. POLYPLEX CELL UPTAKE

3.2.12.1.1. CONFOCAL MICROSCOPY OF POLYPLEXES FORMED BY ELRS WITH ACQUIRED FUNCTIONALITIES

3.2.12.1.2. CONFOCAL MICROSCOPY OF POLYPLEXES COATED WITH APTAMERS

3.2.12.1.3. FLOW CYTOMETRY TO VISUALIZE POLYPLEXES COATED WITH APTAMERS UPTAKE

3.2.12.2. $\mathrm{ARG}_{8}-\mathrm{ELR}_{\mathrm{BC}}$ UPTAKE. 
3.2.12.2.2. INTRACELLULAR DISTRIBUTION BY CONFOCAL MICROSCOPY..... 119 3.2.12.2.3. TRANSFECTION OF PAK1 SIRNA AND EXPRESSION EVALUATION BY WESTERN BLOT 120

3.2.12.2.4. VISUALIZATION OF INTRACELLULAR DISTRIBUTION BY TIRF......... 120

3.2.12.3. LUCIFERASE EXPRESSION 121

3.2.12.3.1. LUCIFERASE ASSAY MEDIATED BY POLYPLEXES FORMED BY ELRS WITH ACQUIRED FUNCTIONALITIES.

3.2.12.3.2. LUCIFERASE ASSAY MEDIATED BY POLYPLEXES COATED WITH APTAMERS

3.2.12.3.3. LUCIFERASE ASSAY MEDIATED BY POLYPLEXES FUNCTIONALIZED WITH APTAMERS 122

3.2.12.4. ASSESMENT OF INTERNALIZATION PATHWAY FOR POLYPLEXES COATED WITH APTAMERS 123

3.2.12.5. p53 EXPRESSION. 123

3.2.12.5.1. POLYPLEXES FORMED BY ELRs WITH ACQUIRED FUNCTIONALITIES 123

3.2.12.5.2. POLYPLEXES COATED WITH APTAMERS 123

3.2.12.5.2.1. QUANTIFICATION OF p53 EXPRESSION-INDUCED CELL DEATH 124

3.2.12.6. PAP-S EXPRESSION 124

3.2.12.7. RICIN EXPRESSION 125

3.2.13. IN VIVO EXPERIMENTS .......................................................................................... 125

3.2.13.1. IN VIVO ASSAYS WITH ELR-pCMVPAP-5TR1 ............................................. 126

3.2.13.2. IN VIVO ASSAYS WITH VOK-PEG-5TR1-pDhMUC1-RICIN......................... 126

3.2.14. STATISTICAL ANALYSIS 126

CHAPTER 4A: DESIGN, PRODUCTION AND CHARACTERIZATION OF ELRs FOR GENE DELIVERY PURPOSES 133

4A. 1. BIOSYNTHESIS OF ELRS....................................................................................... 135

4A.1.1. SYNTHESIS OF HPGX3 AND RPGX3 ...................................................................... 135

4A.1.1.1. EXPRESSION OF HPGX3 AND RPGX3 ...................................................... 140

4A.1.2. SYNTHESIS OF V1K, VOKx48 AND VOKx72 CONSTRUCTIONS.................. 141 
4A.1.2.1. EXPRESSION OF V1K, VOKx48 AND VOKx72 143

4A.2. BIOTECNOLOGICAL MODIFICATIONS OF ELRS 147

4A.2.1. SYNTHESIS OF IKx3OHPGx3 AND VOKx48HPG 147

4A.2.1.1. EXPRESSION OF IKx30HPGx3 AND VOKx48HPGx1 150

4A.2.2. IK120 DERIVED ELRs WITH FUNCTIONAL DOMAINS. 153

4A.2.2.1. EXPRESSION OF IK120CPP AND LAELIK120CPP 157

4A.3. CHARACTERIZATION OF ELRS. 160

4A.3.1. SDS-PAGE 160

4A.3.2. MALDI-TOF ANALYSIS 161

4A.3.3. AMINO ACID ANALYSIS 165

4A.3.4. ${ }^{1} \mathrm{H}$ NUCLEAR MAGNETIC RESONANCE SPECTROSCOPY 166

4A.3.5. THERMAL BEHAVIOUR OF ELRS BY DIFFERENTIAL SCANNING CALORIMETRY 170

4A.3.6. DETERMINATION OF ENDOTOXIN LEVELS 173

4A.4. CHEMICAL MODIFICATIONS OF ELRS AND CHARACTERIZATION. 174

4A.4.1. SYNTHESIS OF THE IMID-IK120 BIOPOLYMER 174

4A.4.1.1. BUFFERING CAPACITY OF IMID-IK120 177

4A.4.2. CONSTRUCTION OF THE VOK-PEG-5TR1 BIOPOLYMER 178

FINAL REMARKS 184

CHAPTER 4B: ELR DIBLOCKS FOR DRUG DELIVERY. 189

4B.1. PRODUCTION AND CHARACTERIZATION OF Arg ${ }_{8}-E L R_{B C}$ 190

4B.1.1. PARTICLE FORMATION OF $\mathrm{Arg}_{8}-\mathrm{ELR}_{\mathrm{BC}}$ 191

4B.2. INTERNALIZATION KINETICS OF Arg ${ }_{8}$-ELRBC 194

4B.3. INTRACELLULAR DISTRIBUTION OF Arg -ELR $_{B C}$. 195

4B.3.1. ASSESMENT OF THE INTERNALIZATION PATHWAY 196

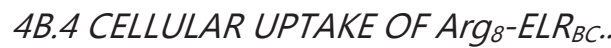
199 FINAL REMARKS 201 
CHAPTER 4C: ELASTIN-LIKE RECOMBINAMERS WITH ACQUIRED FUNCTIONALITIES FOR GENE-DELIVERY APPLICATIONS

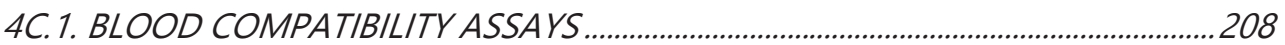



4C.3. DNA CONDENSATION ABILITY AND PLASMA-RELEASE ASSAYS ....................212

4C.4. DETERMINATION OF PARTICLE SIZE AND Z-POTENTIAL..................................213

4C.5. CELL TRANSFECTION AND TRAFFICKING ASSAYS...........................................2216

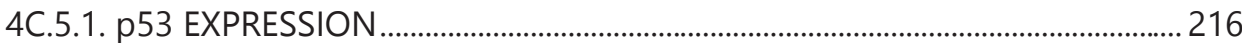

4C.5.2. POLYPLEX CELL INTERNALIZATION................................................................. 218

4C.5.3. LUCIFERASE TRANSFECTION AND EXPRESSION ………………………….......220

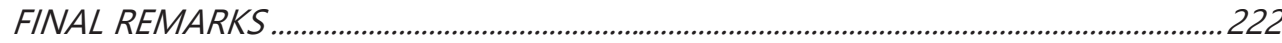

4D. BIOCOMPATIBLE ELR BASED POLYPLEXES COATED WITH MUC1 SPECIFIC

APTAMERS AND TARGETED FOR BREAST CANCER GENE THERAPY.................................227

4D.1 SYNTHESIS AND CHARACTERIZATION OF VOKX72 .........................................230

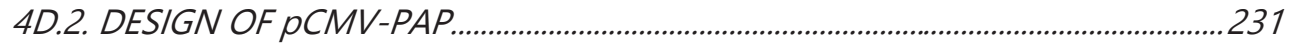

4D.3 PHYSICAL CHARACTERIZATION OF ELR-pDNA POLYPLEXES.............................232

4D.3.1 TRANSITION TEMPERATURE FOR THE ELR IN THE PRESENCE OF PDNA233

4D.3.2. PARTICLE SIZE, ZETA POTENTIAL AND MICROSCOPIC ANALYSIS ............237



4D.4. 1. EFFECT OF THE POLYPLEX-APTAMER SYSTEM ON CELL VIABILITY..............241

4D.4.2. LUCIFERASE EXPRESSION……………………………………………………....2 242

4D.4.3. CELLULAR UPTAKE OF POLYPLEXES ................................................................... 246

4D.4.4. ASSESSMENT OF THE INTERNALIZATION PATHWAY .....................................2 248

4D.4.5. EFFECT OF p53 EXPRESSION OVER BREAST CANCER CELLS ....................... 250

4D.3.5. SUICIDE GENE THERAPY USING PAP-S TOXIN GENE ON HUMAN BREAST

CANCER CELLS 253

4D.4. IN VIVO ASSAYS WITH ELR-pCMVPAP-5TR1 ..................................................25

FINAL REMARKS 259 
4E. ELR BASED SUICIDE GENE THERAPY SYSTEM DIRECTED TO BREAST CANCER USING RICIN GENE

4E. 1. DESIGN OF pDhMUC1-RICIN 267

4E.2 SYNTHESIS AND CHARACTERIZATION OF THE VOK-PEG-5TR1 269

4E.3. POLYPLEX SIZE, ZETA POTENTIAL AND TEM 270

4E.4. TRANSFECTION ASSAYS. 271

4E.5. SUICIDE GENE THERAPY ASSAYS IN VITRO 276

4E.6. SUICIDE THERAPY ASSAYS IN VIVO 277

FINAL REMARKS 281

5. CONCLUSIONS

5. 1. DESIGN, PRODUCTION AND CHARACTERIZATION OF ELRS FOR GENE DELIVERY PURPOSES.

5.2. ELR DIBLOCKS FOR DRUG DELIVERY

5.3. ELASTIN-LIKE RECOMBINAMERS WITH ACQUIRED FUNCTIONALITIES FOR GENE-DELIVERY APPLICATIONS 288

5.4. BIOCOMPATIBLE ELR BASED POLYPLEXES COATED WITH MUC1 SPECIFIC APTAMERS AND TARGETED FOR BREAST CANCER GENE THERAPY.

5.5. ELR BASED SUICIDE GENE THERAPY SYSTEM DIRECTED TO BREAST CANCER USING RICIN GENE.

6. REFERENCES 295

ABREVIATIONS 323 


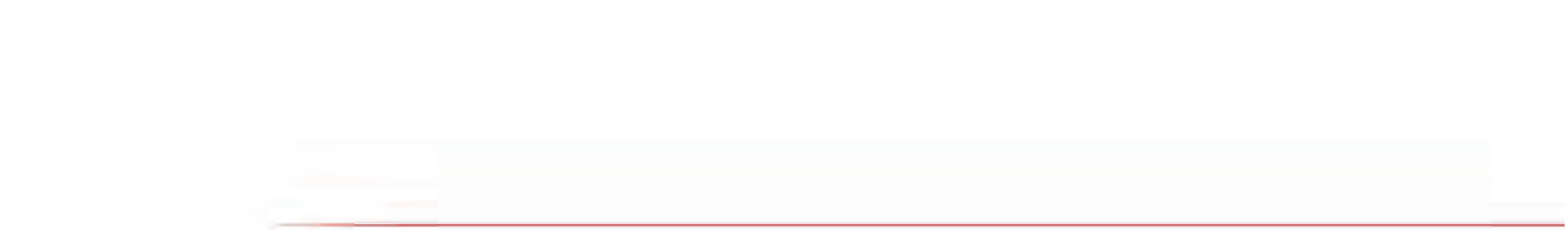

10 


\section{ABSTRACT}

Over the years material science has pursued to mimicking the properties and features inherent to natural proteins. One of these proteins that offer biocompatibility, elasticity and thermosensitive behavior that leads to self-assembled processes is the elastin. From (VPGXG) repeated motifs a variety of Elastin-like recombinamers (ELRs) inspired in natural elastin have been developed. The aim of this thesis is to demonstrate the versatile properties of ELRs in order to create a variety of ELRs able to form nanocomplexes and be applied for biomedical purposes as gene or even drug delivery.

The present work has addressed the whole process of design, production, purification, characterization and direct application of the novel ELRs. For that, the utilization of genetic engineering, microbiology, physico-chemical together with in vitro and in vivo techniques has been performed.

Initially, the design of ELRs through recombinant techniques and focused on gene delivery applications was achieved. A collection of hydrophilic ELRs rich in lysine and histidine amino acids was obtained. In addition, the incorporation of new functionalities by means of penetratin CPP and LAEL peptides was accomplished. Chemical modifications led to the generation of novel ELRs provided of buffering capacity and cell specificity by means of imidazole groups and anti-MUC1 aptamer incorporations.

Indeed, the suitability of a self-assembled ELR diblock (ELR $\mathrm{B}_{\mathrm{BC}}$ ) modified with $\mathrm{Arg}_{8} \mathrm{CPP}$ at $\mathrm{C}$-t for $\mathrm{pH}$ sensitive drug delivery was accomplished. This work explored the cell uptake and accumulation of ELR nanoparticles into acidic vesicles in order to evaluate the incorporation of $\mathrm{Arg}_{8}$ peptide to the $\mathrm{ELR}_{\mathrm{BC}}$ as the best alternative for carrying the drug. In addition, macropinocytosis as cellular entrance pathway was confirmed by the role of heparin sulfate proteglycan (HSPG) and p21 activated kinase 1 (PAK1) molecules.

In addition, the evaluation of ELRs with the biofunctional domains penetratin, LAEL and imidazole groups was assessed in terms of biocompatibility, complexation and transfection abilities. The results showed blood and cell compatibility. Indeed, ELRs were able to condense the plasmid DNA (pDNA) and form polyplexes. These 
polyplexes were uptaken by cells and they were able to express both p53 and luciferase transgenes showing higher expression for polyplexes formed by LAEL and penetratin peptides.

In light of these results, the use of the ELR with high density of lysines was achieved. Higher complexation and transfection abilities were achieved in comparison with the previous ELRs modified with functional domains. Indeed, the incorporation of the anti-MUC1 aptamers in order to provide cell specificity to polyplexes was achieved. As result, stable polyplexes with higher transfection ability in breast cancer cells was obtained. Hence using this system, suicide gene therapy was tested by means of PAP-S gene transfection with high cellular death in vitro. The translation into the in vivo scenario using the PAP-S suicide gene therapy led to inhibition in breast tumor growth evolution.

Finally, this work explored the utilization of a complex system constituting a double safety lock device focused on suicide breast cancer gene therapy. The previously designed biopolymer VOK-PEG-5TR1 provided with cell type specificity was shown to form proper polyplexes in presence of plasmid DNA. Thus, the biopolymer complexed with a therapeutic plasmid containing the ricin gene was tested both in vitro and in vivo. High levels of cytotoxicity were found in the target cells while a protective effect was observed over fibroblasts. In vivo assays with different doses of nanocomplexes showed a significant inhibition of tumor growth when compared with placebo. 


\section{RESUMEN}

A lo largo del tiempo la ciencia de materiales ha perseguido mimetizar las propiedades y características propias que se encuentran en las proteínas naturales. La elastina, dotada de biocompatibilidad, elasticidad y comportamiento termo-sensible que conduce a procesos de auto-ensamblado es una de estas proteínas. Partiendo de la secuencia (VPGXG) encontrada en la elastina natural, se ha creado una gran variedad de recombinámeros tipo elastina (ELRs) inspirados en esta proteína. El objetivo de esta tesis es demostrar la versatilidad de estos recombinámeros para la creación de ELRs capaces de formar nanocomplejos y aplicarlos a fines biomédicos como son la liberación de genes o incluso de fármacos.

El trabajo desarrollado en esta tesis aborda todo el proceso de diseño, producción, purificación, caracterización y aplicación directa de los nuevos ELRs. Para ello, se han utilizado una amplia variedad técnicas de ingeniería genética, microbiología, física, química junto con las correspondientes de cultivos celulares y manejo de animales de experimentación.

En primer lugar se llevó a cabo el diseño de ELRs a través de técnicas recombinantes enfocado a la aplicación final de liberación génica con el que se obtuvo una colección de ELRs ricos en lisinas e histidinas. Además se incorporaron nuevas funcionalidades a los ELRs por medio de los péptidos penetratin y LAEL. Asimismo la versatilidad de los ELRs permitió modificarlos químicamente generando nuevos ELRs provistos de capacidad de tamponamiento y especificidad celular mediada por grupos imidazol y aptámeros anti-MUC1 respectivamente.

En este trabajo también se evaluó la idoneidad de los dibloques de ELRs autoensamblados (ELR $\mathrm{BC}$ ) y modificados con el CPP $\mathrm{Arg}_{8}$ en el extremo C-t para la liberación de fármacos dependiente de pH ácido. Se exploró la internalización celular y acumulación de las nanopartículas de ELR en vesículas ácidas con el fin de evaluar la incorporación de $\mathrm{Arg}_{8}$ al dibloque ELR $\mathrm{BC}_{\mathrm{BC}}$ como mejor alternativa para transportar el fármaco. Además se confirmó la macropinocitosis como vía de entrada celular a través del papel de moléculas como el proteoglicano heparan sulfato (HSPG) y la kinasa 1 activada por p21 (PAK1). 
A continuación se evaluó la biocompatibilidad, capacidad de acomplejamiento con el DNA plasmídico (pDNA) y transfección de los ELRs dotados de dominios funcionales de penetratin, LAEL y grupos imidazol. Se observó la capacidad de estos ELRs para condensar el DNA y formar poliplexos. Cuando las células se incubaron con estos poliplexos, estas fueron capaces de internalizarlos y expresar los genes p53 y luciferasa mostrando una mayor expresión en las tratadas con poliplexos formados por los péptidos LAEL y penetratin.

Como consecuencia de estos resultados, se adoptó la estrategia de utilizar un ELR con alta densidad de lisinas. Se obtuvo un mejor acomplejamiento con el pDNA así como una mejor transfección comparada con los ELRs modificados con dominios funcionales. Asimismo se incorporaron aptámeros anti-MUC1 con el objetivo de proporcionar especificidad celular a los poliplexos. Como resultado de la adición de aptámeros se obtuvo una mayor capacidad transfectiva en las células de cáncer de mama. Por medio de este sistema se procedió a evaluar la estrategia de terapia génica suicida utilizando el gen PAP-S y obteniendo altos niveles de muerte celular in vitro. El paso al in vivo utilizando la terapia génica suicida con PAP-S supuso la inhibición del crecimiento del tumor de mama.

Por último este trabajo exploró la utilización de un dispositivo complejo de terapia génica suicida para el cáncer de mama dotado de un doble sistema de seguridad. El biopolímero VOK-PEG-5TR1 diseñado previamente y dotado de especificidad celular fue capaz de formar poliplexos estables en presencia de pDNA. Este complejo biopolímero-plásmido terapéutico con el gen de la ricina como gen tóxico se evaluó tanto in vitro como in vivo. El resultado mostró unos altos niveles de citotoxicidad en las células diana de cáncer de mama mientras que sugería un efecto protector sobre los fibroblastos. Los ensayos in vivo con diferentes dosis de los nanocomplejos mostraron una inhibición significativa en el crecimiento del tumor de mama. 


$$
1
$$




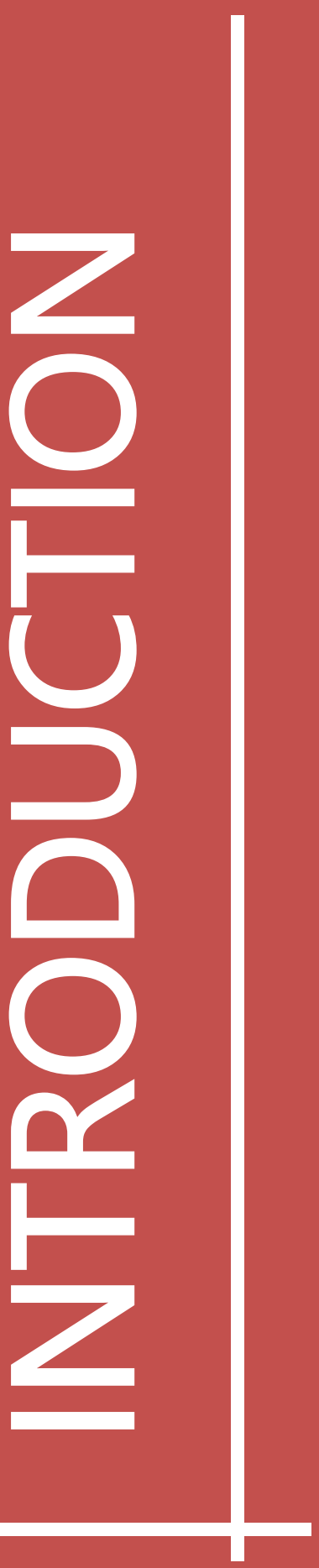


Q

18 


\section{INTRODUCTION}

\subsection{ELASTIN LIKE RECOMBINAMERS}

\subsubsection{NATURAL ELASTIN}

The elastin is the major protein component of tissues that require elasticity and resilience such as arteries, lungs, bladder, skin, elastic ligaments and cartilage besides of playing an active role in the cell behavior modulation and tissue repair promotion $(1,2)$. Moreover, the content of elastin in skin is $5-10 \%$, in ligament is $10-15 \%$ and aorta means $40-50 \%$ of dry mass (3). In addition, elastin is one of the most important components of the extracellular matrix (ECM). The origin of its abilities roots in the amino-acid composition from the soluble elastin precursor named as tropoelastin (72 $\mathrm{kDa})$, which is governed by repeated motifs, such as VPGG, VPGVG, APGVG, and VGVAPG (4). These motifs are responsible for the elastic properties of the insoluble but extremely stable mature elastin. Elastin has a conformational structure that allows it to undergo high deformation without damage and, what is more important, to return to their original state once the stress disappears (Figure 1.1). Furthermore there is a low turnover, so that elastin fibers last from 40 to 70 years (3-5).

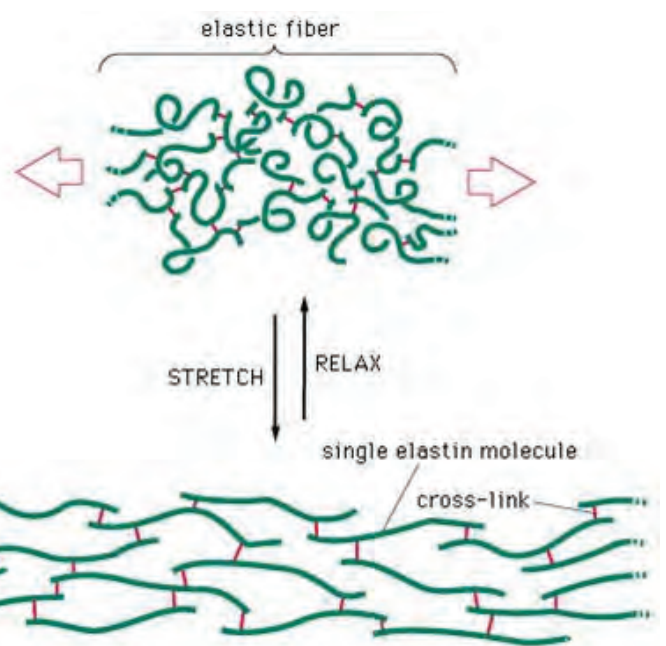

(B)

Figure 1.1. Elastic fiber behavior in response to stretching force. Each elastin molecule uncoils into a more extended conformation when stretch is applied. Once the stretching force is relaxed, elastin molecules will recover their initial conformation. 
Despite of its hydrophobic nature, elastin can be highly hydrated by water molecules from aqueous solvent where in between of its crosslinking moieties the hydrophobic segments maintain considerable mobility (6). As a result of a temperature increment, elastin suffers a transition from a disordered state to an order state where the molecules aggregates giving a sticky and dense separated phase where elastin exhibit its excellent mechanical properties (7).

\subsubsection{A NEW TERM: "ELR"}

Since the detection of elastin repeated motifs as responsible for elasticity of vascular cell walls, "elastin-like" polypeptides (ELPs) have been widely studied. Thus, ELPs are polypeptides whose sequence is bio-inspired and found in natural elastin. A broad number of studies done by Urry $(8,9)$ demonstrated the high potential of ELPs to create a variety of polypeptides with useful mechanical properties. They are formed by repetitions of the sequence (VPGXG)n or its permutations, where $X$ can be any amino-acid with the exception of L-proline and $n$ corresponds with the number of pentapeptide repetitions. Indeed, ELPs undergo a reversible inverse temperature phase transition (ITT) which makes them temperature sensitiveness (9). This ITT allows ELPs to change from a soluble to an insoluble state upon increasing or lowering the temperature(10), this process will be further explained in the next 1.1.3 section.

Recombinant DNA technology has been applied to bioproduce this class of materials in order to have a tight control over the macromolecular architecture involving ELP sequence, chain complexity and monodispersity. Indeed, a new term named as Elastin-like Recombinamers (ELRs), has been created to refer to those ELPs produced by genetic engineering techniques (11). Thus, the term "recombinamer" prevents the reader from automatically identifying these molecules with natural or modified proteins. Contrary, ELR suggests a molecule whose composition is defined strictly by genetic engineering design.

The similarity between elastin protein and the ELR amino sequence results in mimicking the native functional and behavior properties of elastin, specifically related with their biocompatibility, smart nature and mechanical properties.

Their high biocompatibility, which is very relevant for biomedical applications, has been tested by the American Section of the International Association for Testing 
Materials (ASTM) for materials and devices in contact with tissues, tissue fluids and blood (12).The $\beta$-spiral structure presented in ELR seems to be involved in the recognition prevention by the immune system (13). Indeed, degradation products from ELRs have been proved as non-toxic since they are made of natural amino-acids (14).

\subsubsection{MOLECULAR BASIS OF ITT AND $\triangle T \mathrm{Tt}$}

ELRs present a lower critical solution temperature (LCST) behavior (Figure 1.2). Below a critical temperature named as transition temperature $(\mathrm{Tt})$, the ELR chains are hydrophobically hydrated, forming a disordered state of random coils. This hydration is characterized by ordered clathrate-like water structures surrounding the apolar moieties of the polymer with thermodynamic properties of decreased enthalpy and decreased entropy relative to bulk water (15). Whereas above Tt the structure loses its water molecules to form a viscoelastic phase-separated state $(63 \%$ of water and $37 \%$ of polymer in weight) or even to form the strong shrinkage and collapse of hydrogels (16). In this phase separated-state the ELRs adopt a dynamic, regular and ordered $\beta$-spiral structure (13), thereby resulting in a variation in enthalpy. $\beta$-spiral structure involves one type II $\beta$-turn per pentamer stabilized by intra-spiral inter-turn and inter-spiral hydrophobic contacts and hydrogen bonds (11). This increase in order of the polypeptide with raise in temperature is named as inverse transition temperature (ITT).

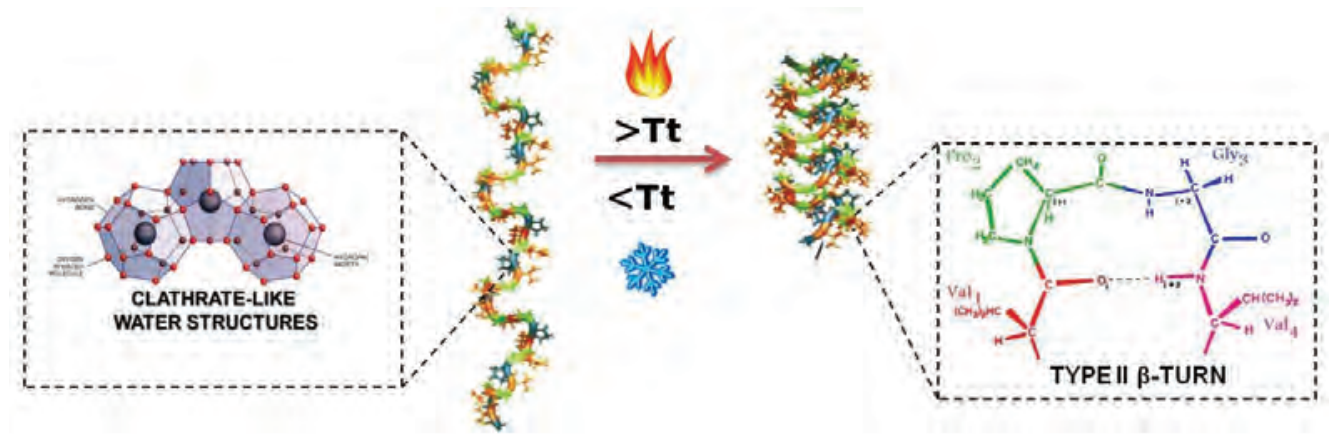

Figure 1.2. Schematic representation of the thermal transition of ELRs from an extended state (low temperatures, hydrophobic moieties surrounded by clathrate water structures) to a folded state (type II $\beta$-turn in VPGVG pentapeptides)

During the initial stages of polymer dehydration, the hydrophobic association of three $\beta$-spirals leads to the formation of filaments (Figure 1.3) $(11,13,17)$. These 
filaments grow up to particles of several hundreds of nanometers in diameter and settle into a visible phase-separated state. The folding which leads to this situation is a reversible process if the temperature is decreased below $\mathrm{Tt}$.

This mechanical behavior retained from elastin conferred them the term as "smart" biomaterials.

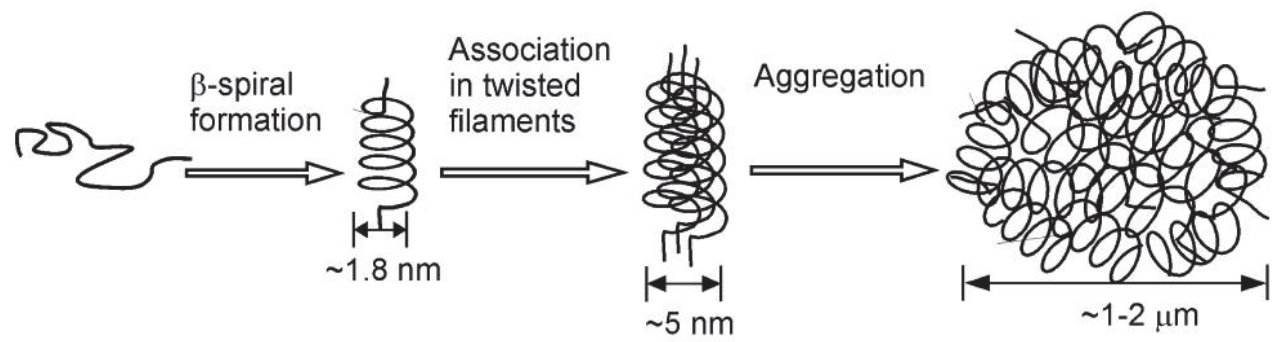

Figure 1.3. Mechanism for the ITT of ELRs. $\beta$-spiral formation, formation of twisted filaments or $\beta$-spiral supercoil and their aggregation into microaggregates (17)

\subsubsection{FACTORS INFLUENCING THE Tt}

Some factors are able to tune the Tt value of ELRs, which opens the door to use them in accordance with the desired application by modifying the Tt. Parameters that might change the Tt of a standard ELR formed by poly(VPGVG) can be divided into intrinsic or extrinsic factors.

\subsubsection{INTRINSIC FACTORS}

\subsection{CONCENTRATION AND CHAIN LENGTH}

Intrinsic factors such as the concentration and chain length of the polymer itself can affect the Tt. In fact Urry et al. described the effect of increasing the concentration of poly(VPGVG) with $50 \mathrm{kDa}$ over the Tt, showing a decrease in the Tt value until a high concentration limit was reached at about $40 \mathrm{mg} / \mathrm{mL}$ (8). However the effect of ELR concentration and chain length on the Tt for different sequences was not accounted for the development of these correlations. For this reason, Chilkoti et al. (18) studied this effect and depicted the logarithmic relation of decreasing temperature with ELR increasing concentration (Figure 1.4A) for high and low chain length (60 to 330 polypeptides) from the ELR $\left(V_{5} A_{2} G_{3}\right)$ which corresponds from $\approx 20 \mathrm{kDa}$ to $\approx 130 \mathrm{KDa}$. In this work, quantitative correlations between ELR chain length and concentration on the Tt were developed. After the comparison of empirical and correlated results, the 
great impact of concentration and chain length on the Tt at low concentration and small chain lengths was evidenced (Figure 1.4B and C). Higher variation in Tt with lower concentrations and chain length was found.
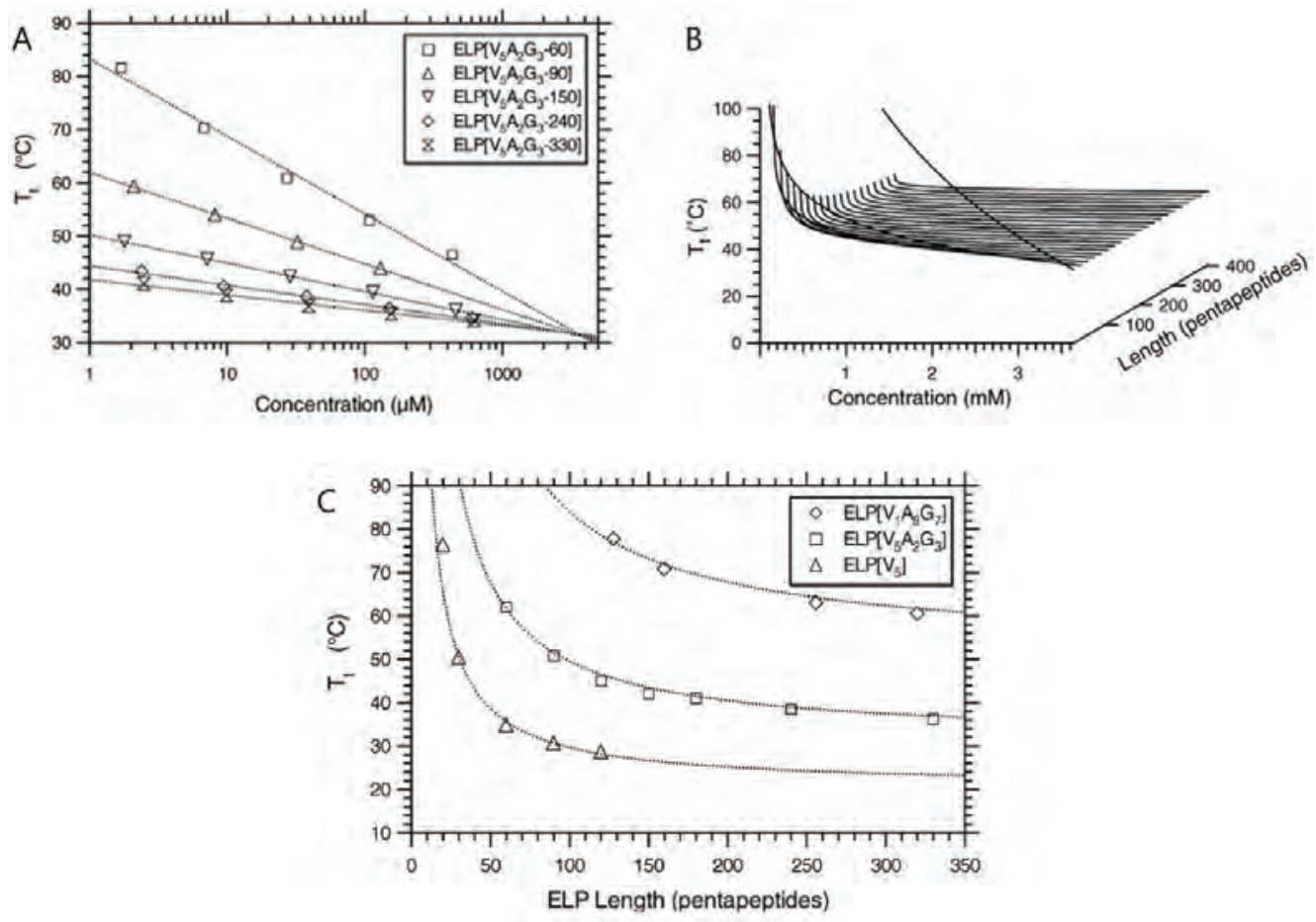

Figure 1.4. Effect of concentration and chain length on ELR Tt. Tt of ELP $\left(V_{5} A_{2} G_{3}\right)$ of different chain lengths as function of their concentration (A). Calculated profiles of $\mathrm{Tt}$ versus concentration for ELR $\left(V_{5} A_{2} G_{3}\right)$ with different chain lengths (B). Tt as a function of ELR chain lengths for three ELR libraries at $25 \mu \mathrm{M}$ in PBS (C). (18).

\subsection{ELR AMINO-ACID COMPOSITION AND IONIZATION DEGREE}

As described by Urry et al., for a polypentapeptide written as poly $\left[f_{v}(V P G V G), f_{x}(V P G X G)\right]$ where $f_{x}$ and $f_{v}$ are mole fractions $\left(f_{x}+f_{v}=1\right)$, residues more hydrophobic than $\mathrm{Val}(\mathrm{V})$ lowers the Tt whereas less hydrophobic residues as $\mathrm{Ala}(\mathrm{A})$, Gly(G) and polar like Asp(COO-) or $\mathrm{Lys}\left(\mathrm{NH}_{3}{ }^{+}\right)$raises the Tt. Hence, Urry demonstrated that the Tt correlated with the mean hydrophobicity of guest residue and proposed a hydrophobicity scale (Figure 1.5).

Further studies of Chilkoti et al. provided a quantitative model to predict the Tt of a pool of ELR (guest residue being Ala and/or Val) from their composition, chain length and concentration in PBS (19). Even more, the importance of amino-acid composition for LCST behavior has conducted to a recently publication that reveals the guiding 
principles sequence heuristics to encode the LCST phase behavior in intrinsically disordered proteins (IDPPs) enriched in Pro and Gly with a repetitive polymer-like structure (20). Accordingly, amino-acid composition is determinant for controlling the LCST behavior from ELR and paves the way in the search for novel biomaterials.

Similarly, the usage of polar basic (Lys, Arg, His) or acid (Glu, Asp) amino-acids in the guest residue can change the Tt of ELR in response to $\mathrm{pH}$ and thereby obtaining a functional polymer. Urry et al. described that substitution of the guest residue by glutamic acid (E) when its side chains were ionized made polymer chains become more hydrophilic and as a consequence the Tt increased. A substitution in poly(VPGVG) by poly(VPGEG) involved the raised in $\mathrm{Tt}$ from $25^{\circ} \mathrm{C}$ at $\mathrm{pH} 2$ to $70^{\circ} \mathrm{C}$ at $\mathrm{pH} 7$ (9).

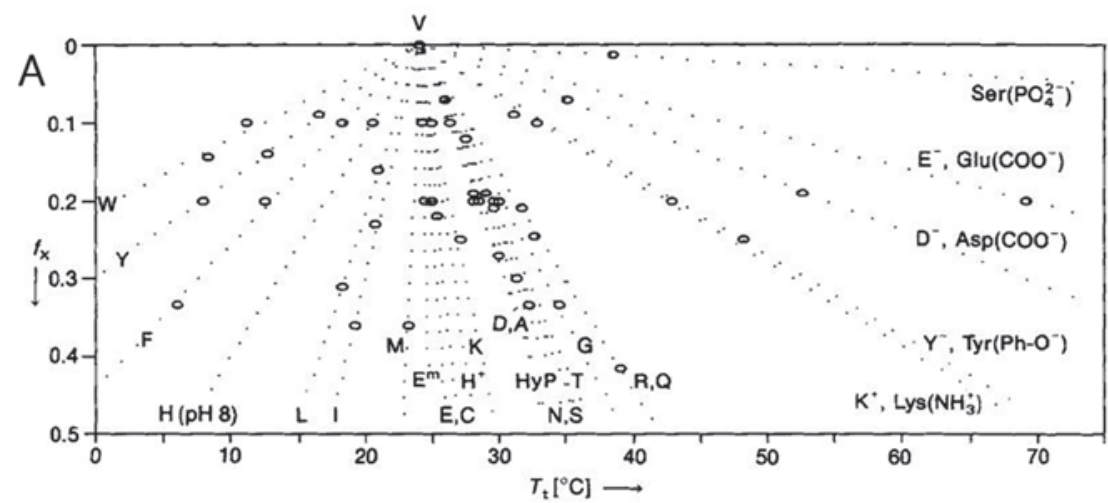

\section{B}



Figure 1.5. (A)Plots of $T_{f}$ fo poly-[ $\left.f_{v}(V P G V G), f_{x}(V P G X G)\right]$, in PBS as a function of $f_{x}$, at small $\mathrm{fx}$. At such low $X$ content the plots are essentially linear. (B) Dependence of $\mathrm{Tt}$ on Amino Acid Composition for poly-[fV(GVGVP), $f X(G X G V P)]$ where $f_{x}=0.2$. (X corresponds with the guest amino acid residue)(9). 


\subsubsection{EXTRINSIC FACTORS: EFFECT OF SALTS}

The addition of salts was reported as an extrinsic factor affecting the Tt of ELRs. The salts with the most potent effect are those with multivalent anions such as carbonates, sulfates and phosphates (9). The study from Cho et al. (21) with ELR $($ VPGVG) 120 and a variety of sodium salts depicted in Figure $1.6 \mathrm{~A}$, revealed a linear "salting out" behavior from this carbonates, sulfates, phosphates, fluorides and chlorides salts named as kosmotropes. Salting out is a physico-chemical effect based on the electrolyte-non electrolyte interactions in which at high saline concentrations, proteins or polymers precipitate due to the increase of hydrophobic interactions between them. By contrast, the salts formed by the named as chaotropic anions $\left(\mathrm{SCN}^{-}, \mathrm{I}^{-}, \mathrm{Br}^{-}, \mathrm{NO}_{3}{ }^{-}\right.$and $\mathrm{ClO}_{4}^{-}$) showed non-linear changes as result of salt addition. $\mathrm{SCN}^{-}$and $\mathrm{I}^{-}$promoted the increase of Tt at low salt concentration before salting-out behavior appears at higher concentrations. Additionally, Reguera et al. (22) showed the inverse influence of $\mathrm{NaCl}$ salt concentration in the Tt for the construct (GVGVP) 251 . When higher amount of $\mathrm{NaCl}$ was added a decrease in the $\mathrm{Tt}$ of the polymer was obtained.
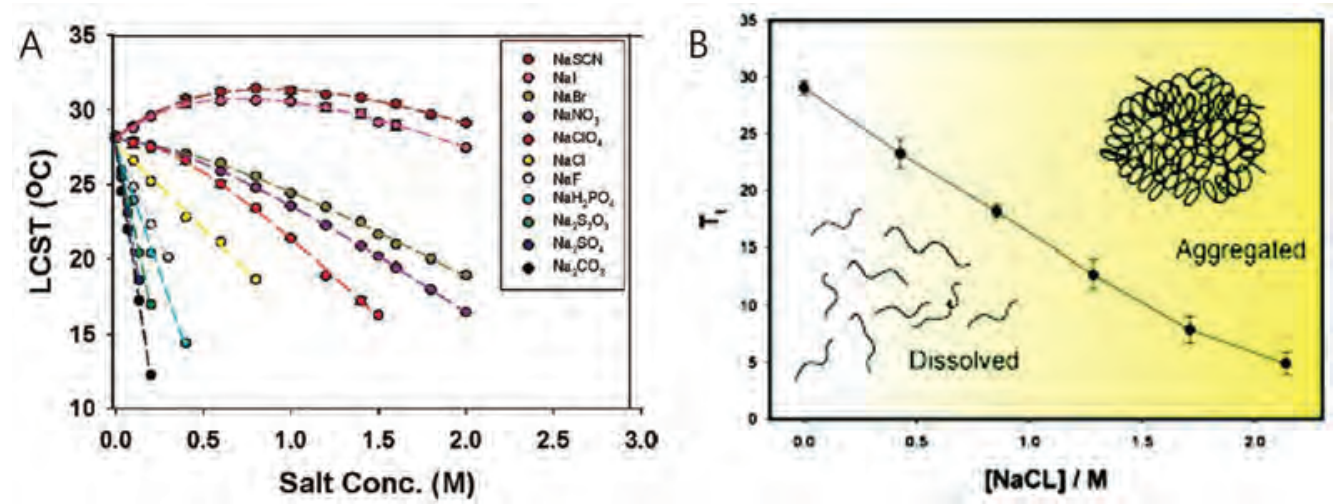

Figure 1.6. LCST behavior as function of salt concentration. With the ELR (VPGVG) 120 (A) (21). Influence of salt concentration in the Tt for $(G V G V P)_{251}$ at $50 \mathrm{mg} / \mathrm{mL}$ in aqueous solution (B)(22).

Furthermore, other factors such as organic solutes or pressure have been reported to affect on the Tt (9). It is important to notice that the final Tt of the ELR is not result of the independent effect of each factor (concentration, chain length, amino-acid composition or salt addition) but the global effect of them. 


\subsection{5. $\triangle T$ MECHANISM}

The ITT observed in ELRs is a reversible process with the formation of a denser, viscoelastic phase in response to raise temperature leading with the formation of elastic matrices. These elastic matrices could perform useful mechanical work and are called as "zero-order molecular machines of the Tt type".

As described above (1.1.4.1.2.), the degree of ionization has effect on the Tt. Changing the $\mathrm{pH}$ of the solution is possible to change the degree of ionization of amino acids from ELR. Thus, ELR with an isothermal $\mathrm{pH}$-driven contraction are capable of doing mechanical work. In general, an elastic matrix in which chemical, thermal or other energy source that could change the Tt causing the formation of dense and viscoelastic phase is named as "first-order molecular machines of the Tt type". In this group salt and reduction sensitive ELRs are also included (9). In Figure 1.7, the Tt-type first order energy conversions are those with arrows ending at the mechanical point. By contrast, second order energy conversions of the Tt type are those that even owing the folding and assembly capacity the mechanical work is not involved. For instance, polypeptides containing both an oxidized component of a redox couple chemical and electrical energy sources are affected and included in this second order.

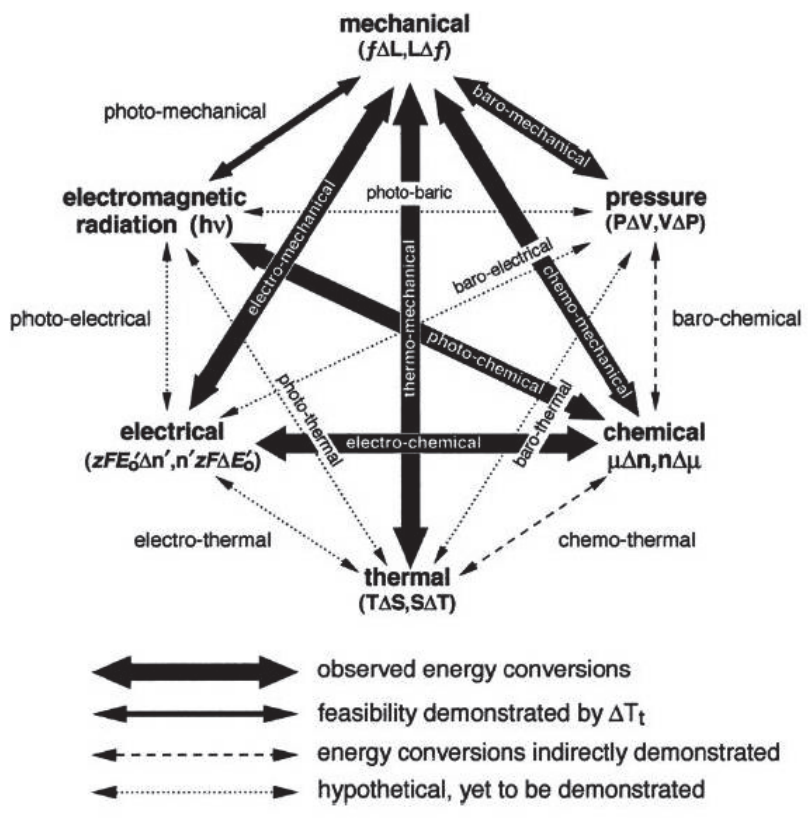

Figure 1.7. Putative energy conversions with molecular machines of the Tt type. Bold arrows indicates the energy conversions existing in elastic protein-based matrices (9). 
Research based on the ITT exhibited by elastic protein-based polymers involving a variety of energy conversions has settled five phenomenological axioms. These axioms which are summarized below have critical importance for the development of elastic-based biomaterials.

Axiom 1. The selection of the guest amino-acid residue as function of its hydrophobicity together with chemical modification alters the Tt since the hydrophobic folding is a measure of its functional hydrophobicity.

Axiom 2. Changing the temperature above Tt results in hydrophobic folding and assembly which can be used as mechanical work source.

Axiom 3. At constant temperature, when moving within a working temperature range (including lower and upper Tt values) it results in hydrophobic folding and assembly that can be use as mechanical work source.

Axiom 4. Factors such as temperature, pressure, chemical concentrations, ionization degree of a functional side chain among others can be used to change the Tt. Two or more functional groups each of which can be acted upon by a different energy input that changes the temperature interval for hydrophobic folding and assembly, can be coupled and being part of the same domain.

Axiom 5. More hydrophobic protein-based polymers make more efficient the energy conversions exposed above.

\subsubsection{BIOSYNTHESIS OF ELRS}

ELRs are designed through the use of genetic engineering techniques that confer the main advantage of total control with regard to chemical synthesis. Moreover, this permit not only to track the whole designing process but the construction of ELRs with novel physical, mechanical or biological properties. The biosynthesis of ELRs can be drafted in the following steps $(23,24)$ :

$\checkmark$ Construction of the synthetic gene in a cloning and expression plasmid together with its transformation into competent E.coli bacteria is required.

$\checkmark$ Screening and DNA sequencing in order to check the presence of ELR gene and to select the positive clones. 
$\checkmark$ Finally, the positive clone's selection and their transformation into expression competent cells and growth are needed.

$\checkmark$ Bioproduction of ELR.

$\checkmark$ Purification of ELR protein from cell lysates.

The design and production of stable and long de novo ELR codifying sequence of frequently small, highly repetitive artificial fragments and expression in heterologous system represents a challenge. To facilitate the biosynthesis of a codifying ELR gene, a balance between the proper codon usage from prokaryotic system and the ELR gene repetitive sequence are necessary to avoid the collapse of the bacteria translational system.

\subsubsection{MONOMER GENE}

The synthesis of monomeric genes is the previous step towards the multimeric ELR construction. Several strategies to create the monomer have been followed such as the use of two fully complementary oligonucleotides (25) (Figure 1.8A1) or the extension of two complementary primers by PCR (26) (Figures $1.8 \mathrm{~A} 2$ and 3). The 5 'and 3'ends usually contains non-palindromic endonuclease restriction sites that allows the unidirectional ligation. The utilization of type II endonucleases has lead to the "seamless cloning" that favors unidirectional ligation avoiding the insertion of undesired nucleotides $(23,24)$.

\subsubsection{MONOMER OLIGOMERIZATION}

There are two main strategies for ELR multimeric gene oligomerization: concatemerization and sequential methods (24). Indeed these strategies can be sequentially combined within the same implementation.

Concatemerization is the method based on a random unidirectional ligation of DNA fragments joined and inserted into the cloning vector through a single step (Figure 1.8B). This technique allows to synthesize homopolymers, however it presents some disadvantages such as low sequence fidelity, uncontrolled order of gene fragments and the presence of circular multimers as byproducts $(24,27)$. When the ELR composition become more complex, due to the needed of multimeric construction, a bigger control of the process is required. 


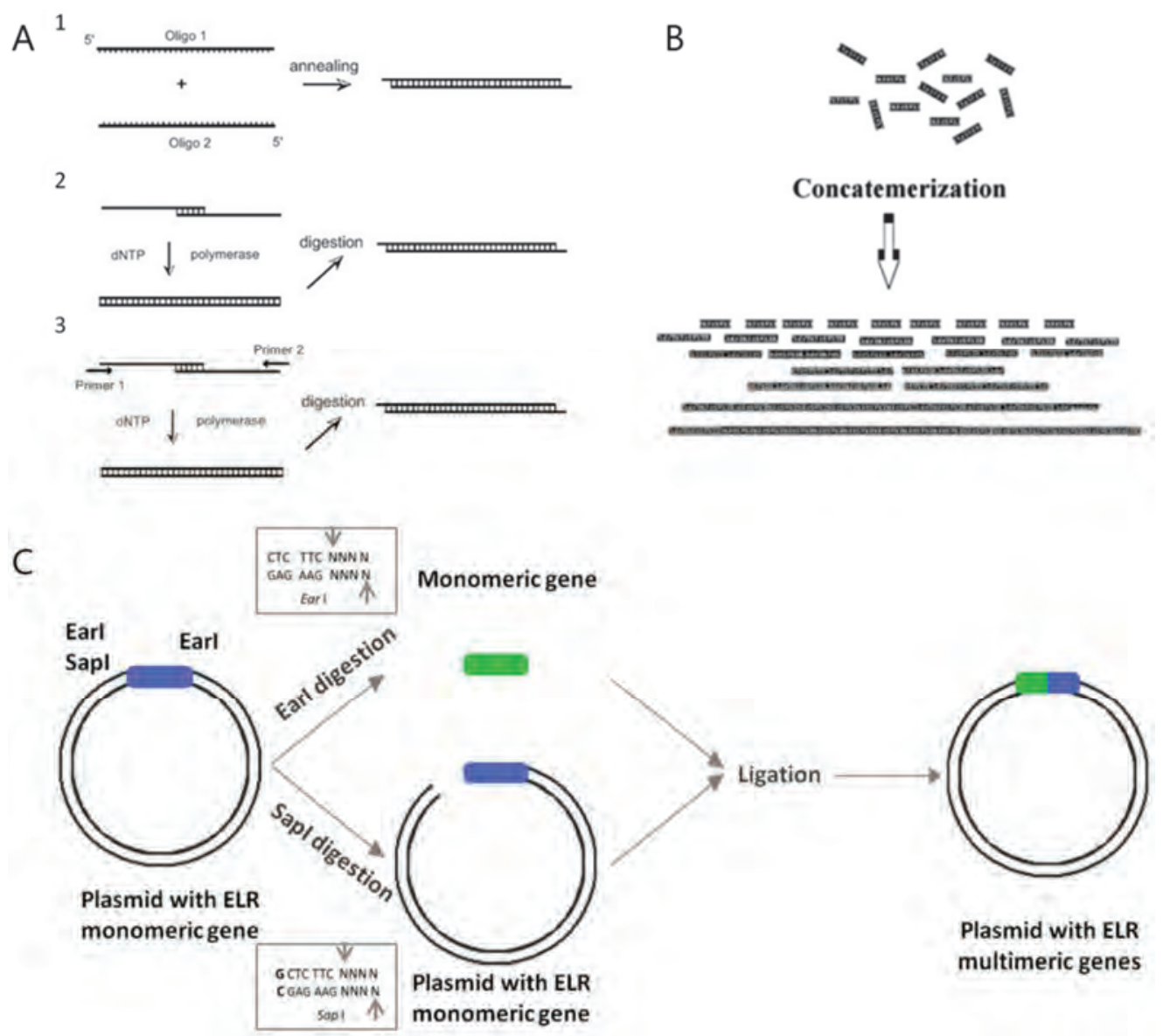

Figure 1.8. Aproaches for the synthesis of monomer and multimer ELRs. Several approaches can be used for the synthesis of the polynucleotide monomer gene by annealing of two chemical synthesized complementary oligonucleotides (1), by extension of two synthetic primers complementary on the $3^{\prime}$ end (2) and last by PCR of a monomer obtain by retrotranscription of two oligonucleotides (3) (A). Schematic representation of concatemerization method (B). Schematic representation of seamless RDL method for the genetic engineering synthesis of multimeric ELR genes (C).

As response to this demand, sequential methods as recursive directional ligation (RDL) appeared (28). In RDL, the addition of monomeric genes is directional and performed in a "step by step" manner. The concatemerization as well as the RDL involve a previous step where the monomer genes contain non-palindromic cohesive ends. That allows any two monomers to be seamlessly joined in a specific orientation "head to tail" by enzymatic ligation. The ligation of these monomers or multimers generates a longer sequence that can be used for more cycles of RDL and increases the structural diversity of the polymer (29). Using this method is possible to create a library of potentially useful monomers in the process of assembling larger genes (30). 
Although RDL method has been shown to be highly useful in the assembly of synthetic genes for repetitive polypeptides, it has some drawbacks. The limited pool of restriction enzymes recognizing non-palindromic sites together with the likely unspecific cleavage of these enzymes can increase the probability of plasmids internal cutting leading to the introduction of undesired amino-acid residues. As an alternative method, the seamless cloning using Sapl and Earl type II restriction enzymes has been developed and applied to ELRs design (31) (Figure 1.8C). This method permits the direct cloning of DNA monomers or multimers into expression vectors reducing the subcloning steps. Since Earl recognition sites are eliminated from the target DNA upon cleavage, only the DNA encoding the desired ELR sequence is joined to the next ligation reaction. This together with the use of Sapl, which cleaves a long recognition sequence reducing the probability of multiple recognition sites located within the target DNA, makes these endonucleases as good strategy for such oligomerization of ELRs by RDL method.

\subsubsection{E.COLIAS PLATFORM FOR RECOMBINANT PRODUCTION}

E.coli is a well-established and one of the most popular expression platforms for recombinant proteins where the codifying DNA is normally introduced in a plasmid expression vector. Nowadays, there are other systems than E.coli used to express ELRs as yeast or plants. For instance, recombinant silk-elastin polypeptides (32) and target proteins fused to ELRs have been successfully expressed in tobacco an potato plants $(33,34)$. However some concerns related with risk of viral and prion contaminations have been found (35). Yeast expression as Pichia pastoris has become an attractive host for the expression of ELRs, however protein yields are often low when compared to E.coli (36).

The main advantages of using E.coli are well known. It has fast growth kinetics which makes that high yields of proteins could be achieved, inexpensive components and fast and easy transformation with exogenous plasmid DNA. Thus, not only the bacteria but the expression vector plays an important role in the success of recombinant expression. In this sense, the selection of an adequate expression vector $(p E T)$ is critical. pET expression vector is one of the most widely used systems for the cloning and in vivo expression of recombinant proteins in E.coli. It contains several 
important elements as T7lac promoter, antibiotic resistance gene, and an origin of replication.

The T7lac promoter is composed by the T7 promoter and lac operator. T7 promoter which is recognized by the T7 RNA polymerase is extremely popular for recombinant protein expression. The lac operator sequence is located just downstream of the T7 promoter. It is regulated by lac repressor (lacl) which expression is controlled by the presence of lactose. In the presence of glucose and absence of lactose, lac repressor binds the operator sequence and blocks the access of T7 RNA polymerase to the promoter site. Lacl gene is usually engineered to be present in both the bacteria chromosome and the expression vector and its expression is controlled by its natural promoter.

In $\mathrm{pET}$ system the expression of recombinant protein is induced by the T7 RNA polymerase expressed in E.coli. For that, a chromosomal copy of the T7 RNA polymerase under lacUV5 control is required in host cell. Indeed, when PET vector is used in DE3 lysogens as BL21(DE3) E.colistrains, in presence of glucose and absence of lactose, the Lacl acts both over the lacUV5 promoter in the host chromosome in order to repress the transcription of the T7 RNA polymerase and over the T7lac promoter in the expression vector to block the transcription of recombinant protein (37). In this manner the control of basal expression for recombinant proteins can be achieved by regulating both glucose and lactose levels.

\subsubsection{ELRs FOR BIOMEDICAL APPLICATIONS}

ELRs have growing application in biomedical field due to the advantage of having the following strengths.

$\checkmark$ The ELR Tt can be "programmed", which permits the design of ELRs for specific applications.

$\checkmark$ Genetic engineering techniques allows the fully control of the architecture and amino-acid composition of ELR. Recent advances in recombinant DNA have provided the tools to produce polymers with a complexity superior to those of chemically synthesized polymers (38).

$\checkmark$ Expression of ELR can be easily scaled up which make them a real alternative to polymers chemically synthesized.

$\checkmark$ The ITT allows obtaining purified ELRs by reducing the purification costs. 


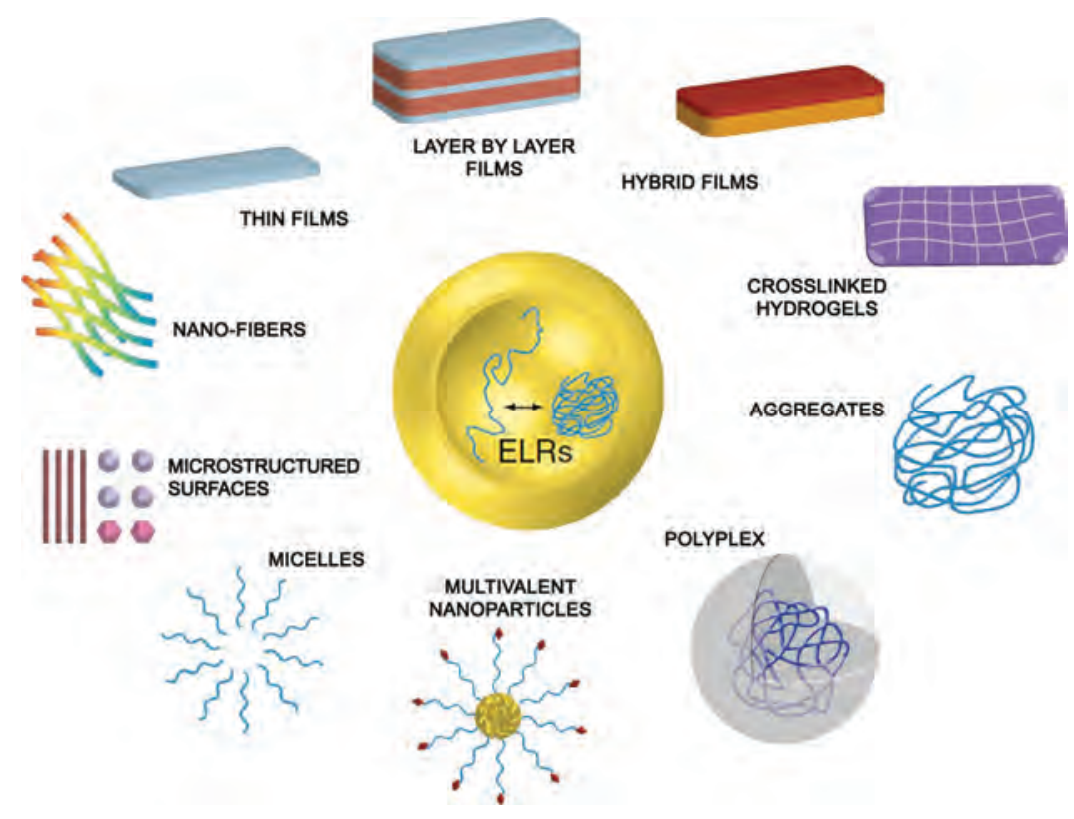

Figure 1.9. Summary of the different ELR-based devices that have been developed for tissue engineering, cell harvesting, drug and gene delivery.

This design versatility together with the biocompatibility inherent to natural elastin, bioactivity and self-assembly behavior make ELRs as an alternative to the existing biomaterials for biomedical purposes. In addition, their physicochemical and mechanical properties can be fine-tuned allowing the formation of a wide variety of ELR-based constructs and composites as response of self-assembling behavior (Figure 1.9). Aggregates (39), films (40-42), hydrogels (43-46), fibers $(47,48)$, micelles $(49,50)$, nanoparticles $(51-53)$ and polyplexes when ELRs are in presence of pDNA $(53,54)$ are the ELR-based devices with potential application in biomedicine. Tissue engineering, drug and gene delivery, are some of the growing application fields of ELRs.

The aim of tissue engineering is to obtain a scaffold that mimics the complexity and characteristics of extracellular matrix. This responds to the inherent function displayed by the natural elastin in the organism that provides appropriate mechanical properties to tissues where it is present. Despite of the inherent reversible selfaggregation capacity of elastin, covalent crosslinking is required to produce stable hydrogels. Crosslinking constitutes a useful tool to achieve hydrogels with tuned properties. Crosslinking conditions let to control the reticulation process(55), microstructured hydrogels, fiber-like architecture, biomemitic Young's modulus and 
even mineralization capacity in which the latter was observed when citric acid is used as cross-linker in HRGD6 ELR for bone regeneration (56). Indeed ELRs have recently been used for treatment of macular degeneration with satisfactory in vitro results with RGD bioactive domain (57) or covering of stents (45) focused on cardiovascular tissue regeneration using ELR-catalyst free click gels with the same RGD domain (43). Other hydrogels made of silk-elastin (46) showed the spontaneous formation of stable physical nanofibrillar hydrogel under physiological conditions which together with zipper-elastin-like recombinamer (ZELR)hydrogels (44) have been recently developed by Fernandez-Colino et al with potential applications for tissue engineering field.

ELRs can be also used to create nanocarriers and, eventually, microcarriers able to encapsulate and deliver drugs in a temporal and spatial controlled manner. With this objective a variety of self-assembled ELR diblocks conjugated to drugs were developed (1.1.7.1.). Indeed ELR aggregates have been tested as drug delivery agents in conditions of mild hyperthermia taking advantage of their smart nature. For instance, a thermally responsive construction named Bac-ELR-H1 and formed by Bac CPP and the inhibitor c-Myc was shown to target and reduce breast tumor growth (58) and rat glioma in vivo (59). Similarly, targeted CPP-ELR has been used in combination with hyperthermia to deliver small molecule drugs such as doxorubicin (60) or paclitaxel (61) increasing the cytotoxic effects of drug when the ELR aggregated as result of external application of mild hypertermia. In addition, ELR hydrogel scaffolds can also be used for the local delivery of proteins and antibiotics (62). Indeed reversible hydrogel formed by intermolecular disulfide chemical crosslinking of ELRs containing cysteine residues showed prolonged tumor retention than ELR coacervates making it suitable for local cancer therapy of tumours (63).

Additionally ELRs have been recently applied in the growing gene delivery field; however little research has been performed so far (1.2.3).

The success of many of these biomedical devices roots in their biocompatibility which has been widely tested (12) (Table 1.1).

Thus, studies from Rincon et al. reported neither non-cytotoxic nor inflammatory response after subcutaneous injection of poly(VPAVG) in rats (64). Additionally 
Sallach et al. reported minimal inflammatory response and in vivo stability for periods exceeding one year for recombinant elastin-mimetic triblock copolymer after subcutaneous and peritoneal implantation (65). Both studies are examples of the biocompatibility features of ELR which paves the way for their application not just in vitro but in vivo.

Table 1.1. Summary of biological test results for poly(VPGVG).

\begin{tabular}{|lll|}
\hline Test & Test system & Results \\
\hline Ames mutagenicity & Salmonella typhimorium & Non-mutagenic \\
Cytotoxicity & L-929 mouse fibroblasts & Non-toxic \\
Systemic toxicity & Mice & Non-toxic \\
Intracutaneous toxicity & Rabbit & Non-toxic \\
Muscle implantation & Rabbit & Favorable \\
IP implantation & Rat & Favorable \\
Systemic antigenicity (BPAT) & Guinea pigs & Non-antigenic \\
Sensitization (Kligman test) & Guinea pigs & Non-sensitizing \\
Pirogenicity & Rabbits & Non-pirogenic \\
Clotting study & Dogs & Normal clotting \\
Hemolysis & Rabbit blood & No hemolysis \\
\hline
\end{tabular}

\subsubsection{SELF-ASSEMBLED ELRs DIBLOCKS FOR DRUG DELIVERY}

ELR diblocks have been subjected to a wide variety of studies due to their selfassembly behavior that leads to the formation of complex morphologies as micelles, fibers and hydrogels among others (Figure 1.9). The thermo-sensitivity nature of ELR diblocks $\left(E L R_{B C}\right)$, constituted by a hydrophobic and hydrophilic part, leads them to the formation of amphiphilic nanoparticles. ELR diblocks (ELRBCS) are capable of temperature-triggered micelle assembly $(51,66)$.As rule of thumb, in an aqueous solution of ELR $\mathrm{BC}$ and upon thermally triggered selective desolvation of the hydrophobic block, a dehydration process and decrease in the polarity of hydrophobic block triggers the conformational change to micelle. In micelles, the hydrophobic block is located inside, hence providing stability to the complex. However, the hydrophilic block is positioned outward forming a corona in contact with the surrounding aqueous media. The temperature at which the transition from a soluble ELR diblock to a micelle occurs is called the critical micelle temperature (CMT). This CMT can be controlled by varying the length and composition of the 
hydrophobic block, whereas the size of the micelle can be controlled by varying the ELR length and the hydrophilic-to-hydrophobic block ratio $(67,68)$.

These self-assembled ELRBCs have been used as carriers for low solubility drugs as rapamycin with high delivery rate, low gross toxicity and anti-cancer activity in vivo in comparison with free drug (69). ELR $R_{B C s}$ have also been used to deliver Doxorrubicin (70), Paclitaxel (71) or poly(2-oxazoline)s (72). In this system, Doxorrubicin and Paclitaxel derivatives with an acid sensitive linker and a terminal maleimide moiety were coupled to cysteine residues at one end of the ELR chain. That led the formation of soluble micelles with a hydrophobic core containing the drug. The release of the drug was then triggered by the acidic cleavage of the linker between the drug and the ELR.

The use of amphiphilic ELR $R_{B C}$ able to self-assemble into higher-ordered structures is of great interest in the development of novel self-assembling systems in the nanoand micro-scale. Thus ELR $R_{B C}$ are suitable for wide variety of approaches in the biomedical field such as drug delivery for poorly soluble drugs improving their delivery and rate of activity in vivo.

\subsection{BASIC PRINCIPLES ABOUT GENE THERAPY}

Gene therapy is defined as the set of strategies that modify the expression of a patient's genes or that correct loss of function mutations in order to treat or improve his health condition. Gene therapy provides a unique approach to deliver a therapeutic gene and its associated regulatory elements, using a vector also named as carrier, into the cellular nucleus to express the deficient gene product at physiological levels $(73,74)$.

One of the most critical points in gene therapy success is the selection of the most appropriate vector. The function of the vector is to protect and deliver the therapeutic material into the patient target cells. Vectors can be administered either ex vivo in which autologous somatic or germ cells are removed, genetically modified and transplanted back into a patient or in vivo in which the therapeutic gene is directly transferred into patient. Depending of the vector, the therapeutic material can be integrated into the host chromosome or remained as episomal plasmid with transient expression $(73,75)$. The modification of patient's altered gene expression 
can be performed by gene addition, correction, gene knockdown or their combination $(73,76)$.

Despite of the situation for gene therapy in USA that according to the American Society of Gene \& Cell Therapy gene therapy is subjected to strictly experimental approaches, many clinical trials are developing worldwide. Indeed, the clinical approval of the AAV-based gene therapeutic Glybera for use in Europe has created a recovered optimism for the biomedical purposes (77). Thus far, the gene therapy trials worldwide have increased in a significant manner in the last 6 years (Figure 1.10A). Most of the clinical trials in gene therapy have been focused in the treatment of cancer (64\%), inherited monogenic (9.5\%), cardiovascular (7.9\%) and infectious diseases (7.9\%) (Figure 1.10B). A range of different vectors and physical delivery techniques for naked DNA such as gene gun, electroporation, hydrodynamic delivery, sonoporation and magnetofection (77) have been applied in gene therapy trials. Although viral vectors remain the carrier most used in about $66 \%$ of the total clinical trials, non-viral vectors are becoming increasingly popular (Figure 1.10C) (78).
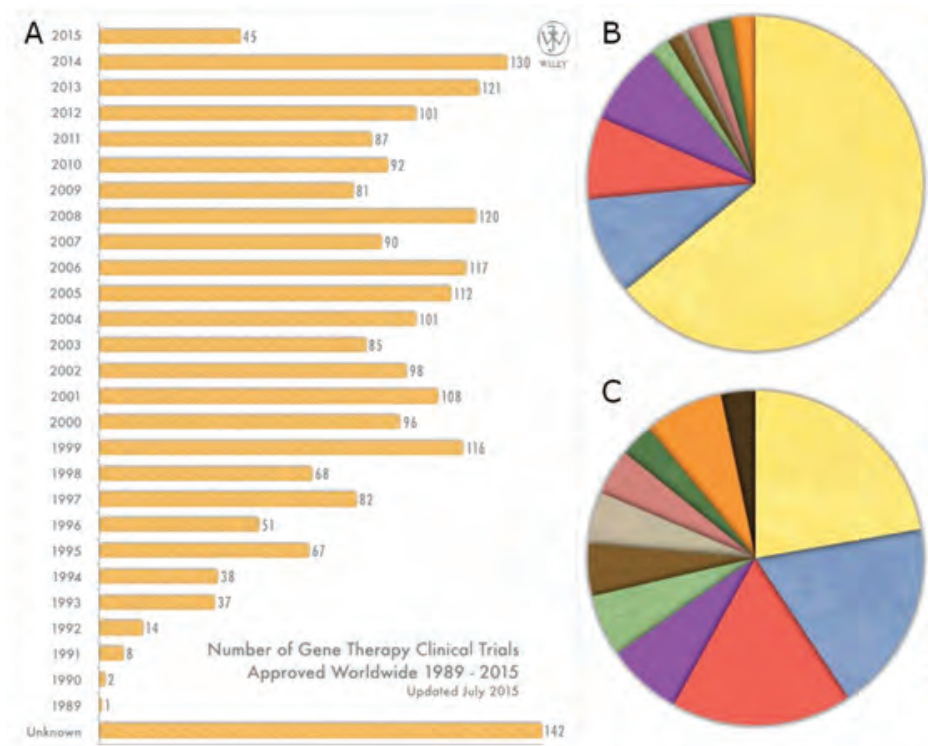

Cancer diseases $64 \%(n=1415)$

Monogenic diseases $9.5 \%(n-209)$

Cordiovascular diseases $7.9 \%(n=175)$

Infectious diseases $7.9 \%(n=174)$

Neurological diseases $1.9 \%(n=43)$

Ocular diseoses $1.4 \% \quad(n=31)$

Inflammatory diseases $0.6 \%(n=14)$

Other diseoses $2.1 \%(n=46)$

Gene marking $2.3 \%(n=50)$

Healthy volunteers $2.4 \%(n=53)$

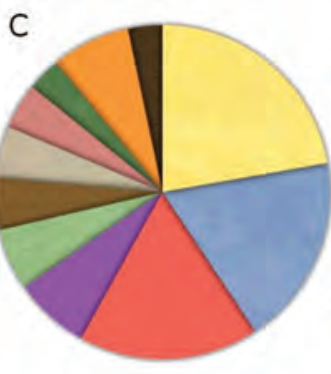

Adenovirus $22.2 \%(n=506)$

Retrovirus $18.4 \%(n=420)$

Naked/Plasmid DNA $17.4 \%(n=397$

Vaccinia virus $7.2 \%(n=165)$

Adeno-associated virus $6 \%(n=137)$

Lipofection $5 \%(n=115)$

Lentivirus $5 \%(n=114)$

Poxvirus $4.4 \%(n=101)$

Herpes simplex virus $3.2 \%(n=73)$

Other vectors $7.6 \%(n=174)$

- Unknown $3.3 \%(n-76)$

Figure 1.10. Gene therapy clinical trials worldwide. Number of gene therapy clinical trials approved worldwide 1989-2015 (A). Diseases addressed by gene therapy clinical up to 2015 (B). Vectors used in gene therapy trials (C).All the data are referred to clinical trials up to July of 2015 (78). 
Table 1.2. Viral vectors used in gene therapy, goods and limitations.

\begin{tabular}{|c|c|c|c|c|c|}
\hline Virus & Adenovirus & Retrovirus & AAV & HSV & Poxvirus \\
\hline \multicolumn{6}{|l|}{ Scheme } \\
\hline Capacity & $<7.5 \mathrm{~kb}$ & up to $10 \mathrm{~kb}$ & $<4 \mathrm{~kb}$ & $30-40 \mathrm{~kb}$ & $>30 \mathrm{~kb}$ \\
\hline Limitations & $\begin{array}{l}\text {-Early activation } \\
\text { of immune } \\
\text { cells } \\
\text {-Short time } \\
\text { expression }\end{array}$ & $\begin{array}{l}\text {-Low vector titer } \\
7 \\
\text { (10 particles/mL) } \\
\text {-Low transfection } \\
\text { efficiency } \\
\text {-Particle instability. } \\
\text { Infecting only } \\
\text { proliferating cells }\end{array}$ & $\begin{array}{l}\text {-Small } \\
\text { packaging } \\
\text { capacity }\end{array}$ & $\begin{array}{l}\text {-Most of } \\
\text { humans posses } \\
\text { antibodies } \\
\text { against HSV } \\
\text { which could } \\
\text { reduce the } \\
\text { efficiency }\end{array}$ & $\begin{array}{l}\text {-Ability of } \\
\text { replication can } \\
\text { cause immune } \\
\text { response }\end{array}$ \\
\hline Goods & $\begin{array}{l}\text { Immunogenicit } \\
\text { y can be used } \\
\text { to stimulate } \\
\text { immune } \\
\text { responses } \\
\text { against tumor } \\
\text { cells }\end{array}$ & $\begin{array}{l}\text { Lentiviruses: HIV-1 } \\
\text { ensure long term } \\
\text { expression and } \\
\text { efficient transfer } \\
\text { without } \\
\text { inflammatory } \\
\text { responses }\end{array}$ & $\begin{array}{l}\text {-Derived } \\
\text { from human } \\
\text { viruses } \\
\text {-More } \\
\text { feasible for } \\
\text { human gene } \\
\text { therapy }\end{array}$ & $\begin{array}{l}\text {-Large cloning } \\
\text { capacity. } \\
\text {-Used in gene } \\
\text { therapy for } \\
\text { cancer }\end{array}$ & $\begin{array}{l}\text { Immune } \\
\text { responses and } \\
\text { direct lysis of } \\
\text { tumor cells } \\
\text { leads to clinical } \\
\text { improvement }\end{array}$ \\
\hline
\end{tabular}

It is important to note the challenge that the design of safe and effective gene delivery vectors involves. As exposed above, more than half of the clinical trials used modified virus such as retrovirus, lentivirus, adenovirus and adeno-associated virus (AAVs) to deliver genes. By contrast, virus have presented several drawbacks such as carcinogenesis (79), immunogenicity in the host (80), broad tropism (81), limited DNA packaging capacity (82) and high cost of vector production (83) (Table 1.2).

Non viral vectors have the potential to address many of these limitations, specifically with respect to safety and production. Non-viral vectors include from naked DNA to chemical based vectors such as lipids or polymers. These chemical-based vectors tend to have lower immunogenicity levels than viral vectors. Thus patients do not have memory immune response as is the situation for some viral systems (84-87). In addition, non-viral vectors are easier to produce on a large scale (88). By contrast, the main limitation of these non-viral vectors is their low delivery efficiency in comparison with viral vectors, hence few of them such as DOTAP-cholesterol, PEI or Poloxamer CRL1005 have been developed clinically so far (77). This drawback may be 
about to change owing to developments in material science and nanotechnology which has enabled the creation of new lipid and polymer-based vectors and a better understanding of nanosized materials for gene therapy. Hence, it is not surprising that this area has been the target for intensive research and the development of a multitude of vectors (Figure 1.11).

\subsubsection{LIPID-BASED NON-VIRAL VECTORS}

Lipid based vectors are among the most popular for non-viral gene delivery. Specifically since first cationic lipid named as DOTMA which formed small liposomes able to entrap and transfect DNA to monkey kidney cells was used by Felgner et al. (89), numerous cationic lipids have been applied for gene delivery in vitro, in vivo and in clinical trials (Figure 1.11A). Cationic lipids are made up of a cationic head group attached by a linker to a lipid hydrophobic moiety composed of steroid or alkyl chains (saturated or insaturated). The positively charged head group is necessary for the binding of nucleic acid phosphate groups (90). DOSPA, DOTAP, DMRIE and DCcholesterol appeared by modifications of these three domains and have been widely used for gene delivery (91). It has been shown that endocytosis played a major role in the lipoplex mediated uptake. Once lipoplex is internalized, it is able to destabilize the endosomal membrane by interaction between the lipoplex bilayer and the endosomal membrane may thus promote the reorganization of phospholipids and gene translocation into the cytoplasm (91). It is interesting to highlight that cationic lipids present some concerns relative to their safety. For instance, they are occasionally known to induce complement activation which can lead to hypersensitivity reactions $(92,93)$, together with inflammatory response in lungs, spleen and liver for DOTAP modified with cholesterol liposomes (94).Despite of these limitations, the US Food and Drug Administration approved PEG modified liposomes for drug as doxorubicin and amphotericin B delivery (95) which shows the commitment for the development of lipid delivery systems. 
A
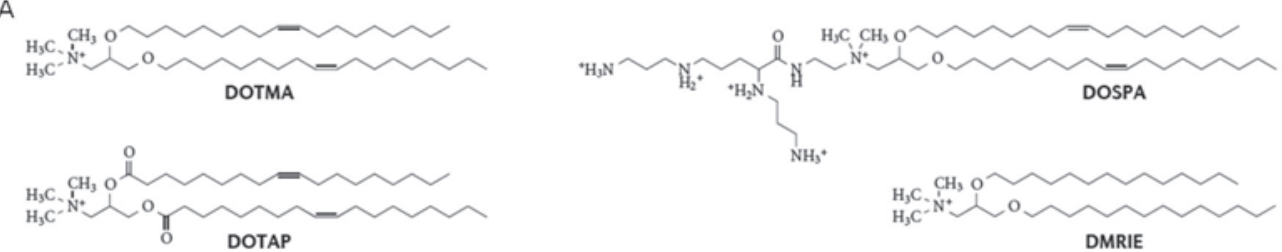

DMRIE
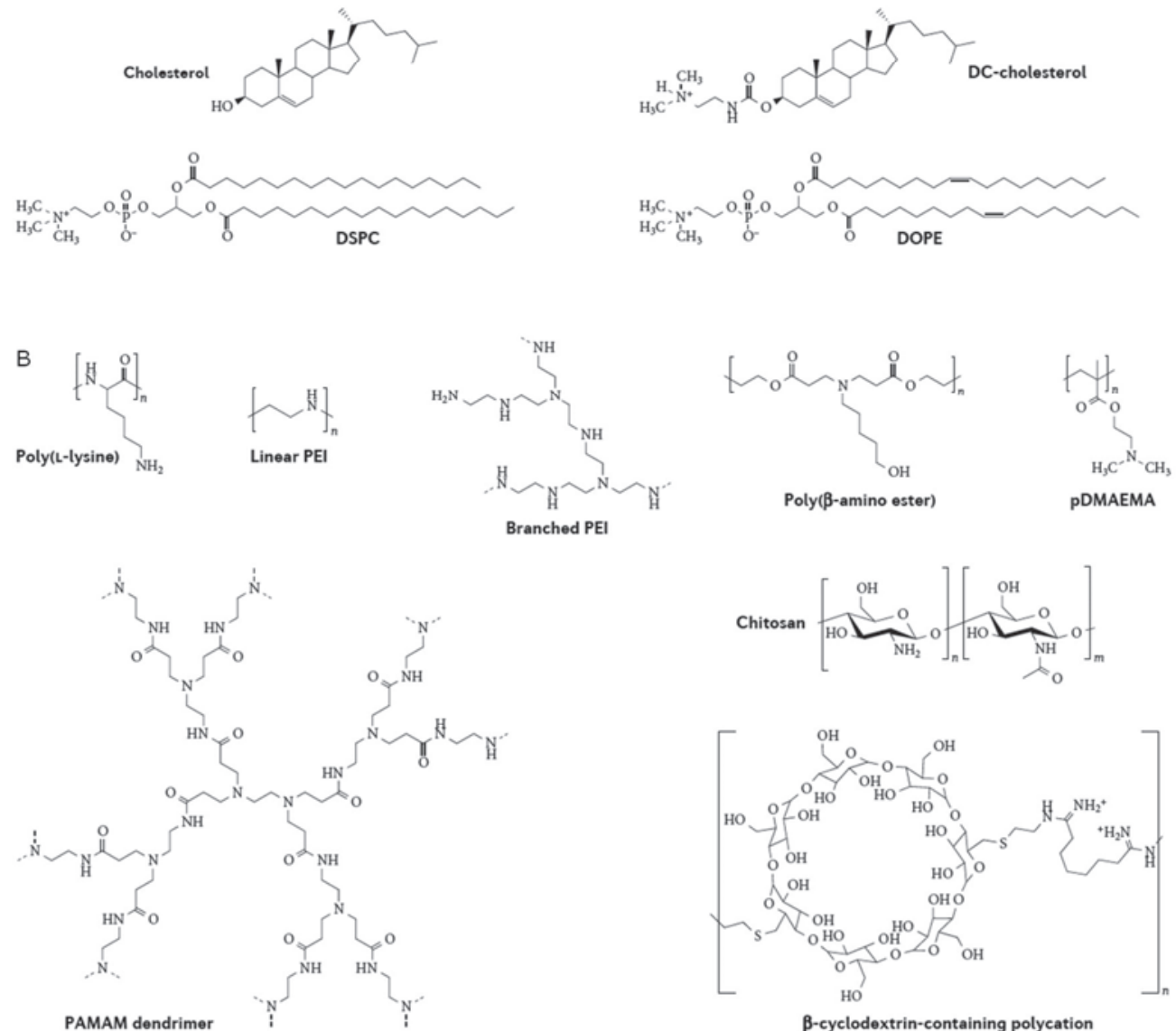

B-cyclodextrin-containing polycation

Figure 1.11. Chemical based non-viral gene delivery vectors. Chemical structures of cationic (such as DOTMA, DOSPA, DOTAP, DMRIE and DC-cholesterol) and neutral lipids (such as the phospholipids DSPC and DOPE, and cholesterol) are shown. Cationic lipids are characterized structurally by a cationic head group, a hydrophobic tail and a linker region. Neutral lipids are used as 'helper lipids' to further enhance nanoparticle stability and overall transfection efficacy (A). Chemical structures of polymer vectors commonly used in gene delivery. Poly(L-lysine) and polyethylenimine (PEI), methacrylatebased polymers such as poly[(2-dimethylamino) ethyl methacrylate] (pDMAEMA), carbohydrate-based polymers such as chitosan and $\beta$-cyclodextrin-containing polycations, polyamidoamine (PAMAM) dendrimers and degradable poly( $\beta$-amino ester) polymers (B)(77). 


\subsubsection{POLYMER-BASED NON-VIRAL VECTORS}

Polymers due to their diversity and potential for functionalization are a real class of non-viral vectors. Thus, cationic polymers are preferred due to their ability to condense large nucleic acids into stabilized nanoparticles (96). This results in a tight DNA-polymer complex, also known as a polyplex, which protects the contents from degradation by nucleases. The earliest polymeric non-viral vectors developed were poly (L-Lysine) (PLL) and polyethylenimine (PEI) (Figure 1.11B). PLL is a homopolypeptide of the amino-acid lysine that due to its biodegradable nature was one of the most used cationic polymers for DNA delivery until 2000 (97). At physiological conditions, the primary $\varepsilon$-amine groups of lysine are protonated and interact with the negatively charged phosphate groups from DNA by electrostatic interactions forming nanocomplexes. However, in absence of a lysosomal disruption agent such as chloroquine, the transfection efficiency of PLL is low (90). Although PLL with high molecular weight showed suitable properties for gene delivery it possesses marked in vitro cytotoxicity and a tendency to aggregate and precipitate depending on concentration, ionic strength, and type of solution $(98,99)$. A wide variety of modifications has been performed to the basis of PLL in order to overcome these limitations. For instance, the modification of PLL with PEG increased the circulation time of complexes by reducing the interaction with plasma components (100).

Otherwise, PEI and PEI derived polymers are among the most popularly employed cationic vectors due to their high transfection levels and consistency in transfection in many cell lines (Figure 1.11B). The strength of PEI is its high charged density which makes it suitable for condensing large amount of genetic material. Linear PEI (IPEI) contains all secondary amines, in contrast branched PEI (bPEI) has primary (25\%), secondary $(50 \%)$ and tertiary amines (25\%) of which two-thirds of the amines are protonated in physiological conditions. The rest of unprotonated amines conferred the buffering capacity at acidic $\mathrm{pH}$ which allows the PEI complexes to escape from endosome by means of "proton-sponge" effect and increase the transfection level (101). "Proton-sponge" hypothesis for PEl proposes that unprotonated amines of PEI absorb protons as they are pumped into the endosome leading to more protons pumping and increasing the influx of $\mathrm{Cl}$ - ions and water $(102,103)$ (Figure 1.12). This hypothesis was demonstrated by Akinc et al. when removing the protonable amino 
groups by $\mathrm{N}$-quarternized versions of $\mathrm{PEI}$ and by the used of bafilomycin $\mathrm{A} 1$ (proton pump inhibitor), the transfection efficiency was reduced 50-fold (104). This proton sponge hypothesis has also been proven for histidine or imidazole modified polymers (88) due to the protonation of imidazole groups at endosomal and lysosomal pH (imidazole pKa of 6.9).

By contrast, although PEI is commonly used in transfection, it often has a strong cytotoxic effect (90), depending on the cell line and PEI branching conformation as reported elsewhere $(100,105,106)$. It has also been observed that high molecular weight PEI results in high cytotoxic effects (90). This effect is probably due to the presence of free PEl after formation of polyplexes which disrupts the plasmatic membrane and causes necrosis (106-108) thereby restricting its clinical application. Nowadays research is focusing in decreasing this toxicity by the use of biocompatible molecules such as chitosan or employing PEG as shell. Moreover, PEI is being broadly investigated for the administration of a wide range of nucleotide-based therapies, including DNA, siRNA and oligonucleotide (109-111).
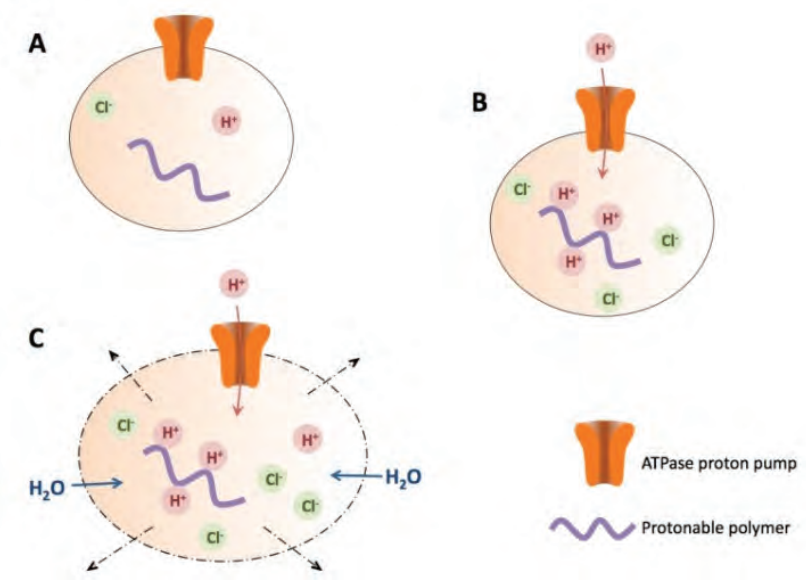

Figure 1.12. Scheme showing the "proton sponge" hypothesis. PEI-pDNA nanocomplexes enter cell via endocytosis and are located in endosomes (A). ATPase proton pumps produce a proton entry into endosomes. PEI polymer becomes protonated and resists the acidification of endosomes leading to more protons pumping (B). This is followed by passive chloride ions entry, increasing ionic concentration and consequently water influx. Hence high osmotic pressure causes the swelling and rupture of endosomes, releasing their contents to cytosol (C) (112).

With the objective of addressing the efficacy and toxicity associated with PLL and PEI, other polymers such as pDMAEMA, chitosan, PAMAM, poly ( $\beta$-amino ester), 
carbohydrate based polymers ( $\beta$-cyclodextrins and chitosan) and dendrimers are being developed over the years reaching even to clinical trials (90). Additionally, polypeptide vectors which are made of short sequences of basic amino acids residues named as cell-penetrating peptides (CPP) have also been used as delivery agents. They are generally divided into two groups: lysine-rich peptides such as the MPG peptide and arginine-rich peptides such as the antennapedia and TAT peptides (90). However the transfection levels were higher when these peptides were conjugated with lipids or polymers (113-116).

Apart from polymeric non-viral vectors, nanoparticles such as quantum dots (QD), gold and silica nanoparticles, carbon nanotubes, lipid-based nanoparticles and polymeric hydrogels (90) have been extensively used as non-viral gene carriers.

\subsubsection{ELRS AS NON-VIRAL VECTORS}

Thanks to the ELRs polymeric nature and their design potential by genetic engineering techniques they are growing and becoming in promising biomaterials to be used in gene delivery. The first studies of ELRs as vectors were accomplished by Furgerson group in 2007, where ELRs were used as oligolysine carriers to deliver the EGFP plasmid inside cells in in vitro assays but with some cytotoxicity (54). Later, Dash et al. in 2011 reported the fabrication of self-assembled ELR hollow spheres of 100, 300, 500 and $1000 \mathrm{~nm}$ with net positive charge. The hollow spheres encapsulated polyplex (formed by using poly (2-dimethyl-aminoethylmethacrylate) (PDMAEMA)block-poly ethylene glycol methyl ether methacrylate (PEGMEMA) / ethylene dimethacrylate (EDGMA) and pDNA) in higher loading efficiency of plasmid DNA than that of self-assembled ELR particles. Additionally, the work from Dr. GarcíaArevalo (53) described the characterization and transfection ability of different ELRs based on $\mathrm{K} 5 \mathrm{~V}$ construct (6K-K5V and H8-6K-K5V). 6K-K5V with 3 lysines at both ends and H8-6K-K5V with poly-histidine tail were also composed by 24 lysines. The transfection efficiency of $\mathrm{K} 5 \mathrm{~V}, 6 \mathrm{~K}-\mathrm{K} 5 \mathrm{~V}$ and $\mathrm{H} 8-6 \mathrm{~K}-\mathrm{K} 5 \mathrm{~V}$ polymers was evaluated. The results showed transfection levels less efficient than lipofectamine, PEI or PLL but higher than nude pDNA. Thus, co-localization experiments showed the no internalization of the H8-6K-K5V by lysosomes. 
It is important to note that in none of the previous studies has been taking advantage of the recombinant nature of ELR in an efficient manner for gene delivery purposes. A well defined amino-acid design of ELR with the incorporation of functional motifs in order to provide ELRs with novel functionalities has not been reported. Indeed, incorporation of tissue-specific components and a deeper study of internalization routes in cells or specific gene therapy application either in vitro or in vivo has not been developed yet. These antecedents only highlight the great potential of ELRs and point the strategy adopted in the present work using the recombinant nature of ELR to design ELRs according to the transfection needs.

\subsubsection{FACTORS AFFECTING THE TRANSFECTION}

It is known that chemical and physical features from vectors play an important role in determining the interactions with cell and hence in transfection efficiency. Genetic material complexation, particle size, and charge together with structural architecture of the vector and the plasmid carried are important factors to take into account.

\subsubsection{DNA COMPLEXATION}

Complexation of DNA mediated by electrostatic interactions (between the positively charged groups from the vector and the negatively charged phosphates from DNA) leads to charge neutralization and compaction of the genetic material. As mentioned before, when the vector utilized is a polymer the nanocomplex formed is called as polyplex. Polymer not only complexes the DNA but in systemic circulation, polyplex attempts protection to the DNA from nuclease degradation.

\subsubsection{SIZE}

Particle size seems to be directly related with the cellular entry pathway. In general, in phagocytic cells the limit for particle uptake is up to $10 \mu \mathrm{m}$. By contrast, nonphagocytic eukaryotic cells can internalize particles $<1 \mu \mathrm{m}$. Rejman et al. (117) investigated the effect of particle size over the internalization pathway using fluorescent beads of a wide range of size of 50-1000 nm in non-phagocytic B16 cells. They demonstrated that beads with a diameter $<200 \mathrm{~nm}$ showed a clathrindependent endocytosis entry. However, beads with higher size up to $500 \mathrm{~nm}$ seemed to be internalized by caveolae-mediated pathway. It has also been observed that for 
non-phagocytic cells, nanoparticles tend to achieve faster cellular entry compared to microparticles.

In addition, nanoparticle size also depends on the type of cationic structure used and preparation conditions such as DNA concentration, $\mathrm{pH}$ and type of buffer or N/P ratio (amino groups/phosphate groups). However the morphology of DNA complexes formed with cationic polymers is independent of the polymer used. For instance, polyplexes formed with PLL, PEl or various dendrimers possess all DNA with toroidal conformation. Despite of the finding of cysteine lipid complexed with plasmid DNA that showed a particle size variation proportional to the cubit root of DNA size (118), polyplex size appears to be more influenced by the polymer molecular weight than DNA. In the case of PLL, high molecular weight polymer (about $220 \mathrm{kDa}$ ) form polyplexes of 100-300 nm while low molecular weight (about 4 $\mathrm{kDa}$ ) form complexes of 20-30 nm (119). In the same way, particle size can be also influenced by aggregation phenomena; aggregation behavior of the complexes has been shown to strongly depend upon the individual cationic polymer structure. It has been proved from high molecular weight PLL and intact polyaminoamine dendrimer (120).

\subsubsection{ZETA POTENTIAL}

Zeta potential is defined to be the electrostatic potential difference between an average point on the shear plane from the particle and bulk solution. Additionally, zeta potential is a parameter which gives an idea of the stability of particles in suspension (121). Generally, suspensions with zeta potential above $30 \mathrm{mV}$ in absolute value are stable (122). Among factors affecting the zeta potential value, salt concentration and $\mathrm{pH}$ are the most important.

A positive zeta potential is thought to improve cellular internalization of nanoparticles as result of interaction with the negatively charged plasmatic membrane (123). For instance, PLGA, chitosan, searylamine-coated PEG-co-PLA among others are known to be positively charged and effectively internalized into cells mainly by clathrin mediated endocytosis (124). In the specific case of cationic PEG-co-PLA nanoparticles were shown to be internalized in polarized epithelial cells MDCK (Madin Darby Canine Kidney) through non-lysosomal degradative via 
including transcytosis (125). Another study with positively and negatively charged PEG-PLA of equal size in HeLa cells showed a superior and rapidly internalization of positively charged NPs via clathrin mediated pathway. Contrary, negatively charged nanoparticles did not utilize the clathrin-mediated endocytosis (124). In contrast, a higher uptake of negatively charged nanoparticles made of quantum dots was reported for HEK cells (126). Indeed, DOXIL $®$ (PEGylated liposomes) and micelles (core-cross linked polymeric micelles of poly(ethylene oxide)-b-polymetacrilic acid) which are also negatively charged were shown to be internalized through caveolaemediated endocytosis (127).

Even so, nanoparticles with a positive surface charge have been reported to have a high non-specific internalization and short blood circulation half-life, due to the presumably interaction with plasma components (121). Despite of this drawback, the presence of positive zeta potential in nanoparticles is considered a good sign due to its ease to interact with negatively charged components from plasmatic membrane.

\subsubsection{SHAPE}

In general, shape influence over transfection is poorly understood. Shape of inorganic particles such as silica particles was proved to affect their biodistribution, clearance and biocompatibility $(128,129)$. In terms of transfection silica particles modified with pDMAEMA showed chiral nanorods of $300 \mathrm{~nm}$ long appearance and they were found to be efficient vectors. In the same study hollow nanosphere-based vectors showed better transfection ability than solid counterparts. In both cases the cytotoxicity was compromised (130).

In the same way certain shapes have demonstrated advantages over spherical systems. Studies performed with PLGA derived particles showed that ellipsoid shape was most effectively adhered to macrophages but the least internalized (131).

Additionally in order to control the particles shape, PRINT (particle replication in nonwetting templates) technology which is a lithography-based molding technology have been recently used to engineering precisely and defined particles. Hence some interesting findings were achieved using PRINT particles. Using PEG based hydrogels with rod-like and cylindrical shape, Gratton et al.(132) evidenced the important role of particle shape in the uptake process, since rod-like particles internalized more 
rapidity than cylindrical counterparts. Thus, cylindrical PLGA PRINT particles were effectively used to incorporate and deliver siRNA (133). In this case the surface modification with cationic lipids facilitated the internalization and transfection of particles which masked somehow the real effect of shape over transfection.

Accordingly, studies of the impact of particle shape over transfection and specifically over cell interactions are still starting and more research is needed in order to elucidate the real mechanisms involved.

\subsubsection{MOLECULAR WEIGHT AND BRANCHING}

Molecular weight and branching degree have been tested as factors that affect the transfection efficiency of non-viral vectors.

As pointed previously, polymer molecular weight directly affect to the particle size of polyplexes (119) and hence to their transfection capacity. For PEI made polyplexes, an increase in transfection efficiency was correlated with the increment in molecular weight for PEI ranging from 600 to $70,000 \mathrm{Da}$, however high molecular weight polymers also resulted in significant cytotoxicity values (134, 135). Accordingly, low molecular weight PEI seems to be less cytotoxic than higher molecular weight polymer with efficient transfection in several cell lines but with the requirement of higher N/P ratio (136).

Besides of the molecular weight, the degree of branching of some polymers as PEI has been proved to affect the transfection efficiency by means of DNA complexation and stability as well. According with that, lineal PEI (IPEI) has been shown to be less effective in condensing DNA than branched PEI (bPEI). Indeed, bPEl makes more stable polyplexes due to the presence of higher amount of primary amines. In particular, bPEl $25 \mathrm{kDa}$ is considered as the gold standard due to its high transfection capacity $(136,137)$. Contrary, bPEI is cytotoxic due to the primary amines which limit the in vivo applications. However, IPEI $25 \mathrm{kDa}$ is shown to be less toxic than bPEI 25 kDa but with lower transfection efficiency (138).

\subsubsection{PARTICLE SURFACE MODIFICATION}

Chemical surface modification has been broadly studied focused to increase the biocompatibility, biodistribution and transfection efficiency. The utilization of cell 
specific targeting directed against certain over-expressed cell surface receptors is a strategy that promotes the receptor-mediated endocytosis as well. These ligands can be small molecules as LDL, fibroblast growth factor receptor or bigger as transferrin or antibodies. For instance, transferrin which is a common gene delivery ligand (139, 140) has been used for the creation of Tf-PEI-pDNA delivery system showing tumor necrosis promotion and inhibition in in vivo assays (141).

Other common strategy used for increasing the biocompatibility of certain systems is the utilization of hydrophilic polymers as PEG. PEG groups have the ability to decrease the adsorption of proteins by serum components through its hydrophobicity and steric repulsion effects reducing opsonization and complement activation $(142,143)$. Thus, PEG is known to elude the uptake by macrophages promoting the longer circulating time of the modified system (144) and to trigger its accumulation in vascularized tissues leading to enhanced permeability and retention (EPR) in tumors (145). Numerous systems from lipids to PLGA, PLL, PEI or PAMAM polymers have been shielded with this polymer increasing their colloidal stability, viability and transfective attributes (90).

A proper balance between the carrier itself and the properties acquired by surface modification would determine the success of the vector as gene carrier.

\subsubsection{PLASMID}

The plasmid DNA (Figure 1.13) is another factor that influences over the transgene expression. Plasmid used for gene delivery purposes are mammalian expression vectors which normally does not integrate into the host chromosome (episomal plasmid). That reduces the risk of insertional mutagenesis, circumstance that is frequent in viral vectors and is considered as a limitation. High quality of pDNA predominantly in supercoiled form, free of contaminant factors such as bacterial DNA, RNA and protein and physically stable along time is required for in vivo purposes.

The major concern for the use of non-viral vectors is the transgene expression and its duration in time. For this reason, some enhancers derived from virus such as cytomegalovirus (CMV), respiratory syncytial virus (RSV) and simian virus 40 (SV40) are popular for gene expression in different cell lines (146). In addition, the use of 
tissue-specific promoter offers the possibility of increase the safety reducing the nonspecific binding to health tissues. For instance, after transfection with non-viral vector the specific expression in liver was achieved by means of a $\alpha$-fetoprotein enhancer together with an albumin promoter element (147). In other studies DF3 (MUC1) promoter was utilized due to the over-expression of MUC1 in breast tumors. Kufe's group (148) demonstrated that gene expression under the control of DF3 promoter after the use of adenovirus vector was limited to DF3 positive breast cancer cells in vitro and in vivo through the expression of herpes virus timidine kinase (HSV-tk). Further studies using Bax transgene codifying for a proapoptotic protein showed the selective cytotoxicity of MUC1 expressing ovarian cells in vitro (149). Additional in vivo experiments demonstrated the eradication of $99 \%$ of tumor implants which verified the tumor selective expression of the proapoptotic protein BAX by means of adenoviral vector.

Plasmid design allows the manipulation of a variety of regulatory elements that can impact on gene transfection. The selection of the appropriate plasmid DNA with the careful design of their regulator elements constitutes a fundamental step that can benefit the transient expression of therapeutic genes in mammalian cells.

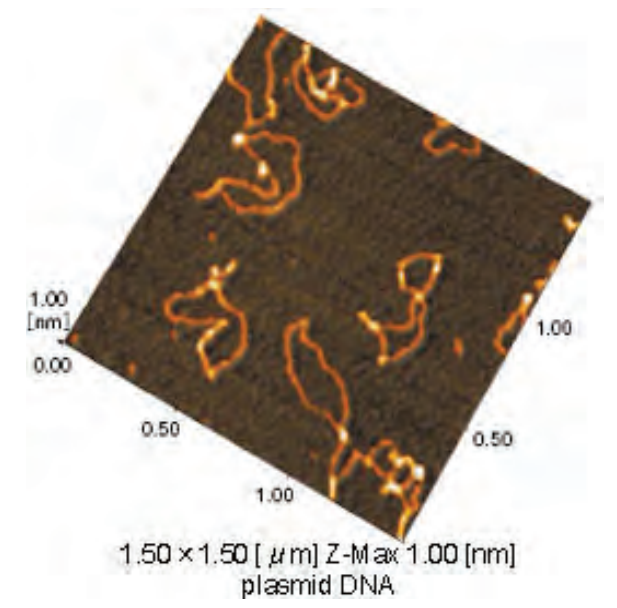

Figure 1.13. AFM image of plasmid DNA.

\subsubsection{CELLULAR BARRIERS}

In gene delivery process extracellular and intracellular barriers are the major obstacles that have to be overcome. The different administration routes such as intra-venous (150), muscular (151), ocular (152) or nasal (153) present as the main 
limitation the presence of nucleases that degrade the therapeutic DNA in physiological fluids and extracellular space.

\subsubsection{INTRA-VENOUS ADMINISTRATION}

Having on mind that the half-life of plasmid DNA has been estimated in $10 \mathrm{~min}$ after intravenous administration in mice (150), the use of non-viral vectors that provide endonuclease protection, evade the immune response and reduce clearance is needed. The incorporation of cationic polymers to therapeutic DNA that form polyplexes thereby increasing the particle size can help in reducing the clearance effects. Indeed the incorporation of PEG by PEGylation has been extensively used to increase circulatory half-life and reduced immunogenicity/antigenicity in drug and gene delivery (154-156).

Upon intravenous administration, nanoparticles enter the vascular system and distribute to the organs and tissues of the host. Within the vascular compartment nanoparticles encounter blood cells, platelets, coagulation factors, and plasma proteins and depending on the size and charge, may undergo adsorption or opsonization by serum proteins. For instance if the positive charge of nanoparticles is too high it can cause causing problems of cell lysis and clotting (157). In addition to enhancing particle recognition by the host immune system, opsonization of nanoparticles may alter the effective size of the particle which may be considerably larger than the in vitro diameter. The nanoparticle size in vivo affects blood clearance and therefore blood and body half-life. As rule of thumb, the particle size is inversely related to rate of glomerular filtration and is directly related to blood and whole body half-life. Kidneys are one of the rapid clearance vias by renal excretion through glomerular filtration. Their capillary walls are typically 6-8 $\mathrm{nm}$ for spherical particles so it is exclusive only for materials with very small hydrodynamic diameters $<5.5 \mathrm{~nm}$ (158). By contrast, clearance in the liver and spleen by the reticuloendothelium system is fast for particles above $200 \mathrm{~nm}$ in diameter. Additionally, particles in the micrometer range $(2-5 \mu \mathrm{m})$ have been shown to accumulate within capillaries of the lungs, providing an advantage when targeting one of the predominant sites of metastatic disease (159). 
Taken together, nanoparticles averaging $100-200 \mathrm{~nm}$ generally prove long-lasting in the circulation. Long half-lives in blood increase the propensity of nanoparticles to extravasate through fenestrations in tumor vasculature. Thus the pores of normal vessel walls are known to have 6-12 nm. By contrast the pore size of tumor vasculature reaches up to $600 \mathrm{~nm}$ which allows the pass of particles of 200-600 nm which has been exploited for passive targeting of nanoparticles to tumors (160).

\subsubsection{INTERNALIZATION}

After escape from the vascular space, the nanocomplex must traverse the interstitial space toward the target cell. Therefore, nanoparticle effectiveness depends on a variety of physiochemical characteristics of both particle and cell surface. Cationic carriers are known to first associate through electrostatic interactions with the anionic proteoglycans located on the cell membrane (161-164) (Figure 1.14 step 1). Cationic liposome complexes were shown to internalize by means of proteoglycans (165). In addition PEI-DNA complexes were found to bind to syndecans 1 and 2 (type of Heparan sulfate proteoglycans (HSPG)), inducing clustering of these syndecans and triggering their internalization process (166). Additionally HSPG appeared to have a crucial role for the internalization of cell penetratin peptides (CPP) as arginine peptides (Table 1.3), where the arginines interact with HS chains leading to their uptake in many cell lines (167).

Table 1.3: Some CPPs and their physical properties. Hydrophobicity calculated according to the values from von Heijne scale (168).

\begin{tabular}{ccccccc|} 
Peptide & $\begin{array}{c}\text { No. of } \\
\text { Arg }\end{array}$ & $\begin{array}{c}\text { No. of } \\
\text { Lys }\end{array}$ & $\begin{array}{c}\text { Hydropho- } \\
\text { bicity }\end{array}$ & $\begin{array}{c}\text { No. of } \\
\text { residues }\end{array}$ & Sequence & $\begin{array}{c}\text { Total } \\
\text { charge }\end{array}$ \\
\hline R9 & 9 & - & 2.58 & 9 & RRRRRRRRR & +9 \\
TAT & 6 & 2 & 2.37 & 13 & GRKKRRQRRRPPQ & +8 \\
Penetratin & 3 & 4 & 1.52 & 16 & RQIKIWFQNRRMKWKK & +7 \\
Pen-Arg & 7 & - & 1.49 & 16 & RQIRIWFQNRRMRWRR & +7 \\
pVEC & 4 & 2 & 1.10 & 18 & LLIILRRRIRKQAHAHSK & +8 \\
M918 & 7 & - & 0.93 & 22 & MVTVLFRRLRIRRACGPPRVRV & +7 \\
TP10 & - & 4 & 0.53 & 21 & AGYLLGKINLKALAALAKKIL & +4 \\
\hline
\end{tabular}



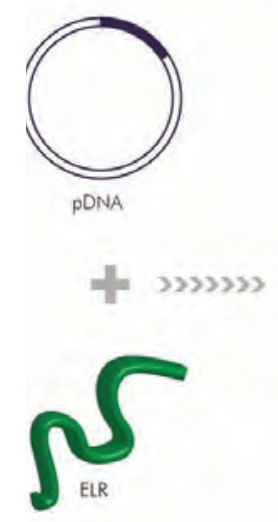

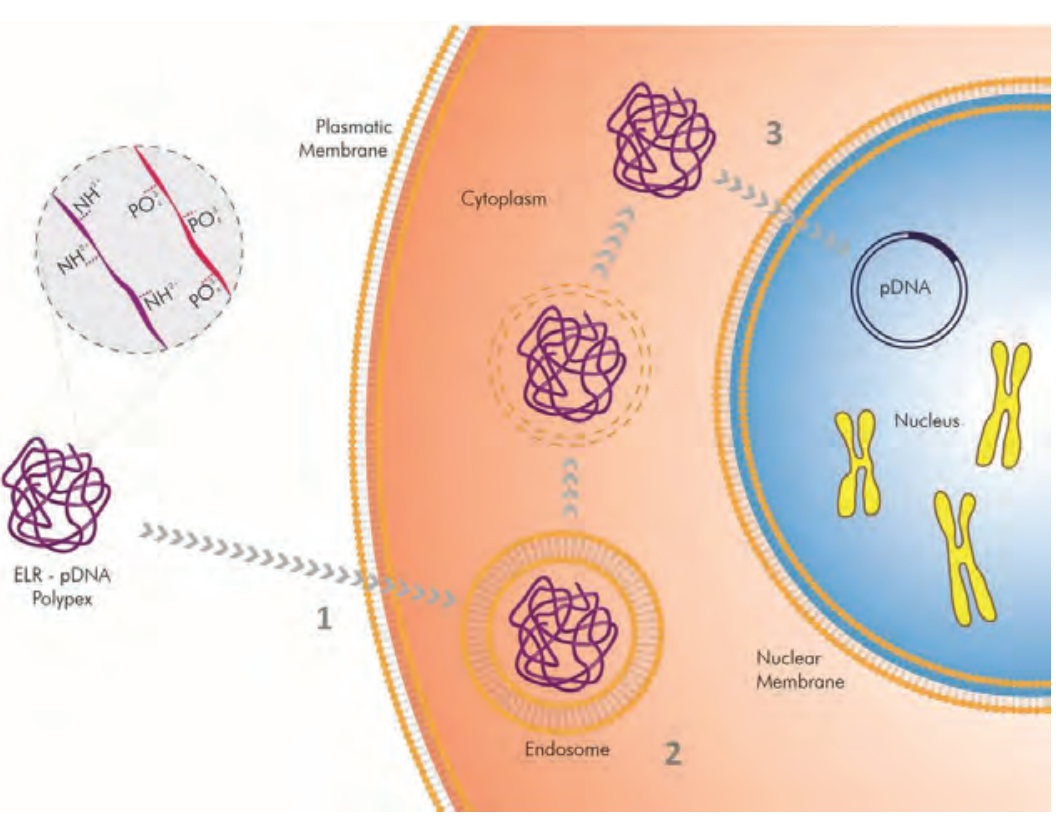

Figure 1.14. Schematic representation of the different barriers found by an ELR polyplex to enter and trafficking in the target cell. Polyplex formed by ELR and pDNA and stabilized through electrostatic interactions have to overpass the plasmatic membrane (step 1), escape from the endosome vesicle (step 2). DNA has to be further transported to the nucleus where it is expressed (step 3).

According with the internalization process, there are several internalization pathways that should be reviewed. Nanocomplexes can be uptaken by endocytosis and/or direct diffusion processes (90). Many entry pathways into cells have been identified, which vary in the cargoes they transport and in the protein machinery that facilitates the endocytic process. Endocytosis can broadly be divided into phagocytosis, clathrin dependent and independent internalization, of which the latter can be further classified into macropinocytosis and caveolin dependent and independent endocytosis pathways (Table 1.4 and Figure 1.15).

Large particles can be taken up by phagocytosis, whereas fluid uptake occurs by macropinocytosis. Both processes appear to be triggered by and are dependent on actin-mediated remodeling of the plasma membrane. Compared with the other endocytic pathways, the size of the vesicles formed by phagocytosis and macropinocytosis is much larger. 


\subsection{PHAGOCYTOSIS}

Mainly occurs in macrophages and polymorphonuclear neutrophils that engulf particles up to $10 \mu \mathrm{m}$ of diameter (131).

\subsection{CLATRIN-DEPENDENT ENDOCYTOSIS}

Clathrin-dependent endocytosis (CME) is also called as receptor mediated endocytosis. It controls constitutive and stimulated internalization of many receptors involved in cellular growth, differentiation, synaptic transmission and homeostasis. This pathway has been also used by toxins, bacteria and virus. Additionally, CME can be stimulated by ligand binding to epidermal growth factor receptor (EGFR) or LDL receptor among others or by other receptors such as transferrin receptor (TfR) that are constitutively internalized by CME (172). The initial step in CME requires the formation of coated pits by assembling of clathrin chains forming the triskelion shape. Afterwards, clathrin-coated pits are formed leading to vesicle formation, next vesicle scission by the GTPase dinamin and clathrin uncoating in order to produce endocytic vesicle containing the cargo occurs (173). It is interesting to highlight that clathrin vesicles have the ability to adapt to cargo requirements. For instance, when transferrin is bound to its receptor the vesicle have a diameter of about $13 \mathrm{~nm}$, by contrast with large spherical virus as H.influenza the vesicle size is about $120 \mathrm{~nm}$ (131, 173). Subsequently, cargo is either transported to the surface by exocytosis process or transported to mature endosomes and lysosomes. Thus for nanocomplexes

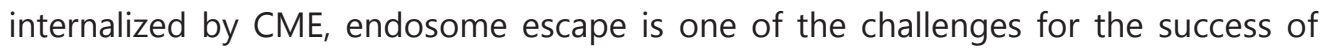
gene delivery.

Table 1.4. Main endocytosis pathways with some of the proteins implicated and chemical inhibitors. (CLIC: Clathrin independent carrier; GEEC: protein enriched early endosomal compartment; GPI, glycosylphosphatidylinositol; MHC, major histocompatibility complex; IL2-R, interleukin 2 receptor; EIPA， 5-(N-Ethyl-N-isopropyl)amiloride; PI3K, phosphoinositide 3-kinase; DMA, 5-(N,N-Dimethyl)amiloride hydrochloride. (117, 127, 169-171)

\begin{tabular}{|c|c|c|c|c|}
\hline $\begin{array}{l}\text { Endocytic } \\
\text { mechanism }\end{array}$ & Properties and functions & $\begin{array}{l}\text { Proteins } \\
\text { implicated }\end{array}$ & $\begin{array}{l}\text { Vesicles } \\
\text { size }\end{array}$ & Chemical Inhibitors \\
\hline Phagocytosis & $\begin{array}{l}\text { Essential for a variety of } \\
\text { biological events, including tissue } \\
\text { remodeling, clearance of dying } \\
\text { cells. As part of immune response } \\
\text { against invading pathogens. } \\
\text { Occurs in macrophages and } \\
\text { polymorphonuclear neutrophils } \\
\text { that engulf large particles. }\end{array}$ & $\begin{array}{l}\text { Actin } \\
\text { IQGAP1 } \\
\text { amphiphysin } \\
1 \\
\text { Rho kinase } \\
\text { Arf6,Cdc42 } \\
\text { rac1, rhoA }\end{array}$ & $<10 \mu \mathrm{m}$ & $\begin{array}{l}\text { Cytoskeletal inhibitors: } \\
\text { Cytochalasin D } \\
\text { Nocodazole } \\
\mathrm{Na}+/ \mathrm{H}+\text { exchange } \\
\text { inhibitors: } \\
\text { amiloride, EIPA, DMA } \\
\text { PI3K inhibitors: Wortmannin } \\
\text { and LY290042 }\end{array}$ \\
\hline
\end{tabular}




\begin{tabular}{|c|c|c|c|c|}
\hline $\begin{array}{l}\text { Clathrin } \\
\text { mediated } \\
\text { endocytosis } \\
\text { (CME) }\end{array}$ & $\begin{array}{l}\text { The most widely studied } \\
\text { endocytic pathway. Includes the } \\
\text { endolysosomal step. } \\
\text { This pathway encompasses the } \\
\text { internalization of nutrients, } \\
\text { antigens, growth factors, and } \\
\text { receptors. }\end{array}$ & $\begin{array}{l}\text { Clathrin } \\
\text { Dynamin } \\
\text { AP2, Epsin } \\
\text { SNX9, actin } \\
\text { amphiphysin } \\
\text { Rab5, etc }\end{array}$ & 60-200 nm & $\begin{array}{l}\text { Chlorpromazine } \\
\text { Monodansylcadaverine } \\
\text { Hypertonic sucrose } \\
\text { K+ depletion } \\
\text { Cytoeskeletal inhibitors: } \\
\text { Cytochalasin D }\end{array}$ \\
\hline $\begin{array}{l}\text { Macro- } \\
\text { pinocytosis }\end{array}$ & $\begin{array}{l}\text { Highly conserved endocytic } \\
\text { process by which extracellular } \\
\text { fluid and its contents are } \\
\text { internalized into cells. Facilitate } \\
\text { MHC-class-II-restricted antigen } \\
\text { presentation by dendritic cells. } \\
\text { Some pathogenic bacteria } \\
\text { internalize through it. }\end{array}$ & $\begin{array}{l}\text { Actin } \\
\text { Dinamin } \\
\text { PAK-1 } \\
\text { Arf6 } \\
\text { Rho GTPases } \\
\text { Rac1, Cdc42 }\end{array}$ & $0.5-10 \mu \mathrm{m}$ & $\begin{array}{l}\text { Cytoskeletal inhibitors: } \\
\text { Cytochalasin D } \\
\text { Nocodazole } \\
\mathrm{Na}+/ \mathrm{H}+\text { exchange } \\
\text { inhibitors: amiloride, EIPA, } \\
\text { DMA } \\
\text { PI3K inhibitors: } \\
\text { Wortmannin and LY290042 }\end{array}$ \\
\hline $\begin{array}{l}\text { Caveolae- } \\
\text { dependent } \\
\text { endocytosis }\end{array}$ & $\begin{array}{l}\text { Characterized by the presence of } \\
\text { caveolae that is present on the } \\
\text { cell surface of muscle cells, } \\
\text { endothelial cells, fibroblasts, and } \\
\text { adipocytes. They are usually } \\
\text { associate with lipid rafts and } \\
\text { characterized by the presence of } \\
\text { the caveolin-1. } \\
\text { Plays important roles in cell } \\
\text { adhesion and anchorage- } \\
\text { dependent cell growth together } \\
\text { with uptake of several viruses. }\end{array}$ & $\begin{array}{l}\text { Caveolin } \\
\text { Dynamin } \\
\text { Cavins } \\
\text { Src, Actin } \\
\text { PKC (many } \\
\text { signaling } \\
\text { proteins } \\
\text { localize on } \\
\text { caveolae) }\end{array}$ & $60-80 \mathrm{~nm}$ & $\begin{array}{l}\text { Cholesterol depletors: } \\
\text { Filipin, methyl- } \beta \text { - } \\
\text { cyclodextrin and genistein } \\
\text { PP2 (src kinase family } \\
\text { inhibitor) } \\
\text { actin polymerization } \\
\text { inhibitor: Cytochalasin D }\end{array}$ \\
\hline $\begin{array}{l}\text { RhoA- } \\
\text { dependent }\end{array}$ & $\begin{array}{l}\text { RhoA-dependent endocytic } \\
\text { vesicles are formed via the } \\
\text { function of RhoA and actin. } \\
\text { Involved in uptake of IL2-R in } \\
\text { lymphocytes. }\end{array}$ & $\begin{array}{l}\text { RhoA } \\
\text { Dynamin } \\
\text { Rac1 } \\
\text { Actin }\end{array}$ & $50-80 \mathrm{~nm}$ & $\begin{array}{l}\text { Cholesterol depletors: } \\
\text { genistein } \\
\text { Actin polymerization } \\
\text { inhibitors }\end{array}$ \\
\hline Arf6 & $\begin{array}{l}\text { Arf6 mediates the formation of } \\
\text { the Arf6-dependent endocytic } \\
\text { vesicles in addition to Rac } 1 \text { which } \\
\text { plays a role in scission of these } \\
\text { vesicles. Internalize } \\
\text { histocompatibility complex molecules } \\
\text { (MHC I), } \beta 1 \text { integrin, carboxy } \\
\text { peptidase E (CPE), E-cadherin. }\end{array}$ & $\begin{array}{l}\text { Arf6 } \\
\text { Rac1 }\end{array}$ & $50-80 \mathrm{~nm}$ & $\begin{array}{l}\text { siRNA against Arf6 } \\
\text { Cholesterol depletors } \\
\text { genistein } \\
\text { Actin polymerization } \\
\text { inhibitors }\end{array}$ \\
\hline $\begin{array}{l}\text { GRAF1/ } \\
\text { Cdc42 }\end{array}$ & $\begin{array}{l}\text { Mediated by the complementary } \\
\text { role of Cdc42 with Arf1 in } \\
\text { meditating actin polymerization. } \\
\text { Actin and GRAF1 then drive the } \\
\text { formation of the endocytic } \\
\text { vesicles (GEECs and CLICs). } \\
\text { This pathway is } \\
\text { cholesterolsensitive and used by } \\
\text { GPI-APs uptake. }\end{array}$ & $\begin{array}{l}\text { Cdc42 } \\
\text { GRAF1 } \\
\text { Arf1 }\end{array}$ & $50-80 \mathrm{~nm}$ & $\begin{array}{l}\text { siRNA against GRAF } \\
\text { Secramine A } \\
\text { Actin polymerization } \\
\text { inhibitor: EIPA } \\
\text { Clostridium difficile toxin B } \\
\text { Cholesterol depletion by } \\
\text { methyl- } \beta \text {-cyclodextrin }\end{array}$ \\
\hline Flotillin & $\begin{array}{l}\text { Flotillin proteins are associated } \\
\text { with membrane lipid rafts } \\
\text { microdomains. } \\
\text { Involved in axonal regeneration, } \\
\text { insulin signaling, and endocytosis } \\
\text { processes. }\end{array}$ & $\begin{array}{l}\text { Flotillin } 1 \text { and } \\
2 \\
\text { Fyn kinase }\end{array}$ & $50-200 \mathrm{~nm}$ & $\begin{array}{l}\text { siRNA against flotillin } \\
\text { Cholesterol depletion by } \\
\text { methyl- } \beta \text {-cyclodextrin and } \\
\text { genistein } \\
\text { Actin polymerization } \\
\text { inhibitors }\end{array}$ \\
\hline
\end{tabular}




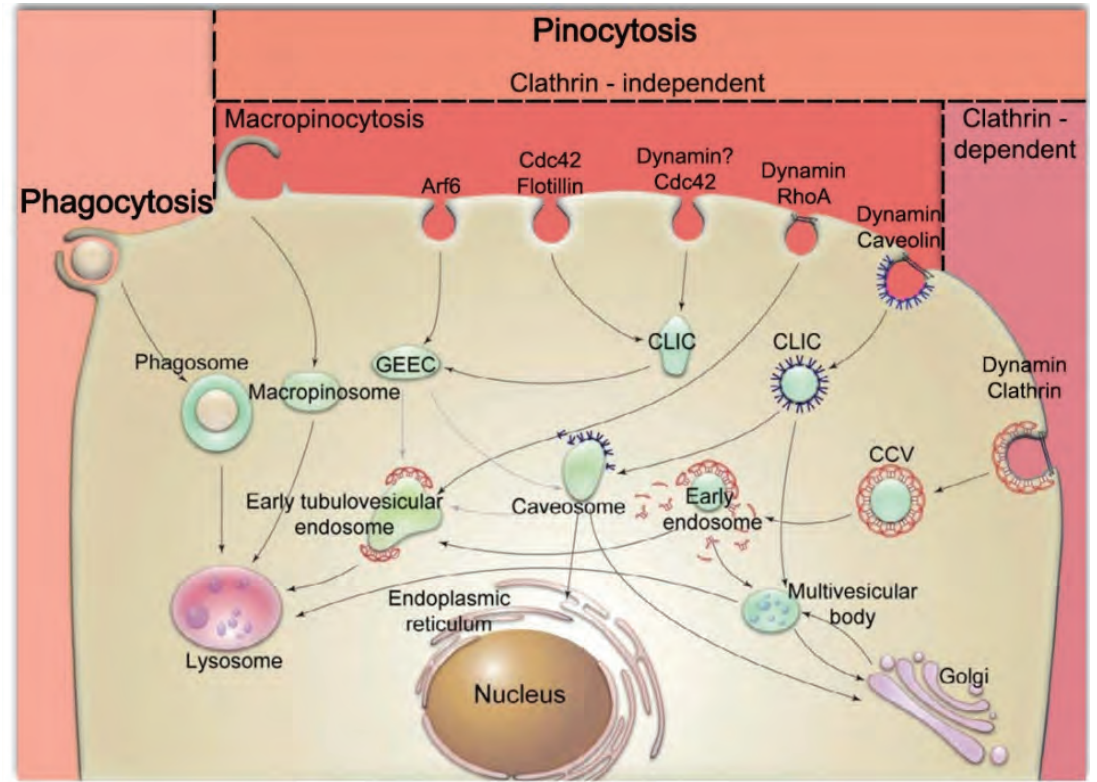

Figure 1.15. Pathways of cellular uptake. Large particles can be taken up by phagocytosis, whereas fluid uptake occurs by macropinocytosis. Both processes appear to be triggered by and are dependent on actin-mediated remodelling of the plasma membrane. Rest of particles are delivered to the early endosome via vesicular (clathrin- or caveolin-coated vesicles) or tubular intermediates (known as clathrin- and dynaminin dependent carriers (CLICs)) that are derived from the plasma membrane. Abbreviations are: clathrin coated vesicles (CCV), clathrin-independent carriers (CLIC), GPI-anchored protein enriched early endosomal compartment (GEEC), multivesicular body (MVB) (127).

\subsection{CLATRIN-INDEPENDENT ENDOCYTOSIS}

\subsection{Macropinocytosis}

Macropinocytosis is a clathrin and caveolin independent pathway by which extracellular fluids and its contents are internalized into cells. Macropinocytosis is often initiated by activation of growth factor receptors. In virus internalization, interaction with HSPGs together with tirosin kinase receptors (RTKs), phosphatidylserine receptors (PS-Rs), integrins, or other surface molecules capable of activating the appropriate signaling pathways constitute the first step (174). That, leads to changes in actin cytoskeleton resulting in plasma membrane ruffling and formation of lamellipodia or blebs over the entire cell surface. The membrane ruffles engulf the fluid, generally macropinocytosis is considered as a non-specific pathway to internalize large particles. The collapse of these ruffles results in the formation of intracellular uncoated, irregularly shaped endocytic vacuoles named as macropinosomes. Macropinosomes size is large $(0.5 \mu \mathrm{m}-10 \mu \mathrm{m})$. Regulatory factors of 
macropinocytosis include p21 activated kinase 1 (PAK1), Arf6, and the Rho family GTPases, Rac1 and Cell division control protein 42 (Cdc42) (175). PAK1 is targeted for the activated Rac and $\mathrm{Cdc} 42$, thus represents one of the key kinase protein regulators as part of the signaling cascade that become activated due to an external stimulus (176). Its activation triggers actin rearrangement, plasma membrane protrusion and ruffling. It activates the dynamin-dependent mechanism of the macropinosome formation as well, including membrane fission event that separate the macropinosomes from the extracellular space and closure (174).

Initial interaction with HSPGs as a cell surface-receptor has been observed to play an important role in the endocytosis of exosomes, cell penetrating peptides, polyplexes, lipoproteins and growth factors among other ligands. However, HSPG mediated endocytosis is not restricted to clathrin independent or dependent endocytosis, it varies depending on the cellular context and the type of extracellular ligand. Thus, HSPG has general role in the uptake of polyarginines, polylysines and arginine-lysine hybrid peptides (177-179). Moreover is key for the macropinocytic uptake of Tat and R8 peptide in studies with proteoglycan-deficient CHO cells (167). Indeed endocytic pathways have always been considered as enduring mechanisms for recycling molecules such as MUC1 glycoprotein from the plasma membrane to different intracellular compartments, and reduce receptor density at the cell surface resulting in signal attenuation $(180,181)$.

Bacteria, apoptotic bodies, necrotic cells, viruses among others are shown to be internalized by macropinocytosis. A variety of nanomaterials has been observed to use this uptake pathway by the utilization of actin formation inhibitors as cytochalasin $\mathrm{D}$ (127) or $\mathrm{Na}^{+} / \mathrm{H}^{+}$exchange inhibitors as amiloride. For instance, macropinocytosis was shown to be the predominant mechanism of cellular uptake in ELR diblocks modified with oligoarginine CPP (51).

\subsection{Caveolae-dependent pathway}

Caveolae/raft-dependent endocytosis is involved in virus entry into host cells, in internalizing glycophospatidylinositol-anchored proteins and regulating some signaling cascades. Caveolae (term that comes from little caves) are sphingolipid and cholesterol-rich plasma membrane invaginations abundant in muscle, endothelial, 
fibroblast and adipocyte cell surface (182). Caveolae are characterized by the presence of the hairpin-like membrane protein caveolin-1 which is necessary for their formation. Caveolae showed a flask-shaped vesicles with a diameter of $60-80 \mathrm{~nm}$. The biogenesis of caveolae occurs in the endoplasmic reticulum where caveolin-1 molecules oligomerize and transfer to the Golgi apparatus where they become associated with cholesterol. Some studies suggest that cavin protein may stabilize the caveolae by acting as a coat protein inducing the membrane curvature (183).

Based on Simian Virus 40 trafficking (184) study which were known to internalized particles through caveolae-dependent pathway, caveolae is thought to pinch off (mediated by dynamin), to fusion with other caveolae and form a vesicle with a neutral $\mathrm{pH}$ named as caveosomes. In this way, caveolae-mediated pathway bypasses the endolysosomal step avoiding the cargo enzymatic degradation. Contrary Hayer et al. (185) proposed a revised model for endocytic trafficking of caveolin-1, where caveosomes correspond to late endosomal compartments in which the accumulated caveolin-1 is awaiting degradation. Moreover, the endolysosomal step seems to be dependent of the cellular type (171). For instance, when caveolae-dependent endocytosis occurs in endothelial cells the cargo may undergo transcytosis across the cell to the underlying tissue avoiding the lysosomal degradation. However, when endocytosis happens in non-endothelial cells the cargo is transported to the endolysosomal vesicles.

The typical molecules that internalize through caveolae-mediated endocytosis are CTB and Shiga toxin. Indeed, this pathway is thought to be beneficial for gene delivery several materials such as DOXIL ${ }^{\circledR}$, polymeric micelles or QDs are reported to enter cells via caveolae-dependent mechanism avoiding the endosomes (127).

\subsection{Caveolae and clathrin-independent pathways}

Caveolae and clatrin-independent pathways includes those that caveolae or clathrin proteins are not involved. Extracellular fluids, SV40, CTB, GPI-linked proteins, IL-2, growth hormones among others are uptaken by caveolae and clathrin independent pathways. Those are classified as function of the effectors implicated named as Arf6, flotillin, Cdc42 or RhoA dependent pathways (Table 1.3 and Figure 1.15). The general trafficking process seems to bypass the rab5 positive early endosomes. For instance, 
the GPI-linked proteins are transported through the GPI-anchored protein enriched early endosomal compartments (GEECs). However, IL-2R $\beta$ or IgE receptor Fc $\varepsilon$ R1 is transported through an independent-GEECs pathway. Another pathway independent of GEEC but requiring Arf6 positive endosomes is the one used by the major histocompatibility class (MHC)-1 protein $(127,182)$.

Most biomaterials used for gene delivery purposes have been shown to internalized through more than one pathway (127). The utilization and design of delivery systems that have a preferred route of entry would address some of the common barriers of transfection. As detailed before, physical features as particle size, zeta potential and shape together with chemical modifications are important tools to consider. For instance, the use of ligands that can specifically recognize certain receptors (HSPG, transferring or folate receptors) to target tumors together with the use of cell penetrating peptides such as penetratin, TAT or R8 in the delivery system design could improve the internalization process. Indeed the utilization of proton sponge triggers as imidazole groups or fusogenic peptides as KALA, HA-2, LAEL (186) that destabilizes the endosome membrane seems to be advantageous to address the nuclear entry. Since the existence of high variability in endocytic processes between cells, it is necessary to highlight the difficulty to extrapolate the uptake behavior of a specific particle to a general model applicable to every cell line.

\subsubsection{ENDOSOMAL ESCAPE}

An ideal gene delivery system has to be able to escape from endolysosomal degradation and enable the translocation of DNA into the nucleus (Figure 1.14 step 2 and 3) (134). ATP-mediated proton accumulation makes endosome and lysosome compartments more acidic $(\mathrm{pH}$ 4.0-6.2) than cytoplasm $(\mathrm{pH}$ 7.4) (187). Non-viral vectors have to take advantage of this situation and escape to degradation in order to exhibit efficient transfection levels. One strategy adopted by non-viral vectors involves the addition of chloroquine during the transfection process. Chloroquine is a lysosomotropic agent that prevents endosomal acidification. It accumulates inside the acidic parts of the cell, including endosomes and lysosomes. This accumulation leads to inhibition of lysosomal enzymes that require an acidic $\mathrm{pH}$, and prevents fusion of endosomes and lysosomes (188). Other strategy lies in the incorporation of 
fusogenic peptides such as HA-2 or LAEL in the cationic polymer design promoting the polyplex escape. For instance, LAEL undergoes a structural change when the $\mathrm{pH}$ drops from physiological values to 5.0 (189), changing from a random coil to $\alpha$-helix, thereby resulting in destabilization of the endosome membrane. And an alternative strategy is the use of amine groups with low pka that has been shown to exhibit "proton sponge" ability. One of these groups is imidazole (pKa of 6.9) which favors disruption of the endosome supported by the proton sponge hypothesis (88). The protonation of imidazole at endosomal $\mathrm{pH}(\mathrm{pH} 6)$ triggers an influx of water and ions, thereby destabilizing and disrupting the endosome and releasing the DNA into the cytoplasm, mechanism which have been already observed in polymers as PEI with high number of unprotonated amines at acidic $\mathrm{pH}(102,103)$.

\subsubsection{NUCLEAR ENTRY}

The nuclear import of the DNA is cell-cycle dependent and is one of the most challenging barriers for non-viral gene delivery. It is cell-cycle dependent since dividing cells often exhibit higher transfectability than non-mitotic cells, indicating that plasmid DNA can reach the nucleus during nuclear envelope disassembly as cell division occurs (190). In general, polyplexes exhibited significantly higher levels of gene expression than nude pDNA. Hence, cationic vectors able to compact tightly and protect the DNA from enzymatic degradation in cytoplasm should help in the movement towards the nucleus. To reach the transcriptional machinery, pDNA has to be able to cross the nuclear membrane. In the case of transfecting siRNA is not necessary to reach the nucleus. The transport to nucleus is thought to involve two processes: passive diffusion and active process coupled to ATP input. Both processes are mediated through the nuclear pore complex (NPC). Based on the nuclear translocation studies on colloidal gold particles and dextrans in 1960-1970s (191193), it was believed that the limit for particles to diffuse passively through the NPC was 9-12 nm in diameter. This size was later reviewed to $60 \mathrm{kDa}(194,195)$. In 2007 Wang (196) showed that proteins of various sizes larger than $60 \mathrm{kDa}$, even reaching 90 and $110 \mathrm{kDa}$ could diffuse through NPC. This finding suggests that many proteins, with higher size that was initially believed, do not require a nuclear localization/export signal to diffuse through the NPC. 
Alternatively to passive transport, proteins may shuttle between the cytoplasm and the nucleus in an ATP-dependent process which is mediated by nuclear localization signals (NLSs) or nuclear export signals (NESs). These signals are specifically recognized by importins and exportins that chaperon the transported proteins into the nucleus.

Gene delivery is a multi-step process in which the appropriate vector is needed to go through each step. Hence, a rational design at molecular level of either polymeric vectors which could overpass the extra and intra-cellular barriers and plasmid should be performed (Table 1.5).

Table 1.5. Gene delivery barriers and design of non-viral vectors.

\begin{tabular}{|c|c|c|c|}
\hline Barriers & $\begin{array}{l}\text { Functional } \\
\text { components }\end{array}$ & Rational strategy & Examples \\
\hline $\begin{array}{l}\text { Extracellular } \\
\text { stability }\end{array}$ & Vectors & $\begin{array}{l}\text { DNA condensation, } \\
\text { protection from } \\
\text { nucleases }\end{array}$ & $\begin{array}{l}\text { Lipids, polymers, dendrimers } \\
\text { (90) }\end{array}$ \\
\hline $\begin{array}{l}\text { Extracellular } \\
\text { stability }\end{array}$ & $\begin{array}{l}\text { Hydrophilic } \\
\text { motif }\end{array}$ & $\begin{array}{l}\text { Steric stabilization, } \\
\text { surface charge } \\
\text { shielding }\end{array}$ & PEGylation (90) \\
\hline Internalization & $\begin{array}{l}\text { Penetrative } \\
\text { motifs } \\
\text { Targeting } \\
\text { ligands }\end{array}$ & $\begin{array}{l}\text { Interaction with plasma } \\
\text { membrane } \\
\text { Receptor-mediated } \\
\text { endocytosis }\end{array}$ & $\begin{array}{l}\text { CPP:penetratin, TAT, } \\
\text { polyarginines among others } \\
(197) \\
\text { Transferrin }(198), \text { EGF (199), } \\
\text { antibodies }(200,201), \\
\text { aptamers }(202,203), \text { RGD (204) }\end{array}$ \\
\hline $\begin{array}{l}\text { Endosome } \\
\text { escape }\end{array}$ & $\begin{array}{l}\text { Endosome } \\
\text { disruptive } \\
\text { agent }\end{array}$ & $\begin{array}{l}\text { Escape from endosome } \\
\text { and unpacking } \\
\text { Proton sponge } \\
\text { hypothesis }\end{array}$ & $\begin{array}{l}\text { PEI }(111,205,206), \text { DOPE }(207) \\
\text { Fusogenic peptides }(208,209)\end{array}$ \\
\hline Nuclear entry & $\begin{array}{l}\text { Nuclear } \\
\text { localization } \\
\text { signal (NLS) }\end{array}$ & Nuclear entry & $\begin{array}{l}\text { Tat, Rev gene as regulatory } \\
\text { elements for nuclear transport } \\
(210)\end{array}$ \\
\hline
\end{tabular}

\subsection{BASIC PRINCIPLES ABOUT NON-VIRAL BREAST CANCER GENE THERAPY}

Breast cancer is the principal malignancy diagnosed in women in Western societies, with an estimated 231,840 new cases of breast cancer being detected in the female population of the USA during 2015 (211). Additionally, it is located in the first 
position according with new cases estimated (29\%) and the second in death estimated (15\%) among cancer diseases in 2015 for USA (Figure 1.16). Breast cancer is a complex and heterogeneous disease where genotypic and phenotypic manifestations lead to tumorigenesis. The development of molecular profiling using DNA microarrays for estrogen receptor $(E R \alpha)$, progesterone receptor $(P R)$ and human epidermal growth factor receptor (HER2) expression allowed the classification of breast cancer into at least five subtypes: luminal A, luminal B, HER2, basal and claudin-low (212) (Table 1.6). ER, which is expressed in luminal A and B types, is target for hormone therapy. However, HER2 groups and luminal B are potential candidates for Trastuzumab therapy. The absence of these therapeutic targets makes basal tumors difficult to treat, more biologically aggressive and often with poor prognosis.

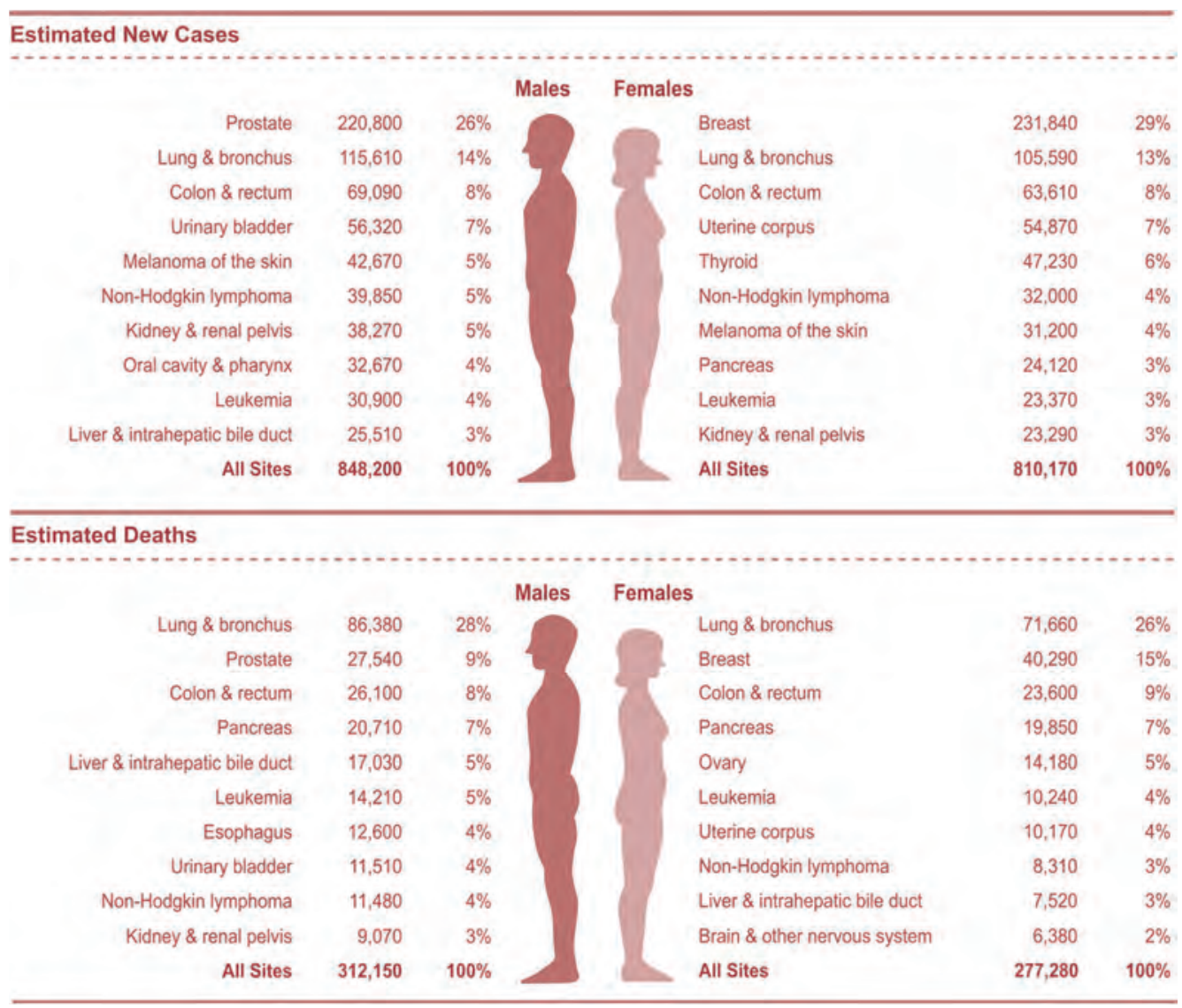

Figure 1.16. Ten Leading Cancer Types for the Estimated New Cancer Cases and Deaths by Sex in United States, 2015(213). 
Although different treatments as targeted therapy using Trastuzumab for HER-2 overexpressed patients, surgery, chemotherapy, radiation or endocrine are available, and all of them have been shown to be effective in advanced breast tumors, they improve the clinical outcome but do not increase the cure rate (215). This situation opens the door for gene therapy treatments which are expected to be a useful therapeutic approach for breast cancer disease among others.

Table 1.6. Molecular classification of breast carcinoma. EGFR, epidermal growth factor; ER, estrogen receptor; HER2, human epidermal growth factor receptor 2; PR, progesterone receptor. Adapted from (214)

\begin{tabular}{|c|c|c|}
\hline Classification & Immunoprofile & Characteristics \\
\hline Luminal A & $\mathrm{ER}^{+}, \mathrm{PR}^{+/-}, \mathrm{HER} 2^{-}$ & $\begin{array}{l}\text { Endocrine responsive, often chemotherapy } \\
\text { responsive,Ki67 low levels }\end{array}$ \\
\hline Luminal B & $\mathrm{ER}^{+}, \mathrm{PR}^{+/-}, \mathrm{HER}^{+}$ & $\begin{array}{l}\text { Usually endocrine responsive, variable to chemotherapy, } \\
\text { HER2 } 2^{+} \text {are Trastuzumab responsive, Ki67 high levels }\end{array}$ \\
\hline Basal & $\mathrm{ER}^{-}, \mathrm{PR}^{-}, \mathrm{HER} 2^{-}$ & $\begin{array}{l}\text { Endocrine nonresponsive, often chemotherapy } \\
\text { responsive, EGFR }{ }^{+} \text {, cytokeratin } 5 / 6^{+} \text {and Ki67 high }\end{array}$ \\
\hline Claudin-low & $\mathrm{ER}^{+}, \mathrm{PR}^{-}, \mathrm{HER} 2^{-}$ & $\begin{array}{l}\text { Intermediate response to chemotherapy, E-cadherin, } \\
\text { claudin-3, } 4 \text { and } 7 \text { low levels. Ki67 }\end{array}$ \\
\hline HER2 & $\mathrm{ER}^{-}, \mathrm{PR}^{-}, \mathrm{HER} 2^{+}$ & $\begin{array}{l}\text { Trastuzumab responsive, chemotherapy responsive, Ki67 } \\
\text { high levels. }\end{array}$ \\
\hline
\end{tabular}

Strategies in ongoing clinical protocols can be divided into three groups:

$\checkmark$ Transference of tumor-supressor genes or suppression of oncogenes

$\checkmark$ Enhancement of immunological response

$\checkmark$ Transference of suicide genes

\subsubsection{TRANSFERENCE OF TUMOR-SUPRESSOR GENES OR SUPRESSION OF ONCOGENES}

The carcinogenesis is a complex process that involves a multiple genetic events which can activate oncogenes or disrupt the function of tumor suppressor genes. The activation of oncogenes results in the stimulation of cell growth, division and survival whereas the functional disruption of tumor suppressor genes leads to loss of control over the cell growth, DNA repair and cell cycle. The frequently abnormalities in breast cancer affects to HER-2, PI3K (phosphatidylinositol 3 kinase), p53 gene which codifies 
for p53 protein, E1A, BRCA1/2, BMI1 and c-myc gene amplification among others (216).

The transference of p53 gene, which is a tumor suppressor gene, has shown activation of the p53 response with curative results in animal studies. Indeed the utilization of adenoviral vectors reached the creation of Advexin, Gendicine which are essentially the same viral structure, with activity in clinical trials directed against various tumor types, including breast cancer (217). Besides of transference of tumor suppressor genes, the elimination of oncogenes can be utilized. It can be achieved by the use of a regulator. For instance, E1A (Adenovirus early region 1) gene therapy is known to decrease the HER-2 expression levels for breast and ovarian cancers in nude mice. Clinical trials were performed with the cationic liposome (DC-Chol) complexed with E1A gene and injected in 6 patients with advanced breast cancer. The result was anti-tumor effect in terms of HER-2 downregulation, increased apoptosis and downregulation (218).So far, this constitutes the only example for suppression of oncogene by non-viral vectors that have reached to clinical studies.

Another viable strategy to eliminate oncogenes is interfered with the expression of the desired genes by means of siRNA or shRNA. Non viral vector made of chitosan (CS) and TAT peptide forming the copolymer TAT-g-CS was used for siRNA delivery targeted to survivin gene with the objective of inhibiting the tumor growth. The result demonstrated that nanoparticles carrying the siRNA inhibit in vitro proliferation and in vivo tumor growth leading to metastasis of the breast tumor in xenograft bearing mice (219). Multidrug resistant phenotype (MDR) in breast cancer cells represents a serious obstacle in the treatment with chemotherapy. It is known that the overexpression of P-glycoprotein encoded by MDR1 gene is responsible for the MDR phenotype. Hence, siRNA directed against the expression of P-glycoprotein can increase the cytotoxicity of drugs as adriamycin. In the work of Gao et al. (220) nanoparticles made of reduction-sensitive cationic click polymer (RCP) and named as RCPNs were able to deliver siRNA against P-glycoprotein expression and increase drug accumulation and cytotoxicity in adriamycin resistant MCF-7 cells. Thus, the combination of RCPNs and adriamycin could suppress the tumor growth more efficiently than administrating the drug alone. Indeed, BMI-1 siRNA was delivered by the cationic PEI-modified laminarin vector. BMI-1 has a synergistic effect with c-Myc 
causing tumor cell migration and metastasis. The antitumor effect of the complex vector-siBMI was shown in both in vitro and in vivo models (221).

\subsubsection{ENHANCEMENT OF IMMUNOLOGICAL RESPONSE}

The human immune system can be manipulated to recognize and kill tumor cells, suggesting that the generation of antitumor immunity may be integrated into the treatment of cancer. Cancer vaccines should not only kill cancer cells with limited toxicity, but also generate ongoing antitumor responses secondary to development of immunologic memory and eradicate residual tumor. Since most of the antigens used are autoantigens the harder obstacle is to overcome the immune tolerance (222). There are a variety of tumor-associated antigens that can be used as targets such as HER-2, MUC-1 and mammaglobin-A (223).

Clinical trials with HER-2 and mammaglobin-A as targets for vaccination were performed with nude CDNA. Transgenic mice for the human HER-2 gene were vaccinated with a chimeric HER-2 sequence and IL-12 as adjuvant. $65 \%$ of mice were free of tumors after 90 weeks compared to 45 weeks for controls. Additionally a sustained level of anti-HER-2 antibodies and IFN-Y production was obtained (224). Otherwise, mammaglobin-A is overexpressed in $80 \%$ of primary and metastatic human breast cancers. Its vaccination leads to a $C D 8^{+}-\mathrm{T}$-mediated immune response. Phase I clinical trials with seven patients in stage-IV of breast metastatic disease were performed (225). The study concluded that mammaglobin-A cDNA vaccination was associated with the expansion and activation of a CD4+ population named as $C D 4^{+}{ }^{+} C S^{\text {hi }} T$ cells which is indicative of antitumor immunity.

By contrast, the use of non-viral vectors can improve the vaccination potency. Endmann et al. study (226) supports the vaccination mediated by a lipidic vector. The pre-designed minimalistic immunogenically defined gene expression (MIDGE-Th1) pDNA complexed with the cationic lipid SAINT-18 and forming lipoplexes were tested in vitro and in vivo at different formulations. The result was an immuneenhancing effect by the vector SAINT-18 and mediated by the higher transfection efficiency in the target cells. Thus the existence of the vector improved the pDNA uptake and hence the immune response. Indeed, Gribben et al. (227) studied the effect of the vaccination with ZYC300, a pDNA encoding an inactivated form of the 
CYP1B1 (carcinogen activator cytochrome P450 1B1) within biodegradable poly-DLlactide-coglycolide microparticles, in seventeen patients with advanced breast cancer. Carcinogen activator cytochrome P450 1B1 (CYP1B1) which is expressed on almost all human tumors had been previously shown to elicit T-cell-mediated responses. Phase I clinical trial results showed the generation of T-cell-mediated responses without autoimmunity improving their prognosis.

\subsubsection{TRANSFERENCE OF SUICIDE GENES}

In the search of alternatives to breast cancer treatments, the use of toxic or proapoptotic genes has emerged as one of the most attractive strategies for cancer treatment. This approach requires the inclusion of a suicide gene in the transfer plasmid that would encode a protein that results in cell killing only when activated by a specific compound (disease associated transcription factor) (Figure 1.17). A suicide gene can encode an enzyme that selectively converts a non-toxic pro-drug into highly toxic metabolites eliminating specifically cells expressing the enzyme. Ganciclovir as drug activator in combination with Herpes simplex virus thymidine kinase (HSVtk) gene constitute the first and most common strategy used in experimental and clinical studies $(228,229)$. The pro-drug is converted to the active, cytotoxic metabolite in the tumor cell, and diffusion to neighbouring cells confers a potent "bystander effect" (229).

The safety and effective approaches are the main concerns of suicide gene therapy. Accordingly, tumor-specific promoters (TSP) are increasingly used to selectively express the gene of interest in cancer cells without damage the healthy ones. HER-2, survivin or MUC-1 promoters have been used to express suicide genes.

HER-2 is overexpressed in about one third of breast tumors and in a variety of other tumors, it is often correlated with a poor prognosis (230). One of the earliest targeted non-viral clinical trials was for patients overexpressing the HER-2 receptor (231). The PERCY plasmid, containing the HER-2 promoter and driving the expression of cytosine deaminase was subjected to Phase I clinical trial. This enzyme allows the activation of fluorocytosine (5-FC) to the active cytotoxic fluorouracil (5-FU). Twelve breast cancer patients received the intratumoral injection of nude plasmid construct combined with the systemic administration of 5-FC. The approach showed to be safe 
and resulted in targeted gene expression in up to $90 \%$ of cases. Thus, significant levels of suicide enzyme were obtained selectively in HER-2 expressing tumor cells.

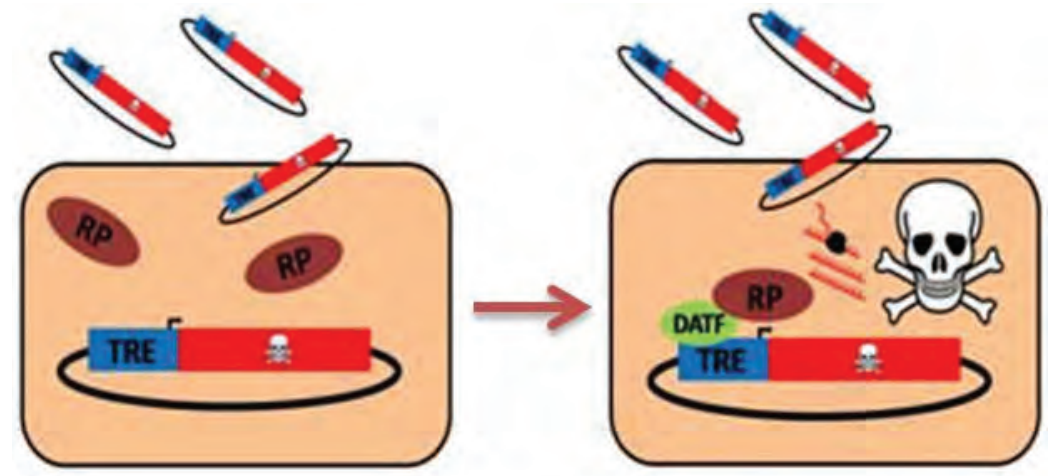

Figure 1.17.Toxin based suicide gene therapy. pDNA encoding for a toxic protein whose expression is regulated by a specific TRE, is delivered to a heterogeneous cell population. Cytotoxic effects occur only in cells expressing the DATF that specifically binds to the TRE and activates the transcription of the toxin. (TRE: transcription regulation element, diseaseassociated transcription factor: DATF and RP: RNA polymerase).

Survivin is known to regulate apoptotic events and be over-expressed in a variety of cancer cells (232). The survivin promoter was used to promote bax expression in several breast cancer lines. Bax which is an apoptotic regulator has been used as candidate for suicide gene therapy $(233,234)$. In vivo studies showed that Bax mutant S184 under the control of survivin promoter (Sur-BaxS184) and complexed with jetPEI significantly enhance the activity of bax in mouse tumor model (235). Tumor growth delay after intratumoral administration of the polyplex was obtained.

MUC1 is a glycoprotein that is over-expressed in presence in $90 \%$ of breast cancers (236). PEGylated PEI polyplexes functionalized with a anti-MUC1 nanobody condensed a plasmid containing the cytotoxic tBid transgene under the control of MUC1 promoter and were applied in suicide gene therapy. In vitro assays showed considerable cell death induced by tBid in MCF-7, SKBR3 and T47D breast cancer cells (237).

Using targeted suicide therapy provides a safe and effective strategy to design gene therapy systems that can be adapted for use with various tumors or delivery systems. So far, most of the research of suicide gene therapy for breast cancer treatment has been focused in the use of viral vectors (238-241) mainly due to their higher 
transfection levels, however the promising advances in non-viral vectors constitute a real alternative for suicide gene therapy approach as well.

\subsubsection{TARGETED THERAPIES}

Amongst the above explained strategies in ongoing clinical protocols the transference of suicide genes by using tumor-specific promoters constitutes a targeted therapy by itself. In addition, all of them can be accompanied by targeting components whose make improving their lack of cell specificity during in vitro and in vivo delivery and consequently the global result of the therapy. The general strategy is targeting over-expressed proteins and markers such as the above described HER-2, PR, MUC1, Ki67, p53, CXCR4, FOXP3 or miRNA amongst others (242).

Targeting agents can be broadly classified as proteins (mainly antibodies and their fragments), nucleic acids (aptamers), or other receptor ligands (peptides, vitamins, and carbohydrates) (Figure 1.18).
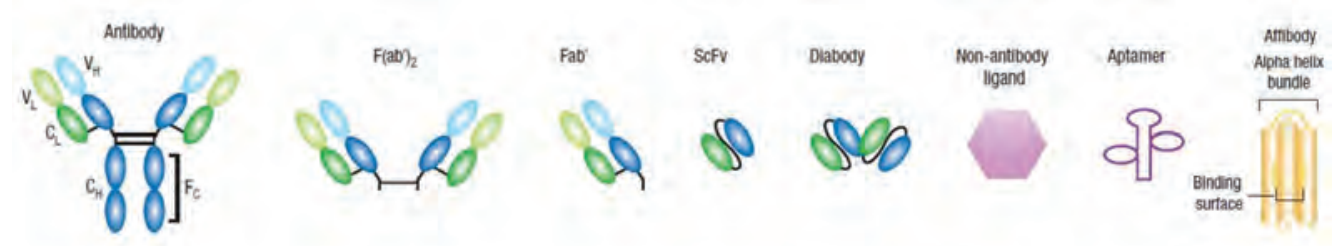

Figure 1.18. Common targeting agents and ways to improve their affinity and selectivity. Monoclonal antibodies, F(ab')2, Fab', scFv, diabodies, non-antibody ligands, aptamers and affibodies. The antibody fragments $F\left(a b^{\prime}\right) 2$ and Fab' are generated by enzymatic cleavage whereas the Fab', scFv, and bivalent scFv (diabody) fragments are created by molecular biology techniques. Non-antibody ligands include vitamins, carbohydrates, peptides, and other proteins. Aptamers can be composed of either DNA or RNA. Affinity and selectivity can be increased by screening for conformational-sensitive targeting agents such as affibodies.

For instance, antibody-mimetic named as affibodies have been used to drive recombinant non-viral delivery systems to HER-2 receptor ligand. The biopolymer FP-(DCE) $n-$ NLS-CS-TM containing repeating units of arginine and histidine, fusogenic peptide, nuclear localization signal and Her-2 targeting affibody showed specific transfection in cells over-expressing HER-2 (243). Another recombinant vector designated as HER-NLS (containing HER-2 targeting moiety and the nuclear localization sequence), was able to specifically transfect MDA-MB-453 HER-2+ breast cancer cells (244). In addition cell-penetrating peptides have been used in 
combination with HER-2 targeting to increment the transfection levels. The recombinant vector TMAF formed by the cell penetrating peptic TAT-Mu (TM) and the HER-2 affibody (AF) was tested both in vitro and in vivo with enhanced results in MDA-MB-453 cells transfection when compared with control. Intratumoral injection of a shRNA against a tissue factor complex with the recombinant vector significantly reduced the tumor progression in MDA-MB-453 xenograft model in mice (245).

As alternative to affibodies and antibodies, aptamers are focusing great research efforts in the last years. Aptamers are short (typically $<100 \mathrm{nt}$ ) and chemically synthesized single stranded (ss) DNA or RNA oligonucleotides which bind with high affinity and specificity other molecules. They are synthesized from random oligonucleotide pools by a process called Systematic Evolution of Ligands by Exponential Enrichment (SELEX) (Figure 1.19) (246). This process is basically controlled by the ability of aptamers to fold in specific 3D structures that makes them functional with high specificity and affinity. Aptamers possess dissociation constants usually in the pico- to nano-molar range (247). A wide variety of targets such as metal ions, toxins, amino-acids, antibiotics, peptides, proteins, cells, virus, bacteria and tissues have been used to generate aptamers (Figure 1.20) (248).

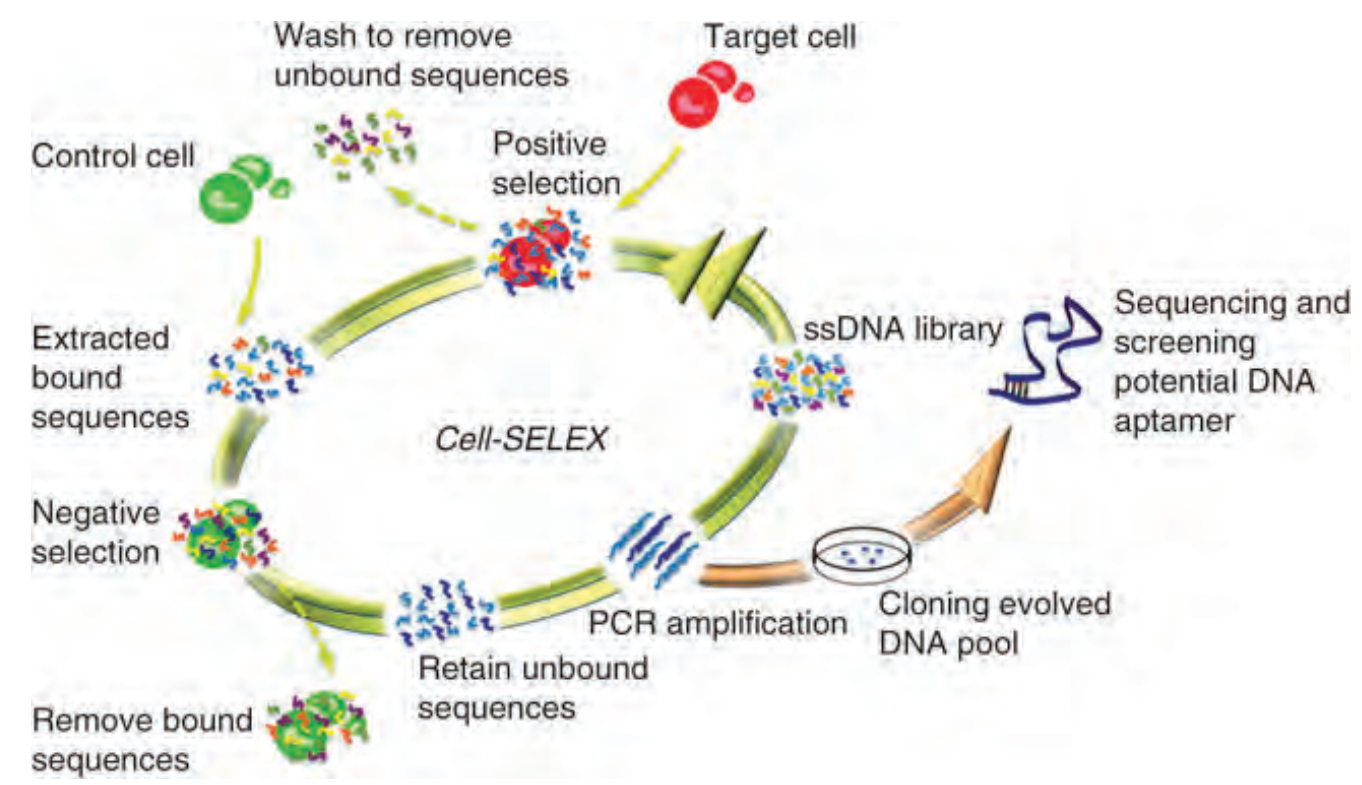

Figure 1.19. Schematic representation of cell-SELEX process. DNA sequences recognize target cells and are subjected to enrich the selection pools. The enriched pools are cloned, and the positive clones are sequenced to identify the potential aptamers 


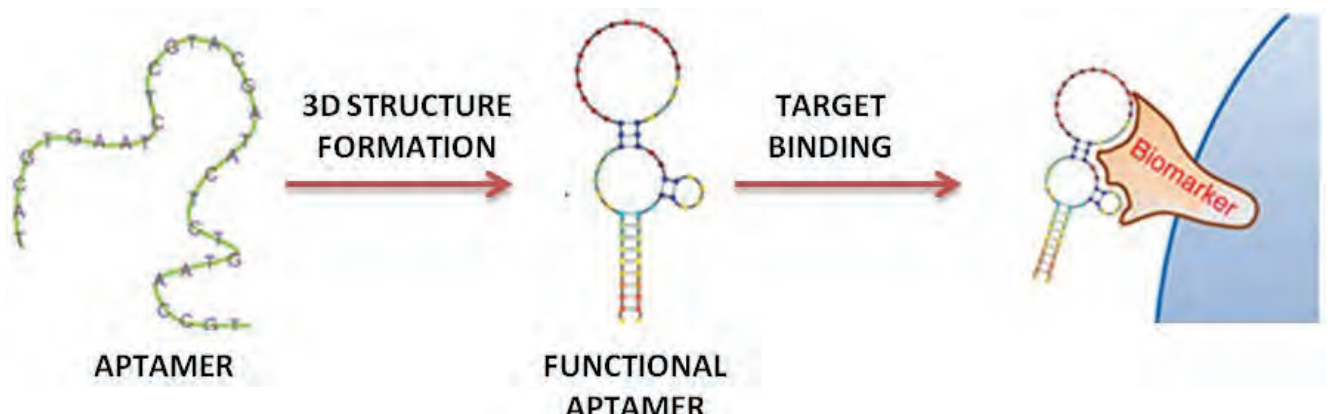

Figure 1.20. Schematic representation of aptamer binding to its target. When aptamer adopts its $3 \mathrm{D}$ structure formation, it becomes functional and binds the marker expressed in the target cell.

Table 1.7. Advantages and limitations of aptamers (203).

\begin{tabular}{|ll|}
\hline $\begin{array}{l}\text { Advantages } \\
\text { Aptamers are produced chemically in a }\end{array}$ & $\begin{array}{l}\text { Limitations } \\
\text { proparmacokinetic and other systemic } \\
\text { predict }\end{array}$ \\
$\begin{array}{l}\text { Chemical production process is not prone to } \\
\text { viral or bacterial contamination }\end{array}$ & $\begin{array}{l}\text { Small size makes them susceptible to renal } \\
\text { filtration and they therefore have a shorter } \\
\text { half-life }\end{array}$ \\
$\begin{array}{l}\text { Non-immunogenic } \\
\text { Snmodified aptamers are highly susceptible } \\
\text { to serum degradation }\end{array}$ \\
$\begin{array}{l}\text { Able to select for and against specific targets } \\
\text { and to select against cell-surface targets }\end{array}$ & \\
$\begin{array}{l}\text { Conjugation chemistries for the attachment of } \\
\text { dyes or functional groups are orthogonal and } \\
\text { can be readily introduced during synthesis }\end{array}$ & \\
\hline
\end{tabular}

Their small size that allows them a fast cellular penetration, their lack of immune response together with their facilities in production offer them advantages over protein antibodies in their clinical applicability. However they have some limitations as well that can be overcome by a variety of strategies. For instance, the addition of PEG or cholesterol in order to increase their circulating half-life. The chemical modification of aptamers including 2' -amino pyrimidines, 2' -fluoro pyrimidines, and $2^{\prime}-O$-methyl ribosepurines and pyrimidines can help in avoiding the nucleasemediated degradation. Indeed, internucleotide linkages modification and high molecular mass PEG can be conjugaed at 5' which can help in this limitation (203). 
It is estimated that about $60 \%$ of cancer-targeting drugs including therapeutic antibodies and small molecule inhibitors target cell surface biomarkers. In the last decade many aptamers have been developed targeting cell surface biomarkers through cell-SELEX process. These aptamers have been studied for hematological malignancies, lung, liver, ovarian, brain, pancreatic (248) and breast cancers (249251).

\subsubsection{MUC1 AS TARGETING AGENT BY APTAMERS}

MUC1 is a single pass type I transmembrane protein with O-glycosylated extracellular domain that extends up to $200-500 \mathrm{~nm}$ from cell surface (236). MUC1 is normally expressed in glandular and luminal epithelial cells of the mammary gland, esophagus, stomach, uterus, prostate, duodenum, pancreas and lungs (252) and in a lesser extend in hematopoetic cells (253). By contrast, it is not present in the skin epithelium and mesenchymal cells. The overexpression of aberrant and incomplete glycosylation is often associated with certain human epithelial cancer cells. Even more, MUC1 is aberrantly overexpressed in $90 \%$ of breast tumors (254). These underglycosylated forms of MUC1 have been considered as biomarkers because they are only expressed on cancer cells and are distinct from those expressed in normal cells. Structurally, MUC1 is a heterodimeric complex composed by a long N-terminal (MUC1-N) and a short C-terminal subunit (MUC1-C); both subunits are associated by stable hydrogen bonds around the SEA domain (Figure 1.21). MUC1-N is composed by the PST domain (proline, serine and threonine-rich) and the SEA domain. The PST domain is also named as VNTR region (variable number tandem repeat). The VNTR consists of 20-120 repeats of 20-21 amino-acids which vary as function of the type of cancer. The amino-acids in VNTR are abundantly O-glycosylated in normal cells (236). The pattern of O-glycosylation is altered in cancer cells to give rise to truncated short sugar chains known as Tn antigens as well as exposing the VNTR peptide chain itself (255). In breast cancer cells MUC1 is highly sialylated which causes truncated sugar branches. This underglycosylation affects the stability and subcellular location of MUC1. Underglycosylated MUC1 shows increased cell uptake by clathrin mediated endocytosis and macropinocytosis with increasing intracellular accumulation (181, 236). By contrast MUC1-C is a short subunit composed by 58 amino-acids in the extracellular domain, 28 in the transmembrane domain and 72 in the cytoplasmic tail. 
In normal conditions MUC1 is a heterodimeric complex however, as response of proinflammatory cytokines as IFN- $\gamma$ and TNF- $\alpha$, the complex can dissociate (236). In cancer cells a significant amount of MUC1-C is detected in the mitochondria and nucleus (256). MUC1-N has been detected in the nucleus as well suggesting that MUC1 can be involved in pre-mRNA splicing (257). In addition MUC1 is involved in a wide variety of processes. MUC1 is shown to mediate the production of growth factors triggering the proliferation and survival of tumor cells (258), together with the expression of proangiogenic factors stimulating the angiogenesis (259). Additionally MUC1-C has been observed to associate with $\beta$-catenin repressing $E$-cadherin expression in breast cancer cells (259). Hence MUC1 underglycosylated may function as ligand for cell adhesion molecules and potentiate the invasion, metastases and tumor aggressiveness. In addition, MUC1 have an active role in apoptosis by decreasing the intracellular reactive oxygen species (ROS) (260) or by direct interaction with p53 which promote the cell growth arrest and suppresses the p53dependent apoptosis in response to DNA damage (261).

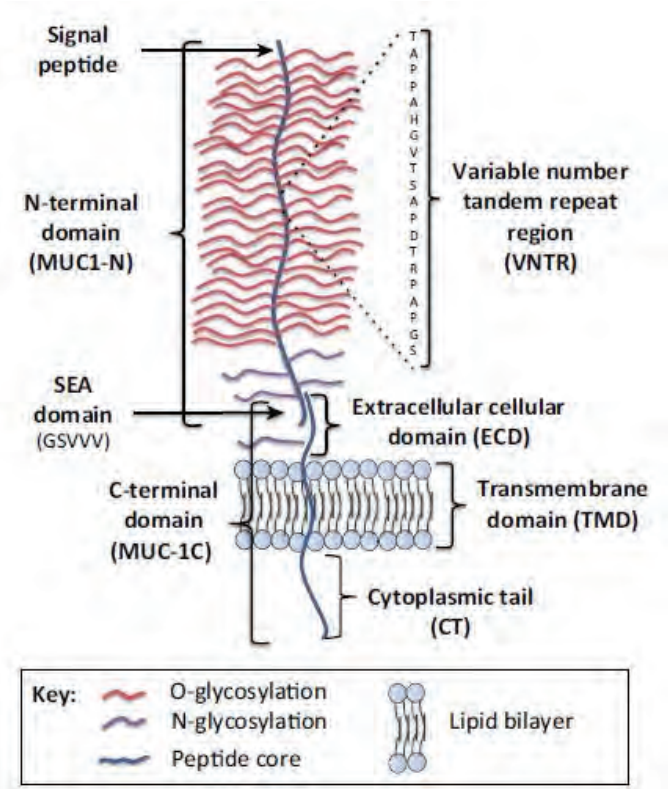

Figure 1.21. Scheme showing the structure of $M U C 1$. The $\mathrm{N}$-terminal subunit (MUC1-N) is associated through the SEA domain to the C-terminar subunit MUC1-C9. MUC1-N is composed by the signal peptide, the variable number tandem repeat (VNTR) region and SEA domain. The MUC1-C is composed by the extracellular domain (ECD), transmembrane TM and cytoplasmic tail (CT) domain (236). 
The high level of the aberrant MUC1 expression in primary and metastatic breast cancer is consequence of MUC1-C action in auto-inductive loops with the STAT1/3 and the transcription factors NF-kB and RelA that confer activation of the MUC1 gene and its overexpression in breast cancer cells (262). MUC1 aberrantly overexpressed results in antigenically recognizable epitopes on the MUC1 molecule making it as potential therapeutic target for aptamers.

Recently, several anti-MUC1 aptamers have been developed by Ferreira et al. (251). Among the published MUC1 aptamers, S.2.2 is a 25 base oligonucleotide (5'-GCA GTT GAT CCT TTG GAT ACC CTG G-3') that binds the protein core of MUC1 with relatively high affinity and specificity. Later, the biodistribution of S2.2 aptamer bound to MAG2 antibody and labeled with $99 \mathrm{mTc}$ radioisotope showed a significant tumor targeting despite of high renal clearance and intestine uptake (263). Additionally, Yu et al. (264) constructed functional MUC1-aptamer nanoparticles of PLGA loaded with paclitaxel showed enhance in vitro drug delivery and cytotoxicity restricted to MUC1-expressing cancer cells.

Since highly expressed and aberrantly glycosylated MUC1 determinants are found in more than $80 \%$ of all primary and metastatic breast cancers, aptamers targeting the under-glycosylated MUC1 were developed by Ferreira et al. (265). They generated a pool of aptamers against a peptide formed by five consecutive repeats mucin MUC1 tandem repeats (5TR). Amongst the analyzed, 5TR1 aptamer (5'-GAA GTG AAA ATG ACA GAA CAC AAC A-3') was one with the highest affinity constant (250). Selectively delivery of phototoxin chlorine $e^{6}$ into MCF-7 cells was probed in vitro. Indeed, they proposed that underglycosylated mucin MUC1 could act as selective portal in importing aptamers in $\mathrm{MUC1}(+)$ cells by receptor-mediated endocytosis. In addition, this 5TR1 aptamer has been used as targeting element in a self assembling gene delivery system formed by PEI polyplexes (266). Adsorbed aptamers increased the transfection efficiency in both in vitro and in vivo for $\mathrm{MUC1}(+)$ cells. Super paramagnetic iron oxide nanoparticles (SPION) have been also conjugated with 5TR1 aptamer but applied to deliver the epirubicin drug in murine (267) colon carcinoma cells. The result was that Epirubicin-5TR1 aptamer-SPION tertiary complex was able to deliver the drug into the cells in vitro and reduce tumor growth in comparison with the drug administrated alone in tumor-bearing mice. 
In addition to MUC1, other biomarkers have been targeted by aptamers such as HER2 or nucleolin. Some studies have used the aptamer-drug conjugates for breast cancer therapy. For instance, HER2 aptamer-Dox conjugates (where Dox is Doxorrubicin) could selectively deliver Dox to HER2-positive breast cancer cells while reducing it for HER-2 negative (268). Others used a non-viral carrier conjugated with aptamers in order to deliver drugs as Dox (269). AS1411 aptamer which targets nucleolin was conjugated to liposomes exhibiting an increased cellular internalization and cytotoxicity to MCF-7 breast cancer cells as compared to non-targeting liposomes. Furthermore, targeted liposomal Dox improved antitumor efficacy against xenograft MCF-7 breast tumors in athymic nude mice, attributable to their enhanced tumor tissue penetration. Likewise DNA aptamers, RNA aptamers have been also used to target HER-2 and being covalently conjugated to siRNA. For instance Thiel et al. (270) used RNA aptamers to form RNA aptamer-siRNA chimeric RNAs and directed them against HER-2 in order to deliver the siRNA targeting $\mathrm{BCl}-2$ antiapoptotic gene. The result was the enhanced of the potent silencing of $\mathrm{BCl}-2$ and sensitization of HER-2+ cells to chemotherapy in aptamers linked to siRNA.

The existence of biomarkers as MUC1 which is considered a tumor associated protein with a crucial role in breast carcinogenesis, have led to the emergence of a high number of aptamers. In the last years, aptamers have been shown as targeting agents with great potential for cancer treatment approach. These targeting agents allow for the conjugation of more complex polymeric molecules and leading to complete nonviral gene delivery systems provider of high specificity and efficiency.

\subsection{BASIC PRINCIPLES ABOUT RIBOSOME INACTIVATING PROTEINS}

The term "ribosome inactivating protein" (RIP) refers to their enzymatic activity. RIPs are a family of proteins that are broadly distributed throughout plants, fungi and even in several species of bacteria. These RIPs can be subdivided into two or three groups (271). Type 1 RIPs consists of a single chain of $30 \mathrm{kDa}$ with enzymatic activity (A-chain). The enzymatic activity of RIPs is rRNA N-glycosidase in the exposed sarcinricin loop of the A-chain that leads to protein synthesis inhibition by removing a single adenine from $28 \mathrm{~S}$ rRNA in the eukaryotic $60 \mathrm{~S}$ subunit, hence preventing recruitment of elongation factors which is key for protein synthesis (272). Type 2 RIPs 
consists of an A-chain linked to one B-chain of $35 \mathrm{kDa}$. B-chain is a lectin peptide with strong affinity for sugars with the galactose structure displayed on the cell surface and acts by helping in the translocation to cells. As a consequence, type 2 RIPs generally tend to be more toxic than type 1 RIPs, thus some type 2 RIPs are potent toxins such as ricin, abrin or volkelsin (273). Type 1 RIPs are much less toxic, due to the lack of B-chain they enter cells with difficulty unless they are not conjugated with molecules able to link with cellular surface. Some type 1 RIPs are pokeweed antiviral protein (PAP) and saporin amongst others (273). In addition another type of RIPs commonly referred as nontoxic type 2 RIPs has been identified. Ebulin 1 or nigrin $b$ belongs to this group (274). They consisted of both a catalytic and lectin $A$ and $B$ chains but with a low cytotoxicity comparable to type 1 RIPs. This lower cytotoxicity can be due for discrepancies in cellular uptake efficiency and intracellular trafficking of proteins. For instance nigrin $b$ which has comparable plasma membrane affinity than volkensin enters the cytosol without passing the trans-Golgi network and endoplasmic reticulum which favor nigrin b degradation and make it less toxic than volkensin (275).

Type 3 includes a single chain with an additional protein segment that has to be removed from RIP to be active as maize b-32 protein $(271,273,276)$.

\subsubsection{RIPs IN THERAPY}

Most RIPs seem to have a role in response to stress in plants, even more they have antiviral, antifungal, insecticidal and abortive properties (274) that are been exploited for agriculture and medical purposes. Thus, RIPs have been extensively investigated as potent and versatile anti-cancer agents. Two main strategies have been followed, named as immunotherapy using immunotoxins (IT) and suicide gene therapy (Figure 1.22). At the moment many of the ITs developed are made of the non-RIP Difteria toxin motifs. Among RIPs, ricin, saporin and PAP produced by Ricinus communis, Saponaria officinalis and Phytolacca americana respectively are the most common used. Thus complete A-chain from ricin, deglycosylated A-chain from ricin, blocked ricin, saporin and PAP amongst others have reached to clinical trials (277). 




Figure 1.22. Schematic representation of strategies in RIPs based therapy. RIPs can be directly conjugates to antibodies, where once in the cytoplasm it inhibits the protein expression (left). In addition RIPs gene can be complexed by cationic polymers and being internalized in cells. Once that DNA reaches the nucleus and is transcribed, the protein is expressed and inhibit the ribosome (right) (278).

Regarding to suicide gene therapy, it is important to have on mind that cytotoxicity of RIPS can depend of factors as tumor accessibility, efficient uptake, intracellular sorting and release of the catalytic chain in the cytoplasm where it exert their activity. Thus, the development of new delivery systems could improve these limitations that make some promising toxin-drug complexes do not have good results in clinical trials. For instance, viral and non viral vectors have been shown to improve the cytotoxic action of the non-RIP difteria toxin. Recently, Phase 2 clinical trial with difteria toxin A gene named as BC-819 under the regulation of $\mathrm{H} 19$ promoter and complexed to $\mathrm{PEI}$, was tested in 47 patients with invasive bladder tumors. It prevented the new tumor growth in two-thirds of the patients and ablates a third of the marker lesions (279). Until now, they are only few examples of RIPs used in suicide gene therapy approach comprising saporin or RTA genes. Initially saporin gene was complexed with FGF2-K construct formed by fibroblast growth factor 2 (FGF-2) and polylysine non viral vector. Hoganson et al.(280) were able to efficiently 
deliver DNA complex encoding saporin to target cells, leading them to death. Later, in 2007 saporin gene under the control of cytomegalovirus promoter and complexed with the cationic lipid DOTAP was administered by repeated direct intratumoral injections (281). Saporin was probed to attenuate the melanoma tumor growth in mice model. By contrast, RTA gene was encapsulated only by retroviral vectors and was able to eradicate experimental induced brain tumor in rats (282).

\subsubsection{POKEWEED ANTIVIRAL PROTEIN (PAP-S)}

Pokeweed antiviral protein (PAP-S) from the seeds of Phytolacca americana is a type 1 RIP that is thought to play an important role in the plant's defense mechanism against foreign pathogens. The rRNA N-glycosidase activity resulting in the translation inhibition and host cell death has been described as the general mechanism for antiviral activity of PAP (Table 1.8). However an alternative mechanism seems to play in some cases as tobacco mosaic virus and brome mosaic virus in plants (276), PAP may bind to the cap m7GpppN (involved in mRNA maduration, translation initiation and RNA turnover), depurinate the capped RNA and inhibit in this way the protein translation (283).

Table 1.8. Properties of PAP-S and ricin as RIPs. IC50: corresponds with the concentration of toxin causing $50 \%$ of protein inhibition in rabbit reticulocyte lysate. CC50: corresponds with the concentration of toxin causing 50\% of cellular death. LD50: Dose to produce $50 \%$ death in mice.

\begin{tabular}{|c|c|c|}
\hline & PAP-S & RICIN \\
\hline RIPs & Type I & Type II \\
\hline Structure & $\begin{array}{l}\text { A-chain (N- } \\
\text { glycosidase) }\end{array}$ & A-chain and B-chain (Lectin) \\
\hline $\begin{array}{l}\text { Molecular } \\
\text { weight }\end{array}$ & $29 \mathrm{kDa}$ & $64 \mathrm{kDa}$ \\
\hline $\begin{array}{l}\text { Mechanism } \\
\text { of action }\end{array}$ & $\begin{array}{l}\text { rRNA N-glycosidase } \\
\text { activity from catalytic } \\
\text { A chain }\end{array}$ & $\begin{array}{l}\text { B Chain helps A-chain to translocate to the cytoplasm } \\
\text { where through its rRNA N-glycosidase activity inhibit } \\
\text { protein synthesis by depurination of 28s RNA in the } \\
60 \text { S ribosome subunit. }\end{array}$ \\
\hline IC50 & $\begin{array}{l}0.067 \mathrm{nM} \text { (rabbit } \\
\text { reticulocytes) (286) }\end{array}$ & $0.01 \mathrm{nM}$ (rabbit reticulocytes) (287) \\
\hline CC50 & $\begin{array}{l}33 \mu \mathrm{M} \text { (HeLa cells) } \\
(288)\end{array}$ & 0.67 pM HeLa cells (289) \\
\hline LD50 & $\begin{array}{l}0.95 \text { mg/kg (i.p. } \\
\text { injection) (286) }\end{array}$ & $\begin{array}{l}20000 \mu \mathrm{g} / \mathrm{kg} \text { (ingestion) } \\
2.8-3.3 \mu \mathrm{g} / \mathrm{kg} \text { (i.p. injection) } \\
1-10 \mu \mathrm{g} / \mathrm{kg} \text { (inhalation)(290) }\end{array}$ \\
\hline
\end{tabular}


As explained before, type 1 RIPs are not as cytotoxic as type 2 RIPs since they are not able to cross the plasmatic membrane by their own. In the producing plant, PAP is synthesized as toxin-precursor and compartmentalizes within the wall matrix. That ensures that Phytolacca americana's ribosomes never encounter with the PAP toxin, as way of protection (276).

In the medical field, PAP has been used as a component of ITs for cancer and HIV-1 treatment. For instance, B43-PAP immunotoxin was administered in SCID mouse model of aggressive human pre-B lymphoblastic leukemia with a reducing in the incidence of paraplegia and improving the survival time (284). Additionally ITs formed by monoclonal antibodies reactive with CDS, CD4 or CD7 antigens and PAP inhibited HIV-1 replication in normal $C D 4^{+} T$ cells infected and HIV-1 protein synthesis (285).

Immunoconjugated toxins made of PAP have shown promising results that make us think about challenging strategies as suicide gene delivery using non-viral delivery systems that may alleviate the obstacles in cancer treatment.

\subsubsection{RICIN}

Ricin is a potent toxin isolated from castor beans found in Ricinus communis plant. Ricin holotoxin with $64 \mathrm{kDa}$ is a heterodimetic protein from type 2 RIPs that is formed by two polypeptide chains (RTA and RTB) joined by a disulfide bond (Table 1.8 and Figure 1.23).

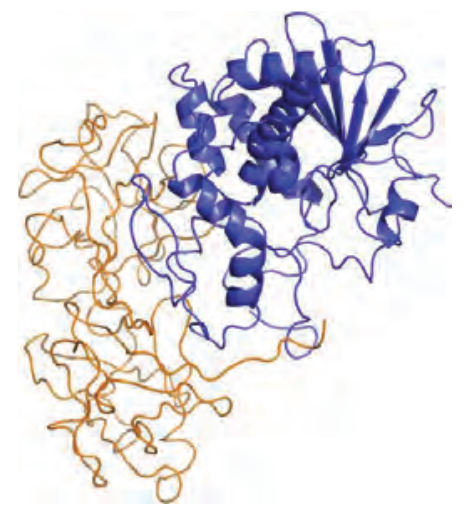

Figure 1.23. Crystallographic structure of ricin. Chain A (blue) and B (orange) bound by disulfide linkage 


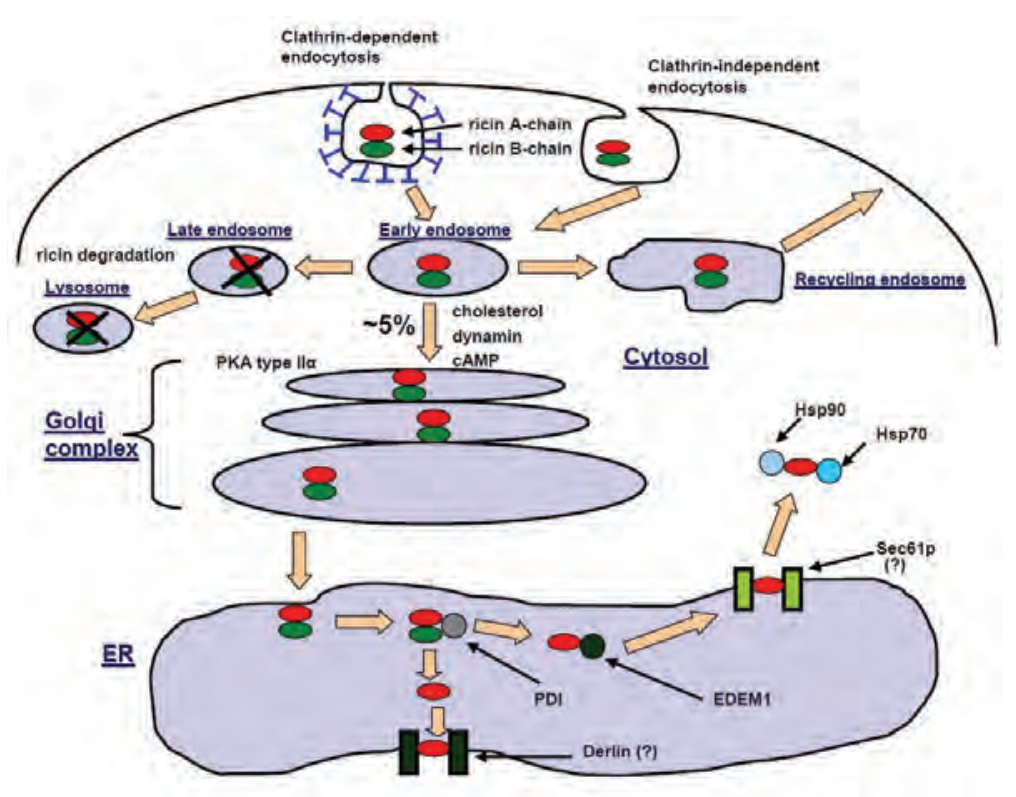

Figure 1.24. Scheme showing the intracellular trafficking of ricin. Ricin by means of its RTB binds $\mathrm{N}$-glycosylated molecules with available $\beta 1 \rightarrow 4$ linked galactosyl at the plasma membrane and after internalization by endocytosis, traffics via early endosomes, the Golgi and the endoplasmic reticulum (ER), where reductive separation of the toxic ricin toxin $A$ (RTA) from the cell-binding ricin toxin B (RTB) occurs. RTA translocates to the cytosol where it re-folds and inhibit the elongation factor 2 binding leading to protein synthesis inhibition (292).

Ricin is synthesized as preproricin consisting of a 24 -amino-acid $\mathrm{N}$-terminal signal sequence followed by the $A$ chain, which is attached to the $B$ chain by a 12 -aminoacid linker (291). During the synthesis, the signal sequence is removed to generate the mature protein where chains $A$ and $B$ are bound by disulfide linkage. Ricin is more potent that type I RIP due to the existence of the sugar binding B-chain or RTB. Once RTB is bound to cell surface by the of $\beta 1 \rightarrow 4$ linked galactose residues present on multiple glycoproteins and glycolipids, endocytic internalization process is triggered. Clathrin mediated endocytosis and clathrin-independent endocytosis processes for ricin have been reported (Figure 1.24) (292). After endocytosis the majority of toxin is exocytosed to the cell surface, the rest go from early to late endosome and lysosome where further degradation occurs. Only $5 \%$ of the ricin is transported to Golgi complex which is the key for the ricin toxicity. Ricin is further transported to the endoplasmic reticulum (ER) where the protein disulfide isomerase (PDI) catalyses the reduction of internal disulfide bond connecting RTA and RTB chains. This allows the translocation of enzymatically active RTA to the cytosol through the Sec61p channel or probably through Derlin translocation channel. Once 
in the cytosol, RTA must refold into its biologically active conformation. For that, Hsp90 and Hsp70 chaperones seem to be involved in this RTA folding. The low content of lysines in RTA may protect it from proteasome degradation (293) and increase the inhibition of protein synthesis (292). A ribotoxic stress response together with activation of multiple pathways leads to ricin-treated cells death by apoptosis (294).

For many years, the main mechanism of action by ricin was thought to be the protein synthesis inhibition. However, it has been reported that the intracellular targets of type II RIPs may not be limited only to rRNA. Deproteinized (naked) RNA, synthetic oligoribonucleotides, nuclear and mitochondrial DNA, polyA and tRNA have been reported to be depurinated by type II RIPs. Ricin has been shown to produce nuclear DNA damage in HUVEC cells but not as consequence of apoptosis. Indeed, toxinmediated depurination at multiple sites may be sufficient to activate the ribotoxic stress response (ROS) (292). In addition, cell apoptosis events and release of proinflammatory cytokines was demonstrated to occur as well. Incubation of ricin with different cell lines results in cell death associated with membrane blebbing, chromatin condensation and DNA fragmentation (295).

The majority of the studies support that ricin activates the intrinsic pathway of apoptosis where caspase 9 is the initiator in the signaling cascade and activates caspase 3. In general, a loss in mitochondrial membrane potential, together with a rapid release of citochrome $c$, activation of caspase 9 and 3, DNA fragmentation and increment of reactive oxygen species (ROS) occurs in cells (292). Ricin has been found to activate caspase 3 in HeLa (296) and U937 (297) cells and to inhibit the repair of DNA in HUVEC cells by a direct action of ricin on DNA (298). Additionally, ricininduced caspase 3 activation also results in DNA fragmentation by means of cleavage of DNA fragmentation factor (DEF) (292). However, some findings suggest that the extrinsic pathway induction may also contribute to ricin-induced apoptosis in some cell lines. It should be noted the difficulty to correlate protein synthesis inhibition unequivocally to the extrinsic or intrinsic mechanisms of apoptosis induction pathways. In breast cancer line MCF-7, which is caspase 3 deficient due to a partial deletion within exon 3 of the CASP-3 (299), gene activation of a caspase 3-like after treatment with B3(Fv)-PE38 immunotoxin (Pseudomonas exotoxin A) was found (300). It induced cell killing by two different mechanisms: inhibition of protein synthesis and induction of apoptosis through caspase activation. Additionally, MCF-7 cells have 
been widely reported to die by apoptosis induced by TNF, Fas, or staurosporine (299) and the lack of studies with ricin open the door to think about other pathways involved as caspase 8 and 6 by means of Bid (237) or caspase 7 induced by pyrrolobenzoxazepine, PBOX-6 with DNA fragmentation (301). Indeed, it has been reported that interaction of RTB is enough to generate an apoptotic response in myeloid leukemia cells (302).

Other proteins that play a crucial role in cellular death are Bcl-2 family proteins. It has been shown that the overexpression of $\mathrm{Bcl}-2$ could partially prevent the cell death induced by ricin in hepatoma cells (BEL7404) (303).

In addition, ricin has been reported to induce the expression of proinflamatory cytokines such as TNF- $\alpha$, IL- 1 , IL- 6 and IL- 8 in human macrophages mediated by RTA (304).

Despite of ricin can be considered a threat to human health; it has great potential to be used as tool in diseases treatment.

Most of the research with ricin has been performed in immunotherapy using the chain $A$ or the blocked ricin where the galactose binding sites of the $B$ chain are blocked (292). The results showed the ability of these immunotoxins to kill human myeloma, lymphoma, lung cancer cells $(277,305,306)$ amongst others. Clinical trials has been also accomplished, where phase I studies with "Combotox", which is a mixture of two immunotoxins prepared by coupling deglycosylated ricin A chain (dgRTA) to monoclonal antibodies directed against CD22 (RFB4-dgRTA) and CD19 (HD37-dgRTA), showed a complete remission of acute lymphoblastic leukaemia (ALL) in 3 of 17 patients with acute lymphoblastic leukemia (307). Recently, mesoporous silica nanoparticles-supported lipid bilayers were used as carrier to deliver deglycosylated RTA. The result was no cytotoxic effects in control hepatocytes but apoptosis in target hepatocytes cells (308). As mentioned before, RTA gene has been applied in suicide gene therapy using retrovirus with promising results that pave the way for further future research. However the whole ricin gene has not been used due to the high cytotoxicity levels depicted by ricin holotoxin. Indeed, compared with conventional therapeutic agents, ricin has some features such as potent action, not induction of resistance and acting on both dividing and non-dividing cells that made it attractive. However, side effects as vascular leak syndrome or demyelination have to be controlled $(292,309)$. 


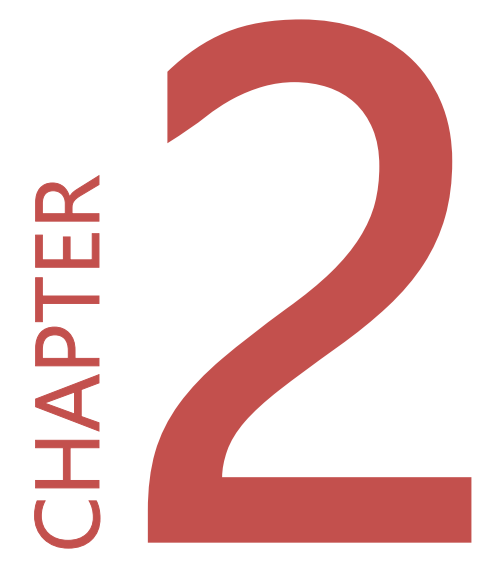




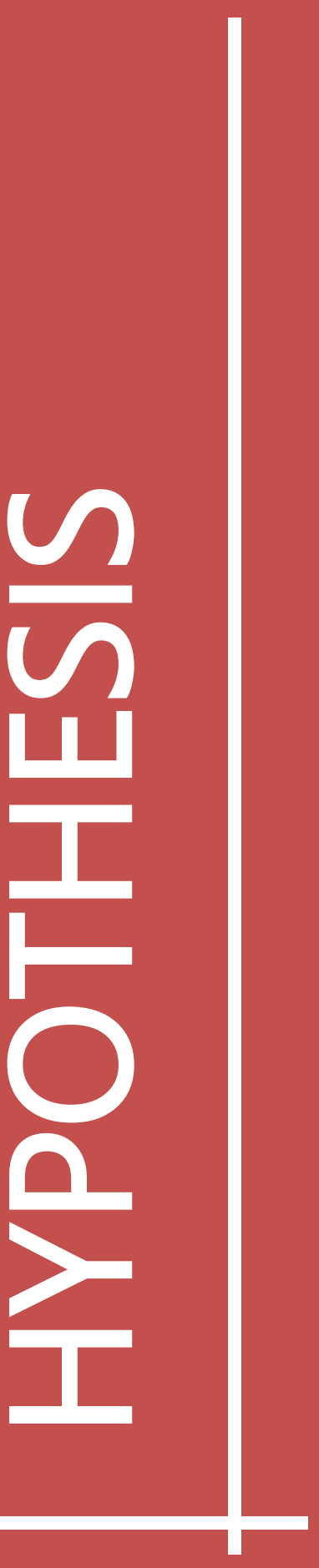


? 


\section{WORK HYPOTHESIS}

A. The DNA recombinant techniques allow the design of novel ELRs in a total control manner. It is hypothesized that use of these recombinant techniques will allow the creation of different tailored hydrophilic ELRs, some of them provided of functional peptides, with the objective of improving their transfection abilities. Additionally, chemical modifications can provide the incorporation of new functionalities as well with the same aim.

B. Self-assembled $E R_{B C S}$ made of hydrophilic and hydrophobic domains and bound to the drug through a $\mathrm{pH}$ sensitive linker can be used to deliver drugs inside of the desired cell. The utilization of an ELR $R_{B C}$ containing the $\operatorname{Arg}_{8}$ peptide at C-t is hypothesized to improve cellular uptake due to the interaction of $\operatorname{Arg}_{8}$ with cellular membrane components such as HSPG thus triggering macropinocytic events.

C. It is thought that ELR with acquired functionalities will possess high cell viability levels besides of the ability to complex and protect the plasmid DNA from degradation. It is hypothesized that the incorporation of penetratin CPP, LAEL fusogenic peptide and imidazole groups can improve the transfection ability of the basis ELR.

D. Lysine rich ELR is hypothesized to improve the complexation ability with plasmid DNA leading to stable polyplexes besides of increasing the transfection efficiency due to its unspecific binding with the negatively charged components of plasmatic membrane. In addition, it is hypothesized the incorporation of adsorbed anti-tumoral marker aptamers to polyplexes providing cellular tumor specificity.

E. It is expected that the use of a double safety lock device constituted by an ELR with tumor-specificity can be suitable to carry a therapeutic plasmid with an inducible promoter for breast cancer treatment. Indeed, it is hypothesized whether the utilization of suicide genes under the control of this tumor-specific promoter can allow the use of cytotoxic toxins affecting the transfected and neighbor cells. 


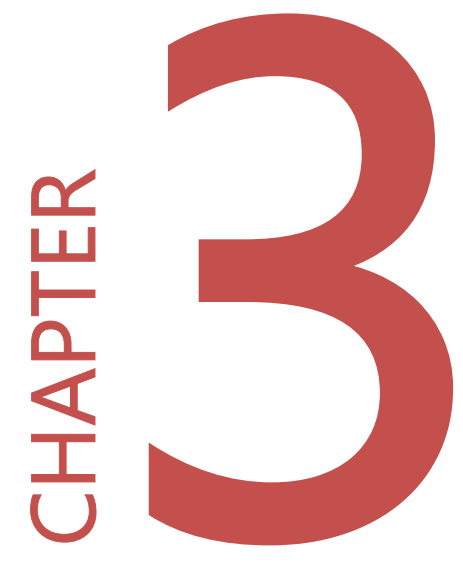



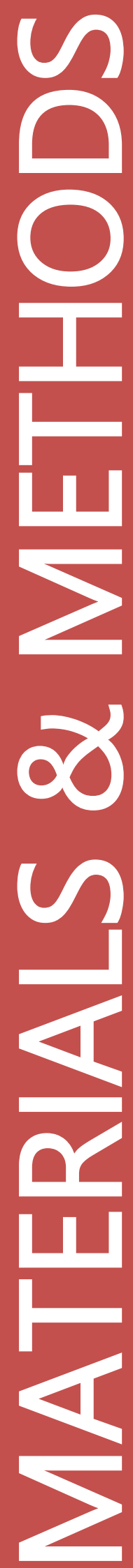
1 


\section{MATERIALS AND METHODS}

\subsection{MATERIALS}

\subsubsection{CHEMICAL REAGENTS}

All the chemical reagents used along this thesis are the highest purity found in the market and are listed below.

Table 3.1. Reagents employed and suppliers

\begin{tabular}{|c|c|}
\hline Reactive and Abbreviation & Brand \\
\hline Acrylamide/Bis-acrylamide & Amresco \\
\hline Agarose seakem & Cambrex \\
\hline Amiloride & Sigma Aldrich \\
\hline Ammonium persulphate (APS) & Sigma Aldrich \\
\hline Ampicilin & Apollo Scientific \\
\hline Bovine serum Albumin (BSA) & Sigma Aldrich \\
\hline Bromophenol blue & Sigma Aldrich \\
\hline Chloridric acid & Merck \\
\hline Chloroquine & Sigma Aldrich \\
\hline Coomassie Brilliant-blue R-250 & Sigma Aldrich \\
\hline Diamidino-2-phenylindole dihydrochloride (DAPI) & Sigma Aldrich \\
\hline Dimethyl sulfoxide (DMSO) & Carlo Erba \\
\hline Ethanol & Merck \\
\hline Ethylenediaminetetraacetic acid(EDTA) & Sigma Aldrich \\
\hline Fetal Bovine Serum (FBS) & Gibco \\
\hline Filipin & Sigma Aldrich \\
\hline GelRed & Biotium \\
\hline Glacial Acetic Acid & Merck \\
\hline Glicerol & Sigma Aldrich \\
\hline Hoechst 33342 & Sigma Aldrich \\
\hline Isopropanol & Invitrogen \\
\hline Isopropy|ß-D-1-thiogalactopyranoside (IPTG) & Sigma Aldrich \\
\hline Lipofectamine $®$ LTX & Thermo Scientific \\
\hline Magnesium Chloride & Merck \\
\hline Methanol & Merck \\
\hline Metaphor agarose & Cambrex \\
\hline Monodansylcadaverine & Sigma Aldrich \\
\hline Paraformaldehyde & Sigma Aldrich \\
\hline Penicillin-Streptomycin & Sigma Aldrich \\
\hline Phenylmethylsulfonyl fluoride (PMSF) & Apollo \\
\hline Phosphate buffered saline (PBS) & Gibco \\
\hline Poly ethylene imine (PEI) $25 \mathrm{kDa}$ branched & Sigma Aldrich \\
\hline Sodium chloride $(\mathrm{NaCl})$ & Sigma Aldrich \\
\hline Sodium dodecyl sulfate (SDS) & Sigma Aldrich \\
\hline Sodium hydroxide & Sigma Aldrich \\
\hline Tetramethylethylenediamine (TEMED) & Sigma Aldrich \\
\hline Tris(hydroxymethyl)aminomethane (Tris) & Sigma Aldrich \\
\hline Triton $\mathrm{X}-100$ & Sigma Aldrich \\
\hline Trypan Blue & Sigma Aldrich \\
\hline Turbofect & Thermo Scientific \\
\hline Ultrapure water & Millipore \\
\hline $\boldsymbol{\beta}$-Mercaptoethanol & Sigma Aldrich. \\
\hline
\end{tabular}




\subsubsection{GLASS MATERIAL AND OTHER MATERIALS}

The glass material was washed with distilled water and sterilized if necessary at $120^{\circ} \mathrm{C}$ for $20 \mathrm{~min}$ and $1 \mathrm{~atm}$.

The material for PCR (Eppendorf microtubes and tips) was bought sterile and DNases/RNases free.

The rest of material used as microtubes, tips, tubes...etc are bought sterile or are sterilized if necessary in autoclave (autester E-75) for $20 \mathrm{~min}$ at $120^{\circ} \mathrm{C}$ and $1 \mathrm{~atm}$.

\subsubsection{BUFFERS}

The buffers used along this work are the following:

PBS (pH 7.4): $5 \mathrm{mM} \mathrm{pH} 7.4$ phosphate buffer, $140 \mathrm{mM} \mathrm{NaCl}$

Sonication Buffer: 20 mM Tris- base, 1 mM pH 8 EDTA, 1mM PMSF

TAE: 40 mM Tris-acetate, 1 mM pH 8 EDTA

TBE: $45 \mathrm{mM}$ Tris-base, 45mM Boric acid, $1 \mathrm{mM} \mathrm{pH} 8$ EDTA

TBS: $20 \mathrm{mM} \mathrm{pH} 8$ Tris-base, $140 \mathrm{mM} \mathrm{NaCl}$

Every solution is prepared using ultrapure de-ionized water (Millipore).

\subsubsection{BIOLOGICAL MATERIALS}

\subsubsection{BACTERIAL STRAINS}

The bacterial strains of Escherichia coli used for cloning, transformation and expression of the polymers are listed below:

BL21 (DE3) Star (Life Technologies)

BLR (DE3) (Novagen)

XL1- Blue Competent Cells (Stratagene)

XL1-Blue Subcloning-Grade Competent Cells (Stratagene)

\subsubsection{CELL LINES}

For the in vitro assays the cell lines used are:

C6 Rat glioma Cell line (ATCC). (ATCC ${ }^{\circledR}$ CCL-107 ${ }^{\mathrm{TM}}$ ).

FaDu Squamous carcinoma cells (ATCC). (ATCC ${ }^{\circledR}$ HTB-43 ${ }^{\mathrm{TM}}$ ). 
HepG2 Hepatocellular Carcinoma cell line (Sigma Aldrich). (85011430 SIGMA).

HFF-1 Human primary foreskin fibroblastic cells (ATCC). (ref SCRC-1041).

HUVEc Human Umbilical Vein endothelial cells (Lonza Walker). (cc-2517).

MCF-7 Human Breast Adenocarcinoma Cells (Sigma Aldrich). (86012803 SIGMA).

MSC Normal Human adipose derived Mesenchymal Stem Cells (Invitrogen) (ref R7788-115).

SKBR3 Human Breast Cancer cell line (ATCC). (ATCC ${ }^{\circledR}$ HTB-30 $0^{\mathrm{TM}}$ ).

\subsubsection{ANIMAL MODELS}

Female Balb/cAnNRj-Foxnu/Foxn1nu mice 5-7 weeks old with a weight of about $17 \mathrm{~g}$ (Janvier Labs).

\subsubsection{OTHER MATERIAL FOR BIOLOGICAL ASSAYS}

Anti-rabbit Fab2 Alexa Fluor 647 (Cell signaling) (\#4414S).

Monoclonal anti-PAK1 (Sigma Aldrich) (SAB1400193 SIGMA).

Polyclonal anti-MUC1 antibody (Sigma Aldrich) (AV41445 SIGMA).

\subsubsection{CULTURE MEDIA}

\subsubsection{CULTURE MEDIA FOR BACTERIA}

The culture media used for bacteria growth and transformations are listed below:

LB-Agar: LB 25g/L+ 1.5\% (p/v) agar (Fluka).

Luria Browth (LB) (Pronadisa): prepared at $25 \mathrm{~g} / \mathrm{L}$ for bacteria growth.

SOC I Medium (Sigma Aldrich).

Terrific Browth (TB) (Formedium): prepared at $55.85 \mathrm{~g} / \mathrm{L}+8 \mathrm{~mL} / \mathrm{L}$ glycerol for production.

Transformation and Storing Solution (TSS): LB with 10\% (w/v) PEG Mw 3350, 5\% (v/v) DMSO and $50 \mathrm{mM} \mathrm{MgCl}$ ( $(\mathrm{pH}$ 6.5). Sterilize by filtration. 


\subsubsection{CULTURE MEDIA FOR CELL LINES}

C6 cells were grown in DMEM medium (Invitrogen) supplemented with $10 \%$ of fetal bovine serum (FBS) (Gibco) and Penicillin/ Streptomycin (100 U/mL/ $100 \mathrm{mg} / \mathrm{mL}$ ) (Gibco).

FaDu cells were grown in EMEM medium (Invitrogen) supplemented with 10\% FBS and Penicillin/ Streptomycin (100 U/mL/ $100 \mathrm{mg} / \mathrm{mL})$.

HUVEC cells were grown in endothelial growth medium (EGM)(Lonza Walker) supplemented with $10 \%$ of FBS and Penicillin/ Streptomycin $(100 \mathrm{U} / \mathrm{mL} / 100 \mathrm{mg} / \mathrm{mL})$. MCF-7 and HepG2 were grown in Eagle's minimum essential medium (EMEM), 2 mM glutamine, 1\% NEAA (Invitrogen), 10 \%FBS and Penicillin/ Streptomycin (100 $\mathrm{U} / \mathrm{mL} / 100 \mathrm{mg} / \mathrm{mL})$.

MSC and HFF-1 cells were grown in basal medium Dulbecco's modified Eagle's medium (DMEM) (Invitrogen), with 10\% and 15\% FBS respectively and Penicillin/ Streptomycin (100 U/mL/ $100 \mathrm{mg} / \mathrm{mL})$.

SKBR3 were grown in McCoy's 5a Medium Modified (ATCC) supplemented with 10\% FBS and Penicillin/ Streptomycin (100 U/mL/ $100 \mathrm{mg} / \mathrm{mL})$.

\subsubsection{OTHER CULTURE REAGENTS}

Alamar Blue Assay (Invitrogen)

Annexin V Apoptosis Assay (Calbiochem)

Bradford Reagent (Sigma-Aldrich)

Label IT ${ }^{\circledR}$ Tracker $^{\mathrm{TM}}$ Fluorescein (Mirus)

Live/ Dead ${ }^{\circledR}$ Cell viability assays (Invitrogen)

MTT Assay (Life Technologies)

Pierce ${ }^{\mathrm{TM}}$ Gaussia luciferase Flash Assay (Life Technologies)

Trypsin/EDTA (Invitrogen)

YOYO-1 lodide (ThermoFisher Scientific)

The reagents were used according the manufacturer instructions.

\subsubsection{IN VIVO ASSAYS REAGENTS}

$17 \beta$ stradiol pellets of $0.72 \mathrm{mg}$ (Innovative Research of America) 
Geltrex $^{\mathrm{TM}}($ Gibco)

Vetflurane (Virbac Animal Health)

\subsubsection{MOLECULAR BIOLOGY MATERIALS}

\subsubsection{RESTRICTION ENZYMES}

The restriction enzymes used in this work are:

BamHl, Dphl, Earl, EcoRl, Hindll, Ndel, Nhel, Sapl, Xhol, Fast EcoRl, Fast Hindll, Fast Xbal, Psd, Ncol (Thermo Scientific)

The reactions followed the manufacturer instructions in all the cases.

\subsubsection{OTHER ENZYMES}

Antartic Alkaline Phosphatase (Thermo Scientific)

Herculase II (Agilent)

Shrimp Alkaline Phosphatase (New England Biolabs)

T4 Ligase (Thermo Scientific)

\subsubsection{CLONING AND EXPRESSION VECTORS}

All the DNA fragments employed were cloned in pDrive cloning vector (Qiagen) under the phage T7 promoter. In figure (Figure 3.1) the endonuclease sites for Earl and Earl/Sapl restriction sites at position 3843bp eliminated during mutagenesis are indicated. This vector named as pDm was used along the work.

pDrive Cloning Vector

\section{Positions of various elements}

Vector size (bp)

Multiple cloning site

locZ apeptide

T7 RNA polymerose promoter

T7 transcription stort

SP6 RNA polymerase promoter

SP6 transcription stort

Ampicillin resistance gene

Kanamycin resistance gene

PUC origin

Phage fl origin

Primer binding sites:

M13 forward $(-20)$

MI 3 forword $(-40)$

M13 reverse

17 promoter primer

SP6 promoter primer

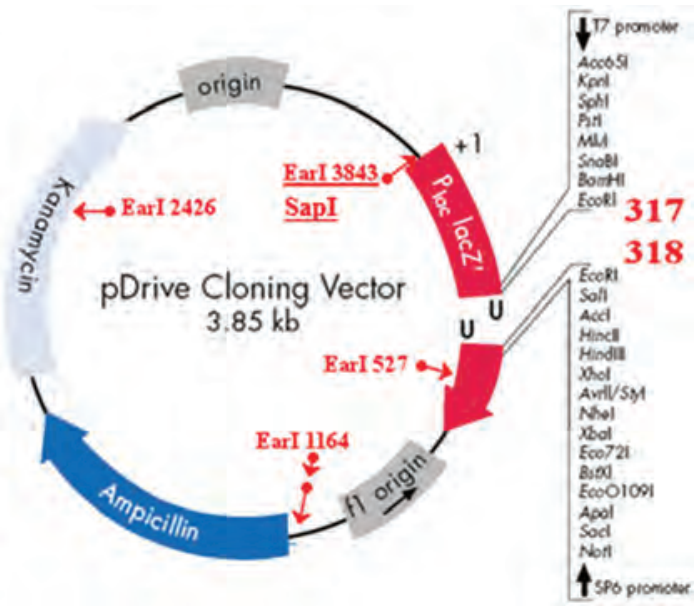

Figure 3.1.Scheme of pDrive cloning vector 

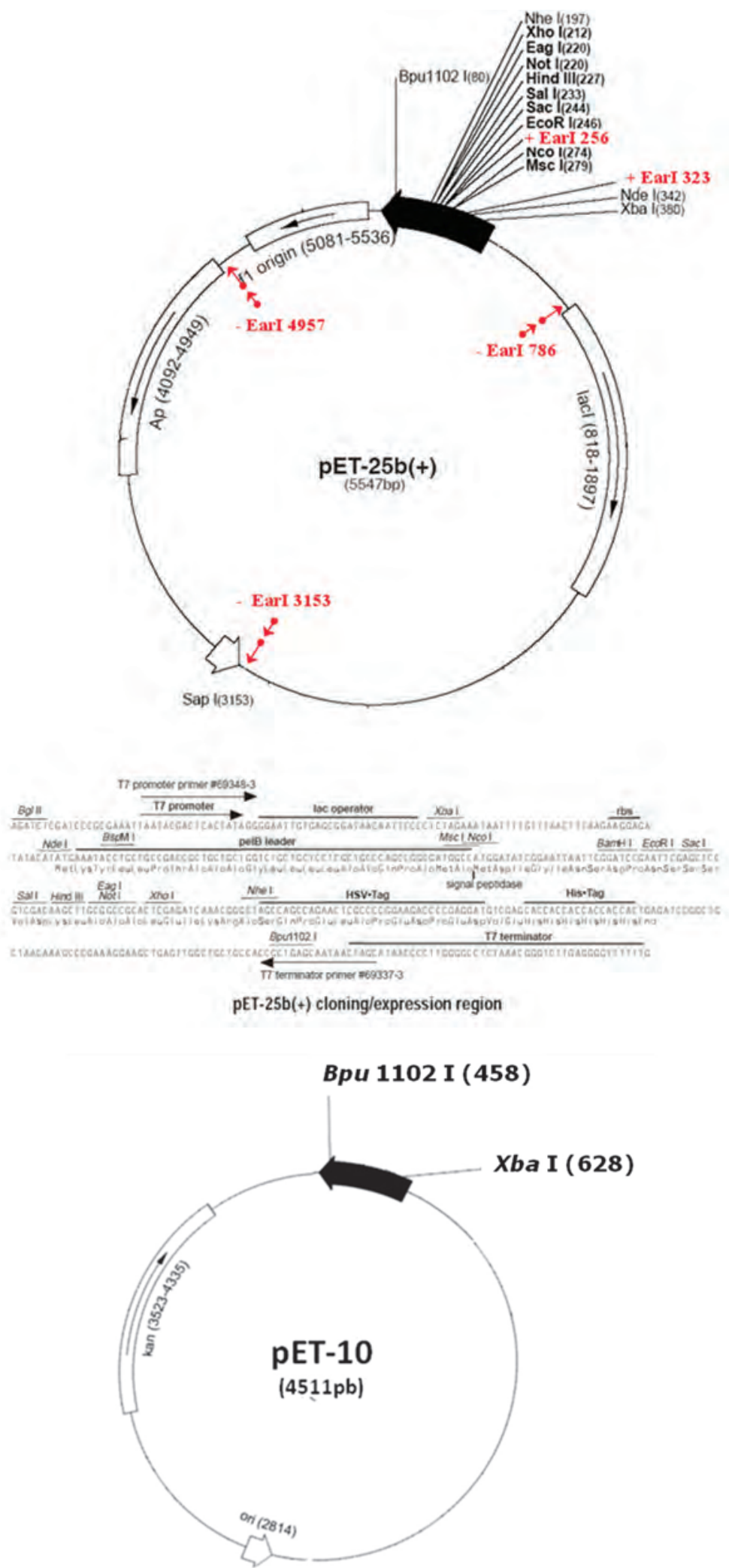

Figure 3.2. Scheme of p7expression vector based on Novagen's pET-25b(+) vector and pET10 based on pET7 and pET9a. 
For the expression of the different recombinant polymers a p7 expression vector has been employed (Error! Reference source not found.. The p7 expression vector was constructed in our laboratory from Novagen's pET-25b (+) vector by Dr. A. Girotti (310) pET-25b vector was modified by the suppression of two Earl recognition sites and the insertion of two of them inside of the polylinker region.
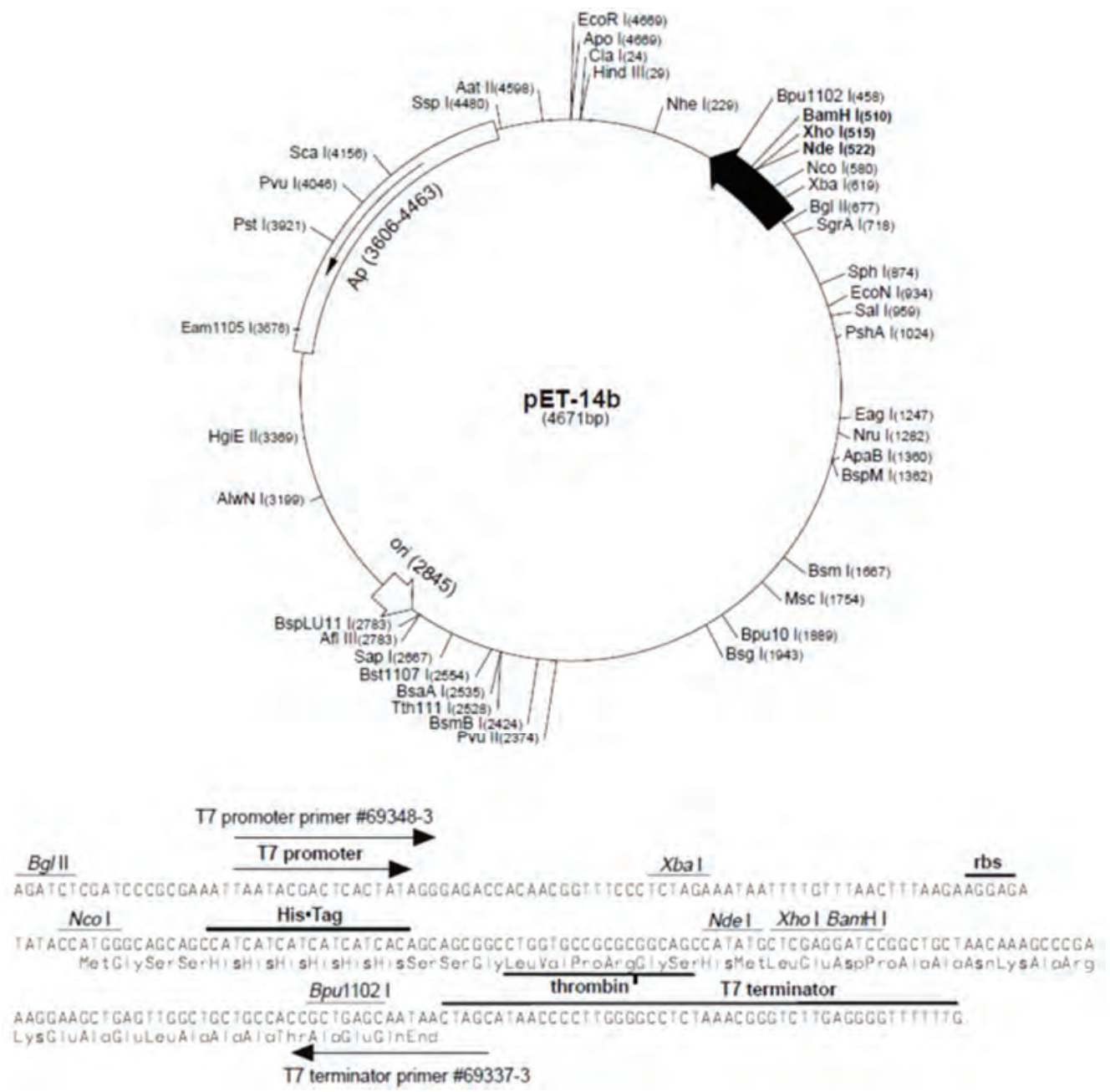

Figure 3.3. Scheme of $\mathrm{pET}-14 \mathrm{~b}$ expression vector

p10 (4511 bp) has been designed by combination of pET7 and pET9a (Novagen). It was created by the incorporation of the multiple cloning site from pET7 into pET9a expression vector and the elimination of Sapl $(2806 \mathrm{pb})$ restriction site by Dr.M.Pierna (311).

Other expression vector used in this work was the $\mathrm{pET} 14 \mathrm{H} 8$ which is derived from the commercial pET-14b (Novagen) (Figure 3.3). pET-14b plasmid is under control of T7 phage promoter and contains a His tag with 6 histidine amino-acids. It was modified with 2 histidines more. Thus, the subcloning of any sequence involves the expression 
of the 8 histidines tag at the $\mathrm{N}$-terminus of the polymer. This modification was performed by Dra. A.Girotti (310).

pCMV-p53 (Clontech) and pDrive5Lucia-hMUC1(Invivogen) were used for mammalian expression vector constructs (Figure 3.4 and 3.5).

pDrive5Lucia-hMUC1 was used to construct the pDhMUC1-ricin plasmid (4403bp). For that, the luciferase enzyme was replaced by the preprotrypsin leader-ricin gene using $\mathrm{NcO}$ and Nhel restriction enzymes and T4 ligase.

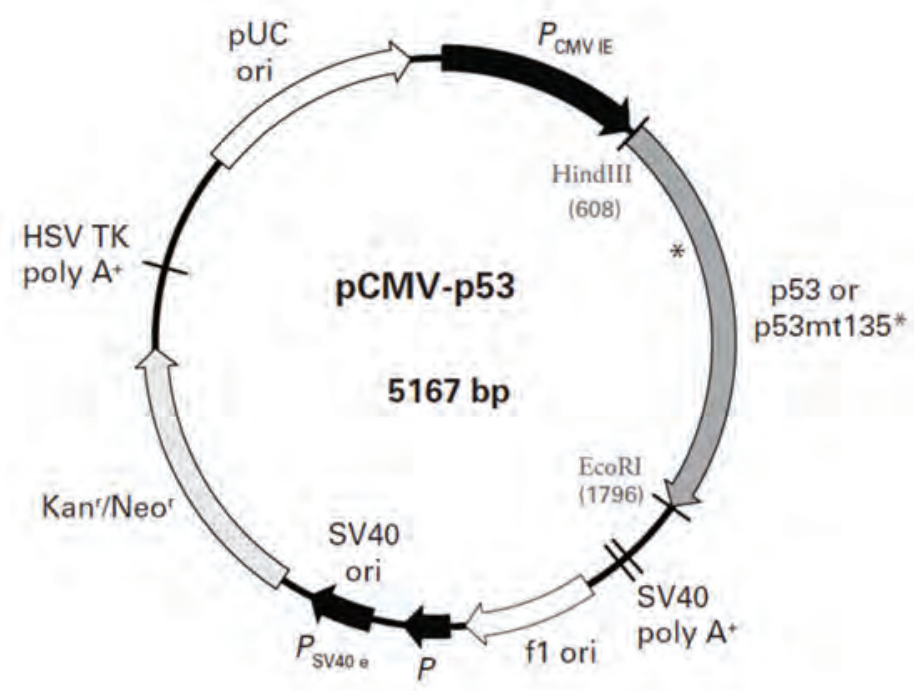

Figure 3.4 .Scheme of pCMV-p53 expression vector

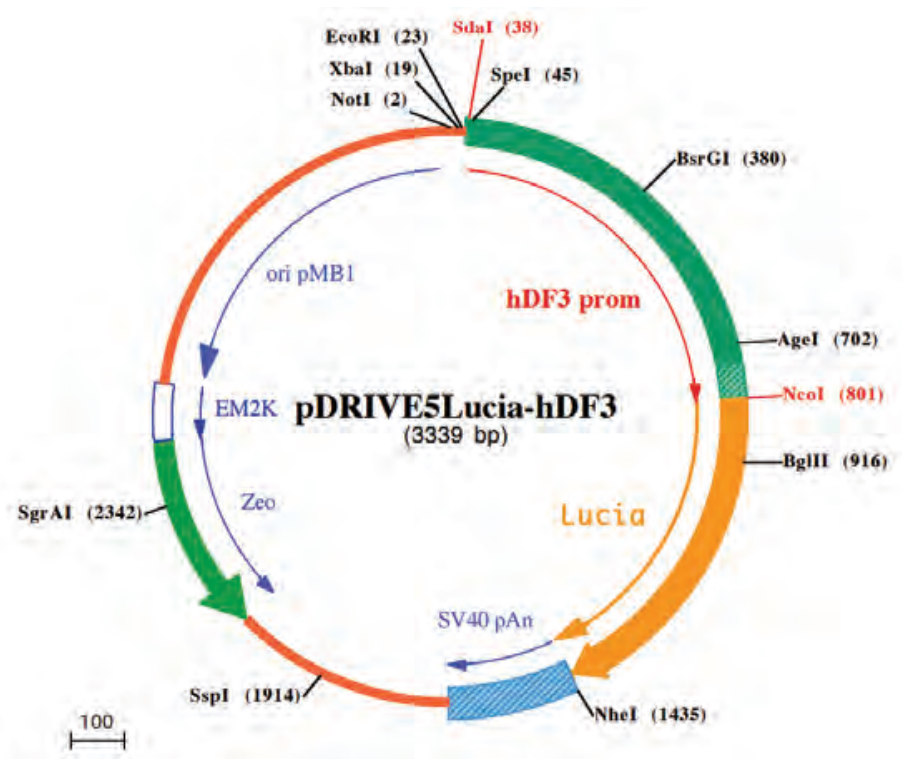

Figure 3.5 .Scheme of pDrive5Lucia-hMUC1 expression vector 


\subsubsection{POLYMERASE CHAIN REACTION (PCR) REAGENTS}

Primers designed in the laboratory and used in the PCR are listed in the table below (Table 3.2).

Table 3.2. Sequences and melting temperature $(T \mathrm{~m})$ of the employed universal and general primers

$\begin{array}{lll}\text { Primer } & \operatorname{Tm}\left({ }^{\circ} \mathrm{C}\right) & \text { Sequence } \\ \text { M13 F } & 52.4 & \text { 5'GTAAAACGACGGCCAGTG 3' } \\ \text { M13 rev } & 50 & \text { 5'AACCAGCTATGACCATG 3' } \\ \text { T7 F } & 54.3 & \text { 5'TAATACGACTCACTATAGGG 3' } \\ \text { T7 term } & 55.7 & \text { 5'GCTAGTTATTGCTCAGCGGTGG 3' } \\ \text { SP6 } & 50.2 & \text { 5'ATTTAGGTGACACTATAGAA 3' }\end{array}$

The oligonucleotides used in the synthesis of the monomeric genes are listed in the following Table 3.3.

Table 3.3. Sequences and melting temperature $(\mathrm{Tm})$ of the primers employed.

\begin{tabular}{lll|}
\hline $\begin{array}{l}\text { Oligonucleotide } \\
\text { LAEL for }\end{array}$ & $\mathrm{Tm}\left({ }^{\circ} \mathrm{C}\right)$ & Sequence \\
LAEL rev & 87.1 & 5'GTACTGGCTGAACTGCTGGCAGAGCTGCTGGCGGAACTG 3' \\
\hline
\end{tabular}

\subsubsection{PLASMIDS AND SIRNA FOR GENE DELIVERY}

pUC18 (Fermentas) (2686 bp)

pRNA Luc/Neo (GeneScript) (7380bp)

pCMV-Gaussia Luc Vector (ThermoFisher) (5483bp)

pDrive5Lucia-hMUC1 (Invivogen) (3339bp)

pCMV-p53 (Clontech) (5167bp)

siPAK1 AUAACGGCCUAGACAUUCAdTdT (GeneScript)

\subsubsection{OTHER REAGENTS}

NucleoSpin ${ }^{\circledR}$ Plasmid (Macherey- Nagel)

PureLink ${ }^{\circledR}$ Quick Gel Extraction Kit (Invitrogen)

Endofree Plasmid Maxi Kit (QIAGEN)

\subsubsection{APTAMERS}

S2.2 (5'GCAGTTGATCCTTTGGATACCCTGG'3) (Metabion). 
5TR1 (5'GAAGTGAAAATGACAGAACACAACA'3) (Metabion).

Thiol-modified 5TR1 (5'thiol (C6-S-S)-GAAGTGAAAATGACAGAACACAACA'3) (Metabion).

5TR1 Azide-modified $\quad 5^{\prime}$ GAAGTGAAAATGACAGAACACAACA-NHS-C3-Azide-3' (Metabion).

Cy5-5TR1-Azide-modified 5'Cy5-GAAGTGAAAATGACAGAACACAACA-NHS-C3Azide-3' (Metabion).

\subsection{METHODS}

\subsubsection{ELRs DESIGN USING GENETIC ENGINEERING TECHNIQUES}

\subsubsection{DNA ELECTROPHORESIS}

DNA electrophoresis was used in order to separate the nucleic acid fragments after an enzymatic digestion with endonucleases and to check the state of the purified DNA. For that, two types of agarose were used (Seakem LE and Metaphor). After electrophoresis gel was stained with SimplySafeTM (EURx).

Seakem allowed the separation of fragments between 500-23000bp (Table 3.5). The preparation of agarose included the following steps. The agarose powder was dissolved in 1XTAE buffer with a concentration depending on the fragment size to separate. The agarose was melted in the microwave. The beaker was weight before and after the heating. Ultrapure water was added in order to maintain the final concentration. The solution was cool to $60^{\circ} \mathrm{C}$ prior to casting and placed in a horizontal tray with the desired comb.

Table 3.5. Optimal resolution for linear DNA

\begin{tabular}{|cc|}
\hline Fragment size (bp) & Agarose \% 1x TAE \\
\hline $1000-23000$ & 0.6 \\
$800-10000$ & 0.8 \\
$400-8000$ & 1 \\
$300-7000$ & 1.2 \\
$200-4000$ & 1.5 \\
$100-200$ & 2 \\
\hline
\end{tabular}


Table 3.6. Bromophenol mobility table

\begin{tabular}{|cc|}
\hline 1xTAE BFB & Agarose \% \\
\hline 24800 & 0.30 \\
11000 & 0.50 \\
10200 & 0.75 \\
6100 & 1.0 \\
3560 & 1.25 \\
2800 & 1.50 \\
1800 & 1.75 \\
1300 & 2.0 \\
\hline
\end{tabular}

Metaphor is a high resolution agarose that allows the separation of DNA fragments from 800 to $20 \mathrm{bp}$ (Table 3.7). The procedure is similar to the Seakem agarose, with the exception of the hydration process of the agarose in the buffer for 15 min before the heating, which reduces the tendency of the agarose solution to foam. Also, after casting the gel was placed at $4^{\circ} \mathrm{C}$ for 20 min to get optimal resolution and uniformity. 0.20 volumes of $5 x$ loading buffer were added to the samples. A fixed voltage, between 2 and $7 \mathrm{~V} / \mathrm{cm}$ according to each sample was applied for Seakem and 4V/cm for Metaphor. The electrophoresis was run having as references the color markers (Table 3.6 and 3.8).

Table 3.7. Optimal resolution for linear DNA in Metaphor agarose

\begin{tabular}{|cc|}
\hline Fragment size (bp) & Agarose \% 1x TAE \\
\hline $150-800$ & 2.0 \\
$100-600$ & 3.0 \\
$50-250$ & 4.0 \\
$20-130$ & 5.0 \\
$<80$ & - \\
\hline
\end{tabular}

Table 3.8. Bromophenol mobility table in Metaphor agarose

\begin{tabular}{|cc|}
\hline 1xTAE BFB & Agarose \% \\
\hline 70 & 2.0 \\
40 & 3.0 \\
35 & 4.0 \\
30 & 5.0 \\
\hline
\end{tabular}




\subsubsection{2. $P C R$}

The Polymerase Chain Reaction (PCR) was performed to screen the resulting colonies from the transformation in XL-1 Blue Competent Cells (312). Herculase polymerase was used because it is specifically recommended for $\mathrm{G}-\mathrm{C}$ rich templates. The final volume of the PCR reaction was $15 \mu \mathrm{L}$ per tube containing $0.5 \mu \mathrm{L}$ of Herculase II Fusion DNA Polymerase. In order to perform the colony screening a single colony was inoculated into the tube with the mixture using a sterile pipette tip. Tubes were in a plate cooler during all the process.

The conditions for the PCR cycle were designed as following:

Initial denaturation: $95^{\circ} \mathrm{C}$ for 5 min

Template denaturation: $95^{\circ} \mathrm{C}$ for $35 \mathrm{sec}$

Primer annealing: Primer $\mathrm{Tm}-5^{\circ} \mathrm{C}$ for $20 \mathrm{sec}$

Primer extension: $72^{\circ} \mathrm{C}$ for $30 \mathrm{sec}$

Final primer extension: $72^{\circ} \mathrm{C}$ for $10 \mathrm{~min}$

Storage: $4^{\circ} \mathrm{C}$

\subsubsection{DNA SEQUENCING}

The automatic DNA sequencing was made in an ABI3730XL capillary electrophoretic system by Cenit Support Systems S.L.U.

\subsubsection{PLASMID DNA PURIFICATION}

After growing in 2-10 mL of LB medium with the corresponding antibiotic, all the plasmids DNA along this work were purified using the NucleoSpin ${ }^{\circledR}$ Plasmid kit and eluted using $70^{\circ} \mathrm{C}$ preheated elution buffer $\mathrm{AE}$.

\subsubsection{DIGESTION WITH RESTRICTION ENZYMES}

Purified DNAs were digested with the corresponding restriction enzymes. Concentration and incubation time at $37^{\circ} \mathrm{C}$ depends of the manufacturer recommendations for each endonuclease. The correct digestion of the DNA was controlled by agarose electrophoresis. 


\subsubsection{DNA DEPHOSPHORYLATION}

In order to avoid vector auto-ligation problems, the linearized DNA was dephosphorylated twice with two different enzymes named as Shrimp Alkaline Phosphatase and Antartic Alkaline Phosphatase. Concentration and time at $37^{\circ} \mathrm{C}$ are specified by the manufacturer.

\subsubsection{DNA PURIFICATION FROM AGAROSE GEL}

DNA fragments from the agarose gel were cut and purified using the PureLink ${ }^{\circ}$ Quick Gel Extraction Kit, an elution buffer was used to elute the DNA.

\subsubsection{LIGATION REACTION}

The ligation reaction was accomplished by the T4 ligase in a final volume of $10 \mu \mathrm{l}$ and with a molar ratio range of 1:1 to 1:5 between vector and insert. A specific T4 ligase buffer was required and the conditions are detailed by the supplier. The reaction was performed at $22^{\circ} \mathrm{C}$ for 1 hour.

\subsubsection{TRANSFORMATION OF COMPETENT CELLS}

Once the ligation was concluded, transformation of the construct into E.coli competent cells was accomplished. For that, different strains were used.

\subsubsection{XL-1 BLUE SUBCLONING}

XL-1 Blue Subcloning-Grade competent cells were specifically used for cloning issues. Their efficiency is $\geq 1.0 \times 10^{6} \mathrm{cfu} / \mu \mathrm{g}$ pUC18 DNA. Transformations are performed with certain quantity of DNA and cells. Following the supplier protocol, the transformation mixture was seeded on LB agar $\leq 200 \mu \mathrm{l}$ containing the appropriate antibiotic. Plates were incubated at $37^{\circ} \mathrm{C}$ overnight.

\subsubsection{XL-1 BLUE COMPETENT}

$\mathrm{XL}-1$ Blue Competent cells were used after ligation. Their efficacy is $\geq 1.0 \times 10^{8} \mathrm{cfu} / \mathrm{\mu g}$ pUC18 DNA. Transformations were performed following the supplier recommendations and the transformation mixture was seeded on LB agar $\leq 200 \mu \mathrm{L}$ containing the appropriate antibiotic and incubated as indicated above. 


\subsubsection{EXPRESSION STRAINS: BLR (DE3) AND BL21 Star (DE3)}

To express the ELR constructs, strains named as BLR and BL21 were used. For BLR (DE3), Transformation and Storage Solution (TSS) was applied firstly to transform competent cells with an efficiency of $1.0 \times 10^{7}-1.0 \times 10^{8} \mathrm{cfu} / \mu \mathrm{g}$ pUC18 DNA and secondly to storage the bacteria (313).

A single colony from LB-agar plate was used to inoculate $10 \mathrm{~mL}$ of $\mathrm{LB}$ media and leave to grow at $37^{\circ} \mathrm{C}$ with shaking until an $\mathrm{OD}_{600}$ of $0.3-0.4$. After that, incubation on ice for $10 \mathrm{~min}$ was accomplished. Cell solution was centrifuged at $3000 \mathrm{rpm}$ for 10 min at $4^{\circ} \mathrm{C}$. The pellet was suspended in $1 \mathrm{~mL}$ of cold $1 \times 1 S S$ solution. A quantity of $1-$ 10ng of plasmid DNA was added to the bacteria and it was kept on ice for 1 hour. After that time, the heat shock was performed by incubation the mix at $42^{\circ} \mathrm{C}$ for 2 min. It was followed by incubation on ice for 2 min in order to stop the heat shock. After that, $1 \mathrm{~mL}$ of warm LB with the appropriate antibiotic was added and the mix was incubated $1 \mathrm{~h}$ shaking at $37^{\circ} \mathrm{C}$. Once bacteria were grown, $\leq 200 \mu \mathrm{L}$ of the transformation mix was seeded in LB agar with the antibiotic and plates were incubated for $16-20 \mathrm{~h}$ at $37^{\circ} \mathrm{C}$.

The procedure followed for BL21 Star (DE3) is similar to the BLR (DE3) with the exception of the initial preparation of bacteria and the addition of TSS which make it a faster method. The protocol was the recommended by the supplier.

\subsubsection{GLICEROL STOCK PREPARATION}

To storage the E.coliclones of interest a glycerol addition was required. The selected clones were grown in LB with $0.5 \%$ of glucose at $37^{\circ} \mathrm{C}$ until an $\mathrm{OD}_{600}$ of $0.6-0.8$ was reached. At this moment 0.1 volumes of $80 \%$ of sterile glycerol was added and the cells were storage in cryovials at $-80^{\circ} \mathrm{C}$.

\subsubsection{PRODUCTION AND PURIFICATION OF ELR}

Once the BLR or BL21 E.coli was transformed with the expression vector containing the ELR gene, the polymer expression was checked and production was performed.

\subsubsection{RECOMBINANT POLYMER EXPRESSION}

Initially the inoculum was prepared, for that a single colony from an LB-agar plate was picked and inoculated in LB with the appropriate antibiotic and $1 \%$ of glucose. It 
was growing at $37^{\circ} \mathrm{C}$ at $250 \mathrm{rpm} \mathrm{o} / \mathrm{n}$ (overnight). After this time, Erlenmeyer containing TB media with antibiotic (1\%) were inoculated in a proportion (1:5000) of media: inoculum. Bacteria grew at $37^{\circ} \mathrm{C}$ with shacking at $250 \mathrm{rpm}$ and $14-16 \mathrm{~h}$ for polymer expression. When using the fermenter, inoculum was added directly to the fermenter of $12 \mathrm{~L}$ containing TB media with antibiotic (1\%). Bacteria were grown for 18-19 $\mathrm{h}$ in the case of VOKx48, VOKx72, VOKx48HPGx1 and IK30HPGx3 and 5-6 $\mathrm{h}$ in the case of IK120CPP and LAELIK120CPP at $37^{\circ} \mathrm{C}$, 499rpm $21 \%$ of oxygen and $\mathrm{pH} 7$. The control of oxygen was required, because an elevated concentration of oxygen could lead to increased levels of bacteria density and may inhibit the induction by lactose in auto-induction media (314). Oxygen values were registered by an electrode located in the fermenter able to sense the requirements of $\mathrm{O}_{2}$ from the culture and to add what was necessary to maintain the $21 \%$ of oxygen during the production. $\mathrm{pH}$ values were also registered by an electrode and $\mathrm{HCl} 37 \%$ and $\mathrm{NH}_{3} 28 \%$ were incorporated in the culture in order to maintain the $\mathrm{pH} 7$.

In both methods, the control of bacteria density was achieved by measuring the absorbance at $600 \mathrm{~nm}$ using the spectrophotometer UV-Visible Varian Cary 50 (Agilent Technologies)

\subsubsection{TOTAL PROTEIN FRACTION ANALYSIS}

$1 \mathrm{~mL}$ of culture media sample with bacteria was taken and the absorbance at $600 \mathrm{~nm}$ was measured. Bacteria were pelleted by spin down for 1 minute at $12000 \mathrm{xg}$ and $4^{\circ} \mathrm{C}$ afterwards it was washed with distilled water. After another spin down at $4^{\circ} \mathrm{C}$, the pellet was resuspended in $20 \mu \mathrm{L}$ of TBS and $5 \mu \mathrm{L}$ of loading buffer. A sample was boiled $5 \mathrm{~min}$ and after a spin-down, the sample was loaded on a polyacrylamide gel. The volume to load was calculated from the absorbance at $600 \mathrm{~nm}$ data in order to normalize the amount of protein analyzed in each well.

\subsubsection{BACTERIA DISRUPTION}

The metabolism and growth of bacteria was stopped by cooling it down at $4^{\circ} \mathrm{C}$. At this time wash of bacteria was accomplished by centrifugation at $6000 \mathrm{rpm}$ for $8 \mathrm{~min}$. Supernatant was removed and pellet was homogenized in wash buffer. Once the supernatant was clear, the pellet was resuspended in $100 \mathrm{~mL} / \mathrm{L}$ of sonication buffer (3.1.3.) and $10 \mu \mathrm{g} / \mathrm{mL}$ of PMSF protease inhibitor was added. Bacteria were lysed by 
pressure disruption using the Constant Cell Disruption System (Model TS 0.75KW Constant System).

\subsubsection{PURIFICATION OF ELRs}

Once bacteria were lysed, the purification process started with the centrifugation of disrupted product at $12,000 \mathrm{rpm}$ for $30 \mathrm{~min}$ at $4^{\circ} \mathrm{C}$.

Purification of ELRs was based on their smart nature and inverse transition cycling that makes them reversible soluble-insoluble allowing the remove of bacterial proteins. Then heat and cold cycles together with salt additions such as $\mathrm{NaCl}$ and $\mathrm{NaOH}$ were performed along it. For the ELR designed and produced in this work, the general procedure is the following.

Once the lysed bacteria were centrifuged, if the ELR remained in the pellet an additional treatment with $3 \%$ of the cationic detergent Myristyltrimethylammonium bromide (MTAB) from Sigma and stirring overnight at RT was performed. After centrifugation at $10,000 \mathrm{rpm}$ for $20 \mathrm{~min}$ at $25^{\circ} \mathrm{C}$ the ELR remained in the supernatant and the detergent was removed by dialysis. After at least 3 days of dialysis against $250 \mathrm{~L}$ of distilled water at RT (when purifying CPP containing polymers the dialysis was prolonged 3 days at maximum). The $\mathrm{pH}$ of the solution containing the solubilized ELR was changed up to $\mathrm{pH} 11.0$ using $\mathrm{NaOH} 1 \mathrm{M}$ solution (in the case of IKx30HPGx3, the $\mathrm{pH}$ was fixed to 4.0 using $\mathrm{HCl} 0.1 \mathrm{~N}$ and a cold spin was accomplished, once the polymer was in the supernatant the $\mathrm{pH}$ was fixed to 11.0). When the $\mathrm{pH}$ was stabilized, a final concentration of $4 \mathrm{M} \mathrm{NaCl}$ was added and the supernatant was heated at $42^{\circ} \mathrm{C}$ for 1 hour (when CPP containing polymers were purified heat cycles are reduced to $10 \mathrm{~min}$ in order to avoid enzymatic degradation processes). The polymer precipitated and remained in the pellet after a centrifugation at $40^{\circ} \mathrm{C}$, $10,000 \mathrm{rpm}$ for $10 \mathrm{~min}$. The supernatant was removed and the pellet was resuspended in cold ultrapure water until it got totally dissolved. After that, a cold spin was performed in which the polymer remained in the supernatant and the heat cycle precipitated it. At least 3 cold-heat cycles were required to obtain a relatively pure ELR. After last purification, the polymer was subjected to the endotoxin removal protocol, dialyzed against ultrapure water with several changes, frozen, lyophilized and storage at $-20^{\circ} \mathrm{C}$. 


\subsubsection{ENDOTOXIN REMOVAL FROM ELRs}

An additional endotoxin removal treatment with $\mathrm{NaOH}$ and $\mathrm{NaCl}$ to a final concentration of $0.4 \mathrm{~N}$ and $2 \mathrm{M}$ respectively was required for in vitro and in vivo applications (65). ELR was precipitated by heating at $42^{\circ} \mathrm{C}$ (when polymers contains CPP the heating was performed at $25^{\circ} \mathrm{C}$ ) and resuspended in cold ultrapure water after centrifugation at $10,000 \mathrm{rpm}$ for $20 \mathrm{~min}$ at $25^{\circ} \mathrm{C}$. This treatment was repeated at least twice. The resulting supernatant was dialyzed against ultrapure water, adjusted the $\mathrm{pH}$ to $6-8$ and sterilized by filtration using $0.2 \mu \mathrm{m}$ filters. The solution was frozen, lyophilized and storage at $-20^{\circ} \mathrm{C}$.

\subsection{DETERMINATION OF ENDOTOXIN LEVELS}

Lyophilized ELRs were resuspended in ultrapure water at serial dilutions from $1 \mathrm{mg} / \mathrm{mL}$ and protein endotoxin levels were measured using the Endosafe ${ }^{\circledR}$-PTS ${ }^{\mathrm{TM}}$ (Charles River). Due to the recombinant origin of ELRs, the bacterial endotoxin levels are important in order to avoid critical side effects. Levels of endotoxin should be typically $\leq 0.1 \mathrm{EU} / \mathrm{mg}$ of protein polymer for in vivo assays ( $1 \mathrm{EU}=100 \mathrm{pg}$ of endotoxin) (315). However, the upper threshold of endotoxin in nonintrathecal intravenous administration is up $5 \mathrm{EU} / \mathrm{kg} / \mathrm{h}$ body weight (316). And up $2000 \mathrm{EU} / \mu \mathrm{g}$ to significantly inhibit the transfection in in vitro culture (317).

\subsubsection{ANALYSIS OF PURIFIED ELRS}

\subsubsection{SDS-PAGE (Sodium Dodecyl-sulfate Polyacrylamide Gel Electrophoresis)}

During production and after ELR purification, SDS-PAGE was required. It was made following the protocol to separate proteins according to their electrophoretic mobility described by Laemmly in its work with the Bacteriophage T4 (318).

SDS-PAGE separates proteins depending to their molecular weight and based on their differential rates of migration through a polyacrylamide gel under de influence of an applied electrical field following the equation below.

$$
V=q E / f
$$

Where $\mathrm{V}$ (migration velocity) is directly proportional to the product of its $\mathrm{q}$ (effective charge) and $E$ (electric potential gradient) and inversely proportional to $f$ (friction coefficient of the protein to the media). 
To separate proteins is necessary to denature and transform them in linear molecules. SDS is an anionic detergent that completely denatures proteins breaking down secondary structures like alpha-helices and beta-sheets that comprise hydrogen bonds, as well as tertiary structures non-disulfide linked. SDS interacts with proteins providing them with about one negative charge per each aminoacid residue and somehow masking the intrinsic effective charge of proteins. The composition of both resolving and stacking geles are shown in Table 3.9 together with the percentage of acrylamide (\%T) which is different according to the protein size sample (Table 3.10).

Table 3.9. Composition of resolving and staking gel for a $15 \% \mathrm{~T}$.

\begin{tabular}{|lcc|}
\multicolumn{1}{ll}{} & Resolving gel & Stacking gel \\
\hline Acrylamide $40 \%$ & $\mathrm{X} \%(\mathrm{w} / \mathrm{v})$ & $4 \%(\mathrm{w} / \mathrm{v})$ \\
Tris-HCL pH 8.8 & $375 \mathrm{mM}$ & - \\
\hline Tris-HCL pH 6.8 & - & $125 \mathrm{mM}$ \\
SDS 10\% & $0.1 \%(\mathrm{w} / \mathrm{v})$ & $0.1 \%(\mathrm{w} / \mathrm{v})$ \\
APS 10\% & $0.05 \%(\mathrm{w} / \mathrm{v})$ & $0.05 \%(\mathrm{w} / \mathrm{v})$ \\
TEMED & $0.05 \%(\mathrm{w} / \mathrm{v})$ & $0.08 \%(\mathrm{w} / \mathrm{v})$ \\
\hline
\end{tabular}

Both geles are prepared in distilled water.

Table 3.10. Optimal \%T in resolving gel according to the protein target size range.

\begin{tabular}{|cc|}
\hline Target size range $(\mathrm{kDa})$ & \% $\mathrm{T}$ in resolving gel \\
\hline $24-205$ & $7.5 \%$ \\
$14-205$ & $7.5 \%$ \\
$14-66$ & $12.5 \%$ \\
$14-45$ & $15 \%$ \\
\hline
\end{tabular}

Before charging the gel, protein samples were briefly heated to near boiling in presence of the reducing agent B-mercaptoethanol which was added in order to break the disulfide bonds existing in the quaternary protein structure.

The electrophoresis was performed using a miniVE vertical electrophoresis system (Hoefer, Amersham Pharmacia Biotech).

\subsection{SDS-PAGE STAINING}

Once the electrophoresis was concluded, the staining of polyacrilamide gel was done in order to visualize the separated proteins. For staining the anionic protein dye Coomassie Brilliant Blue and the negative staining for proteins $\mathrm{CuCl}_{2}$ were used. 
Coomassie staining was made by $2 \mathrm{~h}$ of immersion in a solution containing $0.125 \%$ $(\mathrm{w} / \mathrm{v})$ of Coomassie Brilliant Blue R-250, 40\% (v/v) of methanol and 10\% (v/v) of acetic acid.

The $\mathrm{CuCl}_{2}$ staining was performed following Lee's method (319) by incubation of polyacrilamide gel into $0.3 \mathrm{M}$ of $\mathrm{CuCl}_{2}$ solution.

After the incubation with the corresponding staining, warm distilled water for Coomassie and distilled water solution with $50 \mathrm{mM}$ of EDTA was used for $\mathrm{CuCl}_{2}$.

As result, different bands corresponding to proteins appeared on the gel. To determine the relative molecular weight of the desired protein, a protein marker with known molecular weight was loaded on each gel as well. The protein marker used to compare was the Smart Broad Range Protein Standard from GeneScript and Pierce ${ }^{\mathrm{TM}}$ Unstained Protein MW Marker from ThermoFisher Scientific.

The images from the gel were performed using the digital camera from the Kodak equipment "Gel logic 100 Imaging System".

\subsubsection{AMINO-ACID COMPOSITION}

The amino-acid composition analysis was made in the "Laboratorio de Técnicas Instrumentales" from Universidad de Valladolid with UV detection, using a WATERS600 HPLC gradient system with a WATERS2487 detector. For amino acid analysis after addition of a known quantity of $\alpha$-aminobutyric acid as internal pattern the polymer sample was hydrolyzed $\left(6 \mathrm{M} \mathrm{HCl}, 1 \%\right.$ Phenol and $2.5 \mathrm{~h}$ at $\left.155^{\circ} \mathrm{C}\right)$ and evaporated. The powder was resuspended in $1 \mathrm{~mL}$ of $20 \mathrm{mM} \mathrm{HCl}$ and a $1 / 10$ dissolution was prepared. The quantification of the less represented amino acids was made from the most concentrated sample and the quantification of the most represented amino acids from the $1 / 10$ dissolution

\subsubsection{MALDI-TOF}

The molecular weight of the ELR was determined by MALDI-TOF (Bruker Autoflex) made in the "Laboratorio de Técnicas Instrumentales" from Universidad de Valladolid. Samples for MALDI-TOF were prepared at $1 \mathrm{mg} / \mathrm{mL}$ in ultrapure water. 


\subsubsection{DIFFERENTIAL SCANING CALORIMETRY (DSC)}

Differential Scaning Calorimetry (DSC) studies were accomplished in order to study the inverse transition of ELRs when temperature changes were applied. For that, measurements were performed in Mettler Toledo 822e equipment with a liquidnitrogen cooler. Initially, both temperature and enthalpy were calibrated with a standard sample of indium.

Samples were prepared in ultrapure water or PBS at $50 \mathrm{mg} / \mathrm{ml}$ at $4^{\circ} \mathrm{C} 24 \mathrm{~h}$ before of the measurement. Once they were dissolved, $20 \mu \mathrm{l}$ was loaded into a standard $40 \mu \mathrm{l}$ aluminum pan and sealed hermetically. As reference, $20 \mu \mathrm{l}$ of the solvent was placed in another pan. Both temperature and enthalpy were calibrated using a standard sample of indium. The heating program included an initial isothermal stage $(5 \mathrm{~min}$ at $0{ }^{\circ} \mathrm{C}$ ), followed by heating at $5^{\circ} \mathrm{C} / \mathrm{min}$ from $0{ }^{\circ} \mathrm{C}$ to the desired temperature.

Endothermic processes have been taken as negative values of enthalpy and exothermic as positive values of enthalpy.

\subsubsection{5. ${ }^{1} \mathrm{H}$ NUCLEAR MAGNETIC RESONANCE ( $\left.{ }^{1} \mathrm{H}-\mathrm{NMR}\right)$}

The proton nuclear magnetic resonance of ELRs was determined by RMN 500 (Agilent Technologies) in the "Laboratorio de Técnicas Instrumentales" from Universidad de Valladolid. For ${ }^{1} \mathrm{H}$ NMR $10 \mathrm{mg}$ of polymer was solved in $600 \mu \mathrm{l}$ of $\left(\mathrm{CD}_{3}\right)_{2} \mathrm{SO}$.

\subsubsection{BUFFERING CAPACITY}

The buffering capacity of ELRs was measured as follows. A $2.5 \mathrm{mg}$ sample of the ELR was dissolved in $25 \mathrm{~mL}$ of $0.9 \% \mathrm{NaCl}$ to a final concentration of $0.1 \mathrm{mg} / \mathrm{mL}$ and stored at $4{ }^{\circ} \mathrm{C}$ overnight. The initial $\mathrm{pH}$ of the polymer solution was adjusted to 10 with $0.2 \mathrm{~N} \mathrm{NaOH}$ and titrated by gradual addition of $50 \mu \mathrm{L}$ aliquots of $0.01 \mathrm{~N} \mathrm{HCl}$. The $\mathrm{pH}$ values for all solutions were measured using a pH-meter (Crison GLP22). PEI 25 kDa was used as control. 


\subsubsection{CHEMICAL MODIFICATION OF ELRs}

\subsubsection{IMID-IK120}

An amidation reaction was accomplished in order to conjugate imidazole functional groups to the lysine amino acids in IK120 polymer. For that, a solution of NHS (12 equiv.) in MES (2-(N-morpholino)ethanesulfonic acid buffer) was added to a solution of EDAC (1-ethyl-3-(dimethylaminopropyl) (Sigma Aldrich) (12 equiv.) in MES at pH 4.5. EDAC acted as an activating agent for the carboxyl group. The resulting mixture was stirred at $4{ }^{\circ} \mathrm{C}$ for $1 \mathrm{~h}$ and a solution of 1 - $H$-imidazole-2-carboxylic acid (10 equiv.) and MES buffer was then added. This mixture was stirred at $4{ }^{\circ} \mathrm{C}$ for $1 \mathrm{~h}$. After this time, a freshly prepared solution of IK120 ELR (1 equiv.) in MES was added and the reaction mixture stirred at $25^{\circ} \mathrm{C}$ for $72 \mathrm{~h}$. The IMID-IK120 obtained was diluted in distilled water, dialyzed and lyophilized. Incorporation of the imidazole groups was corroborated by DSC and ${ }^{1} \mathrm{H}-\mathrm{NMR}$.

\subsubsection{VOK-PEG}

1 equiv. of VOKx72 $(20 \mathrm{mg} / \mathrm{mL})$ in DMSO was mixed with 0.46 equiv. of NHS-PEGcyclooctine (2,5-Dioxopyrrolidin-1-yl1- ((1R,8S,9s)- bicycle [6.1.0]non-4-yn-9-yl) 3,14-dioxo-2,7,10-trioxa-4-13-diazaoctadecan-18-oate) (3mg/ml) in DMSO under nitrogen atmosphere at $37^{\circ} \mathrm{C}$. The mixture was stirred over night at $25^{\circ} \mathrm{C}$. After this time $30 \mathrm{~mL}$ of freshly ultrapure water (miliQ) was added to the crude, dialyzed against water and lyophilized. The incorporation of PEG as VOK-PEG-cyclooctine to the ELR was evaluated by ${ }^{1} \mathrm{H}-\mathrm{NMR}$. The adjustment to 50/1/4 (N/P/Papt) ratio was achieved by the incorporation of fresh VOKx72.

\subsubsection{ANALYSIS OF POLYPLEXES}

\subsubsection{POLYPLEXES PREPARATION}

The ELR was dissolved to a concentration of $1 \mathrm{mg} / \mathrm{mL}$ in ultrapure water at $4{ }^{\circ} \mathrm{C}$ overnight. Plasmid DNA was also prepared with the same concentration of $1 \mathrm{mg} / \mathrm{mL}$. Polyplexes were formed in aqueous solution by mixing the PDNA with the ELR solution at the appropriate $(\mathrm{w} / \mathrm{w})$ weight to weight ratio or $\mathrm{N} / \mathrm{P}$ ratio, where $\mathrm{N}$ corresponds to the number of amine groups from the polymer and $\mathrm{P}$ to the phosphate groups from the plasmid DNA. The mixtures were vortexed at $10^{\circ} \mathrm{C}$ for 1 
minute (for IK120 based polymers) or RT (for VOK derived polymers) and incubated at $4{ }^{\circ} \mathrm{C}$ (for IK120 based polymers) or RT (for VOK derived polymers) for $20 \mathrm{~min}$ for nanocomplex formation. For experiments involving polyplexes and aptamers, a solution of each aptamer (S2.2 or 5TR1) in ultrapure water was added to the ELR/pDNA polyplex and the mixture was left for a further $30 \mathrm{~min}$ at RT. The complexes were formed and designated according to the different N/P/Papt ratios, where Papt corresponds to the number of phosphate groups in the aptamers, maintaining the N/P ratio constant and increasing Papt by addition of more aptamer.

\subsubsection{GEL RETARDATION AND PROTECTION ASSAY}

The ELR-pDNA complexes were prepared at different weight to weight ratios (w/w) $(10 / 1,40 / 1,80 / 1,120 / 1$ and 140/1) for IK120 based polymers and N/P ratios of $(0.5$, $1,2,3,5$ and 10/1) for VOKx72 polymer. For the DNA protection experiment, polyplexes and pDNA were additionally treated with $20 \mu \mathrm{L}$ of plasma for $30 \mathrm{~min}$ (IK120 based polymers) or with the restriction enzyme Dpn I for 90 min (VOKx72 polymer). Ik120 preparations were loaded onto a 1\% of agarose gel and VOKx72 onto a $0.8 \%$ agarose gel; electrophoresis was carried out in 1 XTAE buffer at $60 \mathrm{mV}$ for 120 min, staining with SimplySafe ${ }^{T M}$. The complexed pDNA was visualized by exposure to UV light in a transilluminator (Vilber).

\subsubsection{DYNAMIC LIGHT SCATTERING (DLS)}

In Dynamic Light Scattering (DLS), also known as Quasi-Elastic Light Scattering (QELS) or Photon Correlation Spectroscopy (PCS), the time-dependent fluctuations in the scattered light of particles, emulsions or molecules which have been dissolved in a liquid, are measured by a fast photon counter. The Brownian motion of these molecules, which is defined as the random movement of particles suspended in a fluid, causes the scatter light from an incident laser at different intensities. The scattered light is detected in NanoZS (Malvern Instruments) at a fixed angle of $173^{\circ}$. The intensity of these fluctuations (Figure 3.6) are directly related to the diffusion rate of the molecule through the solvent and hence to the particle size. 


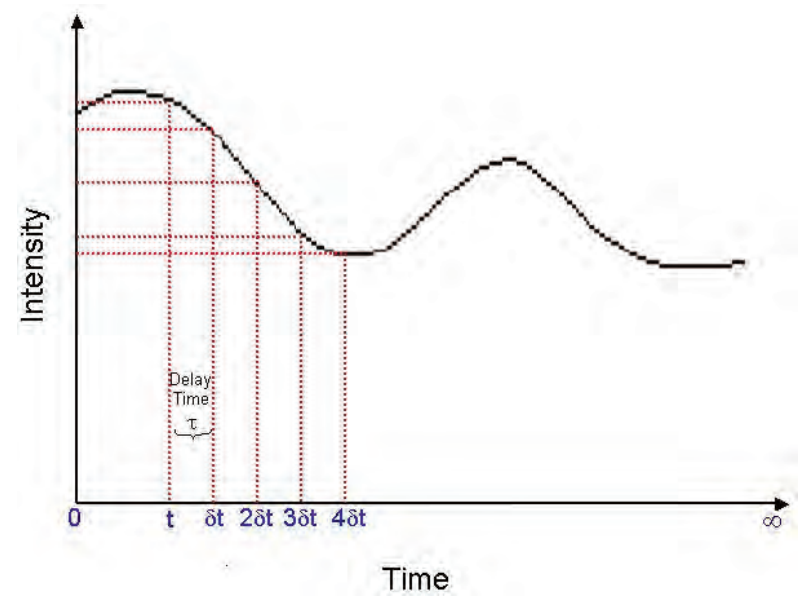

Figure 3.6 Graphic showing the fluctuation in the intensity of scattered light as a function of time

DLS allows to measure the scattered light intensity and provide information about the z-average (cumulant mean size by the use of cumulants algorithm (320)), and estimate the width of the distribution (polydispersity index). Since the calculation of the Z-average is mathematically stable, the Z-average result no sensitive to noise, and that makes it a preferred DLS size parameter. For monodisperse particles in Brownian motion, the autocorrelation function, $G(T)$, is treated as an exponential decay of the following form:

$$
G(\tau)=A[1+B \exp (-2 \Gamma \tau)]
$$

Where $A$ is the baseline subtracted autocorrelation function $T$ is the delay time, B is the intercept of the correlation function and $\Gamma$ is the decay rate. The intensity weighted average diffusion coefficient $\mathrm{D}_{\text {avg }}$ can be calculated from the relation:

$$
\Gamma=\operatorname{Davg} \cdot q^{2}
$$

Where Davg is the overall average of translational diffusion coefficient or velocity of Brownian motion and $\mathrm{q}$ is the wave vector:

$$
q=\frac{4 \pi n}{\lambda} \sin \left(\frac{\theta}{2}\right)
$$

Where $\mathrm{n}$ is the refractive index of the dispersant, $\lambda$ is the wavelength of the laser and $\theta$ is the scattering angle. Finally, Z-average size can be calculated from the StokesEinstein equation. 


$$
D(z)=\frac{k T}{3 \pi \mathrm{\eta} D, a v g}
$$

Where $D(z)$ is the Zeta-average hydrodynamic diameter, $D$ the diffusion coefficient average, $k$ the Boltzmann-Konstant, $\mathrm{T}$ the absolute temperature and $\mathrm{\eta}$ the viscosity of the solvent.

The hydrodynamic diameter refers to the diameter of a spherical particle diffusing within a fluid so the calculated Dh refers to (effective molecule diameter + hydration layer) (Figure 3.7).

The diffusion speed of molecules can be influenced by different parameters such as temperature, viscosity of the solvent and particle size. Temperature is a measure of the kinetic energy within particles, at higher temperatures particles move faster hence increasing their diffusion speed. Viscosity is a measure of resistance of flow due to internal friction when one layer of fluid is caused to move relative to another layer. When the particle to measure is solved in a viscous media its movement through it becomes slower. The size of the molecule is directly related with the scattered intensity fluctuations patterns, the small molecules cause the intensity to fluctuate faster than the large ones.

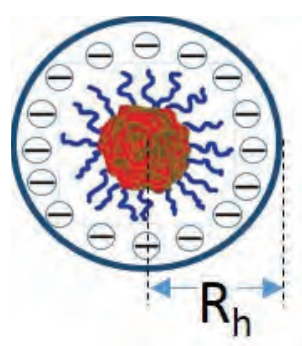

Figure 3.7 Schematic representation of a particle with its hydration layer and hydrodynamic radius.

When the temperature and viscosity of the solvent is known and constant, the diffusion of molecules and hence the scattered light will mainly depend of their size. ELRs previously dissolved in aqueous solution were filtered using $0.45 \mu \mathrm{m}$ PVDF (Millipore) syringe filter. The particle size of the polyplexes at different ratios was measured using the Zetasizer NanoZs at the desired temperature. Z-average mean $(\mathrm{nm})$ and polydispersity index were used for data analysis. 


\subsection{CALCULATION OF Tt FOR THE ELR IN THE PRESENCE OF pDNA}

ELR-pDNA complexes were formed at three different $\mathrm{N} / \mathrm{P}$ ratios $(5 / 1,10 / 1,50 / 1)$. After complexation, the $\mathrm{pH}$ was adjusted with $\mathrm{NaOH} 1 \mathrm{M}$ or $\mathrm{HCl} 1 \mathrm{M}$ and dynamic light scattering (DLS) measurements (Zetasizer NanoZs from Malvern Instruments Ltd., UK) were performed at $\mathrm{pH} 5.0,7.5$ and 11.5 in the temperature range $30-65^{\circ} \mathrm{C}$ in order to calculate the corresponding Tt.

\subsubsection{ZETA POTENTIAL}

Zeta potential of a particle in suspension is the electrical potential on the surface of hydrodynamic shear of this particle (Figure 3.8).

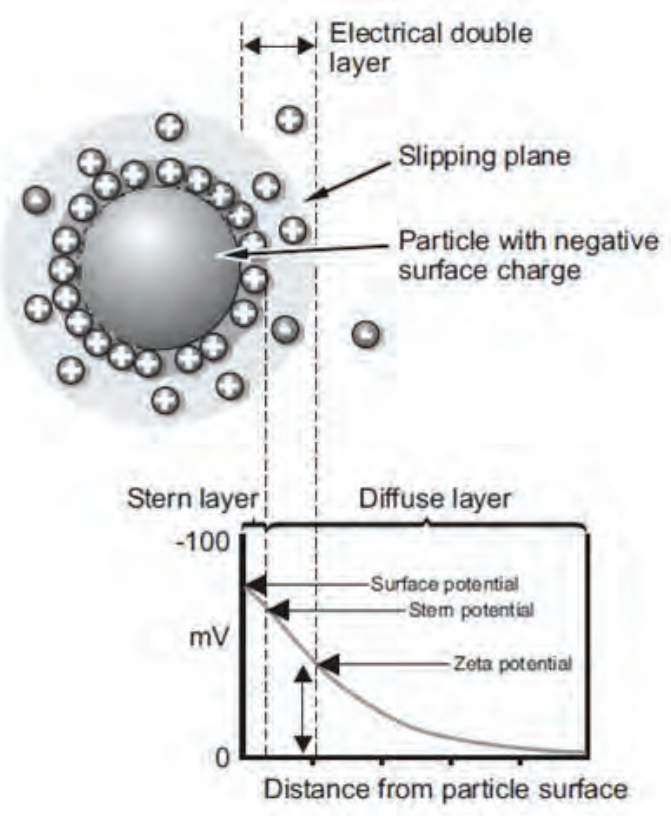

Figure 3.8 .Scheme showing the representation of z-potential

This magnitude is expressed in $\mathrm{mV}$ and is calculated from the Electrophoretic Mobility by applying Henry equation.

$$
U_{\mathrm{E}}=\frac{2 \varepsilon z f(\kappa a)}{3 \eta}
$$

Where $U_{E}$ is the electrophoretic mobility, $z$ the zeta potential, $\varepsilon$ the dielectric constant, $\eta$ the viscosity and $f(\kappa a)$ Henry's function.

Zeta potential gives an indication of the stability of the particles in suspension. As a rule of thumb, suspensions with zeta potential above $30 \mathrm{mV}$ (absolute value) are physically stable. Suspensions with a potential above $60 \mathrm{mV}$ show excellent stability. 
Suspensions below $20 \mathrm{mV}$ are of limited stability and below $5 \mathrm{mV}$ they undergo pronounced aggregation (321).

The most important factor that affects to the zeta potential value is the $\mathrm{pH}$ due to its implication in charging and discharging the molecules by changing it.

The zeta potential of the polyplexes at different ratios was measured using the Zetasizer NanoZS at the desired temperature. Zeta potential $(\mathrm{mV})$ was used for data analysis. Dielectric constant, refractive index and viscosity were assumed to be the same as water and the model used was Smoluchowski approximation. The zeta potential values were plotted as the average of 10 repeated measurements.

\subsubsection{TRANSMISSION ELECTRON MICROSCOPY (TEM)}

TEM measurements were performed using a JEOL JEM-1230 electron microscope operating at $120 \mathrm{kV}$. The polyplex solution was dropped onto carbon-coated copper grids and images recorded after drying for $4 \mathrm{~h}$ at $37^{\circ} \mathrm{C}$. The images were treated with Image J.

\subsubsection{THERMAL TURBIDIMETRY}

Turbidity profiles were obtained for each of the $E L R_{B C}$ and $A R G_{8} E L R_{B C}$ by recording the optical density at $360 \mathrm{~nm}$ as a function of temperature $\left(1^{\circ} \mathrm{C} / \mathrm{min}\right.$ ramp) in an UV-vis spectrophotometer equipped with a multicell thermoelectric temperature controller (Cary 300 Bio). Samples were measured in ultrapure water at three different solution concentrations of 20,25 and $50 \mu \mathrm{M}$.

\subsubsection{GOLD-NANOPARTICLES FUNCTIONALIZATION}

ELR polyplexes were formed as described (3.2.6.1.) at a 50/1/4 N/P/Papt ratio, in this case the 5'thiol-modified 5TR1 aptamer was complexed with the polyplex and incubated for $30 \mathrm{~min}$ at room temperature. Gold nanoparticles (Sigma Aldrich) were mixed with the polyplex solution to a final concentration of $5 \mathrm{nM}$ and incubated for 5 min at room temperature.

\subsubsection{APTAMER FUNCTIONALIZATION BY CLICK CHEMISTRY}

1.1 equiv. of 5TR1-Azide or Cy5.5-5TR1-Azide $(10 \mathrm{mg} / \mathrm{mL})$ was mixed with 1 equiv. of VOK-PEG-cyclooctyne $(10 \mathrm{mg} / \mathrm{mL})$ previously dissolved in ultrapure water. The 
mixture was left at $4^{\circ} \mathrm{C}$ for $48 \mathrm{~h}$, after this time the product was dialyzed against ultrapure water for $24 \mathrm{~h}$ at $4^{\circ} \mathrm{C}$, after 5 changes of water the biopolymer was lyophilized. The incorporation of 5TR1 aptamer by cycloadition of azide and activated cyclooctyne was corroborated with flow cytometry and quantified by spectrophotometry measuring the absorbance $(260 \mathrm{~nm})$. The quantification of the functionalized aptamer allowed the adjustment to 50/1/4 (N/P/Papt) ratio by the addition of fresh and free ELR.

\subsubsection{RETARDATION ASSAY}

VOK-PEG-5TR1 was dissolved in ultrapure water at $1 \mathrm{mg} / \mathrm{mL}$ in presence of $10 \%$ of SDS and loaded into a 3\% metaphor gel and electrophoresis was carried out in 1XTAE buffer at $60 \mathrm{mV}$ for $120 \mathrm{~min}$, staining with SimplySafe ${ }^{\mathrm{TM}}$ (EURx, Poland).5TR1 aptamer was used as control. The conjugated oligonucleotide was visualized by exposure to UV light in a transilluminator (Vilber,).

\subsubsection{ABSORBANCE}

ELR-PEG-5TR1 was dissolved in ultrapure water at $1 \mathrm{mg} / \mathrm{mL}$ and Absorbance at 260 nm was measured using the Nanodrop 2000 (Thermo Scientific) in order to quantify the amount of aptamer bound to VOK-PEG. Taking into account that for DNA $1 \mathrm{AU}=50 \mu \mathrm{g} / \mathrm{mL}$, Concentration of DNA was calculated as followed:

$$
[D N A]=A_{260} \times 50 \times 10^{-3} \times d
$$

( $\mathrm{A}_{260}$ the absorbance at $260 \mathrm{~nm}$ and $\mathrm{d}$ the dilution factor).

\subsubsection{FLOW CITOMETRY}

Polyplexes of ELR-PEG-5TR1-Cy5.5-pDNA were formed at 50/1/4 ratio in aqueous solution. After that, incorporation of 5TR1-Cy5.5 aptamer was evaluated using a Gallios flow cytometer (Beckman Coulter). Side scatter outcome was set to logarithmic. A flow rate of 75.000 events/s were recorded and a total of 100.000 events in each measurement. The data analysis was performed with Flowing Software.

\subsubsection{CONJUGATION OF ELRBCS WITH ALEXA FLUOR 488}

Both $E L R_{B C}$ and $\operatorname{Arg}_{8} E L R_{B C}$ were fluorescently labeled with Alexa Fluor 488 by the cysteine amino acid located at $\mathrm{N}$-t in the hydrophobic block via maleimide chemistry. 
For that, $200 \mu \mathrm{M}$ of purified ELRs was reacted with $500 \mu \mathrm{M}$ of Alexa Fluor 488 C5maleimide (Invitrogen) in 10\% of DMSO, $3 \mu \mathrm{M} \mathrm{TCEP}-\mathrm{HCl}, 10 \mu \mathrm{M} \mathrm{Na}_{2} \mathrm{HPO}_{4}$ at pH 7.The mixture was stirred overnight in dark conditions.

After that time, ELRBCs were collected from the reaction solution by the addition of $\mathrm{NaCl}$ to induce ELR coacervation, and centrifugation for 10 min at 14,000 RPM to collect aggregated ELR. Free fluorophore in the supernatant was discarded and the ELR pellet was resuspended in PBS. Resuspended ELR was passed through a PD-10 desalting column (GE Healthcare, USA) to remove remaining free fluorophore. ELR labeled concentration and labeling efficiency was determined by absorbance at 494 $\mathrm{nm}$ (Alexa 488 peak), and at the $280 \mathrm{~nm}$ (protein peak).

$$
\text { ELR labeled concentration }=\frac{\mathrm{A} 280-0.11 \times \mathrm{A} 494}{\epsilon}
$$

Where $\varepsilon$ is $=5.62 \times 10^{3}(\varepsilon) \mathrm{cm}^{-1} \mathrm{M}^{-1}$

$$
\text { Degree of labeling }=\frac{\mathrm{A} 494}{\mathrm{MW}(\mathrm{Da}) \times \mathrm{ELR} \text { labeled concentration }}
$$

\subsubsection{BIOCOMPATIBILITY ASSAYS}

\subsubsection{HAEMOCOMPATIBILITY STUDIES}

Haemocompatibility studies were performed with blood from non-medicated healthy human donors and collected in tubes containing 3.8\% sodium citrate at a 9:1 (blood:anticoagulant) ratio. IK120, IMID-IK120, IK120CPP and LAELIK120CPP polymers were dissolved in $0.9 \% \mathrm{NaCl}$ at a concentration of $1 \mathrm{mg} / \mathrm{mL}$. For each assay, $100 \mu \mathrm{g}$ of ELR was required.

\subsection{RED BLOOD CELL (RBC) AGGREGATION}

After centrifugation of the anticoagulated blood at $700 \mathrm{rpm}$ for $10 \mathrm{~min}$, the plasma and red blood cell fraction were separated. The RBC fraction was diluted in $0.1 \mathrm{M}$ PBS pH 7.4 (8:1). $100 \mu \mathrm{L}$ of red blood cells was incubated for 30 min with $100 \mu \mathrm{L}$ of ELR solution or PEI $(1 \mathrm{mg} / \mathrm{mL})$. PEI $25 \mathrm{KDa}$ was used as positive control and $0.9 \% \mathrm{NaCl}$ as negative control. 


\subsection{WHITE BLOOD CELL (WBC) AND PLATELET BLOOD CELL (PBC)} AGGREGATION

For separation of WBC and platelets, blood was layered over an equal amount of Histopaque 1077 (Sigma Aldrich) in clean glass tubes. Centrifugation was carried out at $800 \mathrm{rpm}$ for $15 \mathrm{~min}$ to obtain the upper yellow (platelet blood cells) and middle white blood cells. White blood and platelet cells were incubated with $100 \mu \mathrm{g}$ of ELR or PEl for 30 min.

The aggregation results were observed under a Leica DF295 microscope.

\subsubsection{STABILITY ASSAY}

A solution of IK120, IMID-IK120, IK120CPP and LAELIK120CPP $100 \mu \mathrm{L}$ of ELR or PEI $(1 \mathrm{mg} / \mathrm{mL})$ in $0.9 \% \mathrm{NaCl}$ was mixed with $20 \mu \mathrm{L}$ of storage plasma and incubated for 30 min. After that, centrifugation was carried out at 10,000 rpm for $8 \mathrm{~min}$. The pattern of desorbed proteins was analyzed by SDS-PAGE. Samples were loaded in a 7\% of polyacrilamide gel at $100 \mathrm{mV}$ for 90 min using Mini-Protean II electrophoresis system (Bio-Rad, USA). $15 \mu \mathrm{L}$ from the centrifugated sample $+5 \mu \mathrm{L}$ of loading buffer was loaded. The gel was stained with coomassie blue and visualized using Multilmage TM Light Cabinet (Alpha Innotech Corporation, USA). PEI was used as positive control and untreated plasma as negative.

\subsubsection{IN VITRO CELL CULTURE ASSAYS}

\subsubsection{CELL CULTURE}

In vitro and transfection experiments were performed using a pool of tumoral and primary cells. Amongst tumoral, glioma cell line from rat (C6) were seeded in culture flasks with DMEM medium in $10 \%$ FBS supplemented with $100 \mathrm{U} \cdot \mathrm{mL}^{-1}$ penicillin and $0.1 \mathrm{mg} \cdot \mathrm{mL}^{-1}$ streptomycin. MUC1 over-expressing Human breast cancer (MCF-7) and MUC1-lacking liver hepatocellular carcinoma (HepG2) cell lines were maintained in EMEM supplemented with $10 \%$ FBS, $2 \mathrm{mM}$ of glutamine, $1 \%$ of non-essential aminoacids (NEAA) and $100 \mathrm{U} \cdot \mathrm{mL}^{-1}$ penicillin, $0.1 \mathrm{mg} \cdot \mathrm{mL}^{-1}$ streptomycin. An additional MUC1 over-expressing Human breast cancer cell line (SKBR3) was grown in McCoy's 5A medium supplemented with $10 \%$ FBS and $100 \mathrm{U} \cdot \mathrm{mL}^{-1}$ penicillin, 0.1 $\mathrm{mg} \cdot \mathrm{mL}^{-1}$ streptomycin. All tumoral cells were incubated at $37^{\circ} \mathrm{C}$ under $5 \% \mathrm{CO}_{2}$ and 
their medium was replaced every two or three days. Primary cells such as Human mesenchymal stem cells (hMSC) and human fibroblasts (HFF-1) were cultured in DMEM supplemented with $100 \mathrm{U} \cdot \mathrm{mL}^{-1}$ penicillin, $0.1 \mathrm{mg} \cdot \mathrm{mL}^{-1}$ streptomycin and $10 \%$ or $15 \%$ FBS, respectively. Human umbilical vein endothelial cells (HUVEC) were grown in complete endothelial growth medium. Cells were incubated at $37^{\circ} \mathrm{C}$ under $5 \% \mathrm{CO}_{2}$ and their medium was replaced every two days. Hypopharyngeal squamous carcinoma cells (FaDu) were grown in Eagle's Minimum Essential Medium supplemented with $10 \%$ de FBS, $2 \mathrm{mM}$ Glutamine, $1 \mathrm{mM}$ sodium piruvate, $0.1 \mathrm{mM}$ NEAA, $1 \%$ of penicilin-streptomycin. FaDu cells were incubated at $37{ }^{\circ} \mathrm{C}$ under $5 \%$ $\mathrm{CO}_{2}$ and their medium was replaced every two days.

\subsubsection{EFFECT OF THE ELRS AND POLYPLEXES COATED WITH APTAMERS ON CELL}

\section{VIABILITY}

\subsection{IN VITRO VIABILITY ASSAY OF ELRS}

The cell viability of IK120-based ELRs was evaluated using the Alamar Blue and Live/Dead assays on C6 cells. Cells were seeded on 96-well plates at 5000 cells $/ \mathrm{cm}^{2}$ in $100 \mu \mathrm{L}$ DMEM medium with $10 \%$ FBS for $24 \mathrm{~h}$. After that time, the medium was discarded and cells were incubated for $24 \mathrm{~h}$ with $5 \mu \mathrm{L}$ ELR dissolved at different concentrations and made up to $100 \mu \mathrm{L}$ with FBS-free medium. For the Alamar Blue assay, the polymers were removed after $24 \mathrm{~h}$ and $100 \mu \mathrm{L}$ Alamar Blue solution was added to each well to a final concentration of $1 \%$. PEl at $20 \mu \mathrm{g} / \mathrm{mL}$ was used as reference polymer. Thus, the culture was incubated in 10\% Alamar Blue solution in minimum medium for $4 \mathrm{~h}$ at $37{ }^{\circ} \mathrm{C}$ and under a $5 \% \quad \mathrm{CO}_{2}$ atmosphere. Subsequently, $80 \mu \mathrm{L}$ of the reduced medium was transferred to a 96-well plate. Untreated cells were considered to represent the $100 \%$ of cell viability. The fluorescence intensity (F.I.) of test samples and controls was measured at an emission wavelength of $590 \mathrm{~nm}$ after excitation at $560 \mathrm{~nm}$ using a SpectraMax M2 microplate reader (Molecular Devices). Cell viability was calculated as:

$$
\% \text { Cell viability }=100 x \text { (F.I. Treated cells/ F.I. Untreated cells) }
$$

For this assay, three independent experiments with three repetitions per condition were analyzed in order to give a mean \pm standard error (SE). 
For the Live/Dead assay, after removing the polymers, $50 \mu \mathrm{L}$ each of a solution of calcein $\mathrm{AM}$ and ethidium homodimer-1 were added to each well at a final concentration of $2 \mu \mathrm{M}$ and $4 \mu \mathrm{M}$ in D-PBS, respectively. The plate was then incubated in the dark at room temperature for $30 \mathrm{~min}$ and visualized under a fluorescence microscope (Nikon eclipse Ti-SR).

\subsection{IN VITROVIABILITY ASSAY OF POLYPLEXES COATED WITH APTAMERS}

MCF-7 and HepG2 cells were plated at $3 \times 10^{4}$ cells per $\mathrm{cm}^{2}$ and incubated overnight. Afterwards, both cell lines were incubated with the ELR-pDNA polyplexes formed with $0.5 \mu \mathrm{g}$ pCMV-Gaussia Luciferase plasmid at different ratios and $1 \mu \mathrm{g} \mathrm{PEl}$, used as reference polymer, under the same conditions for $5 \mathrm{~h}$ in FBS-free culture medium. After this time, the medium was replaced with a medium supplemented with $10 \%$ FBS and the cells incubated for a further $43 \mathrm{~h}$ at $37^{\circ} \mathrm{C}$. The relative number of metabolically active cells was evaluated using the Alamar Blue assay according to the manufacturer's guidelines as showed in the previous section. For this assay, three independent experiments with three repetitions per condition were analyzed in order to give a mean \pm standard deviation (SD).

3.2.11.2.3. IN VITRO VIABILITY ASSAY OF POLYPLEXES FUNCTIONALIZED WITH APTAMERS

MCF-7 cells were plated at $3 \times 10^{4}$ cells per $\mathrm{cm}^{2}$ and incubated overnight. Afterwards, they were incubated with the ELR-PEG-5TR1-pDNA polyplexes formed with $0.5 \mu \mathrm{g}$ pCMV-Gaussia Luciferase plasmid at 50/1/4 (N/P/Papt) ratio and $1 \mu \mathrm{L}$ of Turbofect, used as reference polymer, under the same conditions for $5 \mathrm{~h}$ in FBS-free culture medium. After this time, the medium was replaced with a medium supplemented with $10 \% \mathrm{FBS}$ and the cells incubated for a further $43 \mathrm{~h}$ at $37^{\circ} \mathrm{C}$. Cells were visualized by contrast phase using Leica SP5 confocal microscope (Leica Microsystems). 


\subsubsection{TRANSFECTION ASSAYS}

\subsubsection{POLYPLEX CELL UPTAKE}

\subsection{CONFOCAL MICROSCOPY OF POLYPLEXES FORMED BY ELRS WITH}

ACQUIRED FUNCTIONALITIES

A total of $1 \times 10^{4} \mathrm{C} 6$ cells per well were seeded onto four-well plates and allowed to grow overnight at $37{ }^{\circ} \mathrm{C}$ under $5 \% \mathrm{CO}_{2}$. p53 plasmid was tagged with YOYO-1 lodide by incubation for 1 hour in the dark. ELR/pDNA nanocomplexes were prepared at a $\mathrm{w} / \mathrm{w}$ ratio of $80 / 1$ and the cells incubated for $3 \mathrm{~h}$ with these complexes. Nuclear staining was performed using Hoechst by incubation at $37{ }^{\circ} \mathrm{C}$ under $5 \% \mathrm{CO}_{2}$ for 30 min. The cells were then washed with PBS and visualized under the fluorescence microscope.

\subsection{CONFOCAL MICROSCOPY OF POLYPLEXES COATED WITH APTAMERS}

MCF-7 were seeded at $3 \times 10^{5}$ cells per well onto six-well plates and left to grow at 37 ${ }^{\circ} \mathrm{C}, 5 \% \mathrm{CO}_{2}$ overnight. Subsequently, cells were incubated with the polyplexes containing fluorescein-labelled pCMVGaussia luciferase (purified using LabellT ${ }^{\circledR}$ Tracker $^{\mathrm{TM}}$, Mirus Bio LLC) and the 5TR1 aptamer (N/P/Papt 50/1/4) in serum-free medium for $3 \mathrm{~h}$. After this time the medium was replaced and washed with D-PBS $1 \mathrm{x}$ twice, fixed with $4 \%$ paraformaldehyde and washed again with D-PBS 1X. An additional treatment with trypan blue was performed for the Z-series in order to visualize the internalized labelled polyplexes. Internalization of the polyplex-aptamer into cells was analysed using a Leica SP5 confocal microscope (Leica Microsystems). Z-series were performed with a Z-step of $0.45 \mu \mathrm{m}$. Fluorescein fluorophore and phase-contrast images were overlaid to obtain a multilayer image using ImageJ.

Additionally, counterstaining of nucleus with $300 \mathrm{nM}$ of DAPI was performed and a zstack composed by 4 images with a $\mathrm{z}$ focal difference of $0.2 \mu \mathrm{m}$ was performed. Further orthogonal projection of $z-y$ planes showing the pDNA nuclear collocation was accomplished. Bright-field and fluorescence microscopy z-series were performed using a NIKON Eclipse Ti fluorescence microscope equipped with a digital camera system (Digital sight DS-2MBWc, Nikon). 


\subsection{FLOW CYTOMETRY TO VISUALIZE POLYPLEXES COATED WITH APTAMERS}

\section{UPTAKE}

The same protocol from the previous section was applied. But once that cells were incubated with polyplexes, the medium was replaced and cells were harvested with $0.05 \%$ trypsin-EDTA, washed with D-PBS $1 \mathrm{x}$ twice, fixed with $4 \%$ paraformaldehyde and washed again with D-PBS $1 \mathrm{x}$. Flow cytometry analysis was performed to assess the fluorescein-labeled polyplexes internalized in cells cells using Gallios flow cytometer.

\subsubsection{2. $\mathrm{ARG}_{8}-\mathrm{ELR}_{\mathrm{BC}}$ UPTAKE}

\subsection{INTERNALIZATION KINETICS BY FLOW CYTOMETRY}

FaDu cells were seeded at $10 \times 10^{4}$ cells per well in 24-well tissue culture plates. After $24 \mathrm{~h}$ the media was removed and replaced with minimum media containing $20 \mu \mathrm{M}$ of 20\% Alexa Fluor 488-labeled ELR $R_{B C s}$ at different time points of 0.5, 1.5, 2.5, 5.3 and 8 h. After that, cells were washed once with PBS, removed from the culture surface with 0.05\% trypsin/EDTA, fixed with $4 \%$ of paraformaldehyde before analysis on a BD ${ }^{\mathrm{TM}}$ LSR II S9 flow cytometer. Cells were gated on the live population by forward and side scatter and no less than 10,000 cells were evaluated to determine cellular uptake by measure of mean cellular fluorescence.

\subsection{INTRACELLULAR DISTRIBUTION BY CONFOCAL MICROSCOPY}

FaDu cells were seeded at $5 \times 10^{4}$ cells per tissue plate (microscope special plate of 1 $\mathrm{cm}^{2}$ ). After $24 \mathrm{~h}$ the media was removed and replaced with minimum media containing $20 \mu \mathrm{M}$ the $\mathrm{Arg}_{8}-\mathrm{ELR}_{\mathrm{BC}}$ or ELR $\mathrm{BC}_{\mathrm{BC}}$ for $1 \mathrm{~h}, 3 \mathrm{~h}$ and $6 \mathrm{~h}$ in minimum media. $1 \mathrm{~h}$ and $30 \mathrm{~min}$ before visualization 1xLysosensor Yellow/Blue DND-160 1x (Invitrogen) was added. Cells were washed with PBS and visualizing using confocal Spinning disk (Andor XD revolution spinning disk). After acquisition images were treated with Image $\mathrm{J}$ and MatLab in order to plot Alexa488 labeled ELR intensity as function of $\mathrm{pH}$. For heparinase treatment, FaDu cells were treated with $2 \mathrm{U} / \mathrm{ml}$ of heparinase III (Sigma Aldrich) for 30 min in minumum media. After this time, media was replaced by fresh one containing the $\mathrm{Arg}_{8}-\mathrm{ELR}_{\mathrm{BC}}$ and protocol continued as previously explained. The percentage of inhibition was calculated as:

$\%$ inhibition $=100 x$ (F.I. Treated cells/ F.I. Untreated cells) 


\subsection{TRANSFECTION OF PAK1 siRNA AND EXPRESSION EVALUATION BY}

WESTERN BLOT

FaDu cells were seeded at $2,5 \times 10^{4}$ cells per well in 6 well plates. After $24 \mathrm{~h}$ media was removed and cells were incubated with lipoplexes formed by 200 pmol of siRNAPAK 1 and $5 \mu \mathrm{l}$ of Lipofectamine ${ }^{\circledR} \mathrm{LTX}$ for $6 \mathrm{~h}$. After that media was replaced by freshly one containing FBS and cells were incubated for $24 \mathrm{~h}$. After that, cells were trypsinazed, centrifuged and lysed. Concentration of protein was calculated using Pierce BCA method and Western Blot was done using the Trans Blot turbo from Biorad and GADPH enzyme (gliceraldehide 3 phosphate deshidrogenase) as control. The membrane was incubated with the primary antibody (anti-PAK1) overnight at $4^{\circ} \mathrm{C}$ and afterwards with the secondary anti-rabbit Fab2 Alexa Fluor 647 (cell signalling) (1:500) after $1 \mathrm{~h}$ in dark.

\subsection{VISUALIZATION OF INTRACELLULAR DISTRIBUTION BY TIRF}

Total Internal Reflection Fluorescence microscope (TIRF) allows the visualization of the contact area between the cell and tissue plate, at a depth of less than $200 \mathrm{~nm}$. When comparing epifluorescence and TIRF some differences are found (Figure 3.9). In epifluorescence the incident fluorescent beam travels through the cover slip and the entire sample interface. In this case all the fluorophores in the specimen sample are strongly excited. In TIRF, the beam of light indices at angle $\theta$ greater than the critical angle represented in Figure 3.9B in dashed lines and it is reflected off the cover slip-sample interface. An evanescent wave is produced on the opposite side of the interface with an intensity that falls off exponentially with distance from the interface. Only the fluorophores located in the evanescence wave are exited (green color). It is important to note that the refractive index of the sample $\left(n_{1}\right)$ must be less than the index of refraction of the cover slip $\left(n_{2}\right)$.

For TIRF visualization, untreated cells incubated with both ELRBC and $A R G_{8}-E L R_{B C}$ for 30 minutes, and treated cells with inhibitors (heparinase and siPAK1) and incubated with $A R G_{8}-E L R_{B C}$ for 30 min as well previously to visualization. Then cells were washed once with PBS and visualized with the fluorescence microscope Leica AM TIRF MC. 

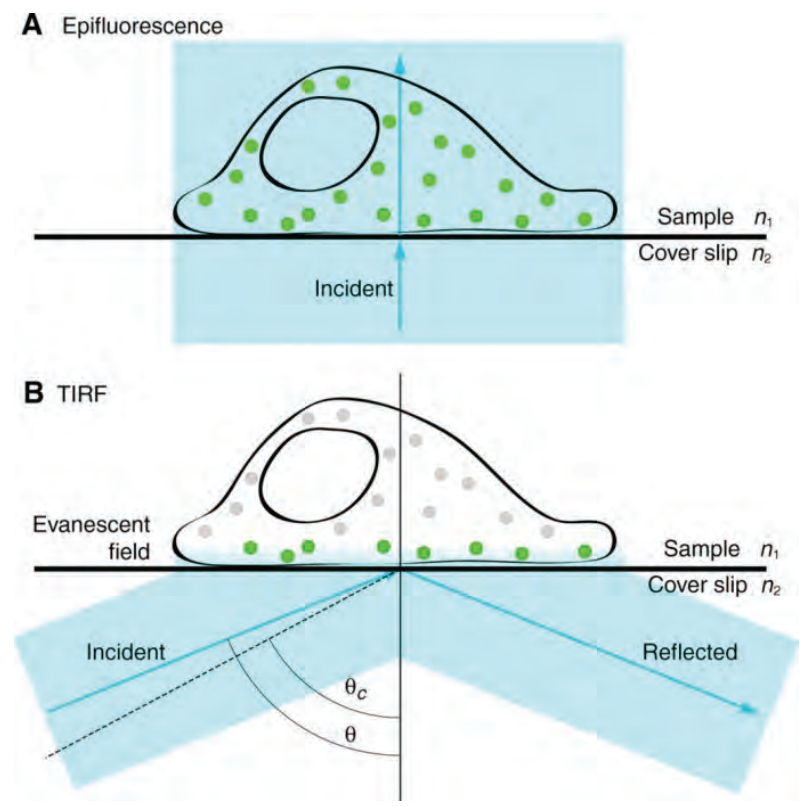

Figure 3.9. Scheme illustrating the cover-slip-sample interface differences between an epifluorescence (A) and TIRF microscope (B) (322).

\subsubsection{LUCIFERASE EXPRESSION}

A total of $3.5 \times 10^{4}$ cells per $\mathrm{cm}^{2}$ of $C 6$ cells, $3 \times 10^{4}$ cells per $\mathrm{cm}^{2}$ of MCF-7, SKBR3 or HepG2 and $1 \cdot 10^{4}$ cells per $\mathrm{cm}^{2}$ of HFF-1, in order to have the same level of cellular confluent (50-60\%), were seeded onto 96-well plates and grown at $37{ }^{\circ} \mathrm{C}, 5 \% \mathrm{CO}_{2}$ overnight.

\subsection{LUCIFERASE ASSAY MEDIATED BY POLYPLEXES FORMED BY ELRS WITH}

\section{ACQUIRED FUNCTIONALITIES}

C6 cells were incubated in a serum-free medium for $5 \mathrm{~h}$ in the presence of the polyplexes formed by ELR-pRNA-Luc/Neo at 80/1 ELR/pDNA w/w ratio. The medium was then replaced by fresh serum-containing medium and cells were cultured for 43 $\mathrm{h}$ more. At this point, the cells were lysed with $100 \mu \mathrm{L}$ Glo lysis buffer (Promega). The Bright Glo luciferase assay system (Promega) was added in a 1:1 proportion of lysate and luciferase reagent. The light produced was measured using a luminometer (SpectraMax L, Molecular Devices). The protein content of the lysate was determined by a Bradford assay using a microplate reader. Luciferase expression was given as relative light units (RLU) per $\mu \mathrm{g}$ of total protein. For this assay, three independent experiments with three repetitions per condition were analyzed in order to give a mean \pm standard error (SE). 


\subsection{LUCIFERASE ASSAY MEDIATED BY POLYPLEXES COATED WITH APTAMERS}

MCF-7 and HepG2 cells were incubated in a serum-free medium for $5 \mathrm{~h}$ in presence of polyplexes formed by ELR-pCMV Gaussia luciferase at specific N/P ratios with gradually increasing Papt ratio for both S2.2 and 5TR1 aptamers. The medium was then replaced by fresh serum-containing medium and the cells cultured for a further 43 h. $1 \mu \mathrm{g}$ of PEI, $3 \mu \mathrm{l}$ of Lipofectamine ${ }^{\circledR}$ LTX or $1 \mu \mathrm{L}$ of Turbofect to complex the pDNA were used as positive controls. Additional transfection experiments with the cells pre-incubated with 50:1 anti-MUC1 for $1 \mathrm{~h}$ at $37^{\circ} \mathrm{C}$ and experiments with incubation of polyplexes in presence of $10 \%$ of serum enriched medium for $5 \mathrm{~h}$, replaced by fresh one and cultured for a total of $48 \mathrm{~h}$ were accomplished. At this poin,t a $20 \mu \mathrm{L}$ aliquot was removed from the culture medium and mixed with the luciferase substrate. The light produced was measured using a SpectraMax L luminometer. The protein content of the lysate was determined by a Bradford assay using a microplate reader (SpectraMax M2 microplate reader, Molecular Devices). Luciferase expression was given as relative light units (RLU) per mg total protein. For this assay, three independent experiments with three repetitions per condition were analyzed in order to give a mean \pm standard error (SE).

\subsection{LUCIFERASE ASSAY MEDIATED BY POLYPLEXES FUNCTIONALIZED WITH} APTAMERS

MCF-7, SKBR3, HepG2 and HFF-1 cells were incubated in a serum-free medium for 5 $h$ in the presence of the polyplexes formed by VOK-PEG-5TR1-pCMVGaussia luciferase or VOK-PEG-5TR1-pDrive5Lucia-hMUC1 at the specific 50/1/4 N/P/Papt ratio. The medium was then replaced by fresh serum-containing medium and the cells cultured for a further 43 h. $1 \mu \mathrm{l}$ of Turbofect and the nude plasmid DNA was used as control. At this point the luminiscence measurement was performed as described in the previous section 3.2.12.3.2. For this assay, three independent experiments with three or four repetitions per condition were analyzed in order to give a mean \pm standard error (SE). 


\subsubsection{ASSESMENT OF INTERNALIZATION PATHWAY FOR POLYPLEXES COATED} WITH APTAMERS

The same protocol as (3.2.12.3.2.) was applied for MCF-7 cells pre-treated with $25 \mu \mathrm{M}$ of chloroquine, $1 \mu \mathrm{g} \mathrm{mL}^{-1}$ of filipin, $5 \mathrm{\mu g} \mathrm{mL}^{-1}$ of amiloride and $100 \mu \mathrm{M}$ of monodansylcadaverine in media without serum for $30 \mathrm{~min}$. After inhibitors treatment, media was replaced by fresh one containing polyplexes and incubated for $5 \mathrm{~h}$. After $48 \mathrm{~h}$ in total, luminescence was measured.

\subsubsection{5. p53 EXPRESSION}

\subsection{POLYPLEXES FORMED BY ELRS WITH ACQUIRED FUNCTIONALITIES}

C6 cells were seeded into four-well plates in a quantity of $1 \times 10^{4}$ per well and allowed to grow at $37{ }^{\circ} \mathrm{C}$ under $5 \% \mathrm{CO}_{2}$ overnight. Polyplexes formed by ELRs with functional motifs and pCMV-p53 plasmid at two different ELR/pDNA w/w ratios (80/1 and 120/1). Cells were incubated with the polyplexes at $37^{\circ} \mathrm{C}$ under $5 \% \mathrm{CO}_{2}$ for $5 \mathrm{~h}$. After this time, the medium was replaced with fresh medium and cells incubated for a total of $48 \mathrm{~h}$. Before the assay, the cells were washed with PBS. Cell viability was then examined by the addition of calcein AM and ethidium homodimer- 1 reagents as part of the LIVE/DEAD assay. Samples were left in the dark at room temperature for 30 min. After this time, the reagent was discarded and PBS was added. The state of the cells was visualized using a fluorescence microscope (Leica DMI 3000 B).

\subsection{POLYPLEXES COATED WITH APTAMERS}

MCF-7, HepG2, MSC, HUVEC in a quantity of $3 \cdot 10^{4}$ per $\mathrm{cm}^{2}$ and $1 \cdot 10^{4}$ per $\mathrm{cm}^{2}$ of HFF1 cells were seeded into 6 -well plates and allowed to grow at $37{ }^{\circ} \mathrm{C}, 5 \% \mathrm{CO}_{2}$ overnight prior to the polyplex treatment. For these experiments, polyplexes ELR/pDNA (N/P 50/1) and ELR/pDNA/aptamer (N/P/Papt 50/1/4) were formed using the pCMV-p53 plasmid. Cells were incubated with the nanocomplexes at $37^{\circ} \mathrm{C}, 5 \%$ $\mathrm{CO}_{2}$ for $5 \mathrm{~h}$. After this time, the medium was replaced with fresh medium containing $10 \% \mathrm{FBS}$ and the cells incubated at $37^{\circ} \mathrm{C}, 5 \% \mathrm{CO}_{2}$ for a further $43 \mathrm{~h}$. Cell viability was analyzed by LIVE/DEAD assay as depicted in the previous paragraph. The state of the cells was also visualized using a fluorescence microscope (Nikon eclipse). 
Cell death was quantified for MCF-7, HepG2, MSC, HUVEC and HFF-1 cells using the LIVE/DEAD assay. The fluorescence intensity (F.I.) of test samples and controls was measured at an emission wavelength of $620 \mathrm{~nm}$ after excitation at $525 \mathrm{~nm}$ using a SpectraMax M2 microplate reader (Molecular Devices). Cell death plotted as mortality increment was calculated as:

\section{Mortality increment $=($ F.I. Treated cells/F.I. Untreated cells $)$}

Additionally, apoptosis and cell dead were evaluated by flow cytometry. To this end, MCF-7 and HepG2 were incubated with polyplexes at 50/1 N/P ratio alone and with the 5TR1 aptamer as described in (3.2.12.5.2.). After $48 \mathrm{~h}$, apoptosis and cell dead were evaluated using the Annexin V-FITC Apoptosis Detection Kit II. Cells were collected with trypsin-EDTA (0.05\%), washed with 1x DPBS and then marked with Annexin V-FITC and Propidium lodide. Late apoptosis and cell dead were assessed by flow cytometry (Gallios flow cytometer) and plotted together as apoptosis and dead increment with respect to each treatment. Late apoptosis and dead increment was calculated as:

Late apoptosis and dead increment $=$ (\% Late apoptosis + dead Treated cells $/ \%$ Late apoptosis + dead Untreated cells)

For this assay, three independent experiments with three repetitions per condition were analyzed in order to give a mean \pm standard deviation (SD).

\subsubsection{PAP-S EXPRESSION}

MCF-7, HepG2, MSC, HUVEC and HFF-1 cells were seeded onto 96-well plates in a quantity of $3 \cdot 10^{4}$ cells per $\mathrm{cm}^{2}$ for tumor cells and $1 \cdot 10^{4}$ cells per $\mathrm{cm}^{2}$ for primary cells, in order to maintain the same levels of confluence for all the cell lines, and allowed to grow at $37{ }^{\circ} \mathrm{C}, 5 \% \mathrm{CO}_{2}$ overnight prior to the polyplex treatment.

For these experiments, the polyplexes ELR/pDNA (N/P 50/1) and ELR/pDNA/aptamer (N/P/Papt 50/1/4) were formed using the PCMV-PAP plasmid. Cells were incubated with the nanocomplexes at $37^{\circ} \mathrm{C}, 5 \% \mathrm{CO}_{2}$ for $5 \mathrm{~h}$. After this time, the medium was replaced with fresh medium containing $10 \% \mathrm{FBS}$ and the cells incubated at $37^{\circ} \mathrm{C}, 5 \%$ $\mathrm{CO}_{2}$ for a further $43 \mathrm{~h}$. Cell dead was quantified using the LIVE/DEAD assay following 
the manufacturer's instructions and measured at an emission wavelength of $620 \mathrm{~nm}$ after excitation at $525 \mathrm{~nm}$ using a SpectraMax M2 microplate reader (Molecular Devices).

$$
\% \text { Dead cells }=100 x \text { (F.I. Treated cells/F.I. Untreated cells) }
$$

For this assay, three independent experiments with three repetitions per condition were analyzed in order to give a mean \pm standard error (SE).

\subsubsection{RICIN EXPRESSION}

MCF-7, and HFF-1 cells were seeded onto 96 -well plates in a quantity of $3 \cdot 10^{4}$ cells per $\mathrm{cm}^{2}$ and $1 \cdot 10^{4}$ cells per $\mathrm{cm}^{2}$ respectively and allowed to grow at $37{ }^{\circ} \mathrm{C}, 5 \% \mathrm{CO}_{2}$ overnight prior to the polyplex treatment.

For these experiments, polyplexes with ELR-5TR1-pDhMUC1-ricin at 50/1/4 (N/P/Papt) were formed. Cells were incubated with the nanocomplexes at $37{ }^{\circ} \mathrm{C}, 5 \%$ $\mathrm{CO}_{2}$ for $5 \mathrm{~h}$. After this time, the medium was replaced with fresh medium containing $10 \%$ or $15 \%$ FBS and the cells incubated at $37{ }^{\circ} \mathrm{C}, 5 \% \mathrm{CO}_{2}$ for a further $43 \mathrm{~h}$. Cell viability was quantified using Alamar Blue assay as shown in the section (3.2.11.2.1.). Thus, CC50 was calculated and considered as the concentration where the $50 \%$ of cell death was observed.

For this assay, three independent experiments with three repetitions per condition were analyzed in order to give a mean \pm standard error (SE).

\subsubsection{IN VIVOEXPERIMENTS}

The in vivo experimental protocols were approved by the Ethics Committee from the University of Valladolid. All the experiments were conducted in accordance with national guidelines for animal care, according with the RD 1201/2005 on protection of animals used for experimental and other scientific purposes, transposing and implementing the European Directive 86/609/CEE.

5-7 weeks old female Balb/c nude mice with a weight of about $17 \mathrm{~g}$ (Janvier Labs) were kept in an air conditioned facility with artificial light-dark regime and provided with standard food and sterile water. Mice were kept in this environment at least four days after the arrival. For (3.2.13.2.), before tumor implantation, 4 mice were randomly separated to form the viability group. The rest of the mice were implanted 
with $17 \beta$ stradiol pellets of $0.72 \mathrm{mg}$. For implantation, mice were first with Vetflurane. Pellets were implanted subcutaneously into the back. After two days, mice were subcutaneously injected with $1.0 \times 10^{6}$ MCF-7 cells suspended in $50 \mu$ l of Minimum Medium with 50 $\mathrm{\mu l}$ of Geltrex ${ }^{\mathrm{TM}}$ (Reduced Growth Factor Basement Membrane Matrix) into the right flank. Tumor size was measured almost every day. Tumor volume was calculated as follows: $0.523 \mathrm{LW}^{2}$ where $\mathrm{L}$ is the length and $\mathrm{W}$ the width of the tumor.

\subsubsection{IN VIVO ASSAYS WITH ELR-pCMVPAP-5TR1}

When tumors attained a volume of $50 \mathrm{~mm}^{3}$, mice were randomly separated in two groups ( 6 animals in each group) and the treatment started, which is considered as day 0 . Placebo group (mice with tumors but treated with $5 \%$ glucose), ELRpCMVPAP-5TR1 group (mice with tumors and treated with $20 \mu \mathrm{g}$ of therapeutic PCMVPAP plasmid). Three peritumoral injections of $20 \mu \mathrm{g}$ of polyplexes formed by pDNA at 50/1/4 ratio on days 0, 2 and 4 were performed for the ELR-pCMVPAP-5TR1 group. Tumors were measured almost every day until 23 days after the first injection.

\subsubsection{IN VIVO ASSAYS WITH VOK-PEG-5TR1-pDhMUC1-RICIN}

When tumors reached a tumor volume of $50 \mathrm{~mm}^{3}$, the mice were randomly divided into four groups with 8 mice in each one and the treatment started, which is considered as day 0 . Viability control group (mice without tumors but treated with the maximum dose of ELR-5TR1-pDhMUC1-ricin), Placebo group (mice with tumors but treated with $5 \%$ glucose), 1.7 dose group (mice with tumors and treated with 1.7 $\mathrm{nM}(0.5 \mu \mathrm{g})$ of therapeutic pDhMUC1-ricin), 17 dose group (mice with tumors and treated with $17 \mathrm{nM}(5 \mu \mathrm{g})$ of therapeutic pDhMUC1-ricin) and 70 dose group (mice with tumors and treated with $70 \mathrm{nM}(20 \mu \mathrm{g})$ of therapeutic pDhMUC1-ricin). All the treatments were administered peritumorally in a volume of $100 \mu \mathrm{L}$ on days $0,2,4,6$ and 9. Tumors were measured and mice were weighed almost every day until 23 days after the first injection. At day 23, after necropsy tumors were extracted from mice and weighed.

\subsubsection{STATISTICAL ANALYSIS}

Data were analyzed using Sigma Plot software version 11.0. 
In RLU/ug for transfection with polyplexes formed by ELRs with acquired functionalities (4C.8.3.), inter-group comparisons were performed through ANOVA using Scheffe's test, with $p$ value $<0.05$ indicating statistical significance for three independent experiments.

$\mathrm{RLU} / \mathrm{mg}$ in transfection of polyplexes with coated aptamers (4D.3.2. and 4D.3.4.) and polyplexes functionalized with aptamers (4E.4.) was analyzed using Student's t-test for pairwise comparisons. Indeed, significant differences in \% dead cells (4D.3.5.), mortality and apoptosis (4D.3.6.) was found using Student's t-test. All results with $p<0.05$ for three independent experiments were considered to be statistically significant.

In animal studies, Student's t-test was used in in vivo assays with ELR-pCMVPAP5TR1 (4D.4.) and with the VOK-PEG-5TR1-pDhMUC1-ricin (4E.6.) for tumor mass with $p<0.05$ as significant. Student Newman Keuls analysis was employed for tumor growth evolution with $p<0.001$ as very significant. 


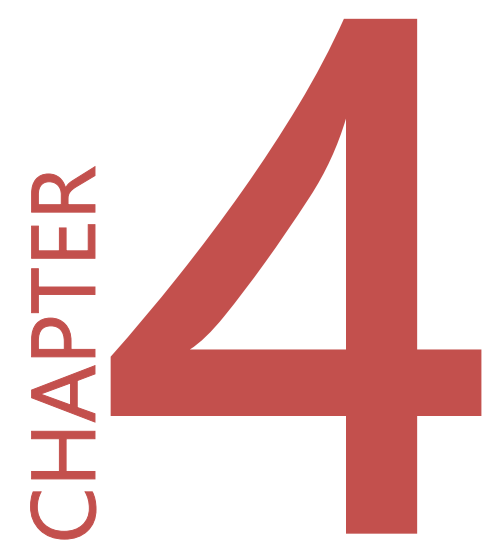




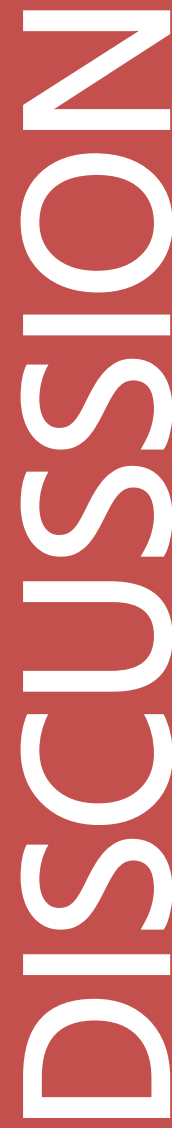

$\infty$

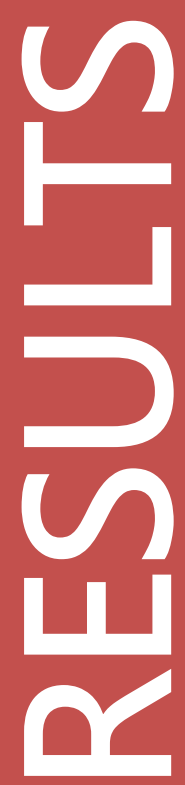




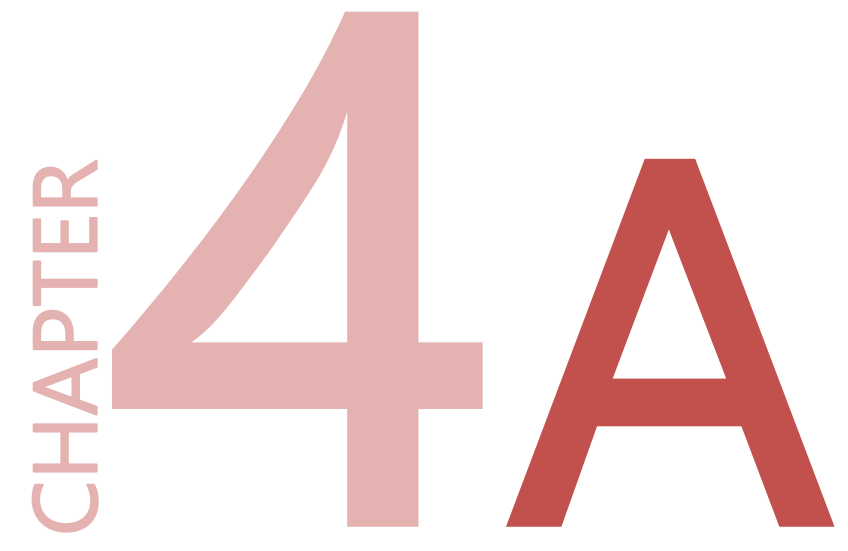




\section{DESIGN, PRODUCTION AND CHARACTERIZATION OF ELRS FOR GENE DELIVERY PURPOSES}

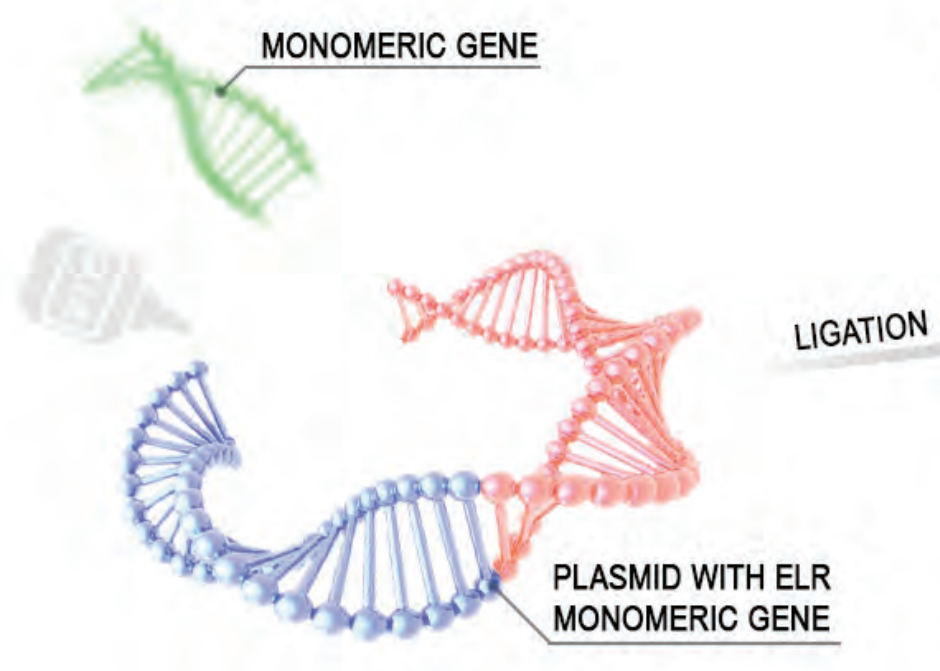

PLASMID WITH ELR
MULTIMERIC GENES 
$+2$

132 


\section{CHAPTER 4A: DESIGN, PRODUCTION AND CHARACTERIZATION OF}

\section{ELRs FOR GENE DELIVERY PURPOSES}

As exposed in the introduction chapter, cationic polymers are preferentially chosen in the design of non-viral vectors due to their ability for interacting with the negatively charged DNA by electrostatic interactions. These amino-phosphate groups interactions allow the polymer to condense the plasmid DNA and protect it from the enzymatic degradation forming what is named as "polyplex" which is then internalized by cells (90). The drawbacks concerning the use of viral vectors for gene delivery such as their immunogenicity $(77,85)$ and their difficulties in the scaling up may be solved by the use of ELRs. The biocompatibility features inherent in ELRs (65) make them candidates for the development of novel biomaterials as gene delivery vectors. The recent progress of advanced genetic-engineering techniques allows absolute control over both the architecture of ELRs and their physical and chemical features (1.1.6.).

In previous work developed by Dr. Garcia-Arevalo (323) (1.2.3.), the design of cationic ELRs with the objective of being used as non-viral gene delivered systems was accomplished. Three different ELRs named as K5V [((VPGVG) $\left.\left.{ }_{5}(\mathrm{VPGKG})_{1}\right)_{24}\right]$, 6K-K5V $\left[3 K\left((V P G V G)_{5}(V P G K G)_{1}\right)_{24} 3 \mathrm{~K}\right]$ and H8-6K-K5V [H8-3K((VPGVG) $\left.\left.)_{5}(\mathrm{VPGKG})_{1}\right)_{24} 3 \mathrm{~K}\right]$ were designed. K5V was composed by 24 lysines arranged along polymer by contrast $6 \mathrm{~K}-$ K5V was designed with two cationic oligomer blocks of three lysine each at both ends of the K5V polymer and H8-6K-K5V included a poly-histidine tail (H8) at the Nterminal end of the $6 \mathrm{~K}-\mathrm{K} 5 \mathrm{~V}$ polymer. $6 \mathrm{~K}-\mathrm{K} 5 \mathrm{~V}$ was thought to improve the condensation ability of $\mathrm{K} 5 \mathrm{~V}$ whilst the histidine tag was thought as endosomolitic domain to favor the escape from endosomes. The results showed H8-6K-K5V>6K$\mathrm{K} 5 \mathrm{~V}>\mathrm{K} 5 \mathrm{~V}$ as effectiveness order of polymers to complex DNA. In terms of transfection, these polymers showed transfection levels considerable less efficient than the selected positive controls as lipofectamine, PEI, PLL or PDMAEMA but higher that the nude DNA. Moreover, the inclusion of the three lysine at both ends of the polymer and poly-histidine tail did not improve the transfection efficiency suggesting, in the latest case that the polyplexes are not internalized by lysosomes. 
In the present work, ELR derived constructions based in the pentapeptide (VPGXG) were performed with three main goals. The first objective was to improve the buffering capacity and cell penetration of ELR by the addition of histidine $(H)$ or arginine $(R)$ amino-acids in the sequence, where the first valine and $X$ were histidine or arginine respectively (HPGX3, RPGX3 and IKx30HPGx3 constructs). Histidine contains an imidazole group which becomes protonated at endosomal $\mathrm{pH}$, favoring the buffering capacity (1.2.5.3.). In contrast, arginine residues are known to provide of cell penetrating functionality (1.2.5.2.). The notation IKx30 (VPGIG) $\left.2(\mathrm{VPGKG})(\mathrm{VPGIG})_{2}\right)_{6}$ refers to the total number of pentapeptide repetitions of the elastomeric sequence, I and $\mathrm{K}$ refer to isoleucine and lysine amino-acids respectively, present as guess residues. Additionally, the buffering capacity was introduced in the basis IK120 $\left.\left[(V P G I G)_{2}(V P G K G)(V P G I G)_{2}\right)_{24}\right]$ polymer by chemical modification with imidazole groups to construct the IMID-IK120 polymer. Thus, IK120 had been previously designed by Dr. Pierna and used as control for ELR surfaces creation in tissue engineering field $(47,311)$. The second objective was focused in the increment of DNA condensation ability and transfection by means of increasing the positive charge by incorporation of a high density of lysine amino acids (K) (VOKx48, VOKx48HPG and VOKx72 constructs). In this case, the notation VOKxn refers to the total number of pentapeptide repetitions ( $n), K$ lysine amino-acid constitutes the only guest residue and coincides with " $n$ ". And the third was to provide the polymer with functional motifs named as cell penetrating peptides (penetratin (1.2.5.2.)) and the fusogenic LAEL (1.2.5.3.) by the use of biotechnological techniques (IK120CPP, LAELIK120CPP constructs). The last IK120CPP, LAELIK120CPP polymers were also based in the mild density of lysine enriched IK120 polymer which composed by CPP and LAEL peptides were thought to improve cell internalization and endosome escape respectively.

Further chemical modification was also used to provide specificity to polymers by the linkage of 5TR1 aptamer molecules to VOKX72 giving as result the modified VOKPEG-5TR1 biopolymer.

The detailed sequences of the biosynthesized ELRs are shown below in Table 4A.1: 
Table 4A.1. Biosynthesized ELRs with their amino-acid sequence, number of histidine $(H)$, arginine $(\mathrm{R})$ or lysine $(\mathrm{K})$ amino-acids and theoretical molecular weight.

\begin{tabular}{|c|c|c|c|}
\hline Polymer & Amino-acid sequence & $\begin{array}{c}\text { Number of } \\
H / R / K\end{array}$ & $\begin{array}{l}\text { Theoretical } \\
\text { MW (KDa) }\end{array}$ \\
\hline HPGx3 & MESLLP V $\left[(\mathrm{PGHGH})_{23} \mathrm{PGVGV}\right]_{3}$ & $138 / 0 / 0$ & 35.90 \\
\hline RPG $\times 3$ & MESLLP V $\left[(P G R G R)_{23} P G V G V\right]_{3}$ & $0 / 138 / 0$ & 38.14 \\
\hline IKx30 HPGx3 & $\begin{array}{c}\text { MESLLP }\left[(\mathrm{VPGIG})_{2}(\mathrm{VPGKG})(\mathrm{VPGIG})_{2}\right]_{6} \mathrm{~V} \\
{\left[(\mathrm{PGHGH})_{23} \mathrm{PGVGV}\right]_{3}}\end{array}$ & $138 / 0 / 6$ & 48.51 \\
\hline V1K & MESLLP [(VPGKG)(VPGVG) $]_{36} \mathrm{~V}$ & $0 / 0 / 36$ & 31.31 \\
\hline VOKx48 & MESLLP $(\mathrm{VPGKG})_{48} \mathrm{~V}$ & $0 / 0 / 48$ & 21.84 \\
\hline $\begin{array}{l}\text { VOKx48 } \\
\text { HPGx1 }\end{array}$ & MESLLP $(\text { VPGKG })_{48} \vee(\mathrm{PGHGH})_{23}$ PGVGV & $46 / 0 / 48$ & 32.90 \\
\hline VOKx72 & MESLLP $(\mathrm{VPGKG})_{72} \mathrm{~V}$ & $0 / 0 / 72$ & 32.36 \\
\hline IK120CPP & $\begin{array}{c}\text { MESLLP[(VPGIG) } \\
\left(\text { VPGKG)(VPGIG) }{ }_{2}\right]_{24} \text { VRQIKIWFQNRRMKWKKV }\end{array}$ & $0 / 3 / 27$ & 54.30 \\
\hline LAELIK120CPP & $\begin{array}{c}\text { MESLLPVLAELLAELLAEL[(VPGIG) })_{2}(\mathrm{VPGKG})(\mathrm{VP} \\
\left.\text { GIG) }{ }_{2}\right]_{24} \text { VRQIKIWFQNRRMKWKKV }\end{array}$ & $0 / 3 / 27$ & 55.68 \\
\hline
\end{tabular}

\section{A.1. BIOSYNTHESIS OF ELRS}

The construction of ELR genes were accomplished in a stepwise manner using the recursive directional ligation method widely explained in the introduction chapter (1.1.6.2.). In this method, the utilization of type II endonucleases allowed the directional and consecutive ligation of the DNA fragments (28). The desired DNA fragments were introduced in the pDrive vector $(\mathrm{pDm})$ (3.1.6.3) which had been mutated deleting the endogenous restriction site for Sapl (Sapl 3845) (310) and adapting the poly-linker of pDm to the seamless iterative-recursive method to obtain multimers (1.1.6.2.).

\section{A.1.1. SYNTHESIS OF HPGX3 AND RPGx3}

The gene sequences were selected to emphasize $E$. coli preferred codons while also minimizing sequence repetition. The synthetic DNA encoding the monomer peptides (HPG and RPG) showed in Figure 4A.1 and flanked by inverted Earl recognition sites was cut by Earl. The resulted monomeric gene was ligated with T4 ligase in order to achieve 3 repetitions of either HPG or RPG genes and inserted into the previously linearized and dephosphorilated pDm plasmid with Sapl. After transformation in XL-1 
Blue Competent cells, pDNA from colonies was extracted and the restriction fragments were analyzed in agarose gel after enzymatic digestion (Figure 4A.2A and B).

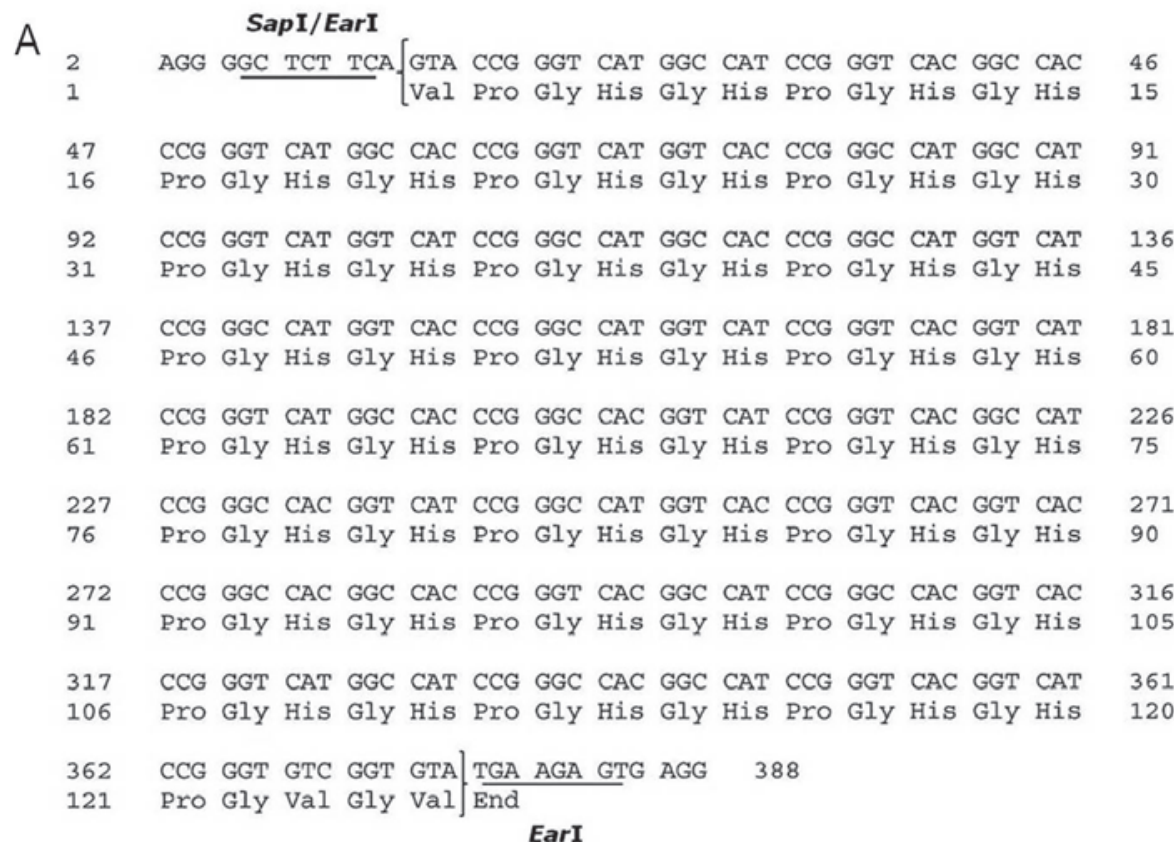

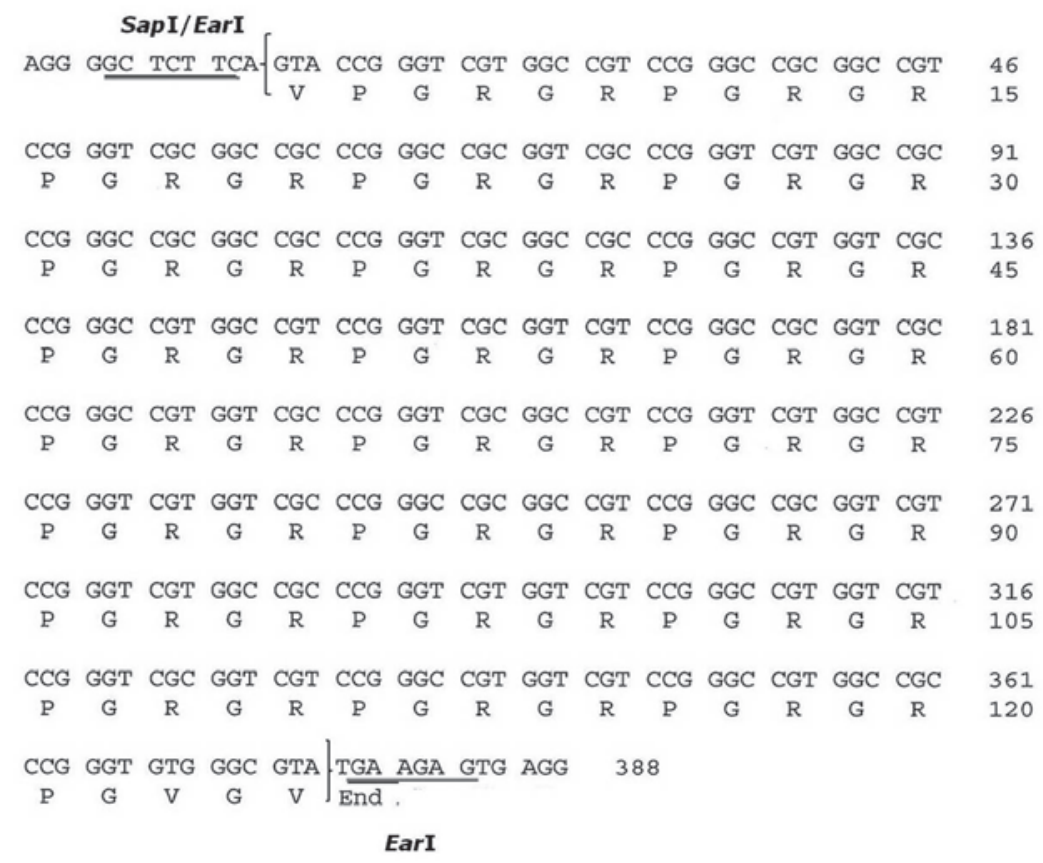

Figure 4A.1. Nucleotide and amino acid sequences of the HPG (A) and RPG (B) ELR monomer genes. The highlight region corresponds with Sapl/Earl and Eart restriction sites. 

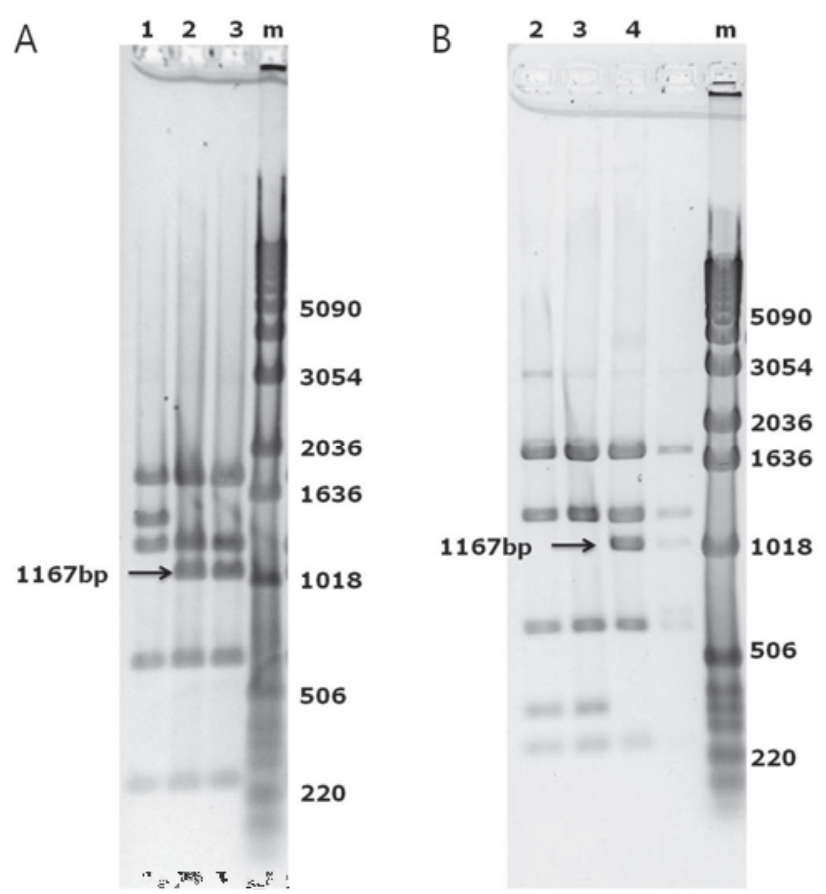

Figure 4A.2. Enzymatic analysis of the colonies containing the plasmid pDm HPGx3 (A) and RPG $\times 3$ (B) with the Earl endonucleases.

Gel A: Lanes 1, 2 and 3 are pDmHPG plasmid from 3 different colonies digested with Ear I. The enzymatic digestion releases the HPG gene, where 4 repetitions of HPG gene were found in lane 1 and 3 gene repetitions in lane 2 and 3 .

Gel B: Lanes 2, 3 and 4 are pDmRPG plasmid from 3 different colonies digested with Ear I. The enzymatic digestion releases the RPG gene, where 1 repetition of RPG gene was found in lane 2 and 3 , and 3 repetitions in lane 4.

In all cases $\mathrm{m}$ lane corresponds with $1 \mathrm{~Kb}$ marker. 1.2\% DNA agarose electrophoresis stained with SimplySafe ${ }^{T M}(2.2 .1 .1$.). The desired bands are indicated by arrows with their corresponding length.

Colonies 2 and 3 from pDmHPG and colony 4 from pDmRPG showed the expected band of $1167 \mathrm{bp}$ that confirms the presence of 3 repetitions of both genes and were selected for DNA sequencing. HPGx3 gene was cut with Earl enzyme and purified from the agarose gel using the gel extraction kit (3.1.6.6) (Figure 4A.3). 


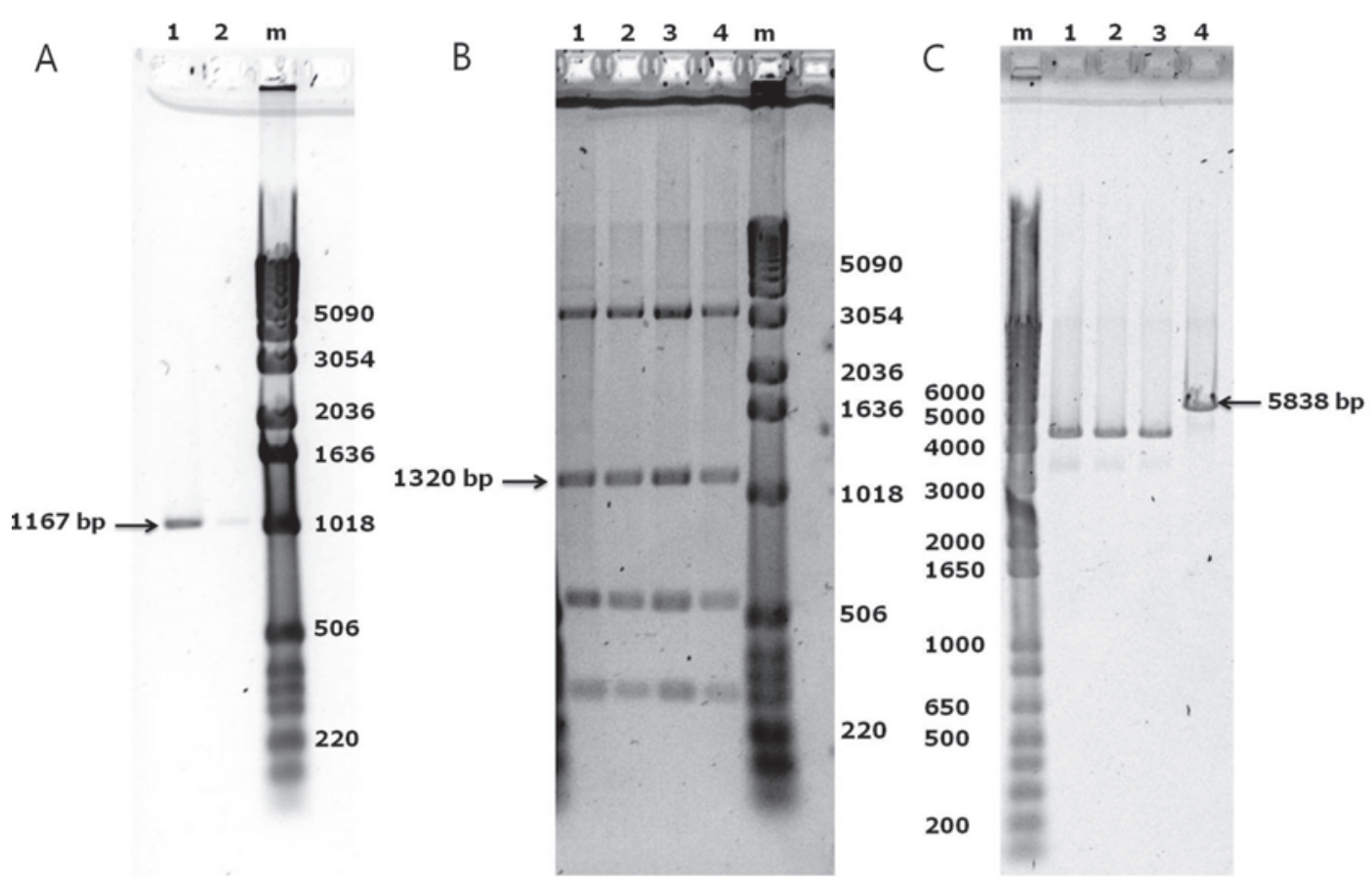

Figure 4A.3. Analysis of HPGx3 gene subcloned into expression vectors.

Gel A: Analysis of HPGx3 after agarose extraction (A) where 1 and 2 lanes are the first and second elutions.

Gel B: Enzymatic analysis of the colonies containing the plasmid p10 HPG 3 cut with Hindll and Xbal enzymes. Lanes 1 to 4 corresponds with 4 different colonies. The double digestion gave 4 fragments $(3484,1320,576,298)$ being the $1320 \mathrm{bp}$ which contains the gene.

Gel C: Enzymatic analysis of the colonies containing the plasmid p14 $\mathrm{H}_{8} \mathrm{HPG} 33$ cut with Xhol which linearized the plasmid.

In all cases $\mathrm{m}$ lane corresponds with $1 \mathrm{~Kb}$ marker. 1.2\% DNA agarose electrophoresis stained with SimplySafe ${ }^{\mathrm{TM}}(2.2 .1$.1.). The desired bands are indicated by arrows with their corresponding length.

HPGx3 gene was subcloned into $\mathrm{p} 10$ and $\mathrm{p} 14 \mathrm{H}_{8}$ expression vector (3.1.7.3.), which had been previously cut by Sapl and desphosphorilated with SAP (Shrink Alkaline Phosphatase) and Anthartic phosphatase (3.2.1.6). The incorporation of HPGx3 into expression vectors was confirmed by an analytic electrophoresis (Figure 4A.3B and C) and further DNA sequencing.

The subcloned construction of RPGx3 gene into $\mathrm{p} 10$ and $\mathrm{p} 14 \mathrm{H}_{8}$ expression vectors is shown in Figure 4A.4. The analytic gels depict the incorporation of RPGx3 gene. 


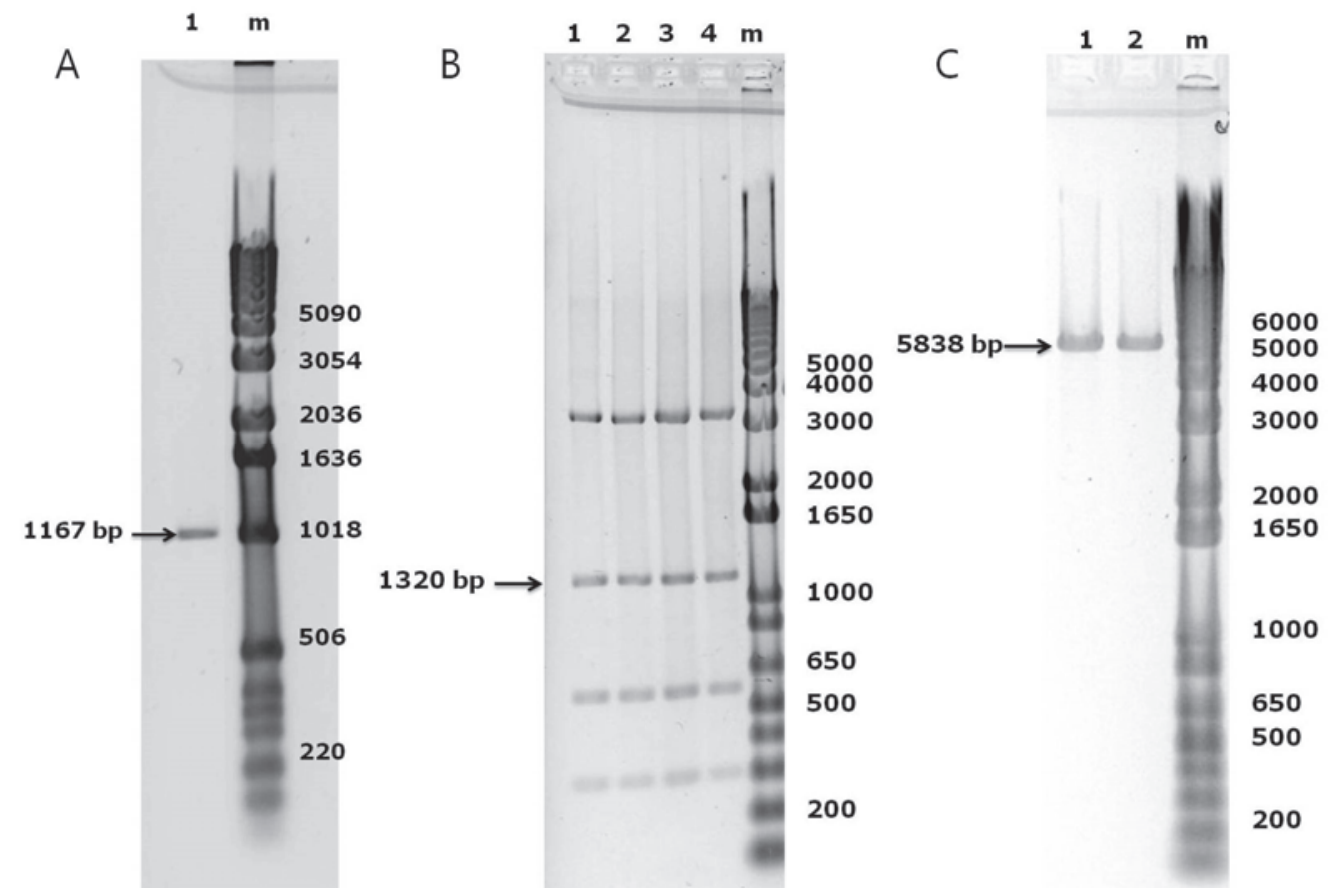

Figure 4A.4. Analysis of RPGx3 gene subcloned into expression vectors.

Gel A: Analysis of RPGx3 gene after agarose extraction where 1 lane is the first elution.

Gel B: Enzymatic analysis of the colonies containing the plasmid p10 RPGx3 cut with Hindll and Xbal enzymes. Lanes 1 to 4 corresponds with 4 different colonies. The double digestion gave 4 fragments $(3484,1320,576,298)$ being the 1320bp which contains the gene.

Gel C: Enzymatic analysis of the colonies containing the plasmid p14 RPG 3 cut with Xhol which linearized the plasmid.

In all cases $\mathrm{m}$ lane corresponds with $1 \mathrm{~Kb}$ marker. 1.2\% DNA agarose electrophoresis stained with SimplySafe ${ }^{T M}(2.2 .1 .1$.$) . The desired bands are indicated by arrows with$ their corresponding length.

The theoretical aminoacid sequence, for both HPGX3 and RPG $\times 3$, after subcloning into $\mathrm{p} 10$ and $\mathrm{p} 14 \mathrm{H}_{8}$ expression vectors was:

p10 HPGX3: MESLLP V [(PGHGH) $)_{23}$ PGVGV $]_{3}$

p14H ${ }_{8}$ HPG $3:$ MGSSH ${ }_{8}$ GLVPRGSHMESLLPV $\left[(P G H G H)_{23} \text { PGVGV }\right]_{3}$

p10 RPGX3: MESLLP V [(PGRGR $)_{23}$ PGVGV $]_{3}$

p14H ${ }_{8}$ RPG 3 : MGSSH ${ }_{8}$ GLVPRGSHMESLLPV [(PGRGR $)_{23}$ PGVGV] $]_{3}$ 


\section{A.1.1.1. EXPRESSION OF HPGX3 AND RPGX3}

Expression vectors containing HPGX3 and RPGx3 genes were transformed into BL21 Star (DE3) E.coli strain (3.2.2.3). A screening of the colonies grown in auto-induction TB medium was performed (Figure 4A.5).
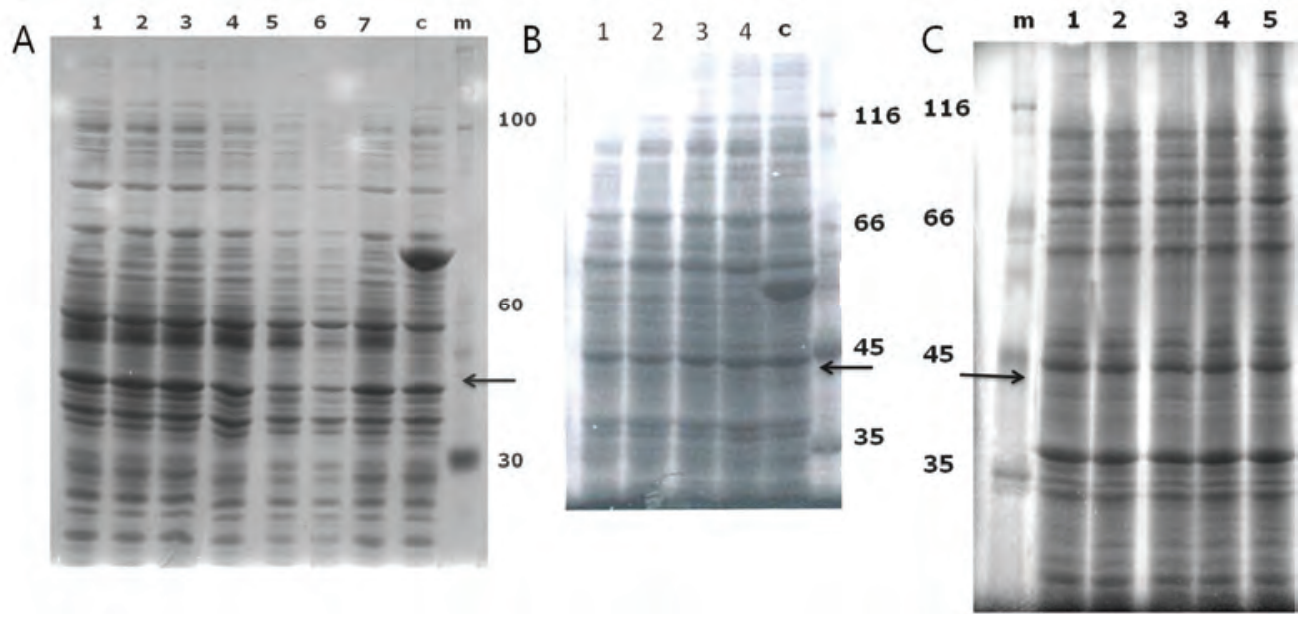

Figure 4A.5. Screening of HPGx3 in p10 (A) and RPGx3 polymer in $\mathrm{p} 10$ (B) and $\mathrm{p} 14 \mathrm{H}_{8}$ (C) expression vectors respectively.

Gel A: Different colonies of bacteria transformed with p10HPG×3 (lanes 1-7) and bacteria without the desired ELR used as control (lane C).

Gel B: Different colonies of bacteria transformed with p10RPGx3 (lanes 1-4) and bacteria without the desired ELR used as control (lane C).

Gel C: Different colonies of bacteria transformed with p14 $4 \mathrm{H}_{8} \mathrm{RPG} \times 3$ (lanes 1-5).

In all cases gels of $12 \%$ SDS-PAGE were stained with $\mathrm{CuCl}_{2}$ (3.2.4.1.). Lane $\mathrm{m}$ corresponds with the protein marker. Arrows indicate the theoretical location of the expressed ELR.

As shown in Figure 4A.5, E.colitransformed with p10HPG $\times 3$ was not able to produce a significant amount of polymer. The same result was found for p10RPGx3 where the bacteria did not show any expression of RPGx3 polymer. p10 expression vector is derived from pET9a which contains the kanamycin antibiotic resistance (3.1.7.3.), however kanamycin is less sensitive to acidic $\mathrm{pH}$ and high temperature than ampicillin (37). After these results, the RPGx3 expression was tried using the ampicillin resistance $\mathrm{p} 14 \mathrm{H}_{8}$ expression vector. $\mathrm{p} 14 \mathrm{H}_{8}$ is characterized by containing a polyhistidine formed by 8 residues at $\mathrm{N}$-t of the polymer (2.1.7.3.). This poly-histidine would facilitate the purification of recombinant proteins and detection by Western Blot (37) increasing the final yield as it has been probed for other ELRs (310). Even 
though the use of both expression vectors we were not able to express the HPGx3 and RPGx3 polymers. This strategy was abandoned by the improvement of lysine based polymers and by the incorporation of two ELR monomers (IKx30 and VOKx48) at N-t of HPGx3 and HPGx1 respectively.

\section{A.1.2. SYNTHESIS OF V1K, VOKx48 AND VOKx72 CONSTRUCTIONS}

In order to increase the net charge of the ELRs, novel constructions highly enriched in lysines were designed. V1K, VOKx48 and VOKx72 monomer genes were flanked by inverted Eall recognition sites as showed in Figure 4A.6.

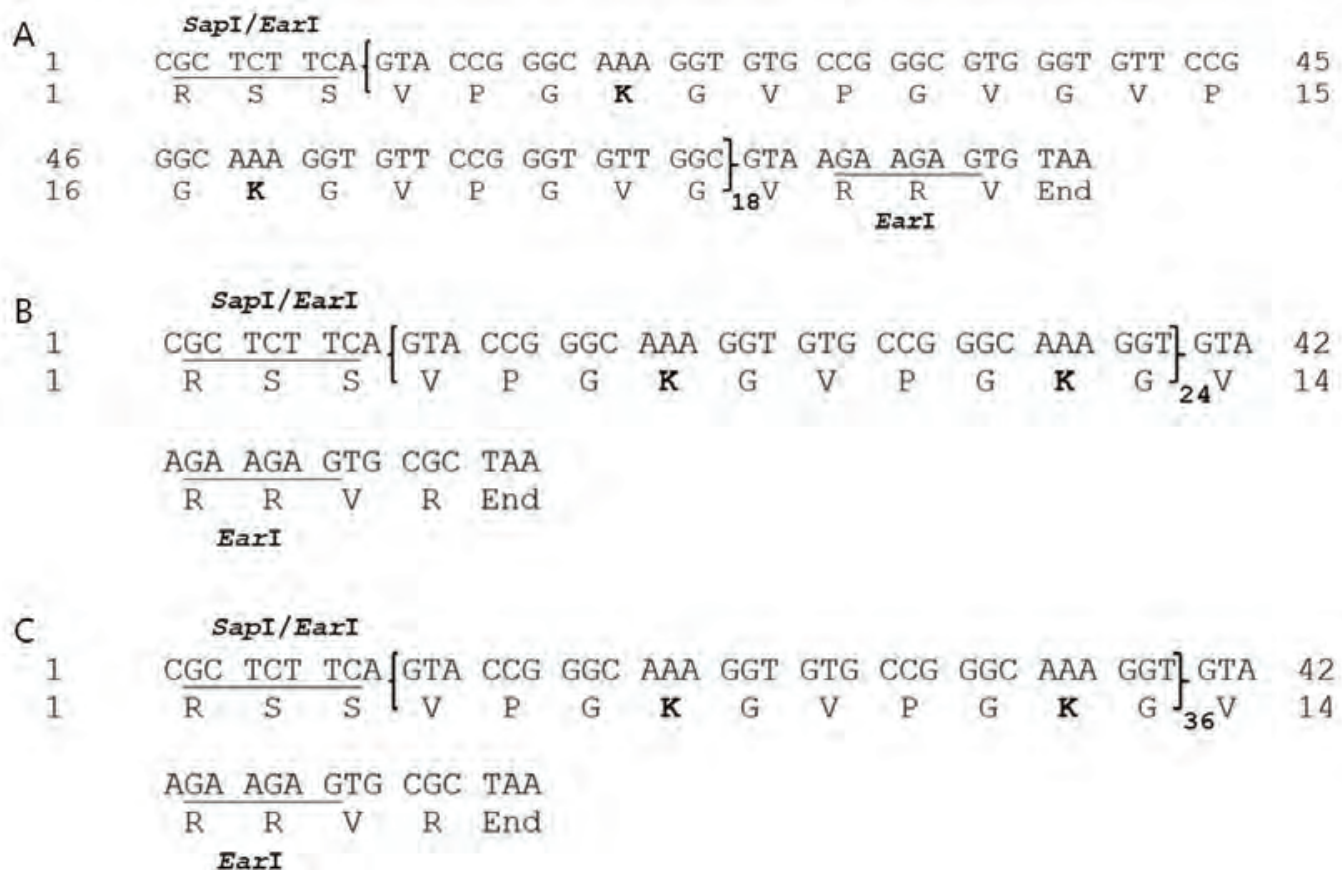

Figure 4A.6. Nucleotide and amino acid sequences of the V1K (A) VOKx48 (B) and VOKx72 (C) ELR monomer gene. The underlined region corresponds with Eart and Sapl restriction sites.

V1K, VOKx48 and VOKx72 monomer genes were extracted from agarose after cutting the pDmV1K, pDmVOKx48 and pDmVOKx72 with Eall restriction enzyme. Afterwards, the monomer gene was subcloned into the expression vector named as p7 (3.1.7.3) which favors the accumulation of expressed polymers in the cytoplasm. Their incorporation was confirmed by analytical gel electrophoresis and by DNA sequencing (Figure 4A.7 and 4A.8). 

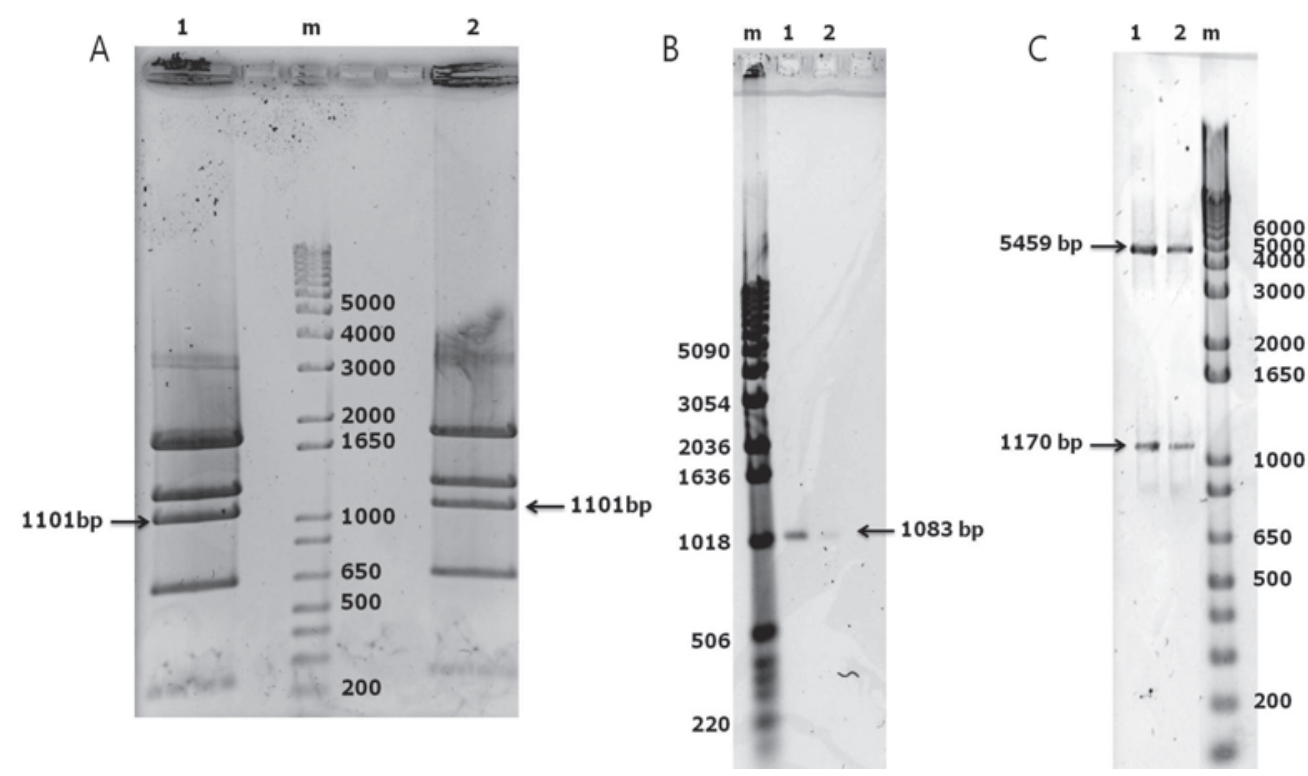

Figure 4A.7. Enzymatic analysis of pDmV1K, pDmVOKx72 and p7V1K, p7VOKx72.

Gel A: Enzymatic analysis of VOKx72 (lane 1) and V1K (lane 2) after digestion with Eart, which liberates the monomer gene of $1101 \mathrm{bp}$.

Gel B: Analysis of VOKx72 gene after agarose extraction where 1 and 2 are the first and second elution.

Gel C: Enzymatic analysis of the colonies containing the plasmid p7 VOKx72 (lane1) and p7 V1K (lane 2) cut with Hindll and Xbal enzymes giving the fragments of $5459 \mathrm{bp}$ and $1170 \mathrm{bp}$.

In all cases $\mathrm{m}$ lane corresponds with $1 \mathrm{~Kb}$ marker. 1.2\% DNA agarose electrophoresis stained with SimplySafe ${ }^{\mathrm{TM}}$. The desired bands are indicated by arrows with their corresponding length. 

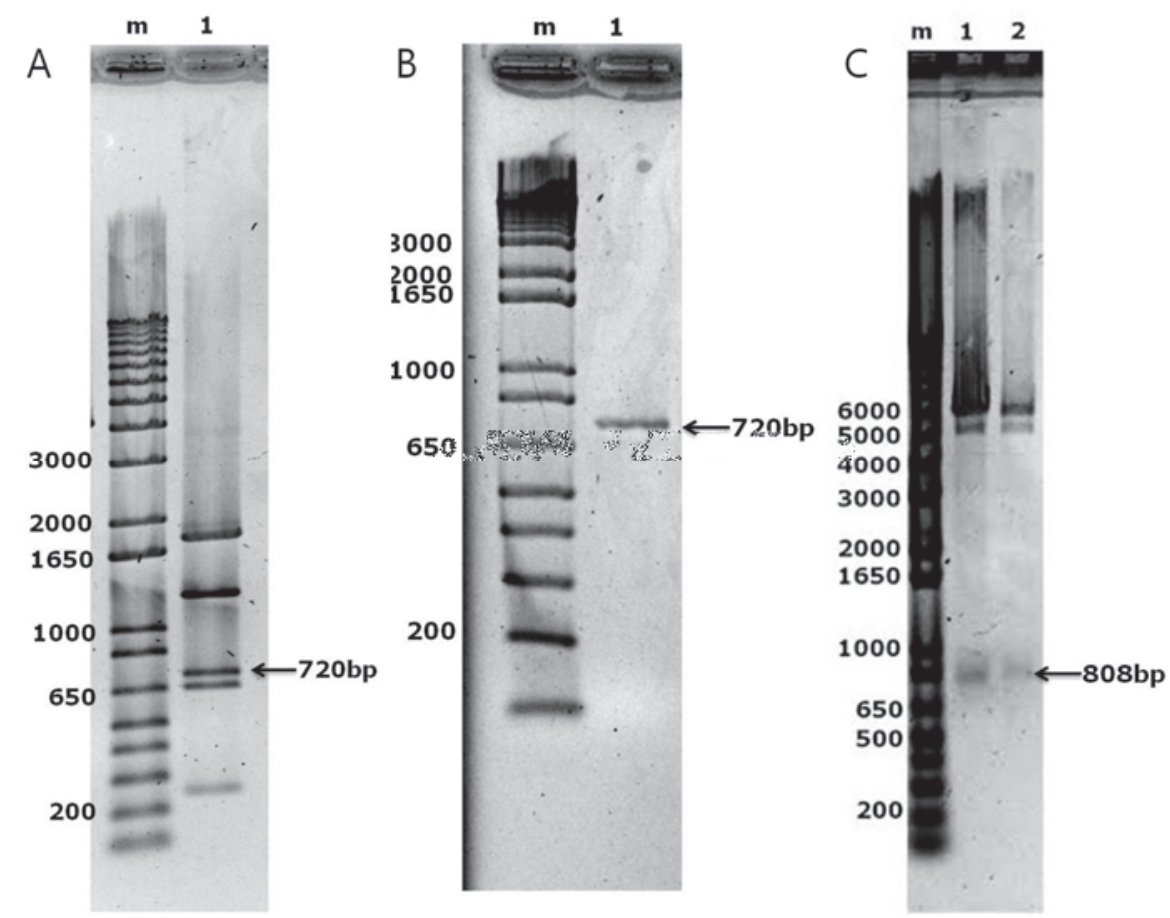

Figure 4A.8. Enzymatic analysis of pDmVOKx48 and p7VOKx48.

Gel A: Enzymatic analysis of VOKx48 after digestion with Eart, which liberates the monomer gene of $720 \mathrm{bp}$.

Gel B: Analysis of VOKx48 gene after agarose extraction where 1 is the first elution.

Gel C: Enzymatic analysis of the colonies containing the plasmid p7 VOKx48 (lane 1 and 2) cut with $X$ hol and $X$ bal enzymes giving the fragments of $5459 \mathrm{bp}$ and $808 \mathrm{bp}$.

In all cases $\mathrm{m}$ lane corresponds with $1 \mathrm{~Kb}$ marker. 1.2\% DNA agarose electrophoresis stained with SimplySafe ${ }^{\mathrm{TM}}$. The desired bands are indicated by arrows with their corresponding length.

The theoretical aminoacid sequences of $\mathrm{V} 1 \mathrm{~K}, \mathrm{VOK} \times 48$ and $\mathrm{VOK} \times 72$ are the following:

V1K:

$$
\text { MESLLP [(VPGKG)(VPGVG) }]_{36} \bigvee
$$

VOKx48: $\quad$ MESLLP $(V P G K G)_{48}$ V

VOKx72: $\quad$ MESLLP $(V P G K G)_{72}$ V

\section{A.1.2.1. EXPRESSION OF V1K, VOKx48 AND VOKx72}

Expression vectors containing the $\mathrm{V} 1 \mathrm{~K}$ and $\mathrm{VOK} \times 48$ genes were transformed into BL21 Star (DE3) E.coli strain; however VOKx72 was transformed in BLR (DE3) E.coli strain (3.2.2.3). BLR (DE3) is a RecA deficient derivative of BL21. RecA have an important role in homologous recombination, DNA repair and maintenance. Thus, BLR (DE3) strain provides stability to plasmid DNA containing high number of 
repetitive sequences during bacterial replication (324), for this reason the ELR with the higher repetitions of VPGKG (VOKx72) was transformed in BLR(DE3).

A screening of the colonies grown in auto-induction TB medium was performed and depicted below (Figure 4A.9).


Figure 4A.9. Total protein fractions analysis of $\mathrm{V} 1 \mathrm{~K}, \mathrm{VOKx} 48$ and $\mathrm{VOKx} 72$ expressing colonies.

Gel A: Different colonies of bacteria transformed with p7V1K (lanes 1-7) and bacteria without the desired ELR used as control (lane C). 12\% SDS-PAGE was stained with $\mathrm{CuCl}_{2}$. Arrow signals the theoretical location of the expressed V1K.

Gel B: Different colonies of BL21 bacteria transformed with p7VOKx48 (lanes 1-6). VOKx48 of $21.84 \mathrm{kDa}$ is pointed with an arrow. 12\% SDS-PAGE were stained with Coomassie.

Gel C: Different colonies of BLR bacteria transformed with p7VOKx72 (lanes 1-5). Bacteria without the desired ELR was used as control (lane C). VOKx72 of $32.36 \mathrm{kDa}$ is pointed with an arrow. 12\% SDS-PAGE were stained with Coomassie.

In all cases lane $m$ corresponds with the protein marker. 
As shown in Figure 4A.9, expression of VOKx48 and VOKx72 were found in BL21 (DE3) and BLR (DE3) E.coli strains respectively. By contrast, V1K was not able to be expressed in BL21 (DE3) strain. The screening was accomplished by incubation of the selected colonies o/n. After selection of colony number 5 for VOKx48 (Figure 4A.9B) and 2 for VOKx72 (Figure 4A.9C), the inoculum in LB with ampicillin and glucose was prepared (3.2.3.1.) and incorporated to the fermenter once it was grown. The production in fermenter allowed the use of higher volume of culture than Erlenmeyer flasks and to obtain higher amount of the desired ELR. After $15 \mathrm{~h}$ bacteria had arrived to the stationary phase and the production stopped at $19 \mathrm{~h}$ (Figure 4A.11A). The high presence of the polar charged lysine at physiological conditions, should improve the solubility of the ELRs. However after bacterial lysis, VOKX48 and VOKX72 ELRs remained in the insoluble fraction. Solubility is generally increased if electrostatic repulsion between molecules is higher than hydrophobic interaction; in this case we suggest the interaction of charged $\varepsilon$-amino groups from lysines with negatively charged components from E.coli membrane and nucleic acids that leads to the prevalence of hydrophobic interactions and the retaining of ELRs in inclusion bodies. By contrast, this is not a bad new because this kind of accumulation have some advantages such as high protein expression level and protection against proteolytic enzymes located in cytoplasm and periplasm (325). In addition, the first studies with ELRs showed the preferably accumulation of these polymers in inclusion bodies (326). As consequence, in both VOKx48 and VOKx72 a solubilization step using the cationic MTAB followed by dialysis was used when polymers remained in the pellet from lysates (Figure 4A.11B) and ITC (Inverse transition cycling) was not enough to solubilize the ELRs (3.2.3.4.). The purification of VOKx48 and VOKx72 was continued by ITC which lies in heat and cold cycles taken advantage of the ELRs smart behavior (3.2.3.4 and 3.2.3.5) and depicted in Figures 4A.10 and 4A.11C. Due to the rich in lysines, the $\mathrm{pH}$ was fixed at 11.0 in order to precipitate the polymers with heat cycles and simplify the purification process. The last step in purification was the endotoxin removal treatment by the use of $\mathrm{NaCl}$ and $\mathrm{NaOH}$ salts (3.2.3.5.). In figures $4 \mathrm{~A} .10$ and 4A.11., the electrophoretic separation of proteins corresponding with the different purification steps appeared in polyacrilamide gels stained with coomassie blue (327) (3.2.4.1.1.). In those SDS-PAGEs was possible to observe the reduction in bacteria 
proteins and the increase in concentration of the ELRs along the purification process. The ELRs appeared as a major band that migrated slower than the theoretical molecular weight (21.84 kDa for VOKx48 and $32.36 \mathrm{kDa}$ for VOKx72) due to their high positive charge. This effect had been previously observed in ELRs and depends on their amino-acid composition $(30,326)$. The final step showed a high purity for both polymers (Figure 4A.10 and 4A.11C). However, it was possible to observe a small band in VOKx48 with a size about $60 \mathrm{kDa}$ which may proceed from bacteria impurities. Thus, the percentage of this band was very low in comparison with the major band from ELR and can be dismissed. The production yield for VOKx48 was 35 $\mathrm{mg} / \mathrm{mL}$ and $90 \mathrm{mg} / \mathrm{mL}$ for VOKx72. Differences in the yield can be attributed to the lower levels of VOKx48 achieved in the selected colony from screening.

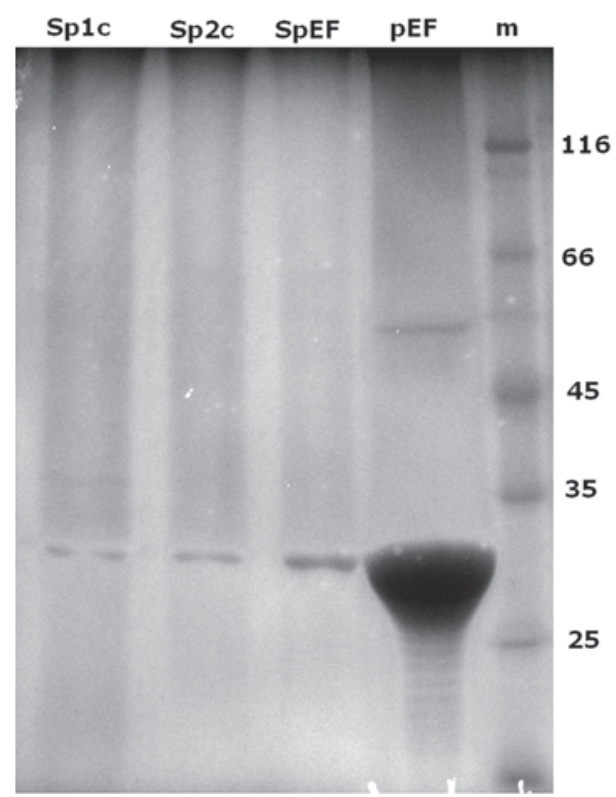

Figure 4A.10. Steps of VOKx48 purification. 12\% SDS-PAGE stained with Coomassie. Supernatant (sp) after first two heat-cold cycles. Supernatant (spEF) and pellet ( $p E F)$ after the last step of endotoxin free (EF) treatment. 

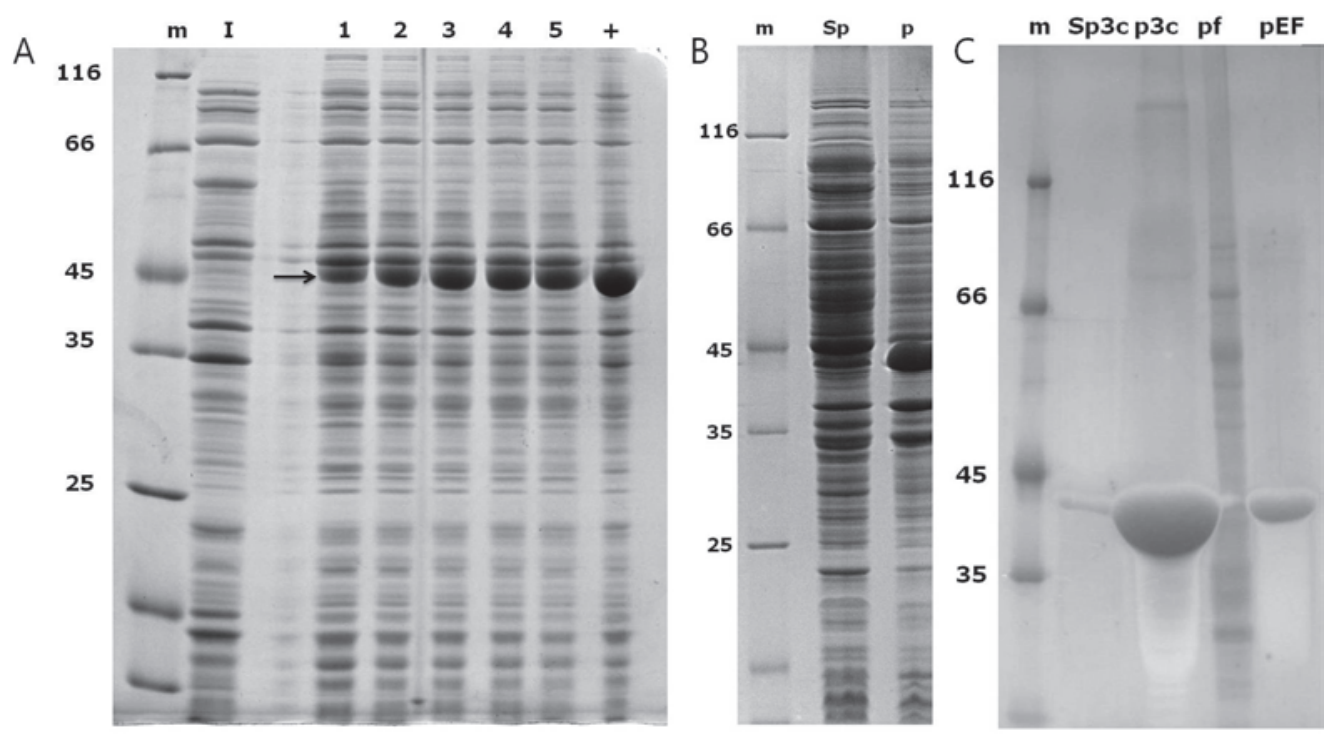

Figure 4A.1 1. Total protein fractions analysis of one VOKx72 producing colony over time and steps of VOKx72 purification.

Gel A: Lane I: bacterial inoculum in LB medium. Lanes 1 to 5 correspond to the analysis of the total protein fractions from the BLR(DE3) VOKx 72 producing transformants after 15, $16,17,18$ and $19 \mathrm{~h}$, respectively, of bacterial inoculation and growth in a fermenter with TBm medium. Lane + : positive control of VOKx72 production.

Gel B: supernatant (sp) and pellet (p) after bacteria disruption step (3.2.3.3.).

Gel C: supernatant (Sp3c) and pellet (p3c) after third heating cycle and pellet after cold cycle (pf). Pellet (pEF) after the endotoxin free treatment.

In all cases $12 \%$ SDS-PAGE gel was stained with Coomassie. Lane $m$ corresponds with the protein marker.

\section{A.2. BIOTECNOLOGICAL MODIFICATIONS OF ELRs}

\section{A.2.1. SYNTHESIS OF IKx3OHPGx3 AND VOKx48HPG}

In order to improve the expression of HPGX3 from (4A.1.1.1.), incorporation of IKx30 $\left[(\mathrm{VPGIG})_{2}(\mathrm{VPGKG})(\mathrm{VPGIG})_{2}\right]_{6}$ at $\mathrm{N}$-t was accomplished through biotechnological modifications. It has been probed that ELRs longer than IKX30 such as IK120 had been expressed previously in E.coli (311). Thus, we expected the expression of the histidine enriched ELR HPGX3 by means of IKx30 located at $\mathrm{N}$-t and constituting the IKx30HPGx3 ELR construct. In addition, the same strategy was taken for the expression of HPGx1 by the incorporation of VOKx48 at N-t and obtaining the VOKx48HPGx1 construct. In VOKx48HPGx1 a higher amount of lysines/histidines (48/46) were incorporated in comparison with IKx30HPGx3 lysines/histidines (6/138) (Table 4A.1.). The cloning strategy for IKx30HPGx3 and VOKx48HPGx1 involved the seamless recursive directional ligation strategy which is depicted in Figure 4A.12 (1.1.6.2.). 


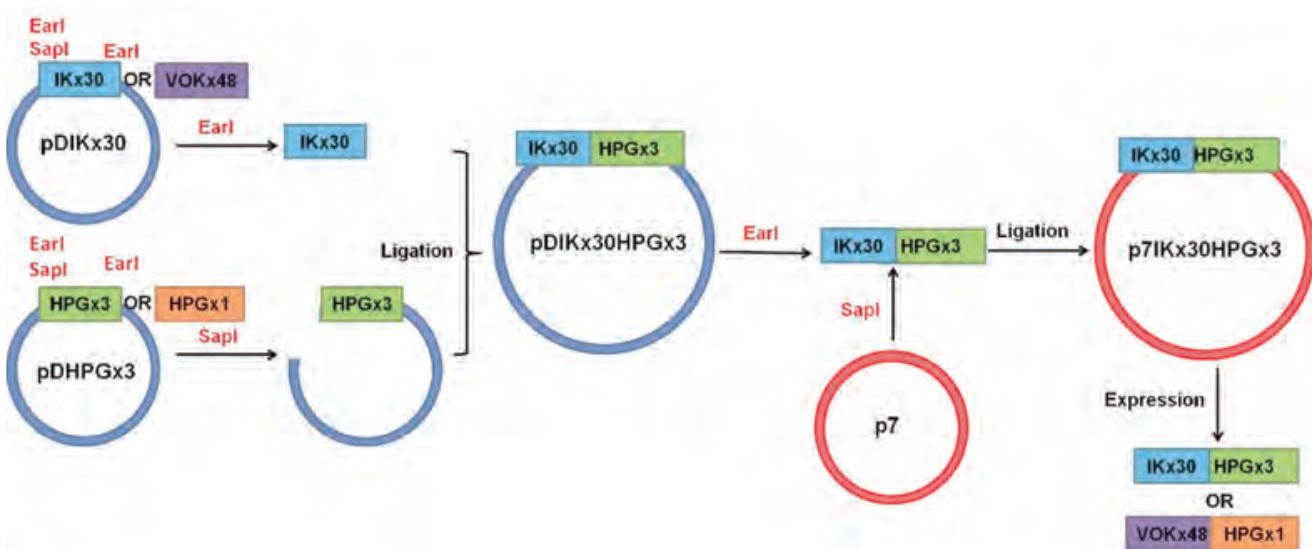

Figure 4A.12. Cloning strategy for IKx30HPGx3 and VOKx48HPGx1.

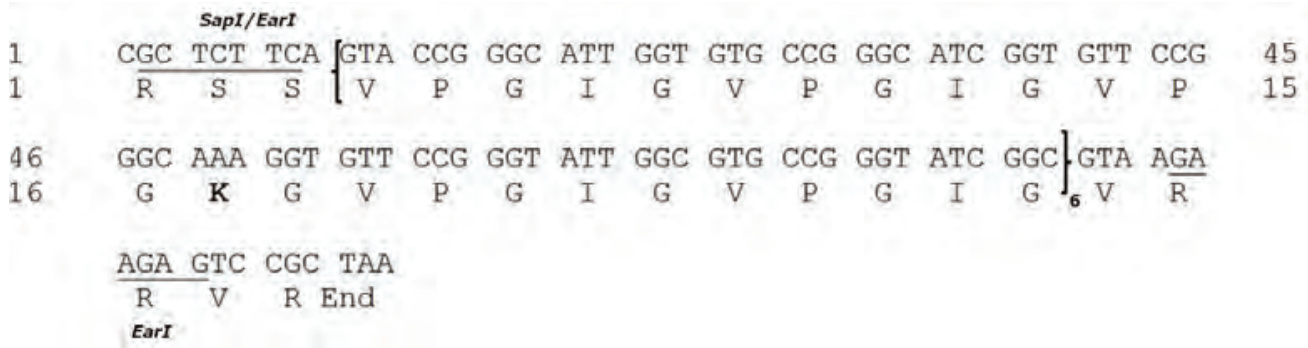

Figure 4A.13. Nucleotide and amino acid sequence of IKx30 ELR monomer gene. The underlined region corresponds with Earl and Sap/restriction sites.

All the genes involved IKx30, VOKx48, HPGx3 and HPGx1 were found in pDm vector. The formation of IKx3OHPGX3 and VOKx48HPGx1 constructs was performed by using the restriction enzyme Sapl to linearize pDmHPGx3 and pDmHPGx1. Consecutively, a ligation with IKx30 and VOKx48 gene respectively which had been previously cut with Eall was performed. As explained before (3.2.1.6.) when the plasmid was linearized by Sapl, dephosphorilation with SAP and Anthartic phosphatase was required in order to avoid self-ligation phenomena. After transformation and once positive colonies were obtained, a second enzymatic digestion of either pDmIKx30HPGx3 or pDmVOKx48HPGx1 with Earl was accomplished and ligated to a previously opened p7 expression vector. The clonation of both constructions into the $p 7$ was confirmed by agarose electrophoresis (Figure 4A.14 and 4A.15) and DNA sequencing. 


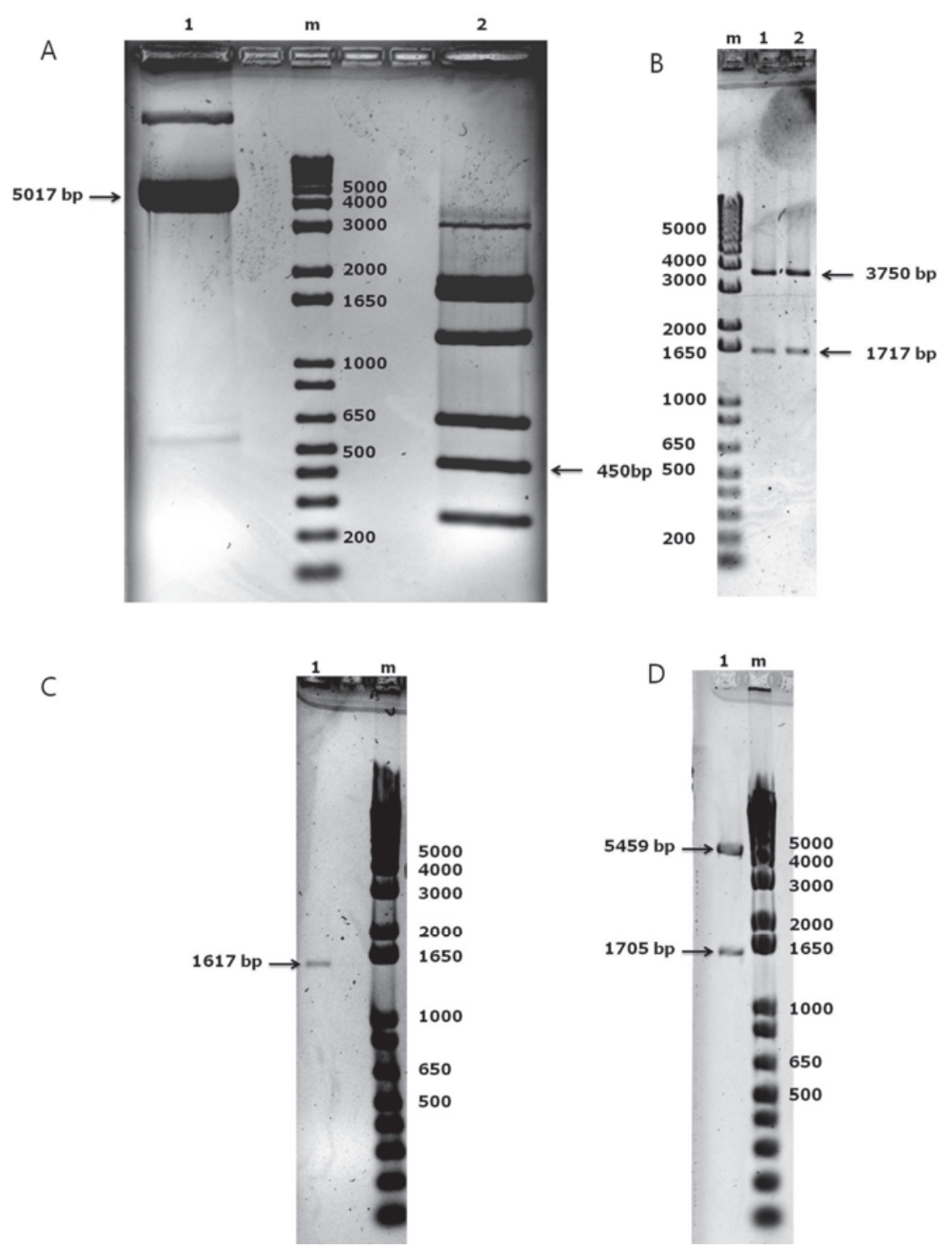

Figure 4A.14. Enzymatic analysis of pDIKx30HPGx3 construction and clonation into p7 vector.

Gel A: Enzymatic analysis of pDmHPGx3 after digestion with Sapl which linearized the plasmid (5017bp) lane 1 and pDmIK×30 after digestion with Earl, which liberated the monomer gene of $450 \mathrm{bp}$ in lane 2.

Gel B: Enzymatic analysis of two colonies of pDmIKx30HPGx3(lane 1 and 2) cut with EcoRl producing the fragments of $3750 \mathrm{bp}$ and $1717 \mathrm{bp}$ where the gene is found.

Gel C: Analysis of IK×3OHPx3 gene after agarose extraction where 1 is the first elution.

Gel D: Enzymatic analysis of the colonies containing the plasmid p7 IKx30HPGx3 cut with Hindll and Xbal enzymes giving the fragments of $5459 \mathrm{bp}$ and $1705 \mathrm{bp}$.

In all cases $\mathrm{m}$ lane corresponds with $1 \mathrm{~Kb}$ marker. 1.2\% DNA agarose electrophoresis stained with SimplySafe ${ }^{\mathrm{TM}}$. The desired bands are indicated by arrows with their corresponding length. 


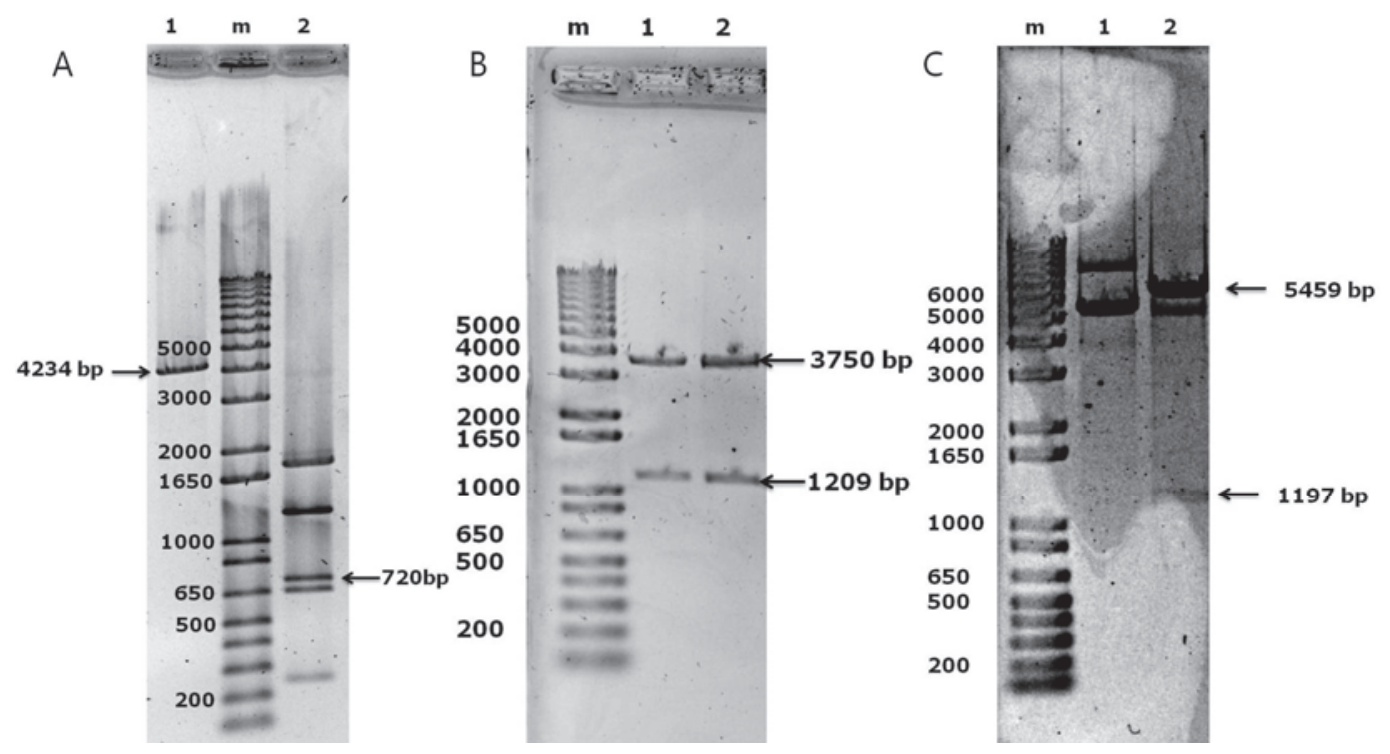

Figure 4A.15. Enzymatic analysis of pDmVOKx48HPGx1 construction and cloned into p7 vector.

Gel A: Enzymatic analysis of pDmHPGx1 after digestion with Sapl which linearized the plasmid (4234bp) lane 1 and pDmVOKx48 after digestion with Eart, which liberated the monomer gene of $720 \mathrm{bp}$ in lane 2.

Gel B: Enzymatic analysis of two colonies of pDmVOKx48HPGx1 (lane 1 and 2) cut with EcoRI producing the fragments of $3750 \mathrm{bp}$ and $1209 \mathrm{bp}$ corresponding with the desired gene.

Gel C: Enzymatic analysis of the colonies containing the plasmid p7 VOKx48HPGx1 cut with Hindll and Xbal enzymes giving the fragments of $5459 \mathrm{bp}$ and $1197 \mathrm{bp}$.

In all cases $\mathrm{m}$ lane corresponds with $1 \mathrm{~Kb}$ marker. 1.2\% DNA agarose electrophoresis stained with SimplySafe ${ }^{\mathrm{TM}}$. The desired bands are indicated by arrows with their corresponding length.

Final sequences of IKx30HPGx3 and VOKx48HPGx1 were the following:

IKx3OHPGx3: MESLLP $\left[(\mathrm{VPGIG})_{2}(\mathrm{VPGKG})(\mathrm{VPGIG})_{2}\right]_{3} \vee\left[(\mathrm{PGHGH})_{23} \mathrm{PGVGV}\right]_{3}$

VOKx48HPGx1: MESLLP $($ VPGKG) 48 V (PGHGH) 23 PGVGV

\section{A.2.1.1. EXPRESSION OF IKx3OHPGx3 AND VOKx48HPGx1}

Expression vectors containing the IKx30HPGx3 and VOKx48HPGx1 genes were transformed into BL21 Star (DE3) E.coli strain. Subsequently, a screening of the selected transformant colonies grown in auto-induction TB medium $\mathrm{o} / \mathrm{n}$ was performed. The total protein fraction separation was achieved by SDS-PAGE electrophoresis in polyacrilamide gel stained with $\mathrm{CuCl}_{2}(\mathrm{IK} \times 3 \mathrm{OHPG} \times 3)$ and Coomassie (VOKx48HPGx1). For ELRs, either coomassie or negative staining with $\mathrm{CuCl}_{2}$ is usually 
used (328). As shown in (4A.1.2.1.) VOK polymers were stained with the anionic coomassie properly, however some ELRs do not stain with coomassie and the utilization of negative stain as $\mathrm{CuCl}_{2}$ is required (326). As depicted in Figure 4A.16, expression of both polymers was achieved, being higher for VOKx48HPGx1. After selection of colony number 6 for IKx30HPGx3 (Figure 4A.16A) and 5 for VOKx48HPGx1 (Figure 4A.16B), the inoculum in LB with ampicillin and glucose was prepared (3.2.3.1.) and incorporated to $2 \mathrm{~L}$ erlenmeyers. The production was performed in a total volume of $8 \mathrm{~L}$ during $18 \mathrm{~h}$, at $37^{\circ} \mathrm{C}$ and $250 \mathrm{rpm}$ (3.2.3.1.). Expression was found for both polymers (Figure 4A.17A and 4A.18A). The purification process was followed as depicted in 3.2.3.4.

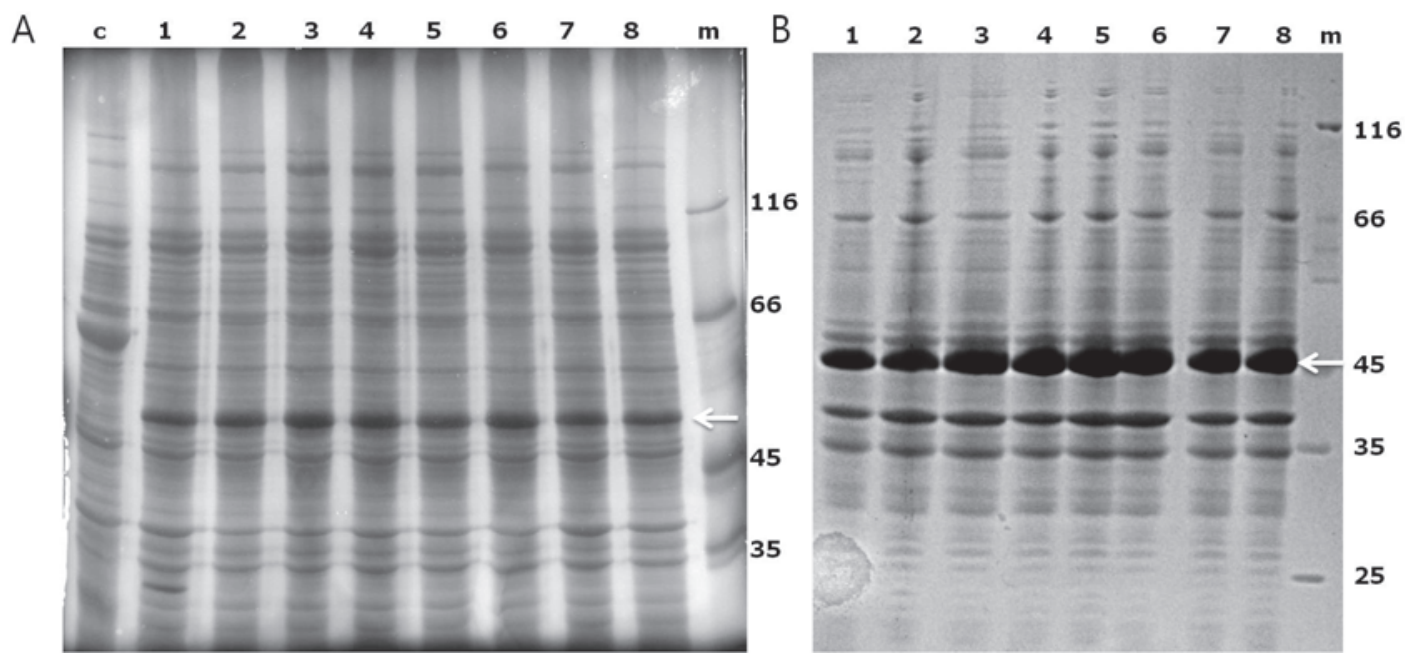

Figure 4A.16. Total protein fractions analysis of IKx30HPG $\times 3$ (A) and VOKx48HPGx1 (B) producing colonies. Total protein fraction of eight BL21 (DE3) producing transformantsafter overnight induction in modified TB medium (lanes 1-8). Lane C corresponds with unstransformed BL21 as negative control and $\mathrm{m}$ is de protein marker. $12 \%$ SDS-PAGE stained with $\mathrm{CuCl}_{2}(\mathrm{~A})$ and Coomassie (B).

In the case of IKx30HPGx3 purification and after bacteria lysis, the acidification of supernatant was accomplished with the subsequent precipitation of proteins from bacteria (3.2.3.4.) (Figure 4A.17B). After this step, $\mathrm{pH}$ adjustment to 11.0 and 3 inverse transition cycles (ITC) were performed for both IKx30HPGx3 and VOKx48HPGx1. The disappearing of bacteria components and concentration of polymer along the process was observed (Figures 4A.17 and 4A.18) (3.2.3.4. and 3.2.3.5.). Additionally and previous to dialysis and lyophilization, both IKx30HPG 3 and VOKx48HPG 1 (Figure 4A.18C) were subjected to the endotoxin removal treatment (3.2.3.5). 
Throughout the entire process, both IKx30HPGx3 and VOKx48HPGx1 appeared as a major band than ran slower along the polyacrilamide gel than theoretical $45.15 \mathrm{kDa}$ for IKx30HPGx3 and $32.90 \mathrm{kDa}$ VOKx48HPGx1. This effect had been found in the previous VOKx48 and VOKx72 ELRs and in the literature $(30,326)$. The final purification step showed polymers with high purity (4A.17D and 4A.18C) although a small band about $65 \mathrm{kDa}$ was observed for IKx30HPGx3. However, the percentage of this band was as low in comparison with the band corresponding to IKx30HPG 3 that it may not be considered. Additionally the production yield for both polymers was 15 $\mathrm{mg} / \mathrm{mL}$, this low yield was attributed to the low number of productions in erlenmeyer in order to set up the purification protocol.
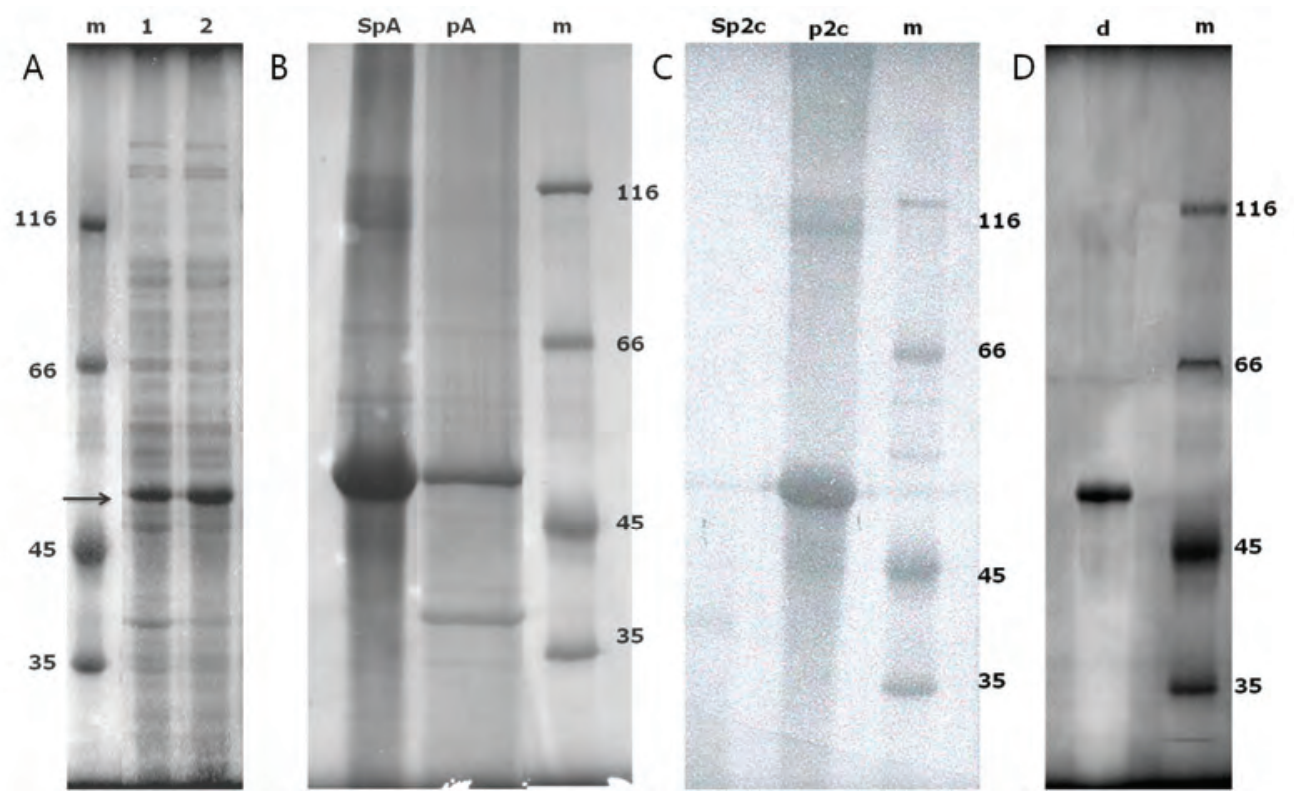

Figure 4A.17. Total protein fractions analysis of one IKx30HPGx3 producing colony over time and steps of IKx30HPG $\times 3$ purification.

Gel A: Lane m: protein marker. Lane corresponds to the analysis of the total protein fractions from the BL21(DE3) IKx3OHPG 3 producing transformant after 17 and $18 \mathrm{~h}$ of bacterial inoculation and growth in erlenmeyer containing TBm medium.

Gel B: supernatant ( $\mathrm{SpA}$ ) and pellet $(\mathrm{pA})$ after acidification at $\mathrm{pH} 4$ and cold spin.

Gel C: supernatant (Sp2c) and pellet (p2c) after the second heat cycle.

Gel D: sample of IK×3OHPG×3 after dialysis (d).

In all cases $12 \%$ SDS-PAGE were stained with $\mathrm{CuCl}_{2}$. Lane $\mathrm{m}$ corresponds with protein marker. 


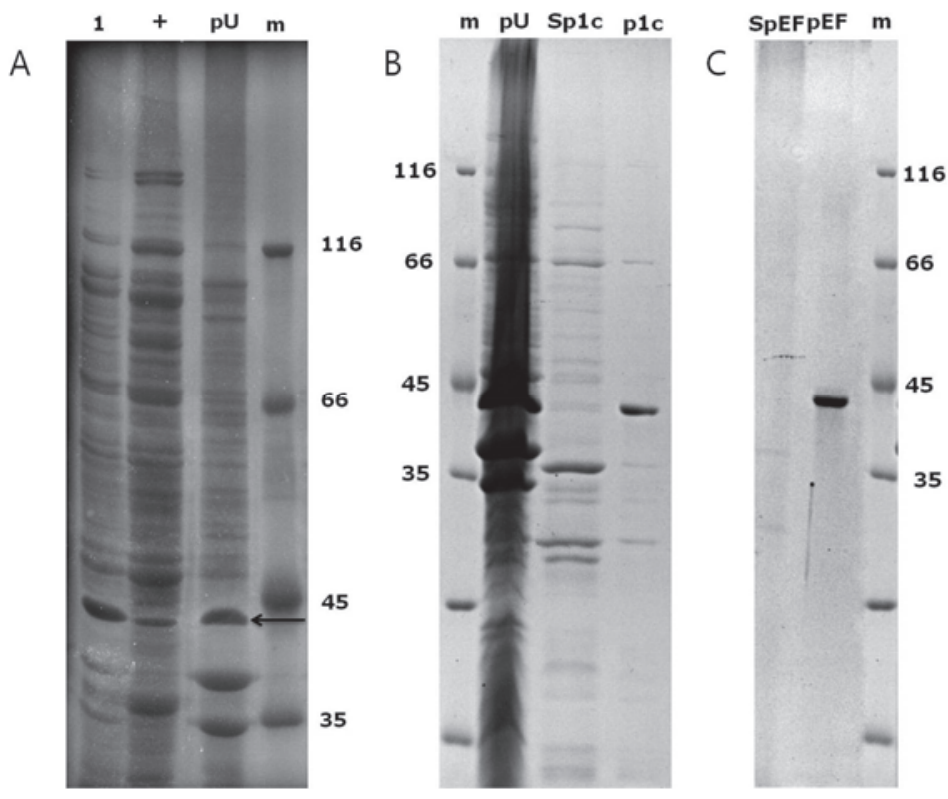

Figure 4A.18. Total protein fractions analysis of one VOKx48HPGx 1 producing colony over time and steps of VOKx48HPGx 1 purification.

Gel A: Lane 1 corresponds to the analysis of the total protein fractions from the BL21 (DE3) VOKx48HPGx 1 producing transformant after $17 \mathrm{~h}$ of bacterial inoculation and growth in TBm medium. Lane + : positive control of VOKx48HPG production. Pellet after bacteria disruption $(\mathrm{pU})$.

Gel B: pellet $(\mathrm{pU})$ after sonication. Supernatant $(\mathrm{Splc})$ and pellet $(\mathrm{plc})$ after first heat cycle.

Gel C: supernatant (SpEF) and pellet (pEF) after the endotoxin free treatment.

In all cases 12\% SDS-PAGE were stained with Coomassie. Lane m corresponds with protein marker.

\section{A.2.2. IK120 DERIVED ELRs WITH FUNCTIONAL DOMAINS}

Biotechnological modifications were also performed in order to generate new ELRs based on the existing IK120 polymer. Using the iterative-recursive method (1.1.6.) the incorporation of functional domains named as cell penetrating peptide (CPP) at C-t and the fusogenic peptide LAEL at N-t was possible. The strategy adopted is depicted in the Figure 4A.19. 


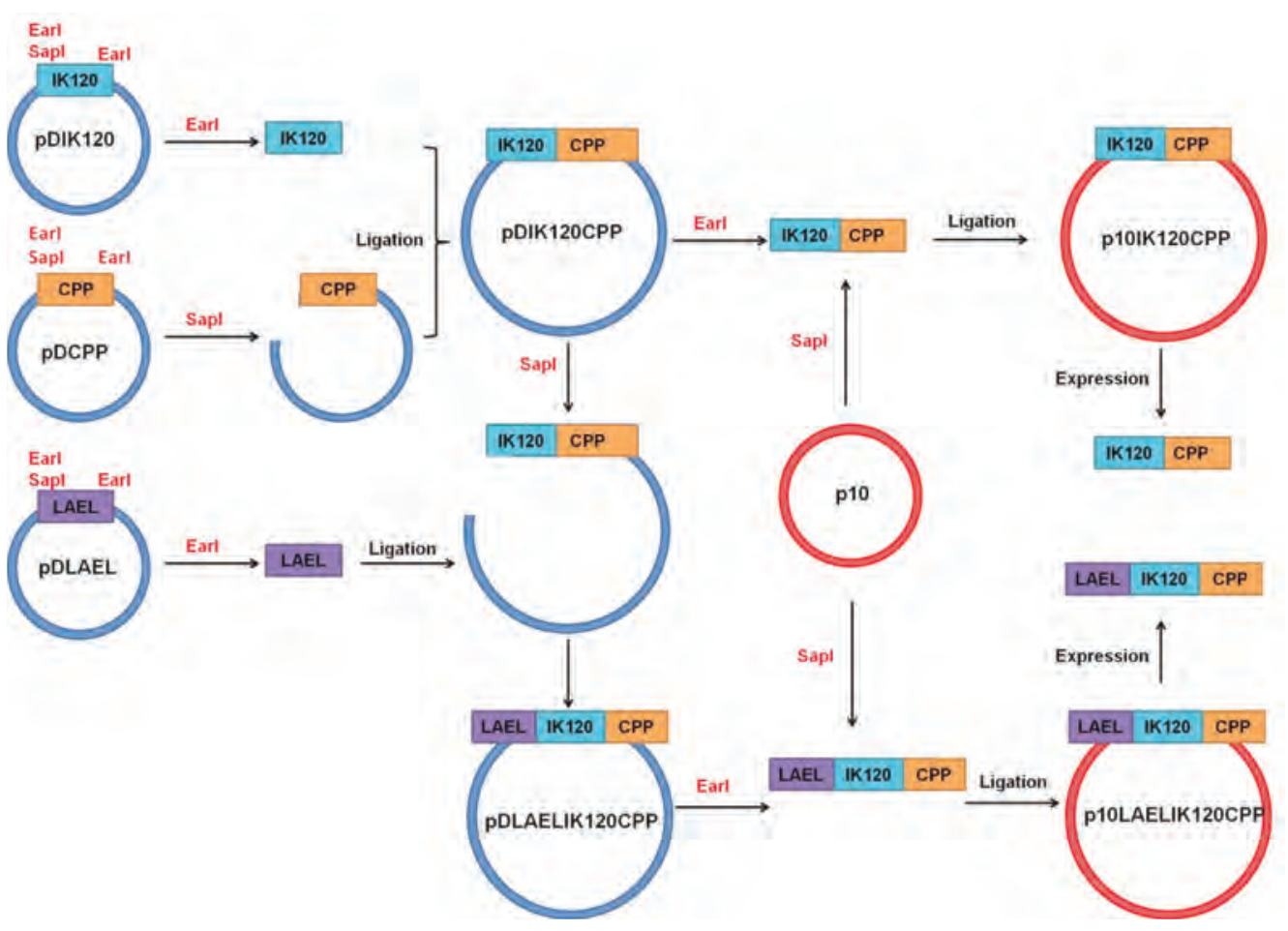

Figure 4A.19. Cloning strategy for IK120CPP and LAELIK120CPP.

The synthetic DNA encoding for LAEL gene and flanked by inverted Earl recognition sites was generated by hybridation of forward and reverse LAEL oligonucleotides $\left(90^{\circ} \mathrm{C}\right.$ for $5 \mathrm{~min}$ and $20^{\circ} \mathrm{C}$ for $20 \mathrm{~min}$ ). The forward and reverse DNA sequences of LAEL primers with the overlapping regions of both oligonucleotides underlined were: LAEL for:

\section{5'GTACTGGCTGAACTGCTGGCAGAGCTGCTGGCGGAACTG 3'}

LAEL rev:

\section{5'TACCAGTTCCGCCAGCAGCTCTGCCAGCAGTTCAGCCAG 3'}

After that, ligation with pDm previously opened with Sapl and dephosphorilated was performed (3.2.1.6). The positive transformants were selected after polymerase chain reaction (PCR) amplification (3.2.1.2.) using T7 F and M13 F primers (3.1.7.4) (Figure 4A.20).

The basis polymer IK120 and CPP were available in pDm vector when this work started. pDmCPP was digested by Sapl (Figure 4A.21A) following with dephosphorilation (3.2.1.6) However, pDmIK120 and pDmLAEL were cut by Earl which 
liberates the IK120 and LAEL gene respectively (Figure 4A.21A and 4A.22A), after the ligation pDmIK120CPP construct was obtained. Once pDmIK120CPP was analyzed by enzymatic digestion with Earl and Dpnl (Figure 4A.21B) the plasmid was linearized with Sapl, dephosphorilated and ligated to LAEL insert. PDmLAELIK120CPP was analyzed by Earl and Msel digestion (Figure 4A.22B) and DNA sequencing. Afterwards both pDmIK120CPP and pDmLAELIK120CPP were digested with Ear/Dpnl and Earl/Msel respectively liberating the insert. These inserts were extracted from agarose (Figure 4A.22C) and ligated to the previously opened p10 expression vector with Sapl. The incorporation of the constructions to the expression vector was confirmed by enzymatic analysis and DNA sequencing (Figure 4A.21C and 4A.22E).

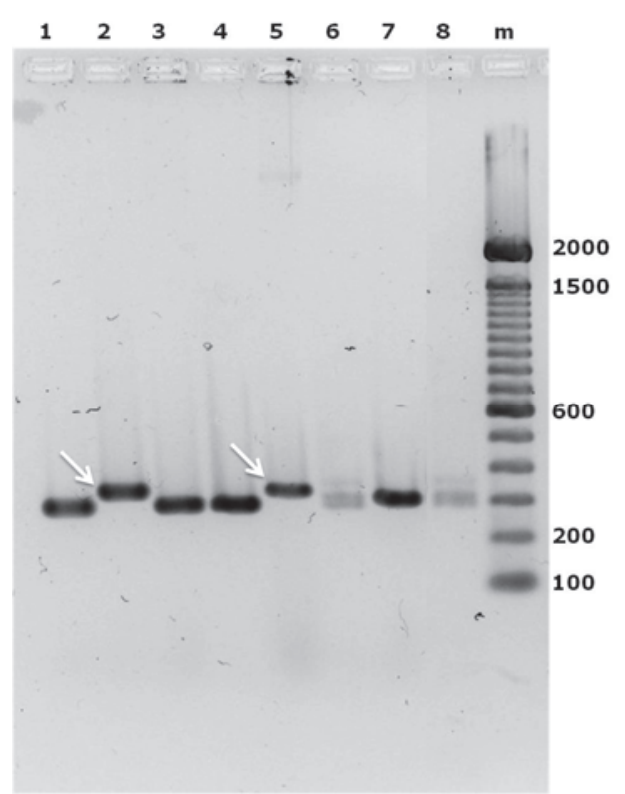

Figure 4A.20. Analysis of pDmLAEL after amplification by PCR. PCR was performed using T7 F and M13 F which amplifies a region of 350bp. Colonies analyzed (lane 1-8). Lane 2 and 5 showed positive transformants. m lane corresponds with 100bp marker. 3\% metaphor DNA agarose electrophoresis stained with SimplySafe ${ }^{\mathrm{TM}}$. Positive transformants were indicated by arrows. 

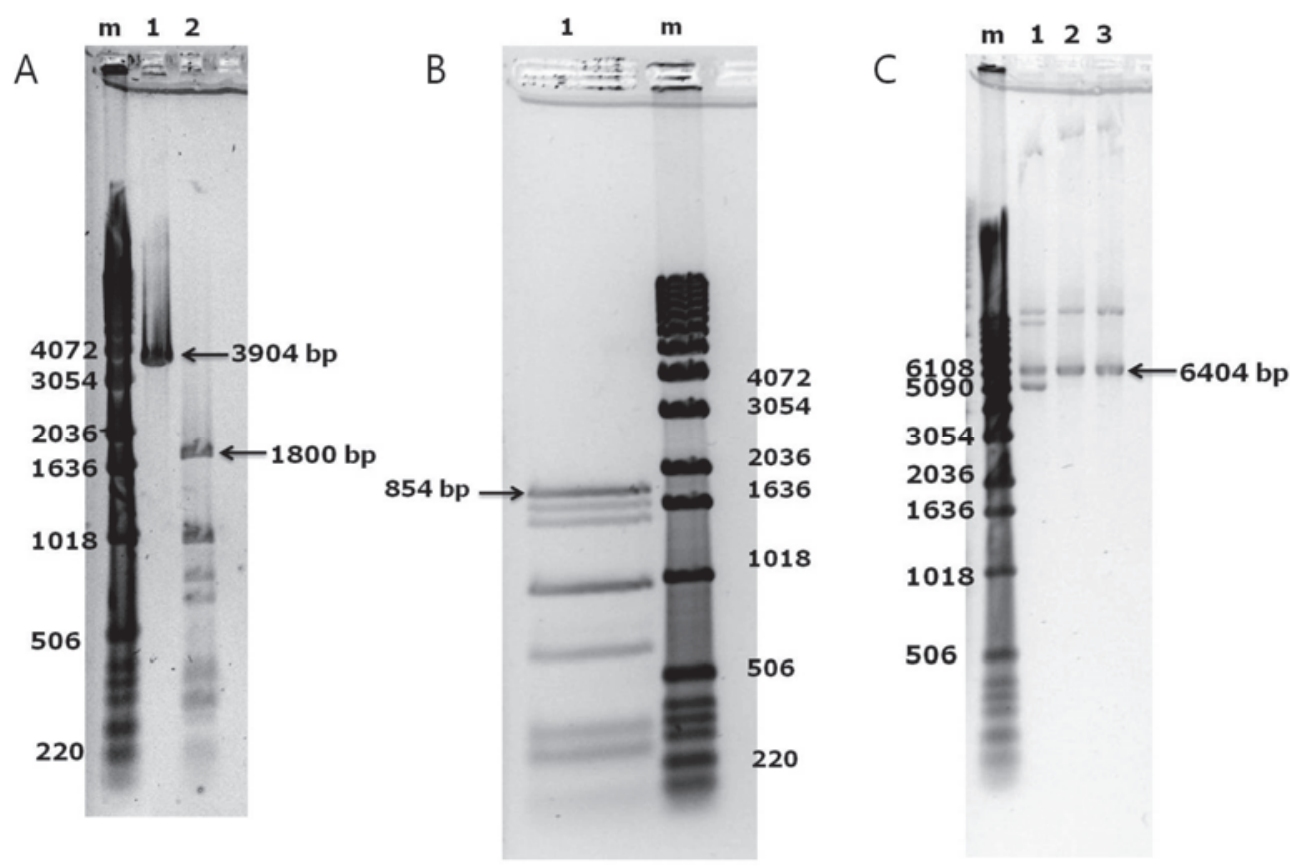

Figure 4A.21. Enzymatic analysis of pDmIK120CPP construction and cloning in p10 vector.

Gel A: Enzymatic analysis of pDmCPP after digestion with Sapl which linearized the plasmid (3904bp) lane 1 and pDmlK120 after digestion with Eart and Dpnl which liberated the monomer gene of $1800 \mathrm{bp}$ in lane 2.

Gel B: Enzymatic analysis of pDmIK120CPP(lane 1) cut with Eart and Dpnl which liberated the insert with 1854bp.

Gel C: Enzymatic analysis of the colonies containing the plasmid p10IK120CPP cut with Xbal which linearizes the plasmid (6404 bp) in the positive colonies (lane 2 and 3).

In all cases $\mathrm{m}$ lane corresponds with $1 \mathrm{~Kb}$ marker. 1.2\% DNA agarose electrophoresis stained with SimplySafe ${ }^{T M}$. The desired bands are indicated by arrows with their corresponding length. 

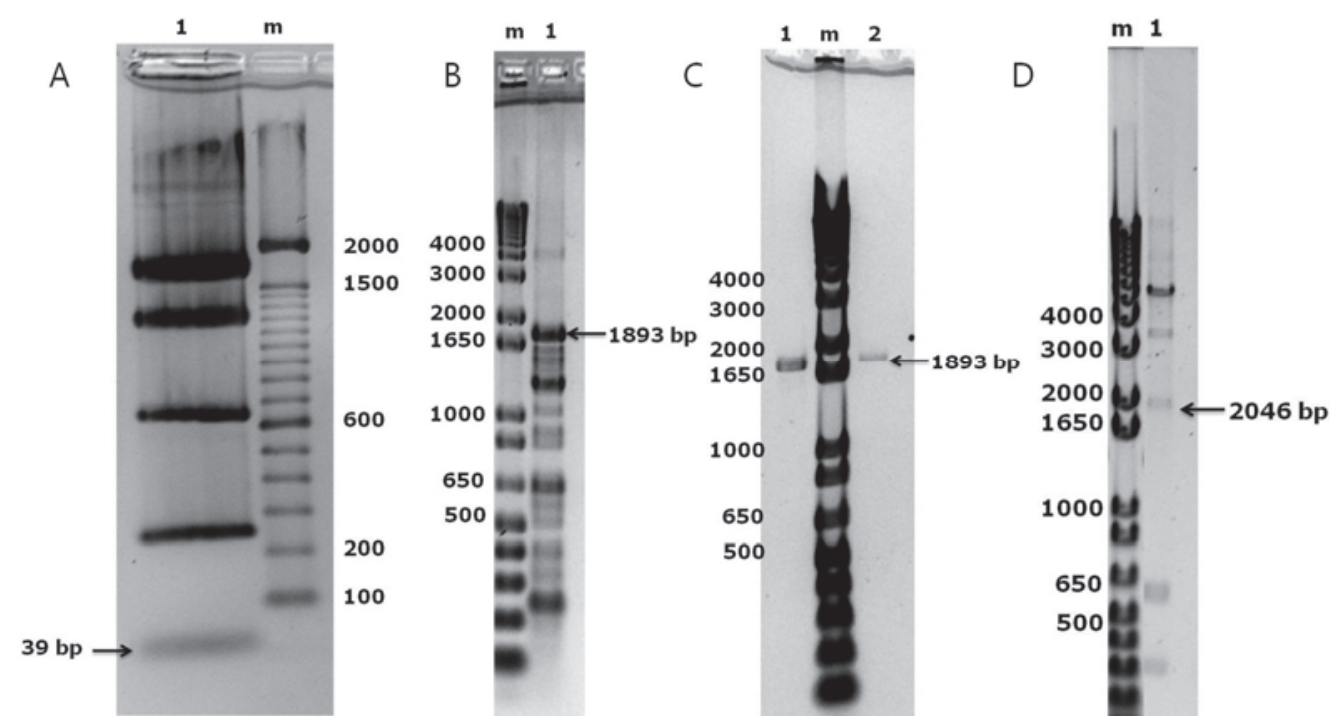

Figure 4A.22. Enzymatic analysis of pDmLAELIK120CPP construction and cloning in p10 vector.

Gel A: Enzymatic analysis of pDmLAEL (lane 1) cut with Eart which produced fragments of $210,637,1262,1742$ and the insert with 39bp.

Gel B: Enzymatic analysis of pDmLAELIK120CPP (lane 1) cut with Eart and Msel which liberated the insert of 1893bp.

Gel C: Analysis of LAELIK120CPP gene after agarose extraction where lane 1 and 2 are the first and second elution respectively.

Gel D: Enzymatic analysis of the colonies containing the plasmid p10IK120CPP cut with Hindll and Xbal which gave fragments 298, 576, 3484 and insert with 2046bp.

In $A$ and $B$ m lane corresponds with $100 \mathrm{bp}$ marker in $3 \%$ of metaphor DNA agarose. In B, $\mathrm{C}$ and $\mathrm{D}$ m corresponds with $1 \mathrm{~Kb}$ marker in 1,2\% of DNA agarose electrophoresis stained with SimplySafe ${ }^{\mathrm{TM}}$. The desired bands are indicated by arrows with their corresponding length.

The theoretical aminoacid sequences of IK120CPP and LAELIK120CPP were the following:

\section{IK120CPP:}

MESLLP [(VPGIG) 2 (VPGKG)(VPGIG) $]_{24}$ VRQIKIWFQNRRMKWKKV

\section{LAELIK120CPP:}

MESLLPVLAELLAELLAEL[(VPGIG) $\left.)_{2}(V P G K G)(V P G I G)_{2}\right]_{24}$ VRQIKIWFQNRRMKWKKV

\section{A.2.2.1. EXPRESSION OF IK120CPP AND LAELIK120CPP}

The production of both IK120CPP and LAELIK120CPP was performed as described in (3.2.3.1). BL21 (DE3) E.coli transformants with the best polymer expression (colony 7 for IK120CPP and colony 1 for LAELIK120CPP) were selected from the screening 
(Figure 4A.23A and B). Differences in the expression patterns among colonies were observed (for instance in colony 5 of IK120CPP). These differences can be due to mutagenesis events that lead to decrease levels of recombinant protein expression. That is the reason why the election of the suitable colony is important. The selected colonies from screening were used to cultivate the inoculums in LB supplemented with glucose and kanamycin $\mathrm{o} / \mathrm{n}$ at $37^{\circ} \mathrm{C}$ and $250 \mathrm{rpm}$ (3.2.3.1.). Once the inoculums were grown, they were transferred into the fermenter containing auto-induction TB medium and antibiotic. Bacteria were grown exponentially until the stationary phase in which they started to produce the recombinant proteins. Bacteria growth was assessed by measuring the absorbance at $600 \mathrm{~nm}$ and production process was prolonged for 5-6 h. Additionally, analysis of total fraction from bacteria over time showed the production of IK120CPP and LAELIK120CPP from $4 \mathrm{~h}$ after the inoculum and maintained more than $1 \mathrm{~h}$ (Figure 4A.24A and 4A.25A). After bacteria lysis and separation of cell debris by centrifugation, both polymers remained in the pellet. An additional treatment with MTAB followed by dialysis was required in order to remove the rest of detergent (3.2.3.4.). Right after, polymers were purified following the ITC method which is detailed in (3.2.3.4) and they were also subjected to endotoxin removal treatment (3.2.3.5). Some steps of the purification process are depicted in Figure 4A.24B and $C$ and Figure 4A.25B and C. IK120CPP (54.30 kDa) and LAELIK120CPP (55.68 kDa) with high purity were obtained (Figures 4A.24C and 4A.25C). However, some bands corresponding to bacteria components in IK120CPP and LAELIK120CPP were found. In addition a small band under the major band of LAELIK120CPP may correspond with a degradation product. These additional bands represent low percentage in comparison with the total polymer that makes us to do not consider them and evaluate them by mass spectrometry. The yield achieved was $35 \mathrm{mg} / \mathrm{L}$ and $50 \mathrm{mg} / \mathrm{mL}$ for IK120CPP and LAELIK120CPP respectively. The decrease in the yield for IKCPP and LAELIK120CPP in comparison with IK120 (90 mg/mL) (311) was attributed to destabilization of the bacterial membrane by CPP (197). 

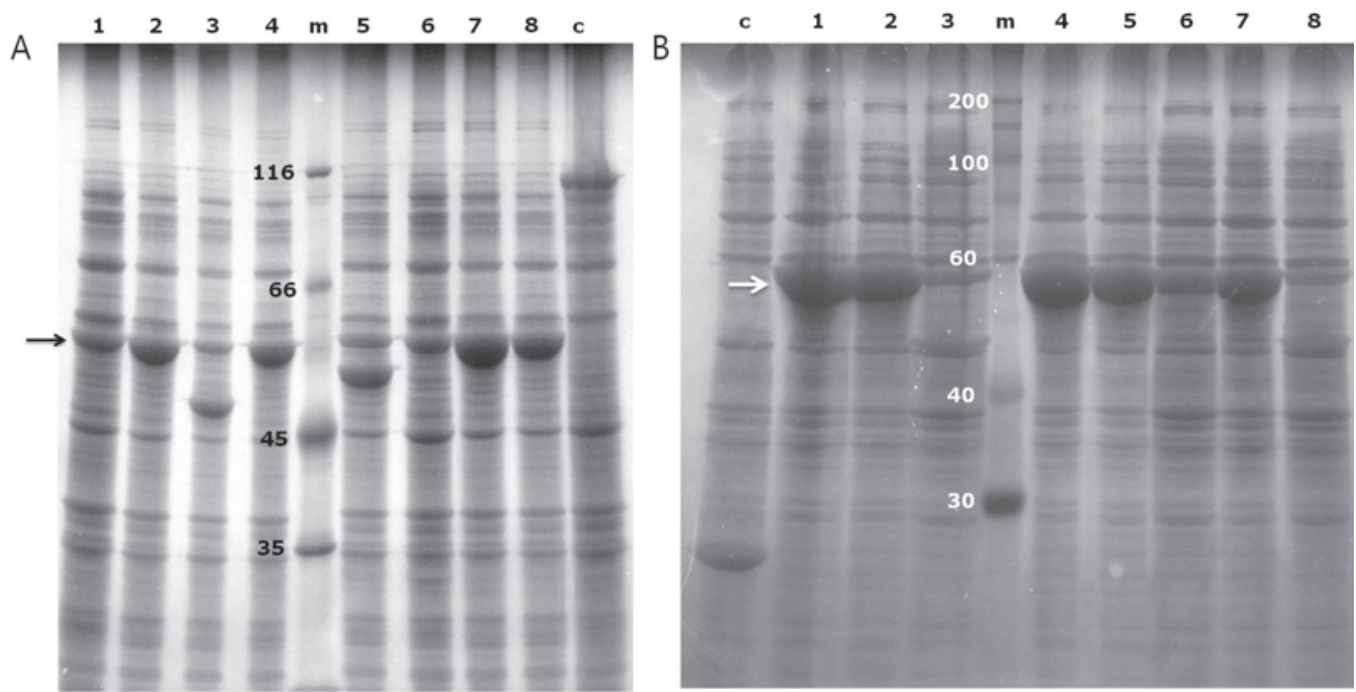

Figure 4A.23. Total protein fractions analysis of IK120CPP (A) and LAELIK120CPP (B) producing colonies. Total protein fraction of eight BL21 (DE3) producing transformants after overnight induction in modified TB medium (lanes 1-8). Lane c corresponds with unstransformed BL21 as negative control and $\mathrm{m}$ is de protein marker. 12\% SDS-PAGE stained with $\mathrm{CuCl}_{2}$.
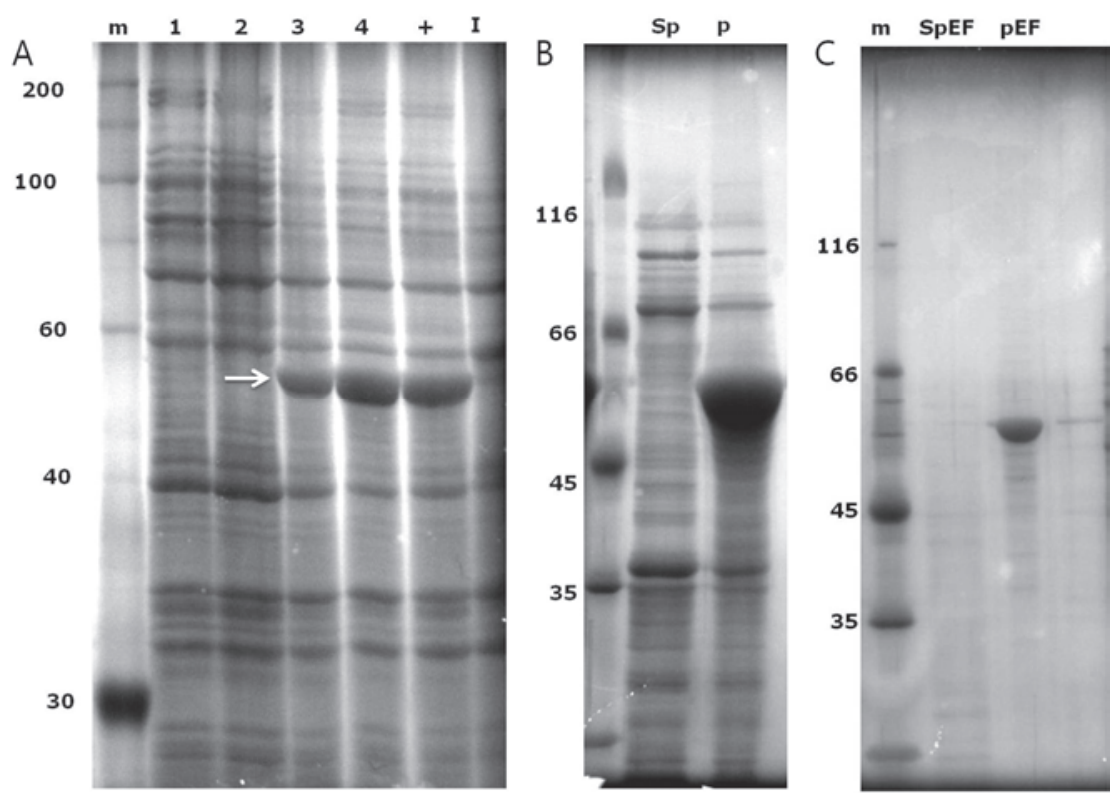

Figure 4A.24. Total protein fractions analysis of one IK120CPP producing colony over time and steps of ELR purification.

Gel A: Lanes 1 to 4 correspond to the analysis of the total protein fractions from the BL21(DE3) IK120CPP producing transformants after 2, 3, 4 and $5 \mathrm{~h}$, respectively, of bacterial inoculation and growth in TBm medium. Lane + : positive control of IK120CPP production. Lane I: bacterial inoculum in LB medium. Lane m: protein marker.

Gel B: supernatant (sp) and pellet (p) after first heating cycle.

Gel C: supernatant (spEF) and pellet ( $p E F)$ after last step of purification through (endotoxin removal treatment. In all cases $12 \%$ SDS-PAGE were stained with $\mathrm{CuCl}_{2}$. 

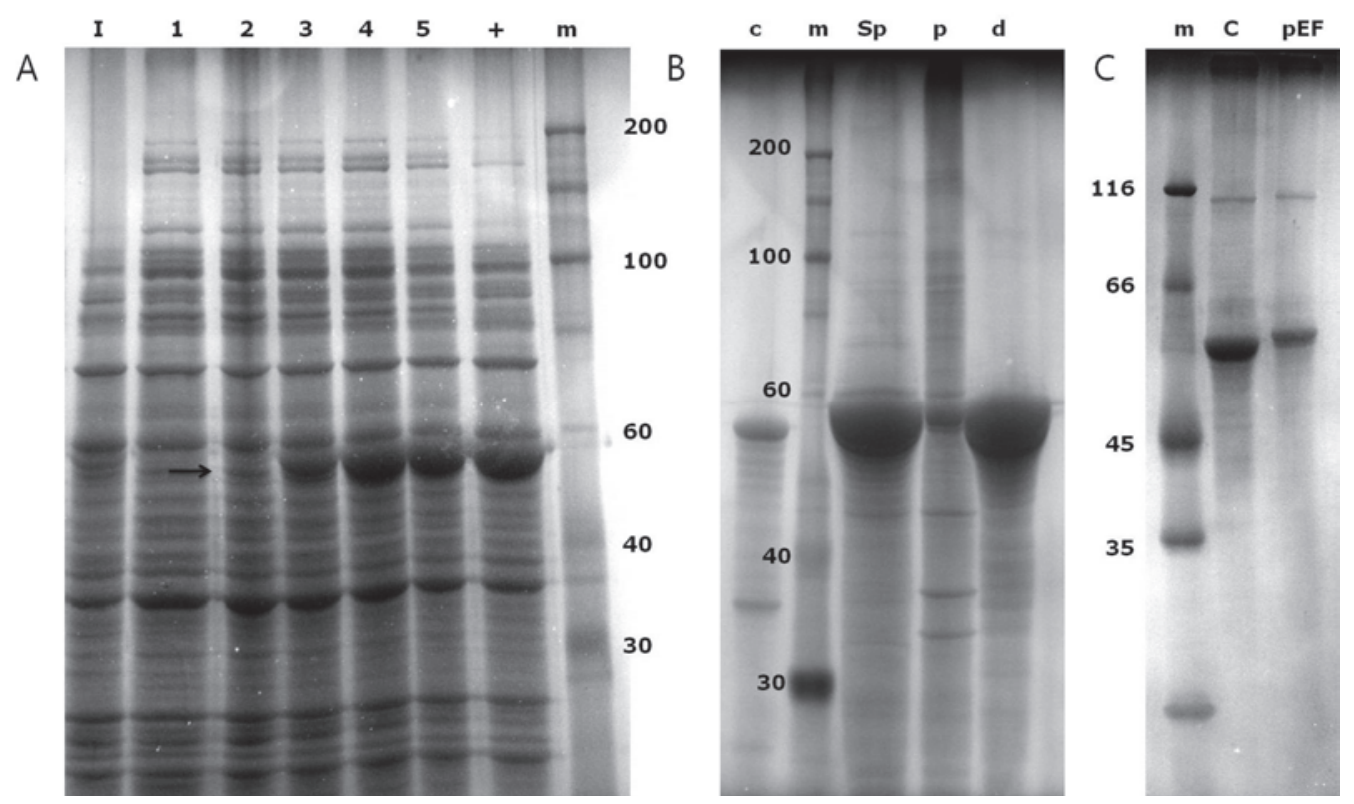

Figure 4A.25. Total protein fractions analysis of one LAELIK120CPP producing colony over time and steps of ELR purification.

Gel A: Lane I: bacterial inoculum in LB medium. Lanes 1 to 5 correspond to the analysis of the total protein fractions from the BL21 (DE3) LAELIK120CPP producing transformants after 2, 3, 4, 5 and $6 \mathrm{~h}$, respectively, of bacterial inoculation and growth in TBm medium. Lane + : positive control of LAELIK120CPP production.

Gel B: supernatant (sp) and pellet (p) after the treatment with 3\% MTAB. Sample after dialysis (d).

Gel C: IK120CPP polymer as control (c) and LAELIK120CPP pellet (pEF) after last step of purification through endotoxin removal treatment.

In all cases $12 \%$ SDS-PAGE were stained with $\mathrm{CuCl}_{2}$. Lane $\mathrm{m}$ corresponds with the protein marker.

\section{A.3. CHARACTERIZATION OF ELRS}

In order to ensure the specific features of the final ELRs products physical and chemical characterization was performed. For that SDS-PAGE, MALDI-TOF, ${ }^{1} \mathrm{H}$ nuclear magnetic resonance spectroscopy, amino acid analysis and differential scanning calorimetry techniques were used.

\section{A.3.1. SDS-PAGE}

SDS-PAGEs of purified ELRs are depicted in Figure 4A.26, where the evaluation of their purity and size was possible. Some ELRs named as VOKx48, VOKx72, VOKx48HPG and IKx30HPGx3 appeared to move slower than theoretical MW, being about $20 \%$ of increase as it had been previously described for other ELRs rich in hydrophobic amino acids $(9,30,40,326)$. 
As explained in 4A.2.2.1. and shown in Figure 4A.26F some bands appeared in LAELIK120CPP. The upper band may correspond with a bacteria component that had not been possible to remove along the purification process. An additional band below the major band may belong to a degradation product from LAELIK120CPP. However it was about $8 \%$ of the total protein fraction calculated by densitometry which means a low percentage. These additional bands represent low percentage in comparison with the total polymer that makes us to do not consider them and evaluate them by mass spectrometry (MALDI-TOF).
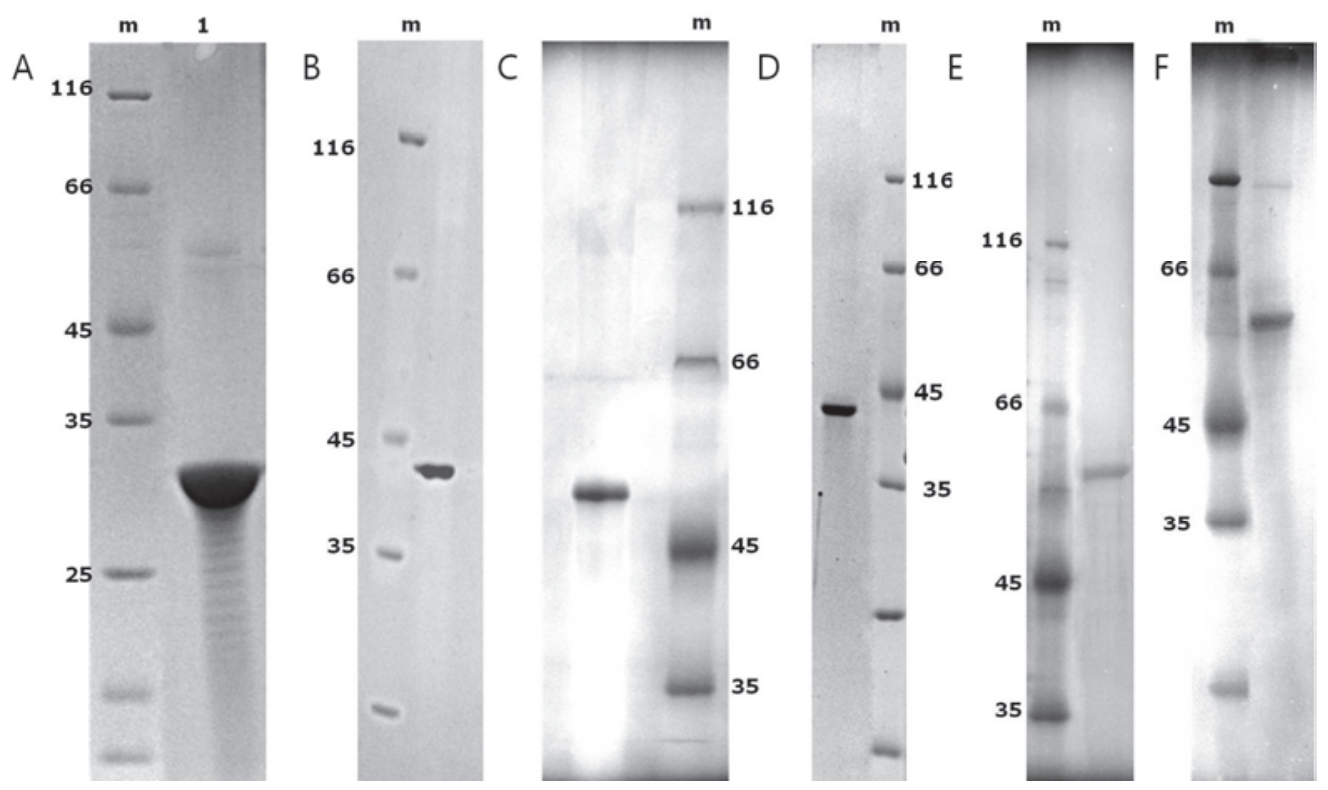

Figure 4A.26. SDS-PAGE of purified ELRs in $12 \%$ poliacrylamide stained with coomassie $(A, B, C$ and $D)$ and $\mathrm{CuCl}_{2}(\mathrm{E}$ and $\mathrm{F})$. VOKx48 (A), VOKx72 (B), IKx30HPG $\times 3$ (C), VOKx48HPGx1 (D), IK120CPP (E) and LAELIK120CPP (F).

\section{A.3.2. MALDI-TOF ANALYSIS}

MALDI-TOF analysis showed the experimental MW for all the produced polymers. A summary of theoretical and experimental MW for the ELRs is showed in Table 4A.2. 
Table 4A.2. Summary of results of the produced ELRs with their sizes measured by MALDITOF.

\begin{tabular}{lccc}
\hline ELR & Theoretical MW $(\mathrm{kDa})$ & $\begin{array}{c}\text { Experimental } \\
\text { MW(Mean } \pm \text { SD) }(\mathrm{kDa})\end{array}$ & $\begin{array}{c}\text { MW } \\
\text { error }(\%)\end{array}$ \\
\hline VOKx48 & 21.84 & $22.16 \pm 4 \times 10^{-3}$ & 1.44 \\
VOKx72 & 32.36 & $32.32 \pm 1 \times 10^{-3}$ & 0.12 \\
IKx30HPGx3 & 49.15 & $48.28 \pm 2 \times 10^{-3}$ & 1.77 \\
VOKx48HPGx1 & 32.90 & $33.88 \pm 5 \times 10^{-3}$ & 2.90 \\
IK120 & 51.86 & $51.99 \pm 4 \times 10^{-2}$ & 0.25 \\
IK120CPP & 54.30 & $54.32 \pm 4 \times 10^{-3}$ & 0.03 \\
LAELIK120CPP & 55.68 & $55.69 \pm 3 \times 10^{-3}$ & 0.02 \\
\hline
\end{tabular}

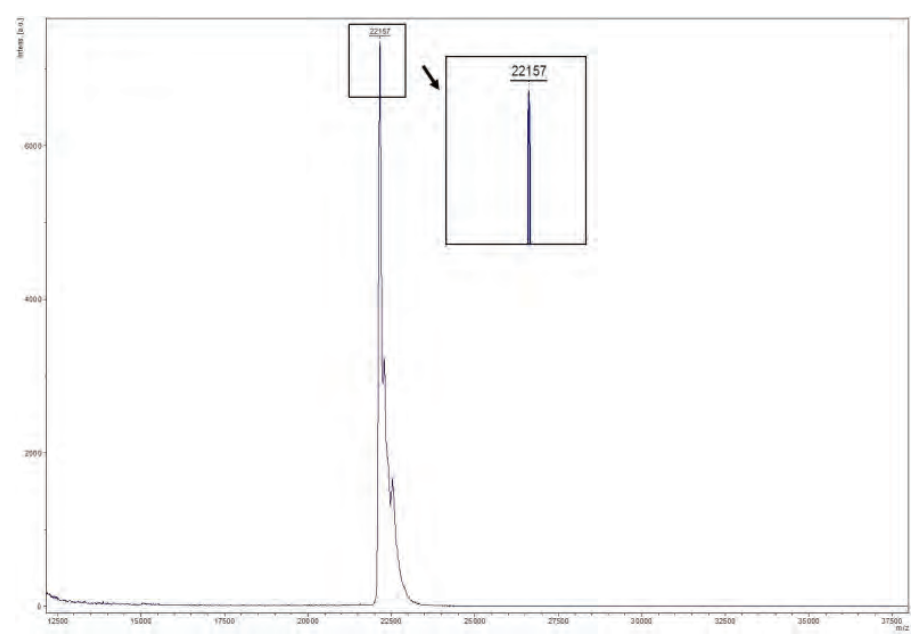

Figure 4A.27. MALDI-TOF spectra of VOKx48. The theoretical mass of the polypeptide is $21.84 \mathrm{kDa}$.

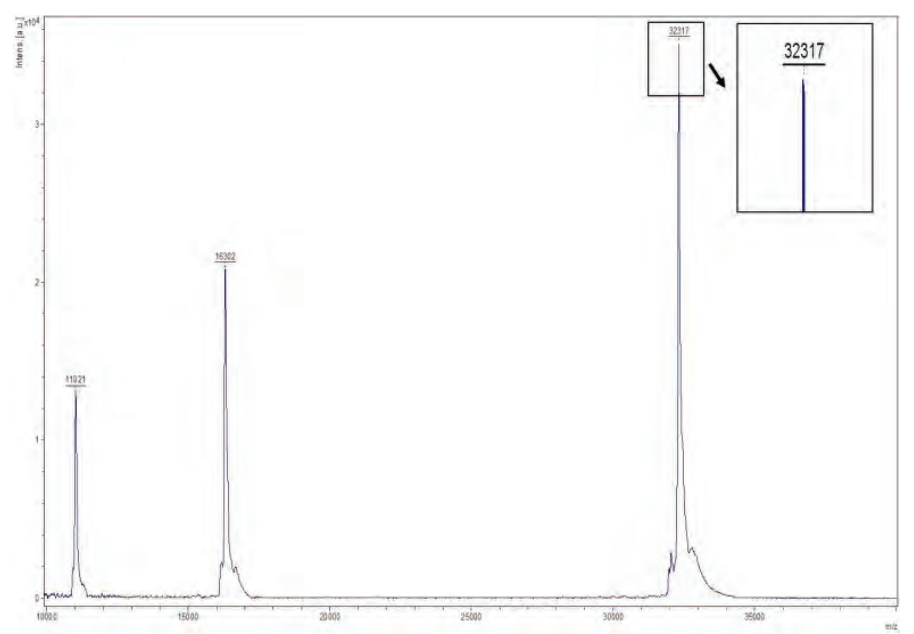

Figure 4A.28. MALDI-TOF spectra of VOKx72. The theoretical mass of the polypeptide is $32.36 \mathrm{kDa}$. Signal at $16.20 \mathrm{kDa}$ is assigned at doubly charged species 


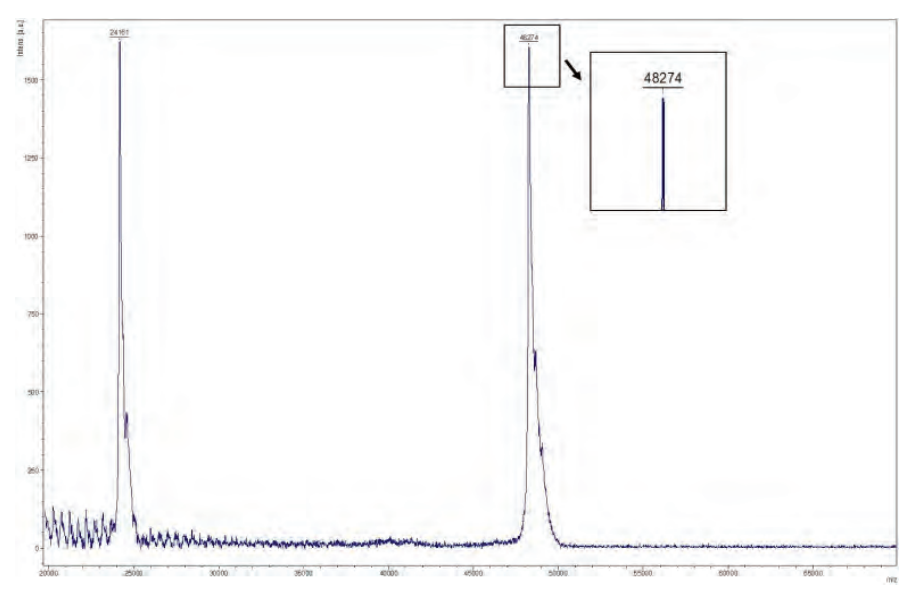

Figure 4A.29. MALDI-TOF spectra of $1 \mathrm{~K} \times 30 \mathrm{HPG} \times 3$. The theoretical mass of the polypeptide is $49.15 \mathrm{kDa}$. Signal at $24.16 \mathrm{kDa}$ is assigned at doubly charged species.

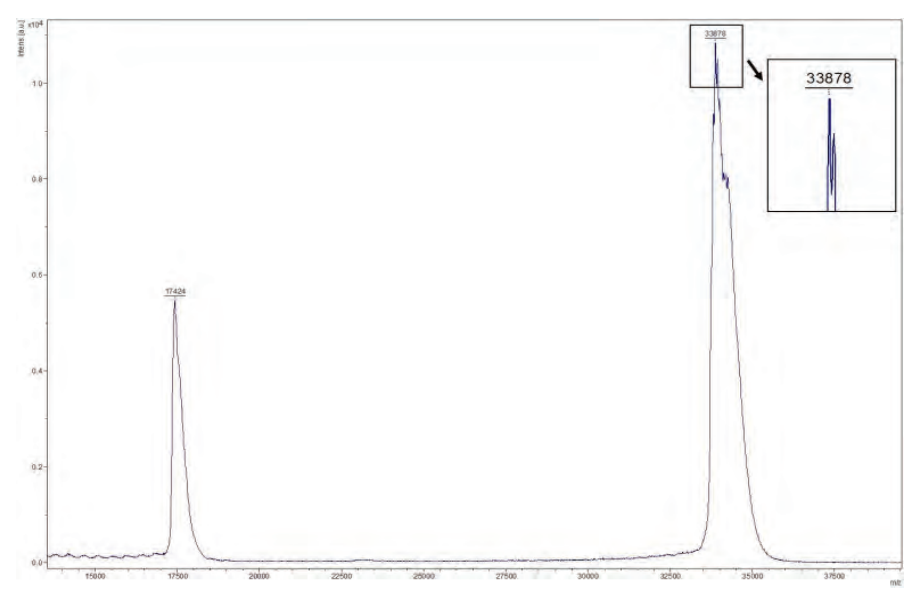

Figure 4A.30. MALDI-TOF spectra of VOKx48HPGx1. The theoretical mass of the polypeptide is $32.90 \mathrm{kDa}$. Signal at $17.42 \mathrm{kDa}$ is assigned at doubly charged species.

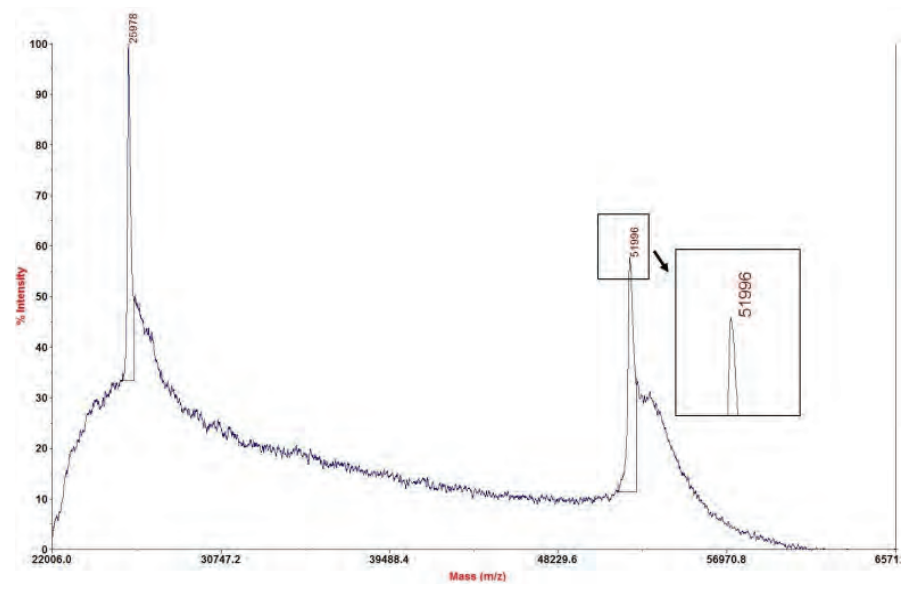

Figure 4A.31. MALDI-TOF spectra of IK120. The theoretical mass of the polypeptide is $51.86 \mathrm{kDa}$. Signal at $25.97 \mathrm{kDa}$ is assigned at doubly charged species. 


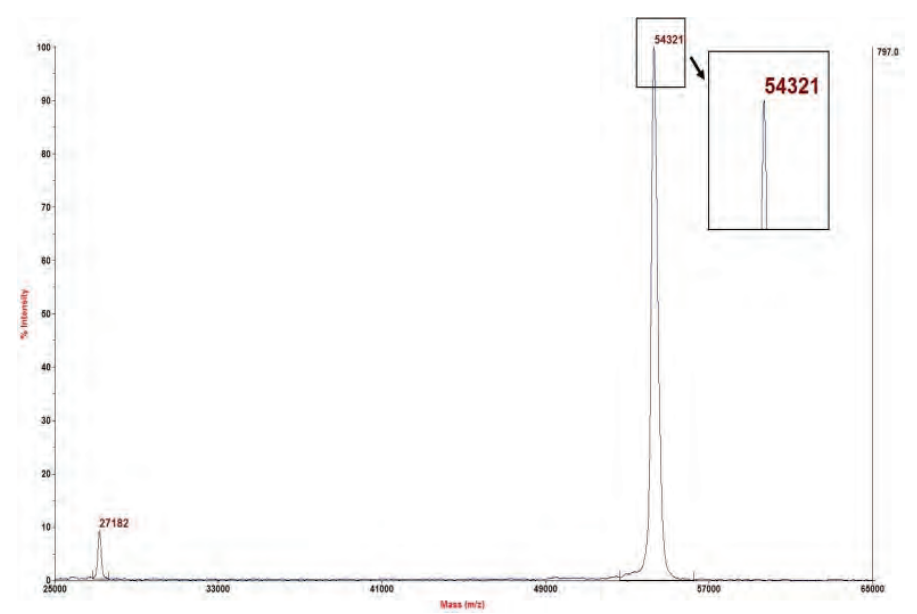

Figure 4A.32. MALDI-TOF spectra of IKI20CPP. The theoretical mass of the polypeptide is $54.30 \mathrm{kDa}$. Signal at $27.18 \mathrm{kDa}$ is assigned at doubly charged species.

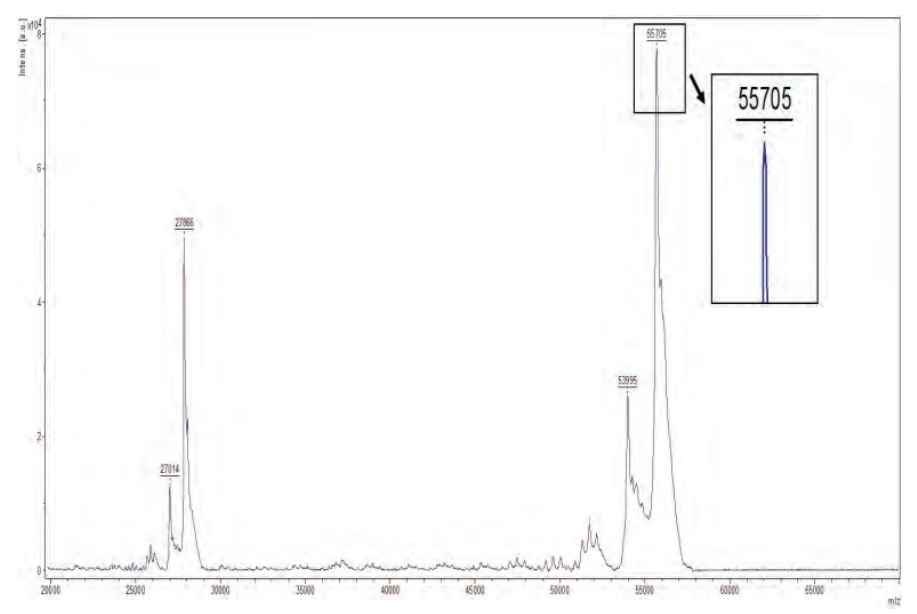

Figure 4A.33. MALDI-TOF spectra of LAELIK120CPP. The theoretical mass of the polypeptide is $55.68 \mathrm{kDa}$. Signal at $27.86 \mathrm{kDa}$ is assigned at doubly charged species.

In general, the experimental MW obtained in MALDI-TOF spectra correlated with the theoretical MW taking into account the experimental error (Table 4A.2). By contrast, as shown in SDS-PAGE (Figure 4A.26F) LAELIK120CPP polymer presented a degradation band with a MW of $53.99 \mathrm{kDa}$. However, this band only represents the $8 \%$ of the total protein which suggests a low impact in the functionality of the polymer. Thus, the highest band from SDS-PAGE did not appear in the spectra probably due to its low presence and high molecular weight (about $116 \mathrm{kDa}$ ), which make us to think about its low impact over the functional polymer as well. The amino acid composition of ELRs was further analyzed by HPLC (Table 4A.3). 


\section{A.3.3. AMINO ACID ANALYSIS}

Table 4A.3. Amino acid analysis for polymers VOKx48, VOKx72, IKx30HPGx3, VOKx48HPGx1 (A) and IK120, IK120CPP and LAELIK120CPP (B). Theoretical and experimental values for number of aminoacids constituting the ELRs.

A

\begin{tabular}{ccccccccc} 
& \multicolumn{2}{c}{ VOKx48 } & \multicolumn{2}{c}{ VOKx72 } & \multicolumn{2}{c}{ IKx30HPGx3 } & \multicolumn{2}{c}{ VOKx48HPGx1 } \\
Aa & Th. & Exp. & Th. & Exp. & Th. & Exp. & Th. & Exp. \\
Glu & 1 & 0.65 & 1 & 0.82 & 1 & 2.87 & 1 & 2.13 \\
Ser & 1 & 1.35 & 1 & 0.73 & 1 & 1.67 & 1 & 1.34 \\
His & 0 & 0 & 0 & 0 & 138 & 133.10 & 46 & 44.01 \\
Gly & 96 & 101.25 & 144 & 148.64 & 204 & 195.50 & 144 & 145.14 \\
Val & 49 & 44.82 & 73 & 74.68 & 37 & 44.41 & 51 & 49.82 \\
Met & 1 & 0.48 & 1 & 0.52 & 1 & 1.07 & 1 & 1.10 \\
Ile & 0 & 0 & 0 & 0 & 24 & 23.22 & 0 & 0 \\
Leu & 2 & 2.59 & 2 & 1.83 & 2 & 2.54 & 2 & 2.20 \\
Lys & 48 & 48.31 & 72 & 75.65 & 6 & 5.27 & 48 & 50.13 \\
Pro & 49 & 49.83 & 73 & 74.09 & 103 & 106.56 & 73 & 71.39 \\
\hline
\end{tabular}

B

\begin{tabular}{ccccccc} 
& \multicolumn{2}{c}{ IK120 } & \multicolumn{2}{c}{ IK120CPP } & \multicolumn{2}{c}{ LAELIK120CPP } \\
Aa & Th. & Exp. & Th. & Exp. & Th. & Exp. \\
Glu & 1 & 1.14 & 1 & 1.10 & 4 & 6.20 \\
Asn & 0 & 0 & 1 & 0.96 & 1 & 3.49 \\
Ser & 1 & 1.29 & 1 & 1.58 & 1 & 3.80 \\
His & 0 & 0 & 0 & 0 & 0 & 0 \\
Gln & 0 & 0 & 2 & 0 & 2 & 3.10 \\
Gly & 240 & 255.41 & 240 & 241.35 & 240 & 236.48 \\
Arg & 0 & 0 & 3 & 1.82 & 3 & 4.26 \\
Ala & 0 & 0 & 0 & 0 & 3 & 8.14 \\
Val & 120 & 116.81 & 122 & 124.33 & 123 & 120.76 \\
Met & 1 & 0.72 & 2 & 1.83 & 2 & 2.33 \\
Trp & 0 & 0 & 2 & 2.13 & 2 & 1.94 \\
Phe & 0 & 0 & 1 & 0.10 & 1 & 1.74 \\
Ile & 96 & 97.34 & 98 & 101.18 & 98 & 98.86 \\
Leu & 2 & 3.51 & 2 & 2.68 & 8 & 10.86 \\
Lys & 24 & 23.23 & 28 & 27.41 & 28 & 27.12 \\
Pro & 121 & 118.59 & 121 & 121.89 & 121 & 114.36 \\
\hline
\end{tabular}

The number of the experimental amino acid residues was similar to the theoretical predicted from the nucleic acid sequence. Differences between both values were attributed to the experimental error associated with the technique. In light to this data, mutations affecting the genetic sequence from ELRs that may lead to variations in size and aminoacid sequence together with impurities present in bacteria were rejected. 


\section{A.3.4. ${ }^{1} \mathrm{H}$ NUCLEAR MAGNETIC RESONANCE SPECTROSCOPY}

Additionally, ${ }^{1} \mathrm{H}$ nuclear magnetic resonance spectroscopy ( $\left.{ }^{1} \mathrm{H}-\mathrm{NMR}\right)$ was performed to continue the evaluation of the ELRs purity (Figure 4A.34-40).

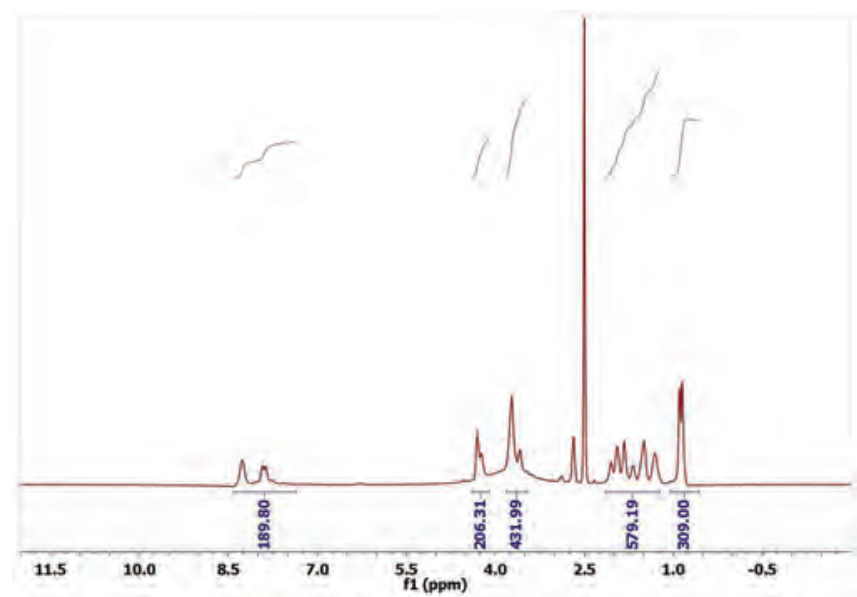

Figure 4A.34. 'H-NMR for the polymer VOKx48. Nuclear magnetic resonance spectra: ' $\mathrm{H}-\mathrm{RMN}\left(400 \mathrm{MHz},\left(\mathrm{CD}_{3}\right)_{2} \mathrm{SO}\right)$ : $\delta$ 8.38-8.08 and 8.01-7.47 (192H, br, $\left.-\mathrm{NH}\right), 4.46-4.09$ and 3.80-3.43 $\left(530 \mathrm{H}, \mathrm{br}, \alpha-\mathrm{CH}-\mathrm{Val}+\alpha-\mathrm{CH}\right.$ - Pro $+\alpha-\mathrm{CH}$ - Lys $+-\mathrm{CH}_{2}-\mathrm{Gly}+\delta \mathrm{CH}_{2}-$ Pro and $\varepsilon \mathrm{CH}_{2}$-Lys $+\alpha-\mathrm{CH}-\mathrm{Met}+\alpha-\mathrm{CH}-\mathrm{Glu}+\alpha-\mathrm{CH}-\mathrm{Ser},+\alpha$ and $\left.\gamma-\mathrm{CH}-\mathrm{Leu}\right), 2.14-1.23$ $\left(498 \mathrm{H}, \mathrm{m}, \beta\right.$ and $\mathrm{Y} \mathrm{CH}_{2}$-Pro; $\beta+\mathrm{Y}$ and $\delta \mathrm{CH}_{2}$-Lys $+\mathrm{Y}$ and $\beta \mathrm{CH}_{2}-$ Met $+Y$ and $\delta \mathrm{CH}_{2}$ $\mathrm{Glu}+\mathrm{CH}_{2}$-Leu and $\mathrm{CH}_{2}$-Ser), 0.96-0.62 (309H, d, $\mathrm{CH}\left(\mathrm{CH}_{3}\right)_{2}-\mathrm{Val}+\mathrm{CH}\left(\mathrm{CH}_{3}\right)_{2}$-Leu and $\left.\mathrm{CH}_{3} \mathrm{~S}-\mathrm{CH}_{2}-\mathrm{Met}\right)$.

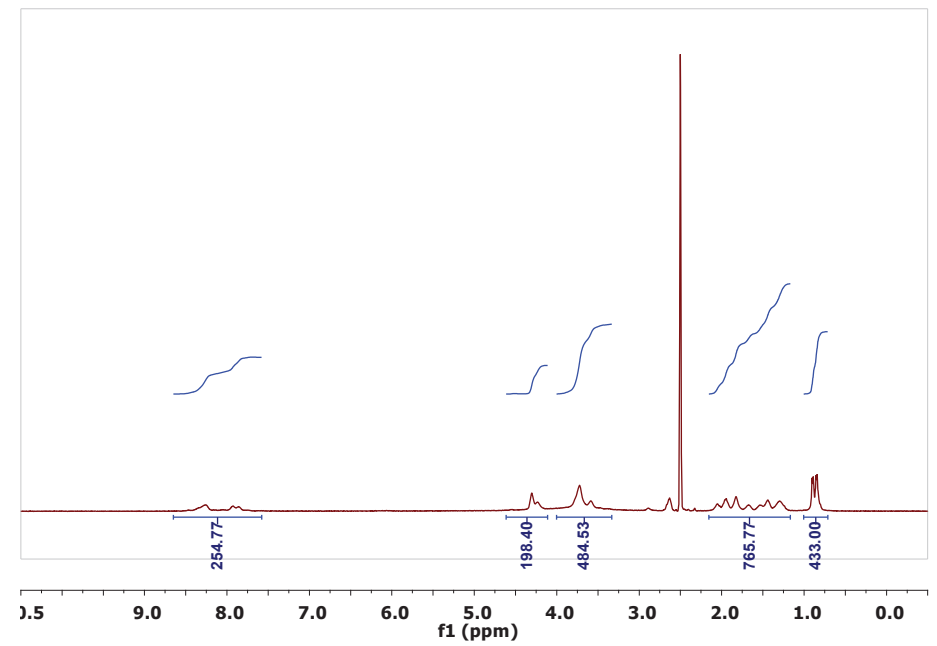

Figure 4A.35. 'H-NMR for the polymer VOKx72. Nuclear magnetic resonance spectra: ${ }^{1} \mathrm{H}-\mathrm{RMN}\left(400 \mathrm{MHz},\left(\mathrm{CD}_{3}\right)_{2} \mathrm{SO}\right): \delta 8.44-8.23$ and 8.18-7.88 (288H, br, $\left.-\mathrm{NH}\right), 4.45-4.24$ and 3.67-3.50 (792H, br, $\alpha-\mathrm{CH}-\mathrm{Val}+\alpha-\mathrm{CH}$ - Pro $+\alpha-\mathrm{CH}$ - Lys $+-\mathrm{CH}_{2}-\mathrm{Gly}+\delta \mathrm{CH}_{2}-\mathrm{Pro}$ and $\varepsilon \mathrm{CH}_{2}$-Lys $+\alpha-\mathrm{CH}$ - Met $+\alpha-\mathrm{CH}-\mathrm{Glu}+\alpha-\mathrm{CH}-\mathrm{Ser},+\alpha$ and $\left.\mathrm{y}-\mathrm{CH}-\mathrm{Leu}\right), 2.14-1.64$ and 1.60-1.35 (746H, m, $\beta$ and $Y \mathrm{CH}_{2}$-Pro $+\beta, \mathrm{Y}$ and $\delta \mathrm{CH}_{2}$-Lys $+\mathrm{Y}$ and $\beta \mathrm{CH}_{2}$-Met+ $\mathrm{Y}$ and $\delta \mathrm{CH}_{2}$-Glu+ $\mathrm{CH}_{2}$-Leu and $\mathrm{CH}_{2}$-Ser), 0.97-0.75 $\left(433 \mathrm{H}, \mathrm{d}, \mathrm{CH}\left(\mathrm{CH}_{3}\right)_{2}\right.$ - $\mathrm{Val}+$ $\mathrm{CH}\left(\mathrm{CH}_{3}\right)_{2}$ Leu and $\mathrm{CH}_{3} \mathrm{~S}-\mathrm{CH}_{2}-\mathrm{Met}$ ). 


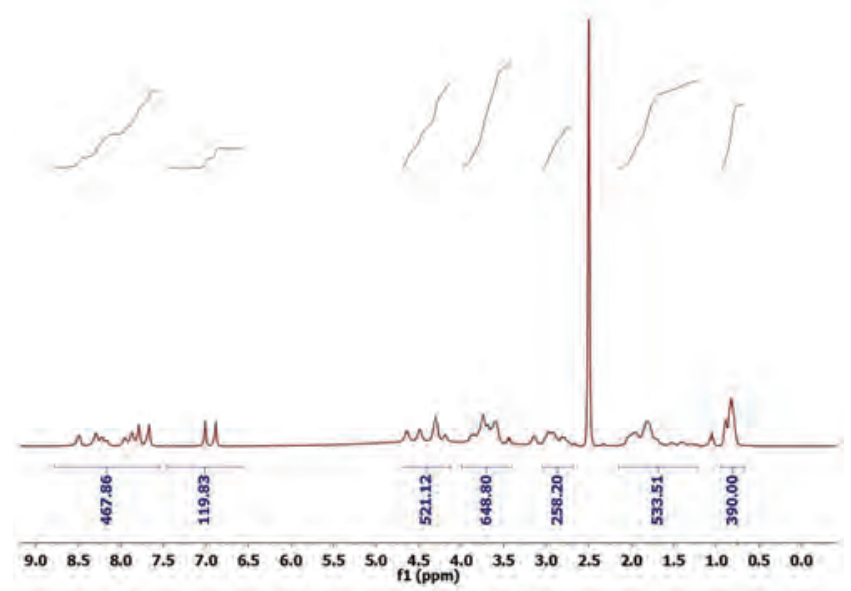

Figure 4A.36. 'H-NMR for the polymer IK×3OHPGx3. Nuclear magnetic resonance spectra: ' $\mathrm{H}-\mathrm{RMN}\left(400 \mathrm{MHz},\left(\mathrm{CD}_{3}\right)_{2} \mathrm{SO}\right): \delta 8.50-7.63\left(492 \mathrm{H}, \mathrm{br},-\mathrm{NH}+\mathrm{His}_{-} \mathrm{C}_{5} \mathrm{H}\right), 7.36-$ 6.71 (276H, br, Ar-H), 4.7-4.12, 3.9-3.49 and 3.2-3.1 (1199H, br, $\alpha-\mathrm{CH}-\mathrm{Val}+\alpha-\mathrm{CH}-$ Pro $+\alpha-\mathrm{CH}-\mathrm{Lys}+\alpha-\mathrm{CH}-\mathrm{Met}+\alpha-\mathrm{CH}-\mathrm{Glu}+\alpha-\mathrm{CH}-\mathrm{Ser},+\alpha$ and $\mathrm{y}-\mathrm{CH}-\mathrm{Leu}+\alpha$ and $\beta-\mathrm{CH}$ - Iso $+\alpha$ and $\gamma-\mathrm{CH}$ - His - $\mathrm{CH}_{2}-\mathrm{Gly}+\delta \mathrm{CH}_{2}-\mathrm{Pro}+\varepsilon \mathrm{CH}_{2}$-Lys $+\beta \mathrm{CH}_{2}$-His), 2.14-1.21 $\left(510 \mathrm{H}, \mathrm{m}, \beta\right.$ and $\mathrm{Y} \mathrm{CH}_{2}$-Pro $+\beta, \mathrm{Y}$ and $\delta \mathrm{CH}_{2}$-Lys $+\mathrm{Y}$ and $\beta \mathrm{CH}_{2}$-Met+ $\mathrm{Y}$ and $\delta \mathrm{CH}_{2}-$ $\mathrm{Glu}+\mathrm{CH}_{2}$ - $\mathrm{Leu}+\mathrm{CH}_{2}$-Ser and $\mathrm{Y} \mathrm{CH}_{2}$-lso), 0.99-0.52 $\left(390 \mathrm{H}, \mathrm{d}, \mathrm{CH}\left(\mathrm{CH}_{3}\right)_{2}-\mathrm{Val}+\mathrm{CH}_{3}-\right.$ $\mathrm{CH}_{2}$-Iso $+\mathrm{CH}\left(\mathrm{CH}_{3}\right)_{2}$.Leu and $\left.\mathrm{CH}_{3} \mathrm{~S}-\mathrm{CH}_{2}-\mathrm{Met}\right)$.

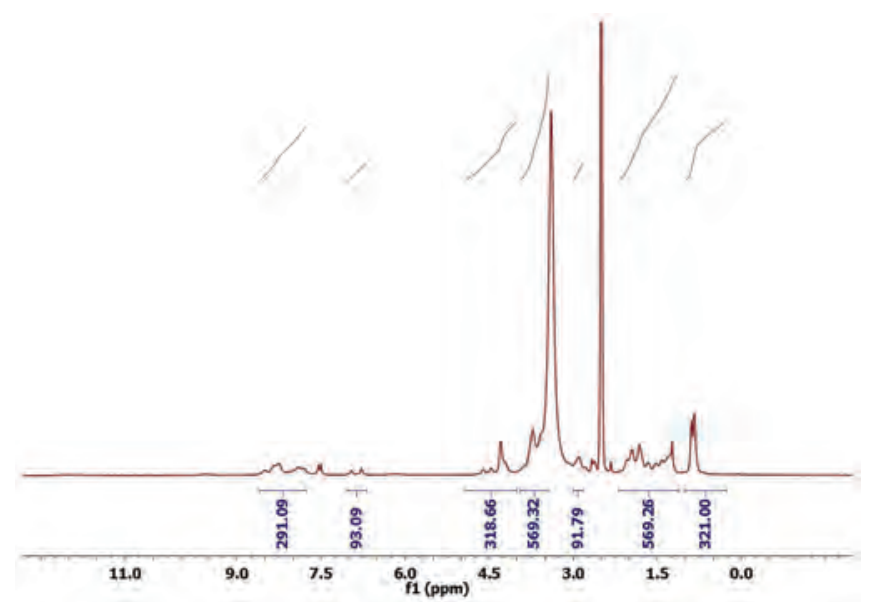

Figure 4A.37. 'H-NMR for the polymer VOKx48HPG. Nuclear magnetic resonance spectra: ' $\mathrm{H}-\mathrm{RMN}\left(400 \mathrm{MHz},\left(\mathrm{CD}_{3}\right)_{2} \mathrm{SO}\right): \delta 8.65-7.70(291, \mathrm{br},-\mathrm{NH}), 7.84-7.70(46 \mathrm{H}, \mathrm{br}$, His- $\left.\mathrm{C}_{5} \mathrm{H}\right), 7.01-6.70(92 \mathrm{H}, \mathrm{br}, \mathrm{Ar}-\mathrm{H}), 4.89-4.01,3.93-3.43$ and 3.0-2.8 $(942 \mathrm{H}, \mathrm{br}, \alpha-$ $\mathrm{CH}-\mathrm{Val}+\alpha-\mathrm{CH}$ - Pro $+\alpha-\mathrm{CH}$ - Lys $+\alpha-\mathrm{CH}-\mathrm{Met}+\alpha-\mathrm{CH}-\mathrm{Glu}+\alpha-\mathrm{CH}-\mathrm{Ser},+\alpha$ and $\gamma-$ $\mathrm{CH}$ - Leu $+\alpha$ and $\delta-\mathrm{CH}$ - His $-\mathrm{CH}_{2}-\mathrm{Gly}+\delta \mathrm{CH}_{2}$-Pro $+\varepsilon \mathrm{CH}_{2}$-Lys $+\beta \mathrm{CH}_{2}$-His), 2.17-1.11 $\left(594 \mathrm{H}, \mathrm{m}, \beta\right.$ and $Y \mathrm{CH}_{2}$-Pro $+\beta$, $Y$ and $\delta \mathrm{CH}_{2}$-Lys $+Y$ and $\beta \mathrm{CH}_{2}$-Met+ $Y$ and $\delta \mathrm{CH}_{2}-$ Glu+ $\mathrm{CH}_{2}$-Leu and $\mathrm{CH}_{2}$-Ser), 1.0-0.3 $\left(321 \mathrm{H}, \mathrm{d}, \mathrm{CH}\left(\mathrm{CH}_{3}\right)_{2}-\mathrm{Val}+\mathrm{CH}\left(\mathrm{CH}_{3}\right)_{2}\right.$-Leu and $\left.\mathrm{CH}_{3} \mathrm{~S}-\mathrm{CH}_{2}-\mathrm{Met}\right)$. 


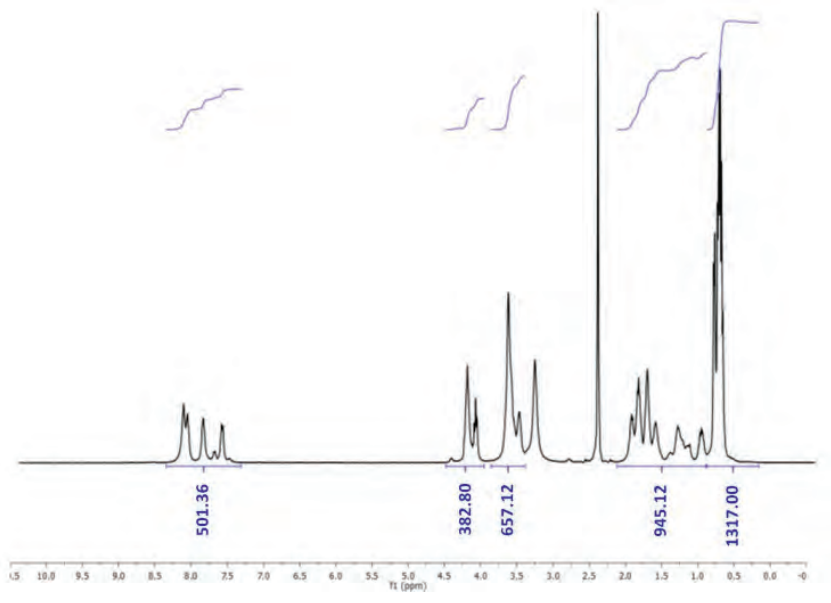

Figure 4A.38. ' $\mathrm{H}-\mathrm{NMR}$ for the polymer IK120. Nuclear magnetic resonance spectra: ${ }^{1} \mathrm{H}-$ RMN $\left(400 \mathrm{MHz},\left(\mathrm{CD}_{3}\right)_{2} \mathrm{SO}\right): \delta$ 8.46-7.45 $(528 \mathrm{H}, \mathrm{br},-\mathrm{NH}), 4.68-4.12(360 \mathrm{H}, \mathrm{br}, \alpha-\mathrm{CH}-$ $\mathrm{Val}+\alpha-\mathrm{CH}-$ Pro $+\alpha-\mathrm{CH}$ - Lys $+\alpha-\mathrm{CH}-\mathrm{Met}+\alpha-\mathrm{CH}-\mathrm{Glu}+\alpha-\mathrm{CH}-\mathrm{Ser},+\alpha$ and $\mathrm{y}-\mathrm{CH}-$ Leu and $\alpha$ and $\beta-\mathrm{CH}$ - Iso), 3.95-3.49, 2.23-1.11 (1608H, $\mathrm{m},+\delta \mathrm{CH}_{2}-$ Pro $+\varepsilon \mathrm{CH}_{2}$-Lys + $\beta$ and $Y \mathrm{CH}_{2}$-Pro $+\beta$, $Y$ and $\delta \mathrm{CH}_{2}$-Lys $+Y$ and $\beta \mathrm{CH}_{2}$-Met+ $Y$ and $\delta \mathrm{CH}_{2}$ - $\mathrm{Glu}+\mathrm{CH}_{2}-$ Leu $+\mathrm{CH}_{2}$-Ser and $\mathrm{Y} \mathrm{CH}_{2}$-Iso), 0.99-0.26 (1317H, d, $\mathrm{CH}\left(\mathrm{CH}_{3}\right)_{2}-\mathrm{Val}+\mathrm{CH}_{3}-\mathrm{CH}_{2}$-Iso + $\mathrm{CH}\left(\mathrm{CH}_{3}\right)_{2}$-Leu and $\mathrm{CH}_{3} \mathrm{~S}-\mathrm{CH}_{2}-$ Met).

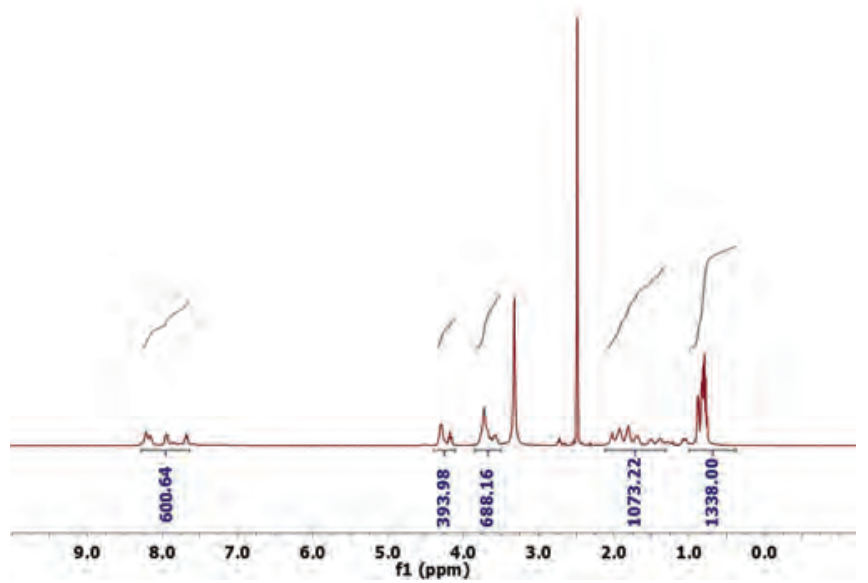

Figure 4A.39. ' $\mathrm{H}-\mathrm{NMR}$ for the polymer IK120CPP. Nuclear magnetic resonance spectra: 'H-RMN (400 MHz, $\left.\left(\mathrm{CD}_{3}\right)_{2} \mathrm{SO}\right): \delta$ 8.46-7.55 (580, br, $\left.-\mathrm{NH}\right), 4.45-4.12(384 \mathrm{H}, \mathrm{br}, \alpha-$ $\mathrm{CH}-\mathrm{Val}+\alpha-\mathrm{CH}$ - Pro $+\alpha-\mathrm{CH}$ - Lys $+\alpha-\mathrm{CH}-\mathrm{Met}+\alpha-\mathrm{CH}-\mathrm{Glu}+\alpha-\mathrm{CH}-\mathrm{Ser},+\alpha$ and $\gamma-$ $\mathrm{CH}-\mathrm{Leu}+\alpha$ and $\beta-\mathrm{CH}-\mathrm{Iso}+\alpha-\mathrm{CH}-\mathrm{Arg}+\alpha-\mathrm{CH}-\mathrm{Asn}+\alpha-\mathrm{CH}-\mathrm{Phe}+\alpha-\mathrm{CH}-\mathrm{Gln}+\alpha-\mathrm{CH}-$ Trp), 3.95-3.52, 2.12-1.41 (1678H, m, $+\delta \mathrm{CH}_{2}$-Pro $+\varepsilon \mathrm{CH}_{2}$ - $\mathrm{Lys}+\beta$ and $\mathrm{y} \mathrm{CH}_{2}$-Pro $+\beta$, $Y$ and $\delta \mathrm{CH}_{2}$-Lys $+Y$ and $\beta \mathrm{CH}_{2}$-Met+ $Y$ and $\delta \mathrm{CH}_{2}$-Glu+ $\mathrm{CH}_{2}$-Leu $+\mathrm{CH}_{2}$-Ser $+Y$ $\mathrm{CH}_{2}$-Iso $+\beta, \mathrm{Y}$ and $\delta \mathrm{CH}_{2}-\mathrm{Arg}+\beta \mathrm{CH}_{2}-\mathrm{Asn}+\beta \mathrm{CH}_{2}-\mathrm{Phe}+\beta$ and $\mathrm{y} \mathrm{CH}_{2}-\mathrm{Gln}+\beta \mathrm{CH}_{2}-$ Trp), 0.99-0.24 (1338H, d, $\mathrm{CH}\left(\mathrm{CH}_{3}\right)_{2}-\mathrm{Val}+\mathrm{CH}_{3}-\mathrm{CH}_{2}$-Iso $+\mathrm{CH}\left(\mathrm{CH}_{3}\right)_{2}$-Leu and $\mathrm{CH}_{3} \mathrm{~S}$ $\mathrm{CH}_{2}$-Met). 


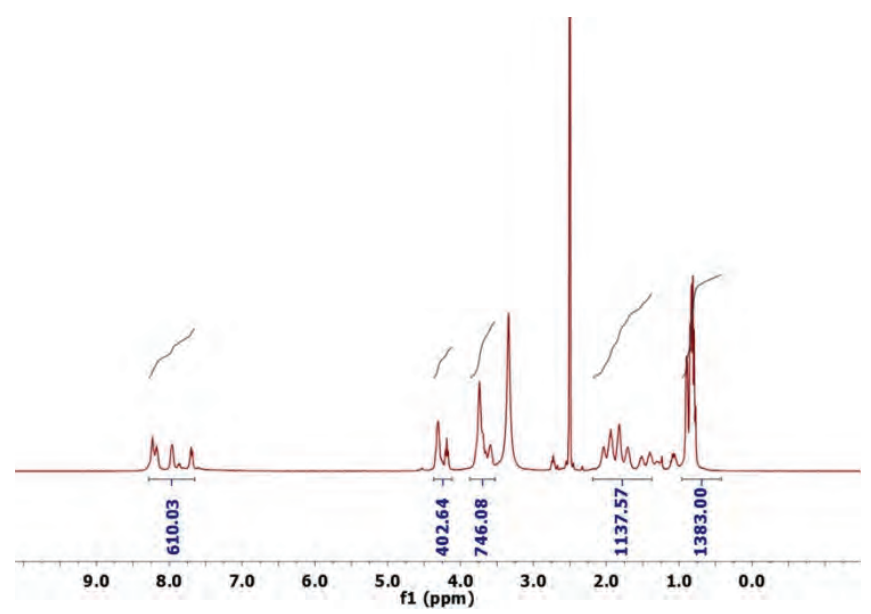

Figure 4A.40. 'H-NMR for the polymer LAELIK120CPP. 'H-RMN $\left(400 \mathrm{MHz},\left(\mathrm{CD}_{3}\right)_{2} \mathrm{SO}\right): \delta$ 8.46-7.55 $(591 \mathrm{H}, \mathrm{br},-\mathrm{NH}), 4.37-4.08(396 \mathrm{H}, \mathrm{br}, \alpha-\mathrm{CH}-\mathrm{Val}+\alpha-\mathrm{CH}$ - Pro $+\alpha-\mathrm{CH}$ - Lys $+\alpha-\mathrm{CH}-\mathrm{Met}+\alpha-\mathrm{CH}-\mathrm{Glu}+\alpha-\mathrm{CH}-\mathrm{Ser},+\alpha$ and $\mathrm{y}-\mathrm{CH}-\mathrm{Leu}+\alpha$ and $\beta-\mathrm{CH}-\mathrm{Iso}+\alpha-$ $\mathrm{CH}-\mathrm{Arg}+\alpha-\mathrm{CH}-\mathrm{Asn}+\alpha-\mathrm{CH}-\mathrm{Phe}+\alpha-\mathrm{CH}-\mathrm{Gln}+\alpha-\mathrm{CH}-\mathrm{Trp}$ and $\alpha-\mathrm{CH}-\mathrm{Ala}), 3.89-3.53$, 2.17-1.36 (1702H, $m,+\delta \mathrm{CH}_{2}$-Pro $+\varepsilon \mathrm{CH}_{2}$-Lys $+\beta$ and $\mathrm{Y} \mathrm{CH}_{2}$-Pro $+\beta, \mathrm{Y}$ and $\delta \mathrm{CH}_{2}-$ Lys $+Y$ and $\beta \mathrm{CH}_{2}$-Met+ $\mathrm{Y}$ and $\delta \mathrm{CH}_{2}$-Glu $+\mathrm{CH}_{2}$-Leu $+\mathrm{CH}_{2}$-Ser $+Y \mathrm{CH}_{2}$-Iso $+\beta$, $Y$ and $\delta \mathrm{CH}_{2}$-Arg $+\beta \mathrm{CH}_{2}$-Asn $+\beta \mathrm{CH}_{2}$-Phe $+\beta$ and $\mathrm{Y} \mathrm{CH}_{2}-\mathrm{Gln}+\beta \mathrm{CH}_{2}$-Trp), 0.97-0.40 $\left(1383 \mathrm{H}, \mathrm{d}, \mathrm{CH}\left(\mathrm{CH}_{3}\right)_{2}-\mathrm{Val}+\mathrm{CH}_{3}-\mathrm{CH}_{2}\right.$-Iso $+\mathrm{CH}\left(\mathrm{CH}_{3}\right)_{2}$ Leu $+\mathrm{CH}_{3} \mathrm{~S}-\mathrm{CH}_{2}$-Met and $\mathrm{CH}_{3}$ CH-Ala).

Differences between the experimental and theoretical data in all polymers are attributed to the experimental error of the technique. ${ }^{1} \mathrm{H}$ from amino groups appeared at 8.5-7.5 ppm, ${ }^{1} \mathrm{H}$ bound to aromatic residues appeared about $7.0 \mathrm{ppm}$, $\mathrm{CH}$ about 5.0-4.0, $\mathrm{CH}_{2}$ 4.0-3.5 and 2.0-1.0 and $\mathrm{CH}_{3}$ about 1 ppm. This technique allowed the evaluation of the purity grade of our polymers as well.

VOKx48 and VOKx72 polymers are very similar in amino-acid composition. VOKx72 possess more repetitions of VPGKG pentapeptide which was reflected in the ${ }^{1} \mathrm{H}-\mathrm{NMR}$ spectra mainly in terms of ${ }^{1} \mathrm{H}$ from amines $(255 \mathrm{H}$ of VOKx72 and $190 \mathrm{H}$ of VOKx48)and $\mathrm{CH}_{3}(433 \mathrm{H}$ of VOKx72 and $309 \mathrm{H}$ of VOKx48).

It is interesting to note that polymers containing both lysines and histidines such as IKx30HPGx3 and VOKx48HPGx1, the main contribution of ${ }^{1} \mathrm{H}$ at position 8.5-7.5 ppm belonged to $\varepsilon-\mathrm{NH}$ from lysine together with a-NH, $\mathrm{H}-\mathrm{N}_{1}$ and $\mathrm{H}-\mathrm{C}_{5}$ from histidine being $468 \mathrm{H}$ for IKx30HPGx3 and $292 \mathrm{H}$ for VOKx48HPGx1. Thus, the presence of histidines in polymers was indicated by two peaks from the aromatic ring $\mathrm{H}-\mathrm{C}_{4}$ and $\mathrm{H}-\mathrm{C}_{2}$ at about $7.0 \mathrm{ppm}$, being $120 \mathrm{H}$ for IKx30HPGx3 and $93 \mathrm{H}$ for VOKx48HPGx1. In IKx30HPGx1 the expected integral was $276 \mathrm{H}$, however the obtained value was less 
than the half. This may be attributed to difficulties in resonance probably due to the buried disposition of $\mathrm{H}$ in the aromatic ring or interactions with impurities. Indeed, the higher number of ${ }^{1} \mathrm{H}$ in IKx30HPG $\times 3$ at these chemical shifts was according with its higher number of histidines (138 histidines) in comparison with VOKx48HPGx1 (46 histidines).

Additionally, the spectra of IK120 based polymers were also very similar with slight variations in ${ }^{1} \mathrm{H}$ from $\mathrm{NH}$ and $\mathrm{CH}_{3}$ due to the incorporation of penetratin and $\mathrm{LAEL}$ peptide. Being LAELIK120CPP the polymer with the higher signal at those chemical shifts $(610 \mathrm{H}$ at position $8.5-7.5 \mathrm{ppm}$ and $1383 \mathrm{H} 1.0-0.5 \mathrm{ppm})$.

In all the cases the ${ }^{1} \mathrm{H}-\mathrm{NMR}$ spectra showed ELRs with acceptable chemical composition and levels of purity.

\section{A.3.5. THERMAL BEHAVIOUR OF ELRs BY DIFFERENTIAL SCANNING CALORIMETRY}

In order to evaluate whether the ELRs posses their expected smart properties, differential scanning calorimetry (DSC) assays following the method depicted in (3.2.4.4) were accomplished (Figure 4A.41-47). The polymers were dissolved in PBS at $50 \mathrm{mg} / \mathrm{mL}$. PBS ( $\mathrm{pH}$ 7.4) was used because recreate the physiological conditions where polymers would act. The heating program for DSC measurements included an initial isothermal stage $\left(5 \mathrm{~min}\right.$ at $\left.0{ }^{\circ} \mathrm{C}\right)$, followed by heating at $5{ }^{\circ} \mathrm{C} / \mathrm{min}$ from $0{ }^{\circ} \mathrm{C}$ to the desired temperature.



Figure 4A.41.DSC for the polymer VOKx48 in PBS solvent. It showed a $T \mathrm{t}>60^{\circ} \mathrm{C}$. 


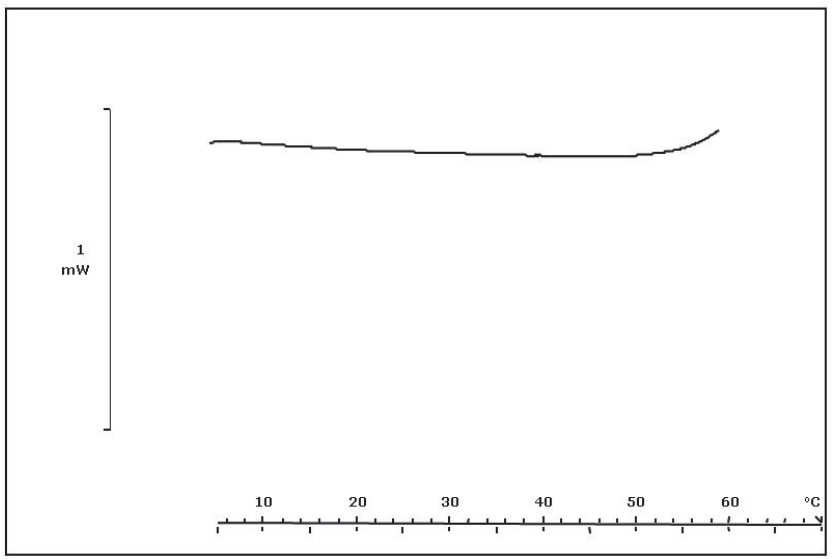

Figure 4A.42.DSC for the polymer VOKx72 in PBS solvent. It showed a $\mathrm{Tt}>60^{\circ} \mathrm{C}$.

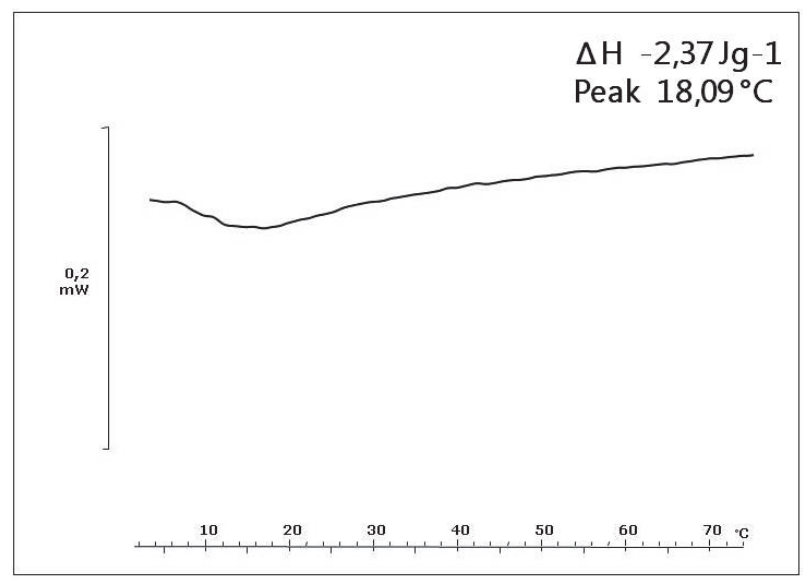

Figure 4A.43.DSC for the polymer IKx30HPGx3. IKx30HPGx3 shows an endothermic process with a $\mathrm{Tt}$ of $18.09^{\circ} \mathrm{C}$ in $\mathrm{PBS}$ solvent.

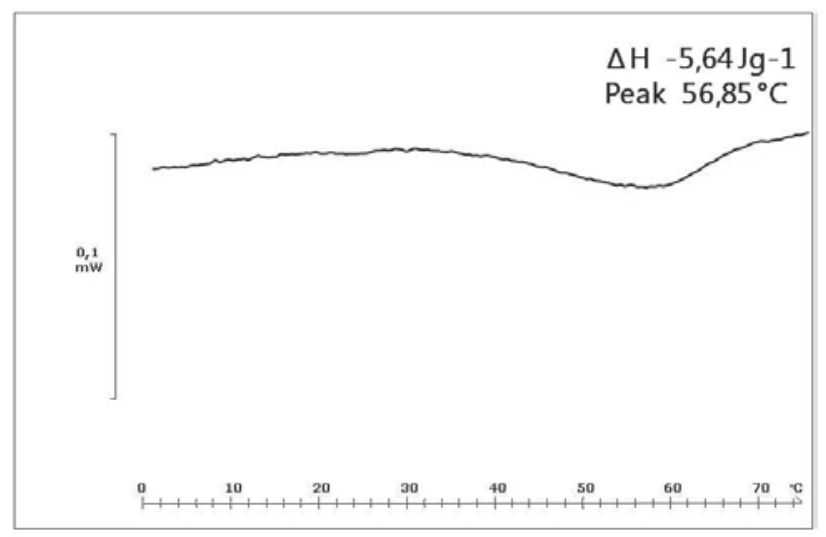

Figure 4A.44.DSC for the polymer VOKx48HPGx1. VOKx48HPGx1 shows an endothermic process with a Tt of $56.85^{\circ} \mathrm{C}$ in PBS solvent. 


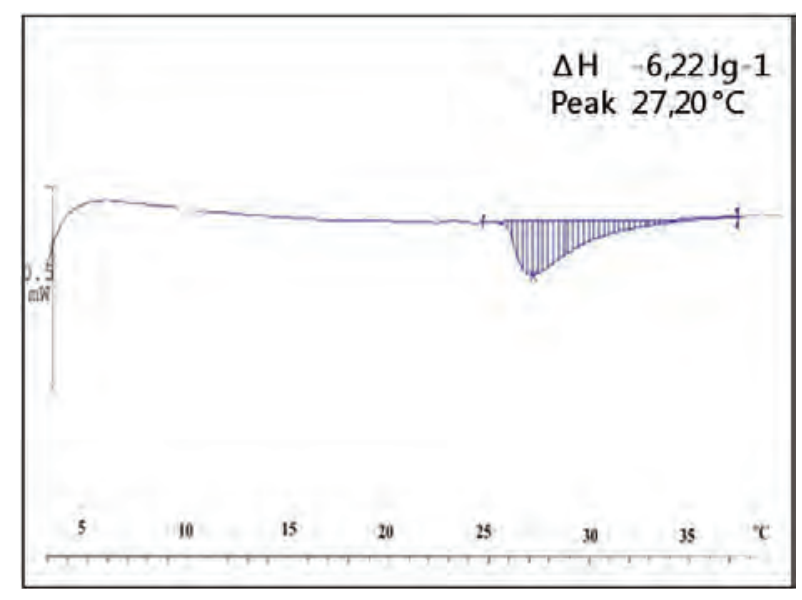

Figure 4A.45.DSC for the polymer IK120. IK120 shows an endothermic process with a $\mathrm{Tt}$ of $27.20^{\circ} \mathrm{C}$ in PBS solvent.

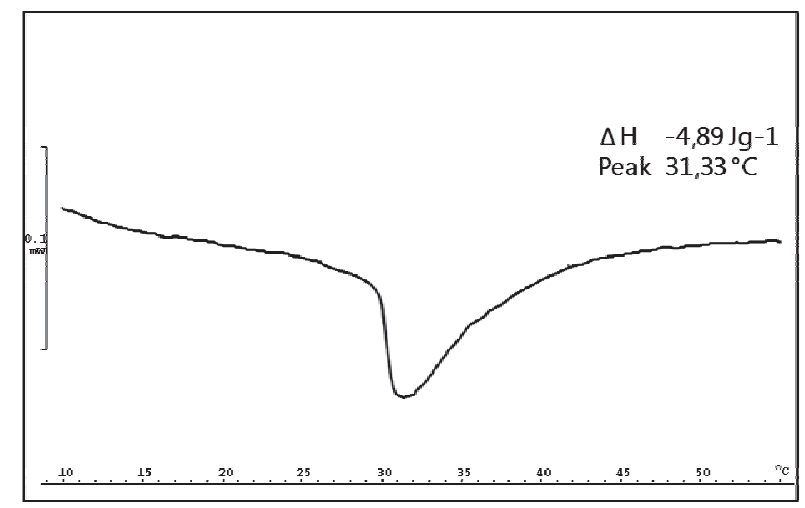

Figure 4A.46.DSC for the polymer IK120CPP. IK120CPP shows an endothermic process with a $\mathrm{Tt}$ of $31.33^{\circ} \mathrm{C}$ in PBS solvent.

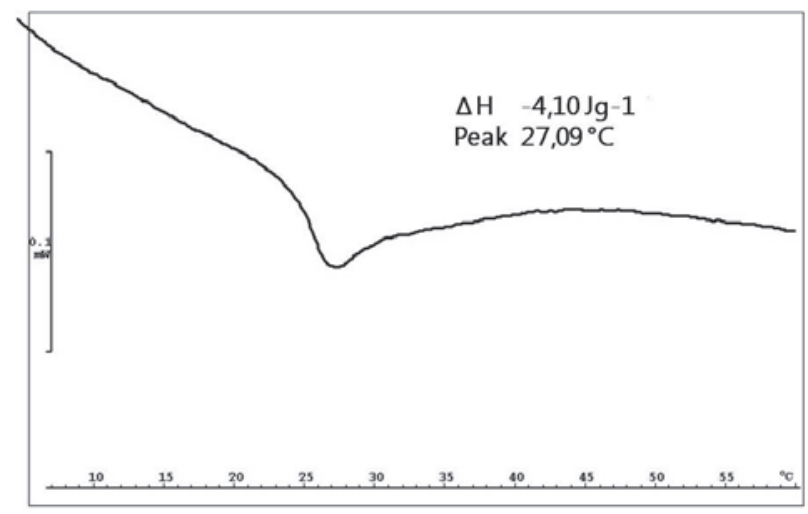

Figure 4A.47.DSC for the polymer LAELIK120CPP. LAELIK120CPP shows an endothermic process with a Tt of $27.09^{\circ} \mathrm{C}$ in PBS solvent. 
In all cases, enthalpy values for endothermic processes were taken as negative and exothermic values as positive. In DSC curves, endothermic transition was shown for all polymers. This transition was due to the change from a disordered state of ELR random coils in hydrophobic hydration to one dense and ordered state where ELR loses its hydrophobic hydration mediated by water clathrate structures and adopts the $\beta$-spiral conformation (329). The temperature at which this conformational change happened named as Tt correlated with the endothermic peak using this technique. As shown in the DSC curves, some differences between them could be observed depending on their aminoacid composition. In VOKx48 and VOKx72 with the highest presence of lysines, the $\mathrm{Tt}>60^{\circ} \mathrm{C}$ was the highest among the analyzed polymers (Figures 4A.41-42). By contrast, when HPGx1 block was bound to VOKx48, the Tt decreased to $56.85^{\circ} \mathrm{C}$ (Figure 4A.44), due to the incorporation of histidines (pKa of the imidazole group of 6.9) instead of lysines (pKa of 10.53 of lysine $\varepsilon$-amino group). Additionally, when the amount of lysines in the polymer decreased down to 24-27 (IK120, IK120CPP and LAELIK120CPP) the Tt decreased considerably to $27-31^{\circ} \mathrm{C}$ (Figures 4A.45-47). Differences among IK120 based polymers can be attributed to the CPP (enriched in arginines with pKa 12.48 and lysines) which increases the Tt and LAEL peptide (enriched in glutamic with a pKa of 4.3 in its side carboxylic group) which decreases the Tt. Finally when the number of lysines decreased down to 6 and histidines increased to 138 such as in IKx30HPGx3 polymer, the Tt resulted to be the lowest among the analyzed polymers (Tt $18.09^{\circ} \mathrm{C}$ ) (Figure 4A.43). Then, the $\mathrm{Tt}$ of the tested ELRs was shown to be highly influenced by the presence of lysines in their aminoacid sequence.

\section{A.3.6. DETERMINATION OF ENDOTOXIN LEVELS}

Endotoxin content of the recombinamers was evaluated from serial dilutions of each sample to determine the presence of a critical endotoxin concentration (3.2.3.5.1.). The IK120, IK120CPP and LAELIK120CPP showed values below 50 EU/mg (Table 4A.4) (1 EU $=100 \mathrm{pg}$ of endotoxin) which are suitable for in vitro assays (317). However VOKx72 reached values $<1 \mathrm{EU} / \mathrm{mg}$ which have been previously demonstrated to do not produce cellular adverse effects (315) and suggesting that the validity of this 
claim can only be fully assessed after determining the clinically-necessary doses and route of administration.

Table 4A.4. Summary of endotoxin levels of the produced ELRs. "Nd" means non determined.

\begin{tabular}{|c|c|}
\hline ELR & Endotoxin level (EU/mg) \\
VOKx48 & $<10$ \\
VOKx72 & $<1$ \\
IKx30HPGx3 & $\mathrm{Nd}$ \\
VOKx48HPGx1 & $\mathrm{Nd}$ \\
IK120 & $<50$ \\
IK120CPP & $<50$ \\
LAELIK120CPP & $<50$ \\
\hline
\end{tabular}

\section{A.4. CHEMICAL MODIFICATIONS OF ELRs AND CHARACTERIZATION}

With the objective to acquire new functionalities and specificities for ELRs, chemical modifications on IK120 and VOKx72 were performed.

\section{A.4.1. SYNTHESIS OF THE IMID-IK120 BIOPOLYMER}

The incorporation of imidazole group, which is naturally present in the histidine amino-acid, was thought to improve the buffering capacity of the polymer IK120 (88). The polymer IMID-IK120 was constructed by chemical incorporation of imidazole 2carboxylic acid into $\varepsilon$-amino groups of lysines contained in the IK120 polymer (Figure 4A.48). The amidation reaction was accomplished by incorporating a solution of 1 equiv. of IK120 ELR in MES buffer to 10 equiv. of 1-H-imidazole-2-carboxylic acid already activated as described in 3.2.5.1.

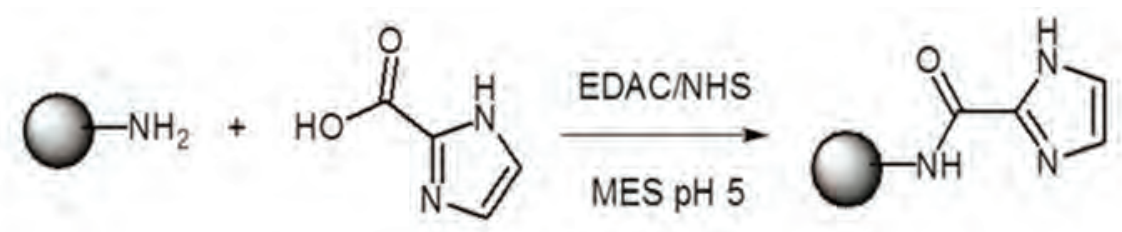

IK120

Figure 4A.48. Amidation reaction between the carboxyl groups from imidazole and the $\varepsilon$ amine from lysine amino acids in polymer IK 120.

The incorporation of imidazole groups was assessed by ${ }^{1} \mathrm{H}-\mathrm{NMR}$ assay and DSC. As shown in Figure 4A.49, the spectra showed signals at 7.7 ppm corresponding to $\mathrm{H}-\mathrm{N} 1$ 
and $\mathrm{H}-\mathrm{C} 5$ protons from imidazole. Additionally, the $\mathrm{CH}_{2}$ group vicinal to the amide groups appeared at $2.9 \mathrm{ppm}$. Both signals indicate the presence of imidazole groups in the IMID-IK120 obtained. Integration of peak at $2.9 \mathrm{ppm}$ led to a substitution percentage of $65 \%$, considering that $100 \%$ of substitution would correspond with $48 \mathrm{H}^{+}$instead of the about $31 \mathrm{H}^{+}$obtained at this chemical shift. This data means the incorporation of 16 molecules of imidazole in every molecule of IK120 (24 lysines). MALDI-TOF spectra showed the IMID-IK120 final product with a MW of $54.62 \mathrm{kDa}$ (Figure 4A.50) that in comparison with IK120 (51.86 kDa) indicates the incorporation of the 1-H-imidazole-2-carboxylic acids.

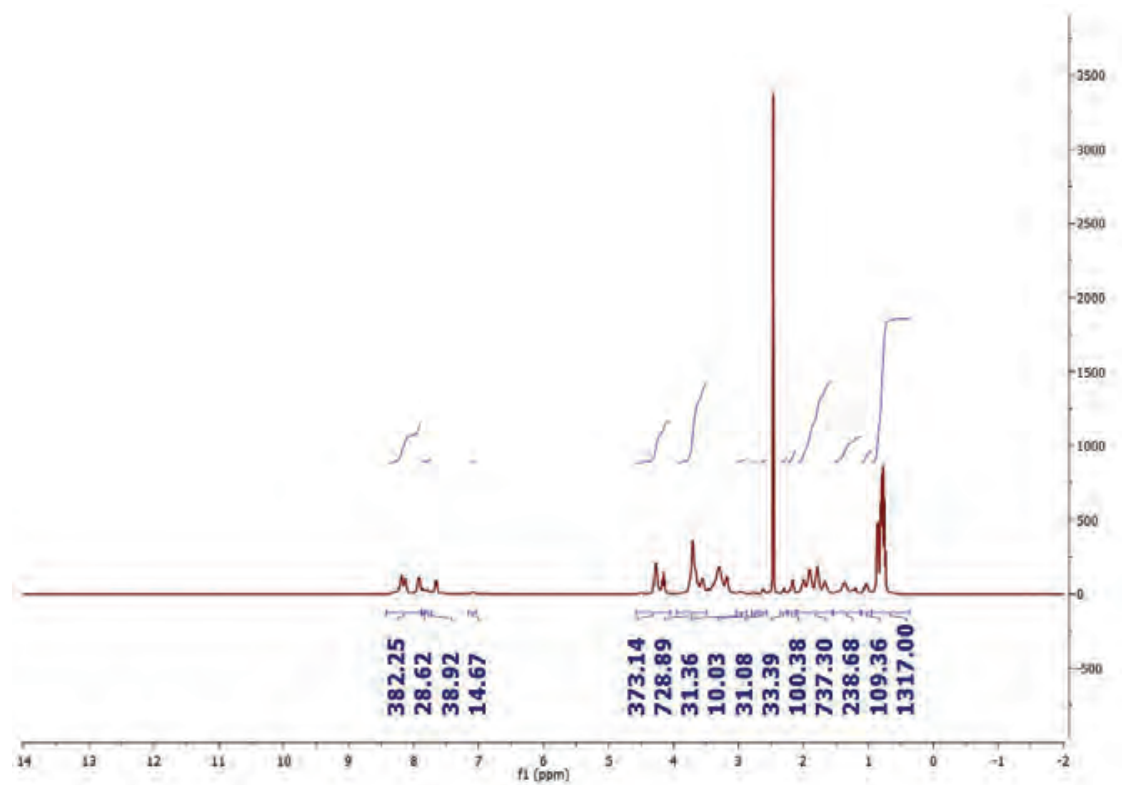

Figure 4A.49. 'H-NMR for the polymer IMID-IK120. Theoretical nuclear magnetic resonance spectra for $100 \%$ of substitution: ${ }^{1} \mathrm{H}-\mathrm{RMN}\left(400 \mathrm{MHz},\left(\mathrm{CD}_{3}\right)_{2} \mathrm{SO}\right)$ : $\delta$ 8.46-7.80 $(485 \mathrm{H}, \mathrm{br},-\mathrm{NH}), 7.14-7.05(24 \mathrm{H}, \mathrm{br}, \mathrm{Ar}-\mathrm{H}), 4.50-4.05(360 \mathrm{H}, \mathrm{br}, \alpha-\mathrm{CH}-\mathrm{Val}+\alpha-\mathrm{CH}-$ Pro $+\alpha-\mathrm{CH}$ - Lys $+\alpha-\mathrm{CH}-$ Met $+\alpha-\mathrm{CH}-\mathrm{Glu}+\alpha-\mathrm{CH}-\mathrm{Ser},+\alpha$ and $\mathrm{y}-\mathrm{CH}$ - Leu and $\alpha$ and $\beta$-CH- Iso), 3.95-3.48, 2.23-1.11 (1608H, $\mathrm{m},+\delta \mathrm{CH}_{2}$-Pro $+\varepsilon \mathrm{CH}_{2}$-Lys $+\beta$ and $Y$ $\mathrm{CH}_{2}$-Pro $+\beta, Y$ and $\delta \mathrm{CH}_{2}$-Lys $+Y$ and $\beta \mathrm{CH}_{2}$-Met+ $\mathrm{Y}$ and $\delta \mathrm{CH}_{2}$-Glu $+\mathrm{CH}_{2}$-Leu + $\mathrm{CH}_{2}$-Ser and $\mathrm{Y} \mathrm{CH}$-lso), 0.99-0.26 (1317H, d, $\mathrm{CH}\left(\mathrm{CH}_{3}\right)_{2}-\mathrm{Val}+\mathrm{CH}_{3}-\mathrm{CH}_{2}$-Iso + $\mathrm{CH}\left(\mathrm{CH}_{3}\right)_{2}$-Leu and $\left.\mathrm{CH}_{3} \mathrm{~S}-\mathrm{CH}_{2}-\mathrm{Met}\right)$. 


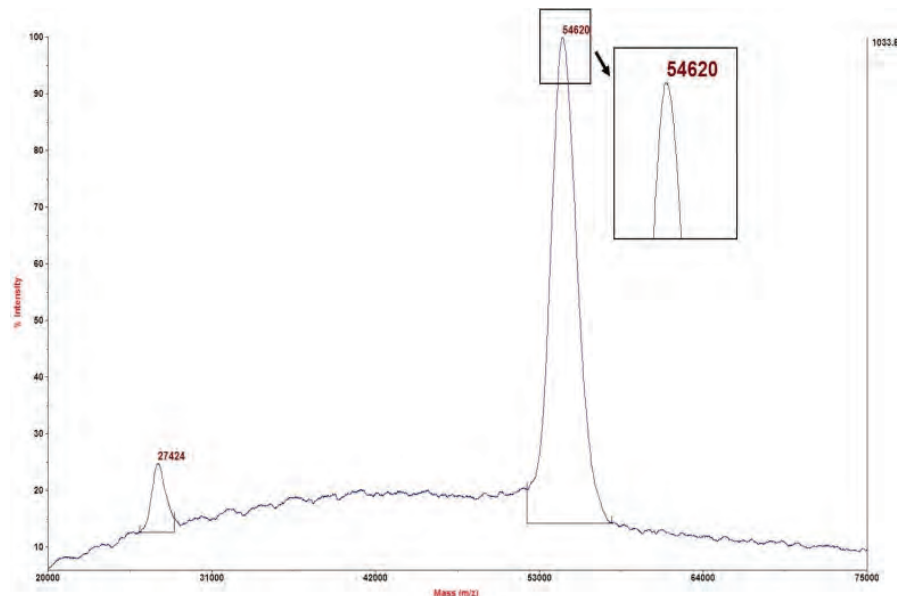

Figure 4A.50. MALDI-TOF spectra of IMID-IK120. The experimental mass of the polypeptide was $54.62 \mathrm{kDa}$. Signal at $27.42 \mathrm{kDa}$ is assigned at doubly charged species.

Moreover, a deeper study of the thermal behavior for IMID-IK120 was conducted (Figure 4A.51 and Table 4A.5). As such, the Tt increased as the polarity increased with decreasing $\mathrm{pH}$. Indeed at $\mathrm{pH} 10.7$, basification of the medium is sufficiently high that the amino groups of the lysines $\left(\mathrm{p} K_{\mathrm{a}}\right.$ 10.5) from the polymer are largely deprotonated. This reduced the mean polarity of the molecule, thereby producing a decrease in Tt to $18.5^{\circ} \mathrm{C}$. Moreover, as the $\mathrm{p} K_{\mathrm{a}}$ of the imidazole is around 6.9 , this group is deprotonated above $\mathrm{pH} 7$, thereby intensifying the reduction of Tt. However, the variation of $4.1^{\circ} \mathrm{C}$ in $\mathrm{Tt}$ at $\mathrm{pH} 10.7\left(18.5^{\circ} \mathrm{C}\right)$ to $8.0\left(22.6^{\circ} \mathrm{C}\right)$ indicated that not all the lysines had been modified with imidazole groups and that their amino groups had therefore been protonated. By contrast, the behavior of IK120 with pH was slightly different since it did not contain imidazole groups and the variation in Tt was mainly due to lysines. Thus, the highest variation on $\mathrm{Tt}$ of $9.7^{\circ} \mathrm{C}$ happened when the $\mathrm{pH}$ was increased from 8.0 to 10.7 . That difference in thermal behavior from $\mathrm{pH} 8.0$ to 10.7 between IMID-IK120 $\left(4.1^{\circ} \mathrm{C}\right)$ and IK120 $\left(9.7^{\circ} \mathrm{C}\right)$ is in accordance and support the incorporation of a high percentage of imidazole groups. 


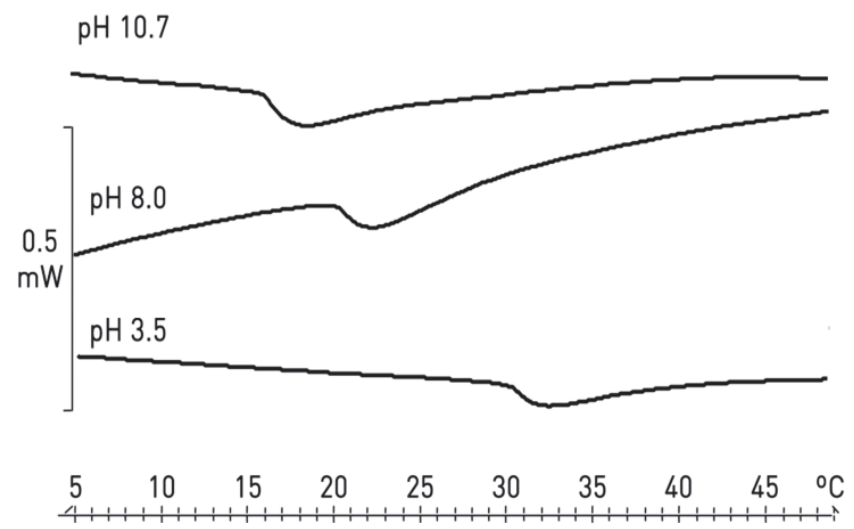

Figure 4A.51. DSC for the polymer IMID-IKI20 at different pH. IMID-IK120 shows an endothermic process with a variation of $\mathrm{Tt}$ as function of $\mathrm{pH}$ in aqueous solvent.

Table 4A.5. Thermal behavior of IMID-IKI20 and IK120. Transition temperature (Tt) and enthalpy variation for ELRs was measured by differential scanning calorimetry in aqueous solution at $\mathrm{pH} 10.7,8.0$ and 3.5 .

\begin{tabular}{|lcccc|} 
& \multicolumn{2}{c}{ IMID-IK120 } & \multicolumn{2}{c|}{ IK120 } \\
\hline $\mathrm{pH}$ & $\mathrm{Tt}\left({ }^{\circ} \mathrm{C}\right)$ & $\Delta \mathrm{H}(\mathrm{Jg}-1)$ & $\mathrm{Tt}\left({ }^{\circ} \mathrm{C}\right)$ & $\Delta \mathrm{H}(\mathrm{Jg}-1)$ \\
\hline 10.7 & 18.5 & -5.0 & 21.60 & -5.51 \\
8.0 & 22.6 & -4.5 & 31.36 & -2.34 \\
3.5 & 32.4 & -2.7 & 33.50 & -1.17 \\
\hline
\end{tabular}

\section{A.4.1.1. BUFFERING CAPACITY OF IMID-IK120}

To evaluate the protonation ability of IMID-IK120, solutions of $0.1 \mathrm{mg} / \mathrm{mL}$ in physiological saline of IK120 based polymers: IK120, IK120CPP, LAELIK120CPP and IMID-IK120 were titrated against $0.01 \mathrm{~N} \mathrm{HCl}$ from $\mathrm{pH} 10.0$ to $\mathrm{pH} 4.0$ (3.2.4.6.). PEI which is $\mathrm{k}$ nown to have a high buffering capacity due to its high unprotonated amine ratio (more than one third) was used as reference polymer (101). The initial hypothesis was the protonation of imidazole at endosomal $\mathrm{pH}(\mathrm{pH} \mathrm{6)}$ would trigger an influx of water and ions, thereby destabilizing and disrupting the endosome. This strategy would improve the buffering capacity of the IMID-IK120 polymer and facilitate the release of the polymer/pDNA complex into the cytoplasm $(330,331)$. Our findings showed that IMID-IK120 showed a milder increase in buffering capacity in the $\mathrm{pH}$ range 8-6 than the other ELRs, thereby correlating with protonation of the imidazole groups (Figure 4A.52). By contrast, PEI polymer possessed larger buffering effect at almost all the $\mathrm{pH}$ tested and especially from $\mathrm{pH} 9$ due to the high amount of unprotonated amines. 


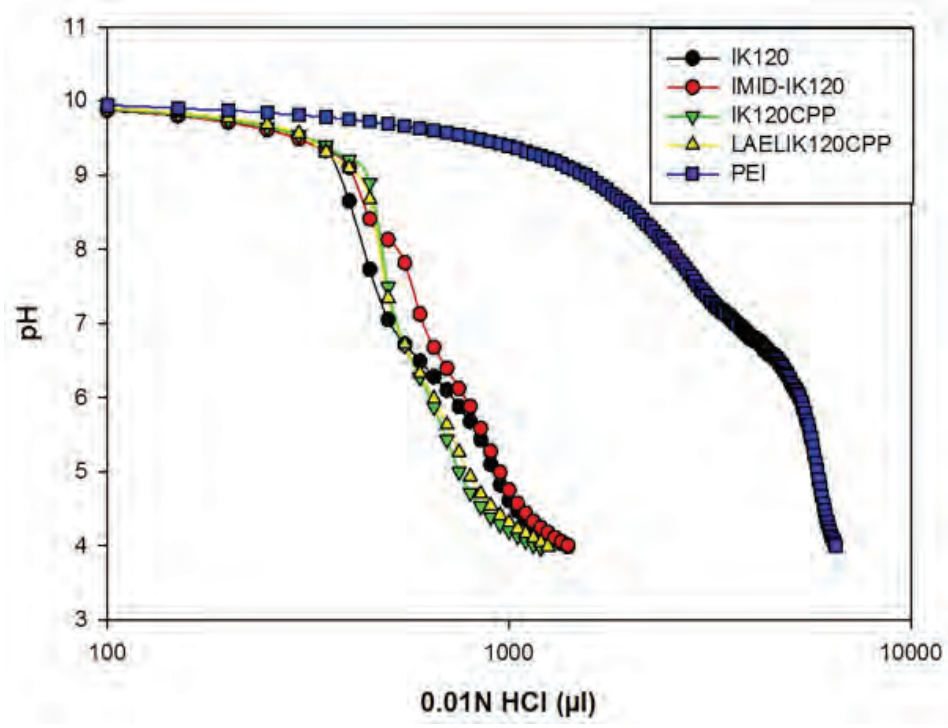

Figure 4A.52. Buffering capacity of the ELRs compared with PEI $25 \mathrm{KDa}$ in $0.9 \% \mathrm{NaCl}$ solution. The $\mathrm{x}$ axis is plotted in logarithmic scale to facilitate visualization of the data.

\section{A.4.2. CONSTRUCTION OF THE VOK-PEG-5TR1 BIOPOLYMER}

5TR1 aptamer as small DNA oligonucleotide of $21 \mathrm{nt}$ was incorporated to the VOKx72 polymer in order to provide cellular specificity to the ELR (1.3.4.). For that, 5TR1 aptamer was covalently linked to the VOKx72 previously modified with PEG-CO (PEGcyclooctyne) by click chemistry. Despite the possibility of electrostatic interaction between the positively charged lysines from VOKx72 and negatively charged phosphates from the 5TR1, the covalent bond would provide more stability to the VOK-PEG-5TR1 biopolymer. Thus, the presence of PEG would serve as spacer between the aptamer and the bulk of polymer which would therefore facilitate the polyvalent binding between the aptamer and MUC1 besides of prolonging the halflife of the construct in blood $(155,156)$ which is beneficial for physiological applications.

The VOKx72 ELR polymer was functionalized with PEG-cyclooctyne by amidation reaction between the $\varepsilon$-amine group from lysines present in 1 equiv. of ELR and the activated carboxylic group as $\mathrm{N}$-succinimidyl ester present in 0.46 equiv. of the reactant NHS-cyclooctyne-PEG (Figure 4A.53) following the protocol described in (3.2.5.2). The conversion was performed with $2.1 \mathrm{~mol}$ of VOKx72: 1 mol of PEGcyclooctyne. After lyophilization a regular appearance of white spongy solid was 
obtained $(92 \mathrm{mg}, 2.83 \mu \mathrm{mol})$ with a $91.6 \%$ chemical yield. Due to the high molecular weight of the VOKx72 (32.36 kDa) in comparison with the low conversion required that would integrate $0.217 \mathrm{kDa}$ of PEG-cyclooctyne, it was not possible to quantify the amount of PEG-cyclooctyne incorporated using mass spectrometry because it may be considered as part of the $0.5 \%$ of experimental error. However by ${ }^{1} \mathrm{HNMR}$, the appearance of new signals showing the typical of cyclooctyne derivative at 7.0 ppm ( $\mathrm{H}-\mathrm{N}$ from carbamate) and $4.0 \mathrm{ppm}$ (methylene group adjacent to carbamate and ciclopropyl group) and $2.9 \mathrm{ppm}$ assigned to the methylene groups adjacent to the nitrogen of lysines forming the new amide bond was depicted (Figure 4A.54). These signals allowed us to deduce that the PEG-cyclooctyne group was present along the peptide chain. Since the integral of these peaks was not clear enough, it was possible to assign the conversion degree taking into consideration the $7.0 \mathrm{ppm}$ peak and being $100 \%$ of conversion for the theoretical $1.37 \mathrm{H}$ and $68 \%$ for the $0.93 \mathrm{H}$ obtained. Adjustment to 50/1/4 (N/P/Papt) ratio was achieved by the addition of fresh VOKx72.

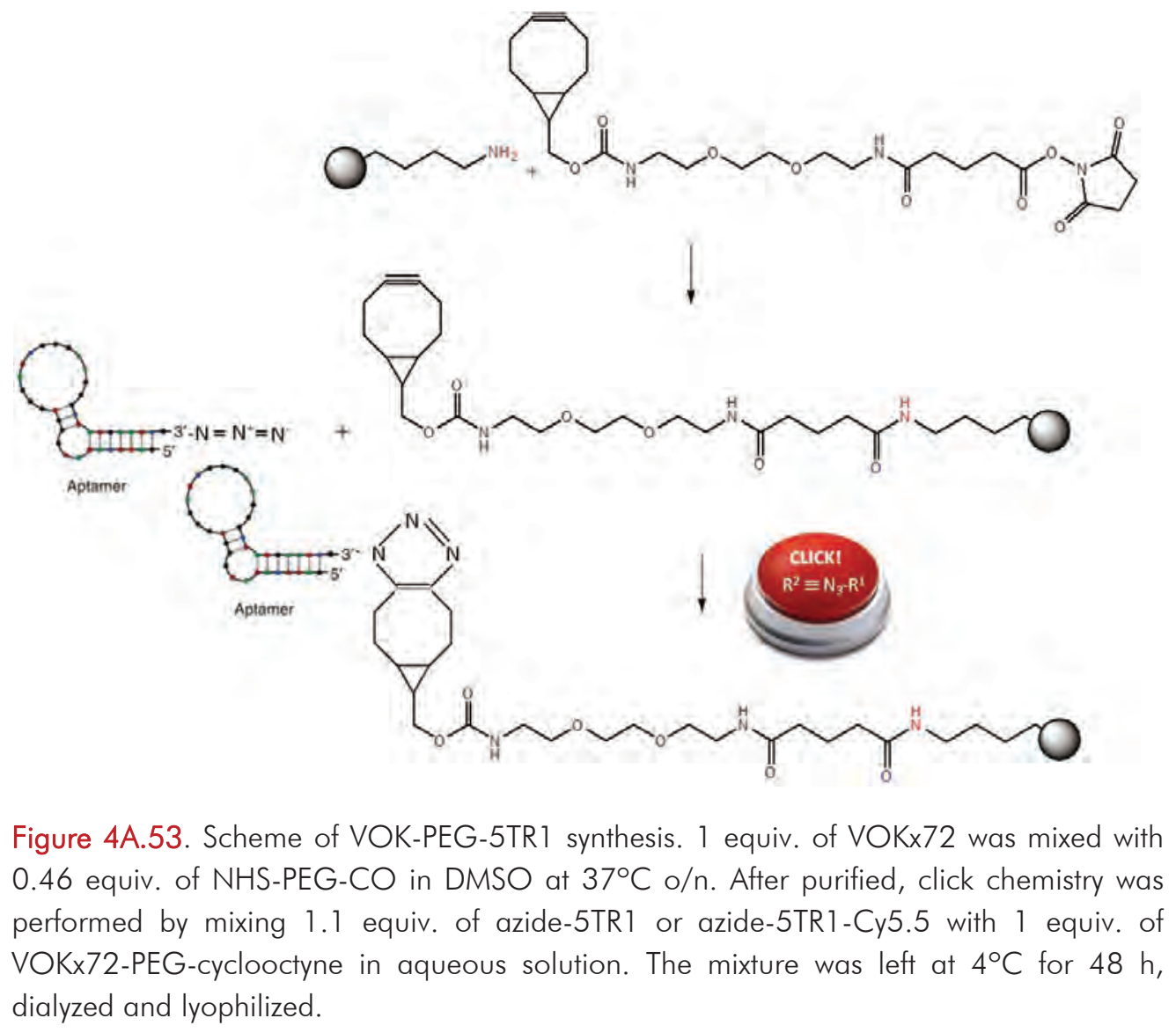




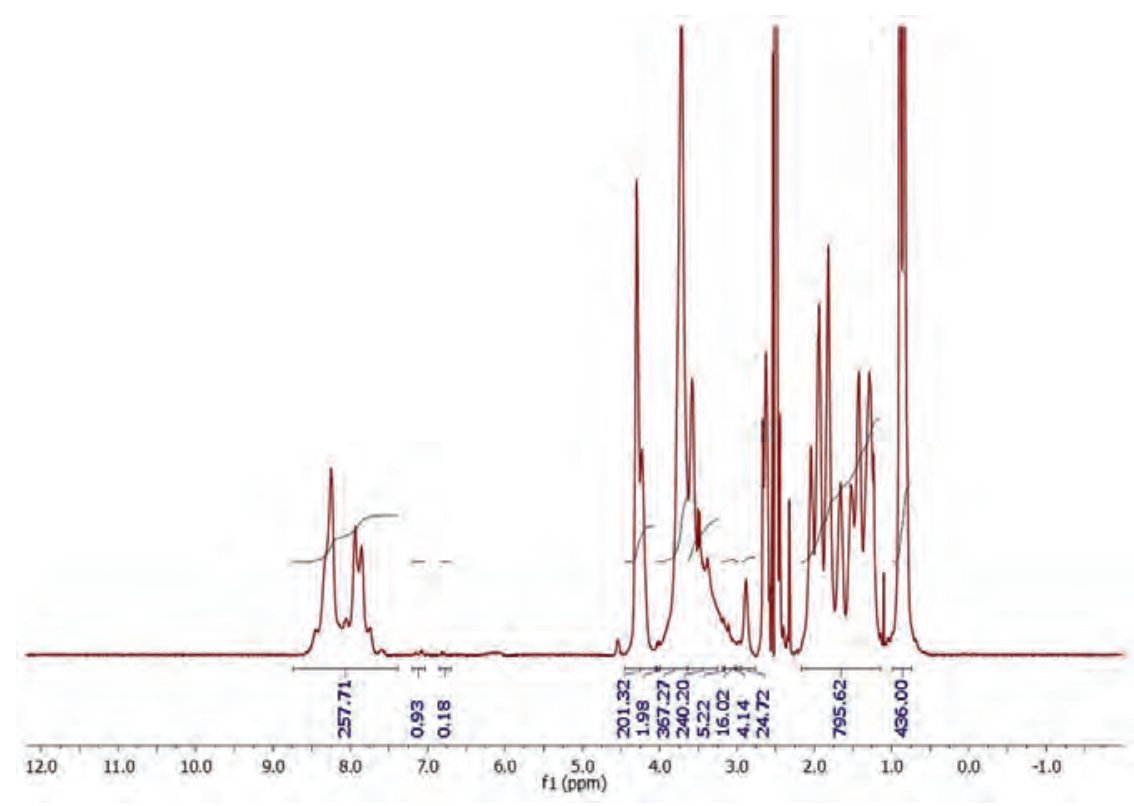

Figure 4A.54. Nuclear magnetic resonance spectra 1H-RMN (400 MHz, (CD3)2SO) of VOKx72-PEG-CO. Theoretical nuclear magnetic resonance spectra: $1 \mathrm{H}-\mathrm{RMN}(400 \mathrm{MHz}$, (CD3)2SO): $\delta 8.44-8.23$ and 8.18-7.88 $(287 \mathrm{H}, \mathrm{br},-\mathrm{NH}), 7.15-7.01(2 \mathrm{H}, \mathrm{br}, \mathrm{H}-\mathrm{N}-$ $\mathrm{C}(3) \mathrm{O} 2$ and $\mathrm{H}-\mathrm{N}-\mathrm{C}(14) \mathrm{O}), 6.7(1 \mathrm{H}, \mathrm{s},-\mathrm{NH}-\mathrm{C}(18) \mathrm{O}), 4.45-4.24$ and 3.67-3.50 $(800 \mathrm{H}$, br, $\alpha-\mathrm{CH}$ - Val $+\alpha-\mathrm{CH}$ - Pro $+\alpha-\mathrm{CH}$ - Lys $+-\mathrm{CH} 2-\mathrm{Gly}+\delta \mathrm{CH} 2$-Pro and $\varepsilon \mathrm{CH} 2$-Lys $+\alpha-$ $\mathrm{CH}-\mathrm{Met}+\alpha-\mathrm{CH}-\mathrm{Glu}+\alpha-\mathrm{CH}-\mathrm{Ser},+\alpha$ and $\mathrm{y}-\mathrm{CH}$ - Leu $+\mathrm{H} 6, \mathrm{H} 8, \mathrm{H} 9$, and $\mathrm{H} 12$ from PEG), $4.0(1.37 \mathrm{H}, \mathrm{d}, \mathrm{H}-\mathrm{C} 1-\mathrm{PEG}), 3.2$ and $3.1(4 \mathrm{H}, \mathrm{d}, \mathrm{H} 5$ and $\mathrm{H} 12), 2.9(2 \mathrm{H}, \mathrm{d}, \mathrm{CH} 2-$ $\mathrm{NH}-\mathrm{C}(18) \mathrm{O}), 2.14-1.64$ and $1.60-1.35(806 \mathrm{H}, \mathrm{m}, \beta$ and $\gamma \mathrm{CH} 2-\mathrm{Pro}+\beta$, $\gamma$ and $\delta \mathrm{CH} 2-$ Lys $+Y$ and $\beta \mathrm{CH} 2-$ Met+ $Y$ and $\delta \mathrm{CH} 2-\mathrm{Glu}+\mathrm{CH} 2$-Leu+ $\mathrm{CH} 2-\mathrm{Ser}+\mathrm{CH} 2$ from H2, $\mathrm{H}$ 3, $\mathrm{H} 6$ and $\mathrm{H} 7$ of $\mathrm{CO}$ and $-\mathrm{CH} 2$ from $\mathrm{H} 15, \mathrm{H} 16$ and $\mathrm{H} 17$ of $\mathrm{PEG}), 0.97-0.75(436 \mathrm{H}, \mathrm{d}$, $\mathrm{CH}(\mathrm{CH} 3)_{2}-\mathrm{Val}+\mathrm{CH}(\mathrm{CH} 3)_{2}-\mathrm{Leu}+\mathrm{CH} 3 \mathrm{~S}-\mathrm{CH} 2-\mathrm{Met}$ and $-\mathrm{CH}$ from $\mathrm{H1}, \mathrm{H} 8$ and $\mathrm{H} 9$ of $\mathrm{CO})$.

Once the PEG-Cyclooctyne was bound to VOKx72 ELR, click reaction was performed between the VOK-PEG-Cyclooctyne and azide-5TR1 with and without Cy5. 5TR1 aptamer labeled with Cy5 was used in a parallel reaction under the same conditions in order to verify the incorporation of aptamers in VOK-PEG-Cyclooctyne as part of polyplexes by fluorescence and detect them using the flow cytometer. For the click chemistry reaction, 1.1 equiv. of azide-5TR1 or azide-5TR1-Cy5 was mixed with 1 equiv. of VOKx72-PEG-Cyclooctyne in aqueous solution at $4^{\circ} \mathrm{C}$ as described in 3.2.8. Click chemistry was performed between the activated cyclooctyne from VOKx72-PEGCyclooctyne and the azide from 5TR1 aptamer that leads to the azide cycloadition (Figure 4A.53). The use of activated alkyne groups, such as in our case a cyclooctyne group has allowed the lack of toxic catalyst as cooper (43). Thus, click reactions has 
been shown to be easy to do in aqueous solution with high reaction yield which make them an appropriate solution for the binding of aptamer. The excess of aptamer was eliminated by dialysis in ultrapure water for $24 \mathrm{~h}$ and 5 changes of water. The incorporation of 5TR1 aptamer was corroborated by gel retardation assay, absorbance and flow cytometry (Figures 4A.55 and 56).



Figure 4A.55. Gel retardation assay confirmed the presence of 5TR1 in VOK-PEG-5TR1. Aproximately $150 \mathrm{ng}$ of 5 TR1 contained in VOK-PEG-5TR1 treated with 10\% SDS and $400 \mathrm{ng}$ of 5 TR 1 as control were loaded into a $3 \%$ of metaphor agarose gel and stained with SimplySafe ${ }^{\text {TM }}$, 100bp marker was used.

A solution of VOK-PEG-5TR1 biopolymer containing about $150 \mathrm{ng}$ of 5TR1 with $10 \%$ of SDS was loaded into a $3 \%$ of methaphor gel (3.2.8.1.). As shown in Figure 4A.54, a band located in the well appeared for VOK-PEG-5TR1 sample whilst the 5TR1 aptamer was able to migrate freely along the gel. The presence of SDS promoted the break of hydrogen bonds from secondary protein structure but not covalent bonds. Since previous experience with click chemistry showed high levels of substitution (43), we may assume that major part of 5TR1 in VOK-PEG was covalently linked to the polymer. In addition, 5TR1 concentration in VOKPEG-5TR1 biopolymer was estimated by measuring the absorbance at $260 \mathrm{~nm}$ (3.2.8.2.). As shown in Figure 4A.56A, the absorbance of VOK-PEG used as control was almost 0 however, it was around $0.62 \mathrm{AU}_{260}$ for VOK-PEG-5TR1 which allowed us to quantify the amount of DNA. $0.1 \mathrm{mmol}$ of 5TR 1 were coupled to $0.4 \mathrm{mmol}$ 
of VOK-PEG-Cyclooctyne after click reaction, being the substitution of $92 \%$. The techniques discussed above showed the presence of 5TR1 in the VOK-PEG but none corroborated the presence of 5TR1 in their functional conformation as polyplexes. For that, labeled 5TR1-Cy5 was used in the click reaction as previously depicted. Once the biopolymer was lyophilized, polyplexes with pDNA were formed and analyzed by flow citometry (3.2.8.3.). As shown in Figure 4A.56B, a homogeneous population corresponding to polyplexes appeared when side versus forward scatter was plotted (left histogram). In addition, when intensity count was plotted as a function of FL6 channel a 100\% of labeling in polyplexes formed by Cy5 labeled 5TR1 appeared in comparison with polyplexes without aptamer (right histogram) used as control. Hence, flow cytometry analysis showed both the incorporation of the labeled 5TR1 aptamer to the VOK-PEG and the ability of this VOK-PEG-5TR1 biopolymer to form polyplexes in presence of plasmid DNA.



Figure 4A.56. Analysis of aptamer conjugation to VOK-PEG polymer. The VOK-PEG5TR1 biopolymer and VOK-PEG as control were dissolved at $1 \mathrm{mg} / \mathrm{mL}$ in ultrapure water and UV absorption of DNA at $260 \mathrm{~nm}$ was measured. Mean of 2 independent measurements \pm SD (A). Flow cytometry analysis of polyplexes formed with 5TR1-Cy5.5 (polyplex-5TR1 Cy5) and without 5TR1 (polyplex) as control. Gate R1, which corresponds to polyplexes population, was set on the side-scatter vs forward-scatter histogram (left histogram). The polyplex count was plotted as a function of FL6, which corresponded to the Cy5 channel for polyplexes containing the Cy5 labelled aptamer and control (right histogram) (B). 
Hence, the construction of the biopolymer VOK-PEG-5TR1 was achieved by click chemistry and the incorporation of 5TR1 aptamer on both the VOK-PEG and polyplex was confirmed along the herein work. 


\section{FINAL REMARKS}

The recombinamer nature of ELRs allows their controlled design through genetic engineering techniques. The fully control of the architecture and amino-acid composition of ELR led the incorporation of high density of aminoacids that would improve the transfection ability of ELRs. Among them, histidine, arginine and lysine were selected.

Histidine enriched ELRs were designed to improve the buffering capacity of polymers and hence their transfection ability. Expression problems in E.coli were found but solved with the addition of the IKx30 ELR block at N-t and creating the IKx30HPG 3 . Indeed, expression problems in bacteria were also found for the similar construction RPGx3. Future incorporation of well expressed ELR blocks at $\mathrm{N}$-t such as IKx30 are recommended in order to achieve its expression. The high amount of arginines would provide it with excellent penetration abilities.

Lysine enriched polymers were thought to complex effectively the pDNA and increase their transfection ability by interaction with the negatively charged components from the plasmatic membrane. For that, three different polymers VOKx48, VOKx72 and VOKx48HPGx1 were designed. All of them were properly expressed in E.coli, produced, purified and characterized. The different number of lysines and histidines in VOKx48HPGx1 would provide them of good features to complex and transfect efficiently the therapeutic DNA inside of cells.

Also biotechnological techniques allowed not just the incorporation of ELR blocks, such as the IKx30 or VOKx48 used in this work to obtain IKx30HPG $\times 3$ and VOKx48HPGx1, but the addition of functional domains. Penetratin and LAEL fusogenic peptides were added at C-t and N-t respectively generating the IK120CPP and LAELIK120CPP polymers. These ELRs were properly expressed in bacteria, produced, purified and characterized by different physicochemical techniques.

In addition to biotechnological modifications, incorporation of functional motifs as imidazole groups could be achieved through chemistry. In this case, amidation reaction led to the modification of IK120 with imidazole groups creating the IMIDIK120 polymer. The objective of this construction was the increase of buffering capacity with interesting applications in gene delivery. This was tested by means of 
$\mathrm{HCl}$ titration in which the improvement of buffering capacity for IMID-IK120 at physiological pH was corroborated.

Furthermore, chemical modification of VOKx72 ELR by means of click chemistry was accomplished in order to link the 5TR1 aptamer to the polymer. 5TR1 aptamer is known to bind MUC1 glycoprotein located in the plasmatic membrane of breast cancer cells. This aptamer would confer the ELR vector complexed with the therapeutic DNA the ability to bind specifically the targeted tumoral cells. Characterization of this modification through different techniques confirmed the presence of the 5TR1 aptamer in the VOKx72 polymer. Click chemistry constitutes a novel technique to link aptamers to polymers in aqueous environment. In addition, this is the first time that aptamers are bound to ELRs which open the way for future research in this field.

Along this chapter, a varied pool of ELRs has been designed by both genetic and chemical modifications with high potential for gene therapy applications. Further research of polyplex formation between the ELR exposed here and therapeutic PDNA together with biocompatibility and transfection assays among others will be accomplished in the following chapters. 

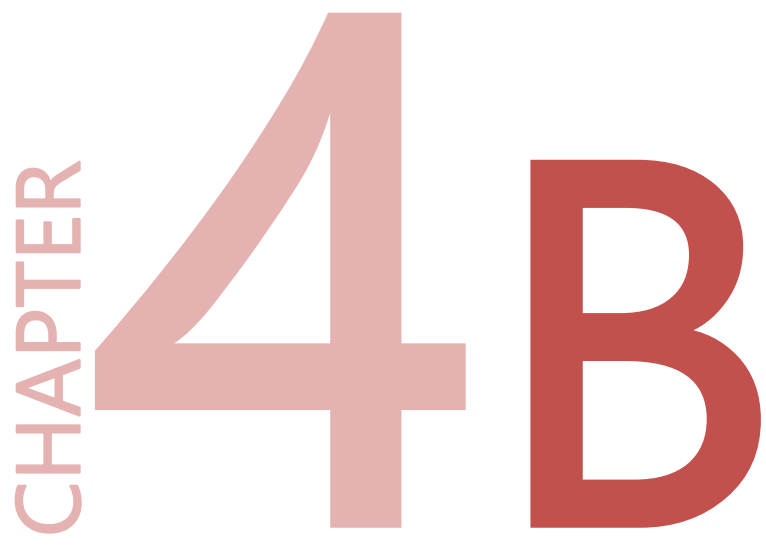


\section{ELR DIBLOCKS FOR DRUG DELIVERY}

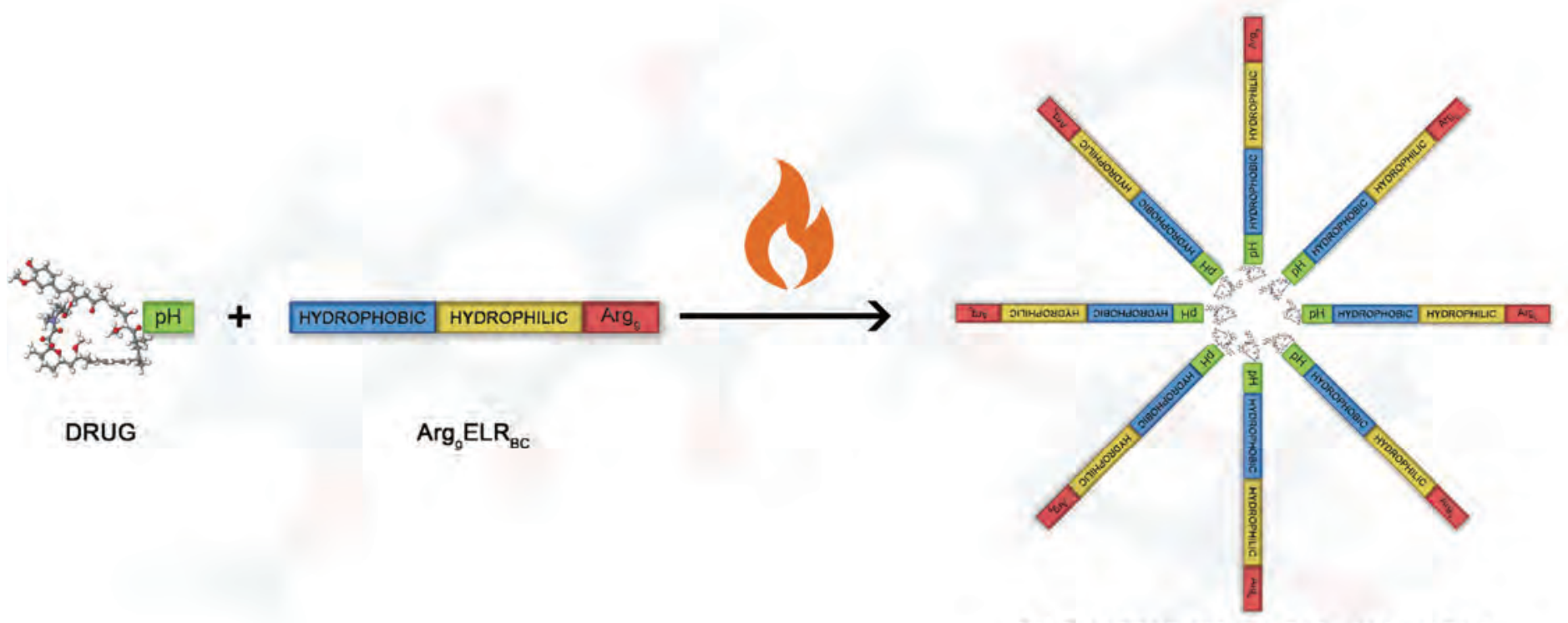

SELF-ASSEMBLED Arg ELR $_{\text {BC }}$ WITH DRUG 
d

$-188$ 


\section{CHAPTER 4B: ELR DIBLOCKS FOR DRUG DELIVERY}

In bio-inspired materials field, ELRs synthesized by recombinant techniques are an innovative source for multiple applications in biomedicine. In fact, the potential about using genetic engineering is reflected in the designing of complex ELRs as block copolymers made of hydrophilic blocks for gene delivery applications as depicted in chapter 4A.1. Indeed the possibilities of these techniques have been widely demonstrated by the creation of self-assembled ELRs as well, such as ELR diblocks $\left(E L R_{B C S}\right)$ made of hydrophilic and hydrophobic domains focused on drug delivery purposes (1.1.7.1.) (332-334).

In drug delivery field, solubility of drugs is an important parameter to consider. Nearly $40 \%$ of active substances indentified through screening are poorly soluble in water which means low bioavailability and low success (335). For this reason, the formulation of ELR nanoparticles that improve the drug availability has been achieved. ELR nanoparticles have been bound to the drug by means of an acidic $\mathrm{pH}$ sensitive linker that allows the delivery of doxorrubicin or paclitaxel (71). The results of ELRs carrying doxorrubicin showed a $90 \%$ of cure in murine colon carcinoma model (336) and greater than $60 \%$ in Lewis lung model (70). Thus, near complete tumor regression in breast and prostate cancer using ELR nanoparticles carrying paclitaxel was achieved (71). Along the present chapter the hypothesis of using ELR $\mathrm{BCs}_{\mathrm{B}}$ to deliver the future drug cargo in acidic environment as endosomes or lysosomes ( $\mathrm{pH}$ 4.0-6.0) has been studied. The design of ELRBCs with a $\mathrm{pH}$ sensitive linker located at hydrophobic domain with the objective of being linked to a drug through it was carried out previously by Chilkoti's group $(70,334,337)$. Additionally the work done by MacEwan et al. (51), in which the incorporation of $\operatorname{Arg}_{5}$ to $\mathrm{ELR}_{\mathrm{BC}}$ $\left[(\mathrm{VPGVG})_{40}(\mathrm{VPGXG})_{60}\right.$ where $\mathrm{x}$ is Ala:Gly] was shown to increase 8 -fold the uptake of the nanoparticles, was considered as starting point for this chapter. Indeed, the internalization pathway for $\operatorname{Arg}_{5}-E_{B C}$ Bas probed to be by macropynocitosis which was taken into account along this work as well. Hence, the suitability of $\operatorname{Arg}_{8}$-ELR $R_{B C}$ as acidic $\mathrm{pH}$ sensitive drug delivery carrier was evaluated through the intracellular distribution of the nanoparticles in the acidic vesicles ( $\mathrm{pH}$ range of 4-6) showing the important role of cell penetratin peptides (CPP) in cellular uptake. Indeed, the function of certain proteoglycans as heparin sulfate proteoglycan (HSPG) and p21 
activated kinase 1 (PAK1) as macropynotic key molecules in the internalization of the $\mathrm{Arg}_{8}-\mathrm{ELR}_{\mathrm{BC}}$ was also assessed.

\section{B.1. PRODUCTION AND CHARACTERIZATION OF Arg ${ }_{8}-E_{\text {ER }}$}

Biotechnological modifications were performed over the control ELRBC (VGVPG)80(SGVPG)80, formed by an hydrophilic block enriched in serine and an hydrophobic block enriched in valine. Incorporation of 8 Arginines at C-t of hydrophilic block led to $\operatorname{Arg}_{8} E L R_{B C}$ construct. The design, production and purification settings of both control and the arginine modified diblock were developed by Chilkoti's group.

$\underline{E L R}_{B C}(68.80 \mathrm{kDa})$

MGCGWPG-(VGVPG)80-(SGVPG)80-PGGS

$\underline{A R G_{8}-E^{-} R_{B C}(70 K D a)}$

MGCGWPG-(VGVPG)80-(SGVPG)80-PGGSRRRRRRRR

$\mathrm{ELR}_{\mathrm{BC}} \quad \mathrm{ARG}_{8}-\mathrm{ELR}_{\mathrm{BC}} \quad \mathrm{m}$

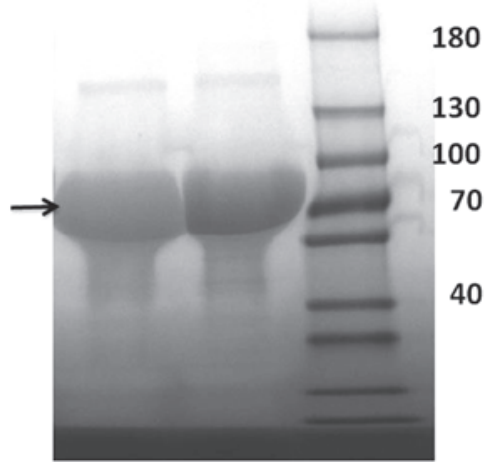

Figure 4B.1. SDS-PAGE of pure ELR $R_{B C}$ and $\operatorname{Arg}_{8}-E_{B} R_{B C}$ in $12 \%$ poliacrylamide stained with coomassie

$E^{E L R_{B C s}}$ purification was accomplished after three rounds of cold-heat cycles of ITC (3.2.3.4.). Indeed, considering the previous experience in Chilkoti's group and MacEwan's studies (51), biochemical characterization of purified ELRs was performed only by SDS-PAGE electrophoresis where the evaluation of purity and size was possible. As depicted in Figure 4B.1, ELRs appeared to move according their theoretical size of $68.80 \mathrm{kDa}$ and $70 \mathrm{kDa}$ for both $\mathrm{ELR}_{\mathrm{BC}}$ and $\mathrm{Arg}_{8}-\mathrm{ELR}$. However, one band at approximately double size $(140 \mathrm{kDa})$ of the $\mathrm{ELR}_{B C}$ and $\mathrm{Arg}_{8} E L R_{B C}$ was observed. This upper band in both polymers may be due to the presence of dimers 
that appeared as consequence of disulphide bonds between $\mathrm{SH}$ groups from cysteine residues despite of the presence of $\beta$-mercaptoethanol as reducing agent. In order to fluorescently label both polymers for the following experiments of cellular uptake, a maleimide reaction between the cysteine amino acid located at $\mathrm{N}-\mathrm{t}$ of the ELR and the maleimide from Alexa Fluor 488 was accomplished (Figure 4B.2).

For that, a parallel reaction of $200 \mu \mathrm{M}$ of both $\mathrm{Arg}_{8}-\mathrm{ELR}_{\mathrm{BC}}$ and $E L R_{B C}$ with $500 \mu \mathrm{M}$ of Alexa Fluor 488 C5-maleimide at pH 7.0 was performed (3.2.9. and Figure 4B.2). After polymer precipitation by means of salt addition, free fluorophore was removed by centrifugation. ELR labeled concentration and labeling efficiency was determined by measuring the absorbance at $494 \mathrm{~nm}$ and $280 \mathrm{~nm}$. The result was a labeling efficiency of $20 \%$ in $190 \mu \mathrm{M}$ of both labeled $\mathrm{Arg}_{8}-\mathrm{ELR}_{\mathrm{BC}}$ and ELRBC.

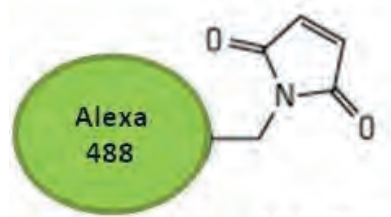

Alexa 488 C5maleimide

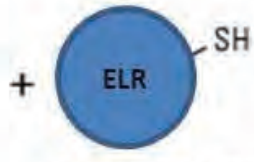

ELR with SH group

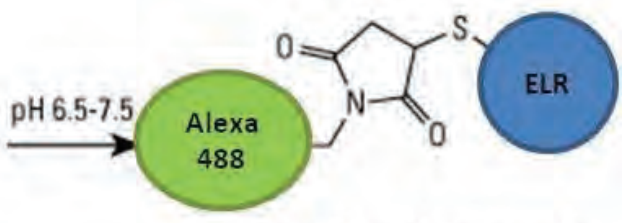

Stable thioether bond Alexa 488-ELR

Figure 4B.2. Scheme of Alexa488-ELR conjugation. Maleimide reaction between the maleimide group from Alexa 488 and SH group from cysteine amino acid in ELR was performed.

\section{B.1.1. PARTICLE FORMATION OF $\mathrm{Arg}_{8}-\mathrm{ELR}_{B C}$}

Once the $\mathrm{Arg}_{8}-E L R_{B C}$ was purified and labeled, the formation of self-assembled nanoparticles was evaluated by turbidimetry and DLS. Previous $\operatorname{Arg}_{5} \mathrm{ELR}_{\mathrm{BC}}$ formed by an hydrophobic block with a low $\mathrm{Tt}$ and hydrophilic block with higher $\mathrm{Tt}$ have been shown to form nanoparticles above $39^{\circ} \mathrm{C}$ (51). Above a critical temperature, ELR diblocks were able to self-assemble into spherical particles where the hydrophobic part formed the core and the hydrophilic formed the corona (1.1.7.1.). As $\operatorname{Arg}_{8} E E_{B C}$ diblock had a different aminoacid composition and length, the aggregation temperature was expected to be different from the previous $\operatorname{Arg}_{5} E L R_{B C}$.

The phase transition of $\mathrm{Arg}_{8}-E L R_{B C}$ and ELR $R_{B C}$ was characterized by monitoring the optical density at $350 \mathrm{~nm}$ of a solution of polymer in ultrapure water at different concentrations as a function of temperature (3.2.6.6.) and in PBS at $20 \mu \mathrm{M}$. As depicted in Figure 4B.3, an increase in optical density appeared in all cases and it is 
indicative of ELR aggregation. However, a two-step turbidity change was observed for the $\operatorname{Arg}_{8} E L R_{B C}$ at all the concentrations tested, showing a sharp peak that is stabilized over the entire temperature range analyzed. As reported in literature, a region of low $\mathrm{OD}_{350}(\approx 0.1-0.5)$ is suggestive of the presence of self-assembled architectures $(51,338)$ by contrast a high $\mathrm{OD}_{350}(\geq 1.0)$ is indicative of coacervation phenomena (53). Hence, the turbidity profiles herein suggest the presence of selfassembled particles from $37.4^{\circ} \mathrm{C}$ in miliQ (Figure 4B.3). When analyzing the aggregation behavior with increasing temperature at different concentrations of $\operatorname{Arg}_{8} E L R_{B C}$ it was possible to find a dependence correlation. At $20 \mu \mathrm{M}$ of $\operatorname{Arg}_{8} E L R_{B C}$ the aggregation process extended from $39.3^{\circ} \mathrm{C}$ to $38.3^{\circ} \mathrm{C}$ at $25 \mu \mathrm{M}$ and up to $37.4^{\circ} \mathrm{C}$ at $50 \mu \mathrm{M}$ (Table 4B.1A). A decrease in temperature in which the aggregation events occurred were found when incrementing the polymer concentration which correlates with previous studies $(9,50)$.

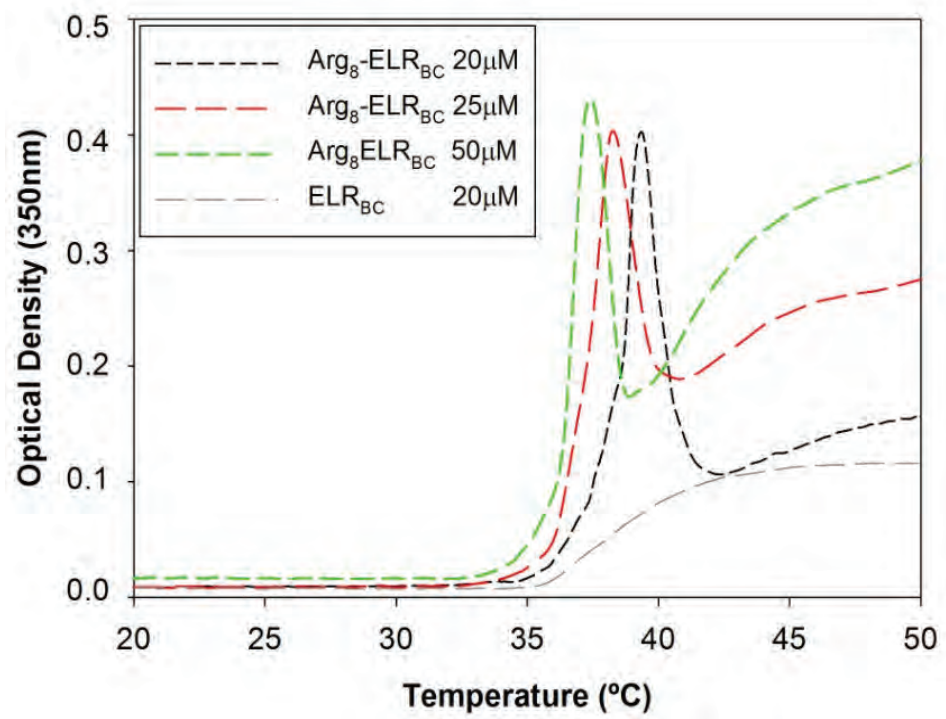

Figure 4B.3. Turbidity measurements for $\operatorname{Arg}_{8} E L R_{B C}$ at increasing concentrations in miliQ as a function of temperature $\left(1{ }^{\circ} \mathrm{C} / \mathrm{min}\right)$ on an UV-visible spectrophotometer. ELR $R_{B C}$ at 20 $\mu \mathrm{M}$ was used as control.

For ELR $R_{B C}$, the increase in optical density was found from $39.0^{\circ} \mathrm{C}$ at $20 \mu \mathrm{M}$ which does not constitute a significant change regarding to the same concentration of $\operatorname{Arg}_{8} E L R_{B C}$ (Figure 4B.3 and Table 4B.1A) and suggests that arginine peptide does not influence over the temperature at which aggregation phenomena occurs in ELR $R_{B C}$. By contrast, differences in the absorbance profile of both $\operatorname{Arg}_{8} E L R_{B C}$ and $E L R_{B C}$ were found probably due to interaction of arginines that lead to higher optical density, however 
it was not considerate as coacervation state $\operatorname{OD}_{350}(\geq 1.0)$. Considering the studies from Urry (9), it is possible to predict the Tt of an individual ELR block with considerable precision being $25^{\circ} \mathrm{C}$ and $36.5^{\circ} \mathrm{C}$ for the hydrophobic and hydrophilic block Tt respectively in PBS. However, the prediction of the aggregation temperature of an $E L R_{B C}$ is subjected by the interactions between the hydrophobic and hydrophilic blocks. Therefore, this interaction as well as the secondary effect that can arise from interactions with the arginine peptide can cause this aggregation temperature to differ in a significant manner from the Tt of hydrophobic block (51). The measurement of Tt in PBS resulted in lower values in comparison with ultrapure water due to the presence of salts and its effect in lowering the Tt (9). So, a Tt of $36.4^{\circ} \mathrm{C}$ $36.6^{\circ} \mathrm{C}$ was found for both $E L R_{B C}$ and $A_{g_{8}} E L R_{B C}$ which is suitable for in vitro applications.

Table 4B.1. Tt of ELR diblocks ELR $\mathrm{BC}_{\mathrm{BC}}$ as control and $\operatorname{Arg}_{8}$-ELRBC in mili $\mathrm{Q}$ at $20 \mu \mathrm{M}, 25 \mu \mathrm{M}$ and $50 \mu \mathrm{M}$ and PBS at $20 \mu \mathrm{M}$ obtained by turbidometry (A). Particle size and Pdl of ELR diblocks: $\mathrm{ELR}_{\mathrm{BC}}$ as control and $\mathrm{Arg}_{8}-\mathrm{ELR}_{\mathrm{BC}}$ measured at $37^{\circ} \mathrm{C}$ in PBS by DLS (B).Nd: non determined.

A

\begin{tabular}{|c|c|c|c|c|}
\hline & \multicolumn{4}{|c|}{ Tt } \\
\hline & \multicolumn{3}{|c|}{ miliQ } & PBS \\
\hline & $20 \mu \mathrm{M}$ & $25 \mu \mathrm{M}$ & $50 \mu \mathrm{M}$ & $20 \mu \mathrm{M}$ \\
\hline$E^{E L R_{B C}}$ & 39.0 & $\mathrm{Nd}$ & $\mathrm{Nd}$ & 36.4 \\
\hline $\mathrm{ARG}_{8}-\mathrm{ELR}$ & 39.3 & 38.3 & 37.4 & 36.6 \\
\hline
\end{tabular}

B

\begin{tabular}{lll} 
& Dh $(\mathrm{nm})$ & Pdl \\
\hline ELR $_{B C}$ & $56.4 \pm 1.0$ & 0.02 \\
ARG $_{8}$-ELR & $64.4 \pm 3.0$ & 0.02 \\
\hline
\end{tabular}

While turbidity measurements gave information about aggregation events, DLS measurements were necessary to confirm the presence of self-assembled particles, their size and stability. Hence DLS measurements were accomplished (3.2.6.3.) at $37^{\circ} \mathrm{C}$ and in PBS that possesses similar buffering capacity than biological fluid. As shown in Table 4B.1B, both ELR $R_{B C}$ and $\operatorname{Arg}_{8} E L R_{B C}$ were able to form particles of about $60 \mathrm{~nm}$ of hydrodynamic diameter and Pdl of 0.02 in PBS and $37^{\circ} \mathrm{C}$. This data confirmed the presence of stable nanoparticles at $37^{\circ} \mathrm{C}$ that are suitable for further in vitro experiments. Previous studies with $\mathrm{Arg}_{5} \mathrm{ELR}_{\mathrm{BC}}$ had shown the formation of micelles over its aggregation temperature with a zeta-potential of $+14.3 \mathrm{mV}$ due to the high density of arginine on the micelle corona (51). However, in this work further studies of static light scattering would be necessary in order to determine the gyration radius and assess the formation of micelles. Indeed, we hypothesized the existence of positive zeta potential value due to the likely distribution of arginines outward of the particle as occurred in MacEwan's work. 


\section{B.2. INTERNALIZATION KINETICS OF Arg8-ELRBC}

Once nanoparticle formation was verified, the internalization kinetics of $\operatorname{Arg}_{8}-E L R_{B C}$ in the target cells was evaluated. For that human hypopharyngeal carcinoma (FaDu) cells, as epithelial cellular model, were incubated with $20 \mu \mathrm{M}$ of both labeled ELR $R_{B C}$ and $\mathrm{Arg}_{8}-\mathrm{ELR}_{\mathrm{BC}}$ at different time points up to 8 hours. After each time point, detached cells were counted showing near $100 \%$ of cell viability and fluorescence intensity of internalized particles was measured by flow cytometry (3.2.12.2). As depicted in Figure 4B.4, a great difference in the internalization was found for $\operatorname{Arg}_{8}-E L R_{B C}$ particles from 30 minutes of incubation reaching nearly 20 times the fluorescence intensity value for cells incubated with control ELRBC after 8 hours. Hence, particles with $\mathrm{Arg}_{8}$ peptide showed higher and faster internalization of nanoparticles. These results are in accordance with a wide range of studies performed with arginine cell penetratin peptides (CPP) showing an increase in cellular uptake when the peptide was present $(197,339,340)$. Thus, the data suggests the existence of a high arginine density on nanoparticles surface that would interact with negatively surface components from the plasmatic membrane. Further research analyzing the role of heparan sulfate proteoglycan (HSPG) in $\mathrm{Arg}_{8} \mathrm{ELR}_{\mathrm{BC}}$ internalization was performed and it is exposed along this work.

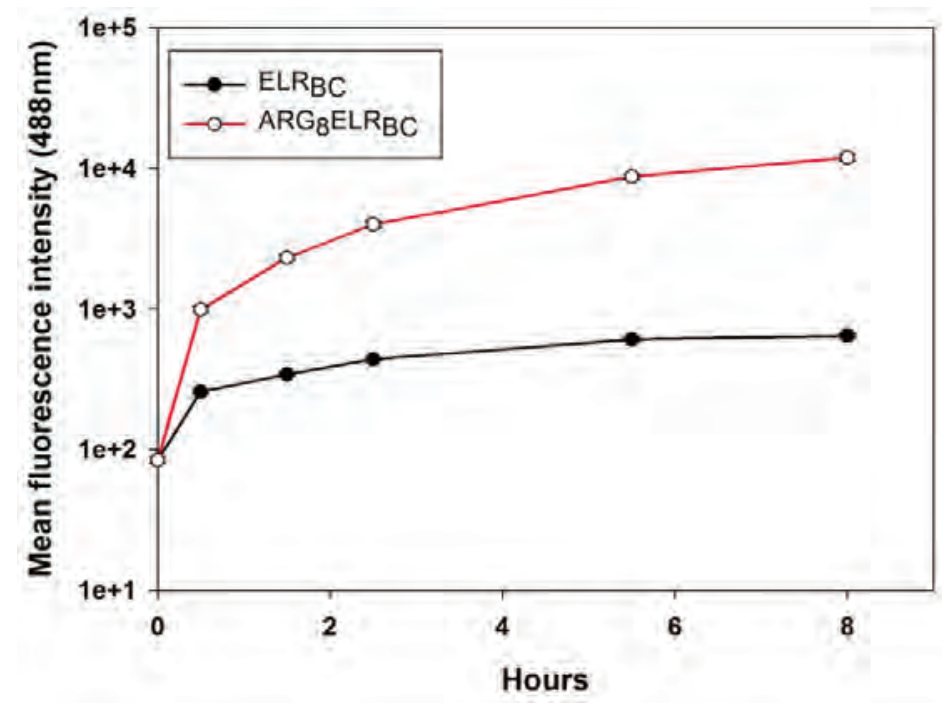

Figure 4B.4 Internalization kinetics of control ELRBC and $A R G_{8}-E_{B C} R_{B C}$ at different hours of incubation with $20 \mu \mathrm{M}$ of ELRs quantified by flow citometry. Results are expressed as mean \pm standard deviation (SD) of two independent experiments. 


\section{B.3. INTRACELLULAR DISTRIBUTION OF Arg8-ELRBC}

According with previous studies, macropynocitosis entrance pathway was demonstrated as the internalization mechanism for $\operatorname{Arg}_{5} E_{L} R_{B C}$ (51) (1.2.5.2.3.). In order to know the suitability of $\mathrm{Arg}_{8} \mathrm{ELR}_{\mathrm{BC}}$ for the $\mathrm{pH}$ sensitive linkage, the accumulation of $\mathrm{Arg}_{8} \mathrm{ELR}_{\mathrm{BC}}$ nanoparticles in acidic vesicles, was analyzed (3.2.12.2). For that, FaDu cells were incubated for $1 \mathrm{~h}, 3 \mathrm{~h}$ or $6 \mathrm{~h}$ with nanoparticles and next $1 \mathrm{~h}$ and $30 \mathrm{~min}$ with Lysosensor. Afterwards, cells were visualized by spinning disk confocal microscopy and analyzed. Lysosensor label is a probe used to measure the $\mathrm{pH}$ of acidic organelles such as lysosomes which produces blue fluorescence in neutral environments but changes to yellow fluorescence in more acidic environments. Lysosensor $\mathrm{pH}$ range of action is from $\mathrm{pH} 3.0$ to $\mathrm{pH}$ 9.0. By contrast, spinning disk confocal microscope is a powerful instrument that allows increasing the velocity of image acquisition by reducing the excitation energy needed to illuminate a sample when compared to other laser scanning microscopes. This instrument is very useful for studying internalization processes in living samples due to the reduced phototoxicity and photo-bleaching (341). In this assay, distribution of labeled $\mathrm{Arg}_{8}-\mathrm{ELR}_{\mathrm{BC}}$ and $E L R_{B C}$ nanoparticles in the $\mathrm{pH}$ range of 4.0-6.0 as function of fluorescence intensity was analyzed and using ImageJ and Matlab software. Distribution of nanoparticles in the $\mathrm{pH}$ range 4.0-6.0 as function of normalized fluorescence intensity was plotted (Figure 4B.5). It is important to note that recorded intensity corresponds exclusively with the co-localization of particles in acidic vesicles labeled by lysosensor. As can be appreciated, the distribution pattern of $\mathrm{Arg}_{8} \mathrm{ELR}_{\mathrm{BC}}$ at 3 and $6 \mathrm{~h}$ was similar. However, it was very different when nanoparticles were incubated with cells for $1 \mathrm{~h}$ showing more accumulation at both endosomal $\mathrm{pH}$ of 6 and late endosomal $\mathrm{pH}$ of 5.0-5.5. This can be explained by the fact that nanoparticles located in endosomes were constantly circulating to late endosomes and lysosomes, which was reflected in a lower accumulation at less acidic $\mathrm{pH}$ when increasing the incubation time at $6 \mathrm{~h}$. Nanoparticles at $1 \mathrm{~h}$ were still in less acidic vesicles but with 3 $\mathrm{h}$ and even more with $6 \mathrm{~h}$ they had enough time to transit to more acidic vesicles. By contrast, interesting differences were found in the distribution pattern of both $\operatorname{Arg}_{8} E_{L} R_{B C}$ and $E L R_{B C}$ nanoparticles after $6 \mathrm{~h}$ of incubation with cells. Despite of ELR $R_{B C}$ nanoparticles were less internalized by cells as depicted in Figure 4B.4, they 
accumulated more in less acidic vesicles than $\operatorname{Arg}_{8} \mathrm{ELR}_{\mathrm{BC}}$ showing a homogeneous distribution pattern. These results correlated with the uptake kinetics that showed a very fast internalization for $\mathrm{Arg}_{8} \mathrm{EL} \mathrm{R}_{\mathrm{BC}}$ incrementing with time of incubation and very low for $E R_{B C}$ nanoparticles and suggests a different internalization pathway when arginine peptide was present. Accordingly, the highest accumulation of $\operatorname{Arg}_{8} E L R_{B C}$ particles at lowest $\mathrm{pH}$ points them as the best option for the incorporation of the drug $\mathrm{pH}$ sensitive linker. For this reason, a deeper study of $\operatorname{Arg}_{8} E L R_{B C}$ nanoparticles internalization was accomplished.



Figure 4B.5. Distribution of $A R G_{8}-E L R_{B C}$ and $E L R_{B C}$ micelles into acidic vesicles plotted as normalized RFU $488 \mathrm{~nm}$ as function of $\mathrm{pH}$ after 1,3 and 6 hours of incubation.

\section{B.3.1. ASSESMENT OF THE INTERNALIZATION PATHWAY}

Once $\mathrm{Arg}_{8}-\mathrm{ELR}_{\mathrm{BC}}$ nanoparticles were shown to be rapidly uptaken by $\mathrm{FaDu}$ cells, which was suggested to be promoted by the presence of the arginine peptide, the evaluation of their internalization pathway was performed. Previous work with $\mathrm{Arg}_{5}$ modified ELRBC $_{B C}\left[(\mathrm{VPGVG})_{40}(\mathrm{VPGXG})_{60}, \quad \mathrm{X}=\mathrm{Ala}\right.$ :Gly] showed their preference by macropinocytosis (51). We hypothesized the same route of entry for our $\operatorname{Arg}_{8}-\mathrm{ELR}_{\mathrm{BC}}$ despite of the different composition of the diblock. To achieve this objective, the study of macropinocytosis markers such as HSPG and PAK1 (1.2.5.2.3.) was accomplished. For that, inhibition treatments were performed using heparinase III enzyme and siPAK1 siRNA on FaDu cells. Earlier studies showed the dependence of presence for HSPG on the cellular surface for the internalization of arginine peptides, 
where the interaction of arginines with heparan sulfate (HS) chains is being considered the first step in the stimulation of uptake for many cells (167). Thus the kinase PAK1 have an essential role in the macropinocytosis process by controlling the actin-dynamin machinery which triggers the membrane profusion and ruffling (174). Initially, FaDu cells were incubated with heparinase III for 30 minutes (3.2.12.2.2.) which is known to cleave HS side chains from HSPG. In this situation, we hypothesized that $\mathrm{Arg}_{8}-\mathrm{ELR}_{\mathrm{BC}}$ would not be able to bind HSPG and the internalization would be decreased. Initially, the effect of heparinase treatment over the nanoparticles uptake was evaluated. For that, FaDu cells were treated with heparinase and cells were then incubated with nanoparticles for $1 \mathrm{~h}$ and $3 \mathrm{~h}$ in order to establish the best conditions. As shown in Figure 4B.6, heparinase had a dramatic effect over the uptake of nanoparticles at both $1 \mathrm{~h}$ ( $83 \%$ of inhibition) and $3 \mathrm{~h}$ (73\% of inhibition) of incubation with cells. So, interaction of $\mathrm{Arg}_{8} E \mathrm{ER}_{\mathrm{BC}}$ particles with $\mathrm{HS}$ chains appeared to be crucial for their internalization. Indeed, some significant differences were obtained between both incubation times achieving higher inhibition at $1 \mathrm{~h}$. This difference can be due existence of other alternative routes apart from HSPG interaction that leads to uptake increment with time. Additional experiments showing the effect of heparinase treatment over nanoparticles accumulation in acidic vesicles were completed. Figure 4B.7A depicted the inhibition of the fluorescence intensity from $\mathrm{Arg}_{8}-\mathrm{ELR}_{\mathrm{BC}}$ nanoparticles in acidic vesicles when cells were incubated with heparinase. The result showed an inhibition of nanoparticles accumulation up to $50 \%$ at $\mathrm{pH} 4$ and $16 \%$ at $\mathrm{pH} 6$. With heparinase treatment it appeared to be a higher distribution at pH 5-6 which corresponds with early and late endosomes suggesting their internalization through clathrin or even caveolin dependent routes. This data clearly shows the inhibition caused by heparinase treatment over the accumulation of $\mathrm{Arg}_{8}-\mathrm{ELR}_{\mathrm{BC}}$ particles in acidic vesicles and over the global uptake. Indeed, it suggests a relevant role of HSPG as "receptor" over the $\mathrm{Arg}_{8}-\mathrm{ELR}_{\mathrm{BC}}$ nanoparticles uptake as part of the macropinocytic entrance pathway. 




Figure 4B.6. Inhibition of $\mathrm{Arg}_{8}-\mathrm{ELR}_{\mathrm{BC}}$ nanoparticles uptake by FaDu cells after heparinase III treatment. After heparinase treatment cells were incubated with nanoparticles for either $1 \mathrm{~h}$ or $3 \mathrm{~h}$. Cells without heparinase treatment and incubated with nanoparticles were considered as control of inhibition. Results are expressed as mean \pm standard deviation (SD) of three independent experiments.

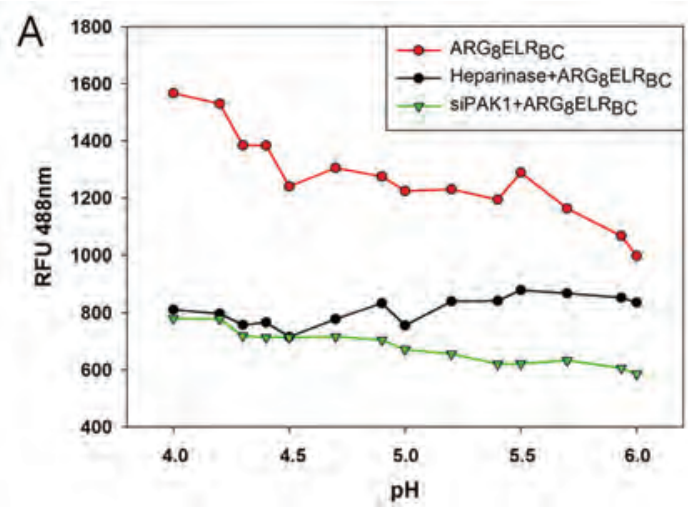

B

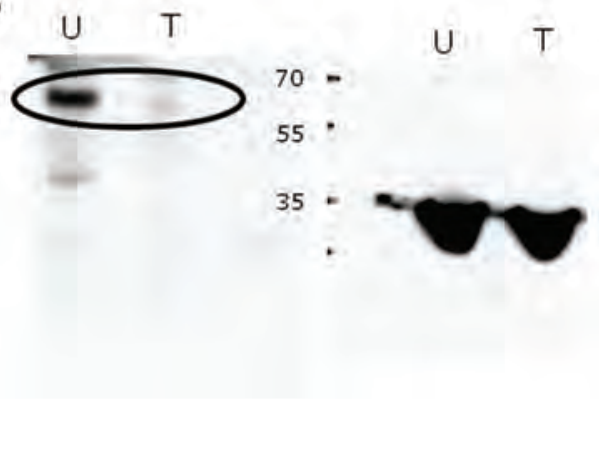

Figure 4B.7. Inhibition of $\mathrm{Arg}_{8}-\mathrm{EL} \mathrm{R}_{\mathrm{BC}}$ nanoparticles accumulation in acidic vesicles after heparinase III and siPAKI treatments. FaDu cells were treated either with heparinase III (dark line) or transfected with siPAKl (green line) and then incubated for $1 \mathrm{~h}$ with Arg8$E L R_{B C}$ nanoparticles. Cells without inhibition treatment and incubated with $\operatorname{Arg}_{8} E L R_{B C}$ nanoparticles for 1 hour was considered as control (red line). After this time Lysosensor was added and incubated for $1 \mathrm{~h}$ and $30 \mathrm{~min}$ more before visualization with spinning disc microscope (A). Inhibition of PAK1 after treatment with siPAK1 by Western Blot in FaDu cells. Cell expression of PAKI (left) and expression of GADPH as control (right). Untreated cells $(U)$, inhibitors treated cells $(\mathrm{T})(\mathrm{B})$.

In order to confirm the internalization of $\mathrm{Arg}_{8}-\mathrm{ELR}_{\mathrm{BC}}$ through macropinocytosis, the influence and the role of another molecule involved in the first events of internalization named as PAK1 was evaluated. Thus, FaDu cells were transfected with 
the siRNA that inhibits the expression of PAK1 protein by means of Lipofectamine (3.2.12.2.3.). After transfection, cell lysis and analysis of PAK1 expression was analyzed by western blot. As shown in Figure 4B.7B, siRNA was able to bind PAK1 mRNA almost completely inhibiting its expression. In this manner, the modulation of actindynamin cytoskeleton by PAK1 that would lead to ruffling and macropinosomes formation was inhibited triggering a blockade of macropynocitosis pathway. This effect was evaluated by means of nanoparticles accumulation in acidic vesicles. As shown in Figure 4B.7A the accumulation of $\operatorname{Arg}_{8}-E^{-E R} R_{B C}$ was reduced about $45-50 \%$ in the $\mathrm{pH}$ range of 4.0-6.0 with a very homogeneous distribution pattern. Since similar inhibition results had been obtained with heparinase treatment for general uptake and accumulation in acidic vesicles, a correlation of both general uptake and vesicles accumulation is suggested for siPAK1 treatment as well. This inhibition data suggests the involvement of PAK1 in $\mathrm{Arg}_{8}-$ ELR $_{\mathrm{BC}}$ accumulation in acidic vesicles and what is more important its main role in the uptake of these nanoparticles and confirmation of macropinocytic internalization route. In light of these results macropinocytosis can be consider as the main route of entry however since a total uptake inhibition with both heparinase or siPAK1 was not obtained, which suggests the involvement of other entry pathways as clathrin dependent or caveolin dependent.

\section{B.4 CELLULAR UPTAKE OF Arg8-ELRBC}

Accordingly with intravesicular micelles accumulation studies, cellular uptake visualization using TIRF (Total Internal Reflection Fluorescence) microscopy was performed (3.2.12.2.4.). TIRF microscope strongly excites fluorophores located in the contact area between cell and tissue culture plate up to $200 \mathrm{~nm}$ depth but those further away are not $(322,342)$. Then, fluorophores of the layer at or near cell surface have little or no interference from fluorescent molecules located in the cytosol. In general, total internal reflection illumination has potential benefits in any application requiring imaging of minute structures such as vesicles undergoing endocytosis or exocytosis, or single protein trafficking in cells (343). FaDu cells were incubated with labeled $E L R_{B C}$ and $A R G_{8} E L R_{B C}$ for $30 \mathrm{~min}$, in addition other samples of cells were treated with heparinase and siPAK1 prior to incubation with $\operatorname{Arg}_{8} E L R_{B C}$ (3.2.12.2.4.) and visualized through TIRF. As expected from kinetics and intravesicular distribution, 
$\operatorname{Arg}_{8} E L R_{B C}$ nanoparticles internalized more efficiently than $E L R_{B C}$ lacking the arginine peptide being widely located in the cytosol (Figure 4B.8). Even more, when inhibitors such as heparinase or siPAK1 were used the amount of internalized nanoparticles was decreased (Figure 4B.8) as shown in the accumulation studies as well (Figure 4B.7A). These images from TIRF correlate the quantitative data from the accumulation assays and confirm the macropinocytosis as the main entrance pathway for $\mathrm{Arg}_{8}-\mathrm{ELR}_{\mathrm{BC}}$. By contrast the lacking of total inhibition suggests that once the macropynocitosis is blocked, $\mathrm{Arg}_{8}-\mathrm{ELR}_{\mathrm{BC}}$ nanoparticles are internalized through other internalization pathways such as clathrin or caveolin endocytosis.
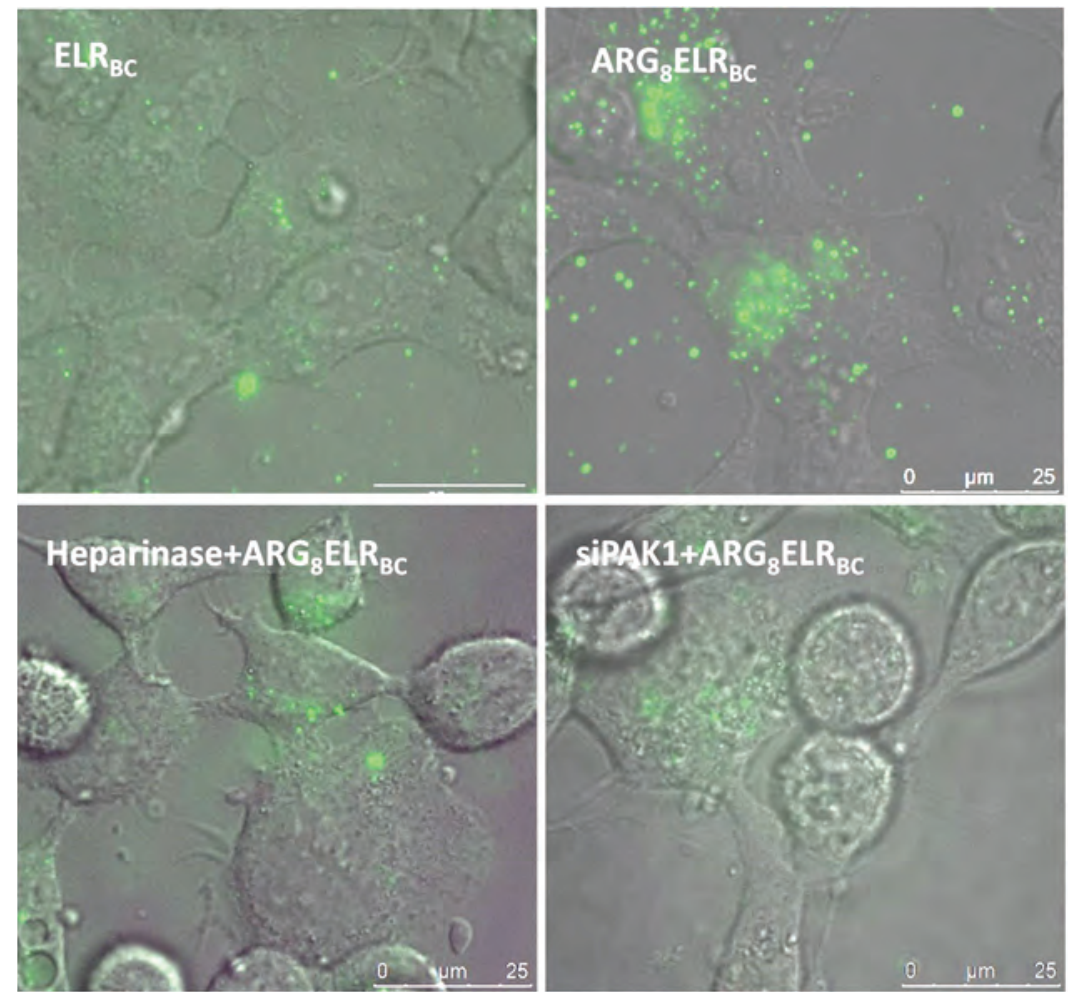

Figure 4B.8. Internalization of $A R G_{8}-E L R_{B C}$ visualized by TIRF microscope. Cells were incubated with $E L R_{B C}$ and $\mathrm{Arg}_{8}-E L R_{B C}$. Cells treated with heparinase or siPAKland incubated with $\mathrm{Arg}_{8}-E L R_{B C}$ were visualized. In all cases cells were incubated with $20 \mu \mathrm{M}$ of ELRs for 30 minutes at $37^{\circ} \mathrm{C}, 5 \% \mathrm{CO} 2$. Scale bars corresponds with $25 \mu \mathrm{m}$. 


\section{FINAL REMARKS}

The incorporation of the arginine CPP to the $E L R_{B C}$ sequence did not influence in the level of purity of the polymer, since both $E L R_{B C}$ and $\operatorname{Arg}_{8} E L R_{B C}$ showed the same protein pattern in SDS-PAGE. In addition, the arginine peptide did not seem to affect over the aggregation temperature of $E L R_{B C}$. Thus, the temperature at which $\operatorname{Arg}_{8} E L R_{B C}$ aggregated was extended from $36.6^{\circ} \mathrm{C}$ at $20 \mu \mathrm{M}$ in PBS. In addition, the formation of nanoparticles of $64.4 \pm 3 \mathrm{~nm}$ at this concentration was confirmed at $37^{\circ} \mathrm{C}$ in PBS solution.

The study about the kinetics of particles internalization showed that $\operatorname{Arg}_{8}-E L R_{B C}$ was internalized faster and in higher amount than the control ELR $R_{B C}$. Thus, this $\operatorname{Arg}_{8}-E L R_{B C}$ was proved not only to improve the cellular uptake but their accumulation into acidic vesicles. High quantities of $\mathrm{Arg}_{8}-\mathrm{ELR}_{\mathrm{BC}}$ micelles were found to be accumulated at endosomal at lower incubation times with cells and at lysosomal $\mathrm{pH}$ at higher incubation times which makes it a better option than the control ELR $R_{B C}$ for the incorporation of $\mathrm{pH}$ sensitive linker.

Additionally, we hypothesized macropinocytosis as the preference route of entry for this $\mathrm{Arg}_{8}-\mathrm{ELR}_{\mathrm{BC}}$. In order to confirm this internalization pathway two markers named as HSPG and PAK1 were tested. HSPG was proved to play an important role as "receptor" for $\mathrm{Arg}_{8}-\mathrm{ELR}_{\mathrm{BC}}$ nanoparticles. The degradation of HSPG by heparinase caused a decreased in $\operatorname{Arg}_{8}-E L R_{B C}$ uptake at 1 and $3 \mathrm{~h}$ of nanoparticles incubation with cells. Indeed accumulation of particles was shown to decrease up to $50 \%$ in lysosomes and only $16 \%$ in endosomes. In addition, siPAK 1 treatment inhibited the expression of PAK1 triggering a homogeneous decrease in intravesicular accumulation about $45-50 \%$ and likely uptake of $\mathrm{Arg}_{8}-\mathrm{ELR}_{\mathrm{BC}}$ showing its role as part of the internalization process.

These quantitative results were in accordance with TIRF visualization, showing an increase in $\mathrm{ELR}_{\mathrm{BC}}$ nanoparticles when $\mathrm{Arg}_{8}$ was present. Additionally, it showed the inhibitory effect and thus the HSPG and PAK1 involvement in $\mathrm{ARg}_{8} \mathrm{ELR}_{\mathrm{BC}}$ internalization.

The inhibitory effect of both heparinase and siPAK1 over the $A R G_{8}-E L R_{B C}$ uptake showed the macropinocytosis as the main entrance pathway. However, the lack of 
total inhibition suggests the existence of alternative entrance pathways such as clathrin or caveolin endocytosis.

Future experiments will be focused in the incorporation of $\mathrm{pH}$ sensitive linker such as hydrazone $(334,344)$ into the $\mathrm{Arg}_{8}-\mathrm{ELR}_{\mathrm{BC}}$ polymer. As well as the role of PAK1 in the internalization of normal and tumor cells as the endothelial HUVEc or the tumor colorectal HCT116 cells will be investigated.

The higher cell uptake obtained with the arginine peptide paves the way for the utilization of arginine enriched CPPs contained in ELRs for other field than drug delivery such as gene delivery. 
品

$\frac{\mathrm{a}}{\mathrm{a}}$

U

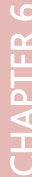









\section{ELASTIN-LIKE RECOMBINAMERS WITH ACQUIRED FUNCTIONALITIES FOR GENE-DELIVERY APPLICATIONS}
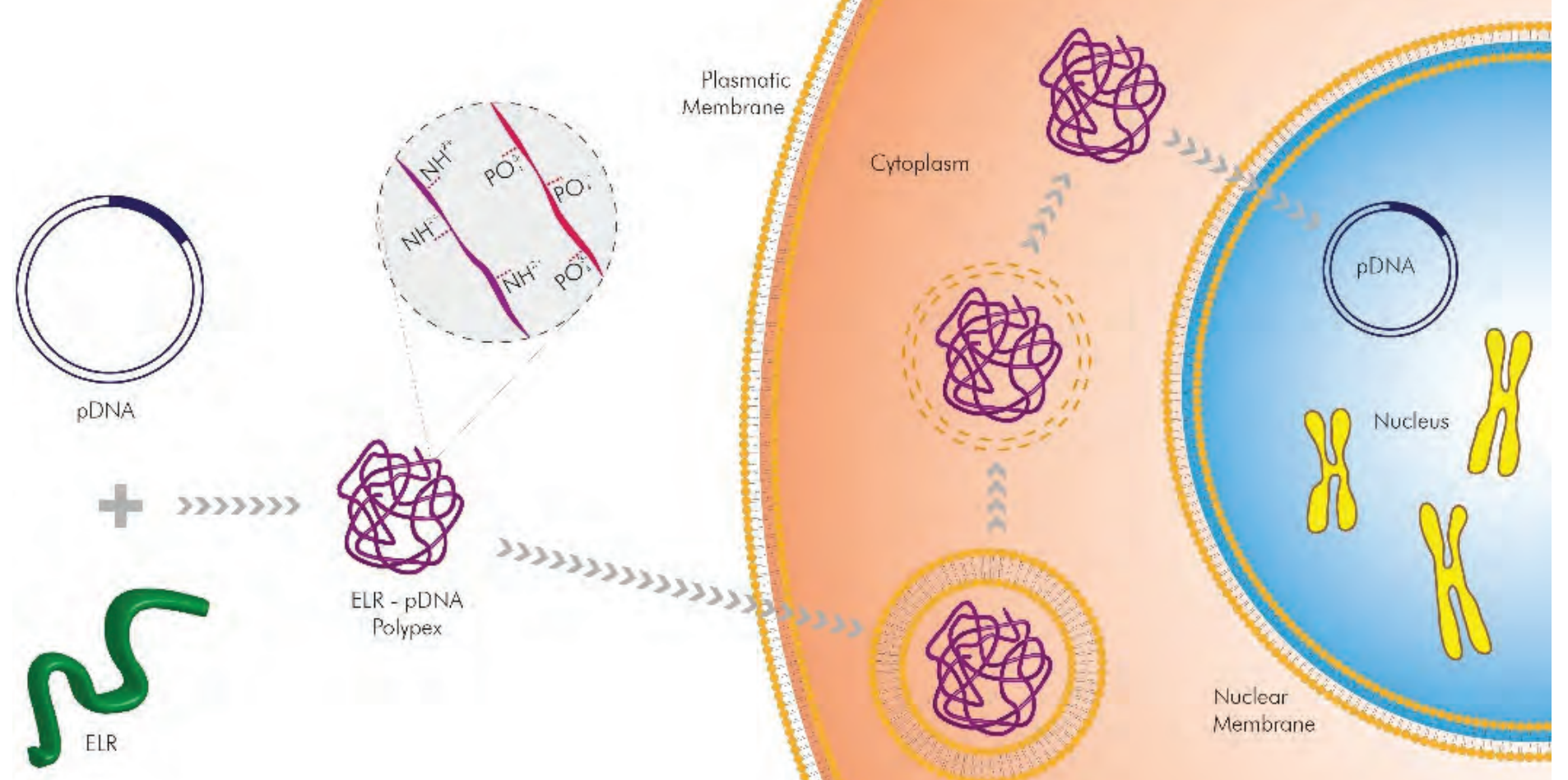


-

$-206$ 


\section{CHAPTER 4C: ELASTIN-LIKE RECOMBINAMERS WITH ACQUIRED FUNCTIONALITIES FOR GENE-DELIVERY APPLICATIONS}

The efficient delivery of genetic material into the cells by the use of non-toxic nonviral vectors is a bottleneck in the design of new gene delivery systems. Previous research with ELRs by Dr. Garcia-Arevalo (53) (1.2.3.) showed the role of lysines in complexing DNA in $\mathrm{H} 8-6 \mathrm{~K}-\mathrm{K} 5 \mathrm{~V}$ and $6 \mathrm{~K}-\mathrm{K} 5 \mathrm{~V}$ polymers. However, low levels of transfection were achieved. With the aim to improve the transfection ability of ELRs, novel ELRs with bio-functional domains were developed by genetic engineering techniques allowing the full control over their composition and positioning them as an alternative to other existing polymers (28). As depicted in (4A.2.2.), a lysine-based ELR termed as IK120 was modified with several motifs in order to improve the delivery of genetic material inside the cells with low cytotoxicity. The cationic backbone IK120 was selected due to its high number of lysines (24 Lys) in order to condense the plasmid DNA and interact with the negatively charged plasmatic membrane. As result, two main strategies were adopted. The first strategy involved improving entry into the cell by designing an ELR with a bio-functional penetratin CPP domain derived from the Antennapedia transcription factor of Drosophila melanogaster (1.2.5.2.). This is an amphiphilic peptide rich in arginines, with a positive charge at physiological $\mathrm{pH}$, that is able to cross the cell membrane and enter the cytoplasm, thereby promoting the internalization of oligonucleotides, peptides and nanoparticles (197). Penetratin (RQIKIWFQNRRMKWKK) was selected as the CPP of choice due to its high transfection efficiency and non-toxicity when complexed with ELRs (345). When the polymeric vector enters the cell via the endocytic pathway, it is encapsulated in an endosome vesicle and therefore experiences a drop in $\mathrm{pH}$ from the physiological value to $\mathrm{pH}$ 6.5-6 in the endosome and $\mathrm{pH}$ 4-5 inside the lysosome (127) (1.2.5.3.). The polymer and its DNA cargo would presumably be degraded by lysosomal enzymes. The second strategy involved stimulating endosome escape by two alternatives, namely recombinant incorporation of the fusogenic peptide "LAEL" (189) (LAELLAELLAEL) into the basic ELR sequence and chemical addition of imidazole functional groups with buffering capacity into the basic ELR polymer. As described in the literature, LAEL undergoes a structural change when the $\mathrm{pH}$ drops from physiological values to 5.0 (189), changing from a random coil to $\alpha$-helix, thereby resulting in destabilization of the endosome membrane. In contrast, the modification 
with imidazole groups ( $\mathrm{pK}_{\mathrm{a}}$ of 6.9 ) favors disruption of the endosome supported by the proton sponge hypothesis (88). By contrast, the protonation of imidazole at endosomal $\mathrm{pH}(\mathrm{pH}$ 6.5-6) triggers an influx of water and ions, thereby destabilizing and disrupting the endosome. This strategy would improve the polymer buffering capacity and facilitate the release of the polymer/pDNA complex into the cytoplasm $(104,330)$.

The designed constructs were named as IK120CPP, LAELIK120CPP and IMID-IK120 according with their different functional groups (Figure 4C.1) and their characterization by different physicochemical techniques was shown along 4A.2.2., 4A.3. and 4A.4.1. sections. Thus, a wide number of experiments focused on showing the biocompatibility of these ELRs with acquired functionalities, their complexation ability with pDNA and formation of polyplexes besides of cell transfection assays were accomplished along this chapter.

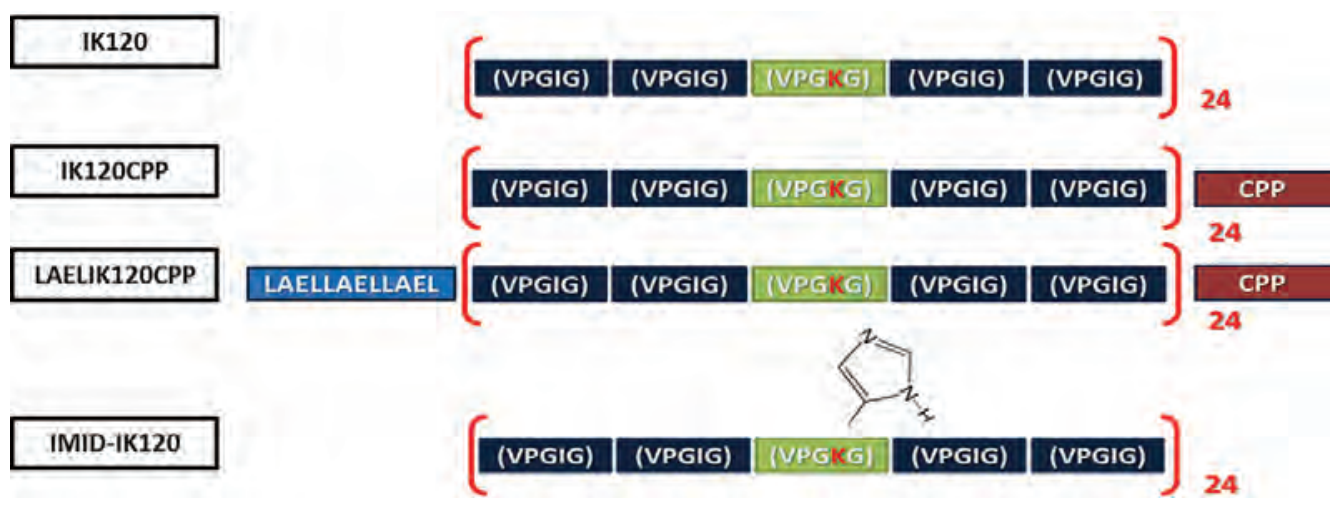

Figure 4C.1. Schematic representation of biotechnological modified ELR with acquired functionalities.

\section{C.1. BLOOD COMPATIBILITY ASSAYS}

The first step was to evaluate the biocompatibility of the novel ELRs in the blood environment. Although the ELR/pDNA nanocomplexes have to be positively charged in order to interact with the cell membrane and ensure transfection, some aggregation processes with blood components may appear if this positive charge is too high, thus causing problems of cell lysis and clotting (157). As such, the biocompatibility of ELRs with blood cells and plasma was addressed to ensure the tolerance of the physiological fluid system of human body to the impact of the polymers, which is a prerequisite for gene-therapy applications. 
A
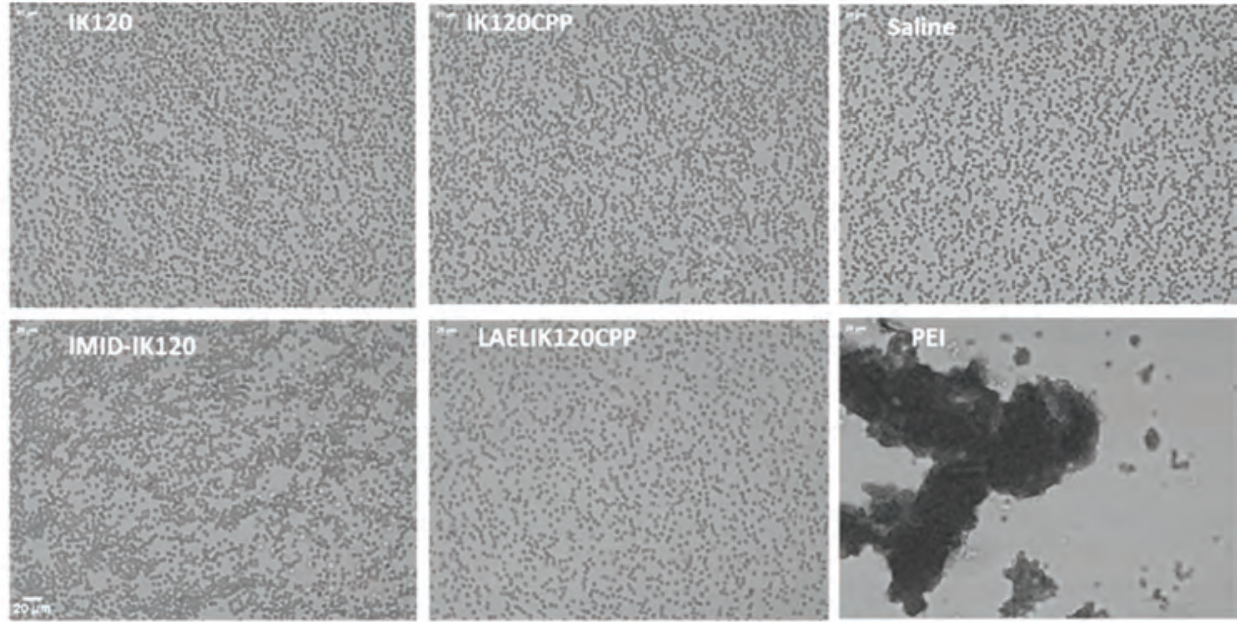

B
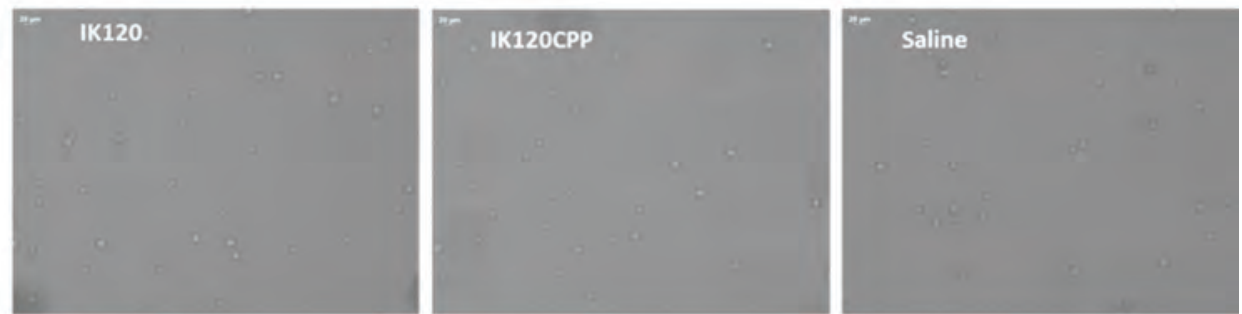

IMID-IK120
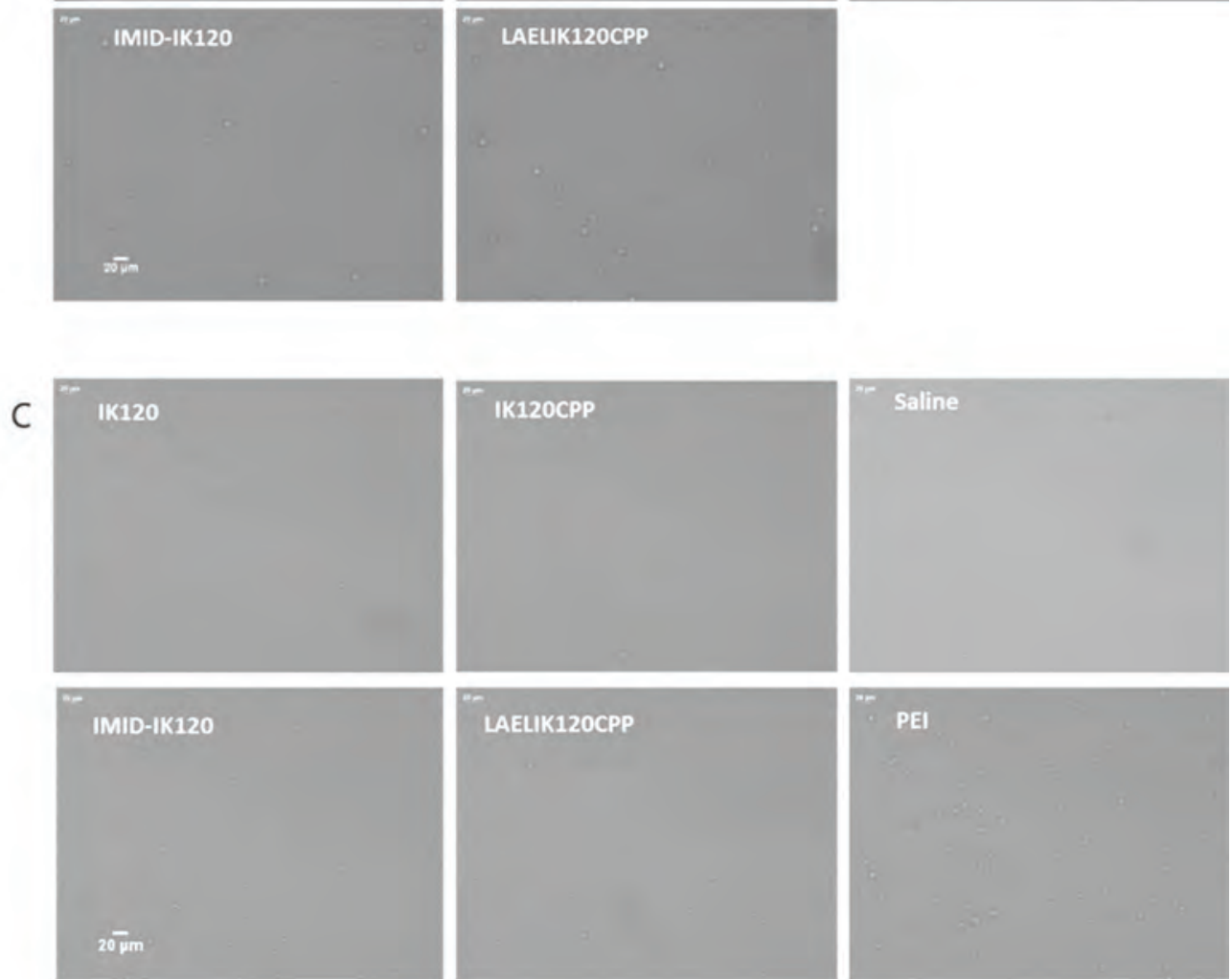

Figure 4C.2. Aggregation studies of the red blood cell fraction (A), white blood cell fraction (B) and platelets (C) with $0.5 \mathrm{mg} / \mathrm{mL}$ ELRs as final concentration. Saline was used as negative control and $0.5 \mathrm{mg} / \mathrm{ml} \mathrm{PEl}$ as positive control. 
For that, red blood cells, white cells and platelets were incubated for 30 min with a solution of ELRs and PEI as positive control (3.2.10.1.). Blood cell aggregation studies (Figure 4C.2) showed no aggregation with any of the blood components in comparison with the striking aggregation process existing in the PEl treated blood cells and platelets. Thus, an additional experiment showing the lack of interaction of our ELRs with main protein components of plasma (IgM, fibrinogen, transferrin and albumin) was conducted (3.2.10.2.). For this assay a solution of ELRs (1 mg/mL) was incubated with plasma for 30 minutes, after centrifugation the pattern of desorbed proteins was analyzed by SDS-PAGE. As depicted in Figure 4C.3, all protein bands from plasma were present in ELRs samples thereby the electrophoresis patterns showed non interaction between plasma components and ELRs. In contrast, PEI induced the complete absence of fibrinogen and partial reduction in the other bands. Accordingly, these results demonstrate that the ELRs studied herein are more compatible with blood components than PEl used as reference polymer.

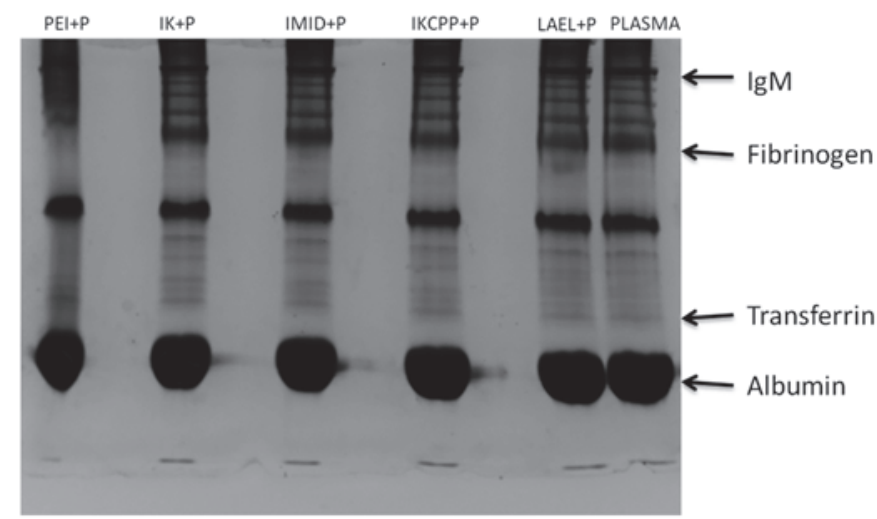

Figure 4C.3. Stability assay for different plasma proteins with polymers PEI (PEI+P), IK120 $(I K+P)$, IMID-IK120 (IMID+P), IK120CPP (IKCPP+P) and LAELIK120CPP (LAEL+P). Their protein pattern was compared with one from plasma treated with normal saline (plasma) used as negative control and plasma treated with PEI (PEI+P) as positive control. SDSPAGE in $7 \%$ of polyacrilamide stained with coomassie.

\section{C.2. CELL VIABILITY}

Additionally, the effect of ELRs over the viability in cell culture was performed as previous step to transfection studies. The influence of the designed ELRs on cellular viability was tested in the adherent $\mathrm{C} 6$ glial tumoral cells (3.2.11.2.1.). The viability of cells incubated for $24 \mathrm{~h}$ with a solution of ELRs at different concentrations (100, 200 
and $450 \mu \mathrm{g} / \mathrm{mL})$ and PEI $(20 \mu \mathrm{g} / \mathrm{mL})$ as reference polymer was assessed. The findings (Figure 4C.4A) showed that the viability of cells incubated with ELRs was clearly higher than $100 \%$, even at the highest concentration studied $(450 \mu \mathrm{g} / \mathrm{mL})$, and about $150 \%$ at a concentration of $100 \mu \mathrm{g} / \mathrm{mL}$. Similar viability levels over $100 \%$ had been previously obtained on mouse myoblastoma cell line $(346,347)$, in human breast cancer cell line (348) and mesenchymal stem cells $(346,349)$ when cells were incubated with ELRs nano/micro-particles, thereby demonstrating the friendly behavior of these polymers (47) .

The quantitative results were visually confirmed by means of the Live and Dead assay images (3.2.11.2.1.), as shown in Figure 4C.4B, where green (live) cells were predominant. In contrast, highly cytotoxic effects of PEI were found at only $20 \mu \mathrm{g} / \mathrm{mL}$ (Figure 4C.4A), which had been previously reported for the C6 glioma cell line (350) and in 293T from human kidney above $4 \mu \mathrm{g} / \mathrm{mL}(105,351)$. PEl produces nonspecific cytotoxicity as a result of destabilization of the plasmatic and mitochondrial membranes, which triggers the activation of apoptotic pathways, thereby restricting its clinical application (106-108). By contrast, the present ELRs appear to be biocompatible towards both cultured adherent cells and blood components at high concentration, both of which are aspects that must be considered when developing gene-therapy strategies.
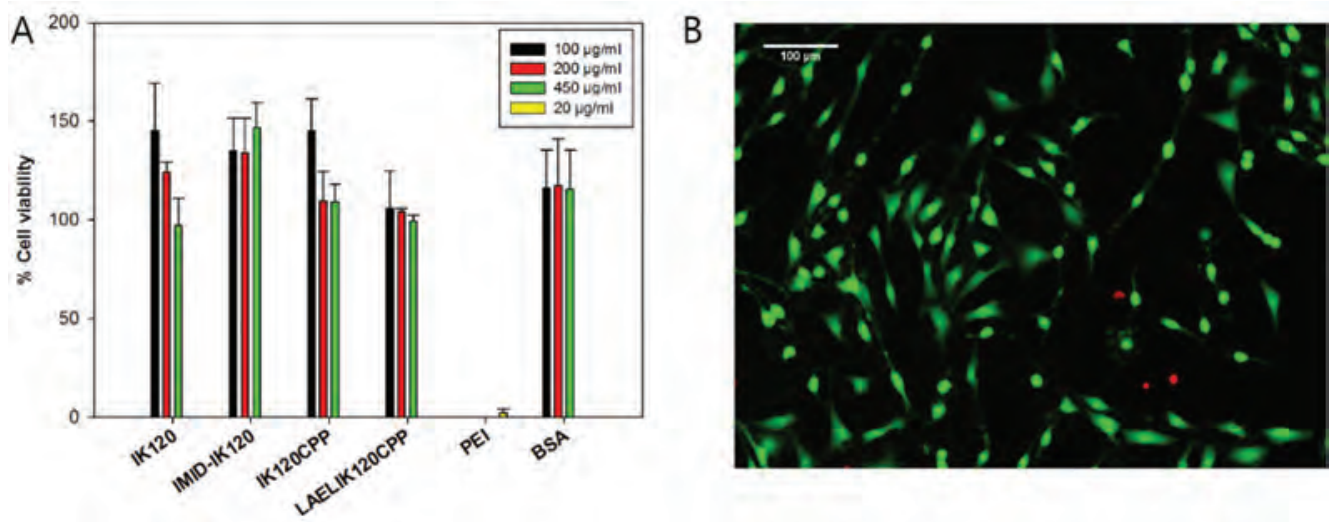

Figure 4C.4. A. Cell viability of C6 cells incubated with ELRs at different concentrations, with PEI as reference polymer and BSA as positive control, respectively. Cells were incubated with the polymer solutions for $24 \mathrm{~h}$. Results are expressed as mean \pm standard error (SE) of three independent experiments (A). Live/Dead assay for C6 cells incubated with $200 \mu \mathrm{g} / \mathrm{mL}$ IKCPP for $24 \mathrm{~h}$ (B). 


\section{C.3. DNA CONDENSATION ABILITY AND PLASMA-RELEASE ASSAYS}

ELR-pDNA polyplexes were prepared at specific (ELR)/ (pDNA) weight ratios (3.2.6.1.). The pDNA used along all the experiments had been previously extracted and purified as endotoxin-free which make it innocuous by itself. Indeed the plasmid used for physical characterization and luminescence assays is totally inoffensive. Having on mind the difficulty to estimate the amine content of PEI 25kDa weight ratios were chosen. PEI $25 \mathrm{kDa}$ is a complex mixture of polymers with different molecular weight and $25 \mathrm{kDa}$ is the average molecular weight. This weight ratio nomenclature was selected in order to compare ELRs with PEI in terms of mass, despite of the known number of amines of these ELRs. The condensation of DNA-forming nanocomplexes is a critical step that influences their entry into cells but also their stability and protection against nucleases attack (352). In this case, the electrostatic interactions between the amino groups from the polymer and the negatively charged phosphate groups from the backbone of the DNA allow this complexation. Polyplexes were formed and incubated at temperatures $\left(15^{\circ} \mathrm{C}\right)$ lower than their $\mathrm{Tt}$ in order to evade aggregation processes between the ELR molecules that would interfere with the polyplex formation. This polyplex formation was evaluated in a gel-retardation experiment (3.2.6.2.). After complexation at different (ELR)/ (pDNA) weight ratios (from 10/1 to 140/1), samples were loaded and run in agarose gel electrophoresis (Figure 4C.5A). As the figure shows, the IK120CPP had the highest and IMID-IK120 polymer the lowest condensation ability with pDNA. The explanation for this finding in IMID-IK120 lies in the fact that this polymer only contains 10 free lysines, with the remaining 15 being substituted by imidazole groups, thus meaning that IMID-IK120 was less able to condense pDNA than the non-modified polymer. In addition, an appropriate stability of the resulting polyplex is required in order to protect the genetic material during trafficking through the physiological environment. Charged serum components, such as albumin, may destabilize the polyplex by competitive binding or by cationic polymer displacement (353). When nanocomplexes at different ratios were incubated with plasma (3.2.6.2.), plasma altered the mobility of pDNA alone, retaining it in the well (Figure 4C.5B). Plasma components were able to compete with pDNA for polymer binding and displace it at a ratio of 10/1. The weak ability of IMID-IK120 polyplexes to condense pDNA was clarified, as shown by the fact that the strongest band appears at a 10/1 ratio. However, the ELR-pDNA interaction was sufficiently strong at ratios of $40 / 1$ and higher; therefore ratios from $40 / 1$ to $120 / 1$ were chosen for physical characterization of the polyplexes. 
A
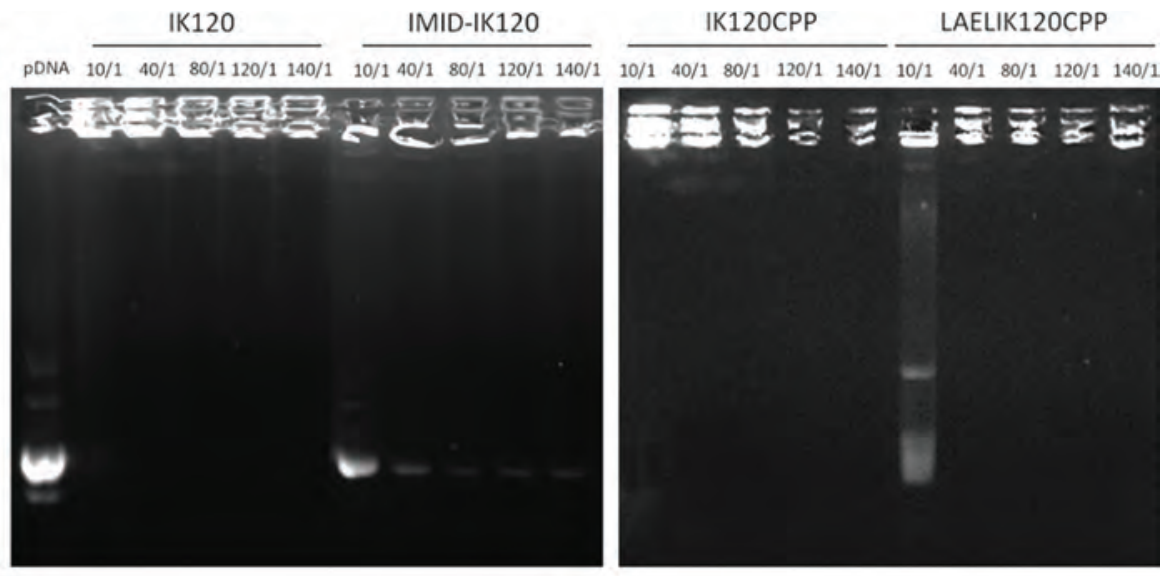

B
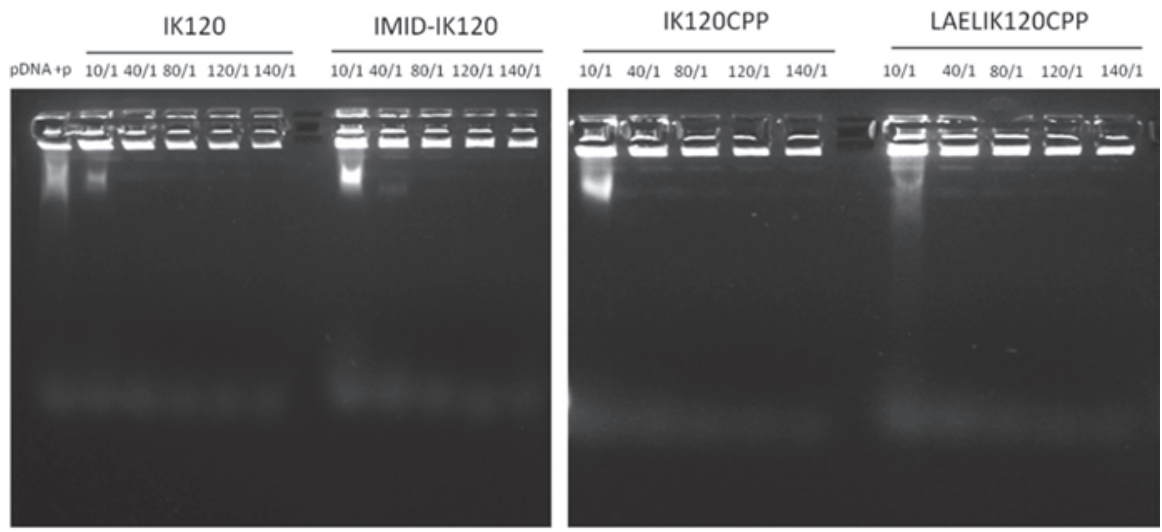

Figure 4C.5. Agarose gel electrophoresis retardation assay at different ELR-pDNA (w/w) ratios. Polymer-free pDNA was used as control (A). Agarose gel electrophoresis plasma release assay at different ELR-pDNA (w/w) ratios. pDNA incubated with plasma ( $\mathrm{pDNA}+\mathrm{p})$ was used as control (B). Samples were run in a $0.8 \%$ of agarose gel and stained with SimplySafe ${ }^{\mathrm{TM}}$.

\section{C.4. DETERMINATION OF PARTICLE SIZE AND Z-POTENTIAL}

Size measurements showed the formation of ELR-pDNA polyplexes triggered by the presence of pDNA, which condenses and promotes ELR complexation and selfassembly (3.2.6.3.). Particle size was measured for polyplexes formed from $40 / 1$ to 140/1 (ELR)/ (pDNA) weight ratio. The particle-size distribution for the resulting ELRpDNA polyplexes varied from 150.0 to $309.4 \mathrm{~nm}$ with a Pdl 0.12-0.27 (Table 4C.1). This range is appropriate for cellular uptake, and particles of this size are thought to be internalized mainly via clathrin-dependent or -independent endocytosis phenomena $(127,184)$. The size of polyplexes made of synthetic polycations may be sensitive to kinetic factors as concentration, temperature or mixing speed $(354,355)$. This study showed that the presence of a sufficiently content of ELR was necessary for the good stability of the polyplexes. For this reason we hypothesized that from (ELR)/ 
(pDNA) weight ratio of $40 / 1$ the polyplexes were stable and the temperature change from incubation $\left(15^{\circ} \mathrm{C}\right)$ to the application in vitro $\left(37^{\circ} \mathrm{C}\right)$ would not affect significantly to their particle size distribution (Figure 4C.6). Indeed, the mixing method used in this study guaranteed the homogeneous distribution of the ELR concentration in the sample and showed the presence of homogeneous particle size populations.

A

IK120

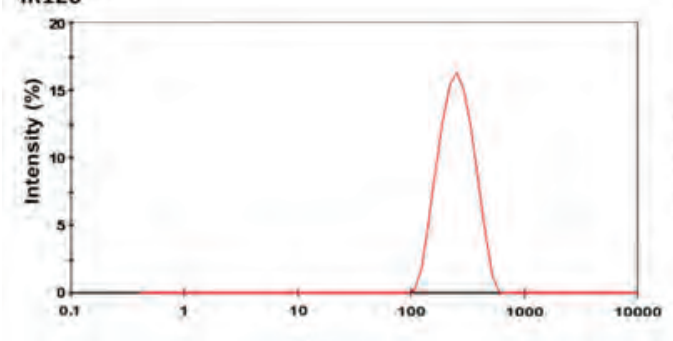

IMID-IK120 Size (d.nm)

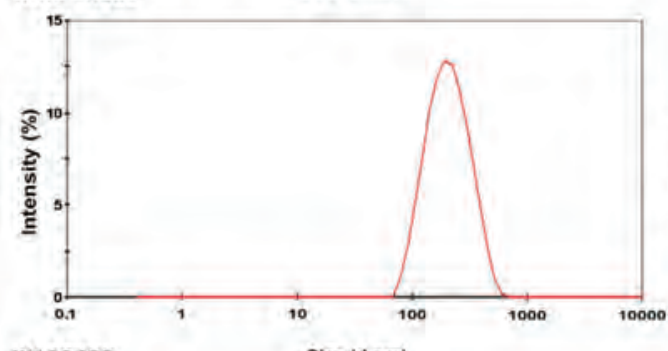

IK120CPP

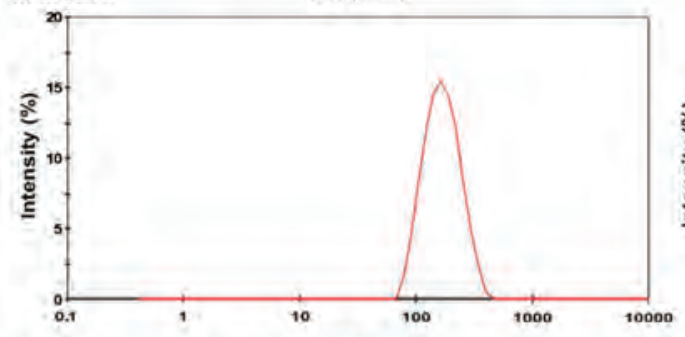

LAELIK120CPP Size (d.nm)

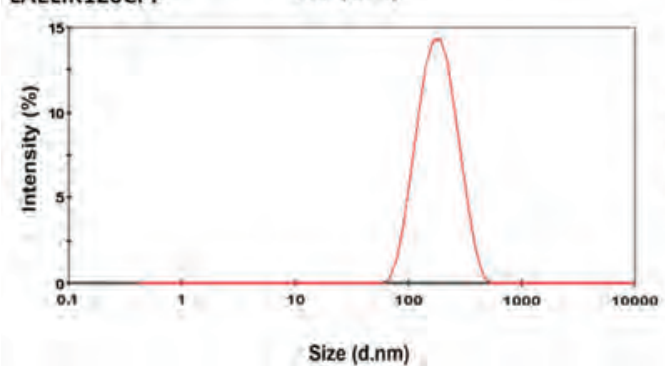

B
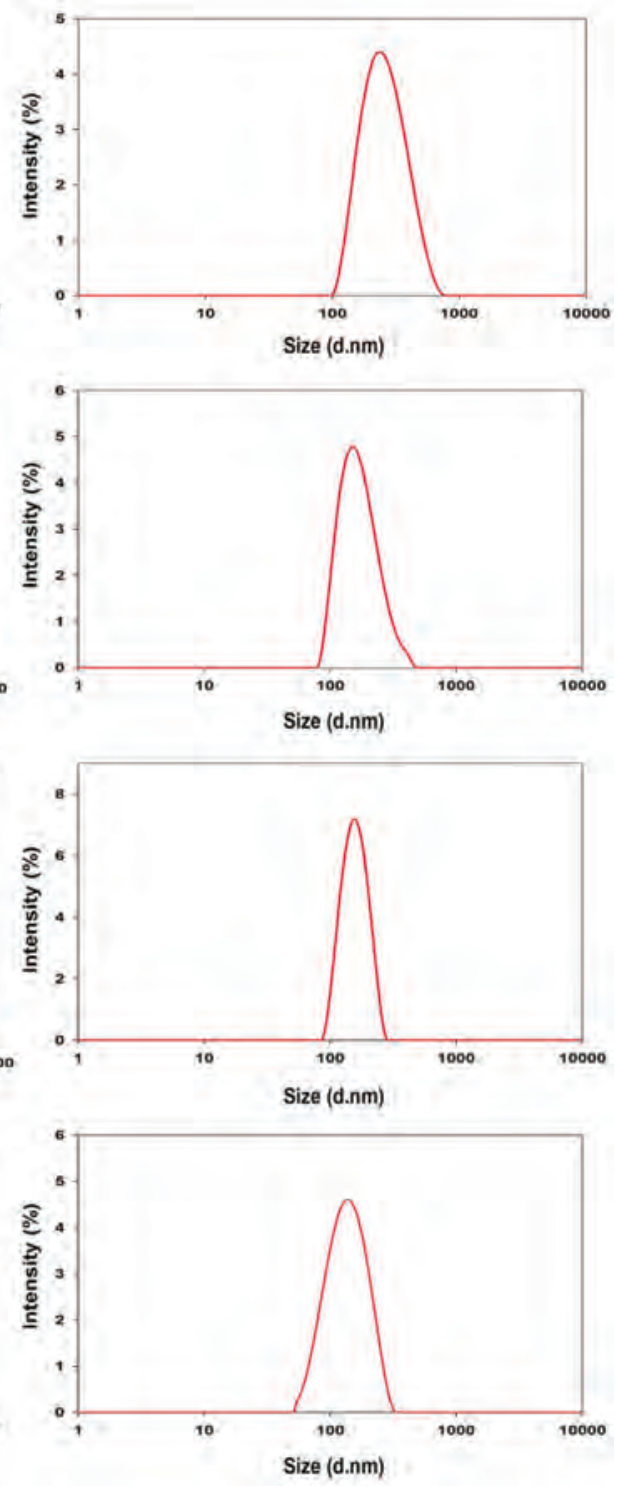

Figure 4C.6. Particle size distribution by Intensity of ELR-pDNA polyplexes formed at weight ratio ELR/pDNA of $80 / 1$ and measured by DLS. Measurements at $15^{\circ} \mathrm{C}$ after mixing ELR and $p D N A$ by vortex (A). Measurement at $37^{\circ} \mathrm{C}$ after polyplex formation (B). 
Table 4C.1. Particle size (z-average $\mathrm{nm}$ ) and Pdl for the ELR-pDNA plasmid nanocomplexes at different weight ratios (mean \pm SD) in deionized water.

\begin{tabular}{|ccccccccc}
\multirow{2}{*}{ ELR/pDNA $(w / w)$} & \multicolumn{2}{c}{ IK120 } & \multicolumn{2}{c}{ IMID-IK120 } & \multicolumn{2}{c}{ IK120CPP } & \multicolumn{2}{c}{ LAELIK120CPP } \\
\cline { 2 - 9 } & Z-size & Pdl & Z-size & Pdl & Z-size & Pdl & Z-size & Pdl \\
\cline { 2 - 10 } $40 / 1$ & $292.1 \pm 6.2$ & 0.14 & $179.1 \pm 4.1$ & 0.14 & $171.9 \pm 1.2$ & 0.16 & $155.7 \pm 2.2$ & 0.11 \\
$80 / 1$ & $272.7 \pm 5.9$ & 0.24 & $190.0 \pm 4.0$ & 0.16 & $175.1 \pm 8.3$ & 0.25 & $159.6 \pm 1.7$ & 0.15 \\
$120 / 1$ & $173.0 \pm 0.9$ & 0.18 & $150.0 \pm 1.8$ & 0.12 & $246.5 \pm 7.7$ & 0.27 & $159.8 \pm 2.1$ & 0.13 \\
$140 / 1$ & $229.2 \pm 8.3$ & 0.19 & $165.0 \pm 9.6$ & 0.20 & $309.4 \pm 10.0$ & 0.27 & $177.1 \pm 3.9$ & 0.22 \\
\hline
\end{tabular}

In contrast the particle size was influenced by the concentration of ELR. A similar trend was observed for IK120 and IMID-IK120, the particle size mainly decreased at high ratios due to the ability of these polymers to pack tightly. However, the particle size for IK120CPP and LAELIK120CPP increased with amount of polymer (Table 4C.1) due to the progressive increase in repulsive forces inside the polyplex favored by the presence of the hydrophilic CPP. The formation of spherical nanoparticles was corroborated by TEM microscopy. IK120CPP $(101.7 \pm 13.9 \mathrm{~nm})$ and LAELIK120CPP $(99.4 \pm 9.8 \mathrm{~nm})$ polyplexes showed a rounded shape (Figure 4C.7). Differences found in particle size between both procedures were attributed to the technique conditions where polyplexes were hydrated for DLS and dried for TEM. The stability of many colloidal systems is directly related to the magnitude of their zeta potential. Thus, if the value of the z-potential from the particle is high (around $+30 \mathrm{mV}$ ), the colloidal system will usually be stable. In contrast, if this value is around $0 \mathrm{mV}$ the system will tend to agglomerate. Indeed, a positive z-potential is thought to improve cellular internalization as a result of interaction with the negatively charged plasmatic membrane (123). The resulting z-potential (3.2.6.4.) of the ELR-pDNA polyplexes was up to $+23.5 \mathrm{mV}$ (Table 4C.2). The positive z-potential obtained suggests the distribution of positive charges from the polymer on the periphery of the polyplexes. As depicted in Table 4C.2, the increase in z-potential value was found to be correlated with an increase in the amount of polymer reaching the highest at 140/1 ratio. Specifically IMID-IK120 showed a lower zeta potential than IK120 at ratios of $40 / 1$ and $80 / 1$ due to substitution of the lysines, although both values were similar at higher ratios. However, the highest zeta potential was found for IK120CPP and LAELIK120CPP, both of which had a value of more than $+20 \mathrm{mV}$ due to the presence of arginine-enriched CPP, which provides more positive charge to the system. 
Despite nanoparticles with this zeta potential have shown to be stable, a value over $+30 \mathrm{mV}$ would confer higher stability and likely higher internalization.
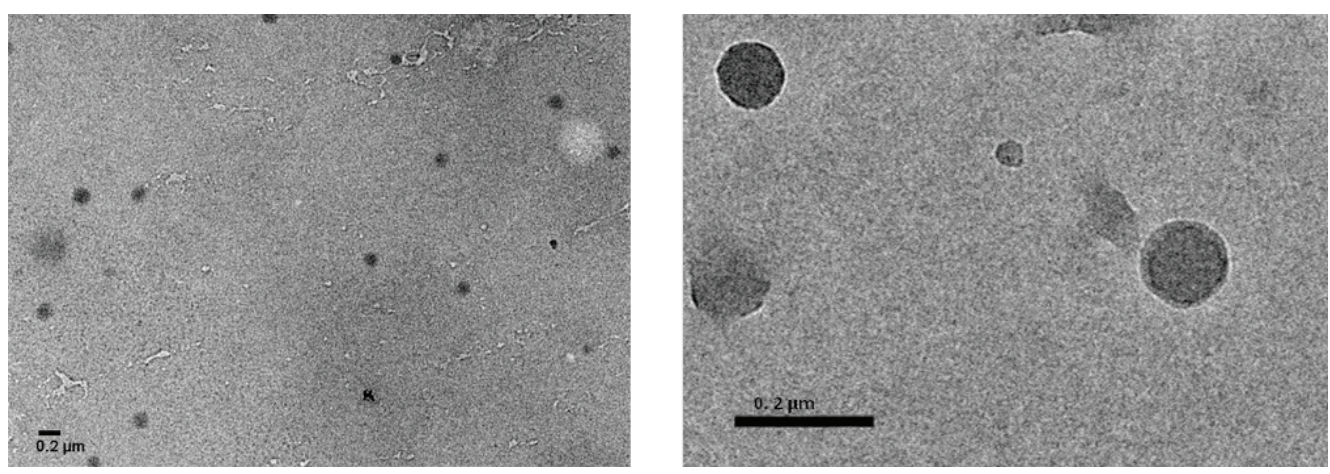

Figure 4C.7. TEM images for polyplexes IK120CPP-pDNA (left side) and LAELIK120CPPpDNA (right side) at $80 / 1(\mathrm{w} / \mathrm{w})$ ratio. Both with a $0.2 \mu \mathrm{m}$ bar scale.

Table 4C.2. Zeta potential $(\mathrm{mV})$ for the ELR-pDNA plasmid nanocomplexes at different weight ratios (mean \pm SD).

\begin{tabular}{|ccccc|}
\hline ELP/PDNA $(\mathrm{w} / \mathrm{w})$ & IK120 & IMID-IK120 & IK120CPP & LAELIK120CPP \\
\hline $40 / 1$ & $+13.6 \pm 0.4$ & $+11.4 \pm 0.5$ & $+19.1 \pm 0.5$ & $+15.6 \pm 0.3$ \\
$80 / 1$ & $+13.7 \pm 0.2$ & $+12.6 \pm 0.3$ & $+21.2 \pm 0.4$ & $+18.1 \pm 0.2$ \\
$120 / 1$ & $+13.9 \pm 0.0$ & $+13.8 \pm 0.3$ & $+23.4 \pm 1.5$ & $+21.4 \pm 0.6$ \\
$140 / 1$ & $+14.2 \pm 0.7$ & $+14.1 \pm 0.5$ & $+23.5 \pm 0.7$ & $+21.5 \pm 0.3$ \\
\hline
\end{tabular}

\section{C.5. CELL TRANSFECTION AND TRAFFICKING ASSAYS}

After these physico-chemical analysis, ELR-pDNA weight ratios of 80/1 and 120/1 showed the best physical characteristics with about $150-270 \mathrm{~nm}$ of size and +13 to $+23 \mathrm{mV}$ of zeta potential for transfection in in vitro assays. Initially, the expression and localization of plasmid DNA containing the p53 gene as a reporter transgen was evaluated by confocal fluorescence (3.2.12.5.1.). Later, the expression of another reporter gene as luciferase was assessed as well and quantified by luminescence (3.2.12.3.1.).

\section{C.5.1. p53 EXPRESSION}

The plasmid DNA containing the p53 transgene and named as pCMV-p53 is a model commonly used to report gene expression (330). Specifically, the successful expression of p53 protein, controlled by the potent and constitutive cytomegalovirus promoter (CMV), would lead to apoptosis activation and cellular death (356). 
Therefore, plasmid DNA containing the p53 transgene was used to evaluate gene expression with ELRs as vectors over a prolonged time period (48 h). For that, $\mathrm{C} 6$ cells were incubated with polyplexes formed ELRs-pCMV-p53 plasmid at two different (ELR/pDNA) w/w ratios (80/1 and 120/1) for $5 \mathrm{~h}$ (3.2.12.5.1.). C6 glioma cells were selected as standard as this cell line is widely used for transfection, especially in glioblastoma research (357-359). Thus, after $48 \mathrm{~h}$ Live and Dead assay (3.2.11.2.1.) was accomplished where live cells are in green and dead in red (Figure 4C.8). With this assay, significant death was observed for cells treated with the different polyplexes formed with IK120CPP and LAELIK120CPP. However, the death effect was visibly higher in cells treated with polyplexes containing LAELIK120CPP at ratios of 80/1 and 120/1 in comparison with IK120 polyplexes and untreated control cells. Thereby, suggesting that LAEL fusogenic peptide plays an essential role in the endosome escape mediated by the polyplex rather than the sponge effect by the imidazole groups. Nevertheless, there was no significant difference between the 80/1 and $120 / 1$ ratios. It is interesting to note that the maximum polymer concentration reached in this assay was $300 \mu \mathrm{g} / \mathrm{mL}$, which corresponds to the highest ratio (120/1). At this concentration and according to the cytotoxicity assays, the cell viability for ELRs was $100 \%$, thereby suggesting that cell death was due to the effect of the p53 gene transfected into C6 glioma cells. By contrast, when incubated with PEI at a weight ratio of 2/1 high level of cell death was induced. One likely explanation for this effect, given the previously reported cytotoxic effects of PEI and after transfection at these conditions, is that cell death was probably due further by the p53 transgene expression but also in lesser extent by the polymer itself. 

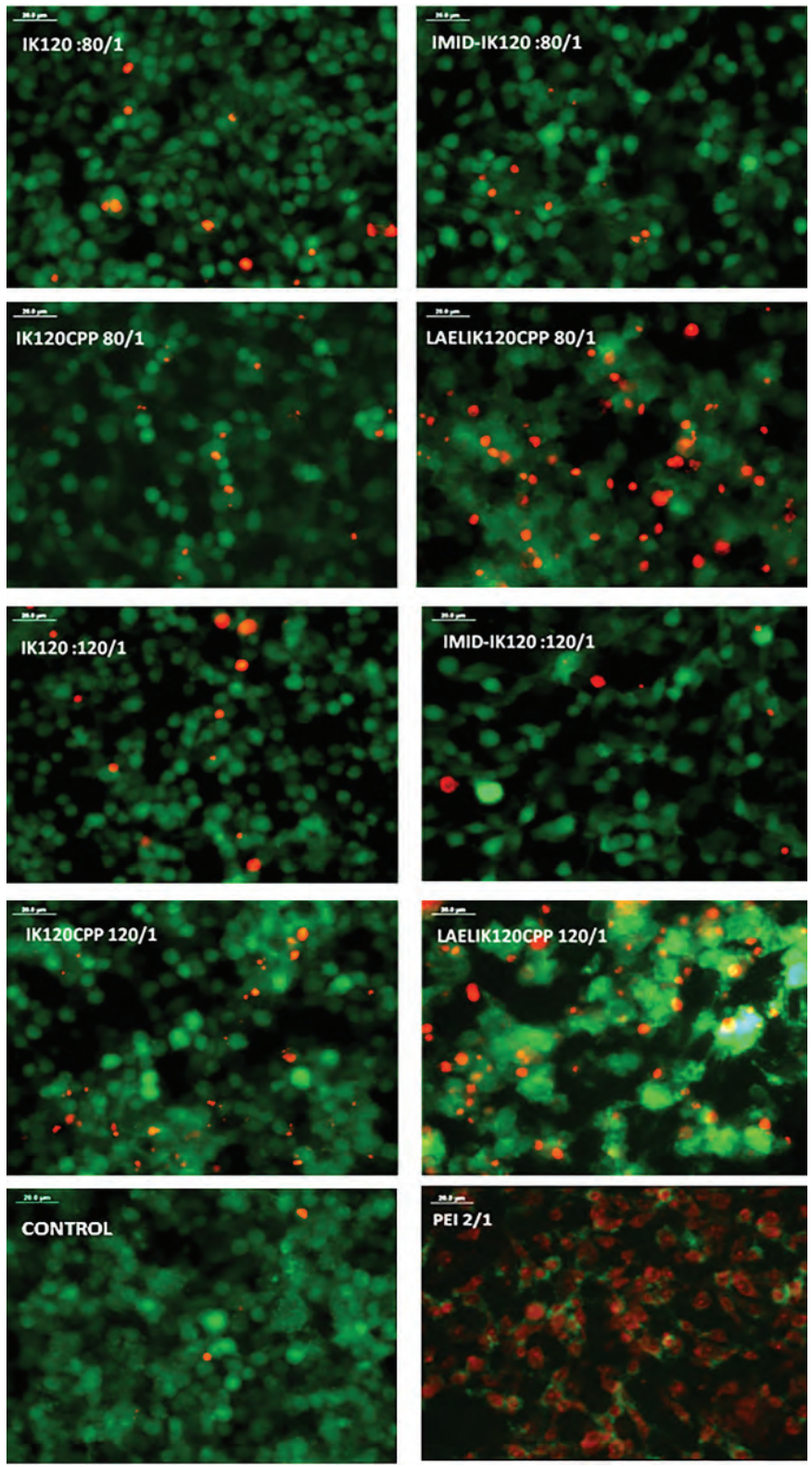

Figure 4C.8. Live/Dead assay for C6 cells transfected with ELR-p53 plasmid and PEI-p53 plasmid polyplexes at different weight ratios. Live cells are stained green and dead cells red. Cells visualized using an inverted fluorescence microscope. Representative images from two independent experiments. Scale bar corresponds with $20 \mu \mathrm{m}$.

\section{C.5.2. POLYPLEX CELL INTERNALIZATION}

Fluorescence microscopy was also used to localize the pDNA once transfected into C6 cells (Figure 4C.9). The selected ratio for this test was $80 / 1$ ratio as this gave together with 120/1 the qualitative highest p53 expression for the IK120 modified polymers (Figure 4C.8). To this end, ELR/pDNA nanocomplexes were prepared at a 
$\mathrm{w} / \mathrm{w}$ ratio of $80 / 1$ and the cells incubated for $3 \mathrm{~h}$ with these complexes. It is interesting to note that $3 \mathrm{~h}$ is not enough to observe toxic effects in cells incubated with this plasmid. pDNA containing the p53 transgene was previously tagged with YOYO fluorescence (green) and the nucleus stained with Hoechst (blue) (3.2.12.1.1.).


Figure 4C.9. Cellular localization of pDNA in C6 cells. ELR polyplexes were formed with pDNA tagged with YOYO and ELR at $(w / w)$ ratio of $80 / 1$ and incubated with $C 6$ cells for $3 \mathrm{~h}$. YOYO-tagged DNA appears green and the nucleus is blue as a result of Hoechst stain. Cells visualized by inverted fluorescence microscopy. Representative images from two independent experiments. Scale bar corresponds with $20 \mu \mathrm{m}$.

The natural ability of penetratin to cross the plasmatic membrane and facilitate the intracellular delivery of macromolecules by either direct translocation or the endosomal pathways is well known (360-362) (1.2.5.2.). In this assay, penetratin favored the presence of the plasmid in the cytoplasm and even inside the nucleus in cells transfected with the IK120CPP-pDNA polyplexes. However, in the case of polyplexes containing LAELIK120CPP, penetratin also triggered their internalization but the LAEL peptide seemed to facilitate the destabilization of the endosome membrane and the escape of the pDNA into the cytoplasm, where it was extensively located after the first three hours of incubation. Similarly, the imidazole groups in IMID-IK120 promoted the leakage of pDNA from the endosome. Histidinylated oligo(ethanamino)amides have recently been found to have enhanced transfection properties mediated by their increased buffering capacity at endosomal pH (363). The 
known "proton sponge effect" (88) appeared to boost some cytoplasmic and even nuclear presence of the plasmid. The widespread location of the polyplexes containing LAELIK120CPP at a ratio of $80 / 1$ in the first $3 \mathrm{~h}$, and the high expression of p53 gene after $48 \mathrm{~h}$, suggest a slower but more efficient endosomal mechanism of escape governed rather by the LAEL peptide than for imidazole groups.

\section{C.5.3. LUCIFERASE TRANSFECTION AND EXPRESSION}

Finally the quantification of transfection by the polyplexes was necessary for the direct application of these ELRs in gene therapy. The utilization of luciferase reporter as transgene allowed this quantification by means of luminescence. Luciferase expression was measured in C6 cells incubated with polyplexes formed by ELRpCMV-Luciferase at $80 / 1$ (ELR/pDNA) w/w ratio (3.2.12.3.1.). In this case, luciferase expression was also controlled by the constitutive CMV promoter. Figure 4C.10 depicted that cells treated with ELR polyplexes showed significantly better results in comparison with cells treated with the plasmid alone $(p<0.05)$. These results are comparable with the obtained of p53 expression and internalization. Thereby it highlighted the need of incorporating functional internalization peptides to lysine enriched ELR as requirement for higher transfection efficiency levels. Indeed, polyplexes containing the LAELIK120CPP polymer exhibited the highest luciferase expression with more than fivefold than pDNA. Once the polyplexes are inside the endosome, LAEL seems to play a key role in leakage of the pDNA from the endosome. After incubation for 5 hours, the luciferase pDNA delivered by LAELIK120CPP was able to reach the nucleus. In contrast, the main role of penetratin appears to be during cell entry and it is not as important as regards endosomal escape even though some plasmid still reaches the nucleus. Additionally, LAEL seems to promote slower but more efficient outflow than the imidazole groups bound to the lysine enriched polymer. Hence, LAEL plays a more relevant role in transfection than CPP alone and incorporation of imidazole groups. It is interesting to note that in absence of CPP, internalization of IK120 may be due to its positive zeta potential. However, lower transfection efficiency for ELRs was found when comparing with PEI probably due to their lower charge density that may give to the ELRs more compatible features. Similar results of transfection had been previously reported for ELRs appended with oligo-lysine or p [Asp(DET)]53 in comparison with $25 \mathrm{kDa}$ PEl 
$(54,364)$, where despite of its toxicity, PEI was also selected to compare luciferase expression levels due to its good transfection properties $(365,366)$. Taking together, the previous research of ELR as non-viral vectors showed higher toxicity than the ELRs developed in this work, with a viability up to $70 \%$ for the oligo-lysine modified ELR and from $80 \%$ for $p$ [Asp(DET)]53. The first was formed by an ELR-based diblock bearing an oligo-lysine for pDNA condensation. The second was constituted by an ELR-based diblock containing diethylenetriamine (DET) modified poly-L-aspartic acid segment which conferred less toxicity. Herein we report cationic and highly biocompatible ELRs with acquired functionalities able to condense and transfer genetic material by themselves, which represents a breakthrough in this regard.

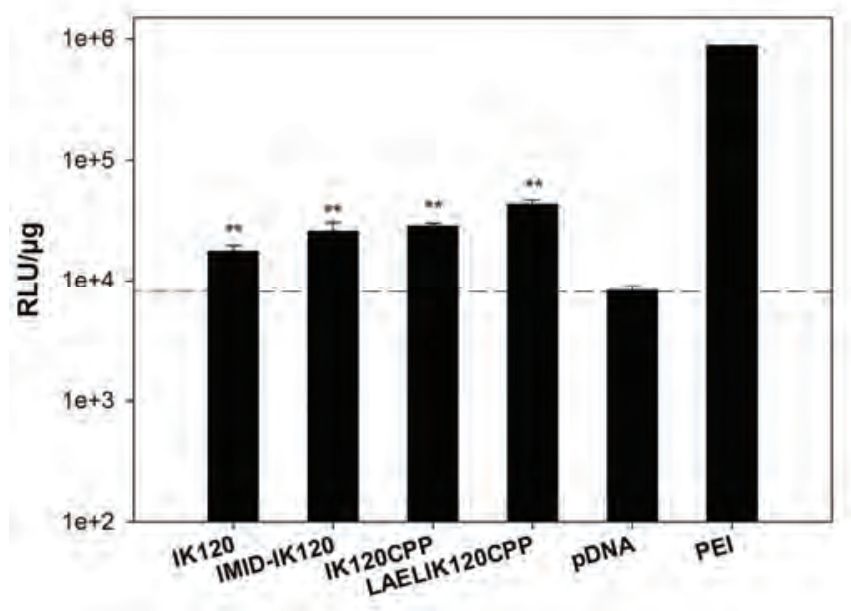

Figure 4C.10. Luciferase expression for different polyplex treatments. C6 cells were transfected with ELR/pDNA polyplexes at an $80 / 1$ weight ratio for $5 \mathrm{~h}$. Luciferase activity was evaluated 48 hours post-transfection and expressed in RLU/ $\mu \mathrm{g}$ protein lysate. pDNA was used as negative control. The results are expressed in logarithmic scale as mean \pm standard error of three independent experiments. ${ }^{* *}: p<0.05$. 


\section{FINAL REMARKS}

We have designed, constructed, produced and tested novel and highly biocompatible ELR materials with different functionalities such as penetratin CPP, LAEL fusogenic peptide or imidazole groups suitable for gene-delivery applications. Unlike other polymeric systems as the reference polymer PEI or virus derived vectors, these ELRs possess a marked potential for protein modifications by recombinant techniques in a totally controlled manner.

Notably, the analyzed ELRs exhibited high levels of blood compatibility and cell viability in vitro which is a striking contrast to PEl cytotoxicity. This biocompatibility is in accordance with previous studies and shows the potential for the biomedical application of ELRs.

In addition, all the ELRs were able to complex and protect the pDNA from 40/1 (w/w) ratio and form polyplexes from 150.0 to $309.4 \mathrm{~nm}$ with a positive zeta potential up to $+23.5 \mathrm{mV}$ ratio.

Indeed, incorporation of acquired functionalities provided by the penetratin, LAEL peptides or protonable imidazole groups provided higher levels of internalization and gene expression in comparison with the polyplexes formed either by the nonmodified ELR or pDNA. All the ELR-pDNA polyplexes studied along this chapter showed cellular entry, with this being higher in the case of LAELIK120CPP complexes, specifically 5 times more than pDNA alone. Penetratin plays a role in the first step of the internalization process, namely cellular entry of the polyplexes, whereas LAEL and imidazole groups to a lesser extent governed endosomal escape of the pDNA via their fusogenic activity and proton sponge effect, respectively.

Despite of the improvement in transfection after the incorporation of functional peptides, higher transfection levels are required. As consequence, future studies will be focused on improving the transfection efficiency of ELR systems. The biocompatible nature of ELRs and their versatility will allow the design of novel ELRs focused in increasing their transfection ability. In light of the results obtained along this chapter, the increment of zeta potential to more stable values over $+30 \mathrm{mV}$ in order to favor their interaction with plasmatic membrane will be pursued. For that the incorporation of lysine amino acids into the ELR sequence will be achieved and the assessment as gene delivery vector will be performed in the next chapter. 


$$
\text { 4D }
$$




\section{BIOCOMPATIBLE ELR BASED POLYPLEXES COATED WITH MUC1 SPECIFIC APTAMERS AND TARGETED FOR BREAST CANCER GENE THERAPY}
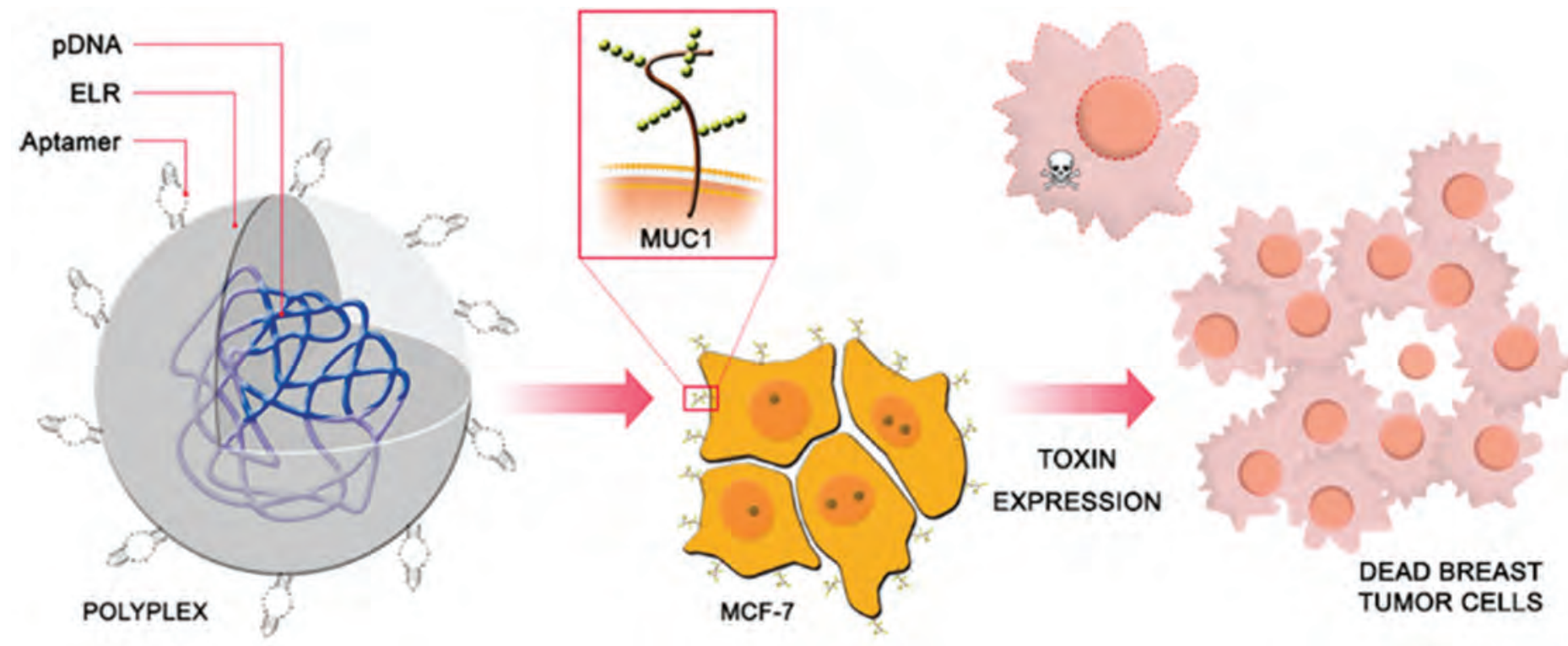
$-226$ 
4D. BIOCOMPATIBLE ELR BASED POLYPLEXES COATED WITH MUC1 SPECIFIC APTAMERS AND TARGETED FOR BREAST CANCER GENE THERAPY

The search for new and biocompatible materials with ample room for improvement through genetic engineering or chemical techniques is a challenge in gene delivery applications. It involves a carefully design of the ELRs composition as depicted in chapter 4A. This meticulously creation of ELRs allows absolute control over both architecture, physical and chemical features, especially surface charge, polydispersity, aggregation and biocompatibility. Once they are produced, purified and characterized, the main objective of these polymers is their application as potential gene delivery carriers. As shown in chapter 4A a pool of ELRs was designed, produced and characterized. The evaluation of their transfection ability in order to select the best candidate for breast cancer gene therapy using the human breast adenocarcinoma MCF-7 as cell line model, which is known to overexpress MUC1 protein (367), was accomplished. For that, LAELIK120CPP as the best of the ELRs with acquired functionalities depicted in chapter 5 was compared with VOKx72, IKx30HPGx3, VOKx48 and VOKx48HPGx1 in terms of transfection. Polyplexes were formed (3.2.6.1.) at N/P ratios: $13 / 1$ for LAELIK120CP; 5/1, 10/1, 20/1 and 50/1 for VOKx72, VOKx48 and VOKx48HPGx1; 5/1 and 10/1 for IKx3OHPGx3 and 2/1 of w/w ratio for PEI as reference polymer. Afterwards, MCF-7 cells were treated with them and transfection ability was evaluated through luciferase expression (3.2.12.3.).

IKx3OHPG 33 and VOKx48HPG 1 were designed with the objective of improving the transfection ability by means of the histidine amino-acids (4A.2.1.). Histidines are thought to favor the endosome escape by increasing the buffer capacity and leading to vesicle disruption. Contrary, VOKx48 and VOKx72 were designed in order to increase the net positive charge which is thought to improve the interaction with the negatively charged cell membrane and transfection (4A.1.2.). When comparing the transfection ability for all of these polymers, it is possible to appreciate significant differences in luciferase gene expression (Figure 4D.1). At first glance, polyplexes formed by VOKx72 and VOKx48 showed the highest transfection levels. By contrast LAELIK120CPP, that initially was the best option, and IKx30HPG 3 exhibited the lowest luciferase expression. In all cases there was a dependence of N/P ratio and transfection, when increasing the amount of polymer the transfection appeared to be enlarged. Incorporation of histidines in the ELR sequence seemed to increase notably 
the transfection when the N/P ratio was high for $V O K x 48 H P G \times 1$ construct. By contrast, at low N/P ratios (5/1 or 10/1) the data from both IKx30HPG $\times 3$ and VOKx48HPGx1 showed lower gene expression levels than VOKx72 and VOKx48 polymers. This fact suggests that the presence of high number of lysines and histidines, such as VOKx48HPGx1 construct at 50/1 ratio, were required to obtain similar levels of transfection than VOKx48 ratios $5 / 1$ to $20 / 1$. However significant differences $(p<0.05)$ were found between VOKx48 and VOKx48HPGx1 at 50/1 ratio suggesting the higher efficacy of lysines in comparison with histidines. This higher transfection can be due to the higher and unspecific binding of charged lysines with the negatively charged components of plasmatic membrane which seems to prevail over the endosome escape mediated by the presence of histidines. Additionally, VOKx72 at highest $50 / 1$ ratio showed significant differences $(p<0.001)$ with all the ratios tested for VOKx48. It indicates that a higher number of lysines improve the transfection ability. Similarly $\operatorname{VOK} \times 72$ at $50 / 1$ ratio showed the best luciferase expression with significant differences with all N/P ratios from the ELRs tested.

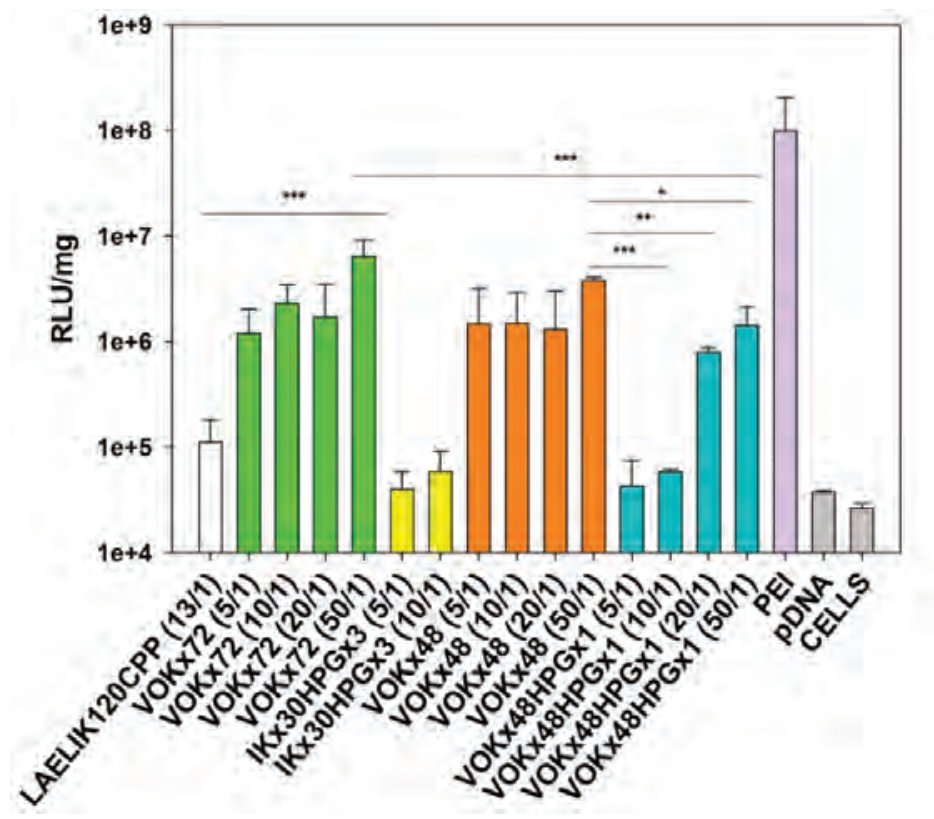

Figure 4D.1.Comparison of luciferase expression by pCMV-Gaussia luciferase contained in a variety of ELR-pDNA polyplexes. MCF-7 cells were incubated with polyplexes formed by LAELIK120CPP, VOKx72, IKx3HPGx3, VOKx48 or VOKx48HPG at different N/P ratios and $1 \mu \mathrm{g}$ of PEl as positive control. pDNA and cells without polyplexes were considered as negative control. Luciferase activity is expressed in RLU/mg protein lysate. The results are expressed in logarithmic scale as mean \pm standard desviation of three independent experiments. ${ }^{*}: p<0.05 ;^{* *}: p<0.01 i^{* * *}: p<0.001$. 
According with these results, VOKx72 polymer was selected for the following studies focused in increasing the transfection levels in MCF-7 cells. In addition VOKx72 with a molecular weight of $32.36 \mathrm{kDa}$ was thought to be appropriate for cellular entry and passively diffusion to the cellular nucleus which has been probed for molecules of 60 kDa or even 100 kDa (194-196). Hence, VOKx72 was complexed with pDNA to form polyplexes which were targeted specifically to breast cancer cells. It is important to note that targeted therapy was focused in increasing the specificity and thereby the global result of the system by reducing the unspecific binding (1.3.4.). Despite of ELRs can be designed with functional peptides (chapter 4C) that could increase its specificity; the incorporation of a type of targeting elements known as aptamers to the already formed polyplexes was selected. Therefore the increase of specificity was addressed by the use of small oligonucleotides named aptamers (1.3.4.) and directed against the MUC1 glycoprotein.

MUC1 is normally O-glycosylated in the VNTR (variable number tandem repeat) region from MUC1-N terminal (236) (1.3.4.1.). However, the pattern of $\mathrm{O}$ glycosylation is altered in $80 \%$ of breast cancers to generate truncated short sugar chains known as Tn antigens as well as exposing the VNTR peptide chain itself (255). Hence, polyplexes with adsorbed MUC1 aptamers were thought to be used and targeted the malignant cells. For this goal two types of aptamers of 25 bp were used: S2.2 and 5TR1 (1.3.4.1.). S.2.2 is an oligonucleotide (5'-GCA GTT GAT CCT TTG GAT ACC CTG G-3') that binds the protein core of MUC1 with relatively high affinity and specificity. Biodistribution studies showed a significant tumor targeting of the aptamer (263). In addition nanoparticles of PLGA and loaded with paclitaxel showed enhance in vitro drug delivery in MUC1-expressing cancer cells (264). On the other hand, 5TR1 aptamer (5'-GAA GTG AAA ATG ACA GAA CAC AAC A-3') was developed to be directed against the underglycosylated tandem repeats of MUC1 present in cancer cells $(250,265)$. This aptamer was used as targeting agent of PEl polyplexes (266) showing increased transfection efficiency in MUC1 (+) cells in vivo. Indeed, 5TR1 aptamer conjugated to SPION nanoparticles showed drug delivery and reduction of tumor growth in murine model (267).

As part of gene therapy strategies to treat breast cancer diseases, the utilization of suicide genes was addressed at the end of this chapter. For that, polyplexes 
containing a therapeutic plasmid and coated with MUC1 aptamers were directed against breast cancer cells. This plasmid was formed by a gene codifying for the toxin Pokeweed Antiviral Protein from the seeds of Phytolacca americana (PAP-S). Making use of the natural toxic features of Ribosome Inactivating Proteins (RIPs) (1.4.), the type 1 RIP PAP-S which lacks the ability to penetrate cells and makes it safe unless it is not transfected inside of the cells (368) was selected. Thus, we hypothesize that transfection of a plasmid containing PAP-S gene facilitated by VOKX72 and MUC1 aptamers would be directed against the breast tumor cells with the objective of killing the malignant cells once PAP-S protein is expressed.

A wide number of experiments focused on polyplex characterization by DLS and TEM as well as in vitro studies of transfection, uptake and suicide gene therapy together with the assessment of anti-tumor effectiveness in vivo were performed along this chapter.

\section{D.1 SYNTHESIS AND CHARACTERIZATION OF VOKx72}

The obtained ELR gene corresponding with the amino acid sequence MESLLP $(V P G K G)_{72}$ Where the pentapeptide VPGKG is repeated 72 times, was corroborated by gene sequencing (4A.1.2.). The main property of this polymer is its high number of lysine amino acids, which confer it a positive charge at physiological $\mathrm{pH}$, together with its temperature- and $\mathrm{pH}$-responsive behavior typical from ELRs. The tracking of ELR production process was assessed by several physical and chemical techniques; SDS-PAGE (4A.3.1.), MALDI-TOF (4A.3.2.), amino-acid composition analysis (4A.3.3.), ${ }^{1} \mathrm{H}$ NMR (4A.3.4.) and DSC (4A.3.5.). The overall results displayed a high purity polymer with suitable chemical compositions. The final endotoxin levels were less than $1 \mathrm{EU} / \mathrm{mg}$ for in vitro and in vivo experiments (4A.3.6.), which have been previously shown to do not produce cellular adverse effects $(65,315,317)$ and suggesting that endotoxin range can only be fully assessed after determining the clinically-necessary doses and route of administration. In addition, the Tt of the ELR was assessed by DLS at different $\mathrm{pH}$ values. Thus, Tt for the ELR at $10.5 \mu \mathrm{M}$ in aqueous solution was above $60{ }^{\circ} \mathrm{C}$ at acidic and neutral $\mathrm{pH}$ and above $50^{\circ} \mathrm{C}$ at $\mathrm{pH}$ 11.5. Indeed a high Tt of $47^{\circ} \mathrm{C}$ had been obtained for ELR diblocks in which the hydrophilic part was formed by $\left[\mathrm{V}(\mathrm{VKG})_{3} \mathrm{VKVPG}\right]_{3}(369)$. 


\section{D.2. DESIGN OF pCMV-PAP}

The therapeutic plasmid DNA was based on the commercial pCMV-p53 plasmid (3.1.7.3.), in which the p53 gene was replaced by the PAP-S gene (Figure 4D.2). Using EcoRI and Hindll restriction enzymes, pCMV plasmid without the original p53 gene (1188 bp) was obtained (Figure 4D.3A). In a parallel reaction, pUC57 plasmid containing the PAP-S gene without its natural leader was digested by the same EcoRI and Hindll enzymes giving the PAP-S gene of $823 \mathrm{bp}$ (Figure 4D.3A). After that, a ligation reaction led to creation of the novel pCMV-PAP (3.1.7.3.). The incorporation of PAP-S gene into the PCMV plasmid was confirmed by agarose electrophoresis after digestion by EcoRI and Hindll enzymes (Figure 4D.3B). The pCMV-PAP was used as therapeutic plasmid at the end of this chapter.

\begin{tabular}{|c|c|c|c|c|c|c|c|c|c|c|c|c|c|c|c|c|}
\hline $\begin{array}{l}1 \\
1\end{array}$ & IGC & TCT & TCA & GTA & $\frac{\text { AAG }}{H i n}$ & $\frac{\mathrm{CTT}}{\mathrm{d} \text { IIII }}$ & $\begin{array}{l}\text { ATG } \\
\text { Met }\end{array}$ & $\begin{array}{l}\text { ATT } \\
\text { Ile }\end{array}$ & $\begin{array}{l}\text { AAC } \\
\text { Asn }\end{array}$ & $\begin{array}{l}\text { ACT } \\
\text { Thr }\end{array}$ & $\begin{array}{l}\text { ATT } \\
\text { Ile }\end{array}$ & $\begin{array}{l}\text { ACC } \\
\text { Thr }\end{array}$ & $\begin{array}{l}\text { TTT } \\
\text { Phe }\end{array}$ & $\begin{array}{l}\text { GAT } \\
\text { Asp }\end{array}$ & $\begin{array}{l}\text { GCC } \\
\text { Ala }\end{array}$ & $\begin{array}{l}45 \\
15\end{array}$ \\
\hline 16 & GGC & AAT & GCG & ACG & ATT & AAC & AAG & TAC & GCG & ACC & TTT & ATG & GAG & AGT & CTG & 8 \\
\hline 6 & Gly & Asn & Ala & Thr & Ile & Asn & Iys & Tyr & Ala & Thr & Phe & Met & Glu & ser & Ieu & 30 \\
\hline & CGC & AAC & CAG & GCG & AAG & GAT & CCG & AAA & TTA & AAA & TGT & TAC & $G G C$ & ATC & $\mathrm{CCG}$ & \\
\hline 1 & Arg & Asn & GIn & Ala & Lys & Asp & Pro & Iys & Leu & Iys & Cys & Tyx & GIY & Ile & Pro & 5 \\
\hline 36 & ATG & CTG & CCG & GAT & ACC & AAC & $A G C$ & $\mathrm{ACT}$ & CCG & AAG & TAC & TTA & CTG & GTC & AAA & \\
\hline 6 & Met & Ieu & Pro & Asp & Thr & Asn & Ser & Thr & Pro & Lys & Tyx & Leu & Ieu & Val & Iys & 0 \\
\hline 81 & CTG & CAG & GGC & GCC & AAT & CTG & AAA & ACG & ATC & ACG & TTG & ATG & CTG & CGT & CGT & \\
\hline 1 & Leu & Gln & GIY & Ala & Asn & Leu & Iys & Thr & Ile & Thr & Leu & Met & Leu & Arg & Arg & 5 \\
\hline 26 & AAC & AAC & CTG & TAT & GTG & ATG & GGT & TAT & TCC & GAT & CCG & TTC & AAC & GGC & $\mathrm{AAC}$ & \\
\hline 6 & Asn & Asn & Leu & TyI & Val & Met & Gly & Tyx & ser & Asp & Pro & Phe & Asn & Gly & Asn & 0 \\
\hline 71 & AAA & TGC & CGC & TAC & CAT & ATT & TTC & AAT & GAC & ATT & $\mathrm{AC}$ & AGT & $\mathrm{ACC}$ & $A \mathrm{~A}$ & $\mathrm{CC}$ & \\
\hline 91 & Iys & Cys & Arg & Tyx & His & Ile & Phe & Asn & Asp & Ile & I & Ser & Thr & u & Arg & \\
\hline 316 & ACC & GAC & GTT & GAA & AAT & ACG & TTA & TGT & AGT & TCC & TCC & AGT & AGT & CGT & GTT & \\
\hline 06 & Thr & Asp & Val & Glu & Asn & Thr & Ieu & Cys & ser & ser & ser & ser & ser & Arg & Val & \\
\hline 361 & GCC & ATG & AGC & ATT & AAT & TAT & AAC & AGC & CTT & TAC & $G$ & $\mathrm{ACC}$ & ATG & GAA & AAA & \\
\hline 21 & Ala & Met & Ser & Ile & Asn & Tyx & Asn & Ser & Leu & Tyr & Pro & Thr & Met & Glu & Iys & \\
\hline 406 & AAA & GCA & GAA & GTT & AAC & AGT & CGC & AAC & $C A A$ & GTG & $G$ & CTC & GGT & ATT & $C A A$ & \\
\hline 36 & Iys & Ala & Glu & Val & Asn & Ser & Arg & Asn & GIn & Val & Gln & Leu & GIY & Ile & Gln & \\
\hline 451 & ATC & CTG & AGT & AGT & GAT & ATT & GGC & AAG & ATC & AGC & & GTC & GAT & AGC & TTC & \\
\hline 151 & Ile & Leu & Ser & ser & Asp & Ile & GIY & Lys & Ile & Ser & GIY & Val & Asp & ser & Phe & \\
\hline 96 & CCG & GTT & AAA & ACG & GAA & GCG & TTT & TTC & TTA & TTG & GTT & GCA & ATT & CAG & ATG & \\
\hline 166 & Pro & Val & Lys & Thr & Glu & Ala & Phe & Phe & Ieu & Ieu & Val & Ala & Ile & Gln & Met & \\
\hline 21 & GTT & AGT & GAA & GCG & GCG & CGC & TTC & AAA & TAT & ATC & GAA & $\mathrm{AAC}$ & CAG & GTG & AAA & \\
\hline 181 & $\mathrm{Val}$ & ser & G1u & Ala & Ala & Arg & Phe & Lys & Tyr & Ile & Glu & Asn & GIn & $\mathrm{Val}$ & Iys & \\
\hline 280 & ACT & AAT & TTT & $A A C$ & CGC & GCA & TTT & TAC & $C C A$ & GAT & & AAA & GTC & ATC & $\mathrm{AAC}$ & \\
\hline 96 & Thr & Asn & Phe & Asn & Arg & Ala & Phe & Tyx & Pro & Asp & & Iys & Val & Ile & Asn & \\
\hline
\end{tabular}




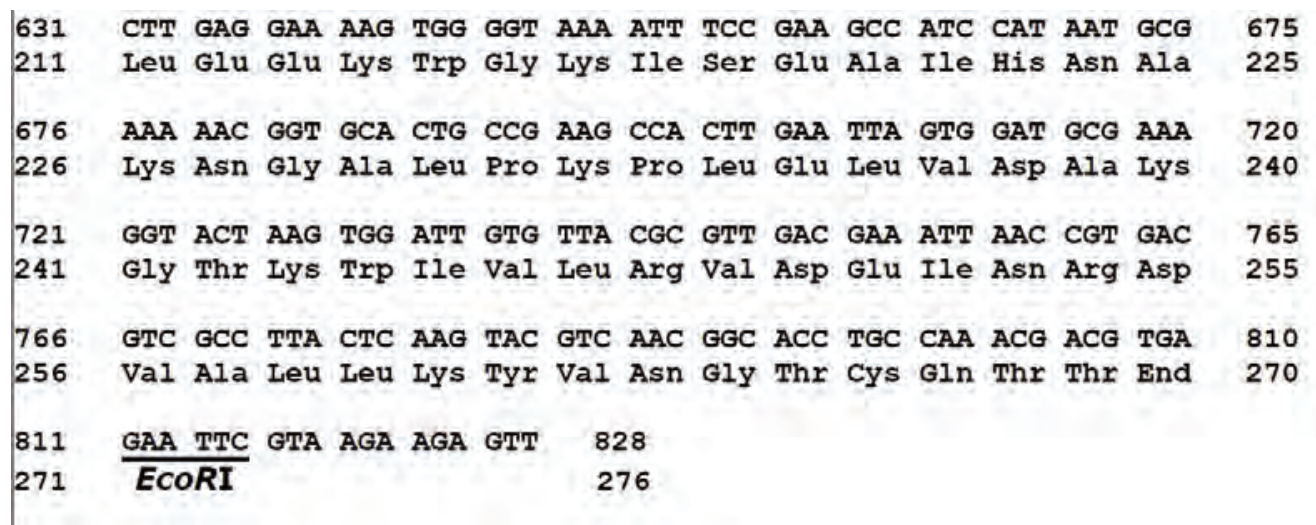

Figure 4D.2. PAP-S gene sequence (370). The highlight region corresponds with Hindll and EcoRI restriction sites.

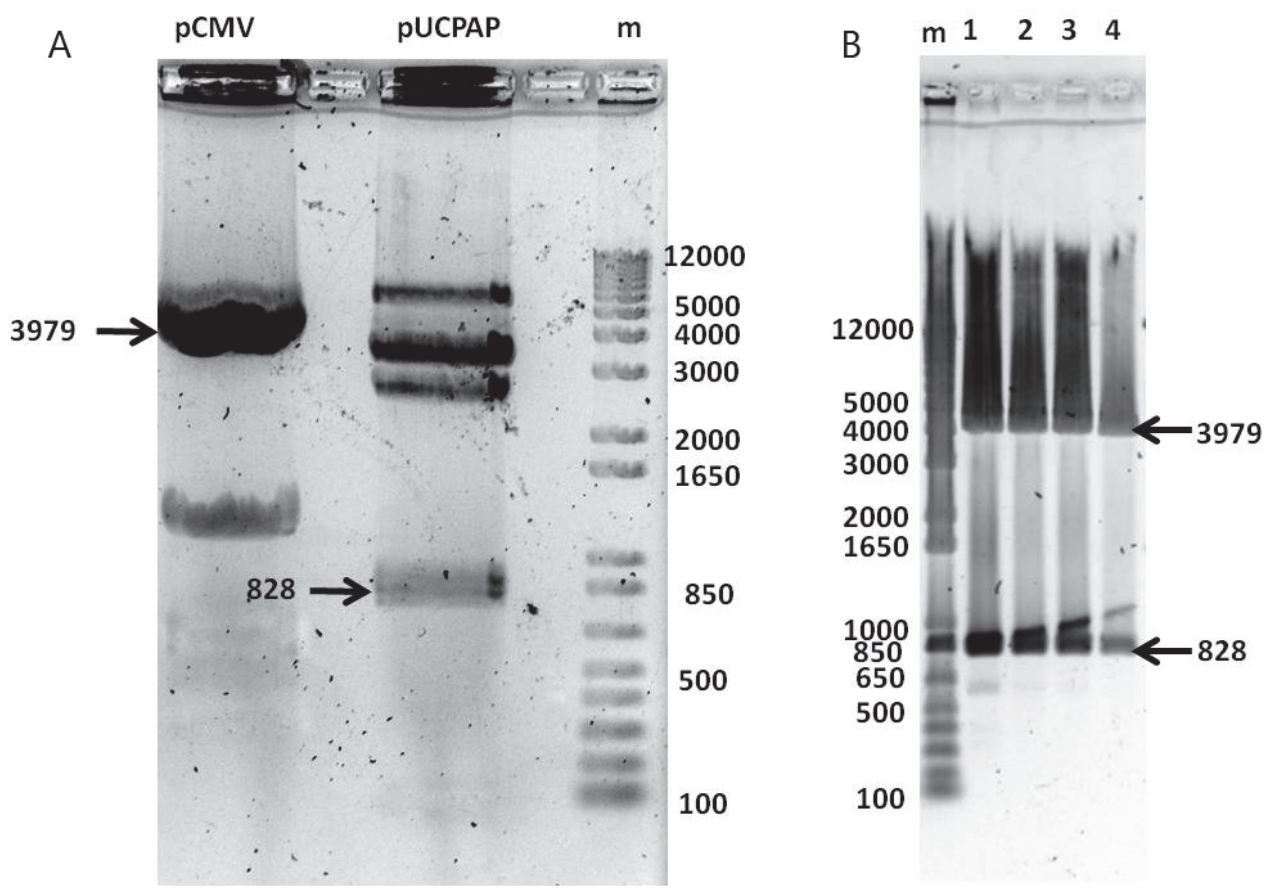

Figure 4D.3. Agarose gel electrophoresis of pCMV-PAP construction. pCMV-p53 was cut with EcoRl and Hindll enzymes and loaded. Double digestion gave two fragments, being the band of 3979 bp which contained the plasmid of interest (pCMV lane). pUC57-PAP was cut with EcoRl and Hindll and loaded. Double digestion gave two fragments, being the 823 bp which contained the PAP-S gene (pUCPAP lane) (A).4 colonies with the construction pCMV-PAP were restricted with EcoRI and Hindll enzymes and loaded. Two fragments of $3979 \mathrm{bp}$ and $823 \mathrm{bp}$ showed the final construction of $4802 \mathrm{bp}$ in total. (B). DNA agarose gel (1.2\%) electrophoresis stained with SimplySafe ${ }^{\mathrm{TM}}$.

\section{D.3 PHYSICAL CHARACTERIZATION OF ELR-pDNA POLYPLEXES}

The ability of the ELR to complex pDNA was previously confirmed by electrophoresis mobility of DNA. Polyplexes of VOKx72 and pCMVGaussia-Luciferase pDNA were 
formed at different ratios and run into an agarose gel (3.2.6.2.). As suggested by the absence of the corresponding DNA bands along the gel and by the increase of DNA material retained into wells, polyplexes were formed from the N/P ratio of 2/1 (Figure 4D.4A). Additionally the stability of the complex by incubation with $D p n$ endonuclease restriction enzyme was probed. As shown in Figure 4D.4B, the ELR was able to retain the plasmid DNA despite of the presence of $D p n$ which cuts the pDNA into 18 restriction sites giving small fragments as can be appreciated in the band pattern of the lane containing the pDNA and Dpnl (pDNA). This assay showed the ability of ELR to protect the pDNA from its hydrolytic effect (Figure 4D.4B) (3.2.6.2.).
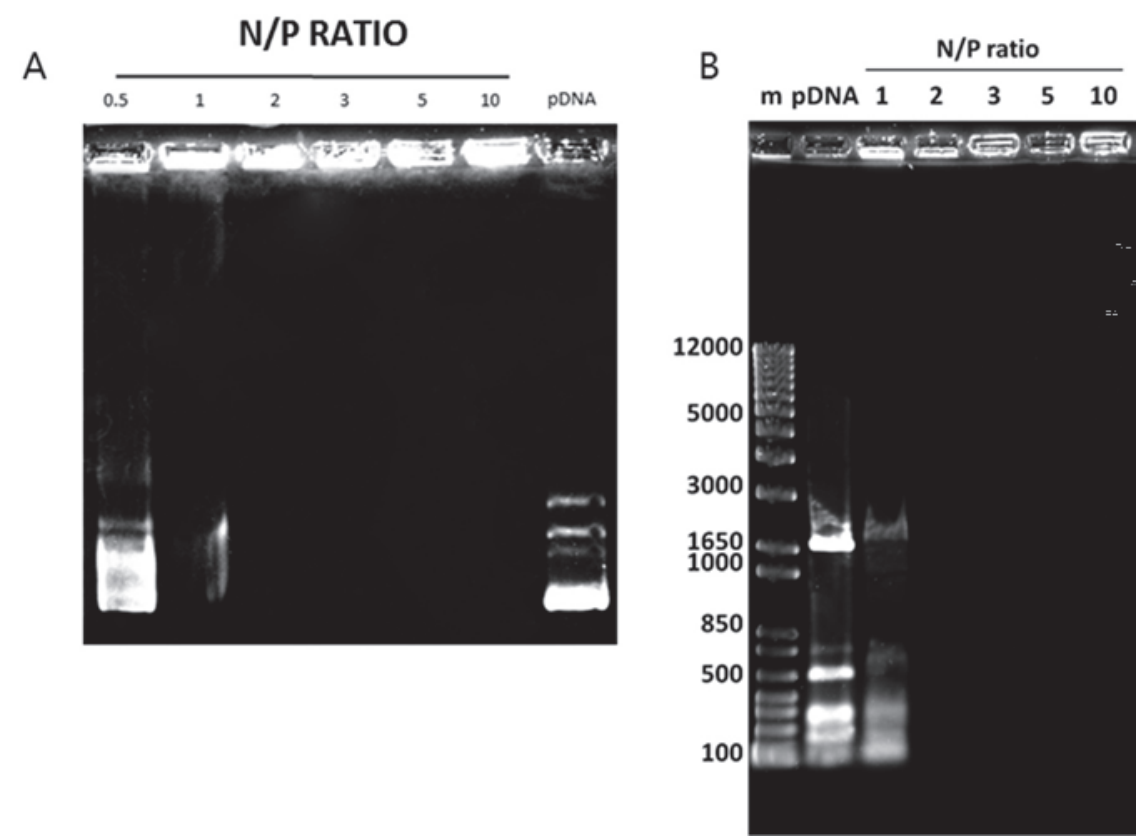

Figure 4D.4. Condensation ability of ELR and stability of polyplexes. Polyplexes were formed at $0.5 / 1,1 / 1,2 / 1,3 / 1,5 / 1,10 / 1 \mathrm{~N} / \mathrm{P}$ ratios and loaded on an agarose gel for electrophoresis (A). Polyplexes were formed at 1/1, 2/1, 3/1,5/1, 10/1 N/P ratios. pDNA and polyplexes were treated with $D p n \mid$ for 90 minutes and then loaded on an agarose gel for electrophoresis in TAE buffer (B). Polymer-free pDNA was used as control (pDNA) and $1 \mu \mathrm{g}$ of $1 \mathrm{~Kb}$ Plus DNA leader as marker $(\mathrm{m})$.

\section{D.3.1 TRANSITION TEMPERATURE FOR THE ELR IN THE PRESENCE OF PDNA}

In order to verify that the designed ELR based polyplexes were stable despite of the ELR smart temperature-responsive behavior, an initial study analyzing the effect of different conditions of $\mathrm{pH}$ and temperature over the Tt was conducted. For that, VOKx72 polyplexes were formed at different $\mathrm{N} / \mathrm{P}$ ratios and once the $\mathrm{pH}$ was adjusted, DLS measurements were performed (3.2.6.3.1.). 
Most of the polymers used for transfection are positively charged, thus allowing them to complex with the negatively charged DNA. In light of inverse transition temperature as an intrinsic characteristic of ELRs, this causes a double effect namely electrostatic interaction between the polymer and pDNA via the lysines, and the smart behavior from the ELR. Electrostatic interaction leads to polyplex formation, and the smart behavior of the ELR triggers its aggregation and conformational change above Tt. This Tt can be changed by extrinsic factors such as the addition of negatively charged phosphate groups that neutralizes the amine groups of the ELR. Since a change of $50 \%$ in the scattering intensity is considered as the transition temperature (49), the Tt of ELR at N/P ratio $1 / 0$ in aqueous solution was found to be higher than $50^{\circ} \mathrm{C}$ for $\mathrm{pH} 11.5$ (Figure 4D.5A). The free $\varepsilon$-amino groups from the Llysines (pKa 10.5) of the ELR were largely deprotonated at $\mathrm{pH} 11.5$, so the change from a disordered state of ELR molecules to one dense and ordered where ELR loses its hydrophobic hydration was found when the temperature was increased over its Tt. However, at lower temperatures and pHs this phase transition and aggregation events between ELR molecules did not occur. Indeed, when ELR was complexed with pDNA and polyplexes were kept at physiological conditions of $\mathrm{pH}$ (5-7) and temperature $\left(37^{\circ} \mathrm{C}\right)$, the complexes remained stable at all the N/P ratios tested (Figure 4D.5A). However, polyplexes were not stable enough at 5/1 ratio, $\mathrm{pH} 5$ and $\mathrm{T}>48^{\circ} \mathrm{C}$, probably due to the low content of amine groups. By contrast, when the $\mathrm{pH}$ was increased to 11.5 , striking variations in light scattering could be observed at all ratios (Figure 4D.5A). Focusing on this $\mathrm{pH} 11.5$ which is summarized in Figure 4D.5B, the presence of pDNA decreased the Tt of the ELR from $\mathrm{Tt}$ of $56.5^{\circ} \mathrm{C}$ at $1 / 0$ ratio to $50.9^{\circ} \mathrm{C}$ at 50/1 ratio. Indeed, this Tt was decreased as the ratio N/P was diminished reaching to $39^{\circ} \mathrm{C}$ at $5 / 1$ ratio. So, an increase in $\mathrm{pH}$ led to a decrease in Tt of the ELR. At $\mathrm{pH} 11.5$, the low light scattering (around 0.1 for all N/P ratios) found at lower temperatures was followed by an increase and nano- and micro-aggregation and likely subsequent sedimentation process which was reflected in the decreasing of light scattering. 

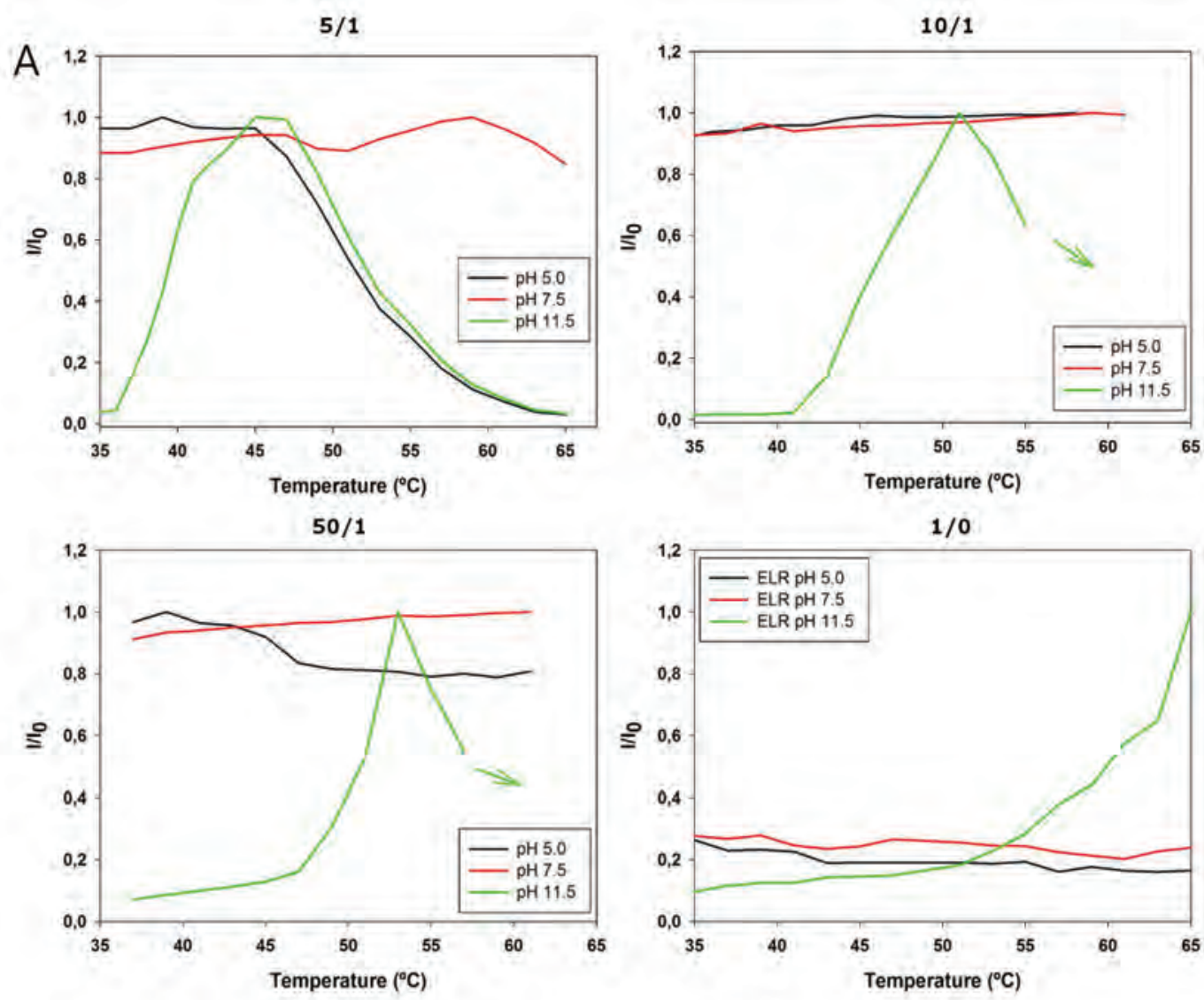

B

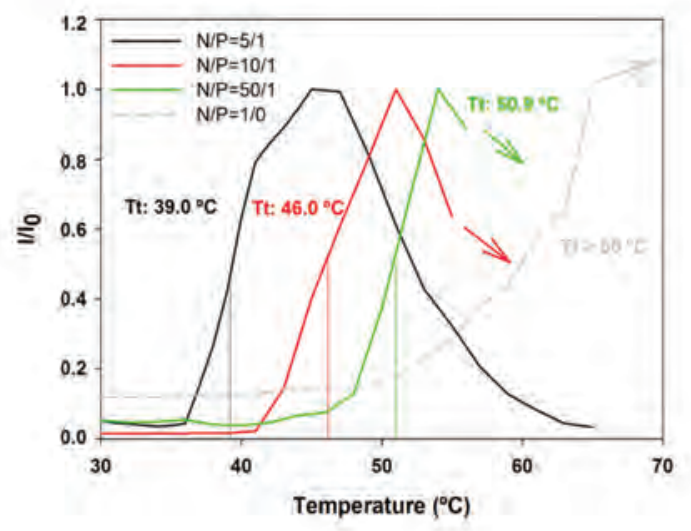

Figure 4D.5. Normalized scattered light intensity as a function of temperature. Normalized intensity of scattered light as a function of temperature for polyplexes formed by $1.05 \mu \mathrm{M}$, $2.10 \mu \mathrm{M}$ and $10.5 \mu \mathrm{M}$ of ELR at different N/P ratios with a constant pDNA concentration of $1.4 \mathrm{nM}$ and $10.5 \mu \mathrm{M}$ of ELR for 1/0 ratio at different $\mathrm{pH}$. Measurements were performed at $\mathrm{pH}$ 5.0, 7.5 and 11.5 (A). Normalized scattered light intensity as a function of temperature at $\mathrm{pH} 11.5$ for ELR-pDNA polyplexes at different N/P ratios (B). Arrows indicate the decreasing trend in light scattering as a result of the presence of nano and micro-aggregates with increasing temperature. 
These changes in the light scattering at $\mathrm{pH} 11.5$ were consequence of polyplexes destabilization. At this $\mathrm{pH}$, the free $\varepsilon$-amino groups from the L-lysines in the polyplex are largely deprotonated, thereby decreasing the net polarity of the complex and promoting destabilization of the polyplexes. This fact was corroborated by the presence of two size-distribution groups at low temperatures $\left(37^{\circ} \mathrm{C}\right)$ from $5 / 1$ to $50 / 1$ ratios tested (Table 4D.1). One of the groups corresponds to the free ELR with a size of around $10 \mathrm{~nm}$ which was majority and responsible for the lower values of light scattering, and the other to the ELR polyplex with a size of around 100-150 nm. Hence two consecutive effects with increasing temperature occurred, namely the initial incorporation of free ELR to the existing polyplexes. And secondly a consecutive drop in the scattered intensity light (Figure 4D.5B) as a result of a cooperative increase in the hydrophobicity of the polymer and aggregation into nano- and even microscale between the ELR on the outside of the polyplexes and free ELR. Interestingly, polymer aggregation led polyplexes to increase in size at all ratios (Table 4D.1). It is remarkable to highlight that polyplexes at physiological pH of 7.5 and 5 were stable due to the absence of transition by the ELR, which make them useful for gene delivery applications (Table 4D.2).

Table 4D.1. Particle size and Pdl as a function of temperature at $\mathrm{pH} 11.5$ for $1.05 \mu \mathrm{M}$, $2.10 \mu \mathrm{M}$ and $10.5 \mu \mathrm{M}$ ELR in ELR-pDNA polyplexes at different N/P ratios with a constant pDNA concentration of $1.4 \mathrm{nM}$. Measurements were performed at $\mathrm{pH}$ N/P ratio of 1/0, $5 / 1,10 / 1$ and $50 / 1$.

\begin{tabular}{|cccc|}
\hline (N/P) ratio $(\mathrm{pH} 11.5)$ & Temperature $\left({ }^{\circ} \mathrm{C}\right)$ & Size $(\mathrm{d} . \mathrm{nm})$ & Pdl \\
\cline { 2 - 4 } $1 / 0$ & 37 & 11.25 & 0.52 \\
& 60 & 1057 & 0.76 \\
$5 / 1$ & 37 & 11.01 and 100.4 & 0.52 \\
& 53 & 181 & 0.01 \\
$10 / 1$ & 37 & 9.5 and 131.6 & 0.52 \\
& 55 & 248.1 & 0.03 \\
$50 / 1$ & 37 & 9.2 and 145.5 & 0.45 \\
& 60 & 323 & 0.03 \\
\hline
\end{tabular}

Table 4D.2. Particle size and Pdl at physiological pHs of 5.0 and 7.5 and $37^{\circ} \mathrm{C} 1.05 \mu \mathrm{M}$, $2.10 \mu \mathrm{M}$ and $10.5 \mu \mathrm{M}$ ELR in ELR-pDNA polyplexes at different N/P ratios with a constant pDNA concentration of $1.4 \mathrm{nM}$. Measurements were performed at $\mathrm{pH}$ N/P ratio of 5/1, $10 / 1$ and $50 / 1$.

\begin{tabular}{|cccc|} 
(N/P) ratio $\left(37^{\circ} \mathrm{C}\right)$ & $\mathrm{pH}$ & Size $(\mathrm{d} . \mathrm{nm})$ & Pdl \\
$5 / 1$ & $\mathrm{pH} 5.0$ & 208.4 & 0.15 \\
& $\mathrm{pH} 7.5$ & 216.7 & 0.14 \\
$10 / 1$ & $\mathrm{pH} 5.0$ & 123 & 0.21 \\
& $\mathrm{pH} 7.5$ & 143 & 0.20 \\
$50 / 1$ & $\mathrm{pH} 5.0$ & 129.7 & 0.19 \\
& $\mathrm{pH} 7.5$ & 137.9 & 0.12 \\
\hline
\end{tabular}




\section{D.3.2. PARTICLE SIZE, ZETA POTENTIAL AND MICROSCOPIC ANALYSIS}

Besides the requirement of stable polyplexes, an appropriate particle size is necessary to obtain positive results in cell transfection. Particles with a size of about $200 \mathrm{~nm}$ are known to be internalized by clathrin mediated or independent endocytosis which is a faster uptake pathway than phagocytosis by which larger molecules up to $10 \mu \mathrm{m}$ are internalized $(117,127,131)$. The size of these ELR-pDNA complexes formed at pH 7.5 and $37^{\circ} \mathrm{C}$ was determined by DLS (Figure 4D.6) and found to range from about 100 $\mathrm{nm}$ at an N/P ratio of $2 / 1$ to $200 \mathrm{~nm}$ at an N/P ratio of 5/1, with a polydispersity index ( $\mathrm{Pdl}$ ) ranging from 0.11 to 0.14 (Figure 4D.6A). A progressive increase in size and polydispersity was found to be correlated with an increase in N/P ratio up to 5/1 (200 $\mathrm{nm}, \mathrm{Pdl}$ 0.14). At ratio 10/1 the highest value of Pdl reached (Pdl 0.20), in contrast the size decreased and remained constant at about $140 \mathrm{~nm}$ up to 50/1 ratio. So, the N/P ratio clearly affected the size and stability of polyplexes. Indeed, the surface charge density studied as zeta potential which is known to be directly related to the stability of many colloidal systems was analyzed. The results of this study showed a progressive increase in zeta potential from $-23 \mathrm{mV}(\mathrm{N} / \mathrm{P} 2 / 1)$ to nearly $+40 \mathrm{mV}(\mathrm{N} / \mathrm{P}$ $10 / 1)$, with the value being dependent on polymer concentration and hence on N/P ratio (Figure 4D.6B). Furthermore, a positive zeta potential is thought to favor interactions with the cell membrane (123). At N/P ratio of 2/1 the polyplex exposes the negative charges from the plasmid outward. At this low ratio, the positive charge from the amine groups in the ELR seems to be strongly affected by the presence of phosphate groups from the pDNA and the hydrophobic environment derived from the ELR polymer structure. A striking increase from negative to positive values was observed on going from a ratio of $2 / 1$ to $3 / 1$ where polyplex exposes its positively charged $\varepsilon$-amino groups to the exterior while maintaining a neutralized charge inside. Additionally, stabilization of the surface charge was observed from $10 / 1$ to 50/1 ratio. In accordance, the progressive increase in size and polydispersity was correlated with an increase in zeta potential values up to 5/1 ratio as response of N/P ratio increment. 5/1 was considered as key ratio since from this point the nanoparticle size decreased and zeta potential reached its highest values. Moreover, the stabilization of polyplex size from $10 / 1$ was correlated with the stabilization of zeta potential from this ratio as well. 

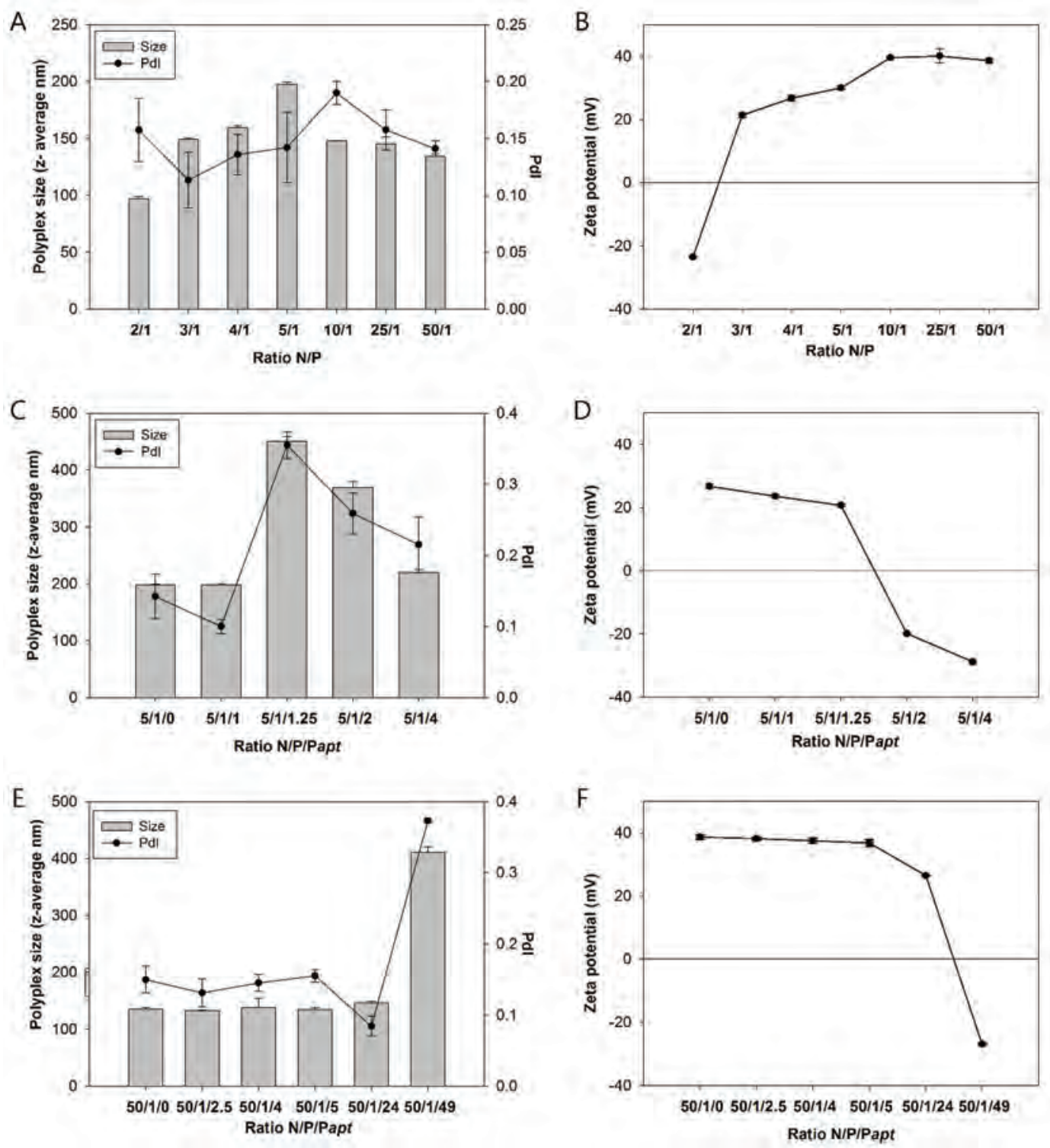

Figure 4D.6. Size, polydispersity index (Pdl) and zeta potential for the ELR-pDNA polyplexes formed at $\mathrm{pH} 7.5$ and $37^{\circ} \mathrm{C}$. Size (A) and zeta potential (B) for ELR-pDNA polyplexes with an N/P ratio ranging from $2 / 1$ to $50 / 1$. Size (C) and zeta potential (D) for ELR-pDNA-Aptamer complexes with an N/P/Papt ratio ranging from $5 / 1 / 0$ to $5 / 1 / 4$. Size (E) and zeta potential (F) for ELR-pDNA-Aptamer complexes with an N/P/Papt ratio ranging from $50 / 1 / 0$ to $50 / 1 / 49$ ( $n=3$, mean $\pm S D$ ).

Polyplexes formed at both 5/1 (200 nm of size and zeta potential of $+27 \mathrm{mV}$ ) and $50 / 1$ ratio (about $134 \mathrm{~nm}$ of size and $+39 \mathrm{mV}$ ) with a different size and sufficiently stables were chosen to evaluate the influence of 5TR1 aptamer addition. Thus, once polyplexes had been formed at 5/1 and 50/1 ratios increasing amounts of 5TR1 aptamer (Papt) were added. The result was a similar concentration-dependent effect 
at both ratios, with polyplex size increasing with aptamer ratio up to 50/1/49 or even earlier at 5/1/2; (Figure 4D.6E and C). Similarly, there was a striking increase in Pdl at the N/P/Papt ratio corresponding to the highest size for ratios of both $5 / 1$ and 50/1. Thus a 50/1 ratio produced more stable polyplexes than 5/1 ratio due to the increase in polydispersity at higher ratios (50/1/49).

The incorporation of aptamers that provide cell specificity may also decrease the surface charge of the polyplex. This hypothesis was corroborated in the assays conducted in this work by means of zeta potential measurements (3.2.6.4.). The addition of higher aptamer concentrations initially resulted in a slight decrease in the zeta potential at the low N/P ratio of $5 / 1$, with a marked drop being observed at $5 / 1 / 2$ (Figure 4D.6D). In contrast, the behavior of the high ratio polyplex (50/1) showed the formation of a stable positively charged particle (about $+40 \mathrm{mV}$ ) up to a ratio 50/1/24, with a striking drop for the neutralization ratio 50/1/49 (Figure 4D.6F). However, the presence of aptamers did not affect the shape or size of the particles (with exception of 50/1/49 ratio), which is in accordance with the DLS results (Figure 4D.6E, 4D.7A and 4D.7B). The gradual incorporation of aptamer provided more negatively charged phosphates to interact with, and neutralize, the free $\varepsilon$-amino groups from lysines, thereby affecting the charge and stability of the polyplex. As result, a marked decrease in the surface charge of the ELR-pDNA due to neutralization of the system and a widespread distribution of the aptamers on the polyplex surface was observed, with polyplexes at a 50/1 ratio being more stable than those at a 5/1 ratio. The decrease in the surface charge density of polyplexes at higher concentrations of aptamer suggests the location of these aptamers on the polyplex surface. By contrast, at lower ratios of aptamer the surface charge density of the polyplex was highly positive pointing the location of amino groups from polymer outward. The outside arrangement of amino groups favored the interaction of aptamers with the nanoparticle surface.

The morphology of the nanoparticle was further characterized by TEM (3.2.6.5.) at a ratio of 50/1 in the absence (Figure 4D.7A) and presence (Figure 4D.7B and C) of 5TR1 aptamer adsorbed on the polyplex at an N/P/Papt ratio of 50/1/4. As can be seen from these figures, the 50/1 polyplexes possessed a rounded shape with a size (123.8 $\mathrm{nm} \pm 12.1 \mathrm{SD})$ that correlates with the values obtained by DLS (134.1 $\mathrm{nm} \pm 2.5$ $\mathrm{SD})$. The pDNA appeared to be located inside the polyplex with the polymer surrounding it, as can be seen from the different density of the particle nucleus 
(Figure 4D.7A). Additionally, there appears to be no difference in the morphology of these two kinds of polyplexes (Figure 4D.7A and B). A further study that showed the non-covalent absorption of the aptamer to the polyplex surface was performed. To this end, gold nanoparticles ( $5 \mathrm{~nm}$ ) were mixed to polyplexes previously made with a thiol-modified 5TR1 aptamer (3.2.7.). The resulting complexes (Figure 4D.7C) possess a homogenous shape and a size in agreement with the TEM for polyplexes with adsorbed aptamers (Figure 4D.7B) (148 nm \pm 15.3 SD) and DLS values (138.3 nm \pm 16 SD) (Figure 4D.6E). Thus indicating that the gold nanoparticles mainly cover the surface of the polyplexes where the thiolated aptamer should be present and corroborated the results obtained from zeta potential where the decrease in the surface charge density of polyplexes at higher concentrations of aptamer suggested the location of these aptamers on the polyplex surface. Additionally, we can appreciate in TEM photography a homogenous distribution of gold nanoparticles on the polyplex. We did not see an increment of gold nanopaticles density or their accumulation in their core, which would make us ensure the entrapment of these particles inside of the polyplex. Hence, this assay together with zeta potential results supports the location of aptamers on the polyplex surface.

Indeed, the polyplexes obtained in this work represent an improvement with regard to previous studies exposed in chapter 5 concerning the zeta potential and stability of particles besides the incorporation of breast cancer cell specific aptamers.
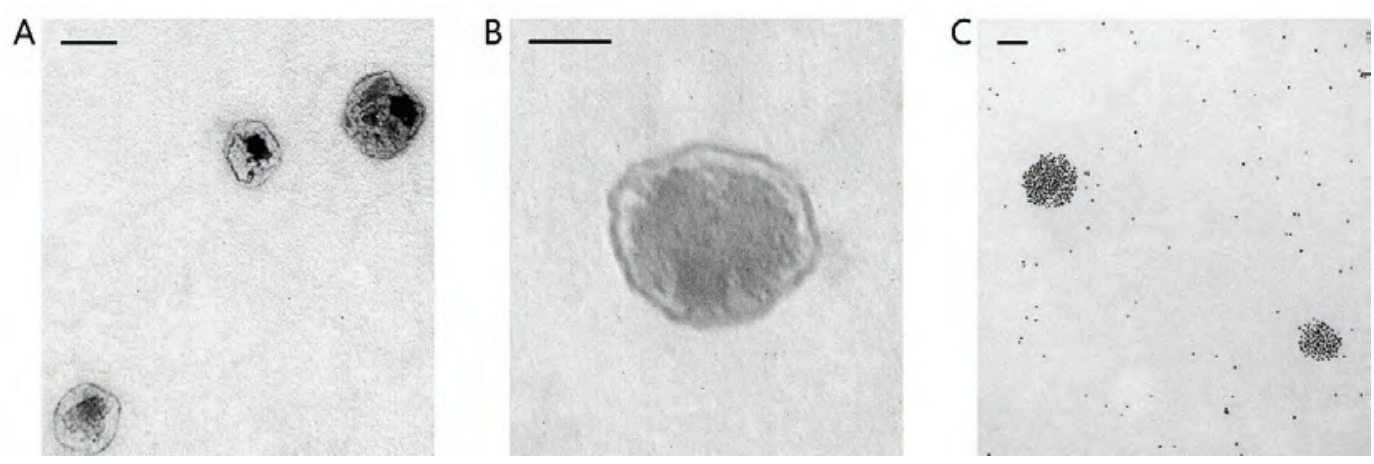

Figure 4D.7.Transmission electronic microscopy images showing the morphology and shape of polyplexes in aqueous solution.ELR-pDNA polyplexes at a 50/1 N/P ratio (A).ELR-pDNA-aptamer polyplexes at a 50/1/4 N/P/Papt ratio with aptamer 5TR1 (B).ELRpDNA-aptamer polyplexes at a 50/1/4 N/P/Papt ratio with thiol-modified aptamer 5TR 1 and gold nanoparticles (C). Scale bars correspond to $100 \mathrm{~nm}$ for $A$ and $C$ and $50 \mathrm{~nm}$ for B. 


\section{D.4. TRANSFECTION ASSAYS}

In light of the previous studies, cell viability and transfection experiments were performed in order to assess the suitability of the polyplex complexes for breast cancer gene therapy. The human cell lines used for the transfection assays were two tumoral cell types, namely MCF-7, which is a breast cancer line overexpressing the MUC1 glycoprotein (371) as cell model for gene therapy, and HepG2, a hepatocarcinoma cell line with no MUC1 expression (372). Given the physical characterization results discussed above, two different ELR-pDNA polyplexes (N/P ratios of 5/1 and 50/1) were chosen to test transfection in these human cell lines. At $5 / 1$ ratio the polyplex has a size of about $200 \mathrm{~nm}$ and a zeta potential of $+27 \mathrm{mV}$ whereas at a 50/1 ratio the nanoparticle has a size of $134 \mathrm{~nm}$ and a zeta potential of almost $+40 \mathrm{mV}$, which confers more stability on the complex and should therefore increase the transfection efficiency. The influence of these differences in particle size and zeta potential over transfection through $5 / 1$ and 50/1 ratio was evaluated

\section{D.4.1. EFFECT OF THE POLYPLEX-APTAMER SYSTEM ON CELL VIABILITY}

ELRs as naturally inspired recombinant polymers are characterized by their biocompatibility in terms of lack of cytotoxicity and immunogenicity (1.1.7.). This has been assessed in both in vitro and in vivo assays thus making them appropriate for local and systemic administration $(53,65)$. Similar results were obtained in in vitro studies involving positively charged ELRs (45).' In light of these findings and the physical characterization of the polyplexes, we evaluated the cytotoxicity of ELRpDNA polyplexes formed with the innocuous pCMV-Gaussia luciferase plasmid DNA at different N/P/Papt ratios along with the aptamers S2.2 and 5TR1 in MCF-7 and HepG2 cell lines (3.2.11.2.2.). Since the viability levels at ratio of $5 / 1 / 0$ were essentially $100 \%$, only the effect of the ratio with higher amounts of polymer (50/1) and increasing quantities of aptamer was shown (Figure 4D.8). No polyplex-induced cytotoxicity was observed for any of the cell lines from a ratio of 50/1/0 to 50/1/49, whereas the value of cell viability reached nearly $150 \%$ in the breast cancer line when a higher proportion of aptamers was used. A similar increase in viability was previously observed in a murine myoblastoma cell line (347), human breast cancer cell line $(348)$ and mesenchymal stem cells $(346,349)$, when treated with several ELRs 
and, recently, when C6 rat glioma cells were co-incubated with ELR polyplexes (4C.2.), thereby demonstrating the friendly nature of these recombinant polymers as well as the supplemental specificity conferred by the aptamers on MUC1(+) cells. Additionally, previous studies with positively charged ELRs incubated with blood components showed the innocuous character of these polymers (4C.1.) making them useful for intravenous administration. By contrast, high level of cytotoxicity was found for cells treated with PEl, probably due to the presence of free PEI after formation of polyplexes which disrupts the plasmatic membrane and causes necrosis $(106,107)$. In our experiments, this polymer exhibited marked cytotoxicity in MCF-7 cells, for which the viability decreased to about $20 \%$. Although PEI is commonly used in transfection for in vitro assays, it often has a strong cytotoxic effect, depending on the cell line, as reported elsewhere $(105,106)$. Nowadays, research is focusing in decreasing this toxicity by the use of biocompatible molecules such as chitosan or employing PEG as shell $(109,110)$.

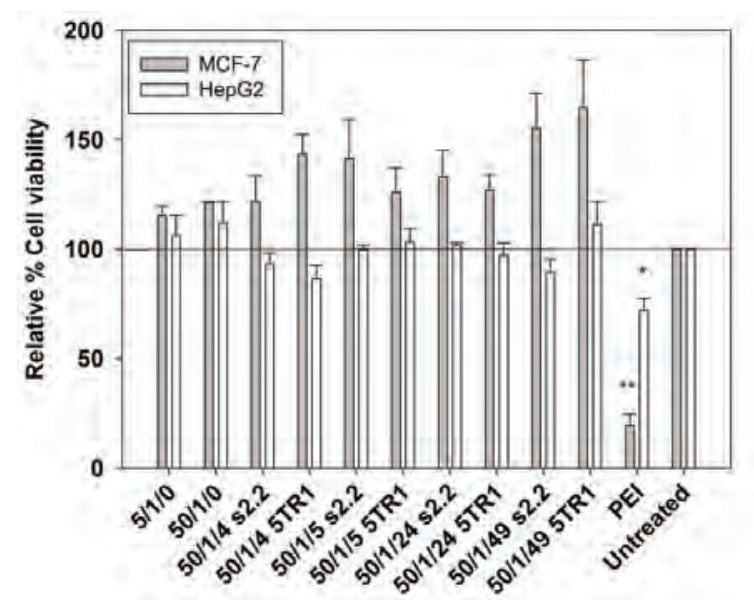

Figure 4D.8.Viability of MCF-7 and HepG2 cell lines at different N/P/Papt ELR-pDNA ratios for aptamers S2.2 and 5TR1. Cells were co-incubated with the polyplexes and a viability assay was performed for all samples. Untreated cells were considered as $100 \%$ viability control and PEI polyplexes as a reference transfection system. $(n=3$ independent experiments, mean $\pm S D) .{ }^{*}: p<0.05,{ }^{* *}: p<0.01$.

\section{D.4.2. LUCIFERASE EXPRESSION}

The next step was the evaluation of transfection level and cell specificity provided by the MUC1 aptamers. Since the binding specificity of both aptamers had been previously studied for MCF-7 cells $(180,264)$ we focused on evaluating the 
improvement provided by aptamers with respect to the ELR-pDNA system. For that luciferase expression of MCF-7 cells and HepG2 cells incubated with different treatments of polyplexes was evaluated (3.2.12.3.2.).

The effect of both types of polyplexes was first studied using MUC1 (+) cells in order to determine the best candidate. As shown in Figure 4D.9A, there were important differences in luciferase expression in MCF-7 cells between the two ELR polyplexes. Thus, in the absence of aptamers, the 50/1 polyplex was found to be more efficient than the 5/1 ratio, exhibiting a 10 -fold higher luciferase expression. Thus, indicating that the physical characteristics of the nanoparticles (134 nm and $+39 \mathrm{mV}$ in 50/1 versus $200 \mathrm{~nm}$ and $+27 \mathrm{mV}$ in 5/1) have a clear influence on transfection efficiency. However, the most marked differences were observed after incorporation of the aptamers. Thus, the use of different ratios of the two aptamers with the $5 / 1$ polyplex had little effect on MCF-7 transfection, whereas the incorporation of both oligonucleotides into the 50/1 polyplex produced an aptamer-dependent amplification of its transfection efficiency. The lower 50/1/4 ratio was the best of those ratios tested. At low ratios (N/P/Papt 50/1/4) the transfection efficiency increased at least six fold with respect to the nude polyplexes. However, transfection was also annulled when the aptamers neutralized their charge (50/1/49). This indicates that the positive effect of aptamers is blocked, probably, according to the physical results (Figure 4D.6E and F), due to the formation of unstable and inefficient nanoparticles in which increasing quantities of aptamers produce, firstly bigger and more polydisperse polyplexes and secondly negatively charged surfaces. These effects over the transfection levels together with potential zeta values and TEM reinforce the hypothesis of polyplexes coated with MUC1 aptamers. Differences were also found between both aptamers, with the 5TR1, which targets the underglycosylated PST domains of MUC1, being more efficient than S2.2, which targets the MUC1 core. The difference between both aptamers had a maximum increase of 2.5 -fold. 

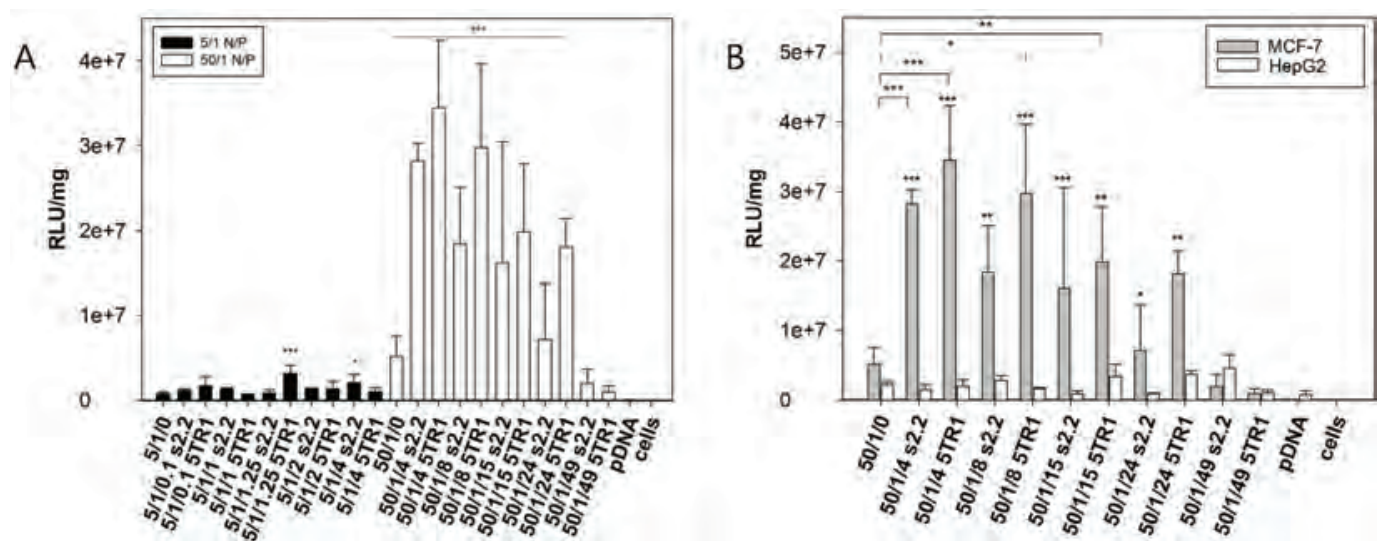

Figure 4D.9.Luciferase expression by pCMV-Gaussia luciferase contained in ELR-pDNAaptamer polyplexes. (A) Polyplexes at a 5/1 N/P ratio with different Papt ratios for aptamers S2.2 and 5TR 1 in MCF-7 cells. (B) Polyplexes at a 50/1 N/P ratio with different Papt ratios for aptamers S2.2 and 5TR1 in MCF-7 and HepG2 cells. Luciferase activity is expressed in RLU/mg protein lysate. The polyplex without aptamers and pDNA were used as controls. The results are expressed in logarithmic scale as mean \pm standard error of three independent experiments. ${ }^{*}: p<0.05,{ }^{* *}: p<0.01,{ }^{* * *}: p<0.001$.

In light of these results, the 50/1 ratio was chosen for the remaining transfection experiments with MCF-7 and HepG2 cell lines (Figure 4D.9B). Initially, the specificity of the polyplex-aptamer system was evaluated using the MUC1 (-) HepG2, with significant differences in luciferase expression being found between both cell lines. These differences were higher for the MUC1 overexpressing MCF-7 cells irrespective of the aptamer used from 50/1/4 to 50/1/24 ratio). Consequently, the intracellular uptake of ELR-pDNA-aptamer polyplexes is MUC1 dependent and is more efficient when a rational quantity of the 5TR1 aptamer is used. In addition commercially available agents like PEI, Lipofectamine ${ }^{\circledR}$ LTX or Turbofect were tested. Lower luciferase expression was found in comparison with the lipid vector Lipofectamine. By contrast comparable levels of transfection were found in comparison with other polymeric vectors for MCF-7 cells (Figure 4D.10A), being the transfection for ELRpDNA-aptamer polyplexes at 50/1/4 ratio slightly higher than Turbofect and in the same order (1e+8 RLU mg-1 protein) than PEI. 

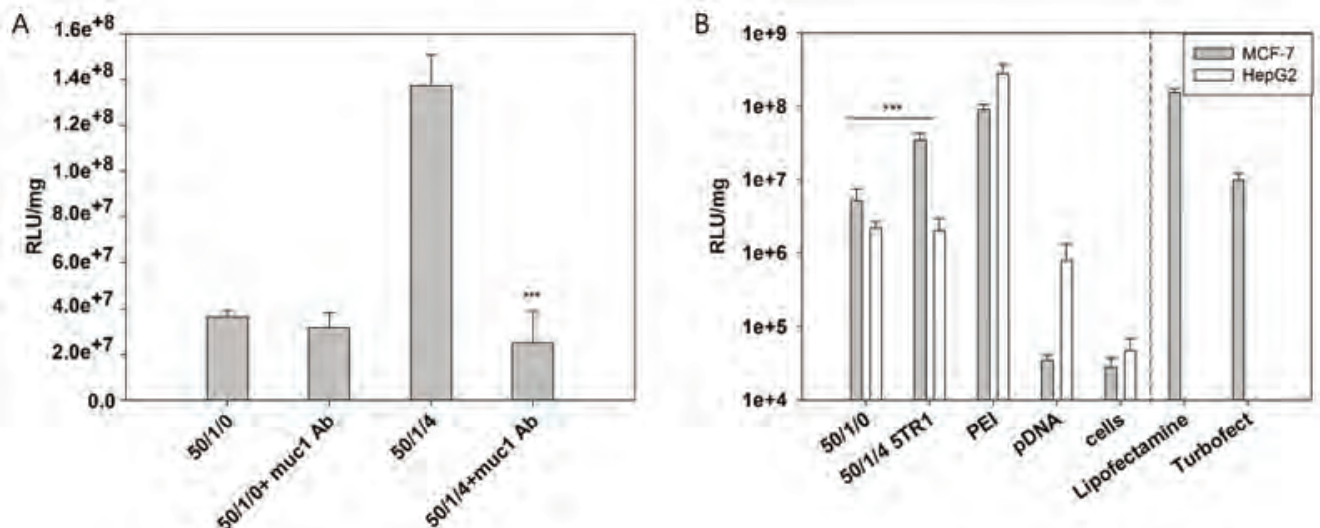

Figure 4D.10. Luciferase expression by pCMV-Gaussia luciferase contained in ELR polyplexes. Polyplexes at 50/1 ratio with and without 5TR 1 aptamer at 50/1/4 ratio and PEI were incubated in MCF-7 and HepG2 cells. Additionally Lipofectamine LTX and Turbofect were incubated with MCF-7 cells (A). Luciferase in presence of anti-MUC1 pAb. Polyplexes with 50/1/4 and 50/1/0 without 5TR 1 aptamer were incubated in MCF-7 cells pre-treated with anti-MUCl (mucl Ab) at 50:1 dilution (B). Luciferase activity is expressed in $\mathrm{RLU} / \mathrm{mg}$ protein lysate. The results are expressed as mean \pm standard error of three independent experiments. ${ }^{* * *} \mathrm{p}<0.001$.

Since the best results on transfection were obtained for 50/1/4 using 5TR1 aptamer, following studies were focused on this condition. Blockade of MUC1 was performed by the pre-treatment of cells with anti-MUC1 antibody for 1 hour at $37^{\circ} \mathrm{C}$ (Figure 4D.10B). After that time, transfection with 50/1/0 and 50/1/4 polyplexes was accomplished. The result showed a total inhibition of 5TR1 specificity in which the transfection levels of 50/1/4 lowered up to 50/1/0 levels. By contrast, 50/1/0 transfection was not affected by the presence of the antibody which support the evidence of the interaction between 5TR1 and MUC1. Further studies of transfection in presence of $10 \%$ of serum were accomplished (Figure 4D.11) as well. A reduction of gene expression was found for both ELR without (2.7 times) and with aptamer (1.6 times). The highest decrease corresponded for the polyplex alone showing the retention of the specificity by the system ELR-pDNA-aptamer in presence of serum. The higher reduction in the polyplex alone can be explained by the general reduction in transfection activity in polymeric polyplexes. Additionally, other commercially available systems such as PEI posses a decrease in transfection when serum is present in several cell lines such as fibroblasts and BMSCs (373). However, it is remarkable to note that the specificity of the system ELR-pDNA-5TR1aptamer was retained despite of the presence of serum. This situation points the possibility of using this system for local or even systemic administration. 


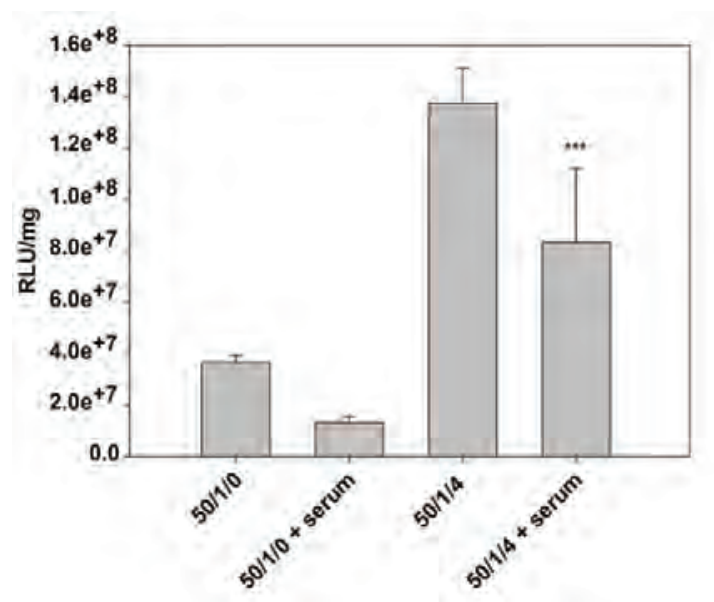

Figure 4D.11. Luciferase expression by pCMV-Gaussia luciferase contained in ELR polyplexes in presence of $10 \%$ of serum. Polyplexes with (50/1/4) and without $(50 / 1 / 0)$ 5TR1 aptamer were incubated in presence or absence of serum in MCF-7 cells. Polyplex without serum was used as control. Luciferase activity is expressed in RLU/mg protein lysate. The results are expressed as mean \pm standard error of three independent experiments. ${ }^{* * *}: \mathrm{p}<0.001$.

\section{D.4.3. CELLULAR UPTAKE OF POLYPLEXES}

The uptake of ELR-pDNA-5TR1 polyplexes by the targeted breast cancer cells was visualized by fluorescence microscopy and quantified by flow cytometry. To this end, MCF-7 cells were incubated with 50/1/4 polyplexes containing fluorescein-labelled pCMV-Gaussia luciferase plasmid for 3 hours and the resulting internalization process was initially visualized by fluorescence microscopy (3.2.12.1.2. and Figure 4D.12A). Although a few polyplexes were observed on the surface of the tissue culture plaque, a broad distribution of nanoparticles associated with the cells could also be seen. The labelled cells were then detached with trypsin and washed with PBS, in order to remove the external binding fluorescence signal that could interfere with the detection of the intracellular polyplexes $(374,375)$, and analyzed by flow cytometry (3.2.12.1.3.). The results were compared with cells transfected using the fluorescent plasmid alone (Figure 4D.12B). The data showed a marked internalization of polyplexes of $85.76 \pm 12.35 \%$ (mean \pm SD) for all cells, in comparison with cells treated with fluorescein-labelled pDNA alone (1.70 $\pm 1.68 \%)$. As described in bibliography, trypan blue has been widely used to quenched external fluorescence (376) in order to visualize and consider only the internalized ones. For that reason, trypan blue treated cells were visualized by confocal microscopy in a z-series succession (3.2.12.1.2.) explained in Figure 4D.12E where the two focal planes confirmed the presence of polyplexes inside the cells (Figure 4D.12C and D) and the likely presence of 
fluorescent plasmid inside the nucleus (indicated by arrows). An additional visualization displayed in Figure 4D.13 showed a z-stack composed by 4 images (AD) with a $z$-focal difference of $0.2 \mu \mathrm{m}$. Thus the orthogonal projection of z-stacks in the z-y planes (D) is displayed as well. Nucleus (light blue) was stained with DAPI and pDNA from polyplexes was shown in pink. The orthogonal projection evidenced the existence of pDNA inside the nucleus (Figure 4D.13) where the likely presence of cationic polymers in the nucleus had been shown to do not prevent disassembly and gene expression (377).
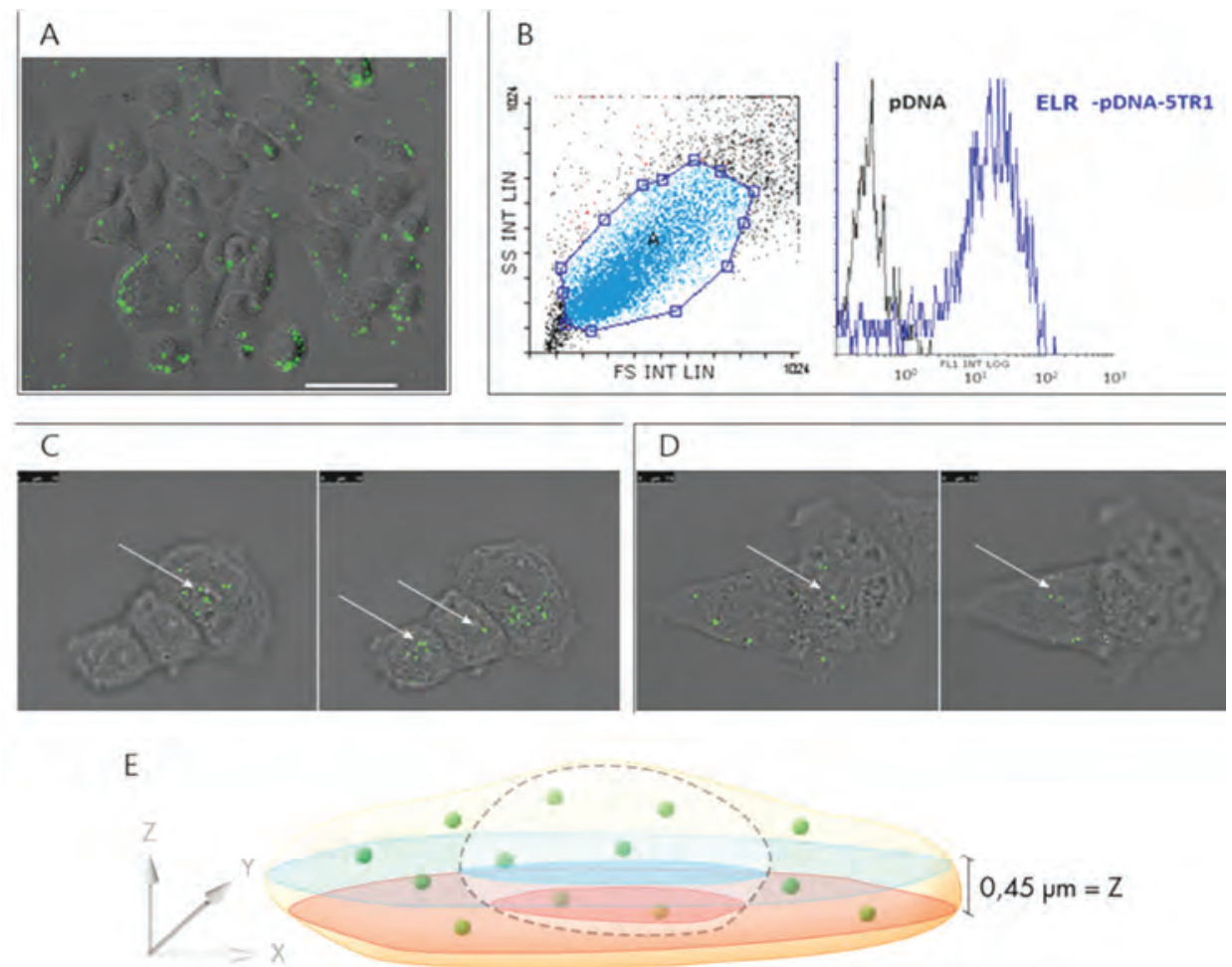

Figure 4D.12.Cellular uptake of ELR-pDNA-5TR1 polyplexes with fluorescein-labelled pDNA. (A) Fluorescence microscopy image of MCF-7 treated with ELR-pDNA-5TR 1 nanoparticles for 3 hours (merged image of the phase-contrast and FITC channels). The scale bar corresponds to $50 \mu \mathrm{m}$. (B) Flow cytometry analysis of MCF-7 cells incubated with polyplexes. Gate A, which corresponds to FITC+ cells, was set on the side-scatter vs forward-scatter histogram. The cell count was plotted as a function of FLI, which corresponded to the FITC channel for pDNA and ELR-pDNA-5TR1 transfected cells. (C and D) Confocal microscopy images of MCF-7 containing fluorescein-labelled polyplexes. Merged bright- and fluorescence-field images of different focal planes have been analysed. The nuclear areas of cells with the bright green dots of polyplexes are indicated by arrows. Cells from (C and D) were treated with trypan blue in order to discriminate fluorescent polyplexes inside the cell.Scale bars correspond to $10 \mu \mathrm{m}$. Z-series succession scheme showing the different focal planes showed in Figure 4D.12C and D accomplished by fluorescence microscopy (E). 


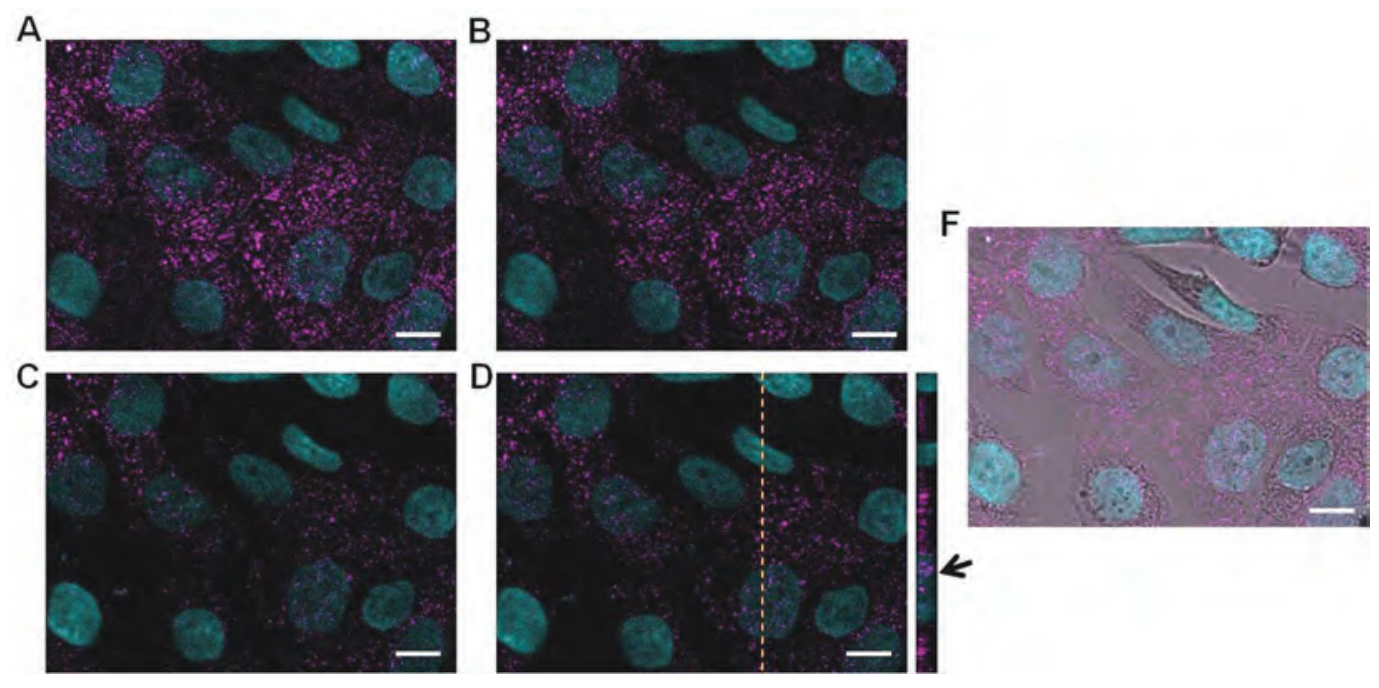

Figure 4D.13. Z-stack (A-D) and orthogonal projection of z-stacks in the z-y planes (D) for MCF-7 cells incubated with ELR-pDNA-5TR1 polyplexes for 3 hours. The z-focal difference between images from $A$ to $D$ is $0.2 \mu \mathrm{m}$. Nucleus that appears in light blue has been stained with DAPI and pDNA from polyplexes that is shown in pink has been stained with fluorescein. Light blue and pink colors have been chosen in order to facilitate its visualization. Merged of DAPI, Fluorescein and phase contrast in B position was performed in order to visualize the healthy state of cells (F). pDNA could be observed in cytoplasm but also co-localized in nucleus ( black arrow in D). Scale bar corresponds with $10 \mu \mathrm{m}$.

This group of assays demonstrated the cellular internalization and nuclear localization of ELR-pDNA polyplexes equipped with cell specificity provided by the MUC1-directed aptamers despite of they did not allow discerning the internalization pathway.

\section{D.4.4. ASSESSMENT OF THE INTERNALIZATION PATHWAY}

Once the uptake of ELR-pDNA-5TR1 polyplexes was visualized, the investigation of the relation between the internalization pathway and subsequent gene expression was accomplished. The knowledge about the internalization pathway helps to understand not only the internalization mechanism but trafficking and proteins involved. For that, MCF-7 cells were treated with a variety of endocytosis inhibitors for 30 minutes at $37^{\circ} \mathrm{C}$ and incubated with polyplexes for 5 hours at $37^{\circ} \mathrm{C}$ (3.2.12.4.). After this time, polyplexes were removed, cells were incubated up to 48 hours and luciferase activity was measured. Inhibition of $\mathrm{Na}^{+} / \mathrm{H}^{+}$exchange required for macropinocytosis by means of amiloride decreased the luciferase expression to $26 \%$ after transfection with ELR-pDNA-5TR1 polyplexes (Figure 4D.14). Moreover, 
inhibition of caveolae-mediated endocytosis by filipin decreased the expression to $44 \%$ and inhibition of clathrin mediated endocytosis by dansylcadaverine resulted to inhibit the expression to $60 \%$. By contrast, the inhibition of acidification in acidic vesicles by chloroquine did not affect significantly the luciferase expression. These data showed evidence about the primary influence of macropinocytosis and in a lesser extent of caveoline and clathrin-endocytosis pathways over the gene expression. In fact MUC1 glycoprotein uptake by macropinocytosis and clathrindependent pathways has been previously reported $(180,181)$ which evidences the interaction of 5TR1 aptamer with the MUC1 located on the cell surface. Further study with chloroquine was performed in order to evaluate the effect of the inhibition of endosome-lysosome maduration over the gene expression. Chloroquine basifies and accumulates in acidic vesicles; this fact did not involve a significant change in luciferase expression. Herein it can suggest the independence on acidic $\mathrm{pH}$ for ELRpDNA-5TR1 polyplexes endosomal escape. We hypothesize that the interaction of ELR-pDNA-5TR1 with MUC1 would favor the escape from endosome somehow, since it is known the existence of high levels of MUC1-C in cytoplasm and even the nuclear presence of both MUC1-C and MUC1-N $(257,262)$.

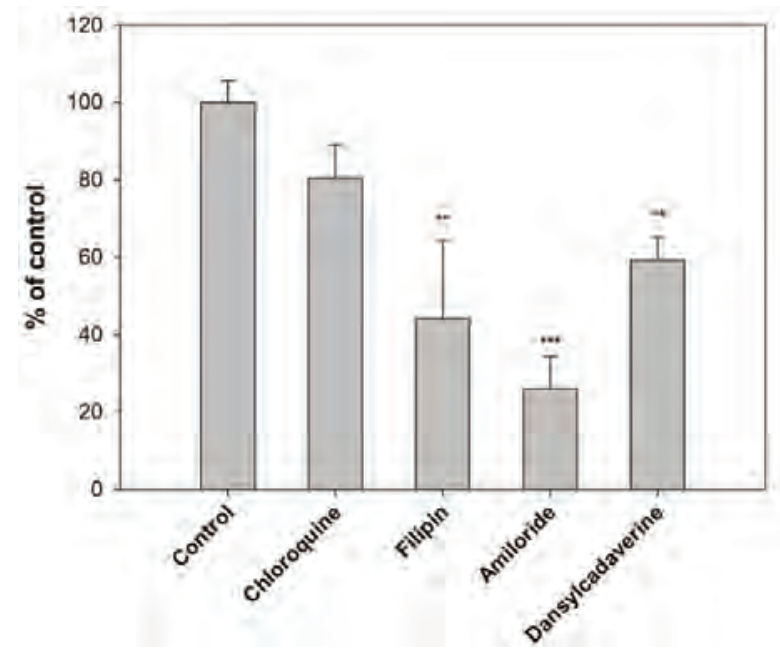

Figure 4D.14. Luciferase expression of ELR-pDNA-5TR1 polyplexes at 50/1/4 ratio in presence of different inhibitors in MCF-7 cells. Polyplexes were incubated with cells after treatment with $25 \mu \mathrm{M}$ of chloroquine, $1 \mu \mathrm{g} / \mathrm{mL}$ of filipin, $5 \mu \mathrm{g} / \mathrm{mL}$ of amiloride and $100 \mu \mathrm{M}$ of monodansylcadaverine. The results expressed as $\%$ of control are mean \pm standard error of three independent experiments. ${ }^{*}: p<0.05,{ }^{* *}: p<0.01$. 


\section{D.4.5. EFFECT OF p53 EXPRESSION OVER BREAST CANCER CELLS}

The plasmid $\mathrm{pCMV}$ containing p53 gene was used in order to evaluate its gene expression and effect of p53 protein over MCF-7 cells. As explained in 4C.5.1., p53 expression would trigger cell growth arrest and both necrotic and apoptotic death (356, 378), with a time window for p53-induced death in transient transfection ranging from 18 to 90 hours (379). In light to the previous results with luciferase gene reporter, five different human cell lines named as MCF-7 MUC1 (+), HepG2 MUC1(-), and the primary non-overexpressing MUC1 HFF-1, HUVEC and MSC were incubated with ELR-pCMV-p53 complexes without and with 5TR1 aptamer for $5 \mathrm{~h}$ (3.2.12.5.2.). After that time, the media was replaced by fresh one consecutively cells were incubated for $43 \mathrm{~h}$ more and the effect of polyplexes over their viability was assessed. Figure 4D.15 shows the viability of the cell lines subjected to four different treatments by way of significant fluorescence optical microscopy photographs. The green calcein staining seen in this figure confirms that the culture phenotype was not affected by any of the treatments. The MSC and HUVEC cell cultures were not affected by nanoparticles (Figure 4D.15 MSC and HUVEC columns). Contrary, fibroblasts appeared to be slightly susceptible to transfection with the polyplex system (Figure 4D.15 HFF1 column). Lack of specificity of the polyplex with aptamers in HFF1 transfection was found due to a previously described characteristic of this cell type, namely that it does not show detectable amounts of MUC1 (380), thus suggesting unspecific binding mediated by the positive charge of the polyplexes. The HepG2 and MCF-7 cancer cell lines analyzed in this study were both similarly affected by co-incubation with the ELR-p53 polyplex containing MUC1 aptamer or not. Indeed, a high and comparable number of dead cells were found for both MCF-7 and HepG2 when treated with polyplexes alone or with 5TR1 aptamer (polyplex 5TR1).

In order to verify the results observed by fluorescence microscopy, the induction of p53 expression was quantified in terms of cell mortality and apoptosis in both HepG2 MUC1 (-) and MCF-7 MUC1 (+) tumor cells. Then, the number of dead cells present after treatment with the polyplex and polyplex-aptamer systems was analyzed by measuring the red fluorescence emission intensity in a viability assay (3.2.12.5.2.1.). The data showed that cells treated with any type of polyplex system showed an increased mortality that at least doubled the number of untreated cells or those 
incubated with p53 plasmid (pDNA) alone, which did not vary with respect to the untreated ones (Figure 4D.16A). Indeed, the detected increase confirmed those observed in the microscopic analysis. Thus, non significant differences were observed between the mortality rate of the cells incubated with polyplex or polyplex plus aptamer in either of the two tumor cell lines. Hence, the effect of p53 expression over MCF-7 cells was dependent on the transfection mediated by polyplex but not by the aptamer presence.

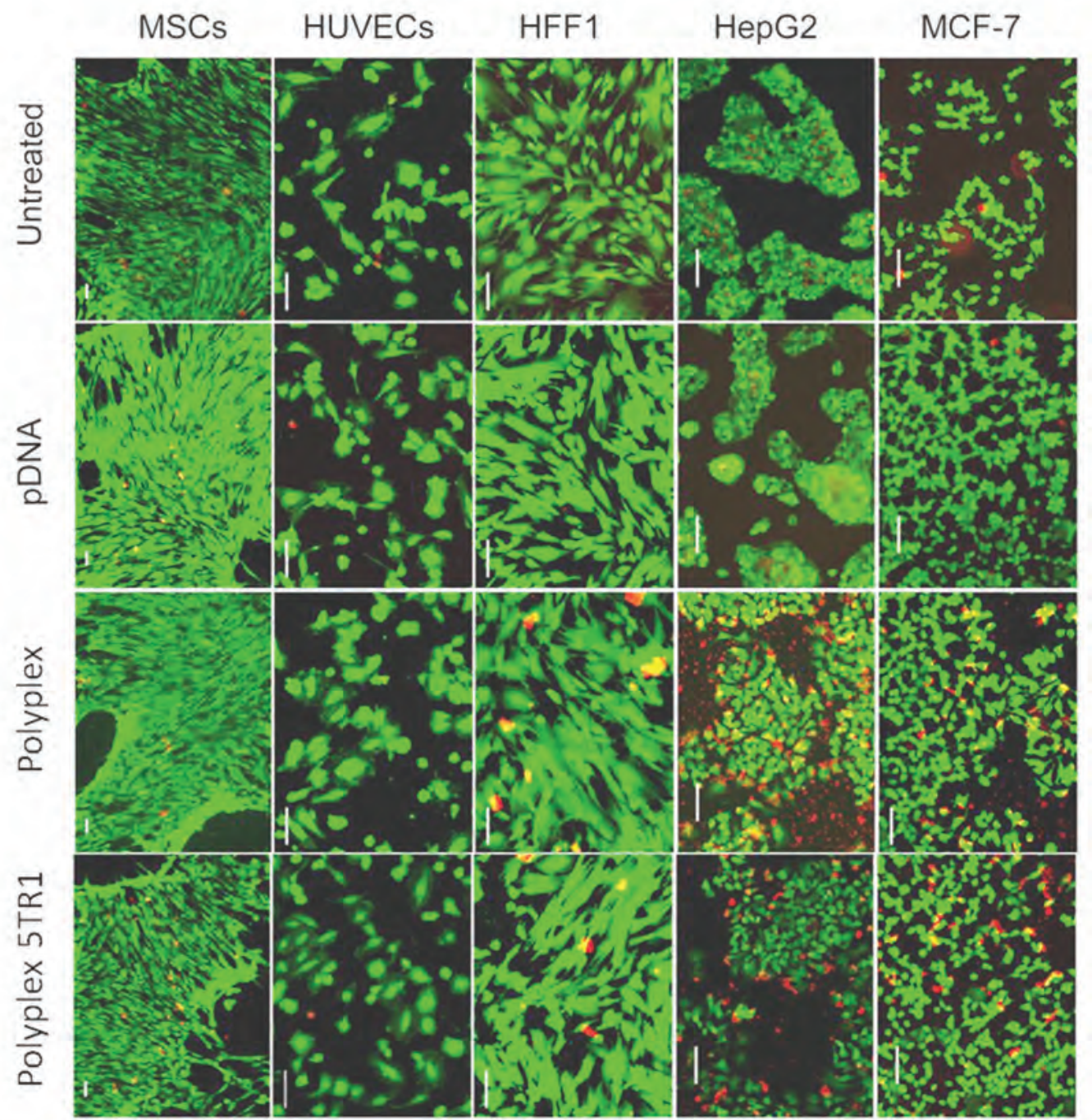

Figure 4D.15. Representative fluorescence microscopy images of MSC, HUVEC, HFF1, MCF-7 and HepG2 cells after five hours of co-incubation with: minimum medium (Untreated), p53 plasmid alone (pDNA), ELR-pDNA (Polyplex), and ELR-pDNA conjugated with aptamer 5TR1 (Polyplex 5TR1), where the pDNA contained p53 transgene. Coincubation was followed by incubation for 48 hours under standard culture conditions. Scale bars correspond to $100 \mu \mathrm{m}$. 

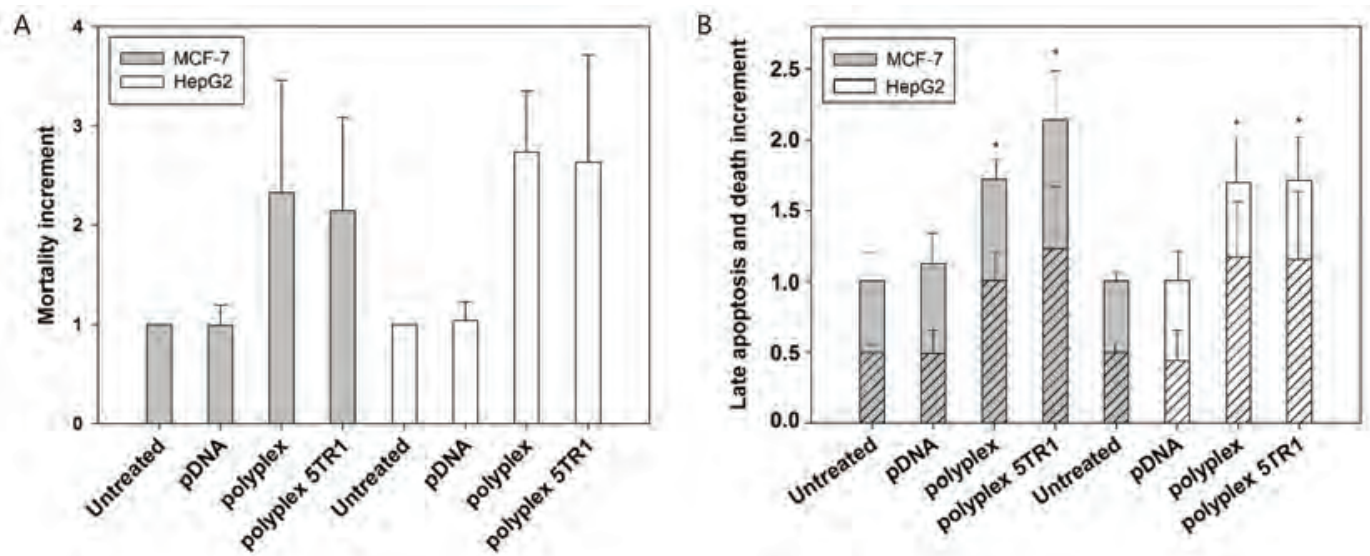

Figure 4D.16. Variation in cell mortality and apoptosis after transfection with p53 transgene plasmid. (A) Mortality increase measured by fluorescence quantification and (B) induced apoptosis and cell death for MCF-7 and HepG2 cell lines, as calculated by flow cytometry. Pattern corresponds with dead cells while stacked shows late apoptosis variation. Cells were pre-incubated for 5 hours with minimum medium (Untreated), p53 plasmid alone (pDNA), ELR-pDNA (Polyplex), ELR-pDNA conjugated with aptamer 5TR1 (Polyplex 5TR 1), where the pDNA indicates p53 transgene plasmid. Additional incubation under standard conditions for 48 hours was then carried out. Data represent means of results as compared to the untreated cells. Error bars represent the mean of three independent experiments \pm standard deviation (SD). A statistical analysis showed significant differences $(p<0.05)$.

Further studies on induced cell death and apoptosis were accomplished by flow cytometry (3.2.12.5.2.1.). Figure 4D.16B shows a significant death and apoptosis increase in both MCF-7 and HepG2 cells co-incubated with polyplexes in comparison with the pDNA alone when cell death and late apoptosis were considered together. Despite these results, and as shown in the previous mortality experiment, there were not significant differences between the two cell lines. According with previous transfection experiments (Figure 4D.9) and specificity blocking assay with anti-MUC1 (Figure 4D.10), transfection was achieved by unspecific binding mediated by the highly positive charge of polyplexes in HepG2 cells MUC1 (-) and by specific binding mediates by aptamers in MCF-7 MUC1 (+). By contrast, the cell mortality and apoptosis induced by p53 transfection contrast dramatically with the marked differences in cell specificity found in the previous luciferase experiments. It is known the role of the carboxylic region from MUC1 (known as MUC1-C) as an oncoprotein that promotes the growth and survival of the $80 \%$ of human breast cancers that overexpress MUC1 $(261,381,382)$. Hence, in view of the dualism demonstrated by p53 transcription (responsible for cell apoptosis but subject to specific fate controlled 
by the intracellular region of MUC1), it can be hypothesized that the lack of significant differences in the use of the system when contains p53 transgene was probably due to the possible role of the overexpressed MUC1 as an oncoprotein Since we had previously described a plasmid internalization over 80\% (Figure 4D.12B) and high-level expression of luciferase for polyplex-5TR1 exclusively in MUC1 (+) MCF-7 cells, our results suggest that MUC1-C would promote the cellular growth and tumor cell survival by interaction with p53 protein. MUC1-C bound to p53 would regulate the activation of $\mathrm{p} 21$ or inhibition of Bax genes transcription leading to a protective mechanism mediated by MUC1 over-expression in MCF-7 cells as had been observed for MCF-7 in response to genotoxic stress (261). The interaction of MUC1 with p53 protein would allow these cells to survive even in the presence of the p53 transgene to the detriment of apoptosis fate thus resulting as affected as MUC1 (-) HepG2 cells.

The overall results demonstrated the dependency of MUC1 over transfection of cytotoxic agents or cell death inducers as p53 and suggest the utilization of other than p53 transgene, such as PAP-S gene for suicide gene therapy. Additionally it confirms the role of MUC1 as onco-protein inhibiting the p53 action and promoting the cell survival.

\section{D.3.5. SUICIDE GENE THERAPY USING PAP-S TOXIN GENE ON HUMAN BREAST} CANCER CELLS

Considering that one of the major challenges in suicide gene therapy is to use the natural killer ability of cytotoxic agents or cell death inducers to selectively eliminate undesirable cells (277), the expression of a Ribosome Inactivating Protein (RIP) was studied in this work. RIPs are part of the natural defense mechanisms against foreign pathogens in several plants. As described in the introduction chapter (1.4.2.), type RIPs as saporin or Pokeweed Antiviral Protein from the seeds of Phytolacca americana (PAP-S) had been commonly used as immunotoxins and even saporin had been used in gene therapy reducing melanoma tumor growth in vivo (277). PAP-S that had been previously expressed in E.coli without its plant leader (370), was selected due to its high enzymatic activity on ribosomes as well. In addition, this recombinant PAP-S expressed in the prokaryotic system led to a fully active protein 
with an in vitro inhibitory effect higher than native PAP isolated from plant. These results indicated that post-translational modification in PAP-S does not seem to alter its ability to inhibit protein synthesis and opened the door for its heterologous expression in eukaryotic cells. In light of the literature, PCMV-PAP plasmid was designed to contain PAP-S gene without its plant leader and controlled by the constitutive and potent cytomegalovirus promoter (CMV) (Section 4D.2.). It is important to note that PAP-S as type I RIP does not have the ability to translocate into cells then its potent cytotoxic activity would be developed only when PAP-S is expressed and reaches the cytoplasm of the transfected cell.

Therefore, when the plasmid containing PAP-S gene is delivered inside of cells by the ELR device and expressed by the cell machinery it should be able to permanently disable the ribosomes by arresting the function of elongation factors EF-1 and EF-2 thereby causing cell death (368). Since we used a plasmid codifying the PAP-S toxin and bearing in mind their potential use for in vivo therapy and transfection efficiency that has previously been reported to be cell-type dependent (383), the transfection effect of ELR-PAP-5TR1 polyplexes was tested in five different human cell lines including non-tumoral primary cells. The tumor cell lines MCF-7 MUC1 (+), HepG2 MUC1 (-) and three human primary cell types (HFF-1, HUVEC and MSC) were chosen. The viability of the five cell lines subjected to the different treatments was shown by fluorescence (Figure 4D.17). Cells acquired their typical morphology in all cases. Any of the cell lines were affected when incubated with pDNA, however MSC and fibroblasts appeared to be slightly affected by polyplexes with and without aptamer (Figure 4D.19 MSC and HFF1 columns). Lack of specificity of the polyplex with aptamers in MSC and HFF1 transfection was observed and due to the absence of MUC1. By contrast, the human liver (Figure 4D.17 HepG2 column) and breast (Figure 4D.17 MCF-7 column) cancer cell lines were both affected by co-incubation with the ELR-CMV-PAP polyplex containing 5TR1 aptamer or not. Similarly, there was a remarkably higher sensitivity of MCF-7 cells to PAP-S in comparison with other nonoverexpressing MUC1 cell lines especially when they were incubated with polyplexes containing 5TR1 aptamer. This result correlated with the previous obtained with luciferase expression and supported the higher transfection and expression of PAP-S in MCF-7 cells due to the overexpression of MUC1. 


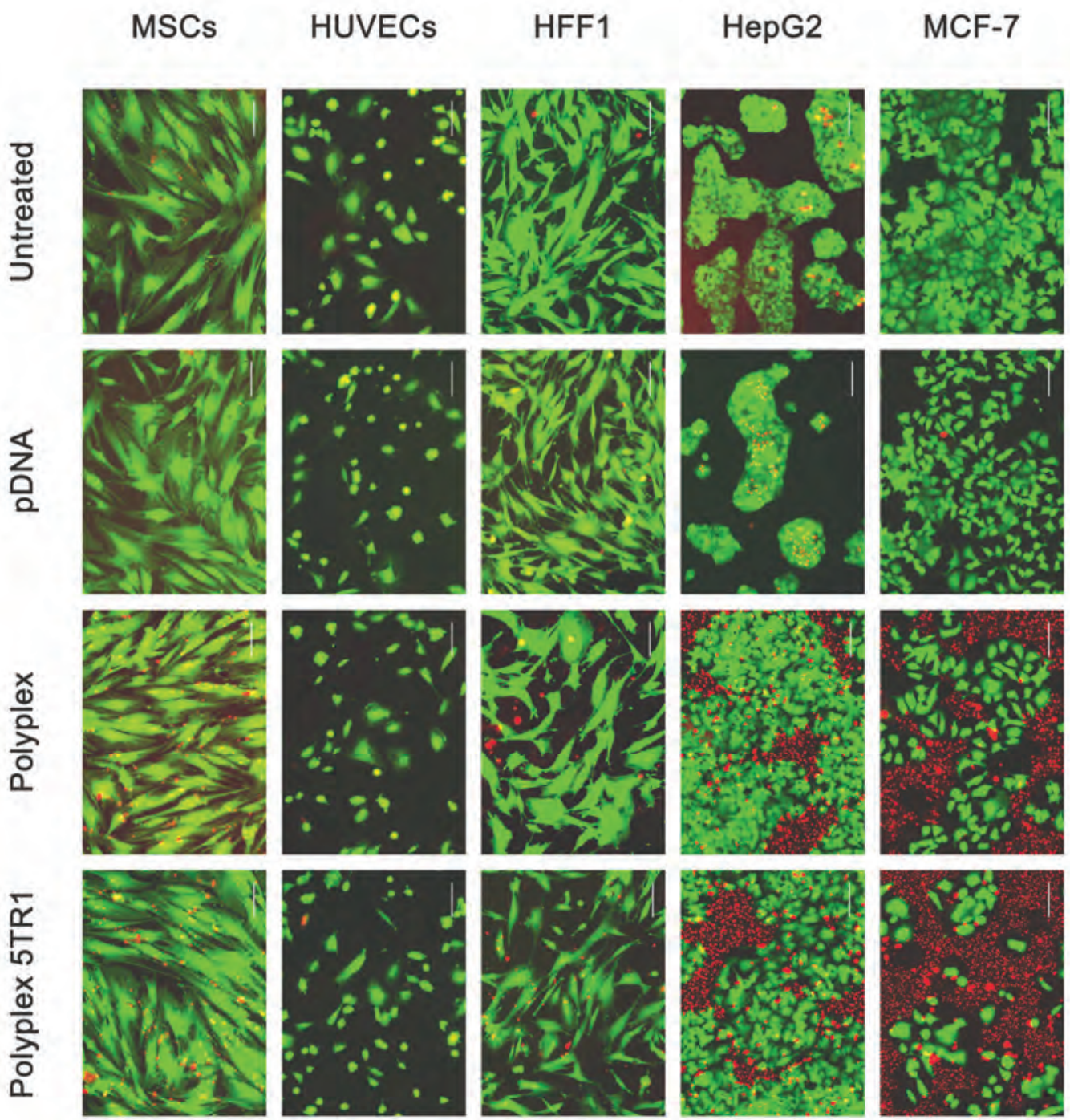

Figure 4D.17 Representative fluorescence microscopy images for MSC, HUVEC, HFF1, MCF-7 and HepG2 cells after five hours of co-incubation with: minimum medium (Untreated), pDNA, ELR-pDNA (Polyplex), ELR-pDNA conjugated with 5TR1 aptamer (Polyplex5TR 1) where the pDNA contained PAP-S transgene under the CMV promoter. The co-incubation was followed by 48 hours of incubation under standard culture conditions. Scale bars correspond to $100 \mu \mathrm{m}$.

In order to evaluate the significance of PAP-S expression effect over cells, the percentage of dead cells in primary cells and in both HepG2 and MCF-7 tumor cells was quantified (Figure 4D.18). The lowest cytotoxic effects were observed when primary cells were incubated with polyplexes obtaining levels of cell death similar to those for untreated cells. In contrast, a significant increase in the percentage of death in breast cancer cells was found reaching nearly 95\% when the 5TR1 aptamer was incorporated into the polyplex thereby suggesting an efficient expression of 
functional PAP-S in the transfected cells. The incorporation of 5TR1 aptamer at the surface of the ELR-PAP polyplexes resulted in a significant increase of more than $25 \%$ in dead MCF-7 cells. In contrast, no differences in percentage of dead cells for polyplexes with aptamer (33\%) and polyplexes alone (40\%) were found for the tumor MUC1 (-) HepG2 cells. The increase of more than $25 \%$ in cellular death when the aptamer was present was lower than the up to 6 fold of increase obtained with luciferase expression. These differences were attributed to the different parameters measured and different techniques used that allowed to increase the mortality of unspecific polyplexes in MUC1 (-) cells. Measurement of luciferase expression by luminescence seemed to be a more sensitive technique than Live and dead assay. Despite of that, significant increase of cellular dead was observed in cells treated with ELR-pCMV-PAP-5TR1 which allowed its utilization in further experiments.

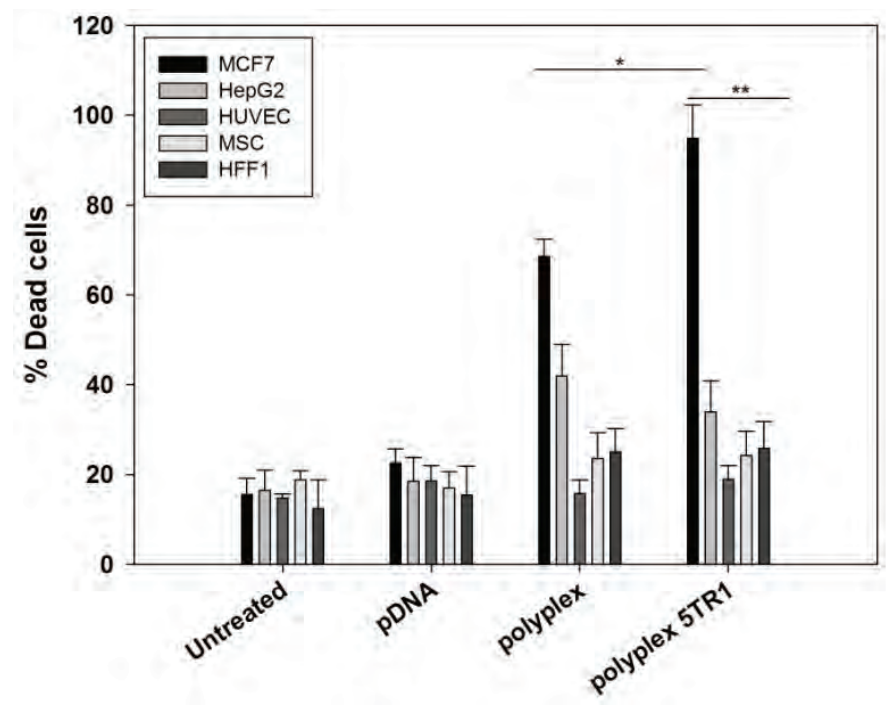

Figure 4D.18.Targeted killing ability of ELR-PAP-5TR1 polyplexes. \% Dead cells was calculated by fluorescence quantification. Cells were pre-incubated for 5 hours with minimum medium (Untreated), pCMV-PAP plasmid alone (pDNA), ELR-pDNA (Polyplex), ELR-pDNA conjugated with aptamer 5TR1 (Polyplex 5TR1). Additional incubation under standard conditions up to 48 hours was then carried out. Mean \pm standard error of three independent experiments. A statistical analysis showed significant differences $\left(^{*}: p<0.05\right.$, **: $p<0.01)$.

The fact that observed effects in primary cells were similar to those for untreated cells, suggests a possible protective effect on them. It is interesting to note that the 
limited effect on MSCs, endothelial and fibroblasts under conditions in which tumor cells have been shown to be extensively affected, is remarkable as it allows us to hypothesize that either local or systemic intravenous route of administration could be used without damage to the bloodstream lineage. These results corroborate the suitability of ELR-5TR1 aptamers for a specific suicide therapy with a novel use of PAP-S as transfecting agent affecting only the target breast cancer cells. Hence, the use of other toxic agent as PAP-S different to p53 allowed understanding that the action of ELR-pDNA-5TR1 is specific of MUC1 presence as it had been previously shown in other transfection experiments.

\section{D.4. IN VIVO ASSAYS WITH ELR-pCMVPAP-5TR1}

Once the effectiveness of the system ELR-pCMVPAP-5TR1 was confirmed to specifically kill the target breast cancer cells in vitro, the inhibition of tumor growth was evaluated in a previous in vivo assay. For that, xenografts were developed in nude mice previously implantated with $17 \beta$ stradiol pellets of $0.72 \mathrm{mg}$ of 90 days of release. MCF-7 cells are estrogen dependent cells and require a maintained level in order to proper tumor take up and growth. After two days a subcutaneous injection of MCF-7 cells mixed with Geltrex ${ }^{\circledR}$ into the right flank (3.2.13.1.) was accomplished. The use of a gel scaffold as Geltrex has been widely used in order to get a suitable tumor implantation and development (384). When tumors attained a volume of $50 \mathrm{~mm}^{3}$ mice were separated in 2 homogeneous groups in terms of size and weight (6 animals in PAP-S group and 8 in placebo) and the treatment started. 2 peritumoral injections of $20 \mu \mathrm{g}$ of pDNA and 1 of $10 \mu \mathrm{g}$ of pDNA with ELR and 5TR1 aptamer at 50/1/4 ratio during the first 4 days were performed for the ELR-pCMVPAP-5TR 1 group. Tumors were measured almost every day until 23 days after the first injection. Data showed difference in tumor growth evolution between placebo ( $5 \%$ glucose) and the treated group from the second injection (day 2) (Figure 4D.19). This difference was maintained along time reaching to very significant values at day 23 with $p<0.001$. The average tumor volume in placebo was $176 \mathrm{~mm}^{3}$ which is similar to those obtained in literature $(385,386)$; by contrast mice treated with ELR-pCMV-PAP5TR1 was $40 \mathrm{~mm}^{3}$ constituting a reduction of more than $75 \%$. This data showed that the expression of PAP-S transgene was able to suppress tumor growth in vivo after the second injection. These results confirmed the anti-tumor effect of the therapy 
and are consistent with the in vitro results. Additionally, mice belonging to both groups did not show either visual toxicity signs or weight loss.

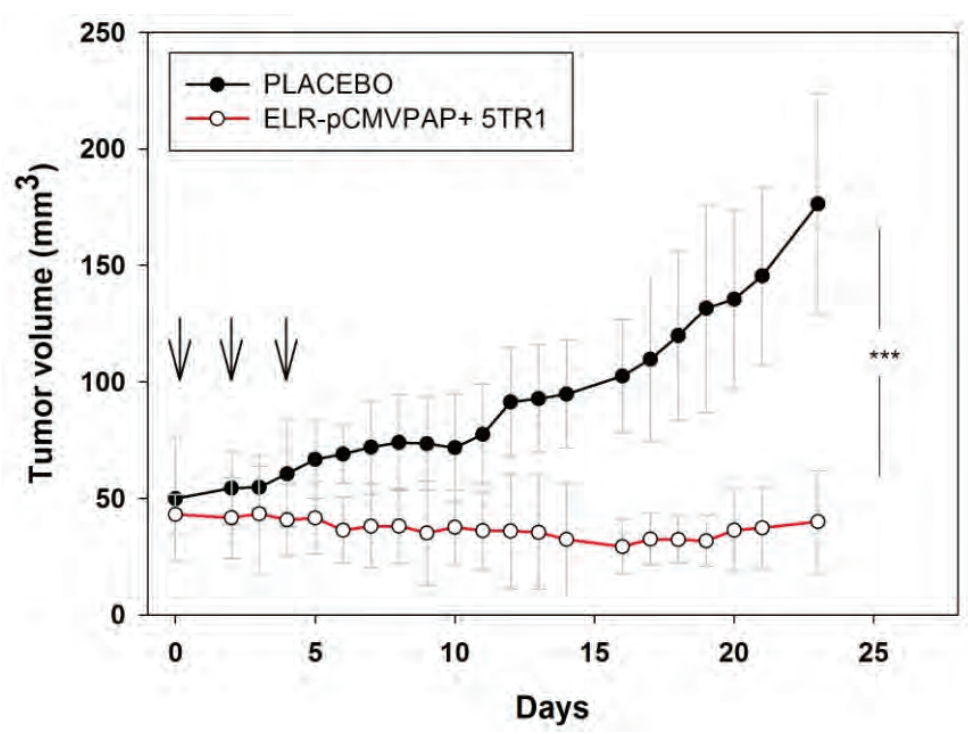

Figure 4D.19. Tumor volume reduction by ELR-pCMVPAP-5TR1 complexes. Tumor volume evolution during 23 days after 3 injections with placebo and $20 \mu \mathrm{g}$ of therapeutic plasmid. Data represent the mean \pm S.D. of 6 mice in ELR-pCMVPAP+5TR1 and 8 mice in placebo group. A statistical analysis showed significant differences $\left({ }^{* * *}: p<0.001\right)$

PAP-S protein had been previously used along the literature as immunotoxin in in vivo models for leukaemia and HIV-1 treatment diseases $(284,285)$. Among type I RIPs, only saporin had ben used before as suicide gene agent. By contrast, this is the first time that PAP-S has been applied in suicide gene therapy as well. This pool of assays using a sophisticated non-viral vector formed by ELR and the adsorbed 5TR1 aptamer together with the PCMVPAP plasmid pave the way for further investigations with PAP-S as therapeutic gene and ELR+5TR1 aptamer as vector for breast cancer treatment. 


\section{FINAL REMARKS}

In summary, we have developed a pool of non-viral gene-delivery systems comprising tailor-made elastin-like recombinamers that showed transfection ability. However, the presence of amine groups appears to be determinant in the designing of an efficient system. As result, VOKX72 ELR was selected and complexed with therapeutic pDNA and MUC1 aptamers with the future and potential application in the treatment of breast cancer.

When bound to plasmid DNA, VOKx72 polymer was able to form stable polyplexes at physiological conditions and possessing positively charged surface of $+20 \mathrm{mV}$ to $+40 \mathrm{mV}$ with a suitable particle size of $150 \mathrm{~nm}-200 \mathrm{~nm}$ for cell internalization.

50/1 N/P ratio ( $134 \mathrm{~nm}$ and $+39 \mathrm{mV}$ ) resulted to be generate more stable polyplexes than $5 / 1$ ratio $(200 \mathrm{~nm}$ and $+27 \mathrm{mV}$ ). The incorporation of $\mathrm{MUC1}$ aptamers by electrostatic interactions at low ratio N/P/Papt (50/1/4) led to stable polyplexes with a positive zeta potential $+38 \mathrm{mV}$ and proper particle size $(138 \mathrm{~nm})$ for transfection purposes.

Transfection assays by means of luciferase expression showed better results for $50 / 1$ than 5/1 ratio getting an increment of nearly seven times. In addition, an improvement in the specificity of six times in comparison with the nude polyplex and provided by the aptamers and specifically by 5TR1 directed against the underglycosylated MUC1 at 50/1/4 ratio was observed.

Cell uptake visualization led to the localization of polyplexes containing 5TR1 in the cytoplasm and even in the nucleus of MCF-7 target cells. Internalization of these nanoparticles was observed to be through macropinocytosis and in a lesser extent through caveoline and clathrin-endocytosis pathways. Macropinocytosis and clathrindependent pathways evidenced the interaction of 5TR1 aptamer with MUC1 on the cell membrane.

Transfection of p53 transgene showed the dependency of MUC1 over the cell transfection. Thus it resulted in a protective effect of MUC1 over breast cancer cells suggesting the utilization of other dead inducing agent as the most effective strategy. 
Suicide therapy by means of type I RIP named as PAP-S was tested. The result showed the ability of this VOK-pDNA-5TR1 system to transfect not only plasmids bearing luciferase but specifically PAP-S genes into tumour cells. The expression of PAP-S was corroborated by cellular death in the target MCF-7 cells. Transfection and expression of PAP-S gene led to cellular death of nearly $95 \%$ of breast cancer cells while protecting MUC1 (-) human cells.

The in vivo assay using MCF-7 xenografts in nude mice and treated with the ELRPCMVPAP-5TR1 system showed the expected anti-tumor effect. A tumor growth inhibition of more than $75 \%$ was observed with high significant differences in comparison with placebo. This work constitutes the first time that ELR together with a PAP-S transgene is applied with optimistic results in breast cancer treatment.

Accordingly, the use of this ELR-aptamer system is a promising strategy in the delivery of therapeutic genes of interest that target breast tumour cells even more considering the high potential of ELRs for improvement. However, improvements focused on covalently link the aptamers to the ELR will be purposed in the next chapter with the objective to standardize the creation of the delivery device and improve its stability in the likely physiological fluids. Additionally, the safety of the suicide therapy can be increased by the use of cell tissue specificity promoters that would control the expression of the therapeutic gene only in the target cells. The utilization of other RIPs as ricin will be accomplished as a novel approach in the employment of RIPs for suicide gene therapy in breast cancer. 


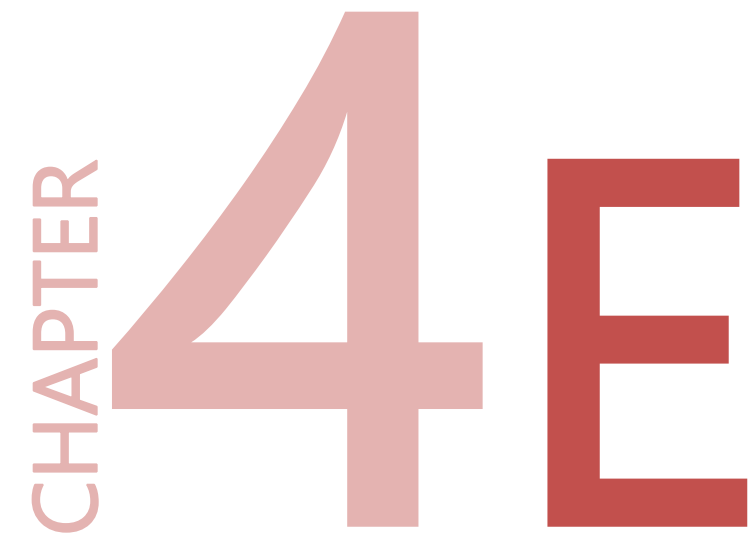




\section{ELR BASED SUICIDE GENE THERAPY SYSTEM DIRECTED TO BREAST CANCER USING RICIN GENE}
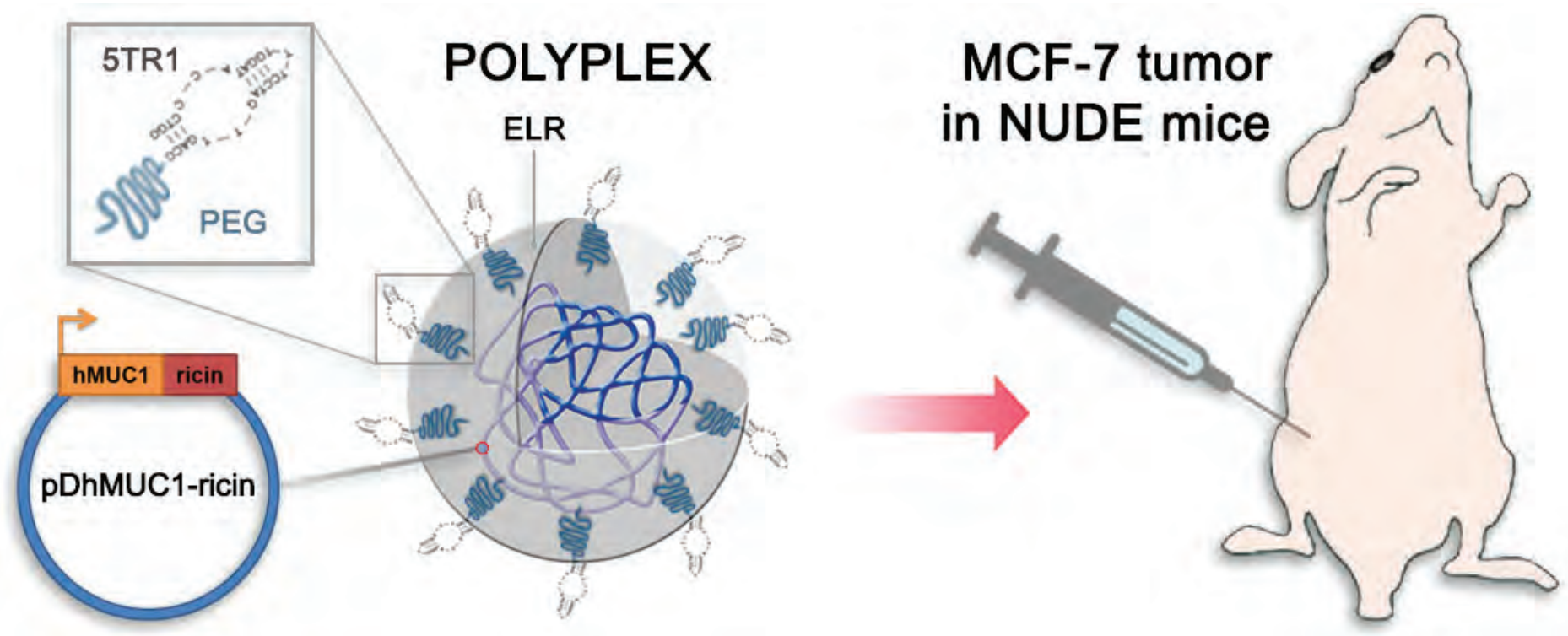


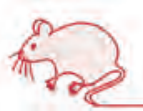




\section{E. ELR BASED SUICIDE GENE THERAPY SYSTEM DIRECTED TO BREAST}

\section{CANCER USING RICIN GENE}

In previous studies we have demonstrated the ability of polyplexes formed by ELR, adsorbed MUC1 aptamers, and a therapeutic plasmid containing the gene of noncytotoxic PAP-S to target breast cancer cells and cause cellular death both in vitro and in vivo (Chapter 4D). It is important to note that death events were induced only in transfected cells, reducing somehow the potential of suicide therapy. Additionally, the versatility of ELRs allows chemical modifications that can be raised in order to improve the stability of polyplexes in body fluids. Accordingly, the present work extends the study of the previous system to a more complex one in order to achieve the known as "bystander effect" in suicide therapy $(229,387)$ and to increase the specificity and stability of polyplexes. In the previous study the main objective was to destroy the transfected breast cancer cells by the action of PAP-S. By contrast, in the present work the main objective is to destroy transfected and neighbor breast cancer cells by the action of a modified ricin thereby increasing the potential harmful without damaging the nontumor cells both in vitro and in vivo. For that, two approaches have been attempted. One related with the design of a therapeutic plasmid containing the cytotoxic ricin gene with the preprotrypsin leader which expression would be controlled by hMUC1 promoter and the other involving the covalent binding of 5TR1 aptamer to the ELR. Thereby constituting a novel double safety lock regulated device controlled by the presence of the glycoprotein MUC1.

The first lock was characterized by the presence of the 5TR1 aptamer which had been functionalized to the VOK ELR through polyethylene glycol (PEG) (4A.4.2.) in order to facilitate the higher accessibility of aptamer to its target and the likely half-life prolongation of polyplexes in bloodstream. PEG had been commonly used as spacer in targeted drug delivery systems $(155,156)$ due to its high aqueous solubility, nontoxicity or immunogenicity and high flexibility that allows PEGylation without steric hindrance. In addition, 5TR1 aptamer was bound to VOK-PEG construction through click chemistry allowing its linkage in an innocuous and high yield manner (4A.4.2.). 
The second lock corresponded to the tumor specific human MUC1 promoter named as hMUC1 that would increase the safety of the system by reducing the non-specific gene expression in health cells instead of potent and constitutive viral promoters as cytomegalovirus (CMV). hMUC1 promoter is known to be overexpressed in breast tumors and its tissue selective activation has been tested along in vitro and in vivo assays $(148,149)$. As an example, the selective expression of BAX proapoptotic protein mediated by hMUC1 promoter led to the eradication of $99 \%$ of ovarian tumor implants (149) which showed its potential as tissue-specific promoter using adenovirus as gene carrier. Moreover, the utilization of the modified ricin gene as therapeutic agent made these two security locks essential. The employment of PAP-S in chapter 4D triggered toxic effects and death only in transfected cells; however the challenging idea of increasing the "harmful potency" was pursued by the ricin. PAP-S is a type I RIP containing only one catalytic chain; by contrast ricin is a type II RIP protein with a catalytic chain (RTA) and a lectin-type translocator chain (RTB) that makes it a potent toxin. Ricin is known to enter in most of cell lines via endocytosis after interaction with glycosylated membrane components. Once internalized, ricin is transported to the endoplasmic reticulum where the RTA is translocated to cytoplasm and becomes active (Figure 1.24) (292). There, RTA triggers protein synthesis inhibition that leads to apoptosis and inflammation events in human cells. The high toxicity of ricin is highlighted when comparing with PAP-S toxin (1.4.2.). For instance the CC50 (concentration causing $50 \%$ of death cell) was shown to be $33 \mu \mathrm{M}$ for PAP-S in comparison with $0.67 \mathrm{pM}$ for ricin in HeLa cells $(288,289)$ and the LD50 (dose to produce $50 \%$ of death in mice) was reported of $0.95 \mathrm{mg} / \mathrm{Kg}$ for PAP-S and $2.8 \mu \mathrm{g} / \mathrm{Kg}$ for ricin in mouse after intraperitoneal injection $(286,290)$.

Hence in this work the expression of the ricin only in MUC1 overexpressing cells (148, 388) was pursued. Both vector (VOK-PEG-5TR1) and therapeutic DNA (pDhMUC1ricin) would constitute the double safety lock device controlled by the presence of MUC1 and applied to directed suicide therapy by means of ricin activity for breast cancer in vitro and in vivo. Since most of the research in suicide therapy has been performed with viral vectors (238-241), the utilization of this complex device formed by the polymeric ELR constitutes a novel approach. Moreover, ricin gene has not been used as delivery agent and applied to breast cancer so far (1.3.3. and 1.4.3.) 
which gives an added value to the present work. Due to the potency of ricin toxin, we consider that this double safety lock is required in order to guarantee the specificity and security of the system.

This chapter reports the design of the therapeutic plasmid pDhMUC1-ricin, the characterization of polyplexes formed by VOK-PEG-5TR1-pDNA and the efficiency of the device as suicide system both in vitro and in vivo.

\section{E.1. DESIGN OF pDhMUC1-RICIN}

The therapeutic plasmid DNA was based on the commercial pDrive5Lucia-hMUC1 plasmid (3.1.7.3.), in which the luciferase gene was replaced by the modified ricin gene. Ricin gene was designed to contain the preprotrypsin leader at $5^{\prime}$ end instead of its original leader sequence (Figure 4E.1) present in Ricinus communis plant, in order to avoid difficulties in post-translational modifications of ricin. However, since $\mathrm{N}$-t modifications have been shown to have important effects in protein expression; a small sequence of $15 \mathrm{bp}$ from the original leader sequence was conserved to assure the expression of the holotoxin in mammalian cells. Once expressed, the objective was to mask the ricin as preprotrypsin protein in order to be directed to the endoplasmic reticulum lumen where the maturation of ricin would take place. Furthermore, preprotrypsin leader sequence had been previously used for the successful secretion of FLAG epitopes in mammalian cells (389). Thus, the use of the preprotrypsin leader sequence in the therapeutic plasmid design would allow the secretion of mature ricin and its diffusion from transfected tumor to neighbor cells (including the expressing cell) triggering the bystander effect (1.4.3.). In PAP-S assays, the transfected cells were able to express the PAP-S in the cytoplasm and cause cellular death but the lacking of B chain did not allow it to translocate into neighbor cells. By contrast, the translocation of ricin to neighbor cells would be mediated by the interaction of RTB chain with sugars from the cell surface and would allow the catalytic RTA chain to reach the cytoplasm where could cleave the ribosome and inhibit the protein synthesis leading to apoptosis and cellular death events $(296,300)$. 


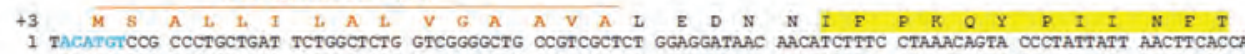
TACATGTCCG CCCTGCTGAT TCTGGCTCTG GTCGGGGCTG OCGTCGCTCT GGAGGATAAC AACATCTTTC CTAAACAGTA CCCTATTATT AACTTCACCA
ATGTACAGGC GGGACGACTA AGACCGAGAC CAGCCCOGAC GGCAGCGAGA CCTCCTATTG TTGTAGAAAG GATTTTGTCAT GGGATAATAA TTGAAGTGGT ATGTACA

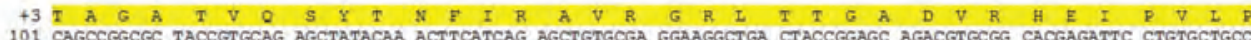
GTCGGCCGCG ATGGCACGTC TCGATATGTT TGAAGTAGTC TCGACACGCT CCTTCCGACT GATGGCCTCG TCTGCACGOC GTGCTCTAAG GACACGACGG

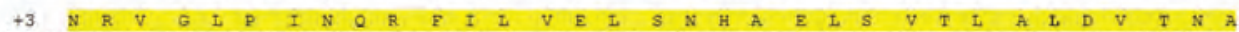
201 AAACCGGGTC GGACTGCCCA TCAATCAGAG GTTCATCCTG GTGGAGCTGA GCAACCATGC CGAACTGTCC GTGACTCTGG OCCTGGATGI CACCAATGCT TITGGCCCAG CCTGACGGGT AGTTAGTCTC CAAGTAGGAC CACCTCGACT CGTTGGTACG GCTTGACAGG CACTGAGACC GGGACCTACA GTGGTTACGA

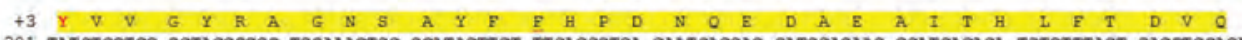

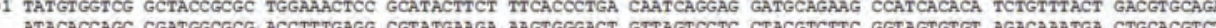

A 401 ACAGGTATAC CTTCGCCTTT GGCGGAAATT ACGATCGACT GGAGCAGCTG GCTGGCAACC TGAGGGAGAA TATCGAACTG GGAAACGGGC CTCTGGAGGA TGTCCATATG GAAGCGGAAA OCGCCTTTAA TGCTAGCTGA CCTCGTCGAC CGACCGTTGG ACTCCCTCTT ATAGCTTGAC CCTTTGCCCG GAGACCTCCT

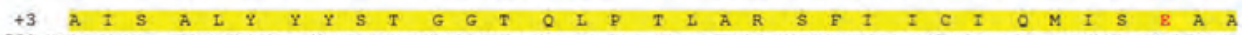
D1 AGCCATTTCT GCTCTGTACT ATTACAGTAC AGGGGGCACT CAGCTGCCAA CACTGGCCAG ATCCTTCATC ATTTGCATCC AGATGATTTC TGAAGCCGCT TCGGTAAAGA CGAGACATGA TAATGTCATG TCCCCCGTGA GTCGACGGTT GTGACCGGTC TAGGAAGTAG TAAACGTAGG TCTACTAAAG ACTTCGGCGA

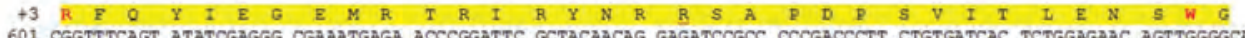
GCCAAAGTCA TATAGCTCCC GCTTTACTCT TGGGCCTAAG CGATGTTGTC CTCTAGGCGG GGGCTGGGA GACACATCAC TCTGGAGAAC AGTTGGGGCA

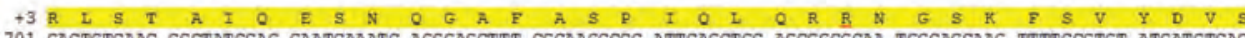
01 GACTGTCAAC CGCTATCCAG GAATCAAATC AGGGAGCTTT CGCAAGCCCC ATTCAGCTGC AGCGGCGCAN TGGCAGCAAG TTTTCCGTGT ATGATGTCAG CTGACAGTTG GCGATAGGTC CTTAGTTTAG TCCCTCGAA GCGTTCGGGG TAAGTCGACG TCGCCGCGTT ACCGTCGTTC AAAAGGCACA TACTACAGTC

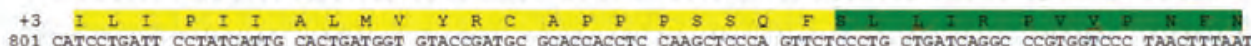
GTAGGACTAA GGATAGTAAC GTGACTACCA CATGGCTACG OGIGGTGGAG GTTCGAGGGT CAAGAGGGAC GACTAGTCCG GGCACCAGGG ATT GAAATTA

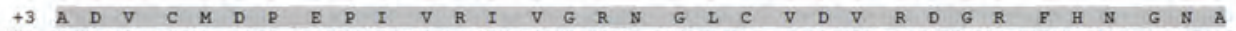
901 GCCGACGTGT GCATGGATCC AGAGCOCATC GTGAGAATTG TCGGCCGGAA CGGACTGTGC GTGGACGTGA GGGATGGCAG GTTCCACAAC GGAAATGCAA CGGCTGCACA CGTACCTAGG TCTCGGGTAG CACTCTTAAC AGCCGGCCTT GCCTGACACG CACCTGCACT CCCTACCGTC CAAGGTGTTG CCTTTACGTT

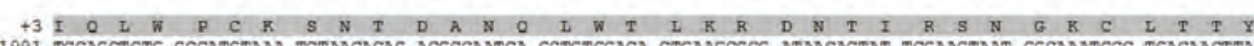

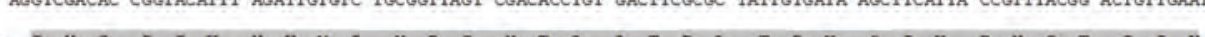

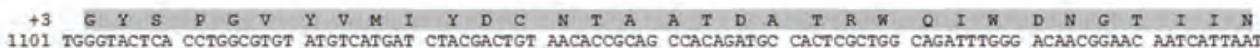
ACCCATGAGT GGACCGCACA TACAGTACTA GATGCTGACA TTGTGGCGTC GGTGTCTACG GTGAGCGACC GTCTAAACOC TGTTGCCTTG TTAGTAATTA

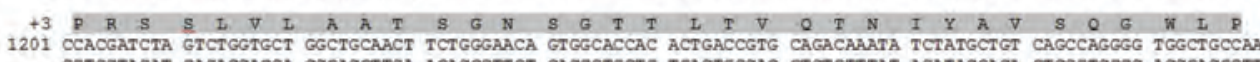
GGTGCTAGAI CAGACCACGA OCGACGTTGA AGACOCTTGT CACCGTGGT TGACTGGCAC GTCTGTTTAT AGATACGACA GTCGGTCCCC ACCGACGGTI

+3 I N N T Q P F V T T I V G L X G I C I Q A N S G O V W I I D C S S E 301 CTAACAATAC CCAGCCCIIC GICACTACCA TCGTCGGACT GTACGGGCTG TGCCTGCAGG CTAACTCTGG GCAAGTGTGG ATTGAGGACT GTTCAAGCG

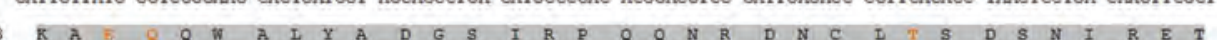
1401 GAAGGCAGAA CAGCAGTGGG CACTGTATGC CGATGGCAGC ATCAGGCCAC AGCAGAACAG AGACAATTGC CTGACCAGTG AITCAAATAT CAGAGAAACA CTICCGTCTT GTCGTCACCC GTGACATACG GCTACCGTCG TAGTCCGGTG TCGTCTTGTC TCTGTTAACG GACTGGTCAC TAAGTTTATA GTCTCTTTGT

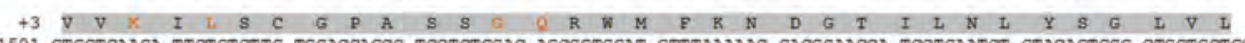
1501 GTGGTCAAGA TTCTGTCTTG TGGACCAGCC TCCTCTGGAC AGCGGTGGAT GTTTAAAAAC GACGGAACCA TCCTGAATCT GTACAGTGGG CTGGTGCTGE CACCAGTTCT AAGACAGAAC ACCTGGTCGG AGGAGACCTG TCGCCACCTA CAAATTTTTG CTGCCTTGGT AGGACTTAGA CATGTCACCC GACCACGACO

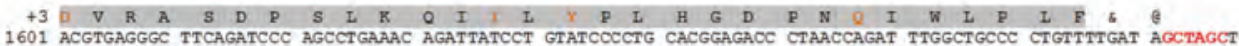
TGCACTCCCG AAGTCTAGG TCGGACTTTG TCTAATAGGA CATAGGGGAC GTGCCTCTGG GATTGGTCTA AACCGACGGG GACAAAACTA TCGATCGA

Figure 4E.1. Ricin gene modified with preprotrypsin leader sequence. Preprotrypsin leader (orange), A chain (highlighted in yellow), linker (highlighted in green), B chain (highlighted in gray). The amino acids in red from Chain A formed jointly the activity conserved site region of ricin A-chain. The amino acids in orange from Chain $B$ constitute the putative sugar binding sites $P_{S C}$ (highlighted in light blue) and Nhel restriction site (highlighted in red).

Using Nhel and Ncol restriction enzymes pDhMUC1 plasmid lacking the luciferase gene (2705 bp) was obtained (Figure 4E.2A). In a parallel reaction, pUC57 plasmid containing the ricin gene was cut by $P S d$ and Nhel enzymes releasing the modified ricin gene of $1698 \mathrm{bp}$ (Figure 4E.2A). After that, a ligation reaction led to creation of the new pDhMUC1-ricin (3.1.7.3.). The final plasmid construct size of 4403 bp was confirmed by agarose electrophoresis after digestion by EcoRI enzyme (Figure 4E.2B). 
This pDhMUC1-ricin was used as therapeutic plasmid for further experiments along this chapter.
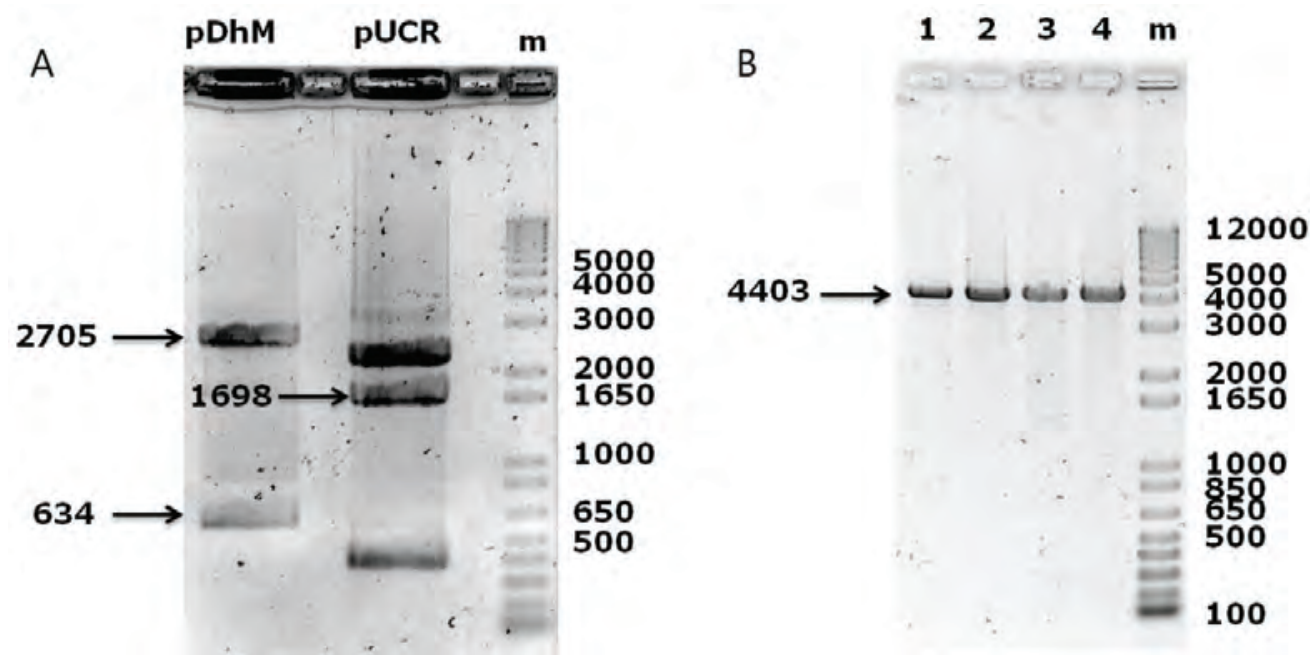

Figure 4E.2. Agarose gel electrophoresis of pDhMUC1-ricin construction. pDrive5LuciahMUCl was cut with $\mathrm{Ncol}$ and Nhel enzymes and loaded. Double digestion gave two fragments, being the band of 2705 bp which contained the plasmid of interest (pDhM lane). pUC57-ricin was cut with Psd and Nhel and loaded. Double digestion gave several fragments, being the 1698 bp which contained the ricin gene (pUCR lane) (A).4 colonies with the construction pDhMUC1-ricin were restricted with EcoRI enzyme and loaded. Plasmid with a size of 4403 bp was linearized (B). DNA agarose gel (1.2\%) electrophoresis stained with SimplySafe ${ }^{\top \mathrm{M}}$.

\section{E.2 SYNTHESIS AND CHARACTERIZATION OF THE VOK-PEG-5TR1}

VOKx72 polymer with the amino acid sequence MESLLP $(\mathrm{VPGKG})_{72} \mathrm{~V}$, where the pentapeptide VPGKG is repeated 72 times, was produced as described in 4A.1.2. The functionalization of VOKx72 with PEG-cyclooctyne was achieved by amidation reaction between the $\varepsilon$-amine group from lysines present in the ELR and the reactant NHS-cyclooctyne-PEG that carries the activated carboxylic group as depicted in section 4A.4.2. After that, click reaction was performed between the VOK-PEGCyclooctyne and azide-5TR1 in two parallel reactions with and without Cy5 in order to visualize by flow cytometry the presence of 5TR1-Cy5 in the VOK-PEG-5TR1-pDNA polyplexes. Thus, the incorporation of $0.1 \mathrm{mmol}$ of 5TR1 aptamer to $0.4 \mathrm{mmol}$ of VOK-PEG-Cyclooctyne (50/1/4 ratio) was quantified by absorbance at $260 \mathrm{~nm}$. In addition flow cytometry data showed that $100 \%$ of polyplexes made of VOK-PEG- 
5TR1-Cy5-pDNA were conjugated to the aptamer (4A.4.2) which confirmed the presence of aptamers in every polyplex.

\section{E.3. POLYPLEX SIZE, ZETA POTENTIAL AND TEM}

It is widely reported that the nanoparticle size is an important parameter in several applications and aspects of nanoparticles clearance. For example in the systemic delivery of anticancer complexes, it is generally accepted that small particles $(<500 \mathrm{~nm})$ can avoid the reticuloendothelial system, resulting in a longer circulation time (390). In the case of solid tumors, small nanoparticles (200 to $600 \mathrm{~nm}$ ) can pass through the leaky tumor vasculature, whereas they are excluded from intact vessels in normal tissues. It has been estimated that the pore size of tumor vasculature reaches up to $600 \mathrm{~nm}$ (contrasting the $6-12 \mathrm{~nm}$ pores of normal vessel walls), and this has been exploited for passive targeting of nanoparticles to tumors (160). Regarding the renal excretion through glomerular filtration, their capillary walls is typically 6-8 nm for spherical particles so it is exclusive only for materials with very small hydrodynamic diameters (158). By contrast, clearance by the reticuloendothelium system in the liver and the spleen is rapid for particles above $200 \mathrm{~nm}$ in diameter (1.2.5.1.). Furthermore at cellular level, it is known that the size of particles have an effect in the internalization pathway and hence in their global uptake (1.2.4.2. and 1.2.5.2.). In this sense, particles with a size about 50-200 nm are known to be internalized mainly by endocytosis pathway which may be beneficial for a rapid entry into cells (127). By contrast, the size cut off limit for particles is up to $10 \mu \mathrm{m}$ to gain cellular entry through phagocytosis $(117,127)$. Size of polyplexes formed by VOKPEG-5TR1-pDNA (50/1/4 ratio) in 5\% glucose was measured by DLS (3.2.6.3.). The obtained value was $190 \pm 7.5 \mathrm{~nm}$ (Figure 4E.3A) (Pdl 0.13) was higher than polyplexes

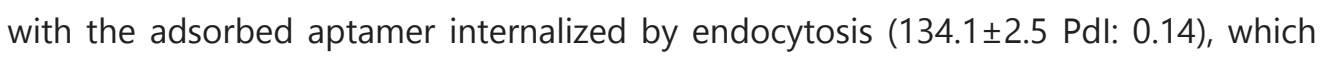
can be due to the presence of the flexible PEG-5TR1, and with similar polydispersity index. Indeed, according to the literature (127) this particle size is suitable for cellular transfection. In addition, zeta potential of polyplexes was measured in the same conditions as DLS (3.2.6.4.). The resulting zeta potential was $+43 \mathrm{mV}$ which provide high stability to polyplexes, this data was slightly higher than the obtained for polyplexes with adsorbed aptamer $(+38 \mathrm{mV})$ and reflects an increase in the stability of the nanoparticles. Thus, a positive surface charge is thought to favor the 
interaction with the negatively charged plasmatic membrane (123) which is appropriate for gene delivery purposes. Further characterization by TEM (3.2.6.5.) helped us to figure out the shape of VOK-PEG-5TR1-pDNA complexes. Figure 4E.3B showed well defined polyplexes with a homogenous shape and size of $135.5 \pm 20 \mathrm{~nm}$ similar to the ones obtained by TEM for adsorbed aptamers $(123.8 \pm 12 \mathrm{~nm})$. Differences in polyplex size between both procedures were attributed to the technique conditions where polyplexes were hydrated for DLS and dried for TEM (391).

A

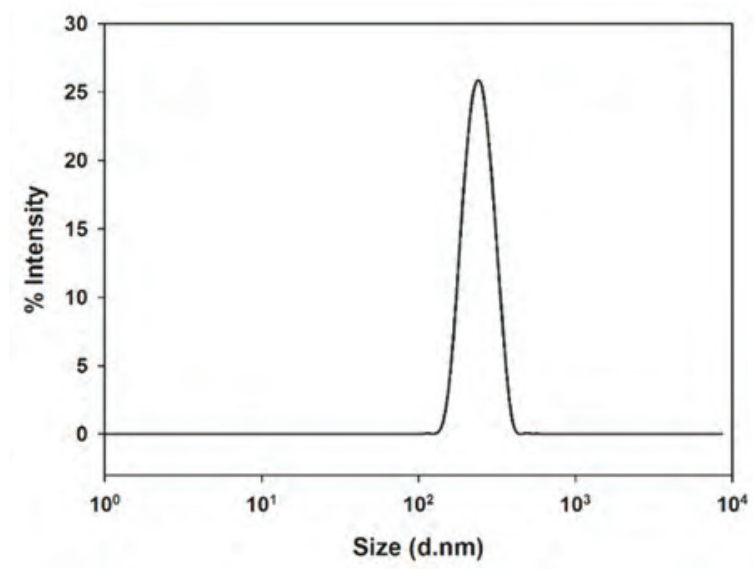

B

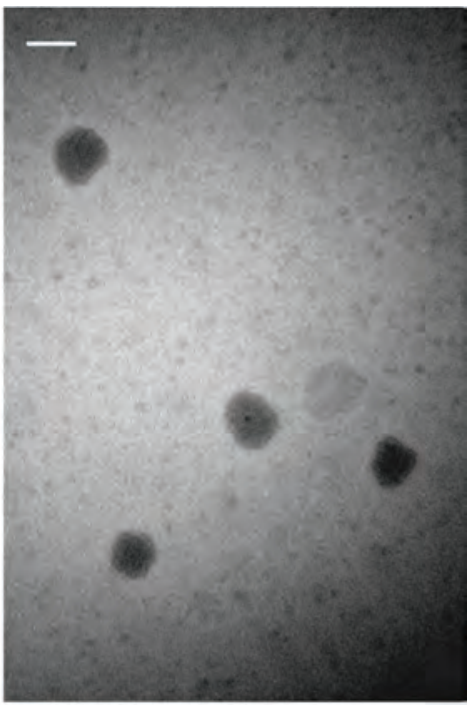

Figure 4E.3. Polyplex size and morphology of VOK-PEG-5TR1-pDNA. Histogram showing the intensity of scattered light (percent) as function of size (A). TEM image of polyplexes formed at 50/1/4 ratio of N/P/Papt with $10.5 \mu \mathrm{M}$ of VOK-PEG-5TR1 and a pDNA concentration of $1.4 \mathrm{nM}$. The bar scale corresponds with $100 \mathrm{~nm}$ (B).

\section{E.4. TRANSFECTION ASSAYS}

The ideal suicide gene therapy device is one that attacks the tumor cells with the lowest concentration possible of toxin but maintaining the healthy ones intact. In order to achieve this objective and taking into consideration the work previously developed with VOK polyplexes coated with adsorbed aptamers in Chapter 4D, the creation of the VOK-PEG-5TR1 biopolymer with the 5TR1 covalently linked for being used as part of the double-lock delivery device was performed as detailed before. It is important to remark the lack of toxicity of this VOKx72 polymer which had been previously reported (4D.3.1.). However, an additional comparison with a commercial non-viral gene delivery system named as Turbofect was performed (3.2.11.2.3.). In 
Figure $4 \mathrm{E} .4 \mathrm{~A}$ cells treated with the biopolymer showed a healthy state, by contrast cells treated with Turbofect exhibited visible signs of toxicity (Figure 4E.4B). Consequently, this assay confirmed the biocompatibility of the biopolymer VOK-PEG5TR1 over the target MCF-7 cells.
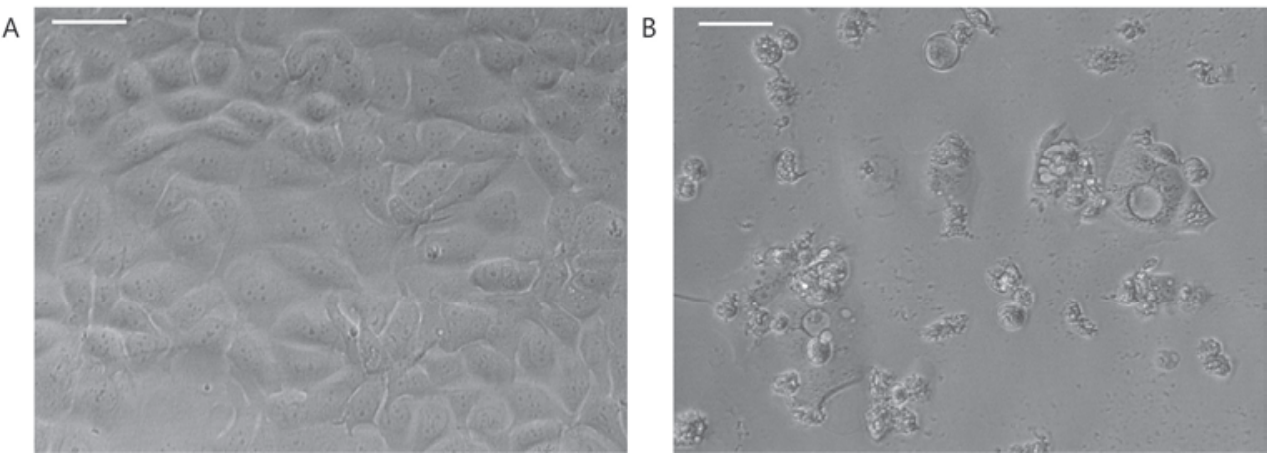

Figure 4E.4. Contrast phase showing the effect on cell viability of VOK-PEG-5TR1 polymer. MCF-7 cells were incubated with with $36 \mu \mathrm{g}$ of VOK-PEG-5TR1 complexed with $0.5 \mu \mathrm{g}$ of pDNA (50/1/4 ratio) (A) and with $1 \mu \mathrm{l}$ of Turbofect complexed with $0.5 \mu \mathrm{g}$ pDNA according to the manufacturer instructions (B). After 48 hours of incubation contrast phase microscope images were taken. Scale bar corresponds with $10 \mu \mathrm{m}$.

With this novel biopolymer, an improvement of transfection ability probably due to the higher availability of 5TR1 for its interaction with MUC1 and mediated by the presence of PEG as spacer was expected in vitro. So, an initial transfection study of polyplexes with both adsorbed 5TR1 (VOK+5TR1) and covalent linked 5TR1 (VOKPEG-5TR1) using MCF-7 MUC1 (+) and HepG2 MUC1 (-) was accomplished. MCF-7 as breast cancer line overexpressing the MUC1 glycoprotein (371) and HepG2 as hepatocarcinoma cell line with no MUC1 expression (372) were selected for this assay. As shown in Figure 4E.5 very significant differences $(p<0.001)$ were observed between cell lines and treatments. Higher luciferase expression was obtained for MCF-7 cells in comparison with HepG2 which correlates with previous results (4D.3.2.) (more than 70 times for adsorbed aptamers and more than 100 times for covalent aptamers) and support the MUC1 specificity from 5TR1. In addition, the highest luciferase expression was obtained for cells treated with the complex VOK-PEG-5TR1pDNA (VOK-PEG-5TR1). In this sense, polyplexes formed by VOK-PEG-5TR1 were able to transfect 1.4 times more than polyplexes formed by VOK with the adsorbed aptamer $(p<0.001)$ increasing their specificity and stability. These results confirm the initial hypothesis that pointed out the use of PEG as spacer, which seems to improve 
the polyvalent binding to MUC1 in MCF-7 cells. Moreover, these data exhibit VOKPEG-5TR1 biopolymer as the best vector alternative for future experiments.

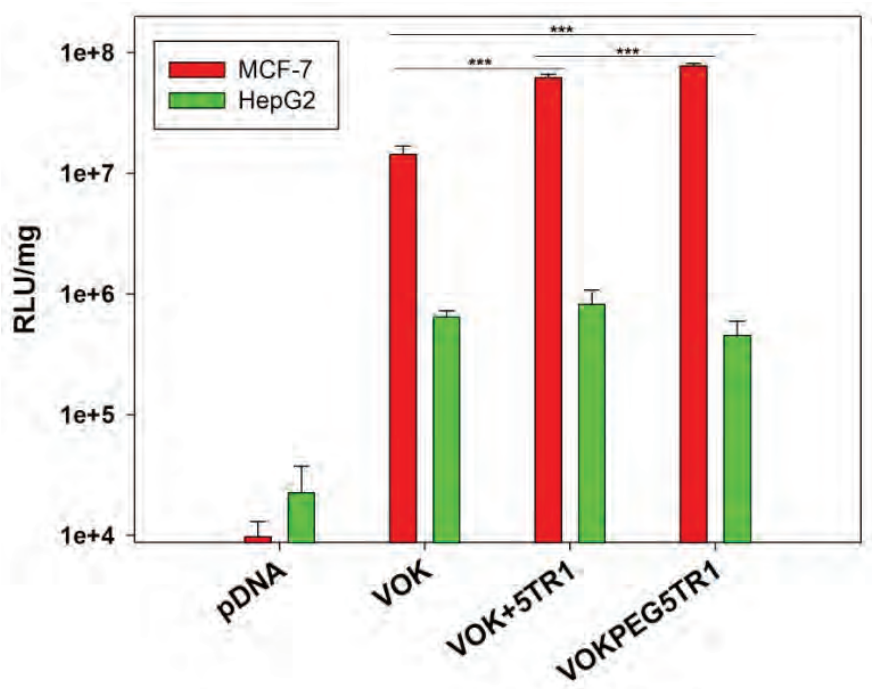

Figure 4E.5. Luciferase expression by pCMV-Luciferase contained in ELR polyplexes. Polyplexes were formed by VOK-pDNA, by VOK-pDNA with absorbed 5TR1 aptamer or by the biopolymer VOK-PEG-5TR1-pDNA with the 5TR1 aptamer covalently linked. pDNA was used as negative control. Luciferase activity is expressed in RLU/mg protein lysate. The results are expressed in logarithmic scale as mean \pm standard error of two independent experiments. ${ }^{* * *}: p<0.001$.

The target MCF-7 human breast cancer cells have shown to overexpress the MUC1 gene which codifies for MUC1 glycoprotein (392). Furthermore, amplification of the MUC1 gene has been found in about $40 \%$ of breast cancers and significantly correlates with increases in MUC1 mRNA and MUC1 protein levels (393). Moreover, MUC1-C subunit acts in auto-inductive loops with the STAT1/3 and the transcription factors NF-kB and RelA that confer activation over MUC1 gene and leads to its overexpression in breast cancer cells (262). Thus, we hypothesize that using a plasmid containing the hMUC1 promoter which is activated in presence of MUC1 is possible to control the therapeutic gene expression only in the target MCF-7 cells. In order to confirm this hypothesis, the luciferase expression controlled by two different promoters (CMV and hMUC1) was assessed. It is important to note that CMV (cytomegalovirus) promoter is commonly used for transient, constitutive and stable gene expression in mammalian cells (394) and hMUC1 promoter is a selective promoter for MUC1 overexpressing cells as explained above. For that, transfection assays with polyplexes formed by the biopolymer VOK-PEG-5TR1 and two plasmids 
with luciferase as reporter gene under the control of CMV or hMUC1 promoters were conducted. Three tumor (MCF-7 MUC1 (+), SKBR3 MUC1 (+), HepG2 MUC1 (-)) and one primary (HFF-1 MUC1 (-)) cell lines were transfected with the VOK-PEG-5TR1pCMV-Luciferase or VOK-PEG-5TR1-pDhMUC1-Luciferase polyplexes at 50/1/4 ratio (3.2.12.3.3). As explained before (4D.3.5), fibroblasts were selected as the most representative cell type of connective tissue (395), however SKBR3 was selected as another breast cancer cell line with MUC1 overexpression (396).

As shown in Figures $4 \mathrm{E} .5$ and $4 \mathrm{E} .6 \mathrm{~A}$, very significant differences in luciferase expression were found in MCF-7 cells transfected with the biopolymer VOK-PEG5TR1 and the reporter luciferase under the control of CMV promoter in comparison with the VOK without aptamer (more than 6 times higher). Indeed, the cell line specificity provided by 5TR1 was evidenced in MUC1 overexpressing cells in which SKBR3 cells showed significant differences $(p<0.05)$ when treated with VOK-PEG5TR1 as well. However, the luciferase expression was higher for MCF-7 than SKBR3 cells. This difference may be due to the diminished expression of MUC1 in SKBR3 cells $(396,397)$. When comparing the luciferase expression with the rest of MUC1 (-) cells, a slightly increase of more than 2.5 times was found between pDNA alone and polyplexes formed by VOK for HepG2. However, there was not increment between cells treated with polyplexes formed by VOK and VOK-PEG-5TR1. Hence, the increment in transfection for MUC1 (+) and no variation for MUC1 (-) cell lines support the gain of specificity mediated by 5TR1 aptamer when CMV promoter was used.

Further transfection assays with the selective hMUC1 promoter contained in pDhMUC1-Luciferase plasmid were performed. Despite lower RLU/mg was obtained for hMUC1 promoter which was attributed to the higher expression potency of CMV and probably to the different luciferase gene used (Gaussia luciferase for CMV and Lucia luciferase for hMUC1 promoter), similar behavior in luciferase expression among treatments was observed. As depicted in Figure 4E.6B, in HepG2 and HFF-1 cells the luciferase expression did not show any variation when comparing both pDhMUC1 with VOK and VOK-PEG-5TR1 with VOK treatments. The lack of increment in HepG2 cells when incubating with polyplexes formed by VOK in comparison with 
the plasmid alone showed the specificity of the hMUC1 promoter. By contrast, some significant increase was observed in SKBR3 cells; however this increment was lower in comparison with the observed in MCF-7 cells. This difference between both MUC1 $(+)$ cell lines coincides with the previous result after pCMV-Luciferase transfection and supports the lower expression of MUC1 in SKBR3 reported in the literature (396, 397). So, the most significant results with hMUC1 promoter were obtained for MCF-7 cells transfected with VOK-PEG-5TR1 polyplexes, being the expression of luciferase nearly six times higher than the control VOK without aptamer and exhibiting the specificity of the system. This result showed similar increase in luciferase expression under the control of the specific hMUC1 promoter in comparison with the constitutive CMV. Moreover, the luciferase expression for MCF-7 cells incubated with VOK-PEG-5TR1-pDhMUC1-Luciferase polyplexes was more than 2 times significant higher $(p<0.01)$ than the obtained with the commercial Turbofect. In light of these results, further transfection experiments related with suicide therapy were conducted using the same VOK-PEG-5TR1 construct as gene delivery vector as first security lock and hMUC1 promoter as second security lock.
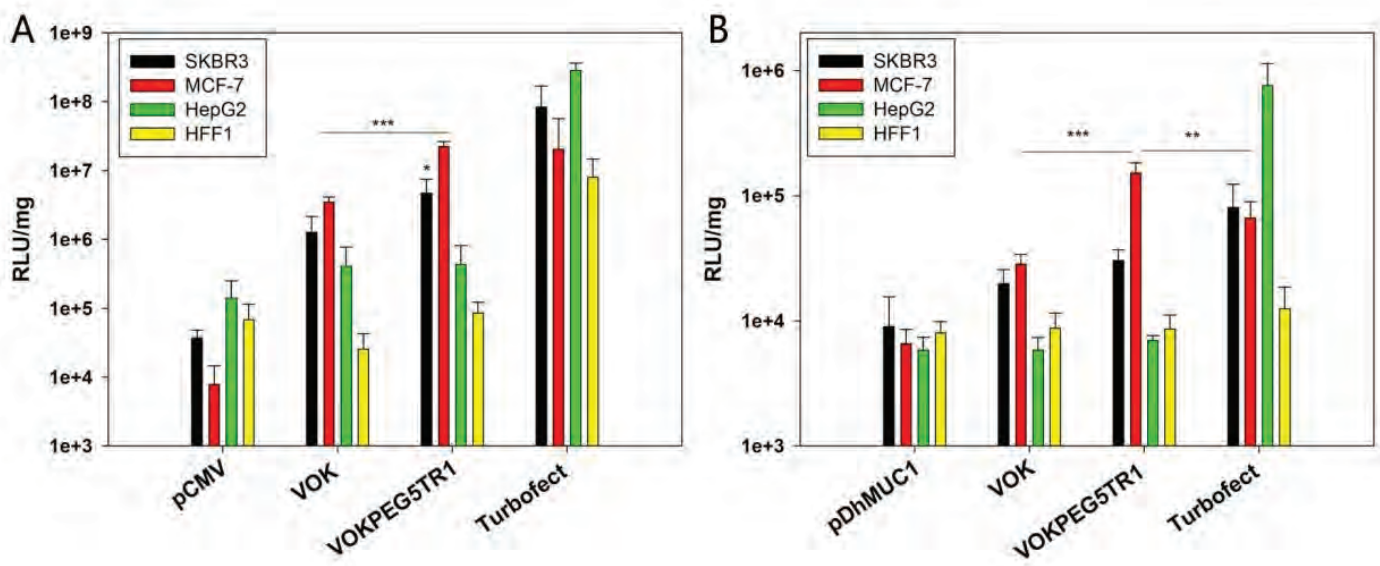

Figure 4E.6.Luciferase expression by pCMV-Luciferase contained in ELR polyplexes (A) and by pDhMUC1-Luciferase contained in VOK-PEG-5TR1-pDNA polyplexes (B). pDNA and Turbofect were used as negative and positive control respectively. VOK polyplexes were used as control for aptamer specificity. Luciferase activity is expressed in RLU/mg protein lysate. The results are expressed in logarithmic scale as mean \pm standard error of three independent experiments. ${ }^{*}: p<0.05,{ }^{* *}: p<0.01,{ }^{* * *}: p<0.001$. 


\section{E.5. SUICIDE GENE THERAPY ASSAYS IN VITRO}

As alternative to breast cancer treatments, the use of toxic or pro-apoptotic genes constitute one of the most stimulating trending in gene therapy (1.3.3.). The suicide gene therapy using ricin as toxic agent was tested and the killing ability of the system VOK-PEG-5TR1-pDhMUC1-ricin was assessed in the target human breast cancer cell line MCF-7 and human fibroblasts HFF1 in vitro. For that, cells were incubated with different concentrations $1.7 \times 10^{-3}, 1.7 \times 10^{-2}, 1.7 \times 10^{-1}$ and $1.7 \mathrm{nM}$ (with $0.5 \mathrm{ng}, 5 \mathrm{ng}, 50$ ng and 500 ng respectively) of the plasmid pDhMUC1-ricin (4E.1) and complexed with VOK-PEG-5TR1 at 50/1/4 (N/P/Papt) ratio. The effect of pDhMUC1-ricin transfection at those concentrations over the viability of HFF-1 and MCF-7 cells was evaluated (3.2.12.7.).

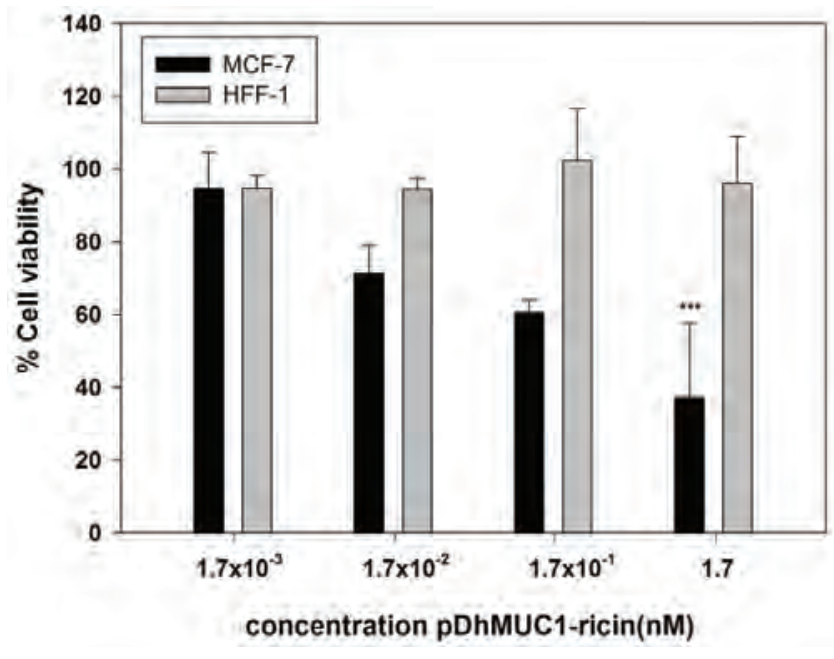

Figure 4E.7. Effect of pDhMUC1-ricin polyplexes over MCF-7 and HFFl cell viability. The co-incubation was followed by 48 hours of incubation under standard culture conditions. These results are representative of three independent experiments and of three replicates in each experiment; they are shown as mean \pm standard error.

As shown in Figure 4E.7, an innocuous effect was observed at all the concentrations of therapeutic treatment tested for HFF-1 cells as the most common cells of connective tissue in animals (395). By contrast, cytotoxic effect was observed from nearly $1.7 \times 10^{-2} \mathrm{nM}$ of pDhMUC1-ricin for MCF-7 cells. The concentration of pDhMUC1-ricin that caused $50 \%$ of cellular death in MCF-7 was shown to be 0.28 $\mathrm{nM}$. This cytotoxic effect found for pDhMUC1-ricin is agreed with the expected effects of the ricin toxin $(398,399)$, suggesting the expression of functional and active ricin. According with literature the CC50 (cytotoxic concentration that causes $50 \%$ of cellular death) for monkey kidney Vero cells incubated for $20 \mathrm{~h}$ with ricin was $7.6 \times 10^{-3}$ 
nM (400), by contrast it was $0.67 \mathrm{pM}$ when HeLa cells were incubated with ricin (289) or $0.1 \mathrm{nM}$ when myeloid U937 cells were incubated for $12 \mathrm{~h}$ (401) which shows that ricin cytotoxicity is cell line dependent mainly due to the different composition of glycoproteins on the cellular surface and the internalization pathway. Hence the cytotoxic effects observed after transfection with VOK-PEG-5TR1-pDhMUC1-ricin system suggests the expression of active ricin holotoxin besides the likely existence of the bystander effect. However, the amount of plasmid required to produce this CC50 (0.28 nM) was higher than the $0.67 \mathrm{pM}$ of ricin required for HeLa cells which is in accordance with the decrease of about 100 times in transfection levels when using the specific hMUC1 promoter in comparison with the constitutive CMV promoter but increasing its specificity. Despite of that, ricin was able to get expressed, secreted and internalized by neighbor cells thereby incrementing the damage potential. In this manner, once that one MCF-7 cell was transfected, ricin would be expressed as preproricin with the preprotrypsin leader sequence at $\mathrm{N}$-t. This leader would allow the preproricin to reach the endoplasmic reticulum (ER), where the leader sequence may be cleaved as part of the protein maturation process (402). From ER, ricin protein would finish its maturation in Golgi where glycosilation events would take place (403). Afterwards, exocytosis processes would occur, secreting the ricin to the culture media and leading to the bystander effect. Part of the mature ricin would be transported back from Golgi to ER where the cleavage of RTA and RTB would be performed by PDI (protein disulfide isomerase). In that moment, the active RTA would translocate to cytosol where it will be able to exert its action over the own transfected cell. Once the ricin is secreted to the media, the RTB would facilitate the translocation to the neighbor cell and its travel to endoplasmic reticulum and Golgi. There, PDI would activate the RTA which would be able to reach the cytoplasm and inhibit the protein synthesis leading to apoptosis and cellular death $(296,300)$. This $0.28 \mathrm{nM}$ concentration was considered for the following in vivo experiments where the minimum concentration was above this value.

\section{E.6. SUICIDE THERAPY ASSAYS IN VIVO}

To confirm whether in vitro anti-tumor therapeutic potency of VOK-PEG-5TR1pDhMUC1-ricin device as suicide gene therapy system candidate would translate to the in vivo scenario, tumor bearing mice were treated with the double lock device. Before tumor implantation, 4 mice were randomly separated to form the viability group. The rest of mice were implanted with $17 \beta$ stradiol pellets of $0.72 \mathrm{mg}$ of 90 
days of release. MCF-7 cells are estrogen dependent cells and require a maintained level of hormone in order to proper tumor take up and growth. Two days later tumor implant was accomplished, for that female Balb/c nude mice were subcutaneously injected with MCF-7 cells previously mixed with cold Geltrex into the right flank. Tumor growth evolution was determined by measuring the tumor volume, when it reached at least $50 \mathrm{~mm}^{3}$ mice were separated in 4 statistically similar groups (placebo, $1.7 \mathrm{nM}, 17 \mathrm{nM}$ and $70 \mathrm{nM}$ with 8 animals per group) and the treatment started (3.2.13.2.). Placebo group was administered with $100 \mu \mathrm{L}$ of $5 \%$ glucose, however viability group (mice without tumors) was administered with $100 \mu \mathrm{L}$ of the maximum dose of the therapeutic treatment $(70 \mathrm{nM})$. The therapeutic groups were dispensed with three different plasmid concentrations of $1.7 \mathrm{nM}, 17 \mathrm{nM}$ and $70 \mathrm{nM}$ corresponding with doses of $0.027 \mu \mathrm{g} / \mathrm{g}, 0.27 \mu \mathrm{g} / \mathrm{g}$ and $1.1 \mu \mathrm{g} / \mathrm{g}$ ( $\mu \mathrm{g}$ plasmid/g mouse) respectively of pDhMUC1-ricin complexed with VOK-PEG-5TR1 in a volume of $100 \mu \mathrm{L}$ of $5 \%$ glucose. All groups were treated with five peritumoral injections arranged along the first 9 days. Tumor volume (3.2.13.) was measured almost every day and weight every 3 days and plotted as function of time (Figure 4E.8A).

Our results showed difference in the tumor growth evolution between the placebo and the treated groups from the second injection at day 2. This difference was maintained over time reaching very significant values at the end of the experiment (day 23) with $\mathrm{p}<0.001$. At day 23, placebo tumors reached an average volume of 176 $\mathrm{mm}^{3}$; by contrast the $70 \mathrm{nM}$ tumors were about $44 \mathrm{~mm}^{3}$ which means a reduction of about $75 \%$. Among the different treatments of $1.7 \mathrm{nM}, 17 \mathrm{nM}$ and $70 \mathrm{nM}$, it was possible to observe significant differences between the higher concentration of 70 $\mathrm{nM}$ and the rest of the treatment groups at day 8. However, no differences among the treatment groups were found for the rest of the experiment suggesting that the lower quantity of $1.7 \mathrm{nM}(0.027 \mathrm{\mu g} / \mathrm{g})$ was enough to observe a significant effect after 23 days of treatment. Having on mind the concentration of $0.28 \mathrm{nM}$ causing $50 \%$ of cellular death obtained in vitro, the cytotoxic effect at $1.7 \mathrm{nM}$ in vivo correlates with this data. In this in vivo assay, at least 6 times more of $0.28 \mathrm{nM}$ was administered in order to ensure the cytotoxicity and having on mind the change from a $2 \mathrm{D}$ culture to a 3D tumor where the cell accessibility would be harder than in 2D. Results showed a reduction of $66 \%$ of tumor volume growth for $1.7 \mathrm{nM}$ of pDhMUC1-ricin and $75 \%$ for $70 \mathrm{nM}$ of pDhMUC1-ricin in comparison with placebo. However, the administration of higher concentration of therapeutic plasmid apparently did not achieve a significant inhibition in tumor volume growth which suggested the treatment of $1.7 \mathrm{nM}(0.027$ 
$\mu \mathrm{g} / \mathrm{g}$ ) was enough to observe the expected effect. After necropsy, tumors were extracted and weighed; the result was plotted in Figure 4E.8B and $C$ and showed significant differences between placebo and treatment groups, being very significant for $70 \mathrm{nM}$ treatment $(1.1 \mu \mathrm{g} / \mathrm{g})$. These data confirmed the anti-tumor effect of the therapy and are consistent with the tumor volume results. Since the measurement of tumor dimensions in vivo uses to give more experimental error, these data after necropsy showed the actual dose dependent effect with a $62 \%$ of volume weight reduction in comparison with placebo. Additionally, mice did not show toxicity signs which were reflected in the normal weight gain during the whole experiment in all groups (Figure 4E.8D) and the lack of toxic symptoms in the viability control group.

A

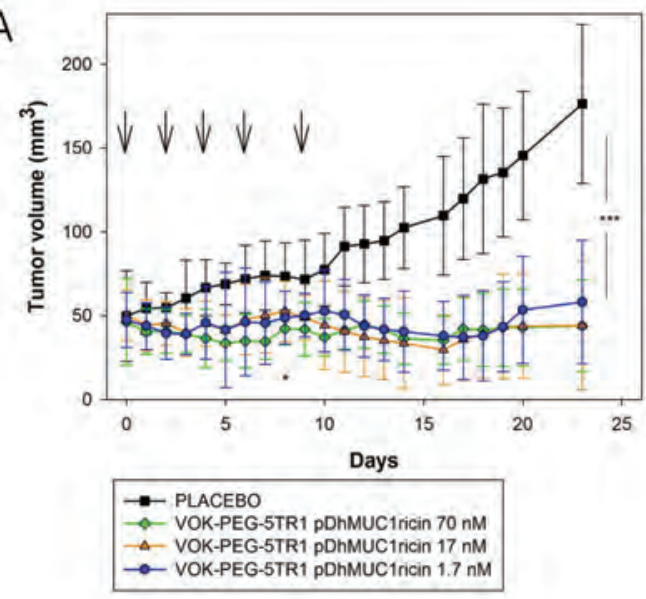

C

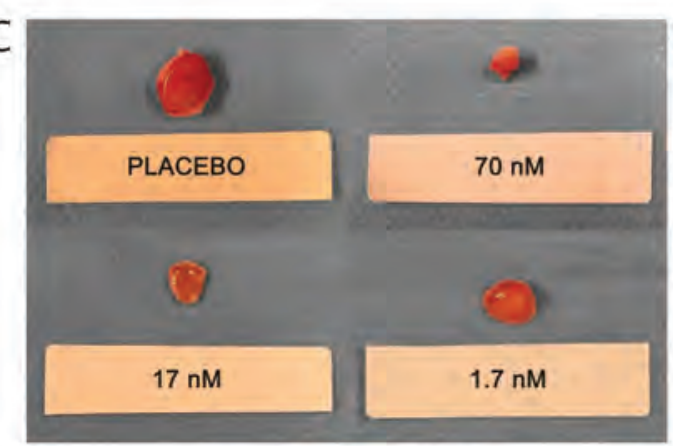

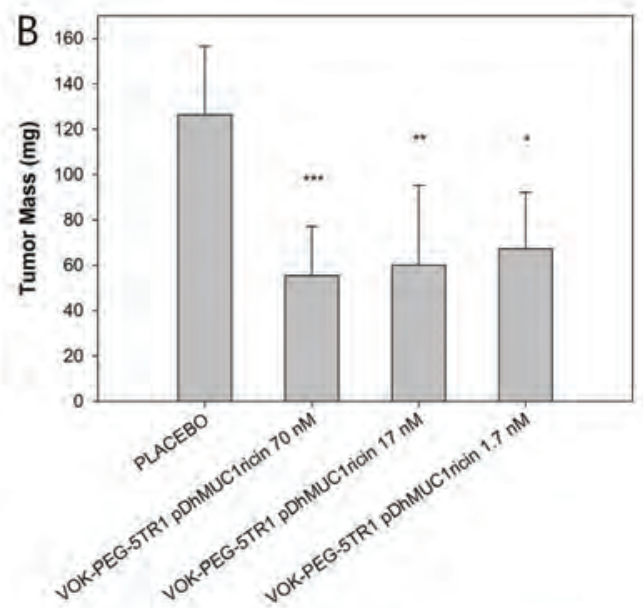

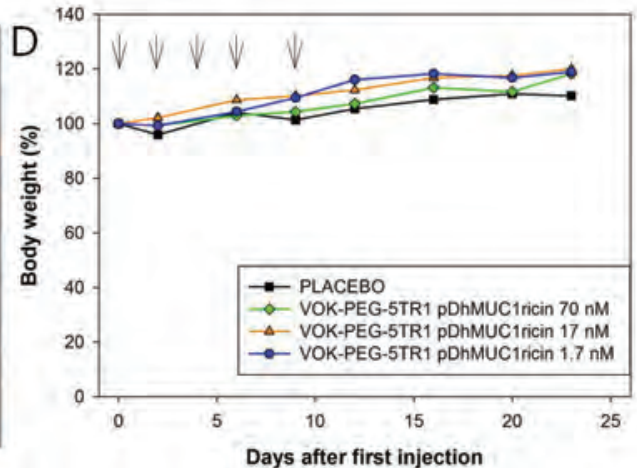

Figure 4E.8. Tumor volume reduction by VOK-PEG-5TR1-pDhMUC1-ricin complexes. Tumor volume evolution during 23 days after 5 injections with placebo, $1.7 \mathrm{nM}, 17 \mathrm{nM}$ and $70 \mathrm{nM}$ of therapeutic plasmid. Arrows indicate the injections (A). Tumor mass after necropsy on day 23 (B). Significant images of tumors after necropsy (C). Body weight evolution for the different treatments (D). Data represent the mean \pm S.D. of 8 mice/group. A statistical analysis showed significant differences $\left({ }^{*}: p<0.05,{ }^{* *}: p<0.01\right.$ and $\left.{ }^{* * *}: p<0.001\right)$. 
Hence, the reduction of up to $75 \%$ of tumor volume growth in comparison with placebo and lacking of toxic side effects showed this VOK-PEG-5TR1-pDhMUC1-ricin double lock system device support it as an efficient device for breast cancer gene therapy. Most of the existing studies with ricin have been performed in immunotherapy with the RTA or the holotoxin with the galactose binding sites blocked(292). To our knowledge, this is the first time that the whole ricin gene is transferred into target cells as part of suicide gene therapy in breast cancer. Indeed, the research exposed along this chapter serves as approach for novel investigations not only focused on the non-viral ELR designed herein but on the therapeutic plasmid containing ricin. 


\section{FINAL REMARKS}

Along this chapter the development of a complex system formed by the biopolymer VOK-PEG-5TR1 and pDhMUC1-ricin plasmid which constitutes a double safety lock device applied to breast cancer therapy has been achieved.

VOK-PEG-5TR1 biopolymer was able to form stable polyplexes in presence of pDNA with a suitable size $(190 \mathrm{~nm})$ and zeta potential $(+43 \mathrm{mV})$ for gene therapy purposes. VOK-PEG-5TR1 was compared with the previous developed system with adsorbed 5TR1 aptamers (Chapter 4D) in terms of transfection. Significant increase in transfection was obtained which allowed its selection for the next experiments.

The double safety lock using hMUC1 selective promoter was first demonstrated in terms of luciferase expression in one primary and three tumor cell lines and compared with the result obtained with the constitutive CMV promoter. Comparable results were obtained with both promoters being the luciferase expression for MCF-7 cells incubated with VOK-PEG-5TR1 significant higher than the value for MCF-7 cells incubated with polyplexes formed by VOK exclusively which showed the specificity provided for the 5TR1. The same level of MUC1 specificity was maintained with the hMUC1 promoter. Hence, luciferase was expressed preferentially in cells overexpressing MUC1 as result of the targeted therapy mediated by 5TR1 aptamer and hMUC1 promoter.

The application of VOK-PEG-5TR1-pDhMUC1-ricin as suicide gene therapy device was tested and targeted against MCF-7 cells. VOK-PEG-5TR1 device was able to deliver pDhMUC1-ricin inside the cells where ricin was further expressed. A concentration of $0.28 \mathrm{nM}$ of pDhMUC1-ricin was enough to cause $50 \%$ of cellular death. By contrast, a protective effect was observed for HFF-1 fibroblasts at all concentrations.

The translation of anti-tumor efficacy of the device from in vitro to in vivo was conducted. After 23 days of experiment and five injections of different doses of therapeutic DNA, a significant decrease in tumor volume growth was found up to 
$75 \%$ and $62 \%$ of volume weight at 23 day after first injection in comparison with placebo. No visual toxic side effect and loss of weigh was observed which support the friendly behavior of the device.

This work is a step forward in breast cancer research, and constitutes a direct proof of a complex device formed by ELRs linked to aptamers as suicide gene delivery vectors in in vivo models. Moreover, this is the first time that ricin gene is used as suicide agent (due to the high toxicity of ricin) for targeted breast cancer treatment and delivered by a novel non-viral vector. Future research will be focused in intravenous administration assays. Indeed, the incorporation of different tissue specificities by means of different aptamers, the increase of transfection efficiency by incorporation of functional motifs to ELR will be performed. Thus, other therapeutic plasmid formulations focused on decreasing the plasmid size or on incorporating other toxicities will be conducted as well. 


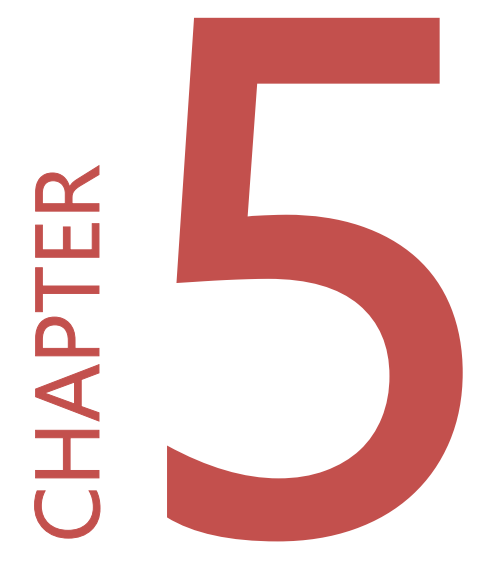




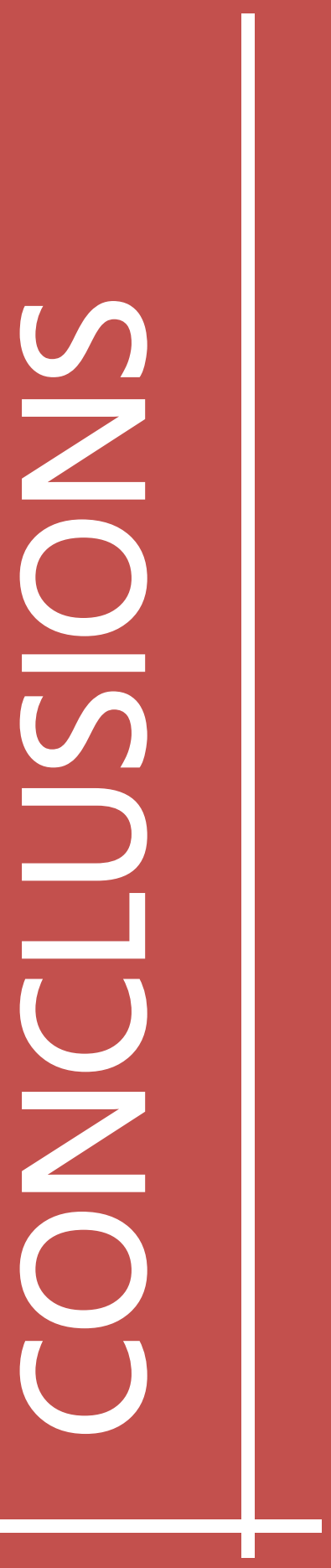


$\theta$

$-286$ 


\section{CONCLUSIONS}

\subsection{DESIGN, PRODUCTION AND CHARACTERIZATION OF ELRs FOR GENE DELIVERY PURPOSES}

With the objective of gene delivery as final application, the incorporation of histidines, arginines and lysines in the (VPGXG) and (XPGXG) sequences as guest residues was accomplished in a total controlled manner. Expression problems in E.coli with histidine enriched ELR were found but solved with the addition of the IK30 ELR block at N-terminal and creating the IKx30HPGx3. By contrast, lysine enriched polymers named as VOKx48, VOKx72 were properly expressed in E.coli. In addition, ELRs were biotechnologically modified with histidine enriched block (HPGx1) or CPP and fusogenic peptides in order to create novel polymers with acquired functionalities. Therefore a pool of ELRs named as VOKx48, VOKx72, IKx30HPGx3, VOKx48HPGx1, IK120CPP and LAELIK120CPP were produced, purified and characterized by physico-chemical techniques showing ELRs with acceptable levels of purity for their application in vitro and in vivo.

Chemical modifications allowed the binding of imidazole groups and PEG to the $\varepsilon$ amine group from lysines of IK120 and VOKx72 ELRs respectively through an amidation reaction and leading to the formation of IMID-IK120 and VOK-PEG ELRs. The IMID-IK120 showed improved buffering capacity at physiological pH range in comparison with IK120. In addition, the construction of the complex biopolymer VOK-PEG-5TR1 was achieved by means of click chemistry and confirmed through retardation assay, spectrophotometry, and flow citometry.

This wide pool of polymers obtained showed the high versatility in the design of ELR with a total control over the process and under specific quality standards for gene therapy purposes.

\subsection{ELR DIBLOCKS FOR DRUG DELIVERY}

The incorporation of the arginine CPP "Args" motif in the hydrophilic moiety of a block copolymer ELR did not seem to affect over the Tt of the polymer, being $36.6^{\circ} \mathrm{C}$ in PBS. Indeed $\operatorname{Arg}_{8} E_{L} R_{B C}$ showed the formation of nanoparticles of $64.4 \pm 3 \mathrm{~nm}$ of hydrodynamic diameter at this concentration in physiological conditions. 
The study about the kinetics of nanoparticles internalization showed that $\operatorname{Arg}_{8}-E L R_{B C}$ was internalized faster and in higher amount than the control ELR $R_{B C}$. Indeed the intracellular distribution of these nanoparticles in acidic vesicles exhibited cell incubation time dependence. These results showed the transport of labeled $\mathrm{Arg}_{8}$ $E L R_{B C}$ nanoparticles from endosomes to lysosomes with time leading to their accumulation at more acidic $\mathrm{pH}$. Indeed, they exhibit $\mathrm{Arg}_{8}-\mathrm{ELR}_{\mathrm{BC}}$ as better option than the control $E L R_{B C}$ for the incorporation of $\mathrm{pH}$ sensitive linker.

In addition, the evaluation of macropinocytosis as uptake pathway for $\operatorname{Arg}_{8}-E L R_{B C}$ was achieved. The degradation of heparan sulfate proteoglycan by heparinase caused a decreased of more than $70 \%$ in $\mathrm{Arg}_{8}-\mathrm{ELR}_{\mathrm{BC}}$ uptake. Indeed accumulation of particles was shown to decrease up to $50 \%$ in lysosomes and $16 \%$ in endosomes. However, siPAK1 treatment inhibited the expression of PAK1 leading a homogeneous decrease in intravesicular accumulation about $45-50 \%$ and likely uptake of $\mathrm{Arg}_{8}-\mathrm{ELR}_{\mathrm{BC}}$ showing its role as part of the internalization process.

The herein results supports the inhibitory effects of both heparinase and siPAK1 over the $\operatorname{Arg}_{8}-E_{B C}$ uptake and suggest the macropinocytosis as the main entrance route. Nevertheless, the lack of total inhibition points to the existence of other alternative entrance pathways than macropinocytosis such as clathrin or caveolin endocytosis.

\subsection{ELASTIN-LIKE RECOMBINAMERS WITH ACQUIRED} FUNCTIONALITIES FOR GENE-DELIVERY APPLICATIONS

ELRs with different functional domains such as penetratin CPP, LAEL fusogenic peptide or imidazole groups and named as IK120CPP, LAELIK120CPP and IMID-IK120 were evaluated as gene delivery systems.

The inherent biocompatibility of ELRs was corroborated with blood and cell viability assays showing high level of compatibility in contrast to the reference polymer PEI.

Indeed, all the ELRs were able to complex and protect the plasmid DNA from 40/1 $(\mathrm{w} / \mathrm{w})$ ratio and form polyplexes ranging 150 to $300 \mathrm{~nm}$ of diameter with a positive zeta potential up to $+23 \mathrm{mV}$ ratio.

In addition, the incorporation of the different functionalities by means of penetratin, LAEL peptides or protonable imidazole groups provided higher levels of 
internalization and gene expression in comparison with the polyplexes formed either by the non-modified ELR or plasmid. Specifically, LAELIK120CPP nanocomplexes were able to show the highest plasmid uptake, expression of p53 transgene and 5 times more luciferase expression than plasmid alone in C6 glioma cells. However, IK120CPP showed similar levels of plasmid uptake but lower p53 and luciferase expression than LAELIK120CPP. By contrast, IMID-IK120 was the less efficient among the ELRs with acquired functionalities.

Hence penetratin seems to play a role in the first step of the internalization process, namely the cellular entry, whereas LAEL and imidazole groups to a lesser extent governed endosomal escape of the plasmid via their fusogenic activity and proton sponge effect, respectively.

\subsection{BIOCOMPATIBLE ELR BASED POLYPLEXES COATED WITH MUC1 SPECIFIC APTAMERS AND TARGETED FOR BREAST CANCER GENE THERAPY}

Among a pool of ELRs tested, VOKx72 with the higher amount of amine groups showed the best transfection abilities. This ELR complexed and protected the plasmid DNA forming stable polyplexes with a particle size ranging 150 to $200 \mathrm{~nm}$ and a positive charge surface up to $+40 \mathrm{mV}$.

The incorporation of MUC1 aptamers on polyplexes already formed did not alter either the particle size or zeta potential in a significant manner at lower ratios of aptamer. Specifically, the N/P/Papt ratio of 50/1/4 with138 nm of diameter and +38 $\mathrm{mV}$ of zeta potential was the best in terms of transfection ability. In fact, a six times improvement in specificity provided by the 5TR1 aptamer targeted against the underglycosylated MUC1 glycoprotein in comparison with the nude polyplex was obtained.

In addition cell uptake experiments confirmed the transfection ability of this system. Thus polyplexes coated with 5TR1 were located in the cytoplasm or even in nucleus of MCF-7 breast cancer cells. Indeed, these polyplexes internalized through macropinocytosis, caveolin or clathrin-endocytosis being macropinocytosis the main 
route of entry. Macropinocytosis and clathrin-dependent pathways evidenced the interaction of 5TR1 aptamer with MUC1 on the MCF-7 cell surface.

The transfection of p53 gene showed the dependency relationship of MUC1 over the cell transfection. Indeed, it resulted in a protective effect of MUC1 over breast cancer cells suggesting the utilization of other toxic agents apart of p53 as the most effective strategy.

The transfection assays of PAP-S RIP type 1 RIP showed the ability of this system to transfect not only plasmids bearing luciferase but PAP-S gene into tumor cells specifically and express it. Transfection and expression of PAP-S gene led to cellular death of nearly $95 \%$ of breast cancer cells while it did not affect human cells lacking MUC1 expression.

The translation into an in vivo scenario showed a more than $75 \%$ of tumor growth inhibition with high significant differences in comparison with placebo.

\subsection{ELR BASED SUICIDE GENE THERAPY SYSTEM DIRECTED TO BREAST} CANCER USING RICIN GENE

The modified ELR named as VOK-PEG-5TR1 biopolymer was able to form stable polyplexes in presence of plasmid DNA with a suitable size of $190 \mathrm{~nm}$ of diameter and zeta potential of $+43 \mathrm{mV}$.

In terms of transfection, this system was able to transfect significant more efficiently plasmid DNA than the previous one with adsorbed aptamers. Indeed when it carried a plasmid containing the luciferase gene under the control of the hMUC1 promoter was able to maintain similar levels of specificity than using the constitutive CMV promoter. Therefore, luciferase was expressed preferentially in cells overexpressing MUC1 glycoprotein over others lacking MUC1 as result of the targeted therapy mediated by both 5TR1 aptamer and hMUC1 promoter.

Additionally, the suitability of the double lock safety device for suicide gene therapy was assessed by means of the RIP type 2 ricin. Thus, polyplexes formed with therapeutic plasmid containing ricin gene were targeted against MCF-7 and HFF1 
cells showing toxic effects for breast cancer cells and protective effects over fibroblasts. Indeed, $0.28 \mathrm{nM}$ of the therapeutic plasmid was enough to cause $50 \%$ of cellular death. Hence, cells were able to express the ricin and likely secrete it and generate the bystander effect affecting the neighbor cells leading to increment the damage potency.

The effectiveness of the system over a murine model showed a significant decrease in tumor volume growth up to $75 \%$ in comparison with placebo and a $62 \%$ in volume weight. In addition any visual toxic side effect and loss of weigh was observed which support the friendly nature of the ELR based system. 


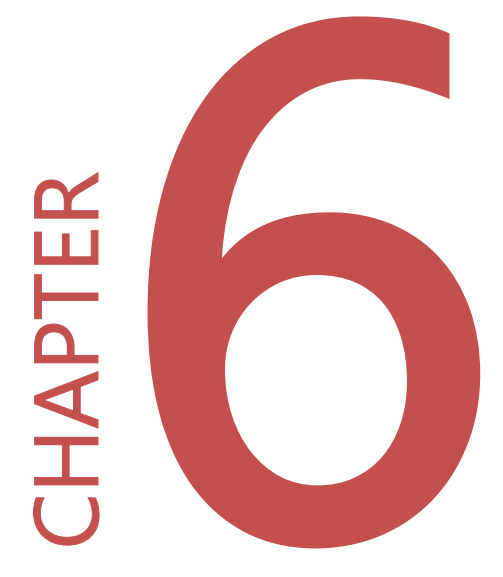




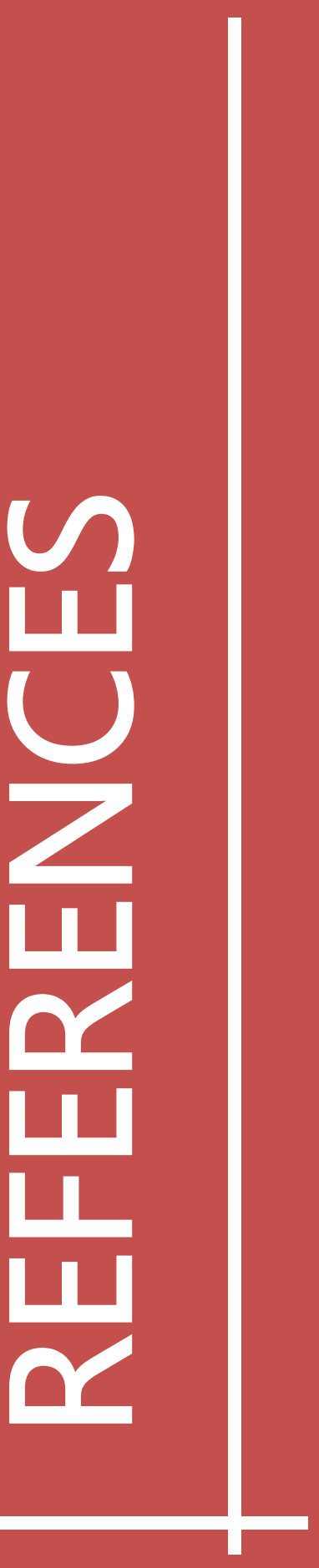


$\alpha$

$-294$ 


\section{REFERENCES}

1. Mithieux SM, Weiss AS. Elastin. Fibrous Proteins: Coiled-Coils, Collagen and Elastomers. 2005;70:437.

2. Bochicchio B, Pepe A, Tamburro AM. Investigating by CD the molecular mechanism of elasticity of elastomeric proteins. Chirality. 2008;20(9):985-94.

3. Costa RR, Martín L, Mano JF, Rodríguez-Cabello JC. Elastin-Like Macromolecules. Biomimetic Approaches for Biomaterials Development: Wiley-VCH Verlag GmbH \& Co. KGaA; 2012. p. 93-116.

4. Miao M, Bellingham CM, Stahl RJ, Sitarz EE, Lane CJ, Keeley FW. Sequence and Structure Determinants for the Self-aggregation of Recombinant Polypeptides Modeled after Human Elastin. Journal of Biological Chemistry. 2003;278(49):48553-62.

5. Rosenbloom J, Abrams WR, Mecham R. Extracellular-Matrix .4. The Elastic Fiber. Faseb Journal. 1993;7(13):1208-18.

6. Debelle L, Tamburro AM. Elastin: molecular description and function. Int J Biochem Cell Biol. 1999;31(2):261-72.

7. Cox BA, Starcher BC, Urry DW. Coacervation of Alpha-Elastin Results in Fiber Formation. Biochimica Et Biophysica Acta. 1973;317(1):209-13.

8. Urry DW, Trapane TL, Prasad KU. Phase-Structure Transitions of the Elastin Polypentapeptide Water-System within the Framework of Composition Temperature Studies. Biopolymers. 1985;24(12):2345-56.

9. Urry DW. Molecular Machines: How Motion and Other Functions of Living Organisms Can Result from Reversible Chemical Changes. Angewandte Chemie International Edition in English. 1993;32(6):819-41.

10. McPherson DT, Xu J, Urry DW. Product Purification by Reversible Phase Transition FollowingEscherichia coliExpression of Genes Encoding up to 251 Repeats of the Elastomeric Pentapeptide GVGVP. Protein Expression and Purification. 1996;7(1):51-7.

11. Rodríguez-Cabello JC, Martín L, Alonso M, Arias FJ, Testera AM. "Recombinamers" as advanced materials for the post-oil age. Polymer. 2009;50(22):5159-69.

12. Urry DW, Parker TM, Reid MC, Gowda DC. Biocompatibility of the Bioelastic Materials, Poly(GVGVP) and Its $\gamma$-Irradiation Cross-Linked Matrix: Summary of Generic Biological Test Results. Journal of Bioactive and Compatible Polymers. 1991;6(3):263-82.

13. Urry DW, editor. What Sustains Life? Consilient Mechanisms for Protein-Based Machines and Materials. New York: Springer-Verlag; 2006.

14. Shokouhi B, Coban C, Hasirci V, Aydin E, Dhanasingh A, Shi N, et al. The role of multiple toll-like receptor signalling cascades on interactions between biomedical polymers and dendritic cells. Biomaterials. 2010;31(22):5759-71.

15. Rodriguez-Cabello JC, Alonso M, Perez T, Herguedas MM. Differential scanning calorimetry study of the hydrophobic hydration of the elastin-based polypentapeptide, poly(VPGVG), from deficiency to excess of water. Biopolymers. 2000;54(4):282-8.

16. Rodriguez-Cabello JC. Smart Elastin-like Polymers. In: Hasirci N, Hasirci V, editors. Biomaterials: From Molecules to Engineered Tissue. Boston, MA: Springer US; 2004. p. 45-57.

17. Rodriguez-Cabello JC, Prieto S, Reguera J, Arias FJ, Ribeiro A. Biofunctional design of elastin-like polymers for advanced applications in nanobiotechnology. J Biomater Sci Polym Ed. 2007;18(3):269-86. 
18. Meyer DE, Chilkoti A. Quantification of the Effects of Chain Length and Concentration on the Thermal Behavior of Elastin-like Polypeptides. Biomacromolecules. 2004;5(3):846-51.

19. McDaniel JR, Radford DC, Chilkoti A. A unified model for de novo design of elastin-like polypeptides with tunable inverse transition temperatures. Biomacromolecules. 2013;14(8):2866-72.

20. Quiroz FG, Chilkoti A. Sequence heuristics to encode phase behaviour in intrinsically disordered protein polymers. Nat Mater. 2015;14(11):1164-71.

21. Cho Y, Zhang Y, Christensen T, Sagle LB, Chilkoti A, Cremer PS. Effects of Hofmeister anions on the phase transition temperature of elastin-like polypeptides. J Phys Chem B. 2008;112(44):13765-71.

22. Reguera J, Urry DW, Parker TM, McPherson DT, Rodriguez-Cabello JC. Effect of $\mathrm{NaCl}$ on the exothermic and endothermic components of the inverse temperature transition of a model elastin-like polymer. Biomacromolecules. 2007;8(2):354-8.

23. Mi L. Molecular cloning of protein-based polymers. Biomacromolecules. 2006;7(7):2099107.

24. Girotti A, Fernandez-Colino A, Lopez IM, Rodriguez-Cabello JC, Arias FJ. Elastin-like recombinamers: biosynthetic strategies and biotechnological applications. Biotechnol J. 2011;6(10):1174-86.

25. Kostal J, Mulchandani A, Chen W. Tunable Biopolymers for Heavy Metal Removal. Macromolecules. 2001;34(7):2257-61.

26. Lewis RV. Spider silk: ancient ideas for new biomaterials. Chem Rev. 2006;106(9):376274.

27. McMillan RA, Lee TAT, Conticello VP. Rapid Assembly of Synthetic Genes Encoding Protein Polymers. Macromolecules. 1999;32(11):3643-8.

28. Rodriguez-Cabello JC, Girotti A, Ribeiro A, Arias FJ. Synthesis of genetically engineered protein polymers (recombinamers) as an example of advanced self-assembled smart materials. Methods Mol Biol. 2012;811:17-38.

29. Kowalczyk T, Hnatuszko-Konka K, Gerszberg A, Kononowicz AK. Elastin-like polypeptides as a promising family of genetically-engineered protein based polymers. World Journal of Microbiology \& Biotechnology. 2014;30(8):2141-52.

30. Meyer DE, Chilkoti A. Genetically encoded synthesis of protein-based polymers with precisely specified molecular weight and sequence by recursive directional ligation: examples from the elastin-like polypeptide system. Biomacromolecules. 2002;3(2):35767.

31. Goeden-Wood NL, Conticello VP, Muller SJ, Keasling JD. Improved assembly of multimeric genes for the biosynthetic production of protein polymers. Biomacromolecules. 2002;3(4):874-9.

32. Scheller J, Henggeler D, Viviani A, Conrad U. Purification of spider silk-elastin from transgenic plants and application for human chondrocyte proliferation. Transgenic Res. 2004;13(1):51-7.

33. Scheller J, Leps M, Conrad U. Forcing single-chain variable fragment production in tobacco seeds by fusion to elastin-like polypeptides. Plant Biotechnology Journal. 2006;4(2):243-9.

34. Lin M, Rose-John S, Grötzinger J, Conrad U, Scheller J. Functional expression of a biologically active fragment of soluble gp130 as an ELP-fusion protein in transgenic 
plants: purification via inverse transition cycling. Biochemical Journal. 2006;398(3):57783.

35. Daniell H, Streatfield SJ, Wycoff K. Medical molecular farming: production of antibodies, biopharmaceuticals and edible vaccines in plants. Trends in Plant Science.6(5):219-26.

36. Sallach RE, Conticello VP, Chaikof EL. Expression of a Recombinant Elastin-Like Protein in Pichia pastoris. Biotechnology progress. 2009;25(6):1810-8.

37. Novagen. pET system manual. Novagen (10th Ed). 2003.

38. Lewis RV, Hinman M, Kothakota S, Fournier MJ. Expression and purification of a spider silk protein: a new strategy for producing repetitive proteins. Protein Expr Purif. 1996;7(4):400-6.

39. Ribeiro A, Arias FJ, Reguera J, Alonso M, Rodriguez-Cabello JC. Influence of the aminoacid sequence on the inverse temperature transition of elastin-like polymers. Biophys J. 2009;97(1):312-20.

40. Costa RR, Custódio CA, Testera AM, Arias FJ, Rodríguez-Cabello JC, Alves NM, et al. Stimuli-Responsive Thin Coatings Using Elastin-Like Polymers for Biomedical Applications. Advanced Functional Materials. 2009;19(20):3210-8.

41. Martínez-Osorio $H$, Juárez-Campo $M$, Diebold $Y$, Girotti $A$, Alonso $M$, Arias FJ, et al. Genetically Engineered Elastin-Like Polymer as a Substratum to Culture Cells from the Ocular Surface. Current Eye Research. 2009;34(1):48-56.

42. Pierna M, Santos M, Arias FJ, Alonso M, Rodriguez-Cabello JC. Efficient cell and cellsheet harvesting based on smart surfaces coated with a multifunctional and selforganizing elastin-like recombinamer. Biomacromolecules. 2013;14(6):1893-903.

43. González de Torre I, Santos M, Quintanilla L, Testera A, Alonso M, Rodríguez Cabello JC. Elastin-like recombinamer catalyst-free click gels: Characterization of poroelastic and intrinsic viscoelastic properties. Acta Biomaterialia. 2014;10(6):2495-505.

44. Fernandez-Colino A, Arias FJ, Alonso M, Rodriguez-Cabello JC. Amphiphilic Elastin-Like Block Co-Recombinamers Containing Leucine Zippers: Cooperative Interplay between Both Domains Results in Injectable and Stable Hydrogels. Biomacromolecules. 2015;16(10):3389-98.

45. de Torre IG, Wolf F, Santos M, Rongen L, Alonso $M$, Jockenhoevel $S$, et al. Elastin-like recombinamer-covered stents: Towards a fully biocompatible and non-thrombogenic device for cardiovascular diseases. Acta Biomater. 2015;12:146-55.

46. Fernandez-Colino A, Arias FJ, Alonso M, Rodriguez-Cabello JC. Self-organized ECMmimetic model based on an amphiphilic multiblock silk-elastin-like corecombinamer with a concomitant dual physical gelation process. Biomacromolecules. 2014;15(10):3781-93.

47. Garcia-Arevalo C, Pierna M, Girotti A, Arias FJ, Rodriguez-Cabello JC. A comparative study of cell behavior on different energetic and bioactive polymeric surfaces made from elastin-like recombinamers. Soft Matter. 2012;8(11):3239-49.

48. Nivison-Smith L, Rnjak J, Weiss AS. Synthetic human elastin microfibers: Stable crosslinked tropoelastin and cell interactive constructs for tissue engineering applications. Acta Biomaterialia. 2010;6(2):354-9.

49. Pinedo-Martin G, Castro E, Martin L, Alonso M, Rodriguez-Cabello JC. Effect of surfactants on the self-assembly of a model elastin-like block corecombinamer: from micelles to an aqueous two-phase system. Langmuir. 2014;30(12):3432-40. 
50. Martín L, Castro E, Ribeiro A, Alonso M, Rodríguez-Cabello JC. Temperature-Triggered Self-Assembly of Elastin-Like Block Co-Recombinamers:The Controlled Formation of Micelles and Vesicles in an Aqueous Medium. Biomacromolecules. 2012;13(2):293-8.

51. Macewan SR, Chilkoti A. Digital switching of local arginine density in a genetically encoded self-assembled polypeptide nanoparticle controls cellular uptake. Nano Lett. 2012;12(6):3322-8.

52. Andrew MacKay J, Chen M, McDaniel JR, Liu W, Simnick AJ, Chilkoti A. Self-assembling chimeric polypeptide-doxorubicin conjugate nanoparticles that abolish tumours after a single injection. Nat Mater. 2009;8(12):993-9.

53. García-Arévalo C, Bermejo-Martín JF, Rico L, Iglesias V, Martín L, Rodríguez-Cabello JC, et al. Immunomodulatory Nanoparticles from Elastin-Like Recombinamers: SingleMolecules for Tuberculosis Vaccine Development. Molecular pharmaceutics. 2013;10(2):586-97.

54. Chen $\mathrm{TH}$, Bae $\mathrm{Y}$, Furgeson DY. Intelligent biosynthetic nanobiomaterials (IBNs) for hyperthermic gene delivery. Pharm Res. 2008;25(3):683-91.

55. Martín L, Alonso M, Girotti A, Arias FJ, Rodríguez-Cabello JC. Synthesis and Characterization of Macroporous Thermosensitive Hydrogels from Recombinant ElastinLike Polymers. Biomacromolecules. 2009;10(11):3015-22.

56. Sánchez-Ferrero A, Mata Á, Mateos-Timoneda MA, Rodríguez-Cabello JC, Alonso M, Planell J, et al. Development of tailored and self-mineralizing citric acid-crosslinked hydrogels for in situ bone regeneration. Biomaterials. 2015;68:42-53.

57. Singh AK, Srivastava GK, Martín L, Alonso M, Pastor JC. Bioactive substrates for human retinal pigment epithelial cell growth from elastin-like recombinamers. Journal of Biomedical Materials Research Part A. 2014;102(3):639-46.

58. Bidwell GL, Perkins E, Raucher D. A thermally targeted c-Myc inhibitory polypeptide inhibits breast tumor growth. Cancer letters. 2012;319(2):136-43.

59. Bidwell GL, Perkins E, Hughes J, Khan M, James JR, Raucher D. Thermally Targeted Delivery of a c-Myc Inhibitory Polypeptide Inhibits Tumor Progression and Extends Survival in a Rat Glioma Model. PLoS One. 2013;8(1):e55104.

60. Bidwell GL, Fokt I, Priebe W, Raucher D. Development of elastin-like polypeptide for thermally targeted delivery of doxorubicin. Biochemical Pharmacology. 2007;73(5):62031.

61. Moktan S, Ryppa C, Kratz F, Raucher D. A thermally responsive biopolymer conjugated to an acid-sensitive derivative of paclitaxel stabilizes microtubules, arrests cell cycle, and induces apoptosis. Investigational New Drugs. [journal article]. 2010;30(1):236-48.

62. Amruthwar SS, Janorkar AV. Preparation and characterization of elastin-like polypeptide scaffolds for local delivery of antibiotics and proteins. J Mater Sci Mater Med. 2012;23(12):2903-12.

63. Arias FJ, Mercedes S, Arturo I-F, M.Jesús P, Sofía S. Elastin-like recombinamers as smart drug delivery systems. Current Drug Targets. 2016;17:1-.

64. Rincon AC, Molina-Martinez IT, de Las Heras B, Alonso M, Bailez C, Rodriguez-Cabello $J C$, et al. Biocompatibility of elastin-like polymer poly(VPAVG) microparticles: in vitro and in vivo studies. J Biomed Mater Res A. 2006;78(2):343-51.

65. Sallach RE, Cui W, Balderrama F, Martinez AW, Wen J, Haller CA, et al. Long-term biostability of self-assembling protein polymers in the absence of covalent crosslinking. Biomaterials. 2010;31(4):779-91. 
66. Li L, Charati MB, Kiick KL. Elastomeric polypeptide-based biomaterials. Journal of polymer science Part A, Polymer chemistry. 2010;1(8):1160-70.

67. Dreher MR, Simnick AJ, Fischer K, Smith RJ, Patel A, Schmidt M, et al. Temperature Triggered Self-Assembly of Polypeptides into Multivalent Spherical Micelles. Journal of the American Chemical Society. 2008;130(2):687-94.

68. Martin L, Castro E, Ribeiro A, Alonso M, Rodriguez-Cabello JC. Temperature-triggered self-assembly of elastin-like block co-recombinamers:the controlled formation of micelles and vesicles in an aqueous medium. Biomacromolecules. 2012;13(2):293-8.

69. Shi P, Aluri S, Lin Y-A, Shah M, Edman M, Dhandhukia J, et al. Elastin-based protein polymer nanoparticles carrying drug at both corona and core suppress tumor growth in vivo. Journal of Controlled Release. 2013;171(3):330-8.

70. Mastria EM, Chen M, McDaniel JR, Li X, Hyun J, Dewhirst MW, et al. Doxorubicinconjugated polypeptide nanoparticles inhibit metastasis in two murine models of carcinoma. Journal of Controlled Release. 2015;208:52-8.

71. Bhattacharyya J, Bellucci JJ, Weitzhandler I, McDaniel JR, Spasojevic I, Li X, et al. A paclitaxel-loaded recombinant polypeptide nanoparticle outperforms Abraxane in multiple murine cancer models. Nat Commun. 2015;6:7939.

72. Nawroth JF, McDaniel JR, Chilkoti A, Jordan R, Luxenhofer R. Maleimide-Functionalized Poly(2-Oxazoline)s and Their Conjugation to Elastin-Like Polypeptides. Macromolecular Bioscience. 2016:n/a-n/a.

73. Glover DJ, Lipps HJ, Jans DA. Towards safe, non-viral therapeutic gene expression in humans. Nat Rev Genet. 2005;6(4):299-310.

74. Kay MA. State-of-the-art gene-based therapies: the road ahead. Nat Rev Genet. 2011;12(5):316-28.

75. Van Craenenbroeck K, Vanhoenacker P, Haegeman G. Episomal vectors for gene expression in mammalian cells. Eur J Biochem. 2000;267(18):5665-78.

76. Ramamoorth M, Narvekar A. Non Viral Vectors in Gene Therapy- An Overview. Journal of Clinical and Diagnostic Research : JCDR. 2015;9(1):GE01-GE6.

77. Yin H, Kanasty RL, Eltoukhy AA, Vegas AJ, Dorkin JR, Anderson DG. Non-viral vectors for gene-based therapy. Nat Rev Genet. 2014;15(8):541-55.

78. Medicine TjoG. Gene therapy clinical trials worldwide. Wiley; 2015.

79. Baum C, Kustikova O, Modlich U, Li Z, Fehse B. Mutagenesis and oncogenesis by chromosomal insertion of gene transfer vectors. Hum Gene Ther. 2006;17(3):253-63.

80. Bessis N, GarciaCozar FJ, Boissier MC. Immune responses to gene therapy vectors: influence on vector function and effector mechanisms. Gene Ther. 2004;11 Suppl 1:S107.

81. Waehler R, Russell SJ, Curiel DT. Engineering targeted viral vectors for gene therapy. Nat Rev Genet. 2007;8(8):573-87.

82. Thomas CE, Ehrhardt A, Kay MA. Progress and problems with the use of viral vectors for gene therapy. Nat Rev Genet. 2003;4(5):346-58.

83. Bouard D, Alazard-Dany D, Cosset FL. Viral vectors: from virology to transgene expression. Br J Pharmacol. 2009;157(2):153-65.

84. Lundstrom K, Boulikas T. Viral and non-viral vectors in gene therapy: technology development and clinical trials. Technol Cancer Res Treat. 2003;2(5):471-86. 
85. Hosel M, Broxtermann M, Janicki H, Esser K, Arzberger S, Hartmann P, et al. Toll-like receptor 2-mediated innate immune response in human nonparenchymal liver cells toward adeno-associated viral vectors. Hepatology. 2012;55(1):287-97.

86. Mays LE, Vandenberghe LH, Xiao R, Bell $P, N a m$ HJ, Agbandje-McKenna $M$, et al. Adeno-Associated Virus Capsid Structure Drives CD4-Dependent CD8(+) T Cell Response to Vector Encoded Proteins. Journal of Immunology. 2009;182(10):6051-60.

87. Anderson WF. Human gene therapy. Nature. 1998;392(6679):25-30.

88. Midoux $P$, Pichon $C$, Yaouanc J-J, Jaffrès $P-A$. Chemical vectors for gene delivery: a current review on polymers, peptides and lipids containing histidine or imidazole as nucleic acids carriers. British Journal of Pharmacology. 2009;157(2):166-78.

89. Felgner PL, Gadek TR, Holm M, Roman R, Chan HW, Wenz M, et al. Lipofection: a highly efficient, lipid-mediated DNA-transfection procedure. Proc Natl Acad Sci U S A. 1987;84(21):7413-7.

90. Mintzer MA, Simanek EE. Nonviral vectors for gene delivery. Chem Rev. 2009;109(2):259-302.

91. Wasungu L, Hoekstra D. Cationic lipids, lipoplexes and intracellular delivery of genes. Journal of Controlled Release. 2006;116(2):255-64.

92. Szebeni J, Baranyi L, Savay S, Milosevits J, Bunger R, Laverman P, et al. Role of complement activation in hypersensitivity reactions to doxil and hynic PEG liposomes: experimental and clinical studies. J Liposome Res. 2002;12(1-2):165-72.

93. Van den Hoven JM, Nemes R, Metselaar JM, Nuijen B, Beijnen JH, Storm G, et al. Complement activation by PEGylated liposomes containing prednisolone. Eur J Pharm Sci. 2013;49(2):265-71.

94. Knudsen KB, Northeved H, Kumar Ek P, Permin A, Gjetting $T$, Andresen $T L$, et al. In vivo toxicity of cationic micelles and liposomes. Nanomedicine: Nanotechnology, Biology and Medicine. 2015;11(2):467-77.

95. Whitehead KA, Langer R, Anderson DG. Knocking down barriers: advances in siRNA delivery. Nat Rev Drug Discov. 2009;8(2):129-38.

96. Putnam D. Polymers for gene delivery across length scales. Nat Mater. 2006;5(6):439-51.

97. Morille M, Passirani C, Vonarbourg A, Clavreul A, Benoit JP. Progress in developing cationic vectors for non-viral systemic gene therapy against cancer. Biomaterials. 2008;29(24-25):3477-96.

98. Choi YH, Liu F, Kim J-S, Choi YK, Jong Sang P, Kim SW. Polyethylene glycol-grafted polyI-lysine as polymeric gene carrier. Journal of Controlled Release. 1998;54(1):39-48.

99. Liu G, Molas M, Grossmann GA, Pasumarthy M, Perales JC, Cooper MJ, et al. Biological Properties of Poly-I-lysine-DNA Complexes Generated by Cooperative Binding of the Polycation. Journal of Biological Chemistry. 2001;276(37):34379-87.

100. Park TG, Jeong JH, Kim SW. Current status of polymeric gene delivery systems. Adv Drug Deliv Rev. 2006;58(4):467-86.

101. Lungwitz U, Breunig M, Blunk T, Gopferich A. Polyethylenimine-based non-viral gene delivery systems. Eur J Pharm Biopharm. 2005;60(2):247-66.

102. Sonawane ND, Szoka FC, Verkman AS. Chloride Accumulation and Swelling in Endosomes Enhances DNA Transfer by Polyamine-DNA Polyplexes. Journal of Biological Chemistry. 2003;278(45):44826-31.

103. Demeneix B, Behr JP. Polyethylenimine (PEI). Advances in Genetics: Academic Press; 2005. p. 215-30. 
104. Akinc A, Thomas M, Klibanov AM, Langer R. Exploring polyethylenimine-mediated DNA transfection and the proton sponge hypothesis. The Journal of Gene Medicine. 2005;7(5):657-63.

105. Deng $R$, Yue $Y$, Jin $F$, Chen $Y$, Kung HF, Lin MC, et al. Revisit the complexation of PEl and DNA - how to make low cytotoxic and highly efficient PEl gene transfection non-viral vectors with a controllable chain length and structure? J Control Release. 2009;140(1):40-6.

106. Hunter AC. Molecular hurdles in polyfectin design and mechanistic background to polycation induced cytotoxicity. Advanced Drug Delivery Reviews. 2006;58(14):1523-31.

107. Fischer D, Bieber T, Li Y, Elsässer H-P, Kissel T. A Novel Non-Viral Vector for DNA Delivery Based on Low Molecular Weight, Branched Polyethylenimine: Effect of Molecular Weight on Transfection Efficiency and Cytotoxicity. Pharmaceutical Research. 1999;16(8):1273-9.

108. Moghimi SM, Symonds P, Murray JC, Hunter AC, Debska G, Szewczyk A. A two-stage poly(ethylenimine)-mediated cytotoxicity: implications for gene transfer/therapy. Mol Ther. 2005;11(6):990-5.

109. Kievit FM, Veiseh O, Bhattarai N, Fang C, Gunn JW, Lee D, et al. PEI-PEG-ChitosanCopolymer-Coated Iron Oxide Nanoparticles for Safe Gene Delivery: Synthesis, Complexation, and Transfection. Advanced Functional Materials. 2009;19(14):2244-51.

110. Sajeesh S, Choe JY, Lee TY, Lee D-k. Guanidine modified polyethyleneimine-gpolyethylene glycol nanocarriers for long interfering RNA (liRNA) based advanced anticancer therapy. Journal of Materials Chemistry B. 2015;3(2):207-16.

111. Wong K, Sun G, Zhang, Dai H, Liu Y, He, et al. PEl-g-chitosan, a Novel Gene Delivery System with Transfection Efficiency Comparable to Polyethylenimine in Vitro and after Liver Administration in Vivo. Bioconjugate Chemistry. 2006;17(1):152-8.

112. Lam WLaJKW, editor. Endosomal Escape Pathways for Non-Viral Nucleic Acid Delivery Systems, Molecular Regulation of Endocytosis.2012.

113. Torchilin VP, Levchenko TS. TAT-liposomes: a novel intracellular drug carrier. Curr Protein Pept Sci. 2003;4(2):133-40.

114. Rudolph C, Plank C, Lausier J, Schillinger U, Muller RH, Rosenecker J. Oligomers of the arginine-rich motif of the HIV-1 TAT protein are capable of transferring plasmid DNA into cells. J Biol Chem. 2003;278(13):11411-8.

115. Huang R, Yang W, Jiang C, Pei Y. Gene delivery into brain capillary endothelial cells using Antp-modified DNA-loaded nanoparticles. Chem Pharm Bull (Tokyo). 2006;54(9):1254-8.

116. El-Andaloussi S, Johansson H, Magnusdottir A, Jarver P, Lundberg P, Langel U. TP10, a delivery vector for decoy oligonucleotides targeting the Myc protein. J Control Release. 2005;110(1):189-201.

117. Rejman J, Oberle V, Zuhorn IS, Hoekstra D. Size-dependent internalization of particles via the pathways of clathrin- and caveolae-mediated endocytosis. Biochem J. 2004;377(Pt 1):159-69.

118. Blessing T, Remy JS, Behr JP. Monomolecular collapse of plasmid DNA into stable viruslike particles. Proc Natl Acad Sci U S A. 1998;95(4):1427-31.

119. Wolfert MA, Seymour LW. Atomic force microscopic analysis of the influence of the molecular weight of poly $(\mathrm{L})$ lysine on the size of polyelectrolyte complexes formed with DNA. Gene Ther. 1996;3(3):269-73. 
120. Tang MX, Szoka FC. The influence of polymer structure on the interactions of cationic polymers with DNA and morphology of the resulting complexes. Gene Ther. 1997;4(8):823-32.

121. Alexis F, Pridgen E, Molnar LK, Farokhzad OC. Factors Affecting the Clearance and Biodistribution of Polymeric Nanoparticles. Molecular Pharmaceutics. 2008;5(4):505-15.

122. Müller RH. Zetapotential und Partikelladung-KurzeTheorie, praktische MeBdurchfuhrung, Dateninterpretation. Stuttgart1996.

123. Blau S, Jubeh TT, Haupt SM, Rubinstein A. Drug targeting by surface cationization. Crit Rev Ther Drug Carrier Syst. 2000;17(5):425-65.

124. Harush-Frenkel O, Debotton N, Benita S, Altschuler Y. Targeting of nanoparticles to the clathrin-mediated endocytic pathway. Biochemical and Biophysical Research Communications. 2007;353(1):26-32.

125. Harush-Frenkel O, Rozentur E, Benita S, Altschuler Y. Surface Charge of Nanoparticles Determines Their Endocytic and Transcytotic Pathway in Polarized MDCK Cells. Biomacromolecules. 2008;9(2):435-43.

126. Zhang LW, Monteiro-Riviere NA. Mechanisms of quantum dot nanoparticle cellular uptake. Toxicol Sci. 2009;110(1):138-55.

127. Sahay G, Alakhova DY, Kabanov AV. Endocytosis of nanomedicines. J Control Release. 2010;145(3):182-95.

128. Zhao Y, Sun X, Zhang G, Trewyn BG, Slowing II, Lin VSY. Interaction of Mesoporous Silica Nanoparticles with Human Red Blood Cell Membranes: Size and Surface Effects. ACS Nano. 2011;5(2):1366-75.

129. Huang X, Li L, Liu T, Hao N, Liu H, Chen D, et al. The Shape Effect of Mesoporous Silica Nanoparticles on Biodistribution, Clearance, and Biocompatibility in Vivo. ACS Nano. 2011;5(7):5390-9.

130. Lin X, Zhao N, Yan P, Hu H, Xu F-J. The shape and size effects of polycation functionalized silica nanoparticles on gene transfection. Acta Biomaterialia. 2015;11:381-92.

131. Wang J, Byrne JD, Napier ME, DeSimone JM. More effective nanomedicines through particle design. Small. 2011;7(14):1919-31.

132. Gratton SE, Napier ME, Ropp PA, Tian S, DeSimone JM. Microfabricated particles for engineered drug therapies: elucidation into the mechanisms of cellular internalization of PRINT particles. Pharm Res. 2008;25(12):2845-52.

133. Xu J, Wong DH, Byrne JD, Chen K, Bowerman C, DeSimone JM. Future of the particle replication in nonwetting templates (PRINT) technology. Angew Chem Int Ed Engl. 2013;52(26):6580-9.

134. Godbey WT, Wu KK, Mikos AG. Size matters: Molecular weight affects the efficiency of poly(ethylenimine) as a gene delivery vehicle. Journal of Biomedical Materials Research. 1999;45(3):268-75.

135. Fischer D, Li Y, Ahlemeyer B, Krieglstein J, Kissel T. In vitro cytotoxicity testing of polycations: influence of polymer structure on cell viability and hemolysis. Biomaterials. 2003;24(7):1121-31.

136. Kunath K, von Harpe A, Fischer D, Petersen H, Bickel U, Voigt K, et al. Low-molecularweight polyethylenimine as a non-viral vector for DNA delivery: comparison of physicochemical properties, transfection efficiency and in vivo distribution with highmolecular-weight polyethylenimine. Journal of Controlled Release. 2003;89(1):113-25. 
137. Zhang $C$, Yadava $P$, Hughes J. Polyethylenimine strategies for plasmid delivery to brainderived cells. Methods. 2004;33(2):144-50.

138. Goyal R, Tripathi SK, Tyagi S, Sharma A, Ram KR, Chowdhuri DK, et al. Linear PEl nanoparticles: efficient pDNA/siRNA carriers in vitro and in vivo. Nanomedicine. 2012;8(2):167-75.

139. Mao HQ, Roy $K$, Troung-Le VL, Janes $K A$, Lin $K Y$, Wang $Y$, et al. Chitosan-DNA nanoparticles as gene carriers: synthesis, characterization and transfection efficiency. J Control Release. 2001;70(3):399-421.

140. Kircheis R, Blessing T, Brunner S, Wightman L, Wagner E. Tumor targeting with surfaceshielded ligand--polycation DNA complexes. J Control Release. 2001;72(1-3):165-70.

141. Kircheis R, Ostermann E, Wolschek MF, Lichtenberger C, Magin-Lachmann C, Wightman $\mathrm{L}$, et al. Tumor-targeted gene delivery of tumor necrosis factor-alpha induces tumor necrosis and tumor regression without systemic toxicity. Cancer Gene Ther. 2002;9(8):673-80.

142. Bazile D, Prud'homme C, Bassoullet MT, Marlard M, Spenlehauer G, Veillard M. Stealth Me.PEG-PLA nanoparticles avoid uptake by the mononuclear phagocytes system. J Pharm Sci. 1995;84(4):493-8.

143. Gref R, Luck M, Quellec P, Marchand M, Dellacherie E, Harnisch S, et al. 'Stealth' coronacore nanoparticles surface modified by polyethylene glycol (PEG): influences of the corona (PEG chain length and surface density) and of the core composition on phagocytic uptake and plasma protein adsorption. Colloids Surf B Biointerfaces. 2000;18(3-4):301-13.

144. Shi B, Fang C, Pei Y. Stealth PEG-PHDCA niosomes: effects of chain length of PEG and particle size on niosomes surface properties, in vitro drug release, phagocytic uptake, in vivo pharmacokinetics and antitumor activity. J Pharm Sci. 2006;95(9):1873-87.

145. Maruyama K. Intracellular targeting delivery of liposomal drugs to solid tumors based on EPR effects. Adv Drug Deliv Rev. 2011;63(3):161-9.

146. Gill DR, Pringle IA, Hyde SC. Progress and prospects: the design and production of plasmid vectors. Gene Ther. 2009;16(2):165-71.

147. Wooddell $\mathrm{Cl}$, Reppen $\mathrm{T}$, Wolff $\mathrm{JA}$, Herweijer $\mathrm{H}$. Sustained liver-specific transgene expression from the albumin promoter in mice following hydrodynamic plasmid DNA delivery. J Gene Med. 2008;10(5):551-63.

148. Chen L, Chen D, Manome Y, Dong Y, Fine HA, Kufe DW. Breast cancer selective gene expression and therapy mediated by recombinant adenoviruses containing the DF3/MUC1 promoter. Journal of Clinical Investigation. 1995;96(6):2775-82.

149. Tai Y-T, Strobel T, Kufe D, Cannistra SA. In Vivo Cytotoxicity of Ovarian Cancer Cells through Tumor-selective Expression of the BAX Gene. Cancer Research. 1999;59(9):2121-6.

150. Kawabata K, Takakura Y, Hashida M. The fate of plasmid DNA after intravenous injection in mice: involvement of scavenger receptors in its hepatic uptake. Pharm Res. 1995;12(6):825-30.

151. Mumper RJ, Duguid JG, Anwer K, Barron MK, Nitta H, Rolland AP. Polyvinyl derivatives as novel interactive polymers for controlled gene delivery to muscle. Pharm Res. 1996;13(5):701-9.

152. Colella P, Cotugno G, Auricchio A. Ocular gene therapy: current progress and future prospects. Trends Mol Med. 2009;15(1):23-31. 
153. Griesenbach U, Geddes DM, Alton EW. Gene therapy for cystic fibrosis: an example for lung gene therapy. Gene Ther. 2004;11 Suppl 1:S43-50.

154. Harris JM, Chess RB. Effect of pegylation on pharmaceuticals. Nat Rev Drug Discov. 2003;2(3):214-21.

155. Patil Y, Toti U, Khdair A, Ma L, Panyam J. Single-Step Surface Functionalization of Polymeric Nanoparticles for Targeted Drug Delivery. Biomaterials. 2009;30(5):859-66.

156. Banerjee SS, Aher N, Patil R, Khandare J. Poly(ethylene glycol)-Prodrug Conjugates: Concept, Design, and Applications. Journal of Drug Delivery. 2012;2012:17.

157. Jokerst JV, Lobovkina T, Zare RN, Gambhir SS. Nanoparticle PEGylation for imaging and therapy. Nanomedicine (Lond). 2011;6(4):715-28.

158. Longmire M, Choyke PL, Kobayashi H. Clearance Properties of Nano-sized Particles and Molecules as Imaging Agents: Considerations and Caveats. Nanomedicine (London, England). 2008;3(5):703-17.

159. Blanco $E$, Shen $H$, Ferrari M. Principles of nanoparticle design for overcoming biological barriers to drug delivery. Nat Biotech. [Research]. 2015;33(9):941-51.

160. Yuan F, Dellian M, Fukumura D, Leunig M, Berk DA, Torchilin VP, et al. Vascular Permeability in a Human Tumor Xenograft: Molecular Size Dependence and Cutoff Size. Cancer Research. 1995;55(17):3752-6.

161. Hess GT, Humphries WH, Fay NC, Payne CK. Cellular Binding, Motion, and Internalization of Synthetic Gene Delivery Polymers. Biochimica Et Biophysica Acta. 2007;1773(10):1583-8.

162. Mislick KA, Baldeschwieler JD. Evidence for the role of proteoglycans in cation-mediated gene transfer. Proceedings of the National Academy of Sciences. 1996;93(22):12349-54.

163. Payne CK, Jones SA, Chen C, Zhuang X. Internalization and Trafficking of Cell Surface Proteoglycans and Proteoglycan-Binding Ligands. Traffic (Copenhagen, Denmark). 2007;8(4):389-401.

164. Ruponen $M$, Yla-Herttuala S, Urtti A. Interactions of polymeric and liposomal gene delivery systems with extracellular glycosaminoglycans: physicochemical and transfection studies. Biochimica Et Biophysica Acta. 1999;1415(2):331-41.

165. Mounkes LC, Zhong W, Cipres-Palacin G, Heath TD, Debs RJ. Proteoglycans Mediate Cationic Liposome-DNA Complex-based Gene Delivery in Vitro and in Vivo. Journal of Biological Chemistry. 1998;273(40):26164-70.

166. Paris S, Burlacu A, Durocher Y. Opposing Roles of Syndecan-1 and Syndecan-2 in Polyethyleneimine-mediated Gene Delivery. Journal of Biological Chemistry. 2008;283(12):7697-704.

167. Nakase I, Tadokoro A, Kawabata N, Takeuchi T, Katoh H, Hiramoto K, et al. Interaction of arginine-rich peptides with membrane-associated proteoglycans is crucial for induction of actin organization and macropinocytosis. Biochemistry. 2007;46(2):492-501.

168. Hessa T, Kim H, Bihlmaier K, Lundin C, Boekel J, Andersson H, et al. Recognition of transmembrane helices by the endoplasmic reticulum translocon. Nature. 2005;433(7024):377-81.

169. Schnitzer JE, Oh P, Pinney E, Allard J. Filipin-sensitive caveolae-mediated transport in endothelium: reduced transcytosis, scavenger endocytosis, and capillary permeability of select macromolecules. J Cell Biol. 1994;127(5):1217-32.

170. Wang LH, Rothberg KG, Anderson RG. Mis-assembly of clathrin lattices on endosomes reveals a regulatory switch for coated pit formation. J Cell Biol. 1993;123(5):1107-17. 
171. El-Sayed A, Harashima H. Endocytosis of gene delivery vectors: from clathrin-dependent to lipid raft-mediated endocytosis. Mol Ther. 2013;21(6):1118-30.

172. Wileman T, Harding C, Stahl P. Receptor-mediated endocytosis. Biochemical Journal. 1985;232(1):1-14.

173. McMahon HT, Boucrot E. Molecular mechanism and physiological functions of clathrinmediated endocytosis. Nat Rev Mol Cell Biol. 2011;12(8):517-33.

174. Mercer J, Helenius A. Gulping rather than sipping: macropinocytosis as a way of virus entry. Curr Opin Microbiol. 2012;15(4):490-9.

175. Mercer J, Helenius A. Virus entry by macropinocytosis. Nat Cell Biol. 2009;11(5):510-20.

176. Dharmawardhane S, Schürmann A, Sells MA, Chernoff J, Schmid SL, Bokoch GM. Regulation of Macropinocytosis by p21-activated Kinase-1. Molecular Biology of the Cell. 2000;11(10):3341-52.

177. Christianson HC, Belting M. Heparan sulfate proteoglycan as a cell-surface endocytosis receptor. Matrix Biol. 2014;35:51-5.

178. Khalil IA, Kogure K, Futaki S, Harashima H. High density of octaarginine stimulates macropinocytosis leading to efficient intracellular trafficking for gene expression. J Biol Chem. 2006;281(6):3544-51.

179. Ma DX, Shi NQ, Qi XR. Distinct transduction modes of arginine-rich cell-penetrating peptides for cargo delivery into tumor cells. Int J Pharm. 2011;419(1-2):200-8.

180. Ferreira CS, Cheung MC, Missailidis S, Bisland S, Gariepy J. Phototoxic aptamers selectively enter and kill epithelial cancer cells. Nucleic Acids Res. 2009;37(3):866-76.

181. Joshi S, Kumar S, Choudhury A, Ponnusamy MP, Batra SK. Altered Mucins (MUC) Trafficking in Benign and Malignant Conditions. Oncotarget. 2014;5(17):7272-84.

182. Doherty GJ, McMahon HT. Mechanisms of endocytosis. Annu Rev Biochem. 2009;78:857-902.

183. Hill MM, Bastiani M, Luetterforst R, Kirkham M, Kirkham A, Nixon SJ, et al. PTRF-Cavin, a conserved cytoplasmic protein required for caveola formation and function. Cell. 2008;132(1):113-24.

184. Le Roy C, Wrana JL. Clathrin- and non-clathrin-mediated endocytic regulation of cell signalling. Nat Rev Mol Cell Biol. 2005;6(2):112-26.

185. Hayer A, Stoeber M, Ritz D, Engel S, Meyer HH, Helenius A. Caveolin-1 is ubiquitinated and targeted to intralumenal vesicles in endolysosomes for degradation. The Journal of Cell Biology. 2010;191(3):615-29.

186. Adler AF, Leong KW. Emerging links between surface nanotechnology and endocytosis: impact on nonviral gene delivery. Nano Today. 2010;5(6):553-69.

187. Ohkuma S, Poole B. Fluorescence probe measurement of the intralysosomal pH in living cells and the perturbation of $\mathrm{pH}$ by various agents. Proc Natl Acad Sci U S A. 1978;75(7):3327-31.

188. Steinman RM, Mellman IS, Muller WA, Cohn ZA. Endocytosis and the recycling of plasma membrane. J Cell Biol. 1983;96(1):1-27.

189. Ohmori N, Niidome T, Wada A, Hirayama T, Hatakeyama T, Aoyagi $H$. The enhancing effect of anionic alpha-helical peptide on cationic peptide-mediating transfection systems. Biochem Biophys Res Commun. 1997;235(3):726-9.

190. Wilke M, Fortunati E, van den Broek M, Hoogeveen AT, Scholte BJ. Efficacy of a peptidebased gene delivery system depends on mitotic activity. Gene Ther. 1996;3(12):1133-42. 
191. Peters R. Nucleo-cytoplasmic flux and intracellular mobility in single hepatocytes measured by fluorescence microphotolysis. EMBO J. 1984;3(8):1831-6.

192. Feldherr $\mathrm{CM}$. The effect of the electron-opaque pore material on exchanges through the nuclear annuli. The Journal of Cell Biology. 1965;25(1):43-53.

193. Paine P. Nucleocytoplasmic movement of fluorescent tracers microinjected into living salivary gland cells. The Journal of Cell Biology. 1975;66(3):652-7.

194. Nigg EA. Nucleocytoplasmic transport: signals, mechanisms and regulation. Nature. 1997;386(6627):779-87.

195. Peters R. Fluorescence microphotolysis to measure nucleocytoplasmic transport and intracellular mobility. Biochimica Et Biophysica Acta. 1986;864(3-4):305-59.

196. Wang R, Brattain MG. The maximal size of protein to diffuse through the nuclear pore is larger than 60kDa. FEBS Letters. 2007;581(17):3164-70.

197. Bechara C, Sagan S. Cell-penetrating peptides: 20 years later, where do we stand? FEBS Letters. 2013;587(12):1693-702.

198. Cardoso AL, Simoes S, de Almeida LP, Pelisek J, Culmsee C, Wagner E, et al. siRNA delivery by a transferrin-associated lipid-based vector: a non-viral strategy to mediate gene silencing. J Gene Med. 2007;9(3):170-83.

199. Yu W, Pirollo KF, Rait A, Yu B, Xiang LM, Huang WQ, et al. A sterically stabilized immunolipoplex for systemic administration of a therapeutic gene. Gene Ther. 2004;11(19):1434-40.

200. Song E, Zhu P, Lee SK, Chowdhury D, Kussman S, Dykxhoorn DM, et al. Antibody mediated in vivo delivery of small interfering RNAs via cell-surface receptors. Nat Biotechnol. 2005;23(6):709-17.

201. Zhang Y, Zhang YF, Bryant J, Charles A, Boado RJ, Pardridge WM. Intravenous RNA interference gene therapy targeting the human epidermal growth factor receptor prolongs survival in intracranial brain cancer. Clin Cancer Res. 2004;10(11):3667-77.

202. Dongxi X, Sarah S, Greg Q, Shu-Feng Z, Yong L, Ming QW, et al. Aptamer-Mediated Cancer Gene Therapy. Current Gene Therapy. 2015;15(2):109-19.

203. Keefe $A D$, Pai $S$, Ellington A. Aptamers as therapeutics. Nat Rev Drug Discov. 2010;9(7):537-50.

204. Oba M, Aoyagi K, Miyata K, Matsumoto Y, Itaka K, Nishiyama N, et al. Polyplex micelles with cyclic RGD peptide ligands and disulfide cross-links directing to the enhanced transfection via controlled intracellular trafficking. Mol Pharm. 2008;5(6):1080-92.

205. Walker GF, Fella C, Pelisek J, Fahrmeir J, Boeckle S, Ogris M, et al. Toward synthetic viruses: endosomal $\mathrm{pH}$-triggered deshielding of targeted polyplexes greatly enhances gene transfer in vitro and in vivo. Mol Ther. 2005;11(3):418-25.

206. Schiffelers RM, Ansari A, Xu J, Zhou Q, Tang Q, Storm G, et al. Cancer siRNA therapy by tumor selective delivery with ligand-targeted sterically stabilized nanoparticle. Nucleic Acids Research. 2004;32(19):e149.

207. Li W, Szoka FC, Jr. Lipid-based nanoparticles for nucleic acid delivery. Pharm Res. 2007;24(3):438-49.

208. Zhang $X$, Collins L, Fabre JW. A powerful cooperative interaction between a fusogenic peptide and lipofectamine for the enhancement of receptor-targeted, non-viral gene delivery via integrin receptors. J Gene Med. 2001;3(6):560-8. 
209. Simoes S, Slepushkin V, Gaspar R, de Lima MC, Duzgunes N. Gene delivery by negatively charged ternary complexes of DNA, cationic liposomes and transferrin or fusigenic peptides. Gene Ther. 1998;5(7):955-64.

210. Li SD, Huang L. Gene therapy progress and prospects: non-viral gene therapy by systemic delivery. Gene Ther. 2006;13(18):1313-9.

211. Society AC. Cancer Facts and Figures. 2014; 1-63.

212. Perou CM, Sorlie T, Eisen MB, van de Rijn M, Jeffrey SS, Rees CA, et al. Molecular portraits of human breast tumours. Nature. 2000;406(6797):747-52.

213. Siegel RL, Miller KD, Jemal A. Cancer statistics, 2015. CA: A Cancer Journal for Clinicians. 2015;65(1):5-29.

214. Holliday DL, Speirs V. Choosing the right cell line for breast cancer research. Breast Cancer Res. 2011;13(4):215.

215. Gonzalez-Angulo AM, Morales-Vasquez F, Hortobagyi GN. Overview of resistance to systemic therapy in patients with breast cancer. Adv Exp Med Biol. 2007;608:1-22.

216. Lee EY, Muller WJ. Oncogenes and tumor suppressor genes. Cold Spring Harb Perspect Biol. 2010;2(10):a003236.

217. Lane DP, Cheok CF, Lain S. p53-based cancer therapy. Cold Spring Harb Perspect Biol. 2010;2(9):a001222.

218. Hortobagyi GN, Ueno NT, Xia W, Zhang S, Wolf JK, Putnam JB, et al. Cationic LiposomeMediated E1A Gene Transfer to Human Breast and Ovarian Cancer Cells and Its Biologic Effects: A Phase I Clinical Trial. Journal of Clinical Oncology. 2001;19(14):3422-33.

219. Yang F, Huang W, Li Y, Liu S, Jin M, Wang Y, et al. Anti-tumor effects in mice induced by survivin-targeted siRNA delivered through polysaccharide nanoparticles. Biomaterials. 2013;34(22):5689-99.

220. Gao Y, Chen L, Zhang Z, Chen Y, Li Y. Reversal of multidrug resistance by reductionsensitive linear cationic click polymer/iMDR1-pDNA complex nanoparticles. Biomaterials. 2011;32(6):1738-47.

221. Ren X, Liu L, Zhou Y, Zhu Y, Zhang H, Zhang Z, et al. Nanoparticle siRNA against BMI-1 with a Polyethylenimine-Laminarin Conjugate for Gene Therapy in Human Breast Cancer. Bioconjugate Chemistry. 2015.

222. Mapara MY, Sykes M. Tolerance and Cancer: Mechanisms of Tumor Evasion and Strategies for Breaking Tolerance. Journal of Clinical Oncology. 2004;22(6):1136-51.

223. McCrudden CM, McCarthy HO. Current status of gene therapy for breast cancer: progress and challenges. Appl Clin Genet. 2014;7:209-20.

224. De Giovanni C, Nicoletti G, Quaglino E, Landuzzi L, Palladini A, lanzano $\mathrm{ML}$, et al. Vaccines against human HER2 prevent mammary carcinoma in mice transgenic for human HER2. Breast Cancer Research. 2014;16(1):R10.

225. Tiriveedhi V, Fleming TP, Goedegebuure PS, Naughton M, Ma C, Lockhart C, et al. Mammaglobin-A cDNA Vaccination of Breast Cancer Patients Induces Antigen-Specific Cytotoxic CD4(+)ICOS(hi) $\mathrm{T}$ Cells. Breast cancer research and treatment. 2013;138(1):109-18.

226. Endmann A, Oswald D, Riede O, Talman EG, Vos RE, Schroff M, et al. Combination of MIDGE-Th1 DNA vaccines with the cationic lipid SAINT-18: studies on formulation, biodistribution and vector clearance. Vaccine. 2014;32(27):3460-7. 
227. Gribben JG, Ryan DP, Boyajian R, Urban RG, Hedley ML, Beach K, et al. Unexpected Association between Induction of Immunity to the Universal Tumor Antigen CYP1B1 and Response to Next Therapy. Clinical Cancer Research. 2005;11(12):4430-6.

228. Immonen A, Vapalahti M, Tyynela K, Hurskainen $H$, Sandmair A, Vanninen $R$, et al. AdvHSV-tk Gene Therapy with Intravenous Ganciclovir Improves Survival in Human Malignant Glioma: A Randomised, Controlled Study. Mol Ther. 2004;10(5):967-72.

229. McCormick F. Cancer gene therapy: fringe or cutting edge? Nat Rev Cancer. [10.1038/35101008]. 2001;1(2):130-41.

230. Menard S, Pupa SM, Campiglio M, Tagliabue E. Biologic and therapeutic role of HER2 in cancer. Oncogene. 2003;22(42):6570-8.

231. Pandha HS, Martin L-A, Rigg A, Hurst HC, Stamp GWH, Sikora K, et al. Genetic Prodrug Activation Therapy for Breast Cancer: A Phase I Clinical Trial of erbB-2-Directed Suicide Gene Expression. Journal of Clinical Oncology. 1999;17(7):2180.

232. Altieri DC. Survivin, versatile modulation of cell division and apoptosis in cancer. Oncogene. 2003;22(53):8581-9.

233. Huh WK, Gomez-Navarro J, Arafat WO, Xiang J, Mahasreshti PJ, Alvarez RD, et al. Baxinduced apoptosis as a novel gene therapy approach for carcinoma of the cervix. Gynecol Oncol. 2001;83(2):370-7.

234. Li X, Marani M, Yu J, Nan B, Roth JA, Kagawa S, et al. Adenovirus-mediated Bax overexpression for the induction of therapeutic apoptosis in prostate cancer. Cancer Res. 2001;61(1):186-91.

235. Garg H, Salcedo R, Trinchieri G, Blumenthal R. Improved nonviral cancer suicide gene therapy using survivin promoter-driven mutant Bax. Cancer Gene Ther. 2009;17(3):15563.

236. Nath S, Mukherjee P. MUC1: a multifaceted oncoprotein with a key role in cancer progression. Trends Mol Med. 2014;20(6):332-42.

237. Sadeqzadeh E, Rahbarizadeh F, Ahmadvand D, Rasaee MJ, Parhamifar L, Moghimi SM. Combined MUC1-specific nanobody-tagged PEG-polyethylenimine polyplex targeting and transcriptional targeting of tBid transgene for directed killing of MUC1 overexpressing tumour cells. Journal of Controlled Release. 2011;156(1):85-91.

238. Castillo-Rodríguez RA, Arango-Rodríguez ML, Escobedo L, Hernandez-Baltazar D, Gompel A, Forgez P, et al. Suicide HSVtk Gene Delivery by Neurotensin-Polyplex Nanoparticles via the Bloodstream and GCV Treatment Specifically Inhibit the Growth of Human MDA-MB-231 Triple Negative Breast Cancer Tumors Xenografted in Athymic Mice. PLoS One. 2014;9(5):e97151.

239. Trepel M, Korbelin J, Spies E, Heckmann MB, Hunger A, Fehse B, et al. Treatment of multifocal breast cancer by systemic delivery of dual-targeted adeno-associated viral vectors. Gene Ther. 2015;22(10):848.

240. Kong H, Liu C, Zhu T, Huang Z, Yang L, Li Q. Effects of an adenoviral vector containing a suicide gene fusion on growth characteristics of breast cancer cells. Mol Med Rep. 2014;10(6):3227-32.

241. Kong H, Tao L, Qi K, Wang Y, Li Q, Du J, et al. Thymidine kinase/ganciclovir and cytosine deaminase/5-fluorocytosine suicide gene therapy-induced cell apoptosis in breast cancer cells. Oncol Rep. 2013;30(3):1209-14.

242. Banin Hirata BK, Oda JM, Losi Guembarovski R, Ariza CB, de Oliveira CE, Watanabe MA. Molecular markers for breast cancer: prediction on tumor behavior. Dis Markers. 2014;:2014:513158. 
243. Canine BF, Wang Y, Hatefi A. Biosynthesis and characterization of a novel genetically engineered polymer for targeted gene transfer to cancer cells. Journal of controlled release : official journal of the Controlled Release Society. 2009;138(3):188-96.

244. Jeyarajan S, Xavier J, Rao NM, Gopal V. Plasmid DNA delivery into MDA-MB-453 cells mediated by recombinant Her-NLS fusion protein. International Journal of Nanomedicine. 2010;5:725-33.

245. Govindarajan S, Sivakumar J, Garimidi P, Rangaraj N, Kumar JM, Rao NM, et al. Targeting human epidermal growth factor receptor 2 by a cell-penetrating peptideaffibody bioconjugate. Biomaterials. 2012;33(8):2570-82.

246. Ellington AD, Szostak JW. In vitro selection of RNA molecules that bind specific ligands. Nature. 1990;346(6287):818-22.

247. Nimjee SM, Rusconi CP, Sullenger BA. Aptamers: an emerging class of therapeutics. Annu Rev Med. 2005;56:555-83.

248. Sun H, Zhu X, Lu PY, Rosato RR, Tan W, Zu Y. Oligonucleotide aptamers: new tools for targeted cancer therapy. Mol Ther Nucleic Acids. 2014;3:e182.

249. Zhang K, Tang L, Sefah K, Zhao Z, Zhu G, Sun W, et al. Novel aptamer developed for breast cancer cell internalization. ChemMedChem. 2012;7(1):79-84.

250. Ferreira CS, Cheung MC, Missailidis S, Bisland S, Gariepy J. Phototoxic aptamers selectively enter and kill epithelial cancer cells. Nucleic Acids Research. 2009;37(3):86676.

251. Ferreira CS, Matthews CS, Missailidis S. DNA aptamers that bind to MUC1 tumour marker: design and characterization of MUC1-binding single-stranded DNA aptamers. Tumour Biol. 2006;27(6):289-301.

252. Gendler S. MUC1, The Renaissance Molecule. Journal of Mammary Gland Biology and Neoplasia. 2001;6(3):339-53.

253. Brayman M, Thathiah A, Carson DD. MUC1: a multifunctional cell surface component of reproductive tissue epithelia. Reprod Biol Endocrinol. 2004;2:4.

254. Rakha EA, Boyce RWG, Abd El-Rehim D, Kurien T, Green AR, Paish EC, et al. Expression of mucins (MUC1, MUC2, MUC3, MUC4, MUC5AC and MUC6) and their prognostic significance in human breast cancer. Mod Pathol. 2005;18(10):1295-304.

255. Orava EW, Cicmil N, Gariepy J. Delivering cargoes into cancer cells using DNA aptamers targeting internalized surface portals. Biochimica Et Biophysica Acta. 2010;1798(12):2190-200.

256. Raina D, Ahmad R, Rajabi H, Panchamoorthy G, Kharbanda S, Kufe D. Targeting cysteine-mediated dimerization of the MUC1-C oncoprotein in human cancer cells. International Journal of Oncology. 2012;40(5):1643-9.

257. Kumar P, Lindberg L, Thirkill TL, Ji JW, Martsching L, Douglas GC. The MUC1 Extracellular Domain Subunit Is Found in Nuclear Speckles and Associates with Spliceosomes. PLoS One. 2012;7(8):e42712.

258. Hattrup $\mathrm{CL}$, Gendler SJ. MUC1 alters oncogenic events and transcription in human breast cancer cells. Breast Cancer Research. 2006;8(4):R37-R.

259. Horm TM, Schroeder JA. MUC1 and metastatic cancer: expression, function and therapeutic targeting. Cell Adh Migr. 2013;7(2):187-98.

260. Yin L, Li Y, Ren J, Kuwahara H, Kufe D. Human MUC1 carcinoma antigen regulates intracellular oxidant levels and the apoptotic response to oxidative stress. J Biol Chem. 2003;278(37):35458-64. 
261. Wei X, Xu H, Kufe D. Human MUC1 oncoprotein regulates p53-responsive gene transcription in the genotoxic stress response. Cancer cell. 2005;7(2):167-78.

262. Kufe DW. MUC1-C oncoprotein as a target in breast cancer: activation of signaling pathways and therapeutic approaches. Oncogene. 2013;32(9):1073-81.

263. Pieve $C D$, Perkins AC, Missailidis S. Anti-MUC1 aptamers: radiolabelling with $(99 \mathrm{~m}) \mathrm{TC}$ and biodistribution in MCF-7 tumour-bearing mice. Nuclear Medicine and Biology. 2009;36(6):703-10.

264. Yu C, Hu Y, Duan J, Yuan W, Wang C, Xu H, et al. Novel Aptamer-Nanoparticle Bioconjugates Enhances Delivery of Anticancer Drug to MUC1-Positive Cancer Cells In Vitro. PLoS One. 2011;6(9):e24077.

265. Ferreira CS, Papamichael K, Guilbault G, Schwarzacher T, Gariepy J, Missailidis S. DNA aptamers against the MUC1 tumour marker: design of aptamer-antibody sandwich ELISA for the early diagnosis of epithelial tumours. Anal Bioanal Chem. 2008;390(4):1039-50.

266. Kurosaki T, Higuchi N, Kawakami S, Higuchi Y, Nakamura T, Kitahara T, et al. Selfassemble gene delivery system for molecular targeting using nucleic acid aptamer. Gene. 2012;491(2):205-9.

267. Jalalian SH, Taghdisi SM, Shahidi Hamedani N, Kalat SAM, Lavaee P, ZandKarimi M, et al. Epirubicin loaded super paramagnetic iron oxide nanoparticle-aptamer bioconjugate for combined colon cancer therapy and imaging in vivo. European Journal of Pharmaceutical Sciences. 2013;50(2):191-7.

268. Liu Z, Duan JH, Song YM, Ma J, Wang FD, Lu X, et al. Novel HER2 aptamer selectively delivers cytotoxic drug to HER2-positive breast cancer cells in vitro. J Transl Med. 2012;10:148.

269. Xing H, Tang L, Yang X, Hwang K, Wang W, Yin Q, et al. Selective Delivery of an Anticancer Drug with Aptamer-Functionalized Liposomes to Breast Cancer Cells in Vitro and in Vivo. Journal of materials chemistry B, Materials for biology and medicine. 2013;1(39):5288-97.

270. Thiel KW, Hernandez LI, Dassie JP, Thiel WH, Liu X, Stockdale KR, et al. Delivery of chemo-sensitizing siRNAs to HER2+-breast cancer cells using RNA aptamers. Nucleic Acids Research. 2012;40(13):6319-37.

271. Walsh MJ, Dodd JE, Hautbergue GM. Ribosome-inactivating proteins: Potent poisons and molecular tools. Virulence. 2013;4(8):774-84.

272. Endo Y, Mitsui K, Motizuki M, Tsurugi K. The mechanism of action of ricin and related toxic lectins on eukaryotic ribosomes. The site and the characteristics of the modification in $28 \mathrm{~S}$ ribosomal RNA caused by the toxins. J Biol Chem. 1987;262(12):5908-12.

273. Stirpe F, Battelli MG. Ribosome-inactivating proteins: progress and problems. Cell Mol Life Sci. 2006;63(16):1850-66.

274. Stirpe F. Ribosome-inactivating proteins: from toxins to useful proteins. Toxicon. 2013;67:12-6.

275. Shang C, Chen Q, Dell A, Haslam SM, De Vos WH, Van Damme EJM. The Cytotoxicity of Elderberry Ribosome-Inactivating Proteins Is Not Solely Determined by Their Protein Translation Inhibition Activity. PLoS One. 2015;10(7):e0132389.

276. Domashevskiy AV, Goss DJ. Pokeweed antiviral protein, a ribosome inactivating protein: activity, inhibition and prospects. Toxins (Basel). 2015;7(2):274-98. 
277. Shapira A, Benhar I. Toxin-based therapeutic approaches. Toxins (Basel). 2010;2(11):2519-83.

278. Vago R. Ribosome Inactivating Proteins: Exploiting Plant Weapons to Fight Human Cancer. J Genet Syndr Gene Ther. 2015;6(272).

279. Gofrit ON, Benjamin S, Halachmi S, Leibovitch I, Dotan Z, Lamm DL, et al. DNA Based Therapy with Diphtheria Toxin-A BC-819: A Phase 2b Marker Lesion Trial in Patients with Intermediate Risk Nonmuscle Invasive Bladder Cancer. The Journal of Urology. 2013;191(6):1697-702.

280. Hoganson DKC, Lois A. Fleurbaaij, Graham A. Ying, Wenbin. Black, Margaret E. Doukas, John. Pierce, Glenn F. Baird, Andrew. Sosnowski, Barbara A. Targeted Delivery of DNA Encoding Cytotoxic Proteins through High-Affinity Fibroblast Growth Factor Receptors. Human Gene Therapy. 1998;9(17):2565-75.

281. Zarovni N, Vago R, Solda T, Monaco L, Fabbrini MS. Saporin as a novel suicide gene in anticancer gene therapy. Cancer Gene Ther. 2006;14(2):165-73.

282. Martín V, Cortés ML, Felipe Pd, Farsetti A, Calcaterra NB, Izquierdo M. Cancer Gene Therapy by Thyroid Hormone-mediated Expression of Toxin Genes. Cancer Research. 2000;60(12):3218-24.

283. Hudak KA, Bauman JD, Tumer NE. Pokeweed antiviral protein binds to the cap structure of eukaryotic mRNA and depurinates the mRNA downstream of the cap. RNA. 2002;8(9):1148-59.

284. Uckun FM, Chelstrom LM, Irvin JD, Finnegan D, Gunther R, Young J, et al. In vivo efficacy of B43 (anti-CD19)-pokeweed antiviral protein immunotoxin against BCL-1 murine Bcell leukemia. Blood. 1992;79(10):2649-61.

285. Zarling JM, Moran PA, Haffar O, Sias J, Richman DD, Spina CA, et al. Inhibition of HIV replication by pokeweed antiviral protein targeted to CD4+ cells by monoclonal antibodies. Nature. [10.1038/347092a0]. 1990;347(6288):92-5.

286. Barbieri L, Bolognesi A, Cenini P, Falasca Al, Minghetti A, Garofano L, et al. Ribosomeinactivating proteins from plant cells in culture. Biochemical Journal. 1989;257(3):801-7.

287. Tagge EP, Chandler J, Harris B, Czako M, Marton L, Willingham MC, et al. Preproricin expressed in Nicotiana tabacum cells in vitro is fully processed and biologically active. Protein Expr Purif. 1996;8(1):109-18.

288. Stirpe F, Barbieri L. Ribosome-inactivating proteins up to date. FEBS Letters. 1986;195(12):1-8.

289. Ferreras JM, Citores $L$, Iglesias $R$, Jiménez $P$, Girbés $T$. Use of Ribosome-Inactivating Proteins from Sambucus for the Construction of Immunotoxins and Conjugates for Cancer Therapy. Toxins. 2011;3(5):420-41.

290. Schep LJ, Temple WA, Butt GA, Beasley MD. Ricin as a weapon of mass terror separating fact from fiction. Environ Int. 2009;35(8):1267-71.

291. Lamb FI, Roberts LM, Lord JM. Nucleotide sequence of cloned CDNA coding for preproricin. Eur J Biochem. 1985;148(2):265-70.

292. Słomińska-Wojewódzka M, Sandvig K. Ricin and Ricin-Containing Immunotoxins: Insights into Intracellular Transport and Mechanism of action in Vitro. Antibodies. 2013;2(2):236.

293. Hazes B, Read RJ. Accumulating Evidence Suggests That Several AB-Toxins Subvert the Endoplasmic Reticulum-Associated Protein Degradation Pathway To Enter Target Cells. Biochemistry. 1997;36(37):11051-4. 
294. Tesh VL. The induction of apoptosis by Shiga toxins and ricin. Curr Top Microbiol Immunol. 2012;357:137-78.

295. Oda T, Komatsu N, Muramatsu T. Cell lysis induced by ricin D and ricin E in various cell lines. Biosci Biotechnol Biochem. 1997;61(2):291-7.

296. Rao PV, Jayaraj R, Bhaskar AS, Kumar O, Bhattacharya R, Saxena P, et al. Mechanism of ricin-induced apoptosis in human cervical cancer cells. Biochem Pharmacol. 2005;69(5):855-65.

297. Komatsu N, Nakagawa M, Oda T, Muramatsu T. Depletion of intracellular NAD(+) and ATP levels during ricin-induced apoptosis through the specific ribosomal inactivation results in the cytolysis of U937 cells. J Biochem. 2000;128(3):463-70.

298. Brigotti M, Alfieri R, Sestili P, Bonelli M, Petronini PG, Guidarelli A, et al. Damage to nuclear DNA induced by Shiga toxin 1 and ricin in human endothelial cells. The FASEB Journal. 2002;16(3):365-72.

299. Jänicke RU, Sprengart ML, Wati MR, Porter AG. Caspase-3 Is Required for DNA Fragmentation and Morphological Changes Associated with Apoptosis. Journal of Biological Chemistry. 1998;273(16):9357-60.

300. Keppler-Hafkemeyer A, Brinkmann U, Pastan I. Role of Caspases in ImmunotoxinInduced Apoptosis of Cancer Cells. Biochemistry. 1998;37(48):16934-42.

301. Mc Gee MM, Hyland E, Campiani G, Ramunno A, Nacci V, Zisterer DM. Caspase-3 is not essential for DNA fragmentation in MCF-7 cells during apoptosis induced by the pyrrolo-1,5-benzoxazepine, PBOX-6. FEBS Letters. 2002;515(1-3):66-70.

302. Hasegawa N, Kimura Y, Oda T, Komatsu N, Muramatsu T. Isolated Ricin B-Chainmediated Apoptosis in U937 Cells. Bioscience, Biotechnology, and Biochemistry. 2000;64(7):1422-9.

303. Hu R, Zhai Q, Liu W, Liu X. An insight into the mechanism of cytotoxicity of ricin to hepatoma cell: roles of $\mathrm{Bcl}-2$ family proteins, caspases, $\mathrm{Ca}(2+)$-dependent proteases and protein kinase C. J Cell Biochem. 2001;81(4):583-93.

304. Gonzalez TV, Farrant SA, Mantis NJ. Ricin induces IL-8 secretion from human monocyte/macrophages by activating the p38 MAP kinase pathway. Molecular Immunology. 2006;43(11):1920-3.

305. Goldmacher V, Bourret L, Levine B, Rasmussen R, Pourshadi M, Lambert J, et al. AntiCD38-blocked ricin: an immunotoxin for the treatment of multiple myeloma [see comments]. Blood. 1994;84(9):3017-25.

306. Epstein C, Lynch T, Shefner J, Wen P, Maxted D, Braman V, et al. Use of the immunotoxin N901-blocked ricin in patients with small-cell lung cancer. Int J Cancer Suppl. 1994;8:57-9.

307. Schindler J, Gajavelli S, Ravandi F, Shen Y, Parekh S, Braunchweig I, et al. A phase I study of a combination of anti-CD19 and anti-CD22 immunotoxins (Combotox) in adult patients with refractory $\mathrm{B}$-lineage acute lymphoblastic leukaemia. $\mathrm{Br} J$ Haematol. 2011;154(4):471-6.

308. Epler K, Padilla D, Phillips G, Crowder P, Castillo R, Wilkinson D, et al. Delivery of ricin toxin a-chain by peptide-targeted mesoporous silica nanoparticle-supported lipid bilayers. Adv Healthc Mater. 2012;1(3):348-53.

309. Gould BJ, Borowitz MJ, Groves ES, Carter PW, Anthony D, Weiner LM, et al. Phase I Study of an Anti-Breast Cancer Immunotoxin by Continuous Infusion: Report of a Targeted Toxic Effect Not Predicted by Animal Studies. Journal of the National Cancer Institute. 1989;81(10):775-81. 
310. Girotti A. PhD Thesis. Universidad de Valladolid. 2007.

311. Pierna M. PhD Thesis. Universidad de Valladolid. 2013.

312. Sandhu GS, Precup JW, Kline BC. Rapid One-Step Characterization of Recombinant Vectors by Direct Analysis of Transformed Escherichia-Coli Colonies. Biotechniques. 1989;7(7):689-90.

313. Chung CT, Niemela SL, H. MR. One-step preparation of competent Escherichia coli: transformation and storage of bacterial cells in the same solution. Proc Natl Acad Sci U S A. 1989;86(7):2172-5.

314. Studier FW. Protein production by auto-induction in high density shaking cultures. Protein Expr Purif. 2005;41(1):207-34.

315. Shamji MF, Chen J, Friedman AH, Richardson WJ, Chilkoti A, Setton LA. Synthesis and characterization of a thermally-responsive tumor necrosis factor antagonist. J Control Release. 2008;129(3):179-86.

316. McHale MK, Setton LA, Chilkoti A. Synthesis and in vitro evaluation of enzymatically cross-linked elastin-like polypeptide gels for cartilaginous tissue repair. Tissue Eng. 2005;11(11-12):1768-79.

317. Butash KA, Natarajan P, Young A, Fox DK. Reexamination of the effect of endotoxin on cell proliferation and transfection efficiency. Biotechniques. 2000;29(3):610-4, 6, 8-9.

318. Laemmli UK. Cleavage of Structural Proteins during Assembly of Head of Bacteriophage-T4. Nature. 1970;227(5259):680-\&.

319. Lee C LA, Branton D. Copper staining: a five-minute protein stain for sodium dodecyl sulfate-polyacrylamide gels. Anal Biochem. 1987;166(2):308-12.

320. Koppel DE. Analysis of Macromolecular Polydispersity in Intensity Correlation Spectroscopy: The Method of Cumulants. The Journal of Chemical Physics. 1972;57(11):4814-20.

321. Müller RH. Zetapotential und Partikelladung-Kurze Theorie, praktische MeBdurchfuhrung, Dateninterpretation. Stuttgart1996.

322. Mattheyses AL, Simon SM, Rappoport JZ. Imaging with total internal reflection fluorescence microscopy for the cell biologist. Journal of Cell Science. 2010;123(21):3621-8.

323. Garcia-Arevalo C. PhD thesis. Universidad de Valladolid.

324. Studier FW. Use of bacteriophage T7 lysozyme to improve an inducible T7 expression system. J Mol Biol. 1991;219(1):37-44.

325. Makrides SC. Strategies for achieving high-level expression of genes in Escherichia coli. Microbiological Reviews. 1996;60(3):512-38.

326. McPherson DT, Xu J, Urry DW. Product purification by reversible phase transition following Escherichia coli expression of genes encoding up to 251 repeats of the elastomeric pentapeptide GVGVP. Protein Expr Purif. 1996;7(1):51-7.

327. McPherson DT, Morrow C, Minehan DS, Wu J, Hunter E, Urry DW. Production and purification of a recombinant elastomeric polypeptide, G-(VPGVG)19-VPGV, from Escherichia coli. Biotechnol Prog. 1992;8(4):347-52.

328. Hassouneh W, Christensen T, Chilkoti A. Elastin-like Polypeptides as a Purification Tag for Recombinant Proteins. In: Coligan JE, editor. Current protocols in protein science2010. p. Unit-6.11.

329. Urry DW, editor. What Sustains Life? Consilient Mechanisms for Protein-Based Machines and Materials. New York: Springer-Verlag; 2006. 
330. Thomas JJ, Rekha MR, Sharma CP. Unraveling the intracellular efficacy of dextranhistidine polycation as an efficient nonviral gene delivery system. Mol Pharm. 2012;9(1):121-34.

331. Akinc A, Thomas M, Klibanov AM, Langer R. Exploring polyethylenimine-mediated DNA transfection and the proton sponge hypothesis. J Gene Med. 2005;7(5):657-63.

332. MacEwan SR, Chilkoti A. Applications of elastin-like polypeptides in drug delivery. J Control Release. 2014;190:314-30.

333. Ryu JS, Raucher D. Elastin-like polypeptide for improved drug delivery for anticancer therapy: preclinical studies and future applications. Expert Opinion on Drug Delivery. 2015;12(4):653-67.

334. Furgeson DY, Dreher MR, Chilkoti A. Structural optimization of a smart doxorubicinpolypeptide conjugate for thermally targeted delivery to solid tumors. J Control Release. 2006;110(2):362-9.

335. Merisko-Liversidge EM, Liversidge GG. Drug nanoparticles: formulating poorly watersoluble compounds. Toxicol Pathol. 2008;36(1):43-8.

336. MacKay JA, Chen M, McDaniel JR, Liu W, Simnick AJ, Chilkoti A. Self-assembling chimeric polypeptide-doxorubicin conjugate nanoparticles that abolish tumours after a single injection. Nat Mater. 2009;8(12):993-9.

337. Bhattacharyya J, Bellucci JJ, Weitzhandler I, McDaniel JR, Spasojevic I, Li X, et al. A paclitaxel-loaded recombinant polypeptide nanoparticle outperforms Abraxane in multiple murine cancer models. Nat Commun. 2015;6:7939.

338. Hassouneh W, Nunalee ML, Shelton MC, Chilkoti A. Calcium binding peptide motifs from calmodulin confer divalent ion selectivity to elastin-like polypeptides. Biomacromolecules. 2013;14(7):2347-53.

339. MacEwan SR, Chilkoti A. Harnessing the power of cell-penetrating peptides: activatable carriers for targeting systemic delivery of cancer therapeutics and imaging agents. Wiley Interdiscip Rev Nanomed Nanobiotechnol. 2013;5(1):31-48.

340. Milletti F. Cell-penetrating peptides: classes, origin, and current landscape. Drug Discovery Today. 2012;17(15-16):850-60.

341. Nakano A. Spinning-disk Confocal Microscopy \&mdash; A Cutting-Edge Tool for Imaging of Membrane Traffic. Cell Structure and Function. 2002;27(5):349-55.

342. Kirchhausen T. Imaging endocytic clathrin structures in living cells. Trends in cell biology. 2009;19(11):596-605.

343. Kaksonen M, Toret CP, Drubin DG. Harnessing actin dynamics for clathrin-mediated endocytosis. Nat Rev Mol Cell Biol. 2006;7(6):404-14.

344. Hu X, Wang R, Yue J, Liu S, Xie Z, Jing X. Targeting and anti-tumor effect of folic acidlabeled polymer-Doxorubicin conjugates with $\mathrm{pH}$-sensitive hydrazone linker. Journal of Materials Chemistry. 2012;22(26):13303-10.

345. Bidwell GL, 3rd, Raucher D. Cell penetrating elastin-like polypeptides for therapeutic peptide delivery. Adv Drug Deliv Rev. 2010;62(15):1486-96.

346. Costa RR, Girotti A, Santos M, Arias FJ, Mano JF, Rodriguez-Cabello JC. Cellular uptake of multilayered capsules produced with natural and genetically engineered biomimetic macromolecules. Acta Biomater. 2014;10(6):2653-62.

347. Bessa PC, Machado R, Nurnberger S, Dopler D, Banerjee A, Cunha AM, et al. Thermoresponsive self-assembled elastin-based nanoparticles for delivery of BMPs. J Control Release. 2010;142(3):312-8. 
348. Sarangthem V, Cho EA, Bae SM, Singh TD, Kim SJ, Kim S, et al. Construction and Application of Elastin Like Polypeptide Containing IL-4 Receptor Targeting Peptide. PLoS ONE. 2013;8(12):e81891.

349. Dash BC, Mahor S, Carroll O, Mathew A, Wang WX, Woodhouse KA, et al. Tunable elastin-like polypeptide hollow sphere as a high payload and controlled delivery gene depot. Journal of Controlled Release. 2011;152(3):382-92.

350. Alex SM, Sharma CP. Enhanced intracellular uptake and endocytic pathway selection mediated by hemocompatible ornithine grafted chitosan polycation for gene delivery. Colloids and Surfaces B: Biointerfaces. 2014;122(0):792-800.

351. Choi YJ, Kang SJ, Kim YJ, Lim YB, Chung HW. Comparative studies on the genotoxicity and cytotoxicity of polymeric gene carriers polyethylenimine (PEI) and polyamidoamine (PAMAM) dendrimer in Jurkat T-cells. Drug Chem Toxicol. 2010;33(4):357-66.

352. O'Rorke S, Keeney M, Pandit A. Non-viral polyplexes: Scaffold mediated delivery for gene therapy. Progress in Polymer Science. 2010;35(4):441-58.

353. Srinivasachari S, Liu Y, Prevette LE, Reineke TM. Effects of trehalose click polymer length on pDNA complex stability and delivery efficacy. Biomaterials. 2007;28(18):2885-98.

354. Oupicky D, Konak C, Ulbrich K, Wolfert MA, Seymour LW. DNA delivery systems based on complexes of DNA with synthetic polycations and their copolymers. J Control Release. 2000;65(1-2):149-71.

355. Zelphati O, Nguyen C, Ferrari M, Felgner J, Tsai Y, Felgner PL. Stable and monodisperse lipoplex formulations for gene delivery. Gene Ther. 1998;5(9):1272-82.

356. Haupt S, Berger M, Goldberg Z, Haupt Y. Apoptosis - the p53 network. J Cell Sci. 2003;116(Pt 20):4077-85.

357. Angelastro JM, Lame MW. Overexpression of CD133 promotes drug resistance in C6 glioma cells. Mol Cancer Res. 2010;8(8):1105-15

358. Li G, Li W, Angelastro JM, Greene LA, Liu DX. Identification of a novel DNA binding site and a transcriptional target for activating transcription factor 5 in c6 glioma and mcf- 7 breast cancer cells. Mol Cancer Res. 2009;7(6):933-43.

359. Naus CC, Elisevich K, Zhu D, Belliveau DJ, Del Maestro RF. In vivo growth of C6 glioma cells transfected with connexin43 cDNA. Cancer Res. 1992;52(15):4208-13.

360. Heitz F, Morris MC, Divita G. Twenty years of cell-penetrating peptides: from molecular mechanisms to therapeutics. Br J Pharmacol. 2009;157(2):195-206.

361. Gupta B, Levchenko TS, Torchilin VP. Intracellular delivery of large molecules and small particles by cell-penetrating proteins and peptides. Adv Drug Deliv Rev. 2005;57(4):63751.

362. Tahara K, Yamamoto $H$, Kawashima Y. Cellular uptake mechanisms and intracellular distributions of polysorbate 80-modified poly (D,L-lactide-co-glycolide) nanospheres for gene delivery. Eur J Pharm Biopharm. 2010;75(2):218-24.

363. Lachelt $U$, Kos $P$, Mickler FM, Herrmann A, Salcher EE, Rodl W, et al. Fine-tuning of proton sponges by precise diaminoethanes and histidines in pDNA polyplexes. Nanomedicine. 2014;10(1):35-44.

364. Chen TH, Bae Y, Furgeson DY, Kwon GS. Biodegradable hybrid recombinant block copolymers for non-viral gene transfection. Int J Pharm. 2012;427(1):105-12.

365. Höbel S, Aigner A. Polyethylenimines for siRNA and miRNA delivery in vivo. Wiley Interdisciplinary Reviews: Nanomedicine and Nanobiotechnology. 2013;5(5):484-501. 
366. Wiseman JW, Goddard CA, McLelland D, Colledge WH. A comparison of linear and branched polyethylenimine (PEI) with DCChol//DOPE liposomes for gene delivery to epithelial cells in vitro and in vivo. Gene Ther. 2003;10(19):1654-62.

367. Ren LF, Marquardt MA, Lech JJ. Estrogenic effects of nonylphenol on pS2, ER and MUC1 gene expression in human breast cancer cells-MCF-7. Chemico-Biological Interactions. 1997; 104(1):55-64.

368. Barbieri L, Battelli MG, Stirpe F. Ribosome-Inactivating Proteins from Plants. Biochimica Et Biophysica Acta. 1993;1154(3-4):237-82.

369. Jeon WB. Contribution of lysine-containing cationic domains to thermally-induced phase transition of elastin-like proteins and their sensitivity to different stimuli. BMB Rep. 2011;44(1):22-7.

370. Poyet JL, Hoeveler A. cDNA cloning and expression of pokeweed antiviral protein from seeds in Escherichia coli and its inhibition of protein synthesis in vitro. FEBS Lett. 1997;406(1-2):97-100.

371. Ren L, Marquardt MA, Lech JJ. Estrogenic effects of nonylphenol on pS2, ER and MUC1 gene expression in human breast cancer cells-MCF-7. Chem Biol Interact. 1997; 104(1):55-64.

372. Croce MV, Isla-Larrain MT, Capafons A, Price MR, Segal-Eiras A. Humoral immune response induced by the protein core of MUC1 mucin in pregnant and healthy women. Breast Cancer Res Treat. 2001;69(1):1-11.

373. Hsu CY, Uludag H. A simple and rapid nonviral approach to efficiently transfect primary tissue-derived cells using polyethylenimine. Nat Protoc. 2012;7(5):935-45.

374. Su X, Fricke J, Kavanagh DG, Irvine DJ. In Vitro and in Vivo mRNA Delivery Using LipidEnveloped pH-Responsive Polymer Nanoparticles. Molecular Pharmaceutics. 2011;8(3):774-87.

375. Xiao Z, Levy-Nissenbaum E, Alexis F, Lupták A, Teply BA, Chan JM, et al. Engineering of Targeted Nanoparticles for Cancer Therapy Using Internalizing Aptamers Isolated by Cell-Uptake Selection. ACS Nano. 2012;6(1):696-704.

376. Gratton SE, Ropp PA, Pohlhaus PD, Luft JC, Madden VJ, Napier ME, et al. The effect of particle design on cellular internalization pathways. Proc Natl Acad Sci U S A. 2008;105(33):11613-8.

377. Pollard H, Remy J-S, Loussouarn G, Demolombe S, Behr J-P, Escande D. Polyethylenimine but Not Cationic Lipids Promotes Transgene Delivery to the Nucleus in Mammalian Cells. Journal of Biological Chemistry. 1998;273(13):7507-11.

378. Montero J, Dutta C, van Bodegom D, Weinstock D, Letai A. p53 regulates a nonapoptotic death induced by ROS. Cell Death Differ. [Original Paper]. 2013;20(11):146574.

379. Deb SDaSP, editor. p53 protocols. Totowa, New Jersey, USA: Humana Press Inc.; 2003.

380. Dubin RF, Robinson SK, Widdicombe JH. Secretion of lactoferrin and lysozyme by cultures of human airway epithelium. American Journal of Physiology - Lung Cellular and Molecular Physiology 2004;286(4):L750-L5.

381. Wen Y, Caffrey TC, Wheelock MJ, Johnson KR, Hollingsworth MA. Nuclear association of the cytoplasmic tail of MUC1 and beta-catenin. J Biol Chem. 2003;278(39):38029-39.

382. Wei $\mathrm{X}, \mathrm{Xu} \mathrm{H}$, Kufe D. Human mucin 1 oncoprotein represses transcription of the p53 tumor suppressor gene. Cancer Res. 2007;67(4):1853-8. 
383. Audouy S, Molema G, de Leij L, Hoekstra D. Serum as a modulator of lipoplex-mediated gene transfection: dependence of amphiphile, cell type and complex stability. The Journal of Gene Medicine. 2000;2(6):465-76.

384. Lu H-L, Syu W-J, Nishiyama N, Kataoka K, Lai P-S. Dendrimer phthalocyanineencapsulated polymeric micelle-mediated photochemical internalization extends the efficacy of photodynamic therapy and overcomes drug-resistance in vivo. Journal of Controlled Release. 2011;155(3):458-64.

385. Wang W, Qin J-J, Voruganti S, Srivenugopal KS, Nag S, Patil S, et al. The pyrido[b]indole MDM2 inhibitor SP-141 exerts potent therapeutic effects in breast cancer models. Nat Commun. 2014;5.

386. Giordano C, Barone I, Vircillo V, Panza S, Malivindi R, Gelsomino L, et al. Activated FXR Inhibits Leptin Signaling and Counteracts Tumor-promoting Activities of CancerAssociated Fibroblasts in Breast Malignancy. Scientific Reports. [Article]. 2016;6:21782.

387. Kuriyama S, Nakatani T, Masui K, Sakamoto T, Tominaga K, Yoshikawa M, et al. Bystander effect caused by suicide gene expression indicates the feasibility of gene therapy for hepatocellular carcinoma. Hepatology. 1995;22(6):1838-46.

388. Tai YT, Strobel T, Kufe D, Cannistra SA. In vivo cytotoxicity of ovarian cancer cells through tumor-selective expression of the BAX gene. Cancer Res. 1999;59(9):2121-6.

389. Chubet RG, Brizzard BL. Vectors for expression and secretion of FLAG epitope-tagged proteins in mammalian cells. Biotechniques. 1996;20(1):136-41.

390. Kommareddy S, Amiji M. Poly(Ethylene Glycol)-Modified Thiolated Gelatin Nanoparticles for Glutathione-Responsive Intracellular DNA Delivery. Nanomedicine : nanotechnology, biology, and medicine. 2007;3(1):32-42.

391. Hall JB, Dobrovolskaia MA, Patri AK, McNeil SE. Characterization of nanoparticles for therapeutics. Nanomedicine (Lond). 2007;2(6):789-803.

392. Abe M, Kufe D. Transcriptional regulation of DF3 gene expression in human MCF-7 breast carcinoma cells. J Cell Physiol. 1990;143(2):226-31.

393. Lacunza E, Baudis M, Colussi AG, Segal-Eiras A, Croce MV, Abba MC. MUC1 oncogene amplification correlates with protein overexpression in invasive breast carcinoma cells. Cancer Genet Cytogenet. 2010;201(2):102-10.

394. Barrow KM, Perez-Campo FM, Ward CM. Use of the cytomegalovirus promoter for transient and stable transgene expression in mouse embryonic stem cells. Methods Mol Biol. 2006;329:283-94.

395. Orimo A, Gupta PB, Sgroi DC, Arenzana-Seisdedos F, Delaunay T, Naeem R, et al. Stromal fibroblasts present in invasive human breast carcinomas promote tumor growth and angiogenesis through elevated SDF-1/CXCL12 secretion. Cell. 2005;121(3):335-48.

396. Singh R, Samant U, Hyland S, Chaudhari PR, Wels WS, Bandyopadhyay D. Targetspecific cytotoxic activity of recombinant immunotoxin scFv(MUC1)-ETA on breast carcinoma cells and primary breast tumors. Mol Cancer Ther. 2007;6(2):562-9.

397. Walsh MD, Luckie SM, Cummings MC, Antalis TM, McGuckin MA. Heterogeneity of MUC1 expression by human breast carcinoma cell lines in vivo and in vitro. Breast Cancer Res Treat. 1999;58(3):255-66.

398. Vitetta ES, Thorpe PE. Immunotoxins containing ricin or its A chain. Semin Cell Biol. 1991;2(1):47-58.

399. Eiklid K, Olsnes S, Pihl A. Entry of lethal doses of abrin, ricin and modeccin into the cytosol of HeLa cells. Exp Cell Res. 1980;126(2):321-6. 
400. Pauly D, Worbs S, Kirchner S, Shatohina O, Dorner MB, Dorner BG. Real-Time Cytotoxicity Assay for Rapid and Sensitive Detection of Ricin from Complex Matrices. PLoS One. 2012;7(4):e35360.

401. Kochi SK, Collier RJ. DNA Fragmentation and Cytolysis in U937 Cells Treated with Diphtheria Toxin or Other Inhibitors of Protein Synthesis. Experimental Cell Research. 1993;208(1):296-302.

402. Guerriero CJ, Brodsky JL. The Delicate Balance Between Secreted Protein Folding and Endoplasmic Reticulum-Associated Degradation in Human Physiology. Physiological Reviews. 2012;92(2):537-76.

403. Roberts LM, Lamb FI, Pappin DJ, Lord JM. The primary sequence of Ricinus communis agglutinin. Comparison with ricin. J Biol Chem. 1985;260(29):15682-6. 



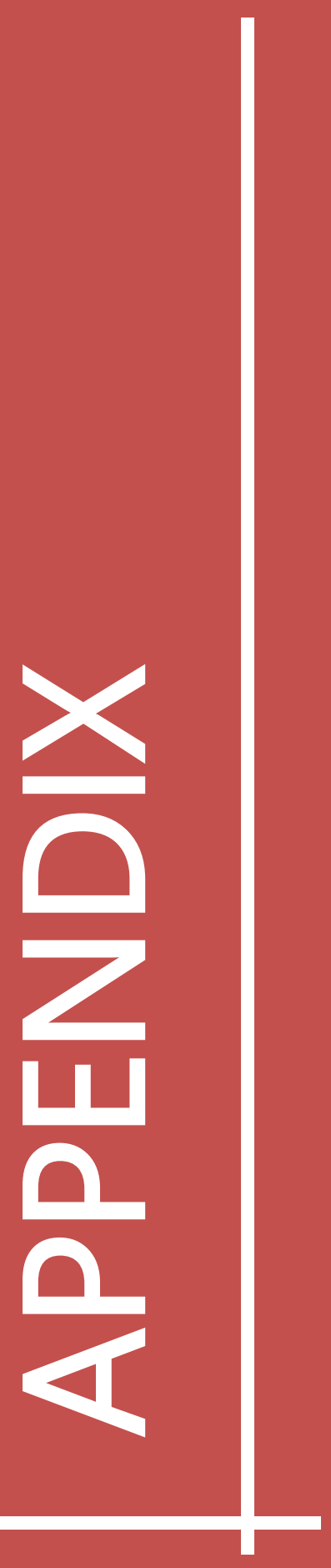


$-322$ 


\section{ABREVIATIONS}

AAV: Adeno-associated virus

CME: Clathrin-mediated endocytosis

CMV: Cytomegalovirus

CPP: Cell Penetratin Peptide

$\mathrm{C}$-t: $\mathrm{COOH}$ terminal of protein sequence.

CTB: Cholera toxin subunit B

DLS: Dynamic light scattering

DSC: Differential Scanning Calorimetry

ELR: Elastin like recombinamer

$E_{\text {ELR }}$ : Elastin like recombinamer Block Copolymer

${ }^{1} \mathrm{H}$-NMR: Proton- nuclear magnetic resonance

HS: Heparan sulfate

HSPG: Heparan sulfate proteoglycan

ITC: Inverse transition cycling

LB: Luria Bertani medium.

MTAB: Myristyl trimethyl ammonium bromide

MW: Molecular weight.

NPs: Nanoparticles

$\mathrm{N}$-t: $\mathrm{NH}_{2}$ terminal of protein sequence.

o/n: Overnight

PAK1: p21 Activated Kinase 1

PDMAEMA: Poly(2-dimethylaminoethyl methacrylate)

pDNA: plasmid DNA

pDm: pDrive cloning vector

PEI: Polyethylenimine

PEG: Polyethyleneglycol

PET: Expression vector

PLL: Poly-lysine

PLGA: Polylacticoglycolic acid)

PRINT: Particle replication in non-wetting templates

PST: Proline-serine-threonine rich domain

RDL: Recursive Directional Ligation

RTA: Ricin A Chain

RTB: Ricin B Chain

TBm: Terrific Browth medium.

TIRF: Total Internal Reflection Fluorescence 
$-\sqrt{324}$ 


\section{AUTHOR'S CONTRIBUTIONS}

\section{PUBLICATIONS}

2016- Maria Jesus Piña, Alessandra Girotti, Raquel Muñoz, Sofia Serrano, Jose Carlos Rodríguez-Cabello and Francisco Javier Arias. Elastin-like recombinamer (ELR) based suicide gene therapy system directed to breast cancer using ricin gene. Breast cancer research. Submitted.

2016- Francisco Javier Arias, Mercedes Santos, Arturo Ibañez-Fonseca, Maria Jesus Piña and Sofia Serrano. Elastin-Like Recombinamers as Drug Delivery Systems. Current Drug Targets. Article ASAP.

2016- Maria Jesus Piña, Alessandra Girotti, Mercedes Santos, Jose Carlos RodriguezCabello, and Francisco Javier Arias. Biocompatible ELR-Based Polyplexes Coated with MUC1 Specific Aptamers and Targeted for Breast Cancer Gene Therapy. Molecular Pharmaceutics. 13 (3), pp 795-808.

2016- Jose Carlos Rodriguez-Cabello, Alicia Fernandez-Colino, Maria Jesus Piña, Francisco Javier Arias, Isabel Lopez., Elastin-Like Recombinamers, in Encyclopedia of Biomedical Polymers and Polymeric Biomaterials. 2016, Taylor and Francis.

2015- Jose Carlos Rodriguez-Cabello, Maria Jesus Piña, Arturo Ibañez-Fonseca, Alicia Fernandez-Colino, and Francisco Javier Arias. Nanotechnological Approaches to Therapeutic Delivery Using Elastin-Like Recombinamers. Bioconjugate chemistry. 26 (7), pp 1252-1265.

2015- Maria Jesus Piña, Susan Alex, Francisco Javier Arias, Mercedes Santos, Jose Carlos Rodriguez-Cabello, Rehka Ramesan, Chandra Sharma. Elastin-like recombinamers with acquired functionalities for gene-delivery applications. Journal of Biomedical Research A. 103(10):3166-78

2013- Jose Carlos Rodriguez-Cabello, Alicia Fernández-Colino, Maria Jesus Piña Matilde Alonso, Mercedes Santos and Ana Maria Testera. Bioactive and smart hydrogels surfaces. Biomaterials Surface Science. 2013, Wiley-VCH Verlag GmbH \& Co. KGaA.

\section{CONGRESS}

2016- 10th World Biomaterials Congress. ORAL COMMUNICATION. "Directed ELRs for breast cancer therapy". Alessandra Girotti, Maria Jesus Piña.

2015- 27th European Conference on Biomaterials. ORAL COMMUNICATION." ELR devices for breast cancer gene delivery". Maria Jesus Piña et al.

2015- Investigadoras de la Uva en la aventura de la Nanociencia. GUEST SPEAKER. Nanotecnología y terapia génica. Maria Jesus Piña.

2014- XXXVII Congreso sociedad ibérica de biomecánica y biomateriales. ORAL COMUNICATION. "Supercharged elastin-like recombinamers as gene delivery carriers". Maria Jesus Piña et al. 
2014- 30th LIAC meeting on vascular research. POSTER. "Bioactive Elastin-like Recombinamers for Gene Delivery purposes". Maria Jesus Piña et al.

2014- E-MRS fall meeting. ORAL COMMUNICATION. "Highly charged elastin like recombinamers as gene delivery systems". Maria Jesus Piña et al.

2014- VIII International Congress of ANQUE. ORAL COMMUNICATION. "Supercharged elrs for gene therapy applications". Maria Jesus Piña et al.

2013- 25th European Conference on Biomaterials. ORAL COMMUNICATION. "Elastinlike Recombinamers containing Cell-interaction Motifs for Gene Delivery". Maria Jesus Piña et al.

2013- TERMIS-EU Istanbul. ORAL COMMUNICATION. "Elastin Like Recombinamers for gene delivery containing bioactive peptides". Maria Jesus Piña et al.

\section{OTHER CONTRIBUTIONS}

2014- TEACHING ACTIVITIES IN UNIVERSIDAD DE VALLADOLID FOR UNDERGRADUTATE STUDENTS. CO-SUPERVISION OF MASTER STUDENT IN BIOMEDICINE RESEARCH. 
